\title{
Novel lipid biomarkers for detecting microbial oxidation of methane in the environment
}

Nadine T. Smit

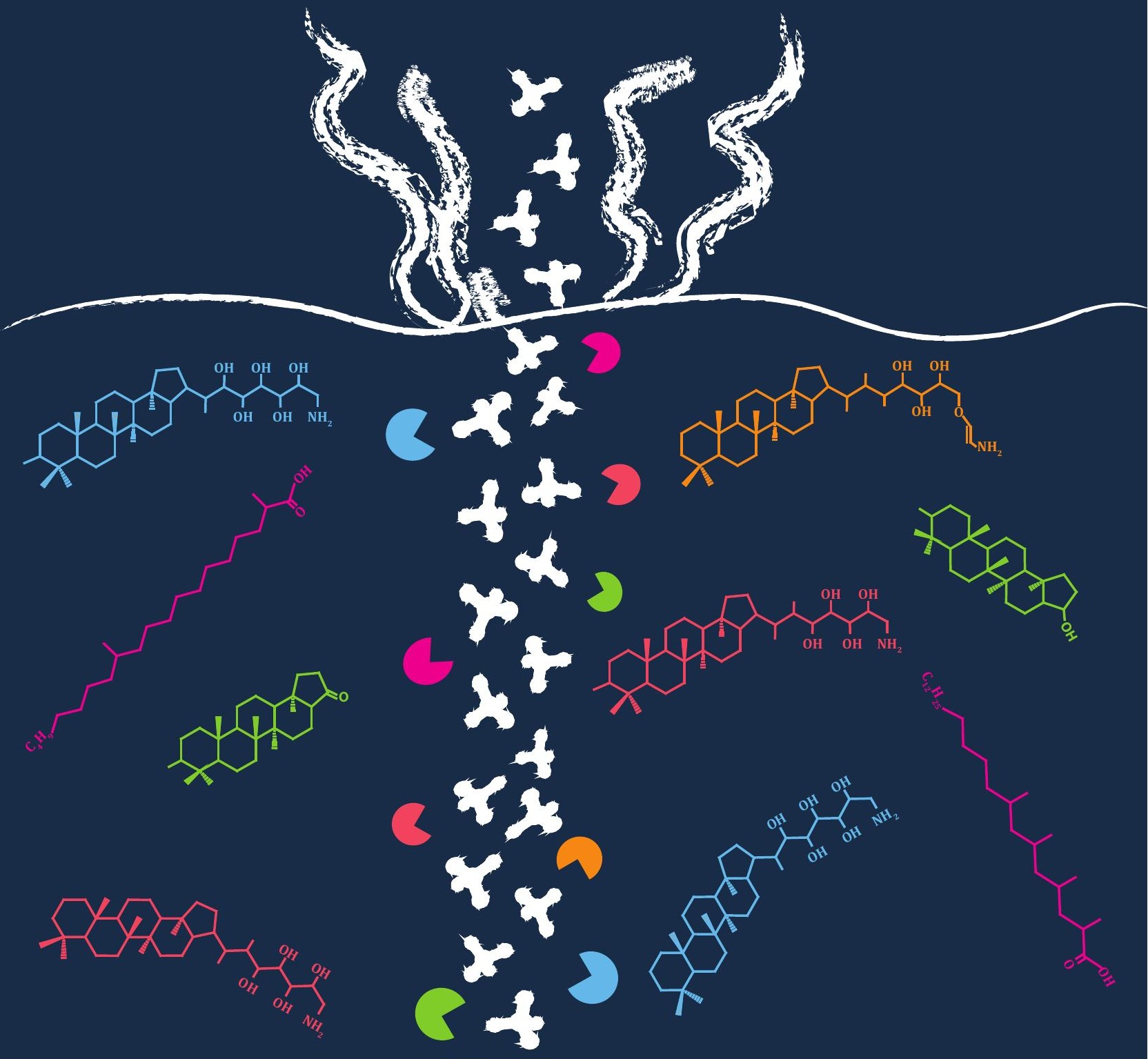



Novel lipid biomarkers for detecting microbial oxidation of methane in the environment

Nadine Talea Smit 
Printed by I pskamp Printing, Enschede

Cover design: Nadine T. Smit

ISB N 978-94-6421-424-6 


\title{
Novel lipid biomarkers for detecting microbial oxidation of methane in the environment
}

\author{
Nieuwe biomarker lipiden voor detectie van microbiële \\ oxidatie van methaan in het milieu \\ (met een samenvatting in het Nederlands)
}

Neuartige Lipid-Biomarker zum Nachweis von mikrobieller Methanoxidation in der Umwelt

(mit einer Zusammenfassung in Deutsch)

\section{Proefschrift}

ter verkrijging van de graad van doctor aan de

Universiteit Utrecht

op gezag van de

rector magnificus, prof.dr. H.R.B.M. Kummeling, ingevolge het besluit van het college voor promoties

in het openbaar te verdedigen op

vrijdag 27 augustus 2021 des ochtends te 10.15 uur

door

Nadine Talea Smit

geboren op 7 juni 1990

te Meerbusch, Duitsland 


\section{Promotoren:}

Prof. dr. ir. S. Schouten

Prof. dr. ir. J.S. Sinninghe Damsté

\section{Copromotor:}

Dr. D. Rush

This work has been funded by the Netherlands Earth System Science Center (NESSC) through a gravitation grant (NWO 024.002.001) from the Dutch Ministry for Education, Culture and Science. 
"If we knew what we were doing, it would not be called research, would it?"

Albert Einstein 



\section{Table of Contents}

$\begin{array}{ll}\text { Summary } & 9\end{array}$

$\begin{array}{ll}\text { Samenvatting in het Nederlands } & 13\end{array}$

$\begin{array}{ll}\text { Zusammenfassung auf Deutsch } & 17\end{array}$

$\begin{array}{ll}\text { Chapter } 1 & 23\end{array}$

Introduction

Chapter 2

Demethylated hopanoids in ' $\mathrm{Ca}$. M ethylomirabilis oxyfera' as biomarkers for environmental nitritedependent methane oxidation

Published in Organic G eochemistry

Chapter 3

59

Anaerobic methanotrophic archaea of the ANM E-2d clade feature lipid composition that differs from other ANME archaea

Published in FEM S M icrobiology E cology

Chapter 4

Lipid biomarker insights into hydrocarbon sources and microbial communities in the terrestrial mud volcanoes of Sicily, Italy

Under review at Organic Geochemistry

Chapter 5

Analysis of non-derivatized bacteriohopanepolyols using

UH PL C -H R M S reveals great structural diversity in

environmental lipid assemblages

Under review at Organic G eochemistry 
Chapter 6

The abundance of nitrogen-containing

bacteriohopanepolyols reflect aerobic methane oxidation

at two terrestrial hydrocarbon seeps in Sicily

In preparation for Geochimica et Cosmochimica Acta

Chapter 7

Novel hydrocarbon-utilizing soil mycobacteria

synthesize unique mycocerosic acids at a Sicilian

everlasting fire

Published in Biogeosciences

Chapter 8

221

The role of soil mycobacteria in the uptake of methane and ethane at a Sicilian everlasting fire

In preparation for Biogeosciences

Chapter 9

237

Synthesis and 0 utlook

References

245

Acknowledgements/ Danksagung

291

About the author 


\section{Summary}

M ethane is a powerful greenhouse gas which has impacted Earth's climate over geological timescales. Anthropogenic emissions have led to a significant increase in its atmospheric concentration in the last two centuries. Various natural and anthropogenic sources are known to emit methane into the atmosphere, e.g. fossil fuels, wetlands, thawing permafrost, marine sediments and hydrocarbon seeps. However, much of this emitted methane is subject to microbial oxidation processes which act as a large sink. Anaerobic methanotrophic archaea (ANMEs) are mainly responsible for the anaerobic oxidation of methane (AOM), while the aerobic oxidation of methane is conducted by methane-oxidizing bacteria (MOBs). In addition to DNA-based techniques, lipid biomarkers offer an additional tool to investigate microbial communities involved in methane oxidation in present-day and past environments. However, to this date, only a few unambiguous biomarkers for methanotrophs like specific fatty acids or bacteriohopanepolyols (BHPs) are known to trace microbes involved in the aerobic oxidation of methane. Therefore, this thesis aims to expand the current toolbox of characteristic biomarkers used to trace aerobic oxidation of methane and other hydrocarbon gasses, especially in terrestrial environments.

In the first part of this thesis, lipid biomarkers for nitrite/nitrate-dependent methane oxidation were investigated in enrichment cultures of the intra-aerobic methanotroph 'Candidatus M ethylomirabilis oxyfera' ('Ca. M . oxyfera') and the A N M E-2d archaeon 'Candidatus M ethanoperedens' . 'Ca. M . oxyfera' directly synthesizes four unique demethylated hopanoids (22,29,30-trisnorhopan-21-ol, 3-methyl-22,29,30-trisnor hopan-21-one and 3-methyl-22,29,30-trisnorhopan21-ol), of which only 22,29,30-trisnorhopan-21-one had been identified previously. A new multiple reaction monitoring method was developed and used to successfully detect these trisnorhopanoids in a peatland. ' $\mathrm{Ca}$. Methanoperedens' produced archaeol and hydroxyarchaeol as well as isoprenoidal GDGTs and unusually high amounts of hydroxy-GDGTs. The novel demethylated hopanoids and high abundances of hydroxy-GDGTs may thus be used in future studies to trace nitrite/nitrate-dependent methane oxidation in various present and past environments.

M ud volcanoes (M V s) release high amounts of methane into the atmosphere and, therefore, three prominent terrestrial Sicilian mud volcanoes were investigated for their lipid biomarker inventories to study microbial communities involved in aerobic and anaerobic methane oxidation. The freshly emitted mud breccias 
showed high abundances of petroleum-derived hydrocarbons but low amounts of microbially derived lipid biomarkers such as fatty acids and hopanoic acids, which were not depleted in ${ }^{13} \mathrm{C}$. These results suggest that these lipids might originate from bacteria other than methane-oxidizing bacteria. Additional analysis of isoprenoidal GDGTs present in one MV show a distribution indicative for anaerobic oxidation of methane by ANME archaea. The possible presence of $\mathrm{AOM}$ in the Maccalube di A ragona MV but not in the other two $M V$ s implies that microbial processes other than methane oxidation may play an important role in these terrestrial M V s in contrast to marine M V systems and warrants further investigations in the future.

The biomarker potential of known and novel bacteriohopanepolyols (BHPs) and their derivatives to trace aerobic methane oxidizing bacteria was investigated in this thesis. First, a new UHPLC-HRM S ${ }^{2}$ method to detect underivatized BHPS was applied to bacterial cultures and a soil near a terrestrial methane seep (Fuoco di Censo everlasting fire in Sicily, I taly). This reveal ed mass spectra with distinct fragmentation patterns of common BHPs and their methylated and unsaturated counterparts as well as aminoBHPs and various novel composite BHPs (e.g. ethenolamineB HPs). A pplication of this methodology to two terrestrial methane seep transects (Censo and Bissana seep) showed high relative abundances of aminoB HPs (i.e. aminopentol) and the novel ethenolamineB HPs at and close to the seeps, which are likely synthesized by Type I M OBs (e.g. M ethylococcaceae) and potentially other Proteobacteria species. The Censo seep showed high relative abundances of a novel late-eluting aminotriol isomer, which was also identified in the verrucomicrobial strain, Methylacidimicrobium cyclopophantes $3 B$, suggesting it as a new biomarker for Verrucomicrobia. A new index (A minoB HP-index) was developed based on selected BHPs, which shows high values close to the seeps $(\geq 0.4)$ and drops to $<0.2$ at distances $>3 \mathrm{~m}$ from the active seeps. This novel AminoBHP-index offers a new biomarker proxy to reconstruct present and past aerobic oxidation of methane in the terrestrial real $\mathrm{m}$.

Soils from a natural everlasting fire named Fuoco di Censo in Sicily, Italy, were also studied. They showed high abundances of novel mycobacteria as revealed by $16 \mathrm{~S}$ rRNA gene sequencing and the presence of mycocerosic acids (M As), multi-methyl branched fatty acids, at and close to the seep. These novel soil mycobacteria are phylogenetically closely related to the M ycobacterium simiae complex but more remotely to well-studied pathogenic mycobacteria such as $M$. tuberculosis. A range of new MAs were identified including unusual ones containing mid-chain methyl branches at positions $\mathrm{C}-12$ and $\mathrm{C}-16$. These MAS 
were depleted in ${ }^{13} \mathrm{C}$, suggesting a direct or indirect utilization of ${ }^{13} \mathrm{C}$ depleted gases such as methane and ethane. Confirmation of the use of these hydrocarbon gasses as a carbon source came from SIP incubations using ${ }^{13} \mathrm{C}$-label ed methane and ethane, which revealed ${ }^{13} \mathrm{C}$ label incorporation of ethane, but not of methane, into the MAs. These results imply that mycobacteria at the Censo seep oxidize ethane but not methane, in agreement with previous studies. Thus, these novel MAs in tandem with ${ }^{13} \mathrm{C}$ depleted isotopic signatures offer new unique biomarkers to trace higher gaseous hydrocarbon oxidation and gas-consuming soil mycobacteria in modern and past environments.

In summary, the results presented in this thesis have substantially expanded the lipid biomarker toolbox for organic geochemists to detect recent and past methane and ethane oxidation. Together with more established biomarker proxies, these newly developed proxies such as mycocerosic acids and the A minoB HP-index may be tested and applied further to trace past methane and higher gaseous hydrocarbon cycles in present and past environments in the future. 


\section{Samenvatting}

$M$ ethaan is een krachtig broeikasgas met een grote invloed op het A ardse klimaat over geologische tijdschalen. A ntropogene emissies hebben de afgelopen twee eeuwen geleid tot een aanzienlijke toename van de atmosferische concentratie van methaan. $V$ an verschillende natuurlijke en antropogene bronnen is bekend dat ze methaan in de atmosfeer uitstoten, zoals moerassen, ontdooiende permafrost, mariene sedimenten en het natuurlijk weglekken van fossiele brandstoffen. Veel van dit uitgestoten methaan is echter onderhevig aan microbiële oxidatieprocessen die als een belangrijke bezinkput fungeren. A naërobe methanotrofe archaea (A N M E's) zijn voornamelijk verantwoordelijk voor de anaërobe oxidatie van methaan ( $\mathrm{O} O \mathrm{M})$, terwijl de aërobe oxidatie van methaan wordt uitgevoerd door methaan-oxiderende bacteriën (M OB's). N aast op DNA gebaseerde technieken bieden lipide biomarkers een extra hulpmiddel om microbiële gemeenschappen op te sporen die actief zijn (geweest) in de methaanoxidatie in zowel huidige als vroegere milieus. Tot op heden zijn er echter slechts enkele eenduidige biomarkers voor methanotrofen bekend om microben te traceren die betrokken zijn bij de aerobe oxidatie van methaan, zoals specifieke vetzuren of bacteriohopaanpolyolen (BHP's). Daarom is het doel van dit proefschrift om de huidige verzameling van karakteristieke biomarkers die kunnen worden gebruikt om aerobe oxidatie van methaan en andere koolwaterstofgassen te traceren, uit te breiden, vooral voor terrestrische milieus.

In het eerste deel van dit proefschrift werden lipide biomarkers voor nitriet/nitraat-afhankelijke methaanoxidatie onderzocht in verrijkingsculturen van de intra-aërobe methanotrofe bacterie 'Candidatus Methylomirabilis oxyfera' ('Ca. M. oxyfera') en de ANME-2d archaeon ' Candidatus M ethanoperedens'. 'Ca. M. oxyfera' synthetiseert vier unieke gedemethyleerde hopanoïden (22,29,30-trisnorhopan-21-ol, 3-methyl-22,29,30-trisnorhopan-21on en 3-methyl- 22,29,30- trisnorhopan-21-ol), waarvan slechts 22,29,30trisnorhopan-21-on eerder was geïdentificeerd. Om deze trisnorhopanoïden succesvol te detecteren in een veengebied, is een nieuwe massapectrometrische methode die gebruik maakt van meervoudige reactie-monitoring ontwikkeld en toegepast. 'Ca. Methanoperedens' produceerde naast archaeol en hydroxyarchaeol ook isoprenoïde GDGT's en hydroxy-GDGT's, die laatsten in ongebruikelijk grote hoeveel heden. Deze specifieke biomarkerdistributie kan in toekomstige studies worden gebruikt om nitriet/nitraat-afhankelijke methaanoxidatie in zow el huidige als vroegere milieus te traceren. 
Moddervulkanen ( $M V$ 's) vormen een belangrijke bron voor atmosferisch methaan. Daarom werden drie prominente terrestrische Siciliaanse MV's onderzocht op lipide biomarkers om microbiële gemeenschappen te bestuderen die betrokken zijn bij zowel aerobe als anaërobe methaanoxidatie. De vers uitgespuwde modderbreccia's bevatte grote hoeveel heden koolwaterstoffen afkomstig van aardolie, maar slechts kleine hoeveel heden microbiële lipide biomarkers zoals vetzuren en hopaanzuren, die niet verarmd waren in ${ }^{13} \mathrm{C}$. Deze resultaten suggereren dat deze lipiden afkomstig kunnen zijn van andere bacteriën dan M OB's. A anvullende analyse van isoprenoïdale GDGT's aanwezig in de $M$ accalube di A ragona $M V$ liet een distributie zien die indicatief is voor anaërobe oxidatie van methaan door A N M E's. De mogelijke aanwezigheid van $A O M$ in de Maccalube di A ragona MV maar niet in de andere twee MV's impliceert dat andere microbiële processen dan methaanoxidatie een belangrijke rol kunnen spelen in deze terrestrische M V 's, in tegenstelling tot mariene M V systemen. Dit rechtvaardigt verder toekomstig onderzoek.

In het tweede deel van dit proefschrift werd het biomarker potentieel van bekende en nieuw-geïdentificeerde bacteriohopaanpolyolen (B HP's) om aerobe M OB's op te sporen onderzocht. Een nieuwe U H PL C-HR M S²-methode om nietgederivatiseerde BHP's te detecteren werd gebruikt in de analyse van culturen van bacteriën en van een bodem in de buurt van een terrestrische methaanbron (de 'Fuoco di Censo', een eeuwig vuur op Sicilië, Italië). De verkregen massaspectra lieten verschillende fragmentatiepatronen zien die het mogelijk maakte bekende BHP's en hun gemethyleerde en onverzadigde tegenhangers, amino-BHP's en verschillende nieuwe samengestelde BHP's (bijv. ethenolamine-BHP's) te identificeren. Toepassing van deze analysetechniek op bodems rondom twee terrestrische methaanbronnen (Censo en Bissana seep) toonde grote hoeveelheden van aminoB HP's (voornamelijk aminopentol) en de nieuwe ethenolamine-BHP's in bodems nabij de methaanbronnen aan. Deze BHP's worden waarschijnlijk gesynthetiseerd door Type I M OB 's (bijvoorbeeld $M$ ethylococcaceae) en mogelijk ook door andere proteobacteria. De Censomethaanbron bevatte ook grote hoeveel heden van een nieuwe, laat-eluerende, aminotriol-isomeer. Deze B HP werd ook aangetroffen in een bacterie behorende tot de Verrucomicrobia, i.e. Methylacidimicrobium cyclopophantes 3B. Mogelijk is dit een nieuwe biomarker voor methaanoxiderende V errucomicrobia. Een nieuwe index (de A minoB HP-index) werd ontwikkeld op basis van geselecteerde specifieke $B H P$ 's. D eze index laat hoge waarden laat zien dichtbij de methaanbron $(>0,4)$ en daalt tot $<0,2$ op afstanden van $>3 \mathrm{~m}$ van de bron. Deze nieuwe A minoBHP-index biedt een nieuwe biomarker-proxy om 
aerobe oxidatie van methaan in huidige en vroegere milieus in het geologisch verleden te reconstrueren.

Ook werden in bodems van een natuurlijk eeuwigdurend vuur, genaamd Fuoco di Censo op Sicilië, Italië, grote hoeveelheden van nieuwe mycobacteriën gevonden. Deze mycobacteriën werden aangetoond in bodems vlakbij de methaanbron middels $16 \mathrm{~S}$ rR NA -gen sequencing al smede door de aanwezigheid van mycocerosinezuren (M A 's), multi-methyl vertakte vetzuren, karakteristieke biomarker lipiden voor mycobacteriën. Deze nieuwe bodembacteriën zijn fylogenetisch nauw verwant aan het M ycobacterium simiae-complex, maar meer op afstand van goed-bestudeerde, pathogene mycobacteriën zoals $M$. tuberculosis. Een aantal nieuwe MA's werd geïdentificeerd. Deze MA's zijn ongebruikelijke omdat zij methylgroepen in het midden van de koolstofketen, op posities $\mathrm{C}-12$ en $\mathrm{C}-16$, bevatten. Deze M A's bevatte relatief weinig ${ }^{13} \mathrm{C}$, hetgeen wijst op een direct of indirect gebruik van ${ }^{13} \mathrm{C}$-verarmde gassen zoals methaan en ethaan. H et gebruik van koolwaterstofgassen als koolstofbron werd bevestigd door middel van incubatiestudies met ${ }^{13} \mathrm{C}$-gelabeld methaan en ethaan. Hieruit bleek dat ${ }^{13} \mathrm{C}$-label van ethaan wel werd opgenomen in de M A 's, maar niet dat van methaan. De implicatie van deze bevindingen is dat mycobacteriën in de Censo bodems ethaan maar niet methaan oxideren. $D$ it is in overeenstemming met suggesties uit eerder werk. Deze nieuwe MA's in combinatie met ${ }^{13} \mathrm{C}$ verarmde isotopensignatuur bieden dus nieuwe unieke biomarkers voor het opsporen van ethaan-oxiderende mycobacteriën in bodems van moderne en vroegere milieus.

Samenvattend kan gesteld worden dat de resultaten beschreven in dit proefschrift het aantal lipide biomarkers dat beschikbaar is voor organisch geochemici om methaan- en ethaanoxidatie te detecteren in vroegere en huidige milieus aanzienlijk uitgebreid hebben. Samen met meer gevestigde biomarker-proxy's, kunnen deze nieuw ontwikkelde proxy's, zoals mycocerosinezuren en de A minoB HP-index, in de toekomst verder worden getest en mogelijk worden toegepast om de biogeochemische kringloop van koolwaterstoffengassen in verschillende milieus te bestuderen. 


\section{Zusammenfassung}

Methan ist ein wirkungsvolles Treibhausgas in der Erdatmosphäre und Änderungen in der atmosphärischen M ethankonzentrationen sind stark verknüpft mit Temperaturschwankungen über geologische Zeiträume. Anthropogene Treibhausgasemissionen haben die atmosphärischen $M$ ethankonzentrationen in den letzten zwei Jahrhunderten erheblich ansteigen Iassen. M ethan wird durch diverse anthropogene und natürliche Quellen in die Umwelt eingetragen, z.B. durch fossile Brennstoffe, Feuchtgebiete, schmelzenden Permafrost, marine Sedimente oder natürliche Kohlenwasserstoffaustritte. Die mikrobielle Methanoxidation spielt eine wichtige Rolle als Senke für atmosphärisches M ethan in terrestrischen als auch in marinen Ökosystemen. Dort wird M ethan entweder anaerob (unter A usschluss von Sauerstoff) von anaeroben methanotrophen Archaeen oder aerob (mit Sauerstoff) von methanoxidierenden Bakterien chemisch umgewandelt. Neben DNA-basierten Analysemethoden, ist der Einsatz von Lipid-Biomarkern (M oleküle hauptsächlich bestehend aus K ohlenwasserstoffverbindungen) eine vielversprechende und zuverlässigere Methode um methanoxidierende Mikroorganismen in der heutigen Umwelt sowie in der geologischen V ergangenheit zu identifizieren. Böden stellen weltweit die größte mikrobielle Senke für atmosphärisches $M$ ethan dar, jedoch beschränken sich bisherige Studien über Lipid-Biomarker in der geologischen Vergangenheit meist auf marine $M$ ethanaustritte. Daher wurden bisher nur wenige spezifische LipidBiomarker, z.B. spezifische Fettsäuren oder die sogenannten Bacteriohopanepolyole (BHPs), gefunden mit denen aerobe methanoxidierende Mikroorganismen in der Umwelt nachgewiesen werden können. Diese Doktorarbeit zielt daher darauf ab, sowohl neue charakteristische Lipid Biomarker für aerobe und anaerobe methanoxidierende Mikroorganismen zu finden als auch ihre Anwendung speziell in der terrestrischen Umwelt zu untersuchen.

Im ersten Teil der vorliegenden D oktorarbeit werden L ipid-Biomarker spezifisch für die Nitrit/ Nitrat-abhängige Methanoxidation in zwei unterschiedlichen A nreicherungskulturen untersucht. Das intra-aerobe methanotrophe Bakterium 'Candidatus M ethylomirabilis oxyfera' (,Ca. M. oxyfera') synthetisiert vier einzigartige demethylierte Hopanoide (22,29,30-trisnorhopan-21-ol, 3-methyl22,29,30-trisnor hopan-21-one and 3-methyl-22,29,30-trisnorhopan-21-ol), von denen nur 22,29,30-trisnorhopan-21-one bereits zuvor identifiziert wurde. $M$ ithilfe einer neuentwickelten A nalysemethode, welche spezifisch nach den vier neuen Trisnorhopanoiden sucht, wurde ,Ca. M. oxyfera' in einem 
M oorgebiet nachgewiesen. Die zweite A nreichungskultur besteht aus vorrangig dem anaeroben methanotrophen (ANME-2d) A rchaeon ,Candidatus M ethanoperedens', diese produzieren hauptsächlich die beiden Komponenten A rchaeol und Hydroxyarchaeol als auch GDGTs und einen hohen A nteil von Hydroxy-GDGTs. Zukünftig können die neu identifizierten Trisnorhopanoide und ungewöhnlich hohe Konzentrationen von Hydroxy-GD GTs in Studien zum Nachweis von Nitrit/ Nitrat-abhängigen Methanoxidation in modernen U mweltproben und älteren geologischen Zeiträumen angewandt werden.

Schlammvulkane sind ideale Lebensräume für methanoxidierende M ikroorganismen, da sie kontinuierlich M ethan in die Erdatmosphäre ausstoßen. Drei große terrestrische Schlammvulkane wurden auf das Vorhandensein von Lipid-Biomarkern für anaerobe und aerobe Methanoxidation in Sizilien untersucht. Der frisch ausgetretene Schlamm wies einen sehr hohen A nteil an erdölspezifischen Kohlenwasserstoffverbindungen auf wohingegen der A nteil von mikrobiellen Lipid-Biomarkern, z.B. Fettsäuren und Hopansäuren, sehr gering war. Des Weiteren waren diese Lipid-Biomarker isotopisch nicht abgereichert in ${ }^{13} \mathrm{C}$, was darauf hindeutet, dass diese Lipide nicht von methanoxidierenden B akterien produziert wurden. Die A nalyse von GDGTs in den Schlammvulkanen zeigte jedoch, dass in einem Schlammvulkan ( $M$ accal ube di A ragona) GDGT-Verteilungen vorhanden waren, welche von anaeroben methanotrophen A rchaeen stammen könnten. Die Ergebnisse zeigen, dass nur wenige bis keine spezifischen Lipid-Biomarker für methanoxidierende Bakterien oder Archaeen in den drei Schlammvulkanen gefunden werden konnten. Daher spielen vermutlich andere mikrobielle Prozesse als M ethanoxidation in terrestrischen Schlammvulkanen eine größere Rolle als in früheren Studien für marine Schlammvulkane gezeigt wurde.

Im nächsten Teil der Doktorarbeit werden bekannte und neue Bacteriohopanpolyole (BHPs) und ähnliche Verbindungen untersucht, um ihr Potential als Lipid-Biomarker für aerobe methanoxidierende Bakterien abzuschätzen. Zuerst wurde eine neuentwickelte UHPLC-HRMS ${ }^{2}$ Methode eingesetzt um nicht derivatisierte B HPs in diversen B akterienkulturen und einer Bodenprobe von einem natürlichen terrestrischen $M$ ethanaustritt in Sizilien (,Fuoco di Censo' - immer brennendes Feuer) zu identifizieren. Diese A nalysen zeigten $M$ assenspektren mit sehr spezifischen Fragmentierungsmustern von weitverbreiteten BHPs und ihren methylierten und ungesättigten verwandten M ol ekülen, sowie typische A minoB H Ps und diverse neue K omposit-B H Ps (z.B. EthenolamineBHPs). Die Anwendung dieser Methodik auf zwei Profile über 
terrestrische Methanaustritte (Censo und Bissana) zeigte hohe relative Vorkommen von AminoBHPs (z.B. A minopentol) und neuartigen EthenolamineBHPs direkt an und nahe um die Austrittsstellen. Diese Verbindungen werden wahrscheinlich von Typ I methanoxidierende Bakterien (z.B. Methylococcaceae) und möglicherweise auch anderen Spezies von Proteobakterien synthetisiert. Der Censo M ethanaustritt zeigt zusätzlich hohe relative $V$ orkommen eines neuartigen A minotriol-Isomers, welches auch in Verrucobakterien (M ethylacidimicrobium cyclopophantes $3 B$ ) gefunden wurde und damit als ein neuer B iomarker für V errucobakterien genutzt werden kann. Ein neuer Index wurde auf Basis ausgewählter B HPs entwickelt (A minoB HPindex), welcher hohe Werte $(\geq 0.4)$ nahe an Methanaustrittsstellen und niedrige W erte $(<0.2)$ in Entfernungen über $3 \mathrm{~m}$ von aktiven $A$ ustritten zeigt. Dieser neue A minoBHP-index bietet einen neuen Biomarker-Proxy, um moderne und vergangene terrestrische aerobe $M$ ethanoxidation zu rekonstruieren.

Im letzten Teil der Arbeit werden Bodenproben von Fuoco di Censo (Sizilien, Italien) untersucht, welche hohe V orkommen von neuartigen M ykobakterien an und nahe den Austrittsstellen durch 165 rRNA Gensequenzierung und Mycocerosic Acids (MAs), d.h. multi-methylierte verzweigte Fettsäuren, zeigten. Diese neuartigen Boden-Mykobakterien sind phylogenetisch eng verwandt mit dem Mycobacterium simiae Komplex jedoch weniger eng verwandt mit den vielfach untersuchten pathogenen M ykobakterien, z.B. M. tuberculosis. An und nahe den Methanaustrittsstellen wurden neue MAs entdeckt, zum Teil mit sehr ungewöhnlichen $M$ ethylverzweigungen in der $M$ itte der M oleküle an Position C-12 und C-16. Diese neuen M A s sind abgereichert in ${ }^{13} \mathrm{C}$, was darauf hindeutet, dass die Mykobakterien die ausgetretenen $\mathrm{G}$ ase (Methan und/oder Ethan) aufnehmen. Um die vorherigen Annahmen zu bestätigen, dass die M ykobakterien die ausgetretenen $\mathrm{G}$ ase als K ohl enstoffquelle nutzen, wurden Inkubationen mit isotopisch gelabelten ${ }^{13} \mathrm{C}$ M ethan und ${ }^{13} \mathrm{C}$ Ethan durchgeführt. Diese Inkubationen zeigen, dass die MAs nur ein ${ }^{13} \mathrm{C}$ I sotopenlabel in den Inkubationen mit Ethan aufzeigen jedoch nicht mit M ethan. Diese Ergebnisse implizieren, dass die Mykobakterien in den Censo-Böden ausschließlich Ethan oxidieren und nicht M ethan, was vorherige Studien zu anderen M ykobakterienarten bestätigt. Daher stellen die neuen M A - M oleküle in $\mathrm{K}$ ombination mit abgereicherten ${ }^{13} \mathrm{C}$ I sotopensignaturen neue einzigartige L ipidBiomarker dar um Gasoxidation und gaskonsumierende B oden-M ykobakterien zukünftig in modernen Ökosystemen sowie in geologisch vergangenen L ebensräumen nachzuweisen. 
Die E rgebnisse dieser A rbeit haben die verfügbaren L ipid-Biomarker-M ethoden signifikant zur Detektion von moderner und vergangener $M$ ethan- und Ethanoxidation erweitert. Zusammen mit etablierten Biomarker-Proxys können diese neuen Proxys, z.B. M ycocerosic A cids und der A minoB H P-Index, getestet und weiterentwickelt werden, um den Kreislauf von $M$ ethan und höheren K ohlenwasserstoffen in der G egenwart und der geologischen V ergangenheit zu rekonstruieren. 
Chapter 1

Introduction 


\section{Introduction}

\subsection{The greenhouse gas methane in the carbon cycle}

The cycling of carbon is a continuous transformation process between the atmosphere, terrestrial biosphere, hydrosphere and geosphere and directly influences global climate systems (Solomon et al., 2007; K irschke et al., 2013). $M$ ethane $\left(\mathrm{CH}_{4}\right)$ is a powerful greenhouse gas and anthropogenic emissions have led to a significant increase in its atmospheric concentration in the last two centuries (Fig. 1). Although methane is the second most abundant greenhouse gas in the atmosphere, its global warming potential is about $25 \mathrm{x}$ that of $\mathrm{CO}_{2}$ over 100 years and $84 x$ over a time period of 20 years (K irschke et al., 2013; M yhre, 2014). However, the average lifetime of methane in the atmosphere is shorter than that of $\mathrm{CO}_{2}$ and so its effect on the warming potential varies with time. Notably, variations in greenhouse gas concentrations, especially in methane and $\mathrm{CO}_{2}$ are strongly correlated with changes in temperature over geological timescales (e.g. D elmotte et al., 2004; Pagani et al., 2006; Frieling et al., 2016). Understanding the sources and sinks of methane is important to mitigate anthropogenic caused climate change.

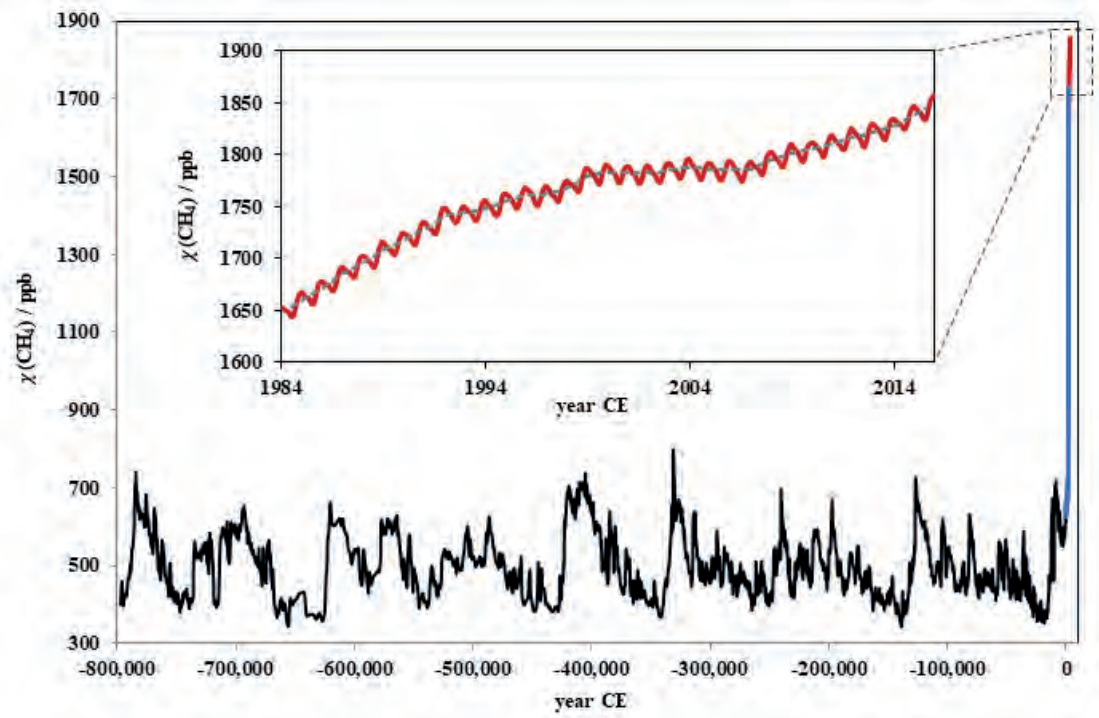

Figure 1 Past and recent fluctuations in atmospheric $\mathrm{CH}_{4}$ concentrations in the last 800,000 years (modified and adapted from Dean et al., 2018). The enlarged insert demonstrates direct atmospheric $\mathrm{CH}_{4}$ measurements from 1984 to 2015, and the dashed grey line is a 12 month running mean fit. Data sources: black - data set from the EPICA D ome C ice core record (data from IGBP PA GES/W orld Data Center for Paleoclimatology, Data Contribution Series \# 2008-054) (L oulergue et al., 2008); blue- merged data set from the Law D ome ice core and firn measurements and Cape Grim atmospheric measurements (Etheridge et al., 1998; Trudinger et al., 2002; Ferretti et al., 2005; M acFarling M eure et al., 2006) (data from IG B P PA GES/W orld Data Center for Paleoclimatology, Data Contribution Series \# 2010-070); and red-global average CH4 mole fraction from direct atmospheric measurements (T sutsumi et al., 2009)(data from W orld Date Center for Greenhouse Gases, W M 0 G reenhouse Gas Bulletin, N 0.12, 2016). 
A tmospheric methane concentration has risen substantially to more than $1800 \mathrm{ppb}$, compared to preindustrial times when the concentrations ranged from 300 to $800 \mathrm{ppb}$ (Fig. 1). Over the industrial period (about 200 years) concentrations increased until the 1990s and stabilized after 2000, which was followed by a new increase in methane concentrations since 2007 until today (Dlugokencky et al., 2009; Nisbet et al., 2014). Past atmospheric methane concentrations are mainly estimated from air which is trapped in polar ice and firn cores (W olff and Spahni, 2007; Sapart et al., 2013) and the oldest methane record only dates back to the Pleistocene (L oulergue et al., 2008). Natural variations in past atmospheric methane concentration were mainly controlled by the 100,000 year orbital cycle of glacial and interglacial periods, the so-called Milankovitch cycles (Loulergue et al., 2008): Low atmospheric $\mathrm{CH}_{4}$ concentrations appeared in the glacial periods whereas high atmospheric methane concentrations were seen during warmer interglacial times. The 23,000 year orbital cycle, related to changes in the Earth's rotational axis, influenced the methane concentrations from 400,000 to 5,000 years ago (Ruddiman, 2003). U nfortunately, quantitative atmospheric methane records prior to the Pleistocene are still unexplored due to the lack of reliable proxies.

To understand the atmospheric methane cycle, it is important to understand the natural sources and sinks which strongly influence global climate feedback mechanisms (Fig. 2). There are various natural and anthropogenic sources emitting methane into the atmosphere. The biggest natural source of methane are wetlands, while other sources include freshwater systems, thawing permafrost, methane hydrates, marine sediments and oceans, diverse fauna and geological sources like hydrocarbon seeps (Reeburgh, 2007; Saunois et al., 2016; Dean et al., 2018). A nthropogenic methane sources include agriculture, waste, biomass burning and fossil fuels (Schwietzke et al., 2016; Dean et al., 2018). $M$ ethane is commonly classified into thermogenic or biogenic derived methane, which feature distinct stable carbon isotopic signatures $\left(\delta^{13} C\right.$ ) (Bernard et al., 1978; Whiticar, 1999). Thermogenic methane is found mainly in gas and petroleum reservoirs, is formed by thermal cracking of buried organic matter at high temperatures and pressure (J udd, 2004; Peters et al., 2005), and shows $\delta^{13} \mathrm{C}$ values of -50 to $-20 \%$. In contrast, the largest source of methane is of biogenic origin and is produced by strictly anaerobic microbes namely methanogenic Euryarchaeota (e.g. from the orders M ethanosarcinales or M ethanomicrobiales) (Deppenmeier et al., 1996; Liu and Whitman, 2008; Thauer et al., 2008). Microbial methanogenesis is the terminal step of anaerobic organic matter degradation and is controlled by the abundance of degradable organic matter. $M$ ethanogenic archaea convert $\mathrm{CO}_{2}$ (with $\mathrm{H}_{2}$ ), acetate, methanol, methylamines, 
or methylsufides into methane via three main biogenic pathways: hydrogenotrophic, methylotrophic or acetoclastic methanogenesis (Deppenmeier et al., 1996; Ferry, 1999; W elte and Deppenmeier, 2014). The biological process of methanogenesis yields strongly ${ }^{13} \mathrm{C}$-depleted methane values ranging from -110 to $-50 \%$.

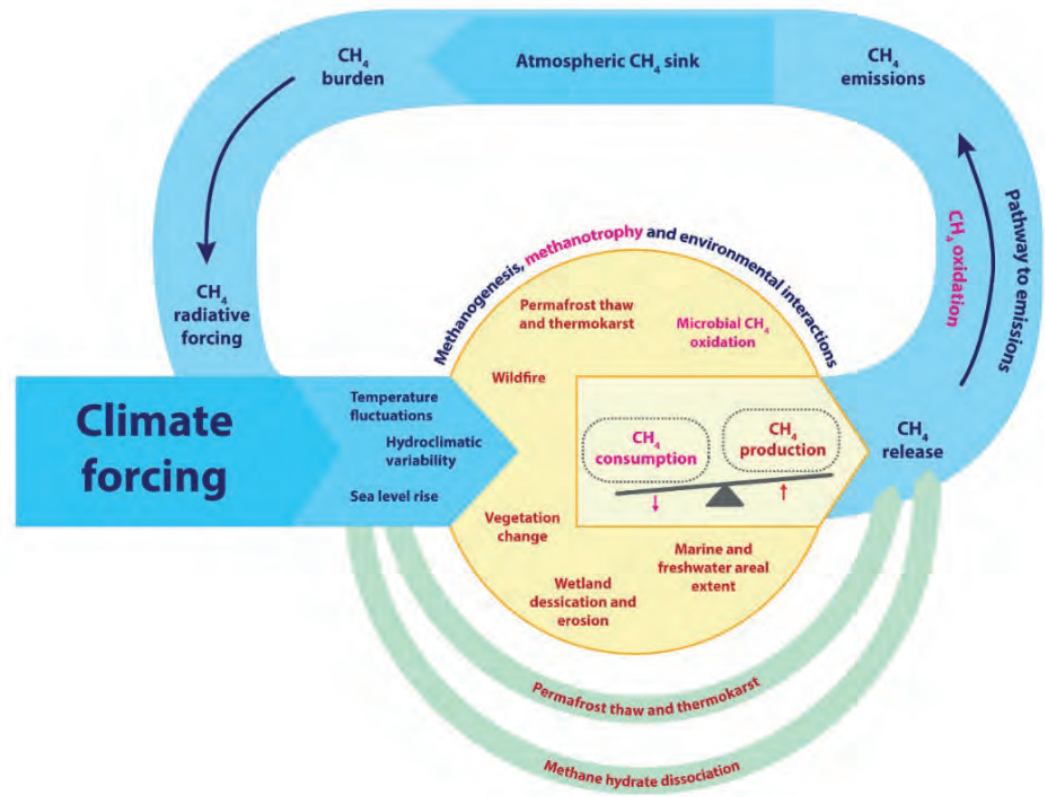

Figure 2 M ethane climate feedback schematic (modified after Dean et al., 2018). The schematic shows each feedback mechanism (within the yellow circle) is forced by climate change, affecting $\mathrm{CH}_{4}$ emissions to the atmosphere. Direct $\mathrm{CH}_{4}$ feedbacks are demonstrated in green arrows, indirect feedbacks are within the yellow circle, and processes of $\mathrm{CH}_{4}$ consumption are shown in pink. The positive $\mathrm{CH}_{4}$ climate feedback cycle is shown in blue.

The largest sink for atmospheric methane is the oxidation by $\mathrm{OH}$ radicals in the troposphere where about $85 \%$ of methane is oxidized. During this process, methane oxidation leads to $\mathrm{O}_{3}$ formation, followed by the production of $\mathrm{H}_{2} \mathrm{O}$ vapor in the stratosphere leading to radiative forcing and finally the $\mathrm{C}$ atom ends up in the form of $\mathrm{CO}_{2}$ (M yhre, 2014). Besides the oxidation of methane in the stratosphere, both biogenic and thermogenic methane are converted to $\mathrm{CO}_{2}$ by anaerobic or aerobic microbial oxidation processes in many terrestrial and marine environments ( $H$ anson and Hanson, 1996; B oetius et al., 2000; $V$ alentine and Reeburgh, 2000; K ip et al., 2010). Terrestrial environments, and especially soils, are one of the largest sinks for atmospheric methane, taking up to 10-15\% of methane worldwide by aerobic methanotrophic bacteria (Hanson and $\mathrm{H}$ anson, 1996; Bull et al., 2000; Smith et al., 2000; Delgado-B aquerizo et al., 2018). In marine environments, most methane is oxidized microbially by the anaerobic oxidation of methane in anoxic sediments or in the water column via the aerobic 
oxidation of methane before reaching the atmosphere (Hinrichs et al., 1999; Valentine and Reeburgh, 2000; Orphan et al., 2001; Reeburgh, 2007). These processes are discussed in more detail below.

\subsection{M icrobial oxidation of methane}

\subsubsection{Anaerobic oxidation of methane}

In the late 1970s the first indications of anaerobic oxidation of methane (A OM) were discovered from geochemical calculations on porewater profiles in anoxic marine environments, but the microbes involved were only identified two decades later (Hinrichs et al., 1999; B oetius et al., 2000; Pancost et al., 2000). AOM is conducted by anaerobic methanotrophic archaea (ANME type 1, 2 and 3) which belong to the Euryarchaeota and are found primarily in marine environments (Hinrichs et al., 1999; B oetius et al., 2000; Pancost et al., 2000; Orphan et al., 2001). The different clades of A N M E-archaea are phylogenetically closely related to methanogenic Euryarchaea and perform the reverse methanogenesis pathway (Hinrichs et al., 1999; K rüger et al., 2003; Hallam et al., 2004). In marine sediments, ANME-archaea form consortia with sulfatereducing bacteria (SRBS), which create sulfate-methane transitions zones in marine sediments via sulfate-dependent AOM processes ( $K$ nittel and Boetius, 2009). Furthermore, AN M E-1 and A NME-2 archaea often form consortia with Desulfosarcina and D esulfococcus while AN ME-3 archaea form consortia with Desulfobulbus. However, they can also exist without SRB -partners (B oetius et al., 2000; Orphan et al., 2001; Niemann et al., 2006).

Besides sulfate-dependent $A O M$, nitrate-dependent $A O M$ was more recently discovered in ANME-2d archaea, namely 'Candidatus Methanoperedens nitroreducens', living in freshwater ecosystems (Haroon et al., 2013; A rshad et al., 2015; V aksmaa et al., 2017). A N M E-2d archaea can coexist with a bacterial partner, 'Candidatus M ethylomirabilis oxyfera' ('Ca. M . oxyfera'). Although 'Ca. M. oxyfera' performs nitrite-dependent methane oxidation under anoxic conditions by reducing nitrite to nitric oxide, it is thought to produce its own intracellular oxygen from nitric oxide for the intra-aerobic oxidation of methane (Raghoebarsing et al., 2006; Ettwig et al., 2008, 2010). M oreover, it has been shown that ' $\mathrm{Ca}$. M. oxyfera' fixes carbon autotrophically by solely using inorganic carbon (K ool et al., 2012, 2014; Rasigraf et al., 2014). ' C a. M . oxyfera' can be found mainly in freshwater sediments or peatlands but was al so recently detected in marine environments (Padilla et al., 2016). In addition, some specific types of methane-oxidizing bacteria like M ethylomonas denitrificans have been shown to be able to oxidize methane under anoxic conditions via nitrate and oxygen reduction ( $K$ its et al., 2015). 


\subsubsection{Aerobic oxidation of methane}

In terrestrial and marine environments, microbial mediated aerobic oxidation of methane plays a key role in oxidizing methane before reaching the atmosphere (Bull et al., 2000; Bodelier et al., 2009; Bowman, 2011). A erobic methane oxidising bacteria (M OBs) are divided into three phylogenetic groups based on their metabolism and morphology: Type I methanotrophs (Gammaproteobacteria), Type II methanotrophs (Alphaproteobacteria) and the (thermo)acidophilic Verrucomicrobia (Hanson and Hanson, 1996; Pol et al., 2007; Op den Camp et al., 2009).

Type I methanotrophs can be classified into the families $M$ ethylococcaceae or Methylothermaceae, which are only known to contain methanotrophic bacteria (Hirayama et al., 2014; Knief, 2015). Type I methanotrophs live mainly in methane-rich terrestrial and marine environments where they fix carbon via the ribulose monophosphate pathway and solely utilize methane as their carbon and energy source (Hanson and Hanson, 1996; K nief, 2015). Some members of the M ethylococcaceae family are also able to utilize higher gaseous hydrocarbons (ethane and propane) in environments where gas or petroleum seepage occurs (K innaman et al., 2007; R edmond et al., 2010). In addition to Type I methanotrophs, a group of gram-positive organisms in the Corynebacterium-N ocardia-M ycobacterium-R hodococcus group (Dworkin and Foster, 1958; Ashraf et al., 1994) as well as some gram-negative Pseudomonas species are able to oxidize higher gaseous hydrocarbons in the environment (Hamamura et al., 1997; T akahashi, 1980).

Type II methanotrophs belong to two families, the M ethylocystaceae and Beijerinckiaceae, which also include various non-methanotrophic genera (K nief, 2015). Type II methanotrophs use the serine cycle for carbon fixation and might assimilate only part of their carbon from methane oxidation, while the rest originates from $\mathrm{CO}_{2}$ (Hanson and Hanson, 1996). Type II methanotrophs are commonly found in the terrestrial realm where they can utilize moderate to low and even atmospheric methane concentrations (Holmes et al., 1999; Bull et al., 2000).

Finally, Verrucomicrobia are phylogenetically distinct from the Type I and II methanotrophic Proteobacteria and were first discovered in a fumarole where they perform aerobic oxidation of methane under high temperature and low pH conditions ( $\mathrm{Pol}$ et al., 2007; Op den Camp et al., 2009; van Teeseling et al., 2014). Two genera of methanotrophic Verrucomicrobia the "Methylacidiphilum" (i.e. Methylacidimicrobium cyclopophantes) and the "M ethylacidimicrobium" (i.e. Methylacidiphilum fumariolicum) (Pol et al., 2007; Op den Camp et al., 2009; van Teeseling et al., 2014), have been shown 
to use both methane and $\mathrm{CO}_{2}$ as their carbon source. Similar to Type II methanotrophs, they fix carbon by the ribulose-1,5-bisphosphate carboxylase/oxygenase pathway (K hadem et al., 2011).

The three groups of MOBs all contain the methane monooxygenase enzyme, which uses $\mathrm{O}_{2}$ for the initial conversion step of methane to methanol (Hanson and Hanson, 1996; K nief, 2015). There are two forms of this enzyme, i.e. the soluble methane monooxygenase (SMMO) and the membrane bound particulate methane monooxygenase (pMMO) (Hanson and Hanson, 1996; $M$ cDonald et al., 2008). The gene encoding for the $\beta$-subunit of the particulate methane monooxygenase ( $\mathrm{pmoA}$ ) is frequently used as a marker to trace M OBs in modern environments since it is present in most M OB-species (Hanson and Hanson, 1996; M cD onald et al., 2008; Ettwig et al., 2010).

\subsection{Biomarkers to trace past microbial oxidation of methane}

Much is known about the present-day role of aerobic and anaerobic methane oxidizers in marine and terrestrial realms, primarily by using DNA based techniques. However, much less is known about their role in the past as DNA is usually not preserved well over very long-time scales (H ofreiter et al., 2001; B rocks and Pearson, 2005; B oere et al., 2011). Combined with the lack of proxies for past atmospheric methane concentrations, this leads to a gap in our understanding of the impact of climate on the methane cycle and vice versa.

One approach to solve this is to use molecular fossils such as biomarkers, which are organic compounds revealing specific information about present and past biogeochemical cycles. Lipid biomarkers are synthesized by defined groups of microorganisms and can thus serve as an indicator for the presence of certain classes of microbes (M adigan et al., 1997; B rocks and Pearson, 2005; Peters et al., 2005; Killops and Killops, 2013). These lipid biomarkers are preserved over long timescales and can reflect for example global climate changes, anoxic conditions in the water column or the role of microbial communities in extreme environments (B rassell et al., 1986; Summons and Powell, 1986; Hinrichs et al., 1999; Brocks et al., 2005). Typical lipid biomarkers biosynthesized by eukaryotes are e.g. steroids (V olkman, 2003), while archaea produce archaeol and glycerol dialkyl glycerol tetraether lipids (GDGTs) (Tornabene and Langworthy, 1979; Schouten et al., 2013) and some bacteria synthesize e.g. hopanoids (Ourisson et al., 1979; Zundel and Rohmer, 1985; Ourisson and A lbrecht, 1992).

Lipid biomarkers characteristic for anaerobic and aerobic methanotrophs can often be detected through their depleted carbon isotope values $\left(\delta^{13} C\right)$ (F reeman et al., 1990; Hayes, 1993; Hayes, 2001). 
As discussed above, biogenic methane is often characterized by a strong depletion in ${ }^{13} \mathrm{C}$ (W hiticar, 1999). M ethane oxidizers often do not only oxidize methane to $\mathrm{CO}_{2}$ but also utilize this methane and/or $\mathrm{CO}_{2}$ for synthesis of their biomass, and therefore for their lipids, which aids in the recognition of past processes of methane oxidation. The depletion of the ${ }^{13} \mathrm{C}$ isotopic values of lipids that derive from methanotrophs depend on the source of methane (thermogenic or biogenic) as well as the pathway of carbon fixation (pM M 0 or SM M O) in the different microbial species (J ahnke et al., 1999). A s discussed in section 1.2.2, Type I M OBs assimilate solely $\mathrm{CH}_{4}$ as their carbon and energy source leading to strongly depleted ${ }^{13} \mathrm{C}$ lipid values, while Type II MOBs, Verrucomicrobia and ' $\mathrm{C}$ a. M. oxyfera' also assimilate $\mathrm{CO}_{2}$ or inorganic carbon and their lipids can show less depleted ${ }^{13} \mathrm{C}$ values. Stable isotope probing (SIP) experiments with ${ }^{13} \mathrm{C}$-labeled methane in environmental samples can also give insight into lipid biomarkers derived from methanotrophs and their methane consumption rate (e.g. B oschker et al., 1998; B ull et al., 2000; Evershed et al., 2006; M axfield et al., 2006; K ellermann et al., 2012). The lipid biomarkers most characteristic for methanotrophs are discussed in more detail below.

Table 1 Characteristic lipid biomarker for microbes involved in anaerobic and aerobic oxidation of methane based on culture and environmental studies. $\mathrm{Key}$ : $\mathrm{ANME}=$ anaerobic methanotrophic archaea; GDGT= glycerol dialkyl glycerol tetraether; $\mathrm{PMI}=2,6,10,15,19$-pentamethyleicosane; $\mathrm{OH}=$ hydroxy; $\mathrm{PH}=$ phosphatidyl hexose; $P G=$ phosphatidyl glycerol; $M A G E=$ non-isoprenoidal mono glycerol ethers; DAGE= non-isoprenoidal dialkyl glycerol ethers; $\mathrm{FAs}=$ fatty acids; $\mathrm{BHP}=$ bacteriohopanepolyol; aminopentol $=35$ aminobacteriohopane-30,31,32,33,34-pentol; aminotetrol=35-aminobacteriohopane-31,32,33,34-tetrol, 3-M e B Hhexol=3-methyl bacteriohopane-30,31,32,33,34,35-hexol.

\section{Methane} oxidation

\section{Phylogeny}

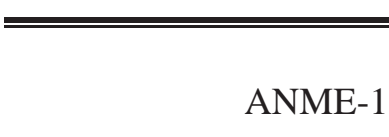

ANME-2

\section{Anaerobic ${ }^{1}$}

ANME-3

SRBS-

Deltaproteobacteria

(i.e. Desulfosarcina)

\section{Main diagnostic lipids}

PM I, GDGTs (mainly GDGT-1 to

GDGT-3 bound to diglycosidic polar headgroups)

PMI, GDGTs \& OH-GDGTs, archaeol $\&$ sn2-OH-archaeol (bound to polar headgroups e.g. PH or dihexose)

A rchaeol \& sn2-OH-archaeol bound to e.g. PG or PH polar headgroups

MAGEs \& DAGEs, characteristic FAs (e.g. i $\mathrm{i}_{15: 0} \&$ ai $\mathrm{C}_{15: 0}, \mathrm{C}_{16: 1 \omega 5}, 10 \mathrm{M}$ e $\mathrm{C}_{16: 0}$ ) 


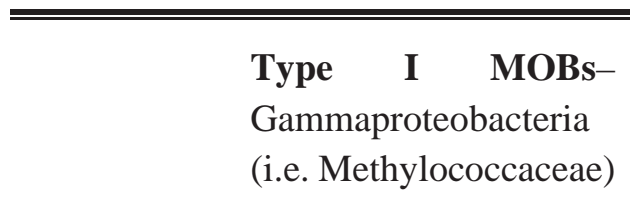

Type II MOBsAerobic $^{2} \quad$ Alphaproteobacteria (i.e. M ethylocystaceae)

Verrucomicrobia (i.e. M ethylacidimicrobium)

'Ca. M. oxyfera'

(intra-aerobic methane oxidation)
BHPS: aminopentol \& aminotetrol, 3$\mathrm{Me}$ aminoBHPs, Characteristic FAs $\left(C_{14: 0}, C_{16: 0}, C_{16: 1}=C_{16: 1 \omega 8 c}\right.$ and $\left.C_{16: 1 \omega 5 t}\right)$, 3-M e hopanoids (e.g. diplopterol)

B HPs: aminotetrol Characteristic FAs $\left(C_{18: 0,}, C_{18: 1}=C_{18: 1 \omega 8 c} \& C_{18: 1 \omega 7 c}, C_{18: 2}=\right.$ $\mathrm{C}_{18: 2 \omega 7 \mathrm{c}, 12 \mathrm{c})}$

BHPs: high aminotriol \& early eluting aminotetrol, Characteristic FAs ( $\mathrm{iC}_{14: 0}$, $\left.\mathrm{aiC}_{15: 0}, \mathrm{iC}_{18: 0}\right)$

\section{3-M e B Hhexol, Characteristic FA}

(10M eC 16:1 $1 \Delta 7$ )

${ }^{1}$ (Pancost et al., 2001b; Schouten et al., 2003; B lumenberg et al., 2004; Niemann and Elvert, 2008; Rossel et al., 2011); ' (Bull et al., 2000; Crossman et al., 2005; Dedysh et al., 2007; Tal bot and Farrimond, 2007; Coolen et al., 2008; B odelier et al., 2009; Op den Camp et al., 2009; van Winden et al., 2012; K ool et al., 2012, 2014; Talbot et al., 2014).

\subsubsection{Lipid biomarkers for anaerobic oxidation of methane}

Sulfate-dependent AOM can be traced by using lipids which derive from A N M E-archaea such as ${ }^{13} \mathrm{C}$ depleted 2,6,10,15,19-pentamethyleicosane (PM I), archaeol and hydroxyarchaeol as well as specific isoprenoidal or intact GDGTs (Table 1 and Fig. 3; structures 1-3) (Hinrichs et al., 1999; Pancost et al., 2000; W akeham et al., 2004). A N M E-1 are known to synthesize mainly GDGTs bound to diglycosidic polar headgroups, while ANME-2 species produce also high amounts of archaeol and hydroxy-archaeol next to GDGTs bound to diverse polar headgroups like dihexose (B lumenberg et al., 2004; Niemann and Elvert, 2008; Rossel et al., 2011; K ellermann et al., 2012). A N M E-3 synthesize only archaeol and hydroxyarchaeol and no GDGTs (Niemann and Elvert, 2008; Rossel et al., 2011). A N M Es can live in consortia with SR BS, which al so produce some specific lipid biomarkers depleted in ${ }^{13} \mathrm{C}$ such as non-isoprenoidal mono and dialkyl glycerol ethers (M A GEs and DAGEs) as well as some characteristic fatty acids (e.g. $\mathrm{iC}_{15: 0} \&$ ai $\mathrm{C}_{15: 0,}, \mathrm{C}_{16: 1 \omega 5}, 10 \mathrm{M}$ e $\mathrm{C}_{16: 0}$ ) (e.g. Pancost et al., 2000, 2001a; Elvert et al., 2003; B lumenberg et al., 2004, 2006).

\subsubsection{Lipid biomarkers for aerobic oxidation of methane}

A erobic methanotrophic bacteria synthesize several saturated and unsaturated phospholipid fatty acids (PLFAs) (Bowman et al., 1993; Bull et al., 2000; 
Bodelier et al., 2009). Type I methanotrophs synthesize high abundances of saturated and specific unsaturated $\mathrm{C}_{16}$ PLFAs (Fig. 3; structures 4 and $4 a$ ) of which some species (i.e. M ethylomonas) also produce $\mathrm{C}_{14}$ PLFA s, whereas Type II methanotrophs typically synthesize high amounts of saturated and specific unsaturated $\mathrm{C}_{18}$ PLFAs (Fig. 3; structures 5 and 5a) (Hanson and Hanson, 1996; Dedysh et al., 2007; Bodelier et al., 2009). Verrucomicrobia of the phylum $M$ ethylacidimicrobium have been shown to produce $C_{14: 0}, C_{15: 0}$ and $C_{18: 0}$ PLFAs (Op den Camp et al., 2009). The intra-aerobic methanotroph 'Ca. M oxyfera' produces the distinct $10 \mathrm{M} \mathrm{eC}$ 16:1 $1 \Delta 7$ PLFA (K ool et al., 2012). However, as PL FAs and fatty acids are not specific to MOBs, these lipids are only useful as biomarkers to trace aerobic oxidation of methane when combined with strongly depleted ${ }^{13} \mathrm{C}$ isotopic values. Furthermore, these lipids are generally not well preserved in the geological record, although sometimes fatty acids can be preserved as bound compounds in old sediments such as in the M iocene (A hmed et al., 2001).
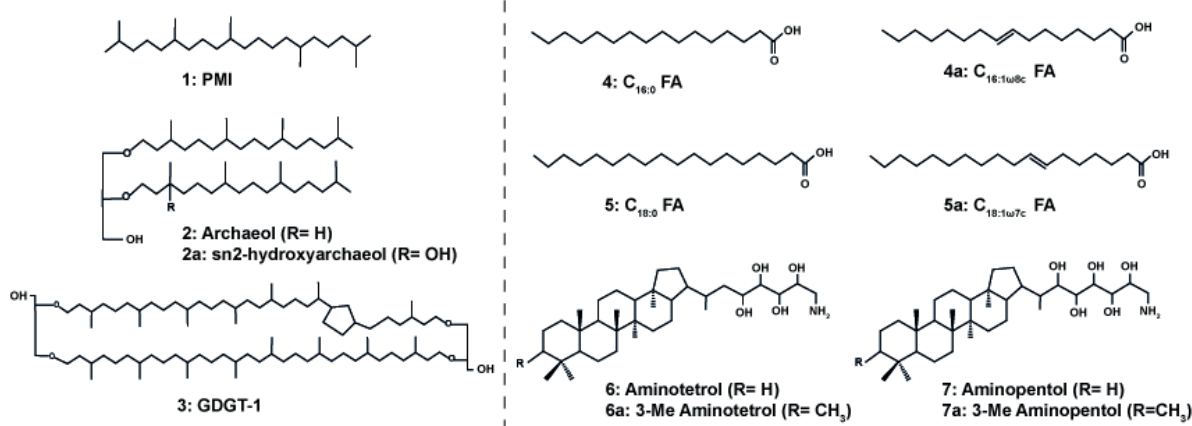

Figure3. Examples of lipid biomarkers indicative for microbial mediated anaerobic oxidation of methane (left column) and aerobic oxidation of methane (right column).

Some Type I methanotrophs (Methylococcus capsulatus and Methylosphaera hansonii) have been shown to produce highly characteristic methylated steroids depleted in ${ }^{13} \mathrm{C}$ detected for example in Ace Lake in A ntarctica or in the marine Haakon M osby mud volcano (Schouten et al., 2000; Elvert and Niemann, 2008). However, these sterols have not been frequently reported in ancient sediments and steroids are mostly sourced by eukaryotes.

Hopanoids and their intact precursors bacteriohopanepolyols (B HPs) are pentacyclic triterpenoids that can contain methylations at $\mathrm{C}-2$ or $\mathrm{C}-3$ and unsaturations at C- 6 and/or C-11 depending on their bacterial producers and preserve well over time (e.g. Rohmer et al., 1984; N eunlist and Rohmer, 1985; Zundel and Rohmer, 1985; Ourisson and Albrecht, 1992; Cvejic et al., 2000; Brocks et al., 2005). Large structural diversity has been observed in BHPs, especially in the extended polyfunctionalized side chains. Cultivated species of 
M OBs have been shown to produce a group of distinct B HPs, namely the $\mathrm{C}-35$ aminoB HPs containing an amine group at position C-35 and 3, 4 or 5 additional hydroxy groups on the side chain (Neunlist and Rohmer, 1985; Cvejic et al., 2000; Talbot and Farrimond, 2007; van Winden et al., 2012). Type I methanotrophs synthesize 35-aminobacteriohopane-30,31,32,33,34-pentol ('aminopentol'; Fig. 3; structure 7) and its unsaturated homologues, which have been detected in different terrestrial and marine environments like peats, geothermal sinters or sediments ( $N$ eunl ist and R ohmer, 1985; Cvejic et al., 2000; Gibson et al., 2008; van Winden et al., 2012; Tal bot et al., 2014). Furthermore, two additional amino-BHPs are produced by Type I and Type II methanotrophs as well as Verrucomicrobia: 35-aminobacteriohopane-31,32,33,34-tetrol ('aminotetrol'; Fig. 3; structure 6) and 35-aminobacteriohopane-32,33,34-triol ('aminotriol') (Talbot et al., 2001; Talbot and Farrimond, 2007; van Winden et al., 2012). A minotetrol is also synthesized in minor amounts by some SRBs of the genus $D$ esulfovibrio, whereas aminotriol is produced by a wide range of nonmethanotrophic bacteria such as cyanobacteria or SRB s (Neunlist et al., 1985; B lumenberg et al., 2006; Talbot and Farrimond, 2007). Thus, aminotriol is less source-specific than aminotetrol and aminopentol to trace MOBs in the environment.

Methylation at the C-3 position in BHPs and aminoBHPs (Fig. 3; structures 6a and 7a) as well as in hopanoids (e.g. 3-methyl diplopterol) was previously suggested to be highly specific to Type I methanotrophs like Methylococcus spp. and Methylocaldum spp. (Neunlist and Rohmer, 1985; Cvejic et al., 2000). Furthermore, 3-methyl BHPs have also been identified in the intra-aerobic methanotroph ' $\mathrm{Ca}$. M . oxyfera', which synthesizes the specific 3-Me BHhexol (3-methyl bacteriohopane-30,31,32,33,34,35-hexol) as well as other more common BHPs (Kool, et al., 2014). However, the hpnR gene responsible for the $\mathrm{C}-3$ methylation in hopanoids was only found in a limited number of methanotrophic bacteria as well as in other bacterial species (W elander and Summons, 2012). N evertheless, the combination of 3-methylated hopanoids and depleted ${ }^{13} \mathrm{C}$ isotopic signals are often used to trace MOBS (Summons et al., 1994; Jahnke et al., 1999; Birgel and Peckmann, 2008). However, Type II methanotrophs and Verrucomicrobia assimilate both $\mathrm{CH}_{4}$ and $\mathrm{CO}_{2}$ and hence their PLFAs and hopanoids show less depleted ${ }^{13} \mathrm{C}$ values.

\section{Scopeand outline of this thesis}

To this date, there are only a few unambiguous biomarkers for methanotrophs to trace microbes involved in the aerobic oxidation of methane, especially in the terrestrial realm. Paleorecords of lipid biomarkers mainly focused on marine 
methane seep systems and much less on terrestrial environments despite soils being the biggest microbial sink for atmospheric methane. Therefore, there is an urgent need for the development of new reliable biomarkers to study the presence of methanotrophs, especially in modern and past terrestrial environments. This thesis aims to expand the current toolbox of characteristic biomarkers used to trace aerobic and anaerobic oxidation of methane and other hydrocarbon gasses.

In Chapter $\mathbf{2}$ the lipid biomarker inventory of the intra-aerobic methanotroph 'Candidatus M ethylomirabilis oxyfera' ('Ca. M . oxyfera') performing nitritedependent methane oxidation under anoxic conditions was investigated. The gas chromatography-amenable hopanoids were dominated by four demethylated hopanoids, of which only one (22,29,30-trisnorhopan-21-one) had been identified previously. We tentatively identified three novel hopanoids as 22,29,30-trisnorhopan-21-ol, 3-methyl-22,29,30-trisnorhopan-21-one and 3methyl-22,29,30-trisnorhopan-21-ol as well as potential candidate genes responsible for the demethylation in hopanoids via bioinformatical analysis. $A$ sensitive multiple reaction monitoring method was developed to trace these four trisnorhopanoids in complex environmental sample matrices. This new method successfully detected the new hopanoids in a peatland profile where ' $\mathrm{Ca}$. $\mathrm{M}$. oxyfera' had been identified before via DNA -based techniques. Thus, the novel trisnorhopanoids may offer a new tool to detect nitrite-dependent methane oxidation in modern and past environments.

Chapter 3 explores for the first time the lipid inventory of intact and core archaeal lipids of ANME-2d archaea ('Candidatus M ethanoperedens'), which synthesize archaeol and hydroxyarchaeol as well as isoprenoidal GDGTs and hydroxy-GDGTs, and occur with the intact polar headgroups dihexose, phosphatidyl-hexose and the rare monopentose. Moreover, SIP incubations using ${ }^{13} \mathrm{C}$ labeled bicarbonate and methane show that ANME-2d archaea assimilate mainly methane and to a lower extent dissolved inorganic carbon (DIC), which is different to ANME-1 archaea that assimilate solely DIC. The differences in the lipid inventory and the carbon assimilation pathway of A NME$2 \mathrm{~d}$ archaea distinguishes them from other ANME species in microbial cultures and in environmental settings.

In Chapter 4, lipid biomarkers indicative for aerobic and anaerobic oxidation of methane were analyzed in three prominent terrestrial Sicilian mud volcanoes (M V s) (M accalube di A ragona, Comitini and Santa Barbara). Freshly emitted mud breccias showed a high abundance of petroleum-derived hydrocarbons 
compared to lipids from recent microbes in all three M V s. Saturated hydrocarbon biomarkers indicate that the mud breccias from the three M V s originate from a similar mix of mature marine carbonate or marl source strata and immature terrestrial strata with slightly more mature organic matter in the $\mathrm{M}$ accalube di A ragona mud breccias. O nly a few microbial lipid biomarkers such as fatty acids and $17 \beta, 21 \beta(\mathrm{H})$ hopanoic acids were found in the MVs. However, they were not substantially depleted in ${ }^{13} \mathrm{C}$, which would allow to attribute them to M OBs. In contrast, isoprenoidal GDGT distributions and a high GDGT-based Methane index $\geq 0.9$ in the Maccalube di Aragona MV suggested the presence of A NMEarchaea involved in anaerobic oxidation of methane at this M V. For the first time these results show characteristic GDGT patterns for anaerobic oxidation of methane involved ANME-archaea in a terrestrial MV system. The other two M V s Santa B arbara and Comitini only showed GDGT distribution indicative of Thaumarchaeota and not for microbes involved in the anaerobic oxidation of methane. Our results imply that microbial processes other than $\mathrm{CH}_{4}$ oxidation may play a major role in terrestrial M V s in contrast to marine $\mathrm{MV} \mathrm{s}$, which host a higher abundance and diversity of ${ }^{13} \mathrm{C}$-depleted lipid biomarkers indicative of aerobic and anaerobic oxidation of methane.

In Chapter 5 a novel method to detect underivatized bacteriohopanepolyol derivatives using UHPLC coupled to electrospray ionization-high resolution multi-stage MS (HRM S ${ }^{2}$ ) was developed. This method provides mass spectra, which show typical fragmentation patterns of the BHP core, the functionalized side chain and the head group in case of composite BHPs. Common B HPS and their methylated and (di)unsaturated homologues as well as aminoBHPs and numerous composite BHPs were detected in bacterial cultures applying this novel technique. In addition, over 130 individual B HPs were identified in a soil near a methane seep (Fuoco di Censo everlasting fire in Sicily, Italy). This soil contains a complex distribution of known and novel adenosylhopanes typical for soils, of which the head group compositions of both adenosylhopane type-2 and type-3 could be identified for the first time. Furthermore, we detected a novel series of BHPs that are conjugated to an ethenolamine moiety. These novel ethenolamineB HPs as well as aminoB HPs were identified acylated to a range of fatty acids. This new analytical method allows simultaneous analysis of the full suite of IPLs including BHPs and is an essential step forward in the detection and application of novel BHPs as well as in environmental lipidomics.

In Chapter $\mathbf{6}$ we apply the novel underivatized B HP method from Chapter 5 to two terrestrial methane seep transects (Bissana and Censo seep) in Sicily, Italy. 
16S rRNA gene sequencing showed the presence of Type I and Type II methanotrophs at both seeps, while methanotrophic Verrucomicrobia were only present at the Censo seep. The Bissana and Censo seeps show high relative abundances of the three aminoB HPs (aminotriol, aminotetrol and aminopentol), as well as the recently identified ethenolamine-BHPs (ethenolamine-BHT, $\mathrm{BH}$ pentol and -BH hexol) and $\mathrm{N}$-acyl-aminotriols at, and close to, the active seep sites. 3-methyl aminoB HPs were detected at the Bissana seep, but not at the Censo seep. A minoB H Ps cluster together with the novel ethenolamineB HPs and $\mathrm{N}$-acyl-aminotriols using principal component analysis (PCA) thus suggesting an origin from likely aerobic methanotrophs at both Sicilian seeps. B esides, the Censo seep showed high relative abundances of a novel late-eluting aminotriol isomer, which was also identified in the verrucomicrobial strain, $M$ ethylacidimicrobium cyclopophantes 3B, suggesting it as a new biomarker for Verrucomicrobia. Both transects showed increasing relative abundances of soilmarker B HPs (i.e. adenosylhopane) with increasing distance from the seeps. A new index (A minoB HP-index) was developed based on selected BHPs, which Shows high values close to the seeps $(\geq 0.4)$ and drop to $<0.2$ at distances $>3 \mathrm{~m}$ from the active seeps. The novel AminoBHP-index offers a new biomarker proxy to reconstruct present and past aerobic oxidation of methane in the terrestrial realm.

Chapter 7 describes the analysis of fatty acid biomarkers in soils from the natural everlasting fire of Fuoco di Censo (Censo seep) in Sicily, Italy. The soils at and close to the seep show high relative abundances of sequences of novel mycobacteria which are phylogenetically close to the Mycobacterium simiae complex and more distant from well-studied pathogenic mycobacteria like M. tuberculosis. Interestingly, the soils contain high abundances of mycocerosic acids (MAs), fatty acids typical for mycobacteria, which decrease with increasing distance from the seep. The major M A at this seep was tentatively identified as 2,4,6,8-tetramethyl tetracosanoic acid. Other unusual MAs with mid-chain methyl branches at positions $\mathrm{C}-12$ and $\mathrm{C}-16$ were also present but in lower abundances. The molecular structures of the Censo seep M A s appear to be different from those of well-studied mycobacteria like $M$. tuberculosis and have ${ }^{13} \mathrm{C}$-depleted values, suggesting a direct or indirect utilization of gases like methane or ethane at the everlasting fire.

To assess the hypothesis that M A s originate from mycobacteria using seep gases, we performed stable isotope probing (SIP) using ${ }^{13} \mathrm{C}$-label ed methane and ethane $\left(\mathrm{C}_{2} \mathrm{H}_{6}\right)$ with the Censo seep soils in Chapter 8 SIP incubations with methane 
and ethane show a ${ }^{13} \mathrm{C}$ label incorporation into regular and unsaturated $\mathrm{C}_{16}$ and $\mathrm{C}_{18}$ fatty acids, indicating Type I and Type II methanotrophs are able to not only oxidize methane but also ethane at the Censo seep. In contrast, ${ }^{13} \mathrm{C}$ label incorporation in MAs was only observed in the ${ }^{13} \mathrm{C}_{2} \mathrm{H}_{6}$ incubations and not in those with ${ }^{13} \mathrm{CH}_{4}$. This suggests that mycobacteria present at the Censo seep oxidize ethane, and probably also higher gaseous hydrocarbons, but not methane, which is in agreement with previous studies on mycobacteria. Soil mycobacteria might be an important group of microbes oxidizing gaseous higher hydrocarbons in global terrestrial gas seeps and soils. Therefore, the structurally distinct M A s in combination with ${ }^{13} \mathrm{C}$ depleted signatures offer a new biomarker tool to trace hydrocarbon gas consuming mycobacteria in present and past environments.

In summary, the results of this thesis offer new lipid biomarker and proxies to trace methane as well as higher gaseous hydrocarbon oxidizing microbes, especially in terrestrial environments. The results of this study have therefore substantially expanded the toolbox for organic geochemists and may be tested and applied to trace past methane and higher gaseous hydrocarbon cycles in present and past environments in the future. 
| Chapter 1 


\section{Chapter 2}

Demethylated hopanoids in ' $\mathrm{Ca}$. Methylomirabilis oxyfera' as biomarkers for environmental nitrite-dependent methane oxidation

Nadine T. Smit, Darci Rush, Diana X. Sahonero-Canavesi, Monique

Verweij, Olivia Rasigraf, Simon Guerrero Cruz, Mike S.M. Jetten, Jaap S.

Sinninghe Damsté, Stefan Schouten

Published in Organic Geochemistry 


\section{Abstract}

Hopanoids are lipids that are widespread in the bacterial domain and established molecular biomarkers in modern and paleo environments. In particular, the occurrence of ${ }^{13} \mathrm{C}$-depleted 3-methylated hopanoids are characteristic of aerobic bacteria involved in methane oxidation. Previously the intra-aerobic methanotroph 'Candidatus M ethylomi rabilis oxyfera' ('Ca. M . oxyfera'), which performs nitrite-dependent methane oxidation in anoxic environments, has been shown to synthesize bacteriohopanepolyols (BHPs) and their 3-methylated counterparts. However, since 'Ca. M. oxyfera' is not utilizing methane as a carbon source, its biomass and lipids do not show the characteristic ${ }^{13} \mathrm{C}$ depletion. Therefore, the detection of ' $\mathrm{Ca}$. M . oxyfera' in various environments is challenging, and still underexplored. Here, we re-investigated the hopanoid content of ' $\mathrm{Ca}$. M . oxyfera' bacteria using enrichment cultures. We found the GC-amenable hopanoids of 'Ca. M. oxyfera' to be dominated by four demethylated hopanoids of which only one, 22,29,30-trisnorhopan-21-one, had been identified previously. The three novel hopanoids were tentatively identified as 22,29,30-trisnorhopan-21-ol, 3-methyl 22,29,30-trisnorhopan-21-one and 3methyl 22,29,30-trisnorhopan-21-ol. These unique demethylated hopanoids are most likely biosynthesized directly by 'Ca. M. oxyfera' bacteria and bioinformatical analysis of the 'Ca. M. oxyfera' genome revealed potential candidate genes responsible for the demethylation of hopanoids. For the sensitive detection of the four trisnorhopanoid biomarkers in environmental samples, a multiple reaction monitoring (MRM) method was developed and used to successfully detect the trisnorhopanoids in a peatl and where the presence of ' $\mathrm{Ca}$. M . oxyfera' had been confirmed previously by DNA-based analyses. These new biomarkers may be a novel tool to trace nitrite-dependent methane oxidation in various (past) environments.

\section{Key words}

demethylated hopanoids; Candidatus Methylomirabilis oxyfera; nitritedependent methane oxidation; trisnorhopanoids; 3-methyl 22,29,30trisnorhopan-21-one; methylation

\section{Introduction}

Hopanoids are pentacyclic triterpenoids that modify the properties of membranes in micro-organisms and can serve as molecular biomarkers in modern and paleo environments (Ourisson et al., 1979; O urisson and A lbrecht, 1992). They are biosynthesized by different bacterial phyla and have been used to trace back the presence of these bacteria as far as the Proterozoic (B rocks et al., 2005). It was 
previously believed that hopanoids indicate oxic environmental conditions, however this changed with the discovery of hopanoid biosynthesis in anaerobic bacteria such as fermentative bacteria (N eunlist et al., 1985; L lopiz et al., 1992), anammox bacteria (Sinninghe Damsté et al., 2004), sulfate reducing bacteria (SRB) (Desulfovibrio) (Blumenberg et al., 2006; Blumenberg et al., 2012) and bacteria of the Geobacter genus (Eickhoff et al., 2013). The molecular structures of hopanoids synthesized by bacteria are structurally very diverse and range from simple $C_{30}$ hopanols, such as diplopterol, to extended $C_{35}$ polyols known as bacteriohopanepolyols (BHPs). During diagenesis, these hopanoids can be abiotically or microbially altered (Rohmer and Ourisson, 1976; Albaiges and Albrecht, 1979) resulting in demethylation, aromatization, sulfurization, skeleton rearrangements and loss or transformation of functional groups. Both BHPs and derived diagenetic products are extensively used as lipid biomarkers for (specific) microbial communities and their metabolic role in modern and ancient ecosystems (e.g. B rocks and Pearson, 2005; Tal bot et al., 2007).

One important example is the use of hopanoids to trace microbes involved in methane oxidation. BHPs with penta- and hexa-functionalized side chains containing an amine group at the $\mathrm{C}-35$ position are characteristic of methane-oxidizing bacteria (M OB) from the alpha- and gammaproteobacterial classes (Talbot and Farrimond, 2007; van Winden et al., 2012). A nother important structural feature in hopanoids is the methylation at the $\mathrm{C}-3$ position of the A-ring. This methylation was first shown in acetic acid bacteria (Rohmer and Ourisson, 1976) and later in MOBs (Zundel and Rohmer, 1985). Subsequently, C-3 methylated hopanoids were used as a biomarker for the presence of aerobic methanotrophy in ancient sediments (Summons and J ahnke, 1992). However, Welander and Summons (2012) identified the hpnR gene responsible for 3-methylation in hopanoids and showed that it is widely distributed among various bacterial taxa, including those not involved in the methane cycle. Nevertheless, the origin of hopanoids from M OB can be inferred from their depletion in ${ }^{13} \mathrm{C}\left(\delta^{13} \mathrm{C}\right.$ below ca. $\left.-40 \%\right)$ as usually ${ }^{13} \mathrm{C}$-depleted $\mathrm{CH}_{4}$ is used as carbon source for their biomass (Summons et al., 1994; J ahnke et al., 1999). Consequently, C-3 methylated hopanoids can be used as an indicator for methanotrophy if accompanied by additional evidence of ${ }^{13} \mathrm{C}$-depleted carbon isotope values.

An apparent exception to this ${ }^{13} \mathrm{C}$ depletion is the intra-aerobic methanotroph, 'Candidatus M ethylomirabilis oxyfera' ('Ca. M. oxyfera'), which belongs to the $\mathrm{NC10}$ phylum and occurs in clusters with ' $\mathrm{Ca}$. Methanoperedens nitroreducens' archaea (ANME-2d) (Raghoebarsing et al., 2006; Ettwig et al., 2010; V aksmaa et al., 2017). 'Ca. M . oxyfera' lives under 
anoxic conditions and reduces nitrite to nitric oxide, and subsequently is believed to produce its own intercellular oxygen from nitric oxide for the intra-aerobic oxidation of methane (Ettwig et al., 2010). Thus, 'Ca. M. oxyfera' directly connects the methane and nitrogen cycle (Ettwig et al., 2010). In contrast to most other M OB lipids, 'Ca. M . oxyfera' lipids were shown not to be depleted in ${ }^{13} \mathrm{C}$ from methane ( $\mathrm{K}$ ool et al. 2012, 2014) as they autotrophically fix carbon dioxide via the Calvin cycle as their carbon source (Rasigraf et al., 2014). These lipids include 3-methyl hopanoids, first recognized through genomic analysis (W elander and Summons, 2012), such as the rare B HP-hexol and a novel B HP identified as 3-methyl-B H P-Hexol (K ool et al., 2014). Further studies of the lipid inventory of ' $\mathrm{Ca}$. M. oxyfera' showed that they produce rare methylated fatty acids such as $10 \mathrm{M} \mathrm{eC}$ 16:0 and $10 \mathrm{M} \mathrm{eC}_{16: 1 \Delta 7}$ ( $\mathrm{K}$ ool et al., 2012). However, the use of fatty acids as biomarkers for nitrite-dependent methane oxidation is limited to more recent geological time periods because these lipids are not resistant to alteration processes (A tlas and B artha, 1973; W enger et al., 2002).

Here, we re-investigated the hopanoid content of 'Ca. M. oxyfera' biomass but now focused on those amenable to gas chromatography (GC) analysis. These biomarkers were then compared to GC-amenable hopanoids detected in a core from a peatland where the occurrence of ' $\mathrm{Ca}$. M . oxyfera' had been confirmed previously.

\section{Material and methods}

\section{1 'Ca M. oxyfera' enrichment cultures}

A n enrichment culture of ' $\mathrm{Ca}$. M. oxyfera' bacteria was obtained from a bioreactor operated under the following conditions described previously by Ettwig et al. (2009). The reactor contained bright fluffy cell material which originated from active 'Ca. M. oxyfera' bacteria, and black material from the bottom of the bioreactor that was most likely dead ' $\mathrm{Ca}$. M . oxyfera' biomass. The bioreactor contained $2 / 3$ of ' $\mathrm{Ca}$. M. oxyfera' bacteria while the rest was composed of a mix of A NM E-2d archaea and different uncharacterized bacteria phyla. The steady state concentration of nitrite in this bioreactor was kept at 0-5 $\mathrm{mg} / \mathrm{L}$.

Biomass from a second reactor enriched from Italian paddy field soils consisted of less 'Ca. M. oxyfera' cell material (30\%), more 'Ca. Methanoperedens nitroreducens' (ANME-2d) archaea (30\%) and other microbial communities (40\%) as described previously (V aksmaa et al., 2017). 


\subsection{Peatland core}

A peatland core from the Brunsummerheide peatland, Netherlands $(B R H)$ was sampled and divided into nine sections from 51 to $102 \mathrm{~cm}$ depth (i.e. $51-60 \mathrm{~cm}$, from 60 to $95 \mathrm{~cm}, 95-102 \mathrm{~cm}$ ) (Kool et al., 2012; Kool et al., 2014). Previous quantitative polymerase chain reaction ( $\mathrm{PPCR}$ ) analysis of ' $\mathrm{Ca}$. M. oxyfera' specific 16S rRNA genes revealed the peak of their abundance at 70 to $90 \mathrm{~cm}$ depth. In this zone both methane and nitrate showed depletion in pore water concentrations (Zhu et al., 2012).

\subsection{F luorescence in-situ hybridization}

Fluorescence in-situ hybridization (FISH) of 'Ca. M . oxyfera' enrichments from the two bioreactors was performed for abundance estimation. Liquid samples of $1.5 \mathrm{~mL}$ from an active enrichment culture were centrifuged for $5 \mathrm{~min}$ at $7000 \mathrm{xg}$ (Eppendorf ${ }^{\mathrm{TM}}$ 5424, Hamburg) and biomass pellets were washed $2 \mathrm{x}$ with $1 \mathrm{~mL}$ phosphate-buffered saline (PBS: $130 \mathrm{mM} \mathrm{NaCl}$ and $10 \mathrm{mM}$ phosphate buffer $\mathrm{pH}$ 7.4). A fter washing, the samples were fixed with $4 \%$ paraformal dehyde at a 3:1 volume ratio to the sample at $4^{\circ} \mathrm{C}$ overnight. FISH was performed as described previously (Ettwig et al., 2008). Formamide concentration in the hybridization buffer was set to $35 \%$. The following oligonucleotide probes were used: DAM OBACT-0193 (CGC TCG CCC CCT TTG GTC) specific for 'Ca. M. oxyfera'-like bacteria; DA M OA RCH-0641 (GGT CCC AAG CCT A CC A GT) specific for ' Ca. M . nitroreducens'-like archaea; EUB 338 (S-D-B act-0338-a-A 18) (A mann et al., 1990), EUB 338 II (S-D-Bact_0338-b-A-18) and EUB 338 III (S-D-Bact-0338-c-A -18) (Daims et al., 1999) for most bacteria; S-D-A rch0915-a-A-20 for most archaea. I mages were collected with a Zeiss A xioplan 2 epifluorescence microscope equipped with a CCD camera and processed with the A xiovision software package (Zeiss, Germany).

\subsection{G enomic analysis}

Identification of potential genes involved in hopanoid biosynthesis in ' $\mathrm{Ca}$. $\mathrm{M}$. oxyfera' (N CBI: taxid671143) was carried out on the NCBI (N ational Center for Biotechnology Information) server with the PSI-BLA ST algorithm (Schäffer et al., 2001) using characterized proteins from different organisms as queries (Suppl.Table 1). Operon analysis and visualization was performed by using the Gene Context Tool NG (http://biocomputo2.ibt.unam.mx/gctng/) and protein analysis was conducted with U niprot (UniProt Consortium, 2018).

\subsection{H opanoid analyses}

2.5.1 Extraction of hopanoids 
Freeze dried biomass of the ' $\mathrm{C}$ a. M . oxyfera' enrichments as well as freeze dried BRH peat core material ( $\mathrm{K}$ ool et al., 2012) were extracted using a modified Bligh and Dyer technique (Schouten et al., 2008; B ale et al., 2013). The samples were ultrasonically extracted with a solvent mixture containing methanol $(\mathrm{MeOH})$, dichloromethane (DCM) and phosphate buffer (2: 1: 0.8, v: v: v). After sonication (10 $\mathrm{min}$ ) and centrifugation the solvent layer was collected and the residue reextracted twice. The combined solvent layers were separated from the aqueous layer by adding additional DCM and phosphate buffer to achieve a ratio of $\mathrm{M} \mathrm{eOH}, \mathrm{DCM}$ and phosphate buffer (1: 1: 0.9, v: v: v). The separated organic bottom layer was removed and collected while the aqueous layer was washed two more times with DCM. The combined DCM layers were dried under a continuous flow of $\mathrm{N}_{2}$.

Aliquots of the total lipid extracts (TLEs) (ca. $0.5-3 \mathrm{mg}$ ) were base hydrolyzed (saponified), with $2 \mathrm{~mL}$ of $1 \mathrm{~N} \mathrm{KOH}$ in $\mathrm{M} \mathrm{eOH}$ solution, refluxed for 1 hour at $130{ }^{\circ} \mathrm{C}$, the $\mathrm{pH}$ adjusted to 5 with a $2 \mathrm{~N} \mathrm{HCL}$ in $\mathrm{MeOH}$ solution, separated with $2 \mathrm{~mL}$ bidistilled water and $2 \mathrm{~mL} \mathrm{DCM}$ and washed with DCM two more times. The combined DCM layers were dried over a $\mathrm{Na}_{2} \mathrm{SO}_{4}$ column. A fterwards the saponified fraction was methylated with diazomethane in diethyl ether, filtered over a small silica column with ethyl acetate and silylated with pyridine and $\mathrm{N}, \mathrm{O}-\mathrm{Bis}$ (trimethylsilyl)trifluoroacetamide (BSTFA) at $60^{\circ} \mathrm{C}$ for 20 min. These total lipid extracts (TLEs) were analyzed using GC and GC-mass spectrometry (MS).

\subsubsection{Instrumental analysis}

GC-M S analyses of the TLEs of different ' $\mathrm{C}$ a. M . oxyfera' biomass and BRH peat core material were performed on an A gilent Technologies GC/M S Triple Quad 7000C in full scan and multiple reaction monitoring (M RM) mode. The chromatography was carried out using a CP-Sil5 CB column ( $25 \mathrm{~m} \times 0.32 \mathrm{~mm}$ with a film of $0.12 \mu \mathrm{m}$, Agilent Technologies) with helium as carrier gas (constant flow $2 \mathrm{~mL} / \mathrm{min}$ ). For each sample $1 \mu \mathrm{L}$ was injected on-column at 70 ${ }^{\circ} \mathrm{C}$, temperature was increased at $20^{\circ} \mathrm{C} / \mathrm{min}$ to $130^{\circ} \mathrm{C}$, raised further by $4{ }^{\circ} \mathrm{C} / \mathrm{min}$ to $320^{\circ} \mathrm{C}$, which was held for $20 \mathrm{~min}$ for full scan mode and for $10 \mathrm{~min}$ for the MRM analysis. GC-M S full scan analysis was conducted over a mass range of $\mathrm{m} / \mathrm{z} 50$ to 850 , the gain on 3 and with a scan rate of $700 \mathrm{~ms}$. Compounds were identified by comparison with those previously published (Zundel and Rohmer, 1985; Sinninghe Damsté et al., 2004; Kool et al., 2012).

A new GC-MS/MS MRM method was developed to detect hopanoid ketones and alcohols in environmental samples using transitions and collision energies shown in Table 1. The MS1 and MS2 resolution was set on wide, the 
gain on 10 and the dwell time on $10 \mathrm{~ms}$ for all scans. As collision gases in the MRM scan mode He was admitted at a flow of $1.5 \mathrm{~mL} / \mathrm{min}$ and $\mathrm{N}_{2}$ at a flow of $1 \mathrm{~mL} / \mathrm{min}$.

Table 1. Specifications of the M RM method for the four ' $\mathrm{Ca}$. M . oxyfera' trisnorhopanoids, showing the target transition $(\mathrm{m} / \mathrm{z})$ and optimized collision energy $(\mathrm{eV})$.

\begin{tabular}{|c|c|c|}
\hline & $\begin{array}{c}\text { Target transition } \\
\mathbf{( m / \mathbf { z } )}\end{array}$ & $\begin{array}{c}\text { Collision energy } \\
(\mathbf{e V})\end{array}$ \\
\hline trisnorhopan-21-one & $384.3 \rightarrow 191.1$ & 10 \\
\hline trisnorhopan-21-ol & $458.3 \rightarrow 237.2$ & 15 \\
\hline 3-methyl trisnorhopan-21-one & $398.4 \rightarrow 205.2$ & 10 \\
\hline 3-methyl trisnorhopan-21-ol & $472.4 \rightarrow 237.2$ & 15 \\
\hline
\end{tabular}

\section{Results and Discussion}

3.1 L ipid analysis of ' $\mathrm{Ca}$. M . oxyfera' reveals novel demethylated hopanoids

The microbial community composition and microstructure of the ' $\mathrm{Ca} . \mathrm{M}$. oxyfera' enrichment culture was assessed by FISH. Based on the average fluorescence signal, we estimated that approximately two thirds of the biomass granules were composed of bacteria related to 'Ca. M . oxyfera' (Suppl. Fig. 1). The lipid composition of this biomass was dominated by a series of fatty acids in particular the $\mathrm{C}_{16: 0}, 10 \mathrm{M} \mathrm{eC}_{16: 1 \Delta 7}$ and $10 \mathrm{M} \mathrm{eC}_{16: 0}$ fatty acids, as described previously ( $\mathrm{K}$ ool et al., 2012). We also detected a series of hopanoids using mass chromatography m/z 191 and m/z 205 revealing diploptene, diplopterol, $C_{32} 17 \beta$, $21 \beta$-hopanoic acid and some of their 3-methylated homologues (Fig. 1). These hopanoids, especially diploptene and diplopterol, are found in a diverse range of aerobic and anaerobic bacteria (Rohmer et al., 1984; Summons et al., 1994; Sinninghe Damsté et al., 2004; Blumenberg et al., 2006). Furthermore, these hopanoids have been found in various environments like oxygen minimum zones (Wakeham et al., 2007), marine hydrocarbon seeps (Niemann et al., 2006), lacustrine sediments (Innes et al., 1997), peatlands (van W inden et al., 2010) or soils (C rossman et al., 2005).

The GC-M S analysis also revealed the presence of four more minor peaks which we tentatively identified as hopanoids (Fig. $1 \& 2$ ). Of these four, 22,29,30-trisnorhopan-21-one (compound 1-TNHone in Fig. 1) was tentatively identified based on a published mass spectrum (Simoneit, 1977). This hopanoid was first identified in sediments from the Black Sea (Simoneit, 1977) and has since been found in various marine sediment and water column samples, where it is believed to be formed by aerobic diagenetic alteration processes of BHPS (Conte et al., 1998; Botz et al., 2007). Directly eluting after 22,29,30- 
trisnorhopan-21-one is a compound (labelled $2 \mathrm{TNH}$ ol in Fig.1) with a diagnostic fragment of m/z 191 suggesting a non-A ring methylated hopanoid (Fig. 2B).

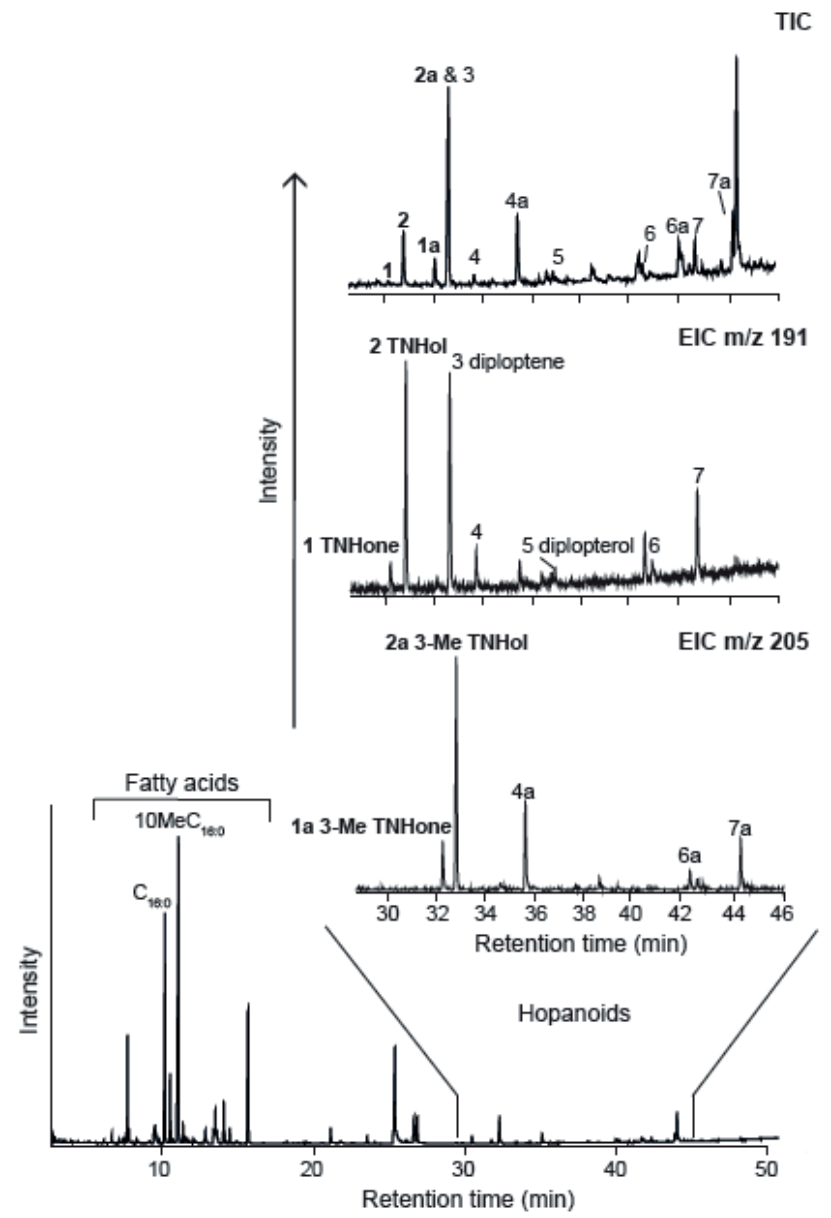

Figure 1. Gas chromatogram of saponified and silylated total lipid extract from 'Ca. M . oxyfera' biomass. Enlarged inserts show the TIC (total ion chromatogram) of the hopanoids, the EIC (extracted ion chromatogram) of m/z 191 specific for hopanoids and m/z 205 specific for methylated-hopanoids indicating the main hopanoids in 'Ca. M . oxyfera' biomass. $3=$ diploptene, $5=$ diplopterol, $6=\mathrm{C}_{32} 17 \beta, 21 \beta$ hopanoic acid, $7=C_{32}$ 17 $3,21 \beta$-30-hydroxy hopanoic acid and one unknown hopanoid (4) as well as their methylated counterparts in the top EIC of $\mathrm{m} / \mathrm{z} 205$. New tentatively identified hopanoids for 'Ca. M. oxyfera' are $1=$ 22,29,30-trisnorhopan-21-one (TNHone), 2= 22,29,30-trisnorhopan-21-ol (TNHol), 1a= 3-methyl 22,29,30trisnorhopan-21-one (3-M e TN Hone) and 2a=3-methyl 22,29,30-trisnorhopan-21-ol (3-M e TH N ol).

The difference of $74 \mathrm{Da}$ between the molecular ions of 22,29,30-trisnorhopan21-one and unknown compound $2 \mathrm{TNHol}$, as well as ions at $\mathrm{m} / \mathrm{z} 73$ and 75 , suggests the presence of a TMSi-derivatized alcohol. This is confirmed by the second diagnostic fragment of $\mathrm{m} / \mathrm{z} 237$, compared to the $\mathrm{m} / \mathrm{z} 163$ in the 22,29,30trisnorhopan-21-one, suggesting that the alcohol is located at the D- or E-ring position. The fragment at $\mathrm{m} / \mathrm{z} 367$ indicates that the alcohol is likely at the Ering position (Fig. 2B). This hopanoid was therefore tentatively identified as 
22,29,30-trisnorhopan-21-ol. A similar doublet of peaks (compounds la 3-M e TNHone and 2a 3-M e TN Hol, in Fig. 1) eluted after the 22,29,30-trisnorhopan21-one and 22,29,30-trisnorhopan-21-ol, respectively. Both mass spectra (Fig. $2 \mathrm{C}$ and $2 \mathrm{D}$ ) show the diagnostic fragment of $\mathrm{m} / \mathrm{z} 205$, which indicates a methylation at the A-ring. Furthermore, both have molecular ions which are 14 Da heavier ( $\mathrm{m} / \mathrm{z} 398$ and $\mathrm{m} / \mathrm{z}$ 472) than of 22,29,30-trisnorhopan-21-one and 22,29,30-trisnorhopan-21-ol, respectively (Fig. 2A and 2B, respectively). The first eluting compound 1a 3-M e TNHone shows the diagnostic ion of the D/Ering fragmentation of 22,29,30-trisnorhopan-21-one (m/z 163; Fig 2C), whereas compound 2a 3-M e TNH ol shows that of 22,29,30-trisnorhopan-21-ol (m/z 237; Fig. 2D).
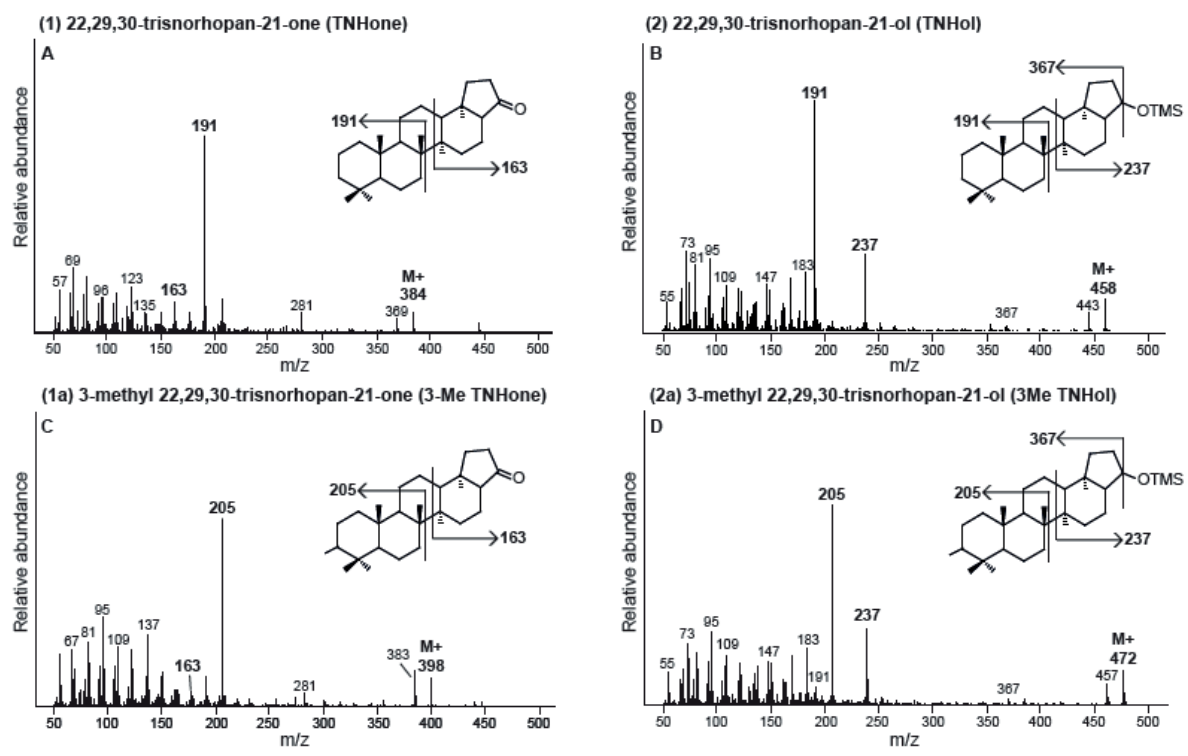

Figure $2 \mathrm{M}$ ass spectra with fragmentation and molecular structures of trisnorhopanoids in 'Ca. M . oxyfera' biomass. The mass spectra of 22,29,30-trisnorhopan-21-one was described previously by Simoneit, 1977.

Therefore, we tentatively identify these two compounds as the methylated counterparts of 22,29,30-trisnorhopan-21-one and 22,29,30-trisnorhopan-21-ol, respectively. Previous studies have shown the presence of the HpnR gene responsible for the 3-methylation of hopanoids in the 'Ca. M . oxyfera' genome (W elander and Summons, 2012), as well as the presence of 3-methylated B HPS of BHP-hexol, BHP-pentol and BHP-tetrol in 'Ca. M. oxyfera' biomass (K ool et al., 2014). Thus, we tentatively identified these two methylated compounds as 3-methyl 22,29,30-trisnorhopan-21-one (Fig. 2C) and 3-methyl 22,29,30trisnorhopan-21-ol (Fig. 2D). 


\subsection{Origin of (3-methyl) 22,29,30-trisnorhopan-21-one and 22,29,30- trisnorhopan-21-ol}

To the best of our knowledge, the three novel hopanoids (22,29,30-trisnorhopan21-ol, 3-methyl 22,29,30-trisnorhopan-21-one and 3-methyl 22,29,30trisnorhopan-21-ol) have not been identified before in any other bacterial cultures nor have they previously been detected in environmental samples. Since 'Ca. M . oxyfera' biomass derives from highly enriched, but not pure cultures, it cannot be fully excluded that other bacteria in the bioreactor produce these hopanoids. However, this possibility seems to be rather unlikely because of the low amounts of other individual bacterial species (less than $5 \%$ ) in the total enrichment culture, most of which are not known to produce 3-methylated hopanoids. Furthermore, we investigated another enrichment culture from a methanotrophic bioreactor fed with nitrate and methane which contained a lower proportion of ' $\mathrm{Ca}$. M. oxyfera' (30\%) and higher abundance of other species, mainly A N M E-2D archaea (30\%) (V aksmaa et al., 2017). This showed a much lower abundance of the trisnorhopanoids (Fig. 3), suggesting that ' $\mathrm{Ca}$. M. oxyfera' is the likely source of these hopanoids.

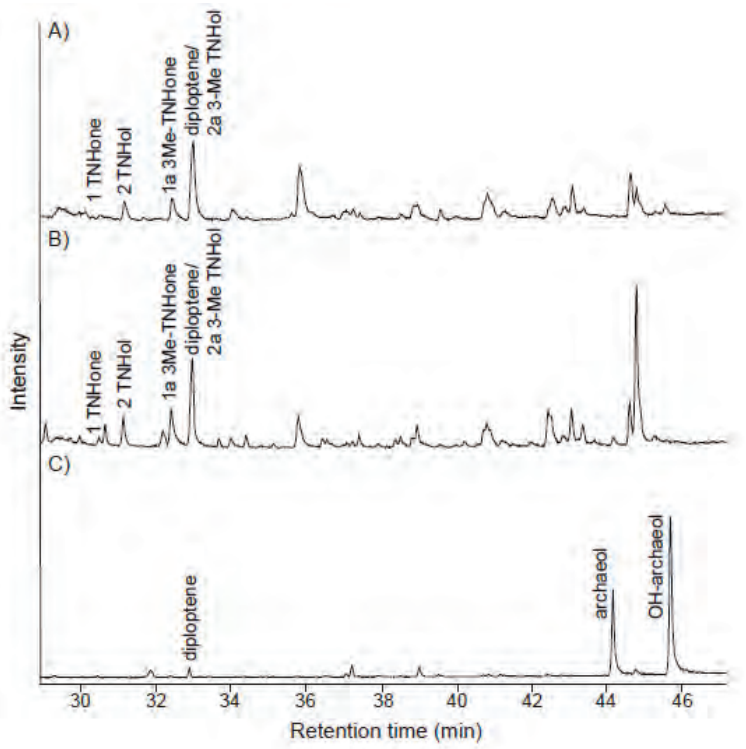

Figure 3. Gas chromatograms of saponified and silylated total lipid extracts from (A) 'Ca. M. oxyfera' active biomass (bright fluffy cell material), (B) 'Ca. M. oxyfera' dead biomass (black cell material from bioreactor bottom) and (C) 'Ca. M. oxyfera' (30\%) with enriched ANME-2D archaea (30\%) from Italian paddy field soils. The four novel trisnorhopanoids $1=22,29,30$ trisnorhopan-21-one (TNHone), $2=$ 22,29,30-trisnorhopan-21-ol (TNHol), $1 a=3$-methyl 22,29,30trisnorhopan-21-one (3-M e TN Hone) and $2 a=3$-methyl 22,29,30trisnorhopan-21-ol (3-Me THNol) as well as the typical archaeal lipids archaeol and $\mathrm{OH}$-archaeol (sn2hydroxy-archaeol) are annotated in the chromatograms.

Of the four trisnorhopanoids, only the 22,29,30 trisnorhopan-21-one has been reported previously, i.e. in anaerobic enrichment cultures of planctomycetes by Sinninghe Damsté et al., (2004) and in various environmental samples such as the anoxic brine-filled basins in the M editerranean (Ten Haven et al., 1987), in coals and shales from Indonesia (Hoffmann et al., 1984) or anaerobic sediments (Pancost and Sinninghe Damsté, 2003). These studies have suggested that 
trisnorhopan-21-one is a diagenetic or microbial altered product of BHPS such as bacteriohopanetetrol (BHT) and diplopterol formed under oxic conditions (Santos et al., 1994; Conte et al., 2003). Moreover, trisnorhopan-21-one is believed to be an indicator for high bio-productivity when found in the water column or sediments (Simoneit, 1977; B otz et al., 2007). However, since 'Ca. M. oxyfera' biomass was incubated under strictly anaerobic conditions, aerobic degradation processes can be most likely excluded. We also analyzed black cell material from the bottom of the ' $\mathrm{Ca}$. M . oxyfera' enrichment bioreactor, which mostly represents dead cell material from ' $C$ a. M . oxyfera'. This material had no elevated abundances of the novel trisnorhopanoids compared to living cell material (Fig. 3), suggesting that the trisnorhopanoids are not formed after cell death. Together, these results suggest that the trisnorhopanoids in ' $\mathrm{Ca}$. M. oxyfera' bacteria are more likely formed via a direct biosynthesis rather than by degradation processes in the bioreactor itself.

\subsection{Potential biosynthesis of demethylated hopanoids in 'Ca. M . oxyfera'}

To further investigate the potential direct biosynthesis of the trisnorhopanoids, we explored biosynthetic genes that could be involved in the demethylation of the hopanoids (i.e., 22,29,30-trisnorhopan-21-one, 22,29,30-trisnorhopan-21-ol and their 3-methyl homologues) in 'Ca. M . oxyfera'.

This demethylation of the $\mathrm{C}_{22}, \mathrm{C}_{29}$ and $\mathrm{C}_{30}$ carbon atoms can either take place before the cyclization of squalene to a hopane or thereafter. Squalene biosynthesis in bacteria involves a three-step reaction encoded by the HpnD, $\mathrm{HpnC}$ and $\mathrm{HpnE}$ genes and are usually found in one operon (Pan et al., 2015). We found the gene that potentially codes for HpnD (DAMO_1512) in the genome of ' $\mathrm{Ca}$. M . oxyfera', but we did not find any homologous sequence for HpnC nor HpnE using BLAST searches (Suppl. Table 1). Previous studies suggested that these steps can al ternatively be performed by farnesyl diphosphate farnesyl transferase (FdfT) activities as found in for example acidobacteria, gammaproteobacteria or cyanobacteria (Lee and Poulter, 2008; Ohtake et al., 2014; Sinninghe Damsté et al., 2017). The gene DA M O_2922 is annotated as a farnesyl-diphosphate farnesyltransferase and could be responsible for the squal ene formation by this mechanism. Thus, a demethylated intermediate could potentially be formed by an alternative pathway to the three-step reaction by $\mathrm{HpnD}, \mathrm{HpnC}$ and $\mathrm{HpnE}$ genes prior the cyclization reaction by the squalene synthetase DA M 0_0045 gene and thus directly form the trisnorhopanoids.

A lternatively, and perhaps more likely, the demethylation of hopanoids could occur after the squal ene cyclization in 'Ca. M . oxyfera'. W e speculate that such a process can be caused by oxidative activities similar to the removal of the 
C-4 methyl from lanosterol to generate 4-desmethyllanosterol in bacteria catalyzed by SdmA and SdmB proteins (Lee et al., 2018). However, a BLAST search for SdmA and SdmB homologue proteins in the 'Ca. M . oxyfera' genome did not indicate the presence of these two proteins, suggesting that the SdmA $\mathrm{SdmB}$ proteins are only present in bacteria (e.g. M ethylococcus capsulatus) that produce the C-4 demethylation in lanosterol. In eukaryotes, the C-4 sterol demethylation is performed by other proteins i.e. ERG 25, ERG26 and ERG27 (Bard et al., 1996; G achotte et al., 1998; Gachotte et al., 1999). In this process, a C-4 sterol methyl oxidase (ERG 25), a C-3 sterol dehydrogenase (C-4 decarboxylase) (ERG 26) and a 3-keto sterol reductase (ERG27) are involved in an iterative mechanism for the demethylation of sterols. However, no homolog sequence for ERG25 and ERG27 were found in the 'C a. M. oxyfera' genome, although a BLAST algorithm search using ERG26 (P53199) from the yeast Saccharomyces cer evisiae retrieved DA M 0_0933 gene, which potentially codes for a NA D-dependent epimerase/dehydratase (Suppl. Table 1). DA M 0_0933 is part of the predicted operon mox-DAM 0_0930 which is composed of genes that codes for a protein of unknown function (DAMO_0930), a predicted glycosyltransferase (DAM 0_0931), a potential methyltransferase (DA M 0_0932), the NAD-dependent epimerase/dehydratase (DA M O_0933), a short-chain alcohol dehydrogenase (DAMO_0934) and a potential oxidoreductase (DAM 0_0935). This combination of enzymes suggests that the trisnorhopanoids can be formed by a sequential oxidative process of diplopterol catalyzed by the genes in the DA M 0_0930 operon (Suppl. Fig. 2). We propose that the oxidoreductase activity coded by the DA M O_0935 gene in combination with the dehydrogenase activity coded by the DAMO_0934 gene and the potential dehydratase coded by DAM 0_0933 could be involved in a sequential demethylation process (Suppl. Fig. 2 ). Future work should involve the verification of the proposed enzymatic processes for the demethylation of hopanoids to better understand the mechanism involved in the synthesis of trisnorhopanoids in 'Ca. M. oxyfera' and potentially other demethylated hopanoids in bacterial phyla.

\subsection{E nvironmental occurrence of novel 'Ca. M . oxyfera' trisnorhopanoids}

To investigate whether the novel hopanoids detected in ' $\mathrm{C}$. . M . oxyfera' are also present in the environment, we developed an M R M method to sensitively detect the novel trisnorhopanoids in environmental samples. For this, product ion scans of the molecular ions for 22,29,30-trisnorhopan-21-one, 22,29,30-trisnorhopan21-ol and their 3-methylated counterparts were conducted using GC-M S/M S. The selection of the target ions was based on the most selective and abundant 
ions in these product scans (Fig. 2). The collision energies were then optimized to provide an optimal abundance for the different transitions within the M RM method (Table 1). The resulting MRM chromatograms show substantially enhanced signal to noise ratio compared to extract ion chromatograms of $\mathrm{m} / \mathrm{z}$ 191 and m/z 205 from full scan runs and thus provides a substantially enhanced sensitivity (Fig. 4A).

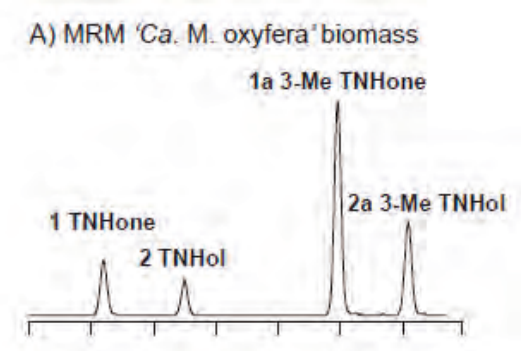

B) MRM BRH peatland $90-95 \mathrm{~cm}$ depth

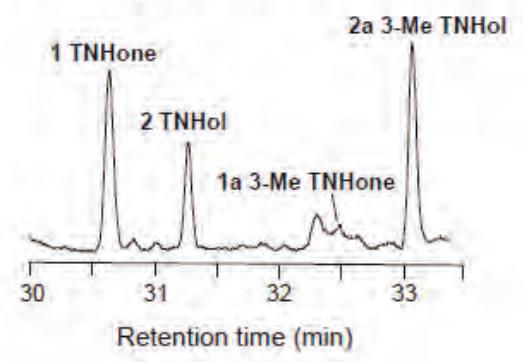

Figure 4. MRM (metastable reaction monitoring) chromatograms of the four distinct trisnorhopanoids ( $1=$ 22,29,30- trisnorhopan-21-one; $2=22,29,30$-trisnorhopan21-ol; 1a=3-methyl 22,29,30-trisnorhopan-21-one; and $2 a=3$-methyl 22,29,30-trisnorhopan-21-ol) in (A) 'Ca. M. oxyfera' biomass and (B) Brunsummerheide (BRH) peat from $90-95 \mathrm{~cm}$ depth.

Application of this MRM method to a peatland core from the Brunsummerheide, which previously revealed the presence of 'Ca. M. oxyfera' based on DNA and fatty acids (Kool et al., 2012; K ool et al., 2014), showed the presence of the novel hopanoids (Fig. 4B). However, the peat showed a different relative abundance of the four hopanoids than the 'Ca. M. oxyfera' biomass, i.e. with low abundance of the 3-methyl 22,29,30-trisnorhopan-21-

one and a higher relative abundance of 22,29,30-trisnorhopan-21-one and 22,29,30-trisnorhopan-21-ol as well as a dominant 3-methyl 22,29,30trisnorhopan-21-ol (Fig. 3B). Due to the lack of standards to quantify these hopanoids in the M RM transitions a hopanoid ratio was developed, i.e. the 3-M e trisnorhopanone / (3-M e trisnorhopanone + trisnorhopanone) ratio (Fig. 4D). This is based on the assumption that 22,29,30-trisnorhopan-21-one can also originate from bacteria other than 'Ca. M. oxyfera' as it has been reported in many environments (Ten Haven et al., 1987; B otz et al., 2007), in contrast to its 3-methylated version. The peak of this hopanoid ratio is at 70-90 cm depth and corresponds to the peak in 'Ca. M . oxyfera' cell abundance data based on qPCR $16 \mathrm{~S}$ rRNA gene analysis as well as the specific $10 \mathrm{M} \mathrm{eC}_{16: 0}$ and $10 \mathrm{M} \mathrm{eC}_{16: 1}$ fatty acids (Fig. 4B; K ool et al., 2012). Thus, this ratio of trisnorhopanoids may be a complimentary biomarker tool for the detection of 'Ca. M. oxyfera' in the environment. Moreover, these trisnorhopanoids may be better preserved over geological timescales than fatty acids and thus be a tool for the detection of past 
intra-aerobic methanotrophy in paleo-environments, in contrast to $\delta^{13} \mathrm{C}$ analysis of hopanoids (K ool et al., 2014; Rasigraf et al., 2014).

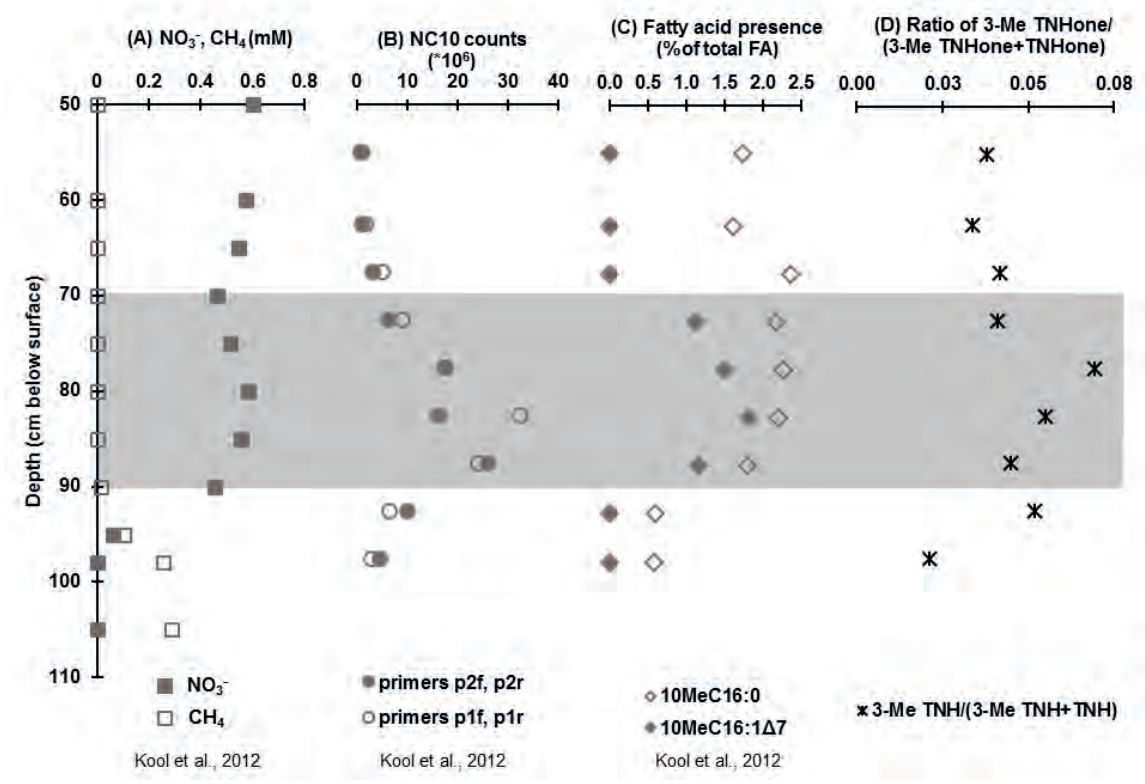

Figure 5. Depth profile of the Brunsummerheide $(\mathrm{BRH})$ peatland core, showing (A) $\mathrm{NO}_{3^{-}}$and $\mathrm{CH}_{4}$ concentrations in pore water; (B) NC10 bacteria 16S rRNA gene copy number abundance; (C) specific fatty acids (FAs) of ' $\mathrm{Ca}$. M . oxyfera' (Kool et al., 2012); and (D) the novel hopanoid ratio 3-Me TNH/ (3-Me $\mathrm{TNH}+\mathrm{TNH}$ ) of ' $\mathrm{Ca}$. M . oxyfera'. The maximum in RNA abundance of ' $\mathrm{Ca}$. M . oxyfera' is indicated with the grey area.

\subsection{Implications}

Our results may have consequences on how we view the origin and sources of demethylated hopanoids detected in present and past environments. Up to now demethylation processes of hopanoids were mainly attributed to diagenetic alteration processes like the microbial reworking of organic matter for bisnorand trisnorhopanes or heavy biodegradation of petroleum for the presence of 25norhopanes (Moldowan et al., 1984; Noble et al., 1985; Moldowan and M cCaffrey, 1995). For example, the $18 \alpha(\mathrm{H})-22,29,30$-trisnorhopane (Ts) and the $17 \alpha(\mathrm{H})-22,29,30$-trisnorhopane $(\mathrm{T} \mathrm{m})$, are thought to derive from diplopterol by a simple side-chain cleavage followed by an acid-catalyzed methyl shift (Seifert and M oldowan, 1978) and are often used to determine the source and the thermal maturity of petroleum (Peters et al., 2005; Seifert and M oldowan, 1978). It has been suggested that the 25-demethylation of 28,30-bisnorhopane to 25,28,30trisnorhopane, common biomarker lipids in petroleum and organic rich sediments (e.g. N oble et al., 1985; Peters et al., 2005), occurs during advanced stages of petroleum biodegradation in which the 28,30-bisnorhopane probably derives from a hopene precursor having a 17(18) double bond (R ullkötter et al., 
1982; Volkman et al., 1983). A tentative identification of 28,30-bisnorho17(18)-ene as a precursor has been made previously in sediments from the Gulf of Cal ifornia (R ullkötter et al., 1982). However, it was also suggested that 28,30bisnorhopane and 25,28,30-trisnorhopane were biosynthesized directly since they are absent as sulfur bound hydrocarbons (Schoell et al., 1992; Schouten et al., 2001a).The ${ }^{13} \mathrm{C}$-content of both compounds and their distribution strongly suggest that they are derived from anaerobic bacteria or those living under low oxygen conditions (Schoell et al., 1992; Schouten et al., 2001b). Our finding of demethylated hopanoids in 'Ca. M. oxyfera' as well as those reported in the anaerobic planctomycetes (Sinninghe Damsté et al., 2004) now strongly suggest that demethylated hopanoids may be indeed biosynthesized as such and not be derived from (aerobic) diagenetic processes.

\section{Conclusion}

The intra-aerobic methanotroph 'Ca. M ethylomirabilis oxyfera' synthesizes a series of unique demethylated hopanoids identified as 22,29,30-trisnorhopan-21one, 22,29,30-trisnorhopan-21-ol, 3-methyl 22,29,30-trisnorhopan-21-one and 3-methyl 22,29,30-trisnorhopan-21-ol. These unique hopanoids suggest a possible demethylation process of hopanoids by 'Ca. M . oxyfera'. This is further supported by the finding of potential candidate genes responsible for the demethylation of hopanoids in the 'Ca. M . oxyfera' genome. For the sensitive detection of these four hopanoids, an MRM method was developed and successfully applied to an environmental setting where 'Ca. M. oxyfera' was previously detected by specific fatty acids and genomic analysis. The novel trisnorhopanoids and the developed M RM method offer a new tool to investigate the presence of ' $\mathrm{Ca}$. M. oxyfera' and nitrite-dependent methane oxidation in modern and past environments. Moreover, the identification of demethylated hopanoids in living bacterial biomass gives a new perspective on the origin and sources of demethylated hopanoids found in the geological record.

\section{A uthor contributions}

NTS, DR and SS planned research. M M M, OR and SCG provided biomass and FISH analysis data. NTS performed lipid analysis and NTS and SS interpreted the data. MV, SS and NTS developed M RM method. DXSC analyzed genome data for potential biosynthesis pathways of demethylated hopanoids. NTS wrote the paper with input from all authors.

\section{Declaration of Competing Interest}

The authors declared that there is no conflict of interest. 


\section{Acknowledgements}

We thank Irene Rijpstra for laboratory assistance and helpful comments in compound identification as well as Laura Villanueva for discussions about hopanoid biosynthesis pathways. We also thank A nnika $V$ aksmaa for providing methanotrophic A N M E-2D/ 'C a. M . oxyfera' biomass for comparison. W e thank $M$ artin B lumenberg and anonymous reviewer, as well as the A ssociate E ditor for constructive comments. This study received funding from the $\mathrm{N}$ etherlands Earth System Science Center (NESSC) and Soehngen Institute for A naerobic Microbiology (SIAM) through Gravitation grants (024.002.001 and 024.002.002) from the Dutch Ministry for Education, Culture and Science. DXSC received funding from the European Research Council (ERC) under the European Union's Horizon 2020 research and innovation program (grant agreement $n \circ 694569$ - MICROLIPIDS) and MSMJ by ERC AG ecomom 339880 .

Supplemental material (can be found online at https://doi.org/10.1016/j.orggeochem.2019.07.008)

Suppl. Fig. 1 Fluorescent micrograph of the granular biomass sample from ' $\mathrm{Ca}$. M. oxyfera' enrichment culture.

Suppl. Fig. 2 Predicted operon in 'Ca. M. oxyfera' potentially involved in hopanoid demethylation.

Suppl. Table 1 Potential genes involved in the synthesis and modification of hopanoids in 'Ca. M. oxyfera'. 


\section{Chapter 3}

Anaerobic methanotrophic archaea of the ANME-2d clade feature lipid composition that differs from other ANME archaea

Julia M. Kurth, Nadine T. Smit, Stefanie Berger, Stefan Schouten, Mike S.M. Jetten, Cornelia U. Welte

Published in FEMS Microbiology Ecology 
| Chapter 3 


\section{Abstract}

The anaerobic oxidation of methane $(A O M)$ is a microbial process present in marine and freshwater environments. AOM is important for reducing the emission of the second most important greenhouse gas methane. In marine environments anaerobic methanotrophic archaea (ANME) are involved in sulfate-reducing AOM. In contrast, $\mathrm{Ca}$. Methanoperedens of the ANME-2d cluster carries out nitrate A OM in freshwater ecosystems. Despite the importance of those organisms for A OM in non-marine environments little is known about their lipid composition or carbon sources. To close this gap, we analysed the lipid composition of ANME-2d archaea and found that they mainly synthesize archaeol and hydroxyarchaeol as well as different (hydroxy-) glycerol dialkyl glycerol tetraethers, albeit in much lower amounts. A bundant lipid headgroups were dihexose, monomethyl-phosphatidyl ethanolamine and phosphatidyl hexose. M oreover, a monopentose was detected as a lipid headgroup which is rare among microorganisms. $B$ atch incubations with ${ }^{13} \mathrm{C}$ labelled bicarbonate and methane showed that methane is the main carbon source of A NME-2d archaea varying from ANME-1 archaea which primarily assimilate dissolved inorganic carbon (DIC). A N M E-2d archaea al so assimilate DIC, but to a lower extent than methane. The lipid characterization and analysis of the carbon source of $\mathrm{Ca}$. M ethanoperedens facilitates distinction between A N M E-2d and other A N M Es.

\section{Introduction}

Methane is the second most important greenhouse gas on earth with an atmospheric methane budget of about $600 \mathrm{Tg}$ per year (Conrad, 2009; Dean et al., 2018). A bout $69 \%$ of methane emission into the atmosphere is caused by methanogenic archaea (Conrad, 2009). On the other hand, aerobic and anaerobic methanotrophic microorganisms can oxidize methane back to carbon dioxide that is a 25-times less potent greenhouse gas than methane. The anaerobic oxidation of methane $(A O M)$ is a microbial process present in marine and freshwater environments. AOM has first been described to be performed by a consortium of anaerobic methanotrophic archaea (A N M E) and sulfate-reducing bacteria in microbial mats in the deep sea or in marine sediments (H oehler et al., 1994; Hinrichs et al., 1999; Boetius et al., 2000; Hinrichs and Boetius, 2002; Orphan et al., 2002). ANME archaea are related to methanogens and oxidize methane by using the reverse methanogenesis pathway (Hallam et al., 2004; A rshad et al., 2015; M cA nulty et al., 2017; Timmers et al., 2017). In addition to sulfate, also oxidized nitrogen compounds (Raghoebarsing et al., 2006; Ettwig et al., 2010; H aroon et al., 2013) as well as iron and manganese (B eal et al., 2009; 
Ettwig et al., 2016; Cai et al., 2018) can be used as electron acceptors within the AOM process.

A naerobic methanotrophic archaea can be assigned to three distinct clusters within the Euryarchaeota, A N M E-1, A N M E-2 and A N M E-3, which are related to the orders $M$ ethanosarcinales and $M$ ethanomicrobiales ( $K$ nittel and B oetius, 2009). The phylogenetic distance between the groups is quite large (16S rRNA gene sequence identity between 75-92\%) (K nittel and Boetius, 2009). Most analysed members of the three ANME clades have been described to perform sulfate driven AOM in marine environments (Pancost et al., 2001; Blumenberg et al., 2004; Niemann and Elvert, 2008; Rossel et al., 2008; Wegener et al., 2008; Kellermann et al., 2012). However, members of the ANME-2d cluster have not been found in consortia with sulfate reducers. Instead, ANME-2d archaea are the main players in nitrate-dependent AOM. $M$ icroorganisms conducting nitrate $A O M$ have been enriched from anoxic freshwater sediments, digester sludge and rice paddies (Raghoebarsing et al., 2006; H u et al., 2009; A rshad et al., 2015; V aksmaa, Guerrero-Cruz, et al., 2017). Denitrifying $\mathrm{AOM}$ can either be conducted by a consortium of nitrate-reducing ANMEs, Ca. M ethanoperedens sp., and nitrite reducing NC10 bacteria, Ca. M ethylomirabilis sp. (Raghoebarsing et al., 2006; Haroon et al., 2013; A rshad et al., 2015) or by a consortium of those A NME archaea and anammox bacteria (Haroon et al., 2013). In those consortia Ca. M ethylomirabilis sp. or anammox bacteria are important to reduce the toxic nitrite produced during nitrate A OM by $\mathrm{Ca}$. M ethanoperedens sp.

To understand the preval ence of anaerobic methane oxidation in past and present environments and identify the key players at different environmental sites, it is necessary to identify biomarkers for those organisms. As core lipids are much more stable than DNA over time, lipid biomarkers are a useful tool to trace microorganisms and therefore specific microbial processes back in time. Moreover, intact polar lipids are crucial to examine present microbial communities and to distinguish between different microorganisms (R uetters et al., 2002; Sturt et al., 2004). Quite some information is available on core and intact polar lipids as well as on carbon assimilation in marine A OM consortia of A N M E archaea and sulfate-reducing bacteria (Pancost et al., 2001; B lumenberg et al., 2004; N iemann and Elvert, 2008; R ossel et al., 2008; W egener et al., 2008; Kellermann et al., 2012). In contrast, lipids from one of the main players in denitrifying AOM, Ca. Methanoperedens sp., have hardly been studied: a preliminary study on the lipids of a culture containing $\mathrm{Ca}$. M ethanoperedens $\mathrm{sp}$. and $\mathrm{Ca}$. M ethylomirabilis oxyfera only detected sn2-hydroxyarchaeol as the dominant lipid of the archaeal partner (Raghoebarsing et al., 2006). 
Besides the characterization of lipids in A N M E archaea it is al so pivotal to understand which carbon source those organisms use for biomass production. The main carbon assimilation pathway in methanogenic Euryarchaeota is the reductive acetyl-CoA pathway (Whitman, 1994; Berg et al., 2010). In this pathway a carbonyl group and a methyl group are combined to form acetyl-C OA . In archaea, acetyl-COA is used for formation of membrane lipids via the isoprenoid compound geranylgeranylphosphate in the mevalonate pathway, although not all of the enzymes involved in this pathway are known with certainty (K oga and M orii, 2007; M atsumi et al., 2011). A $n$ ether bond is formed between the glycerol-1-phosphate backbone and the isoprenoid side chains. Subsequently cytidine-diphosphate is attached and finally the unsaturated isoprenoid side chains are reduced to form diphytanylglycerol diether, also known as archaeol (M atsumi et al., 2011).

The isotopic composition of lipids provides information on the carbon source used by the microorganism. The lipids of ANM Es involved in sulfatedriven $\mathrm{AOM}$ are usually strongly depleted in ${ }^{13} \mathrm{C}$, with $\delta^{13} \mathrm{C}$ values ranging from - 70 to $-130 \%$ (Elvert et al., 1999; Pancost et al., 2000; Niemann and Elvert, 2008). Such low $\delta^{13} \mathrm{C}$ values of lipids have been explained by the assimilation of 13C -depleted methane carbon during methane uptake into biomass (Elvert et al., 1999; Hinrichs et al., 1999; Pancost et al., 2000; Orphan et al., 2002). M ixed assimilation of $\mathrm{CH}_{4}$ and $\mathrm{CO}_{2}$ has been reported for marine AN M E-1, -2a, and $2 b$ strains indicating that at least some A N M E strains can use methane-derived carbon for biomass production (W egener et al., 2008). H owever, for A N M E-1 it has been shown that methane oxidation is decoupled from the assimilatory system and that $\mathrm{CO}_{2}$-dependent autotrophy is the predominant mode of carbon fixation (K ellermann et al., 2012). In general, A N M E archaea seem to be able to assimilate both, methane and dissolved inorganic carbon, and the preferred carbon source for assimilation might vary between the different A N M E clusters.

In this study, we performed analysis of the lipids from ANME-2d archaea and compared these with previous studies about different A N M E lipids. Moreover, we analysed the incorporation of ${ }^{13} \mathrm{C}$-labelled methane and bicarbonate in lipids of these archaea to establish the carbon sources used for assimilation.

\section{M aterials and methods}

\subsection{A NM E-2d bioreactor operation and sampling for lipid analysis}

For lipid analysis of $\mathrm{Ca}$. M ethanoperedens $\mathrm{sp}$. two different bioreactors were sampled. One bioreactor contained archaea belonging to the ANME-2d clade enriched from the Ooijpolder (NL) (A rshad et al., 2015; B erger et al., 2017) and 
the other reactor ANME-2d archaea enriched from an Italian paddy field (Vaksmaa, Jetten, et al., 2017; Guerrero-Cruz et al., 2018). The anaerobic enrichment culture dominated by $\mathrm{Ca}$. Methanoperedens sp. strain BLZ2 originating from the Ooijpolder (Berger et al., 2017) was maintained in an anaerobic $10 \mathrm{~L}$ sequencing batch reactor $\left(30^{\circ} \mathrm{C}, \mathrm{pH} 7.3 \pm 0.1\right.$, stirred at $\left.180 \mathrm{rpm}\right)$. The mineral medium consisted of $0.16 \mathrm{~g} / \mathrm{L} \mathrm{M} \mathrm{gSO}_{4}, 0.24 \mathrm{~g} / \mathrm{L} \mathrm{CaCl}_{2}$ and $0.5 \mathrm{~g} / \mathrm{L}$ $\mathrm{KH}_{2} \mathrm{PO}_{4}$. T race elements and vitamins were supplied using stock solutions. 1000 $x$ trace element stock solution: $1.35 \mathrm{~g} / \mathrm{L} \mathrm{FeCl}_{2} \times 4 \mathrm{H}_{2} \mathrm{O}, 0.1 \mathrm{~g} / \mathrm{L} \mathrm{M} \mathrm{nCl}{ }_{2} \times 4 \mathrm{H}_{2} \mathrm{O}$, $0.024 \mathrm{~g} / \mathrm{L} \mathrm{CoCl}_{2} \times 6 \mathrm{H}_{2} \mathrm{O}, 0.1 \mathrm{~g} / \mathrm{L} \mathrm{CaCl}_{2} \times 2 \mathrm{H}_{2} \mathrm{O}, 0.1 \mathrm{~g} / \mathrm{L} \mathrm{ZnCl}_{2}, 0.025 \mathrm{~g} / \mathrm{L} \mathrm{CuCl}_{2}$ $\times 2 \mathrm{H}_{2} \mathrm{O}, 0.01 \mathrm{~g} / \mathrm{L} \mathrm{H}_{3} \mathrm{BO}_{3}, 0.024 \mathrm{~g} / \mathrm{L} \mathrm{Na}_{2} \mathrm{M} \mathrm{OO}_{4} \times 2 \mathrm{H}_{2} \mathrm{O}, 0.22 \mathrm{~g} / \mathrm{L} \mathrm{NiCl}_{2} \times 6 \mathrm{H}_{2} \mathrm{O}$, $0.017 \mathrm{~g} / \mathrm{L} \mathrm{Na} \mathrm{SeO}_{3}, 0.004 \mathrm{~g} / \mathrm{L} \mathrm{Na} \mathrm{WO}_{4} \times 2 \mathrm{H}_{2} \mathrm{O}, 12.8 \mathrm{~g} / \mathrm{L}$ nitrilotriacetic acid; $1000 \times$ vitamin stock solution: $20 \mathrm{mg} / \mathrm{L}$ biotin, $20 \mathrm{mg} / \mathrm{L}$ folic acid, $100 \mathrm{mg} / \mathrm{L}$ pyridoxine- $\mathrm{HCl}, 50 \mathrm{mg} / \mathrm{L}$ thiamin- $\mathrm{HCl} \times 2 \mathrm{H}_{2} \mathrm{O}, 50 \mathrm{mg} / \mathrm{L}$ riboflavin, $50 \mathrm{mg} / \mathrm{L}$ nicotinic acid, $50 \mathrm{mg} / \mathrm{L}$ D-Ca-pantothenate, $2 \mathrm{mg} / \mathrm{L}$ vitamin B 12, $50 \mathrm{mg} / \mathrm{L} \mathrm{p}$ aminobenzoic acid, $50 \mathrm{mg} / \mathrm{L}$ lipoic acid. The medium supply was continuously sparged with $\mathrm{Ar}: \mathrm{CO}_{2}$ in a 95:5 ratio. Per day $30 \mathrm{mmol}$ nitrate added to the medium were supplied to the bioreactor and were completely consumed. $M$ ethane was added by continuously sparging the reactor content with $\mathrm{CH}_{4}: \mathrm{CO}_{2}$ in a 95:5 ratio at a rate of $15 \mathrm{~mL} / \mathrm{min}$. The reactor was run with a medium turnover of $1.25 \mathrm{~L}$ per $12 \mathrm{~h}$. A 5 min settling phase for retention of biomass preceded the removal of supernatant. Under these conditions nitrite was not detectable with a colorimetric test with a lower detection limit of $2 \mathrm{mg} / \mathrm{L}$ (M Quant test stripes, Merck, Darmstadt, Germany). Growth conditions and operation of the bioreactor containing ANME-2d archaea enriched from an I talian paddy field soil are described by Guerrero-Cruz et al., 2018 (GuerreroCruz et al., 2018). Sampled material from both reactors was centrifuged (10000 $\times \mathrm{g}, 20 \mathrm{~min}, 4^{\circ} \mathrm{C}$ ) and pellets were kept at $-80^{\circ} \mathrm{C}$ until subsequent freeze-drying and following lipid and isotope analysis.

\subsection{A nalysis of the microbial community}

For the Ooijpolder enrichment we performed whole genome metagenome sequencing. DNA extraction, library preparation and metagenome sequencing were performed as described before by Berger and co-workers (Berger et al., 2017). Quality-trimming, sequencing adapter removal and contaminant filtering of Illumina paired-end sequencing reads were performed using B B Tools B B Duk 37.76 (BB M ap - Bushnell B. - sourceforge.net/projects/bbmap/). All processed paired-end reads were assigned to a taxon using K aiju 1.6.2 (M enzel et al ., 2016) employing the NCBI BLAST non-redundant protein database (NCBI Resource Coordinators, 2016). 


\subsection{B atch cultivation of ANME-2d bioreactor cell material for ${ }^{13} \mathrm{C}$-labelling experiment}

$60 \mathrm{ml}$ bioreactor material of a C a. M ethanoperedens sp. B LZ2 culture enriched from the Ooijpolder (A rshad et al., 2015; B erger et al., 2017) were transferred with a syringe to a $120-\mathrm{ml}$ serum bottle that had been made anoxic by flushing the closed bottle with argon gas for 10 min. A fterwards, the culture was purged with $90 \%$ argon and $10 \% \mathrm{CO}_{2}$ for $5 \mathrm{~min} .2 .5 \mathrm{mM}$ bicarbonate and $18 \mathrm{ml}$ methane (Air Liquide, Eindhoven, The N etherlands) were added. Except for the negative controls, either ${ }^{13} \mathrm{C}$-labelled methane (99 atom\%; I sotec Inc., M atheson Trigas Products Division) or ${ }^{13} \mathrm{C}$-labelled bicarbonate (Cambridge Isotope Laboratories Inc., Tewksbury, USA) was used in the batch incubations. The bottles were incubated horizontally on a shaker at $30^{\circ} \mathrm{C}$ and $250 \mathrm{rpm}$ for one or three days. All bottles contained sodium nitrate $(0.6 \mathrm{mM})$ at the start of incubation and additional nitrate was added when the concentration in the bottles was close to 0 , as estimated by MQuant (M erck, Darmstadt, Germany) test strips. The methane concentration in the headspace was measured twice a day by gas chromatography with a gas chromatograph (Hewlett Packard 5890a, A gilent Technologies, Santa Clara CA, US) equipped with a Porapaq Q 100/120 mesh and a thermal conductivity detector (TCD) using $\mathrm{N}_{2}$ as carrier gas. Each measurement was performed by injection of $50 \mu$ headspace gas with a gas-tight syringe. With this technique a decrease in methane concentration from $\sim 24 \%$ to $\sim 20 \%$ within three days of incubation was observed. A fter batch incubation, cell material was centrifuged $\left(10000 \times \mathrm{g}, 20 \mathrm{~min}, 4^{\circ} \mathrm{C}\right)$ and pellets were kept at $-80^{\circ} \mathrm{C}$ until subsequent freeze-drying and following lipid and isotope analysis. It has to be considered that cultures with ${ }^{13} \mathrm{C}$-labelled bicarbonate also contained ${ }^{12} \mathrm{C}$ derived from $\mathrm{CO}_{2}$. Having in mind that $10 \%$ of $\mathrm{CO}_{2}$ were added to the culture $\left(\mathrm{pCO}_{2}=0.1 \mathrm{~atm}\right)$ the $\mathrm{CO}_{2}$ concentration in the solution was cal culated to be about $3.36 \mathrm{mM}$ by use of the equation $\left[\mathrm{CO}_{2}\right] \mathrm{aq}=\mathrm{pCO}_{2} / \mathrm{kh}$ ( $\mathrm{H}$ enry constant $(\mathrm{kh})$ is 29.76 $\mathrm{atm} /(\mathrm{mol} / \mathrm{L})$ at $\left.25^{\circ} \mathrm{C}\right)$. Therefore, it has to be assumed that about half of the carbon in the cultures where ${ }^{13} \mathrm{C}$ labelled bicarbonate was added derived from ${ }^{12} \mathrm{C}-\mathrm{CO}_{2}$ dissolved in the medium after gassing with a mixture of $10 \% \mathrm{CO}_{2} / 90 \%$ Argas.

\subsection{L ipid extraction and analysis}

\subsubsection{Bligh and Dyer extraction}

B ligh and Dyer extraction was used to extract Intact Polar Lipids (IPLs) from the A N M E-2d enrichment. Lipids of freeze-dried biomass (between 20 and $70 \mathrm{mg}$ ) were extracted by a modified Bligh and Dyer method as described by B ale et al. 
(B ale et al., 2013) using a mixture of methanol, dichloromethane and phosphate buffer at $\mathrm{pH} 7.4(2: 1: 0.8 \mathrm{v} / \mathrm{v} / \mathrm{v})$. After ultrasonic extraction (10 min) and centrifugation the solvent layer was collected. The residue was re-extracted twice. The combined solvent layers were separated by adding additional DCM and phosphate buffer to achieve a ratio of $\mathrm{MeOH}, \mathrm{DCM}$ and phosphate buffer (1:1:0.9 v/v/v). The separated organic DCM layer on the bottom was removed and collected while the aqueous layer was washed two more times with DCM . The combined DCM layer was evaporated under a continuous stream of nitrogen.

\subsubsection{Acid hydrolysis}

Head groups of archaeal lipids were removed using acid hydrolysis. Therefore, this method is used to analyse the core lipids of the microorganisms present in the ANM E-2d enrichment. A bout $20 \mathrm{mg}$ freeze-dried biomass was hydrolyzed with $2 \mathrm{ml}$ of a $1.5 \mathrm{~N} \mathrm{HCl} / \mathrm{M} \mathrm{eOH}$ solution and samples stirred for $2 \mathrm{~h}$ while heated at $130^{\circ} \mathrm{C}$ with a reflux system. A fter cooling, the $\mathrm{pH}$ was adjusted to $\mathrm{pH} 4-5$ by adding $2 \mathrm{~N} \mathrm{KOH} / \mathrm{M} \mathrm{eOH}$ solution. $2 \mathrm{ml} \mathrm{DCM}$ and $2 \mathrm{ml}$ distilled $\mathrm{H}_{2} \mathrm{O}$ were added. The DCM bottom layer was transferred to a new vial and the $\mathrm{MeOH} / \mathrm{H}_{2} \mathrm{O}$ layer washed twice with DCM. Combined DCM layers were dried over a $\mathrm{Na}_{2} \mathrm{SO}_{4}$ column and the solvent removed by evaporation under a stream of nitrogen.

\subsection{3 $\mathrm{BF}_{3}$ methylation and silylation}

For gas chromatography (GC) analysis aliquots of the acid hydrolyzed samples were methylated using $0.5 \mathrm{ml}$ of $\mathrm{BF}_{3}$-methanol and react for $10 \mathrm{~min}$ at $60^{\circ} \mathrm{C}$ in an oven. $0.5 \mathrm{ml} \mathrm{H}{ }_{2} \mathrm{O}$ and $0.5 \mathrm{ml} \mathrm{DCM}$ were added to the heated mixture to separate the DCM and aqueous layers. Samples were mixed, centrifuged and the DCM -layer taken off and collected. The water layer was washed three more times with DCM . The combined DCM -layer were evaporated under a $\mathrm{N}_{2}$ stream and water was removed by use of a $\mathrm{M} \mathrm{gSO}_{4}$ column. After dissolving the sample in ethyl acetate, the extract was cleaned over a small silicagel column and lipids were eluted with ethyl acetate. The extract was dried under $\mathrm{N}_{2}$. For GC analysis, extracts $(0.3$ to $0.5 \mathrm{mg}$ ) were dissolved in $10 \mu \mathrm{l}$ pyridine and $10 \mu \mathrm{l}$ BSTFA. Samples were heated for $30 \mathrm{~min}$ at $60^{\circ} \mathrm{C}$ and afterwards diluted with ethyl acetate to $1 \mathrm{mg} / \mathrm{ml}$.

\subsubsection{GC-MS}

This method was used to analyse bacterial fatty acids as well as archaeal diether lipids. Gas chromatography linked to mass spectrometry (GC-MS) was performed with a 7890B gas chromatography system (A gilent) connected to a 
7000 GC/M S Triple Quad (A gilent). The gas chromatograph was equipped with a fused silica capillary column $(25 \mathrm{~m} \times 0.32 \mathrm{~mm})$ coated with CP Sil-5 CB $(0.12$ $\mu \mathrm{m}$ film thickness) and a Flame Ionization D etector (FID). Helium was used as the carrier gas. The samples were injected manually at $70^{\circ} \mathrm{C}$ via an on-column injector. The oven temperature was programmed to a temperature increase from 70 to $130^{\circ} \mathrm{C}$ with $20^{\circ} \mathrm{C} / \mathrm{min}$ and a further increase to $320^{\circ} \mathrm{C}$ with $4^{\circ} \mathrm{C} / \mathrm{min}$ to, $320^{\circ} \mathrm{C}$ was held for $10 \mathrm{~min}$. The mass range of the mass spectrometer was set to scan from $\mathrm{m} / \mathrm{z} 50$ to $\mathrm{m} / \mathrm{z} 850$.

\subsubsection{GC-IRMS}

To analyse the incorporation of ${ }^{13} \mathrm{C}$ labelled methane or bicarbonate into lipids present in the ANME-2d enrichment GC-IRMS was conducted. Gas chromatography coupled to isotope-ratio mass spectrometry (GC-IRMS) was performed on a TRACE 1310 Gas Chromatograph (Thermo Fisher Scientific) interfaced with a Scientific GC IsoLink II Conversion U nit connected to an IRM S DELTA V Advantage Isotope-ratio mass spectrometer (Thermo Fisher Scientific). The gas chromatograph was equipped with a fused silica capillary column ( $25 \mathrm{~m} \times 0.32 \mathrm{~mm}$ ) coated with CP Sil-5 CB (0.12 $\mu \mathrm{m}$ film thickness). Helium was used as the carrier gas. The acid hydrolyzed samples containing the core lipids were injected at $70^{\circ} \mathrm{C}$ via an on-column injector. The oven temperature was programmed to a temperature increase from 70 to $130^{\circ} \mathrm{C}$ with $20^{\circ} \mathrm{C} / \mathrm{min}$ and a further increase to $320^{\circ} \mathrm{C}$ with $4^{\circ} \mathrm{C} / \mathrm{min}, 320^{\circ} \mathrm{C}$ was held for 10 min. $\delta^{13} \mathrm{C}$ values were corrected for methyl group derived from $\mathrm{BF}_{3}$ methanol in case of carboxylic acid group (bacterial lipids) and methyl groups derived from BSTFA in case of hydroxyl groups (mainly archaeal lipids). Averaged $\delta^{13} \mathrm{C}$ values are based on experimental triplicates, but not on analytical duplicates.

\subsubsection{UHPLC-APCI-TOF-MS}

UHPLC-A PCI-TOF-M S analysis of the acid hydrolyzed lipids was conducted in order to obtain information about the tetraether lipids. A bout 0.4 to $0.8 \mathrm{mg}$ of the acid hydrolyzed lipid extract was dissolved in a mixture of hexane/isopropanol 99:1. Extracts were filtered by use of a $0.45 \mu \mathrm{m}, 4 \mathrm{~mm}$ diameter PTFE filter. A bout $2 \mathrm{mg}$ per $\mathrm{ml}$ core lipid containing extracts were used for analysis by ultrahigh performance liquid chromatography linked to time-of-flight atmospheric pressure chemical ionization mass spectrometry using a (UHPLC-APCITOFMS). Core lipid analysis was performed on an Agilent 1260 Infinity II UHPLC coupled to an A gilent 6230 TOF-M S. Separation was achieved on two UHPLC silica columns (BEH HILIC columns, $2.1 \times 150 \mathrm{~mm}, 1.7 \mu \mathrm{m}$; Waters) in series maintained at $25^{\circ} \mathrm{C}$. The injection volume was $10 \mu \mathrm{l}$. L ipids were eluted 
isocratically for 10 min with $10 \%$ B, followed by a linear gradient to $18 \% \mathrm{~B}$ in $15 \mathrm{~min}$, then a linear gradient to $30 \% \mathrm{~B}$ in $25 \mathrm{~min}$, then a linear gradient to $100 \%$ $B$ in $30 \mathrm{~min}$, and finally $100 \%$ B for $20 \mathrm{~min}$, where $A$ is hexane and $B$ is hexane: isopropanol (9:1). Flow rate was $0.2 \mathrm{ml} / \mathrm{min}$ and pressure $400 \mathrm{bar}$. Total run time was 120 min with a 20 min re-equilibration. Settings of the ion source (APCI) were as follow ed: gas temperature $200^{\circ} \mathrm{C}$, vaporizer $400^{\circ} \mathrm{C}$, drying gas $6 \mathrm{l} / \mathrm{min}$, nebulizer $60 \mathrm{psig}$. The lipids were identified using a positive ion mode $(600-$ $1400 \mathrm{~m} / \mathrm{z}$ ).

\subsubsection{UHPLC-ESI-MS}

This method was used to analyse the intact polar lipids (IPLs) of the AN M E-2d enrichment. 0.3 to $0.7 \mathrm{mg}$ of B ligh and Dyer sample was dissolved in an injection solvent composed of hexane/isopropanol/water $(72: 27: 1 ; \mathrm{v} / \mathrm{v} / \mathrm{v})$ and filtered through a $0.45 \mu \mathrm{m}$ regenerated cellulose filter with $4 \mathrm{~mm}$ diameter prior to analysis by ultra-high performance liquid chromatography linked to ion trap mass spectrometry using electrospray ionization (UHPLC-ESI-MS). UHPLC separation was conducted on an A gilent 1200 series UHPLC equipped with a Y M C-Pack Diol-120-NP column $(250 \times 2.1 \mathrm{~mm}, 5 \mu \mathrm{m}$ particle size $)$ and a thermostated autoinjector, coupled to a Thermo LTQ X L linear ion trap with Ion Max source with electrospray ionization (ESI) probe (Thermo Scientific, Waltham, MA). Solvent A contained 79\% hexane, 20\% isopropanol, $0.12 \%$ formic acid, 0.04\% ammonium and solvent B 88\% isopropanol, $10 \% \mathrm{H}_{2} \mathrm{O}$, $0.12 \%$ formic acid, $0.04 \%$ ammonium. Lipids were eluted with $0 \% \mathrm{~B}$ for $1 \mathrm{~min}$, a linear gradient from 0 to $34 \%$ B in $17 \mathrm{~min}, 34 \%$ B for $12 \mathrm{~min}$, followed by a linear gradient to $65 \%$ B in $15 \mathrm{~min}, 65 \%$ B for 15 min and finally a linear gradient to $100 \%$ B in $15 \mathrm{~min}$. The IPLs were identified using a positive ion mode $(\mathrm{m} / \mathrm{z}$ 400-2000) and a collision energy of $35 \mathrm{eV}$.

\section{Results and Discussion}

\subsection{A nalysis of microbial community}

W e performed phylogenetic analysis of the microbial community in the A N M E$2 \mathrm{~d}$ enrichment originating from the 0 oijpolder by assigning all processed pairedend reads to a taxon. Twenty-three percent of the reads were assigned to $\mathrm{Ca}$. Methanoperedens sp. strain BLZ2, 33\% to Ca. Methylomirabilis sp. acting as nitrite scavenger, $8 \%$ to A I phaproteobacteria, $6 \%$ to Gammaproteobacteria, 5\% to Betaproteobacteria $1 \%$ to Deltaproteobacteria, 3\% to Terrabacteria, 3\% to Sphingobacteria and $1 \%$ to Planctobacteria. The only archaeon in the bioreactor was Ca. M ethanoperedens sp. strain BLZ2. A nalysis of the microbial community in the I talian paddy field A N M E-2d enrichment using a bioreactor approach has 
been described by Guerrero-Cruz et al., 2018. M etagenome sequencing of the DNA derived from this bioreactor revealed that $83 \%$ of $16 \mathrm{~S}$ rRNA gene reads were assigned to $\mathrm{Ca}$. Methanoperedens nitroreducens strain Verserenetto (Guerrero-Cruz et al., 2018). In this study we mainly show the results derived from lipid analysis of the $C$ a. M ethanoperedens sp. B L Z2 enrichment originating from the Ooijpolder (A rshad et al., 2015; B erger et al., 2017). However, the results deriving from a $\mathrm{Ca}$. M ethanoperedens sp. Versenetto enrichment originating from Italian paddy field soil (Guerrero-Cruz et al., 2018) look very similar, indicating that our results are not dependent on the strain or the environment from which the strain was enriched.

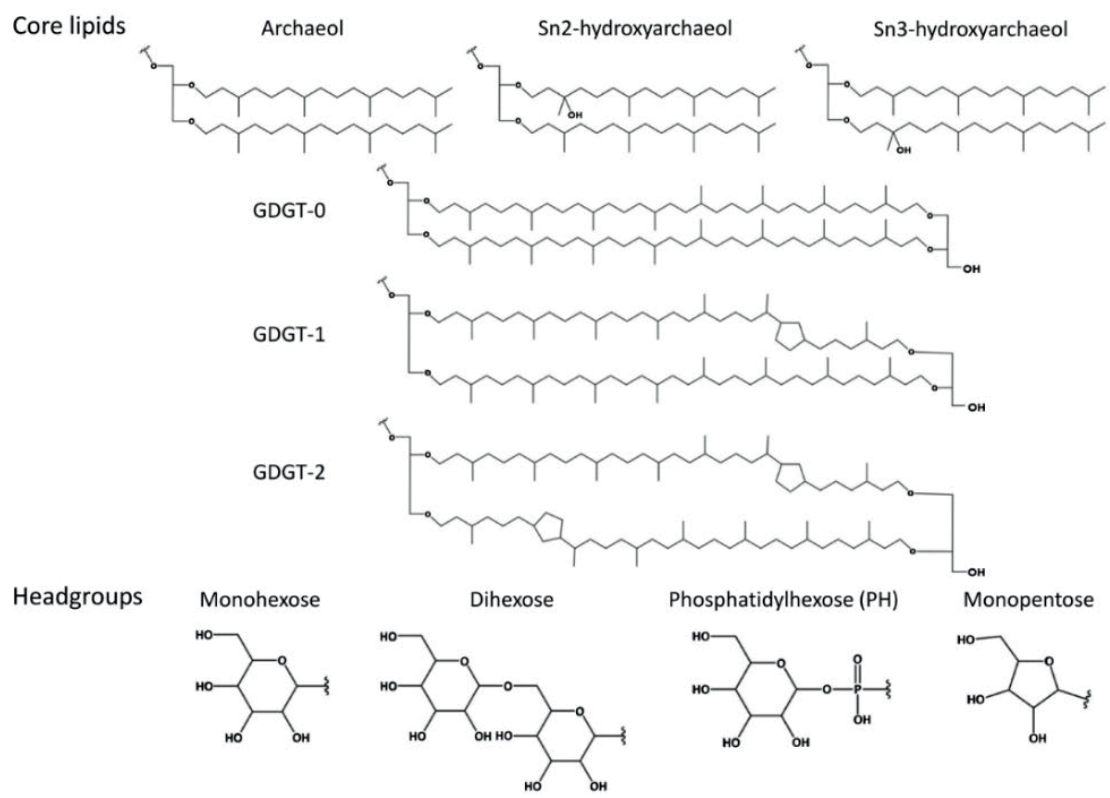

Phosphatidyl ethanolamine (PE) Monomethyl-PE (MMPE) Dimethyl-PE (DMPE) Phosphatidyl glycerol (PG)
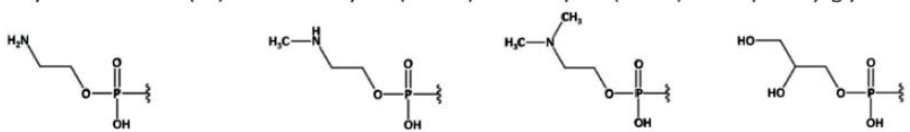

Figure 1 Structures of archaeal core lipids and headgroups. The main core lipids and headgroups that we found to be present in ANM E-2d archaea are shown. The exact structure of monounsaturated archaeol as well as the pentose headgroup is not known. Intact polar lipids consist of a core lipid and one or two headgroups (only GDGTs can contain two headgroups). GDGT = glycerol dialkyl glycerol tetraethers.

\subsection{Corelipids of Ca. Methanoperedenssp.}

To analyse the lipids of ANME-2d archaea, biomass from a bioreactor containing Ca. M ethanoperedens sp. BLZ2 enrichment was sampled and core lipid analysis with GC-M S and UH PLC-A PCI-TOF-M S was performed. Shorter archaeal lipids like archaeol (Fig. 1) can be detected via GC-M S, whereas longer archaeal lipids like GD GTs can only be detected via U H PLC-A PCI-T OF-M S. 
GC analysis of the core lipids released by acid hydrolysis showed that of the microbial community harbored bacterial fatty acids and isoprenoidal archaeal lipids (Fig. 2). We detected the typical membrane lipids of $\mathrm{Ca}$. M ethylomirabilis sp., namely 10-methylhexadecanoic acid (10M eC 16:0) and its monounsaturated variant $(10 \mathrm{MeC16:1 \Delta 7)}$ (Kool et al., 2012). The archaeal isoprenoids were predominantly composed of archaeol with lower amounts of sn2-hydroxyarchaeol and sn3-hydroxyarchaeol as well as two monounsaturated archaeols (Fig. 1) which could be identified with help of literature references (Nichols and Franzmann, 1992). M onounsaturated archaeol has already been described to be present in environmental samples containing lipids of archaea associated with anaerobic methane oxidation in marine environments (Pancost et al., 2001; Blumenberg et al., 2005). However, the monounsaturated archaeol might be produced from hydroxyarchaeol during acidic treatment of the lipids and therefore might not be part of native membrane lipid structures (Ekiel and Sprott, 1992). Alteration of the hydroxyarchaeol structure caused by different reaction conditions during lipid treatment has also been shown by Hinrichs and co-workers (Hinrichs et al., 2000). On the other hand, monounsaturated archaeols have also been described for Halorubrum lacusprofundi (Franzmann et al., 1988; Gibson et al., 2005), M ethanopyrus kandleri (N ishihara et al., 2002), Methanococcoides burtonii (Nichols and Franzmann, 1992; Nichols et al., 1993), even if using mild alkaline hydrolysis instead of acidic treatment for lipid extraction (Nishihara et al., 2002).

One possibility to distinguish between the different A N M E groups is the sn2-hydroxyarchaeol to archaeol proportion (Blumenberg et al., 2004). For ANME-1 this ratio is described to be $0-0.8$, for marine ANME-2 1.1 to 5.5 and for ANME-3 within the range of A NME-2 (B lumenberg et al., 2004; Niemann et al., 2006; Nauhaus et al., 2007; N iemann and Elvert, 2008). In our study with the non-marine ANME-2d archaea we observed a sn2-hydroxyarchaeol to archaeol ratio of around 0.2. A s mentioned before, the monounsaturated archaeol species might be an artefact of hydroxyarchaeol. If the monounsaturated archaeols are added to that of the sn2-hydroxyarchaeol abundance, the ratio would still be only around 0.3 . That means that the hydroxyarchaeol to archaeol ratio of ANME-2d is more similar to that of ANME-1 archaea than to that of other AN M E-2 or A N M E-3 archaea. M embers of the related methanogen order $M$ ethanomicrobiales only contain archaeol and GDGT-0 in their membranes but not hydroxyarchaeol (Koga et al., 1998). In the order M ethanosarcinales the lipid composition varies between the different members. M ost strains produce archaeol and hydroxyarchaeol, but the ratio differs and also the type of hydroxyarchaeol isomer varies. M ethanosarcinaceae mainly produce the sn2- 
isomer, whereas Methanosaetaceae mainly produce the rare sn3-isomer (K oga et al., 1998).

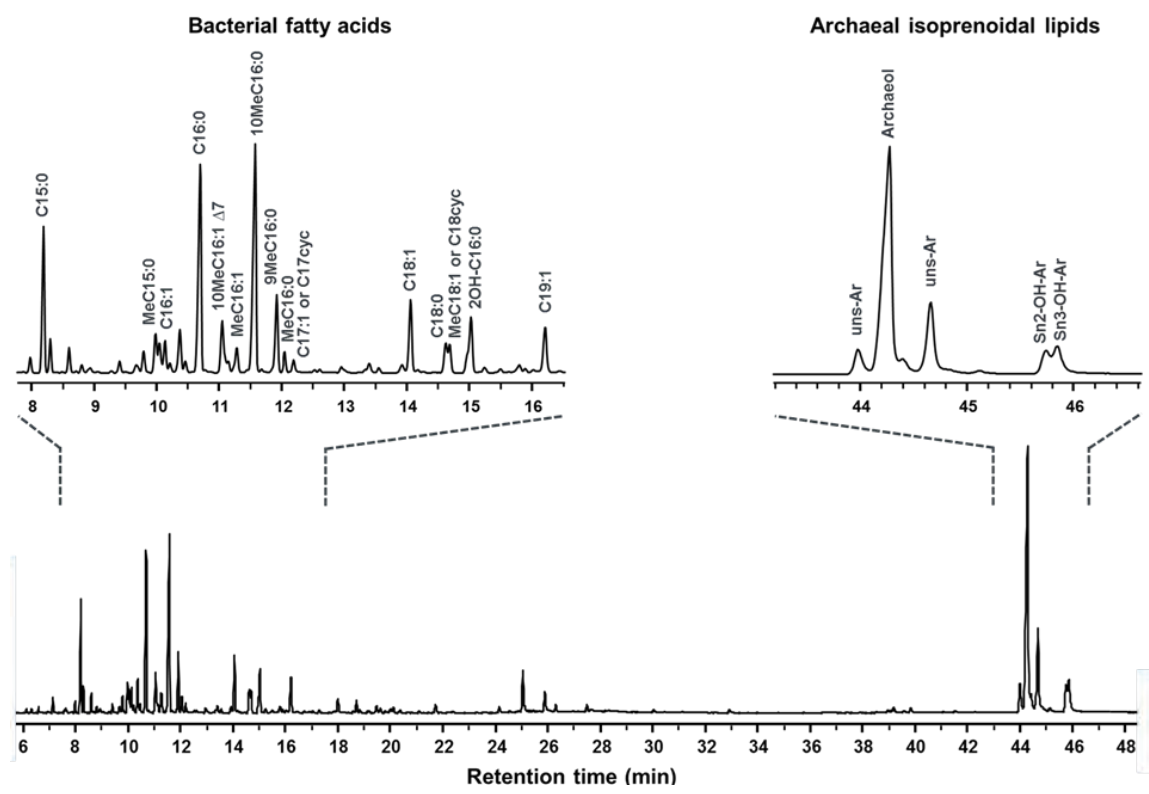

Figure $2 \mathrm{G}$ as chromatogram of core lipids released by acid hydrolysis from $\mathrm{Ca}$. M ethanoperedens $\mathrm{sp}$. (A N M E2d) enrichment. The enriched biomass of A N M E-2d originates from the O oijpolder (NL) (A rshad et al., 2015). Enlarged inserts show the TIC (total ion chromatogram) of the bacterial and archaeal lipids. The most abundant compounds are annotated with their compound name and following abbreviations: $\mathrm{Uns}-\mathrm{Ar}=$ monounsaturated archaeol, $\mathrm{OH}-\mathrm{Ar}=$ hydroxyarchaeol.

Subsequently, UHPLC-APCI-TOF-MS analysis of the lipid extract was conducted in order to obtain information about the tetraether lipids (Fig. 1). This revealed that the relative abundance of archaeol was two times higher than that of glycerol dialkyl glycerol tetraethers (GDGTs) (Table 1). M oreover, several types of GDGTs were present in the enrichment. GDGTs contained either no (GDGT-0), one (GDGT-1) or two (GDGT-2) cyclopentane rings and about $64 \%$ of the GDGTs were hydroxylated (OH-GDGTs). The most abundant GDGTs were GDGT-0 with $6 \%$ and di-OH-GDGT-2 with $5 \%$ of total lipids. In conclusion, ANME-2d archaea synthesize various core-GDGTs, however archaeol and its homologues are the main isoprenoidal core-lipids in this enrichment.

Environmental samples from Mediterranean cold seeps with marine AOM associated archaea mainly contained GDGTs with 0 to 2 cyclopentane rings (Pancost et al., 2001). In a study on distinct compartments of A O M -driven carbonate reefs growing in the northwestern Black Sea, GDGTs could only be found in samples when ANME-1 archaea were present, but not when only 
A N M E-2 archaea were found, which led to the conclusion that A N M E-2 archaea are not capable of synthesizing internally cyclized GDGT (Blumenberg et al., 2004). Later on in a study on methanotrophic consortia at cold methane seeps, samples associated with ANME-2C were shown to contain relatively high amounts of GDGTs (Elvert et al., 2005). In general, GDGTs are dominant in ANME-1 communities, while in marine ANME-2 and ANME-3 communities archaeol derivatives are most abundant (N iemann and E Ivert, 2008; R ossel et al., 2008). GDGTs are not only present in marine archaea but are also produced by soil microbiota. For example, several members of the phylum Thaumarchaeota from soil environments have been shown to produce GDGTs with crenarchaeol as the major core GDGT similar to the aquatic thaumarchaeota (Sinninghe Damsté et al., 2012). Next to crenarchaol GDGTs with 0 to 4 cyclopentane moieties and GDGTs containing an additional hydroxyl group were detected in by Sinninghe Damsté and co-workers. In comparison to ANME-2d archaea, members of the related methanogen order Methanomicrobiales produce relatively high amounts of GDGT-0 (K oga et al., 1998; Schouten et al., 2012), whereas other members of the Methanosarcinales produce no or only minor amounts of GDGTs, mainly GDGT-0 (De R osa and Gambacorta, 1988; Nichols and Franzmann, 1992; Schouten et al., 2012). Hydroxylated GD GTs seem to be relatively rare. In marine sediment samples the hydroxy-GDGT to total core GDGT ratio has been shown to vary between 1 and $8 \%$ and the dihydroxyGDGT to total core GDGT ratio is below 2\% (Liu et al., 2012). Hydroxylated GDGTs have so far only been identified in the methanogenic Euryarchaeon Methanothermococcus thermolithotrophicus (Liu et al., 2012) and in several Thaumarchaeota (Schouten et al., 2012; Sinninghe Damsté et al., 2012). Until now only hydroxylated GDGTs with 0 to 2 cyclopentane rings have been found (Liu et al., 2012; Schouten et al., 2012; Sinninghe Damsté et al., 2012). In conclusion, the substantial abundance of GDGTs, especially hydroxylated GDGTs, is a distinct feature of the non-marine ANME archaeon $\mathrm{Ca}$. M ethanoperedens sp., as GDGTs have so far mainly been described for marine archaea like those of the A N M E-1 clade as well as Thaumarchaeota present in marine and non-marine environments.

Comparing the results obtained in this study and lipid characterizations of marine ANMEs, it is apparent that the ratio of archaeol and GDGTs are distinctive in the different ANME groups: ANME-1 and partially ANME-2C contain substantial amounts of GDGTs and especially in ANME-1, GDGTs are the predominant membrane lipids (Niemann and Elvert, 2008). In contrast to ANME-1, but similar to other ANME-2 and ANME-3, we found that the dominating lipids in the membrane of clade A NME-2d archaea were archaeol 
variants and not GDGTs. However, about $30 \%$ of the membrane lipids in A N M E-2d archaea were GDGTs. M ost strikingly, the majority of those GDGTs were hydroxylated, which is quite rare and has not been observed for other ANMEs so far.

\subsection{Intact polar lipids of Ca. Methanoperedens sp.}

Although intact polar lipids (IPLs) degrade more quickly than core lipids, IPLs are of higher taxonomic specificity and therefore useful to study especially present environments (Ruetters et al., 2002; Sturt et al., 2004). To identify IPLS of $\mathrm{C}$ a. M ethanoperedens archaea, UHPLC-ESI-M S was performed.

Table 1 A bundance of archaeol and GDGTs of Ca. M ethanoperedens sp. Lipid extraction was performed in quadruplicates, error is given as standard deviation. For calculation of the relative abundance of archaeol also peaks derived from archaeol artefacts created during the experimental procedure were used.

\begin{tabular}{ccc} 
Lipid & $\begin{array}{c}\text { Relative } \\
\text { abundance(\%) }\end{array}$ & $\begin{array}{c}\text { Relativeabundance } \\
\text { (\%) }\end{array}$ \\
\hline A rchaeol & $68 \pm 5$ & $68 \pm 5$ \\
\hline GDGT-0 & $6 \pm 1$ & \\
GDGT-1 & $3 \pm 1$ & \\
GDGT-2 & $2 \pm 1$ & $32 \pm 5$ \\
OH-GDGT-1 & $3 \pm 1$ & \\
OH-GDGT-2 & $1 \pm 1$ & \\
di-OH-GDGT-1 & $3 \pm 2$ & \\
di-OH-GDGT-2 & $5 \pm 2$ & \\
other GDGT-2 & $9 \pm 4$ & \\
derivatives & & \\
\hline
\end{tabular}

The three most abundant archaeal IPL s detected were archaeol with a dihexose headgroup and hydroxyarchaeol with either a monomethyl phosphatidyl ethanolamine (M M PE) or a phosphatidyl hexose (PH) headgroup. Further headgroups attached to archaeol were monohexose, M M PE, dimethyl phosphatidyl ethanolamine (DMPE), phosphatidyl ethanolamine (PE) and PH. Next to M MPE and PH, hydroxyarchaeol based IPL $s$ also contained dihexose, monopentose, DM PE, PE, pentose-M M PE, hexose-M M PE and pentose-PE (Fig. 1). Headgroups of GDGTs were found to be diphosphatidyl glycerol and dihexose phosphatidyl glycerol. The identification of a pentose as a headgroup of hydroyxarchaeol (mass loss of $\mathrm{m} / \mathrm{z}$ 132) was unexpected. To our knowledge, this is the first description of a pentose as headgroup for microbial IPL s. 
A N M E-1 archaea mainly produce diglycosidic GDGTs, whereas lipids of marine ANME-2 and ANME-3 are dominated by phosphate-based polar derivatives of archaeol and hydroxyarchaeol (ANME-2: phospatidyl glycerol, phosphatidyl ethanolamine, phosphatidyl inositol, phosphatidyl serine, dihexose; ANME-3: phospatidyl glycerol, phosphatidyl inositol, phosphatidyl serine) (Rossel et al., 2008). Furthermore, marine ANME-2 archaea produce only minor amounts of GDGT-based IPLs and ANME-3 archaea produce no GDGT -based IPL s at all (Rossel et al., 2008). Intact GDGTs are assumed to be synthesised by head-to-head condensation of two intact archaeol molecules and substitution of the headgroups (De Rosa et al., 1980; Nishihara et al., 1989; K ellermann et al., 2016). In a study of W egener and co-workers IPL $s$ of marine ANME-2 and ANME-1 enrichments were analysed (Wegener et al., 2016). In the marine ANME-2 archaea mainly archaeol with a diglycosyl, monoglycosyl or phoshatidyl glycerol headgroup and hydroxyarchaeol with a monoglycosyl or phoshatidyl glycerol headgroup were detected. The ANME-1 enrichment contained mainly GDGTs with a diglycosyl headgroup (W egener et al., 2016). IPL $s$ of A N M E-2d archaea can be distinguished from those of A N M E-1 archaea by the prevalence of phosphate containing headgroups as well as archaeol and hydroxyarchaeol based IPL s. Furthermore, A N M E-2d can be distinguished from other ANME-2 and ANME-3 archaea by the high abundance of dihexose as headgroup, the rare MMPE and DMPE headgroups and putatively also the pentose headgroup, which so far has not been described in the literature. In contrast to A N M E-3 archaea, A N M E-2d and marine A N M E-2 archaea produce GDGT-based IPLs, al beit only in minor amounts.

In marine environments, a variety of archaeal lipids including those identified in ANME archaea can be found, e.g. those of the abundant Thaumarchaeota (GDGTs with hexose or phosphohexose headgroups, Sinninghe Damsté et al., 2012) and uncharacterized archaea (mainly GDGTs with glycosidic headgroups and in subsurface sediments al so archaeol with glycosidic headgroups, Sturt et al., 2004; Lipp et al., 2008). In freshwater environments, IPLs of methanotrophic archaea have hardly been studied. Two studies on peat samples identified GD GT s with a glucose or glucuronosyl headgroup (Liu et al., 2010) and with a hexose-glycuronic acid, phosphohexose, or hexosephosphoglycerol head group (Peterse et al., 2011). GDGTs with a hexosephosphoglycerol head group were also identified in our study for ANME-2d archaea. Therefore, AN M E-2d together with other archaea might be part of the peat microbial community based on the IPL profile. Using DNA biomarkers, most notably the $16 \mathrm{~S}$ rRNA gene, Ca. M ethanoperedens sp. has been detected in 
various peat ecosystems (C adillo-Q uiroz et al., 2008; Zhang et al., 2008; W ang et al., 2019).

Other members of the order M ethanosarcinales mainly produce archaeol and hydroxyarchaeol with the headgroups glucose, phosphatidyl glycerol (only Methanosarcinaceae), phosphatidyl inositol, phosphatidyl ethanolamine, galactose (only Methanosaetaceae) (Koga et al., 1998). On the other hand, members of the related order M ethanomicrobiales contain GDGT-0 and archaeol with the lipid headgroups glucose, galactose, phosphatidyl aminopentanetetrols, phosphatidyl glycerol (Koga et al., 1998). Therefore, IPLs from Ca. $M$ ethanoperedens sp. differ from methanogen IPLs by the high abundance of dihexose, M MPE and phosphatidyl hexose as lipid headgroup and the absence of the quite common headgroup phosphatidyl serine.

\subsection{Incorporation of carbon derived from methane and bicarbonate in lipids}

W e were not only interested in characterizing the lipids of $\mathrm{C}$ a. M ethanoperedens $\mathrm{sp}$. , but also in answering the question if the organism incorporates carbon derived from methane or from dissolved inorganic carbon (DIC) in its lipids. In a labelling experiment from 2006 with an ANME-2d enrichment culture, incorporation of carbon derived from methane could hardly be detected for archaeal lipids (Raghoebarsing et al., 2006). To establish the carbon sources for $\mathrm{C}$. M ethanoperedens sp. we incubated the enrichment culture with ${ }^{13} \mathrm{C}$ labelled bicarbonate and methane and analysed lipid extracts for $\delta^{13} \mathrm{C}$ depletion by GCIRM S (Fig. 3).

A nalysis of the isotopic composition of archaeol and its derivatives showed that A N M E-2d archaea incorporated carbon derived from both methane and bicarbonate into their lipids. However, the main carbon source for biomass production seemed to be methane and not DIC as the former shows more label in the archaeal lipids. However, it has to be considered that the cultures to which ${ }^{13} \mathrm{C}$ labelled bicarbonate was added did not exclusively contain ${ }^{13} \mathrm{C}-\mathrm{DIC}$. A bout half of the DIC in the cultures derived from ${ }^{12} \mathrm{C}-\mathrm{CO}_{2}$ dissolved in the medium after gassing with a mixture of $10 \% \mathrm{CO}_{2} / 90 \%$ A rgon gas (calculations in the methods part). Considering this, the $\delta^{13} \mathrm{C}$ values of the archaeol isomers without ${ }^{12} \mathrm{C}$-DIC in the incubations would vary most probably between -40 and $-60 \%$. Nevertheless, the respective lipids were still quite depleted in $\delta^{13} \mathrm{C}$ in comparison to the incubations with labelled methane (-2 to $12 \% ; 3$ days incubation). Therefore, we concluded that mainly methane and not DIC is incorporated in the lipids of $\mathrm{Ca}$. M ethanoperedens sp.. Supporting this result, cultures containing marine AN M E-1 and AN M E-2 were shown to incorporate carbon derived from labelled methane into archaeol, monounsaturated archaeol and biphytanes 
(Blumenberg et al., 2005). In another study it was found that A NM E-1 archaea assimilated primarily inorganic carbon (K ellermann et al., 2012). Incubations with sediments containing A N M E-1, 2a \& 2b archaea showed that both, labelled methane and inorganic carbon, were incorporated into the archaeal lipids (W egener et al., 2008).

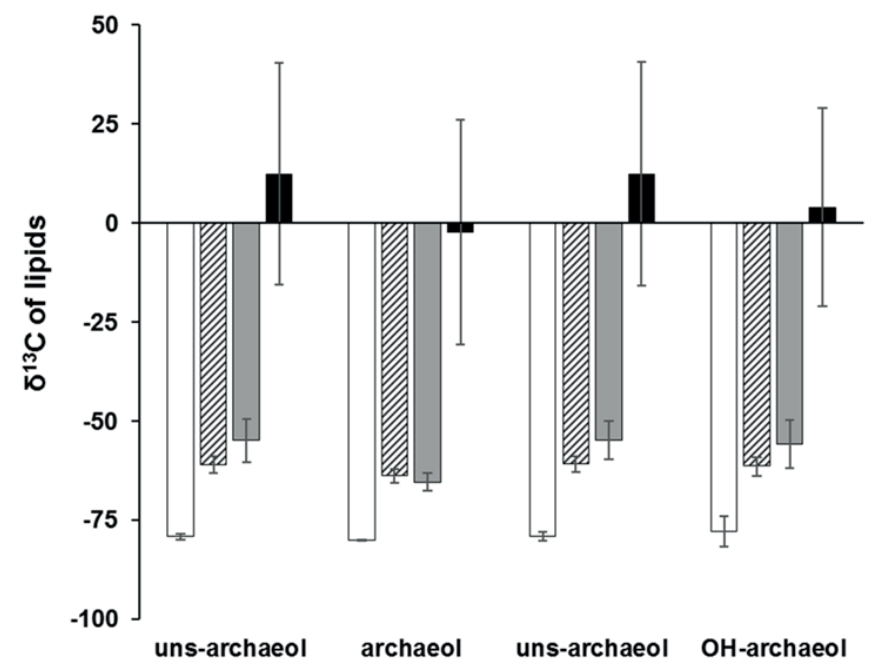

Figure 3. $\delta^{13} \mathrm{C}$ values of $\mathrm{Ca}$. M ethanoperedens sp. lipids after batch cultivation with labelled bicarbonate or methane. A N M E-2d reactor material originating from the 0 oijpolder was incubated in anaerobic batch cultures with either ${ }^{13} \mathrm{C}$ labelled bicarbonate for three days (striped columns) or ${ }^{13} \mathrm{C}$ labelled methane for one (light grey columns) or three days (black columns). Controls contained only non-labelled carbon sources (white columns). Incubations were performed in triplicates, error bars $=$ standard deviation. $\delta^{13} \mathrm{C}$ values were obtained by analysing acid hydrolysed samples that only contained the core lipids by GC-IRM S. Peak identification was conducted with the help of GC-MS analysis of the same samples, showing that lipid extracts contained archaeol, hydroxyarchaeol and two monounsaturated archaeols (Fig. 1). Uns-archaeol = monounsaturated archaeol.

Incubations with freshwater sediments including A N M E-2d archaea followed by RNA stable isotope probing demonstrated that those microbes mainly incorporated methane into their lipids but may have the capability of mixed assimilation of $\mathrm{CH}_{4}$ and dissolved inorganic carbon (Weber et al., 2017). O ur data confirmed that A N M E-2d archaea are capable of mixed assimilation of $\mathrm{CH}_{4}$ and DIC, but that methane is the preferred carbon source. In contrast to anaerobic methanotrophs, aerobic methanotrophs require oxygen for methane oxidation and the first step of methane oxidation to methanol is catalysed with the enzyme methane monooxygenase (Dalton, 1980). Also the nitrite-dependent intraaerobic methanotroph $\mathrm{Ca}$. M ethylomirabilis sp. which is assumed to use nitric oxide to generate internal oxygen to oxidize methane encodes enzymes for the conventional aerobic methane oxidation pathway, including the monooxygenase (Ettwig et al., 2010). A erobic methanotrophs have different pathways of carbon fixation: proteobacterial methanotrophs assimilate $\mathrm{C} 1$ compounds deriving from 
methane oxidation via the ribulose monophosphate (RuMP) and/or the serine pathway (Dalton, 1980) while verrucomicrobial methanotrophs and NC10 bacteria like $\mathrm{Ca}$. M ethylomirabilis sp. use the Calvin-Benson-B assham cycle, mainly assimilating dissolved inorganic carbon (K hadem et al., 2011; Rasigraf et al., 2014). A s mentioned before, the reductive acetyl-CoA pathway is the main carbon assimilation pathway in methanogenic Euryarchaeota (W hitman, 1994; Berg et al., 2010) and most likely also in ANME-1 and ANME-2d archaea (Hallam et al., 2004; H aroon et al., 2013). In this pathway a carbonyl group and a methyl group are combined to form acetyl-COA.

Table 2. Lipids of different A NME groups. For A NME-2d lipid analysis we used Ca. M ethanoperedens sp. enriched bioreactor material. For the other ANME groups information was based on publication about the specific lipid characteristic (Blumenberg et al., 2004; Niemann and Elvert, 2008) or ${ }^{13} \mathrm{C}$ labelling experiments (Blumenberg et al., 2005; Wegener et al., 2008; K ellermann et al., 2012). GDGT: glycerol dialkyl glycerol tetraether, PE: phosphatidyl ethanolamine, M M PE: monomethyl phosphatidyl ethanolamine, DM PE: dimethyl phosphatidyl ethanolamine, PG: phosphatidyl glycerol, $\mathrm{MH}$ : monohexose, $\mathrm{DH}$ : dihexose, $\mathrm{PH}$ : phosphatidyl hexose, PC: phosphatidyl choline.

\begin{tabular}{|c|c|c|c|c|c|}
\hline & $\begin{array}{c}\text { ANME - } \\
1\end{array}$ & $\begin{array}{c}\text { ANME - } \\
2 a / b\end{array}$ & $\begin{array}{c}\text { ANME - } \\
2 c\end{array}$ & ANME-2d & ANME-3 \\
\hline E nvironment & marine & marine & marine & freshwater & marine \\
\hline Core lipids & GDGT & $\begin{array}{c}\text { (OH-) } \\
\text { archaeol }\end{array}$ & $\begin{array}{c}\text { (OH-) } \\
\text { archaeol, } \\
\text { GDGTs }\end{array}$ & $\begin{array}{c}\text { (OH-) } \\
\text { archaeol, } \\
\text { (OH)- } \\
\text { GDGTs }\end{array}$ & $\begin{array}{c}\text { (OH-) } \\
\text { archaeol }\end{array}$ \\
\hline $\begin{array}{l}\text { Sn-2-OH- } \\
\text { archaeol / } \\
\text { archaeol } \\
\text { ratio }\end{array}$ & $0-0.8$ & $1.1-5.5$ & $1.1-5.5$ & $0.1-0.3$ & $1.1-5.5$ \\
\hline IPLs & $\begin{array}{l}\text { GDGT + } \\
\text { dihexose }\end{array}$ & $\begin{array}{c}(\mathrm{OH}-) \\
\text { Archaeol } \\
+\mathrm{PG}, \\
\mathrm{PE}, \mathrm{PH}, \\
\mathrm{PS}, \\
\text { dihexose }\end{array}$ & $\begin{array}{c}\text { (OH-) } \\
\text { Archaeol } \\
+ \text { PG, } \\
\text { PE, PH, } \\
\text { PS, } \\
\text { Dihexose }\end{array}$ & $\begin{array}{c}(\mathrm{OH}-) \\
\text { archaeol + } \\
\text { dihexose, } \\
\text { hexose, } \\
\text { pentose, } \\
\text { PH, PE, } \\
\text { MMPE, } \\
\text { DMPE }\end{array}$ & $\begin{array}{c}\text { (OH-) } \\
\text { A rchaeol } \\
+ \text { PG, } \\
\text { PH, PS }\end{array}$ \\
\hline $\begin{array}{c}\text { Main carbon } \\
\text { source }\end{array}$ & DIC & & & $\mathrm{CH}_{4}$ & \\
\hline
\end{tabular}


W e were able to show in this study, that A N M E-2d archaea are capable of mixed assimilation of $\mathrm{CH}_{4}$ and $\mathrm{DIC}$, but preferably incorporate methane in their biomass. For this reason, it can be concluded that the $\mathrm{C} 1$ compounds required for the reductive acetyl-COA pathway derive from oxidation of methane as well as from DIC, whereby methane is the primary carbon source. A lthough A N M E1 archaea are assumed to use the same carbon fixation pathway (Hallam et al., 2004), they have been shown to primarily assimilate inorganic carbon (K ellermann et al., 2012). Therefore, the type of carbon fixation pathway does not directly allow conclusions on the preferred carbon source used for carbon assimilation of a microorganism.

\section{Condusion}

In this study, we analysed the lipids from the main player in nitrate A OM , Ca. $M$ ethanoperedens $\mathrm{sp}$. We found several lipid characteristics that enable distinction between ANME-2d and other ANME groups (Table 2).

A N M E-2d archaea therefore can be distinguished from A NM E-1 by the higher ratio of archaeol and hydroxyarchaeol instead of GDGTs as well as phosphate containing headgroups. Furthermore, A N M E-2d can be distinguished from other ANME-2 and ANME-3 archaea by the high abundance of dihexose as headgroup, the rare M MPE and DMPE headgroups and putatively also the pentose headgroup, which so far has not been described in the literature. The appearance of a monopentose as headgroup of A N M E-2d lipids is an interesting observation and might be further analysed in the future.

In contrast to other AN ME groups AN M E-2d archaea have been shown to produce relatively rare hydroxylated GDGTs. ANME groups do not only differ in their membrane lipids itself, but also in the way they incorporate carbon into their biomass. For A N M E-1 it has been shown that primarily carbon derived from DIC is incorporated into the lipids (Kellermann et al., 2012). In case of A N M E-2d archaea, we were able to demonstrate that both, carbon derived from DIC and from methane, are incorporated into their lipids, with methane as the preferred carbon source.

\section{Funding}

CUW and MSMJ were supported by the Nederlandse Organisatie voor Wetenschappelijk Onderzoek through the Soehngen Institute of Anaerobic M icrobiology Gravitation G rant 024.002.002 and the N etherlands Earth System Science Center Gravitation Grant 024.002.001. M SMJ was supported by the European Research Council A dvanced Grant Ecology of A naerobic M ethane Oxidising M icrobes 339880. JK was supported by the Netherlands Earth System 
Science Center Gravitation Grant 024.002.001 and the Deutsche Forschungs Gesellschaft Grant KU 3768/1-1. SB and CW were supported by the Nederlandse Organisatie voorW etenschappelijk Onderzoek through Grant ALW OP.293.

\section{Acknowledgements}

We thank M ichel Koenen for IPL analysis, Ronald van Bommel for technical assistance with the GC-IRMS, Denise Dorhout and Monique Verweij for technical assistance with GC-MS and UHPLC systems. Moreover, we thank A nnika V aksmaa for supplying bioreactor material, Theo van A len for technical assistance with metagenomics sequencing and Jeroen Frank for helping with metagenomics analysis.

\section{Conflict of inter est}

The authors have no conflict of interest to declare 
| Chapter 3 


\section{Chapter 4}

Lipid biomarker insights into hydrocarbon sources and microbial communities in the terrestrial mud volcanoes of Sicily, Italy

Nadine T. Smit, Fausto Grassa, Anchelique Mets, Jaap S. Sinninghe

Damsté, Stefan Schouten

Under review at Organic Geochemistry 


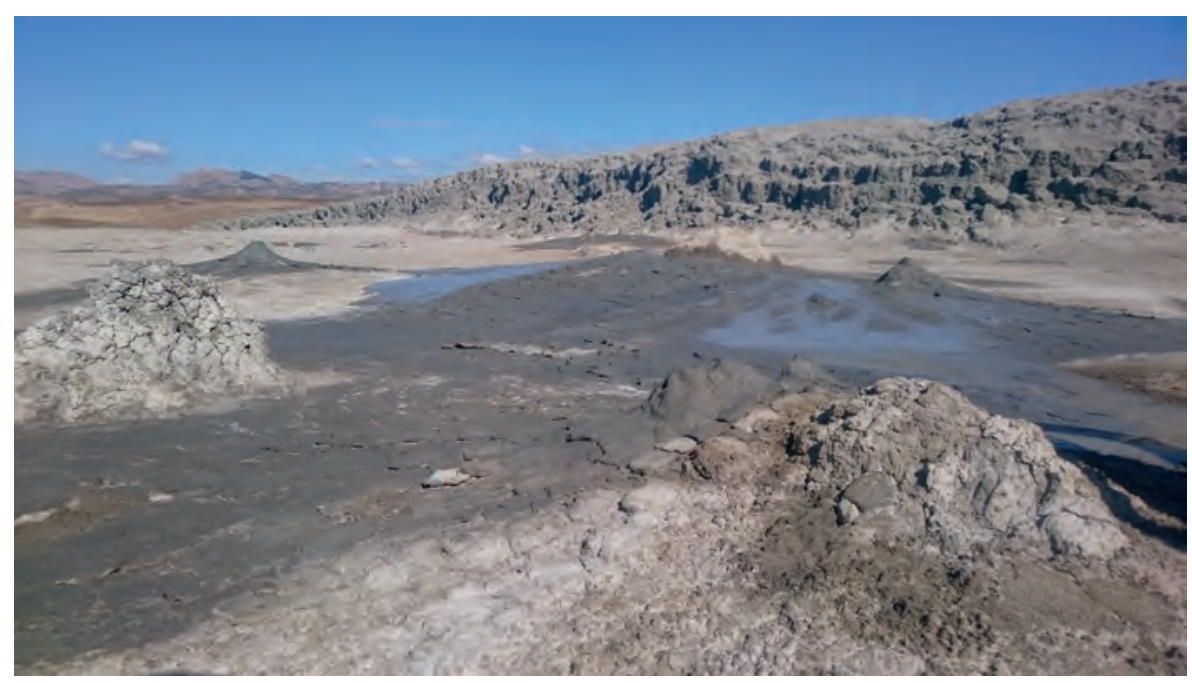

M accalube di A ragona mud volcano in Sicily, Italy

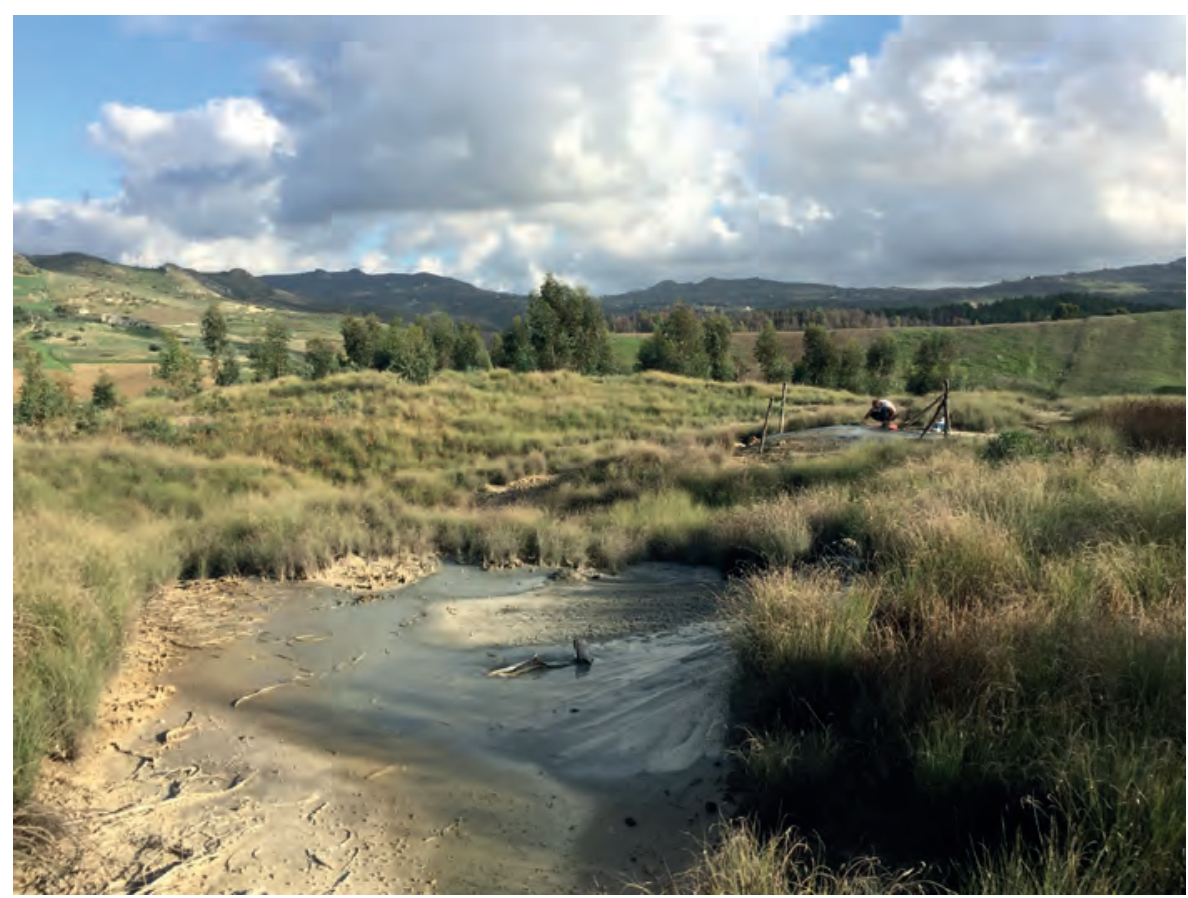

Comitini mud volcano in Sicily, Italy 


\section{Abstract}

M ud volcanoes ( $M V s$ ) are one of the most prominent geological sources of the greenhouse gas methane and release about $33 \mathrm{Tg} \mathrm{yr}^{-1}$ of methane into the Earth's atmosphere, directly effecting global warming. However, the sources and thermal maturity of organic matter as well as microbial gas utilization processes have been rarely investigated in terrestrial MV systems. Here, three prominent terrestrial Sicilian M Vs (M accalube di A ragona, Comitini and Santa Barbara) were investigated to analyze the composition and origin of organic matter, microbial aerobic methane oxidation (AM O) and anaerobic methane oxidation (AOM) processes using lipid biomarker techniques. Lipid analysis was conducted on freshly emitted mud breccias which showed a high abundance of petroleum-derived hydrocarbons compared to lipids from extant microbes in all three M V sites. The n-alkane distribution as well as saturated hydrocarbons (e.g. $\mathrm{CPI}$ and $\mathrm{Pr} / \mathrm{Ph}$ ) and hopane indices (Ts/Tm and 22S/(22S+22R) isomerization) indicate that all mud breccias derive from a similar mix of mature marine carbonate or marl source strata and immature terrestrial strata. The $\mathrm{M}$ accalube di A ragona mud breccias seem to originate from slightly more mature, possibly marine, source organic matter with an admixture of less immature material than the mud breccias from the other two MVs. Microbial biomarkers including saturated, and unsaturated short chain fatty acids $\left(C_{14}, C_{16}\right.$ and $\left.C_{18}\right)$, 10-methyl $C_{16}$ fatty acid and $22 R C_{31}, C_{32}$ and $C_{33} 17 \beta, 21 \beta(\mathrm{H})$-hopanoic acids did not reveal depleted $\delta^{13} \mathrm{C}$ isotopic signals attributable to methane utilizers and suggest a mixture of different bacterial sources. These results suggest no major abundance of at least A M O processes in the three Sicilian MV s probably due to limited oxygen availability in the mud breccias. However, mud breccias from the $M$ accalube di A ragona M V indicate the presence of A NM E-archaea involved in AOM based on the relatively high abundance of GDGT-1 to -4 and a high GDGT-based Methane index $\geq 0.9$, similar to marine AOM influenced environments. To the best of our knowledge, this is the first time that isoprenoidal GDGTs characteristic for A OM could be identified in a terrestrial MV system. In contrast, the Comitini and Santa Barbara MV s demonstrate signals of marine or terrestrial Thaumarchaea with high relative abundances of crenarchaeol and GDGT-0 as well as the presence of the crenarchaeol isomer, all probably originating from immature marine or terrestrial $M V$ subsurface strata. Overall, the terrestrial Sicilian mud volcanoes reveal organic matter which derives from several source strata with different degrees of thermal maturity. Moreover, recent microbial lipids suggest the presence of $A O M$ in the $M$ accalube di A ragona $M V$ but not in the other two M V s implying that microbial 
processes other than methane oxidation may play a more important role in these terrestrial M V s.

\section{Keywords}

terrestrial mud volcanoes; anaerobic methane oxidation (AOM); aerobic methane oxidation (AMO); source organic matter; biomarker indices; isoprenoidal-GDGTs; M ethane index

\section{Introduction}

The greenhouse gas methane $\left(\mathrm{CH}_{4}\right)$ is an important contributor to natural and anthropogenic global climate changes in present and past environments (Reeburgh, 1996, 2007; V alentine and Reeburgh, 2000). A better understanding of the sources, sinks and chemical reaction pathways in methane cycling is important to constrain the impact of methane on global warming. Several natural marine and terrestrial sources of methane are known, e.g. biogenic methane produced in marine sediments, peatlands and thawing permafrost soils, as well as thermogenic derived methane from seeps and mud volcanos (Dimitrov, 2002; Etiope et al., 2009; O 'Connor et al., 2010; D ean et al., 2018).

$\mathrm{M}$ ud volcanoes ( $\mathrm{M} \mathrm{V} \mathrm{s}$ ) are one of the main contributors of atmospheric methane releasing about $33 \mathrm{Tg}$ methane annually from about 1800 prominent individual M V systems (Dimitrov, 2003; K opf, 2003; M ilkov, 2005). M V s are remarkable geological structures formed by semi-liquid and gas-enriched mud breccias, which derive from deeper sedimentary layers often connected to petroleum systems (K opf et al., 2001; Dimitrov, 2003). Their formation is mainly driven by abnormally high pore-fluid pressures that can be caused by a combination of in-situ gas generation, high sedimentation and structural or tectonic compression. B esides, the morphologically structures of $\mathrm{M} \mathrm{V} \mathrm{s}$ are very diverse occurring from plano-conical shapes rising some hundred meters high to irregular, negative funnel-shapes, which range up to areas of $100 \mathrm{~km}^{2}$ to only several hundred $\mathrm{m}^{2}$ of size in submarine or terrestrial environments (K opf et al., 2001; Dimitrov, 2002).

The M V s are gas- and often petroleum-rich environments that feature diverse biogeochemical processes fueling different microbial communities of bacteria and archaea (Stadnitskaia et al., 2005; A lain et al., 2006; Niemann et al., 2006a; Niemann et al., 2006b). Two of the most investigated processes are the aerobic (AM 0 ) and anaerobic oxidation of methane ( $O M$ M), and the latter was previously found to be significant in marine M V s (B oetius et al., 2000; Pancost et al., 2000; Stadnitskaia et al., 2005; Niemann et al., 2006a; Niemann et al., 
2006b). In general, AMO is performed by type I and II methanotrophs (Gammaproteobacteria and A Iphaproteobacteria) (Dedysh et al., 2007; B odelier et al., 2009) or Verrucomicrobia (Op den Camp et al., 2009), while AOM is thought to be mediated by several clades of methanotrophic archaea (ANME type 1, 2 and 3), often in syntrophic consortia with bacteria such as sulfatereducing bacteria (SRBs) (Hinrichs et al., 1999; B oetius et al., 2000; Pancost et al., 2000; Orphan et al., 2001). AMO can be traced using specific lipid biomarkers like ${ }^{13} \mathrm{C}$-depleted unsaturated $\mathrm{C}_{16}$ and $\mathrm{C}_{18}$ fatty acids, hopanes and bacteriohopanepolyols (e.g. Elvert and Niemann, 2008; B odelier et al., 2009; van W inden et al., 2012). Sulfate-dependent A OM can generally be traced by ${ }^{13} \mathrm{C}$ depleted archaeal lipids like hydroxyarchaeol and glycerol dibiphytanyl tetraethers (GDGTs) as well as SRB characteristic fatty acids and dialkyl glycerol diethers (DAGE) with depleted ${ }^{13} \mathrm{C}$ contents (Pancost et al., 2000; Blumenberg et al., 2004; N iemann and Elvert, 2008; R ossel et al., 2011).

In contrast to marine M V s, only a few studies have examined the lipid biomarker inventory and microbial communities in terrestrial M V s (A lain et al., 2006; Chang et al., 2012; Cheng et al., 2012; Heller et al., 2012). These studies found similar biogeochemical processes as in marine M V s like A M O, A OM or methanogenesis but with lower abundances of characteristic lipid biomarkers than in marine M V systems (A lain et al., 2006; Chang et al., 2012; H eller et al., 2012). Biomarker and genetic data showed that methane oxidation mainly occurred at the surface and in biofilms at Northern I talian and Tai wanese M V s, while microbial genes associated with methanogenesis are generally more abundant in the deeper layers of the Tai wanese M V s (Chang et al., 2012; Cheng et al., 2012; W rede et al., 2012). Furthermore, the terrestrial M V s in Romania and Northern Italy featured mainly lipid biomarkers typical for SRBs (e.g. various DAGE or 10-methyl $C_{16}$ fatty acid), methanogenic Euryarchaea (archaeol) and minor abundances of hydroxyarchaeol characteristic for ANM Earchaea performing A OM. However, these terrestrial MV systems showed less depleted ${ }^{13} \mathrm{C}$ lipid biomarkers then observed in typical sulfate-dependent A OM lipids next to low AOM rates in incubation experiments, probably due to the restricted abundance of sulfate in terrestrial MVs compared to marine MV (A lain et al., 2006; Heller et al., 2012). Therefore, it seems likely that petroleum biodegradation and associated methanogenesis play a more important biogeochemical role than $\mathrm{AOM}$ in terrestrial $\mathrm{MVS}$ in contrast to marine $\mathrm{MV}$ systems.

High amounts mature organic matter are often emitted by $\mathrm{MVs}$ originating from deep subsurface reservoirs of up to $20 \mathrm{~km}$ of depths (Ivanov et 
al., 1996; Dimitrov, 2002). Hence, the petroleum like hydrocarbons can serve as a carbon source for microbes involved in the biodegradation of oil as shown by numerous studies of petroleum seeps, for example, offshore in the Gulf of Mexico or Santa Barbara Basin (Sassen et al., 2004; Farwell et al., 2009; Schubotz et al., 2011). Besides, the analysis of certain hydrocarbons (e.g. $n$ alkanes, acyclic isoprenoids or hopanes) can give insight into the source organic matter and maturity degree (Seifert and M oldowan, 1978; Peters et al., 2005) of the erupted material and provide key information about the geological history of the area. However, to the best of our knowledge only a few studies on marine M V s (Stadnitskaia et al., 2007; López-Rodríguez et al., 2014) and none on terrestrial M V s explored the source organic matter and its thermal maturation history as they mostly focus on the gas composition or the microbial lipid biomarker inventory and microbial communities.

Here we study terrestrial MVs located in Sicily, Italy. I talian MV s release about $10^{5} \mathrm{~T} \mathrm{yr}^{-1}$ of methane into the atmosphere of which the Sicilian onshore MV s are responsible for $400 \mathrm{~T} \mathrm{yr}^{-1}$ (Etiope et al., 2002, 2007). We investigated the biomarker composition of three major terrestrial M V s on Sicily named $M$ accalube di Aragona, Comitini and Santa Barbara. The biomarker results were used to gain insights into the sources and thermal maturity degree of organic matter in the Sicilian MVs as well as to identify microbial communities, in particular those involved in methane oxidation processes (A M 0 and $A O M$ ).

\section{M aterial and methods}

\subsection{Geological setting and study area}

M ore than half of the total number of global M V s are located along the A I pine Himalayan active tectonic belt where approximately 110 deep-sea M V s and 52 onshore $M V$ s are situated on the $M$ editerranean Ridge with a high number of M V s located in Italy (Dimitrov, 2003; Etiope et al., 2009). Sicily is located along the boundary between the convergent A frican and European plates and is largely controlled by the compressional regime of the $\mathrm{M}$ aghreb-A pennine fold and thrust belt (Lickorish et al., 1999; Catalano et al., 2008). Three main geological complexes mark the collisional complex of Sicily and its offshore continuation (Fig.1): the Hyblean Foreland; the Caltanisetta Basin, an intensively faulted syntectonic accretion foredeep basin from $L$ ate $M$ iocene to the Quaternary; and a complex chain composed of the Calabrian A rc and the M aghrebian thrust belt (Catalano et al., 2008; M adonia et al., 2011). Onshore Sicilian M V s occur over the accretionary wedge, which was developed in front 
of the Sicilian-M aghrebian fold and thrust belt mainly in the Caltanisetta Basin. These MVs originate from clastic sediments deposited in thrust-top basins, which were progressively shortened and displaced during the $L$ ate $M$ iocene to Pleistocene (M onaco and Tortorici, 1996; Lickorish et al., 1999). The M V s in Sicily are smaller than those typically occurring in other hydrocarbon-prone areas like Romania or Azerbaijan (Etiope et al., 2002, 2007) and feature infrequent hazardous paroxysmal eruptions (B onini, 2009; M adonia et al., 2011). Some of these M V s form water pools of several meters in diameter, where gas actively bubbles out while others form cone shaped craters with bubbling fluid mud. In the Caltanisetta Basin, the emitted gas is comprised of a mix of thermogenic and biogenic methane. In contrast, the Paterno mud volcano near Mount Etna is emitting a major amount of carbon dioxide originating from igneous volcanic activity (Etiope et al., 2002, 2007; G rassa et al., 2004). Daily emission rates from single methane emitting vents in the different $M V$ sites range from 0.01 to $6.8 \mathrm{~kg}$ per day (Etiope et al., 2002, 2007).

The first site investigated here is $M$ accalube di A ragona, (M DA; Fig. 1) the biggest M V of I taly (E tiope et al., 2007), located in Southern-Central Sicily next to the town of A ragona where the M V spreads over a large area of about 1.4 $\mathrm{km}^{2}$ and releases a mix of thermogenic and biogenic methane into the atmosphere (Etiope et al., 2002). The emitted gas consists of $90-99 \%$ methane $\left(\delta^{13} \mathrm{C}=-\right.$ $48 \%$ ) and minor amounts of other gasses such as $\mathrm{CO}_{2}, \mathrm{O}_{2}, \mathrm{~N}_{2}$ and $\mathrm{H}_{2}$ ( $\mathrm{G}$ rassa et al., 2004). The MDA site features different active gas and mud emitting vents including an active field with mud craters emitting fluid mud ranging from a few centimeters to half a meter height, 3 active bubbling mud ponds and a huge area covered with altered clay from past eruptions. Furthermore, the site is characterized by a clayey body, with marls (M iocene) and stone blocks of different composition and age (Cretaceous to M iocene) and clastic sediments of the Terravecchia Formation (Tortonian), with no soil coverage (Etiope et al., 2002).

North to the MDA site, another active MV was investigated, named Comitini (COM ; Fig. 1). This site is located on a forested hillside, which features several small active vents combined with watery pools with visible mud fluid and gas bubbling and no conical shaped crater structures. The emitted gas consists of $91 \%$ methane $\left(\delta^{13} \mathrm{C}=-45 \%\right)$ and minor amounts of other gases like $\mathrm{N}_{2}, \mathrm{CO}_{2}$ and higher gaseous hydrocarbons (e.g. ethane and propane) (Heller, 2011; Cangemi and M adonia, 2014). 


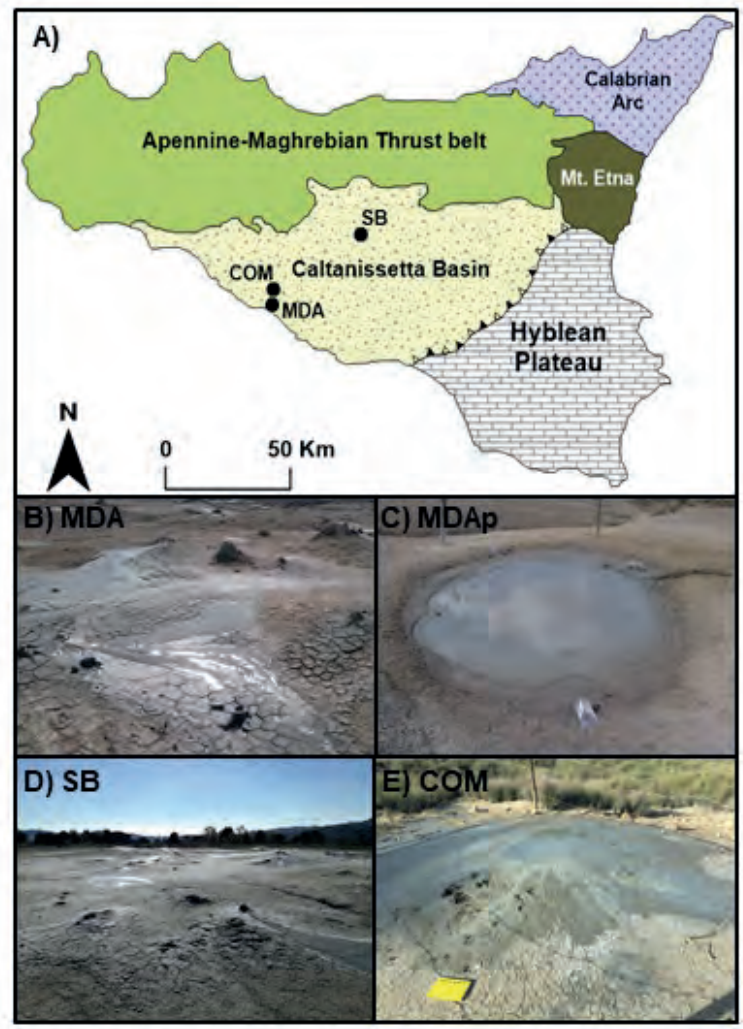

Figure 1 A) Map of the Sicily region showing the locations of the three investigated mud volcano sites $M$ accalube di A ragona (M DA), Santa B arbara (SB) and Comitini (COM). B-E) Images of the three MV sites, Italy. $\mathrm{K}$ ey: $\mathrm{B})=\mathrm{M}$ accalube di $\mathrm{A}$ ragona $\mathrm{M} V$ field $(\mathrm{MDA}), \mathrm{C})=\mathrm{M}$ accalube di $\mathrm{A}$ ragona mud pond (M DA p), D) $=$ Santa B arbara MV field $(S B)$ and $E)=$ Comitini $M V$ crater $(C O M)$.

Finally, in Central Sicily, a large MV field named Santa Barbara (SB) was investigated, located in the village of Santa B arbara in the north-easternmost part of the city of Caltanisetta (Fig. 1). The active Santa B arbara M V field covers an area of about $0.5 \mathrm{~km}^{2}$ and hosts a multitude of small conical mud-emitting structures up to tens of centimeters high. The main emitted gas is thermogenic methane $\left(\delta^{13} \mathrm{C}=-50 \%\right)$ with minor amounts of other gases like $\mathrm{CO}_{2}, \mathrm{~N}_{2}$ and higher gaseous hydrocarbons. Furthermore, the site is characterized by a clayey body, with elements from different geological formations which span from the Late M iocene to the Quaternary (M adonia et al., 2011; Ogniben, 1954). The bottom is represented by Tortonian clays, which are covered by evaporites (diatomites, limestones and gypsum interbedded with clay levels) from the $M$ essinian salinity crisis in the M editerranean, and marls and marly limestones from the Trubi Formation (Pliocene) (Ogniben, 1954; M adonia et al., 2011). 
Deposits from these formations outcrop the SB field, with no soil coverage. First historical notifications of paroxysmal eruptions of this $\mathrm{MV}$ are reported back to the early 1820s by a Sicilian abbot (Bonini, 2009; M adonia et al., 2011).

\subsection{Sample collection}

Freshly emitted mud samples and mud samples from past eruptions (altered, dry mud) were recovered during field campaigns in October 2017 and October 2018 from the three different $M V$ sites. At all three sites the fresh fluid mud breccias were directly taken from active mud and gas emitting mud craters (conical mudemitting structures up to about $30 \mathrm{~cm}$ high), while altered dry muds from past eruptions were retrieved from several meters distance to the active area where plant vegetation started (Table 1). A t MDA, two samples were also recovered from the edges of one of the active gas and mud bubbling ponds ( $M$ accalube di A ragona mud pond $=$ M DA p) up to $3 \mathrm{~m}$ in diameter which are located about 100 $\mathrm{m}$ Northwest from the main active mud volcano field. A ll mud breccias were collected from a horizon 5 to $10 \mathrm{~cm}$ below the surface with in-situ temperatures of about $20-25{ }^{\circ} \mathrm{C}$ at time of collection. The mud breccias were directly transferred into clean geochemical sampling bags and stored frozen at $-20{ }^{\circ} \mathrm{C}$ until freeze drying and lipid extraction.

\subsection{Extraction, saponification and derivatization}

Ca. $10 \mathrm{~g}$ of freeze dried mud breccias from the three MV sites were extracted using a modified Bligh and Dyer method (Schouten et al., 2008; Bale et al., 2013). Mud samples were ultrasonically extracted with a solvent mixture of methanol $(\mathrm{MeOH})$, dichloromethane (DCM) and phosphate buffer (2:1:0.8, $\mathrm{v} / \mathrm{v} / \mathrm{v}$ ) for $10 \mathrm{~min}$ and centrifuged. A fterwards the solvent layer was collected, combined and the residues re-extracted twice. The combined solvent layers were separated from the aqueous layer by the addition of DCM and phosphate buffer to a ratio of $\mathrm{MeOH}, \mathrm{DCM}$ and phosphate buffer $(1: 1: 0.9, \mathrm{v} / \mathrm{v} / \mathrm{v})$. The bottom layer (DCM) was removed by pipetting and collected, while the remaining aqueous layer was washed twice with DCM. The combined DCM layers were dried under a continuous flow of $\mathrm{N}_{2}$.

A liquots of the total lipid extract (TLE) were saponified using $2 \mathrm{ml}$ of a $1 \mathrm{~N} \mathrm{KOH} \mathrm{MeOH}$ solution and refluxed for $1 \mathrm{~h}$ at $130^{\circ} \mathrm{C}$. A fter cooling the $\mathrm{pH}$ was adjusted to 5 with a $2 \mathrm{~N} \mathrm{HCL} \mathrm{M} \mathrm{eOH}$ solution. The layers were separated by $2 \mathrm{ml}$ bidistilled water and $2 \mathrm{ml} \mathrm{DCM}$, and the organic bottom layer was collected. The aqueous layer was washed two more times with DCM and the combined organic layers were dried first over a $\mathrm{Na}_{2} \mathrm{SO}_{4}$ column and then by $\mathrm{N}_{2}$. 


\begin{tabular}{|c|c|c|c|c|c|c|}
\hline$\not \underbrace{\frac{I}{p}}$ & ด̂ & ĥn & $\stackrel{8}{0}$ & 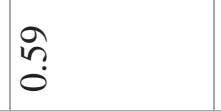 & in & $\begin{array}{l}\text { นُ } \\
\text { on }\end{array}$ \\
\hline$\nexists \underbrace{\frac{I}{j}}$ & ก̂. & นึ. & $\begin{array}{l}\text { ڤn } \\
0 \\
0\end{array}$ & $\begin{array}{l}\text { ஸी } \\
0\end{array}$ & గ̂n & $\begin{array}{l}\text { ִִ } \\
0\end{array}$ \\
\hline 竞 & 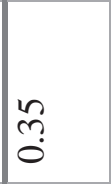 & m. & 吕 & 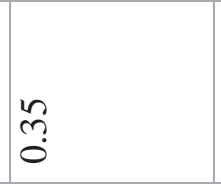 & $\begin{array}{c}\text { m } \\
\text { o. }\end{array}$ & $\begin{array}{l}\vec{m} \\
0 \\
0\end{array}$ \\
\hline 勇 & $\begin{array}{c}n \\
0 \\
0\end{array}$ & $\begin{array}{l}\infty \\
\infty \\
0\end{array}$ & $\begin{array}{l}0 \\
0 \\
0\end{array}$ & 0 & j & $\begin{array}{l}\text { N } \\
\text { S }\end{array}$ \\
\hline $\begin{array}{l}-1 \\
0 \\
0 \\
0\end{array}$ & $\begin{array}{l}m \\
\stackrel{0}{r} \\
r\end{array}$ & $\begin{array}{l}\text { L } \\
\text { i }\end{array}$ & $\underset{i}{8}$ & $\underset{r}{9}$ & $\underset{7}{9}$ & $\begin{array}{l}9 \\
7 \\
7\end{array}$ \\
\hline$\frac{\bar{a}}{u}$ & å. & $\begin{array}{l}\dot{\theta} \\
-i\end{array}$ & ภู & $\underset{m}{m}$ & $\underset{\text { q }}{\text { q }}$ & Нु \\
\hline$\frac{5}{2}$ & $\underset{i}{O}$ & $\begin{array}{l}\infty \\
0 \\
0\end{array}$ & i & $\begin{array}{l}\infty \\
\stackrel{\infty}{n} \\
0\end{array}$ & ब. & $\begin{array}{l}8 \\
i \\
i\end{array}$ \\
\hline 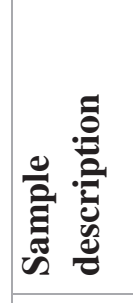 & 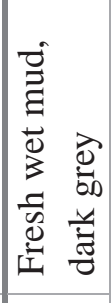 & 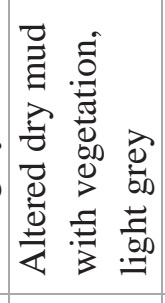 & 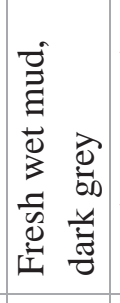 & 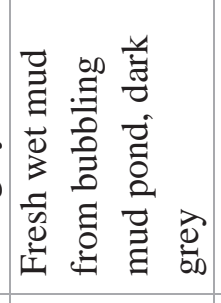 & 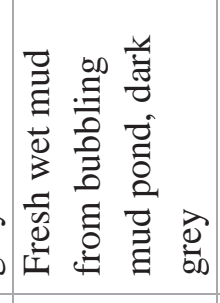 & 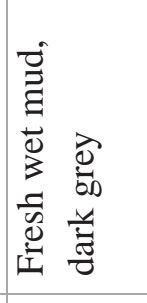 \\
\hline$\frac{9}{0}$ & 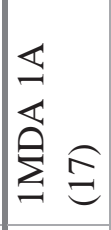 & 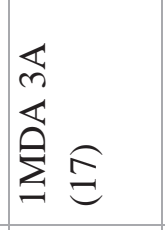 & 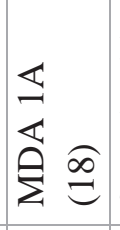 & 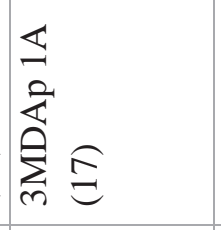 & $\begin{array}{l}\frac{8}{4} \\
\frac{0}{4} \\
\stackrel{0}{0} \\
\Sigma\end{array}$ & 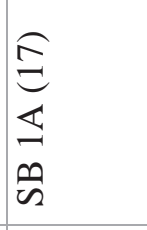 \\
\hline$\frac{8}{n}$ & 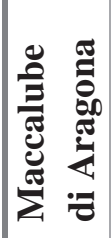 & 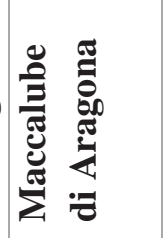 & 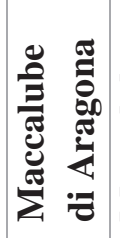 & 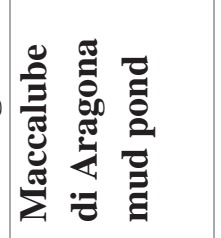 & 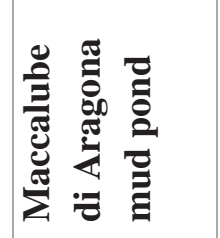 & 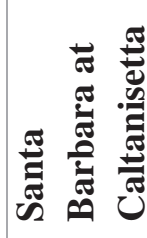 \\
\hline
\end{tabular}




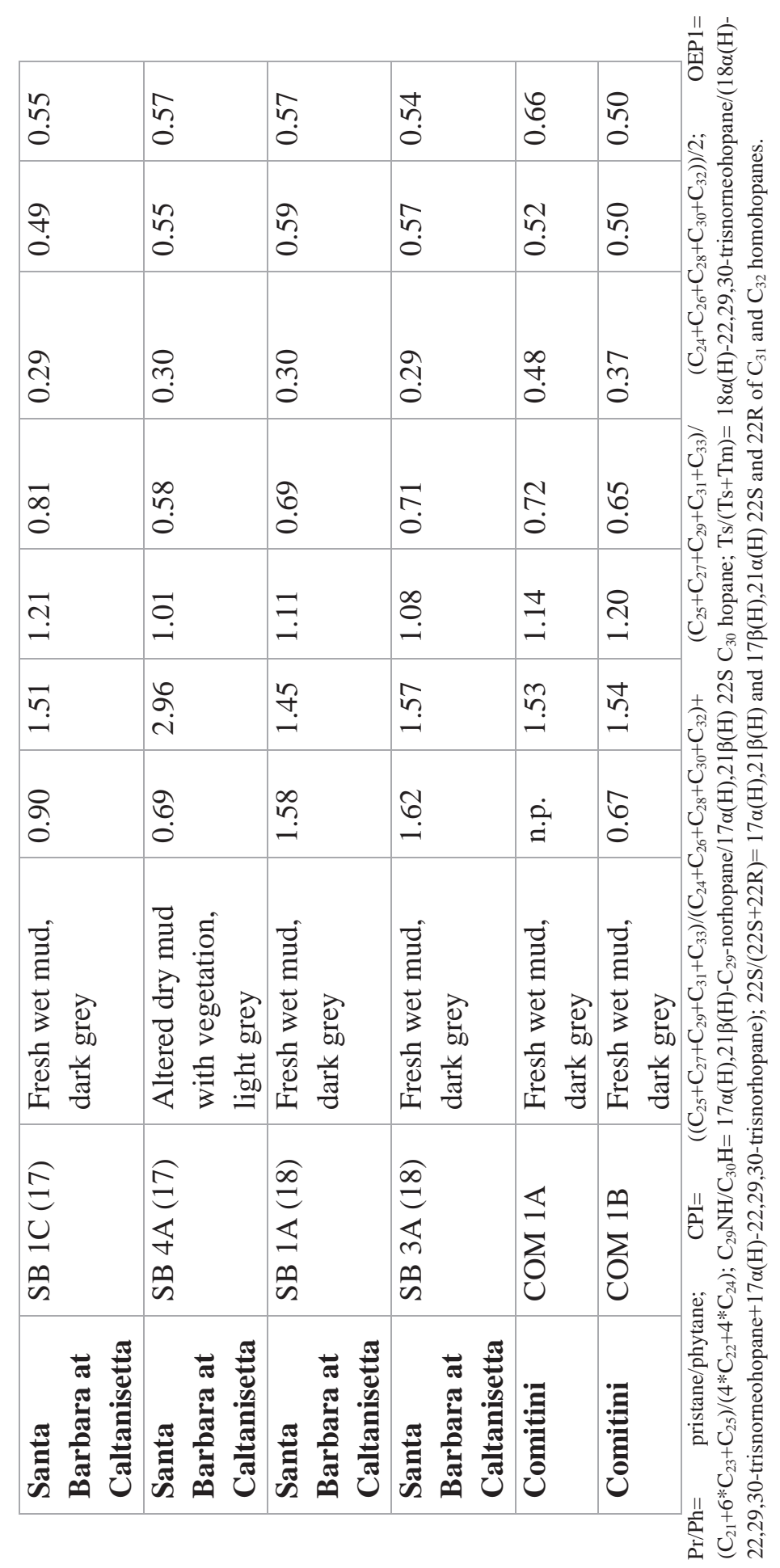


The saponified TLEs of the M V samples were subsequently esterified by heating with $0.5 \mathrm{ml}$ of a boron trifluoride-methanol solution ( $\mathrm{BF}_{3}$ solution) for $10 \mathrm{~min}$ at $60{ }^{\circ} \mathrm{C}$, before adding $0.5 \mathrm{ml}$ bidistilled water and $0.5 \mathrm{ml} \mathrm{DCM}$ and mixing to separate the aqueous and organic layer. The organic layer was collected, and the water layer was extracted twice with DCM. The combined DCM layers were dried over an $\mathrm{MgSO}_{4}$ column and afterwards eluted over a small silica gel column with ethyl acetate to remove polar high molecular weight molecules.

Extracts were subsequently separated using a small column packed with activated aluminum oxide into three fractions. The first fraction (saturated hydrocarbon fraction) was eluted with 4 column volumes of hexane, followed by a second fraction (fatty acid methyl ester fraction) eluted with 4 column volumes of DCM , and a third fraction (polar fraction) eluted with 3 column volumes of $\mathrm{DCM} / \mathrm{M} \mathrm{eOH}(1: 1, v / v)$. The fractions were dried under a continuous flow of $\mathrm{N}_{2}$ and aliquots of the polar fraction were silylated with pyridine and $\mathrm{N}, 0$ bis(trimethylsilyl) trifluoroacetamide (BSTFA) at $60^{\circ} \mathrm{C}$ for $20 \mathrm{~min}$. Afterwards the fractions were analyzed using gas chromatography-mass spectrometry (GCMS), GC- ion ratio mass spectrometry (GC-irMS) and ultra-high-performance liquid chromatography-mass spectrometry (UHPLC-M S).

\subsection{Instrumental analysis}

2.4.1 Gas chromatography-mass spectrometry (GC-MS) and gas chromatography-isotope ratio mass spectrometry ( $G C$-irM S)

GC-MS was performed using an Agilent Technologies GC-MSD in full scan mode with a scan time of $700 \mathrm{~ms}$ and a mass range of $\mathrm{m} / \mathrm{z} 50$ to 850 . GC-IRM S was carried out with a Thermo Scientific Trace 1310 with a GC-Isolink II, a Conflo IV and a Delta Advantage IRMS. GC was performed on a CP-Sil 5 column ( $25 \mathrm{~m} \times 0.32 \mathrm{~mm}$ with a film thickness of $0.12 \mu \mathrm{m})$ with $\mathrm{He}$ as carrier gas (constant flow $2 \mathrm{ml} \mathrm{min}^{-1}$ ). The $\mathrm{BF}_{3}$ methylated samples (dissolved in ethyl acetate) were on-column injected at $70 \stackrel{\circ}{\circ}$ and subsequently, the oven was programmed to $130{ }^{\circ} \mathrm{C}$ at $20{ }^{\circ} \mathrm{C} \mathrm{min}^{-1}$, and then at $4{ }^{\circ} \mathrm{C} \mathrm{min}^{-1}$ to $320{ }^{\circ} \mathrm{C}$, which was held for $10 \mathrm{~min}$. Stable carbon isotope ratios are reported in delta-notation against VPDB ${ }^{13} \mathrm{C}$ standard. V alues were determined by triplicate analysis, corrected for the $\mathrm{BF}_{3}$-methanol methylation and results averaged to a mean value. 
2.4.2 Ultra-high-performance liquid chromatography-mass spectrometry (UHPLC-MS)

UHPLC-MS was carried out on an A gilent 1260 UHPLC coupled to a 6130 quadrupole M SC in selected ion monitoring mode following a modified method of (Hopmans et al., 2016). The UHPL C was performed on two BEH HILIC silica columns ( $2.1 \times 150 \mathrm{~mm} ; 1.7 \mu \mathrm{m}$, Waters) in series, equipped with a $2.1 \times 5 \mathrm{~mm}$ pre-column of the same material as the main columns and operated at $30^{\circ} \mathrm{C}$. I socratic elution was used for GDGT separation, starting with $90 \%$ of eluent A (hexane) and $10 \%$ of eluent $B$ (hexane: isopropanol, 9:1) for $10 \mathrm{~min}$, followed by $70 \%$ eluent $A$ and $30 \%$ eluent $B$ for $40 \mathrm{~min}$, then a linear gradient to $100 \%$ eluent $B$ in $30 \mathrm{~min}$ and $100 \%$ eluent $B$ for $20 \mathrm{~min}$ at a flow rate of $0.2 \mathrm{ml} / \mathrm{min}$. Ionization was achieved by atmospheric pressure chemical ionization $(\mathrm{APCl})$ with following settings: probe heater temperature, $350{ }^{\circ} \mathrm{C}$; sheath gas $\left(\mathrm{N}_{2}\right)$ pressure, $50 \mathrm{AU}$ (arbitrary units); auxiliary gas $\left(\mathrm{N}_{2}\right)$ pressure, $5 \mathrm{AU}$; spray current, $5 \mu \mathrm{A}$; capillary temperature, $275^{\circ} \mathrm{C}$; S-lens, $100 \mathrm{~V}$. GDGT s and archaeol were identified by detecting the $[\mathrm{M}+\mathrm{H}]^{+}$ions in selected ion monitoring (SIM) mode for $\mathrm{m} / \mathrm{z}$ 651.6, 653.6, 743.8, 1286.3, 1288.3, 1290.3, 1292.3, 1294.3, $1296.3,1298.3,1300.3,1302.3,1304.3,13016.3,1330.3$ and 1344.3.

\section{Results}

\subsection{Distribution of hydrocarbons}

A nalysis of the saturated hydrocarbon fractions of the mud breccias from the three different $\mathrm{M} V \mathrm{~s}$ showed that they are dominated by saturated $\mathrm{n}$-alkanes $\left(\mathrm{C}_{16}\right.$ to $C_{35}$ ), pristane and phytane as well as a series of hopanes (Fig. 2 and Table 1). Furthermore, the presence of an unresolved complex mixture (UCM) was observed in all samples. Below, we describe the distributions of the different saturated hydrocarbon classes for representative samples of the three M V s in more detail.

\subsubsection{N-alkanes and acyclic isoprenoids}

The fresh mud breccia M DA $1 A$ taken from a mud cone from the M accalube di A ragona $\mathrm{MV}$, has a unimodal distribution of $n$-alkanes maximizing around $\mathrm{C}_{22} / \mathrm{C}_{24}$ and a weak odd over even carbon number predominance (Fig. 2A) as well as a high relative abundance of pristane and phytane. In contrast, the M D A p 4A sample (Fig. 2B) from the same MV site but from a mud pond reveals a bimodal distribution with a strong odd over even predominance of the longer chain $n$-alkanes $\left(C_{25}\right.$ to $\left.C_{31}\right)$. The shorter chain $n$-alkanes, maximize around $C_{19}$ with high relative abundances of pristane and phytane. A multimodal distribution 
of saturated $n$-alkanes is visible in the chromatograms of freshly emitted mud breccias from the Santa B arbara M V (SB 1C; Fig. 2C) and Comitini M V (COM 1B; Fig. 2D) with dominating $C_{25}$ to $C_{31}$ n-alkanes featuring an odd over even carbon number predominance. Furthermore, SB $1 \mathrm{C}$ and COM 1B also contain high relative abundances of pristane and phytane.
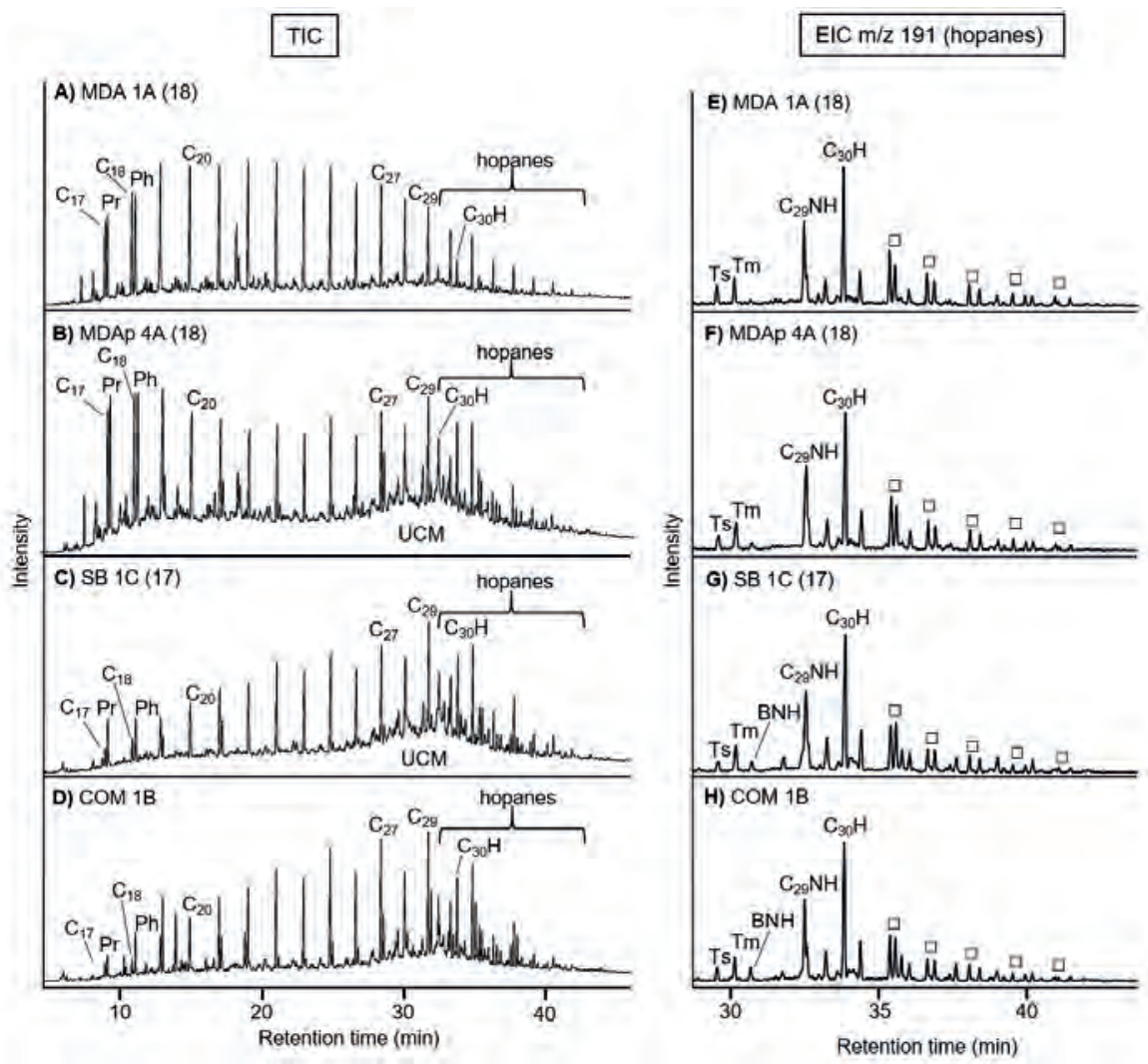

Figure 2 Total ion chromatograms (TIC) (A-D) and mass chromatograms of $\mathrm{m} / \mathrm{z} 191$ (E-H) of the saturated hydrocarbon fractions of fresh mud breccias from the three investigated M V s M accalube di A ragona (M DA), Santa B arbara (SB) and Comitini (COM) in Sicily. The chromatograms shown in the left panels (A-D) reveal the distribution of the $n$-alkanes (e.g. $C_{20}$ ), isoprenoid hydrocarbons ( $\mathrm{Pr}=$ pristane, $\mathrm{Ph}=$ phytane) and hopanes. The right panel mass chromatograms $(\mathrm{E}-\mathrm{H})$ show the distribution of the hopanes. Key: Ts $=18 \alpha(\mathrm{H})-22,29,30-$ trisnorhopane, $\mathrm{Tm}=17 \alpha(\mathrm{H})$-22,29,30-trisnorhopane, $\mathrm{BNH}=29,30$-bisnorhopane, $\mathrm{C}_{29} \mathrm{NH}=17 \alpha(\mathrm{H}), 21 \beta(\mathrm{H})$ 29-norhopane, $\mathrm{C}_{30} \mathrm{H}=17 \alpha, 21 \beta(\mathrm{H}) \mathrm{C}_{30}$ hopane, open squares $(\square)=\mathrm{C}_{31}$ to $\mathrm{C}_{35} 22 \mathrm{~S}$ and $22 \mathrm{R} 17 \alpha, 21 \beta(\mathrm{H})$ and $17 \beta, 21 \alpha(\mathrm{H})$ homohopane series.

To compare n-alkane and acyclic isoprenoid distributions of all M V samples we calculated the biomarker ratio of the isoprenoids pristane/phytane ( $\mathrm{Pr} / \mathrm{Ph})$ as well as the carbon preference index (CPI) and the odd-to-even predominance (OEP) of saturated $n$-alkanes (B ray and Evans, 1961; Scalan and Smith, 1970) (Table 1). The M accalube di A ragona MV samples demonstrate $\mathrm{Pr} / \mathrm{Ph}$ values of 0.58 to 1.04 , while the Santa Barbara MV shows a greater 
variation in this ratio ranging from 0.69 to 1.62 . Interestingly, the SB MV samples taken in 2018 feature much higher values ( $\geq 1.5$ ) of the $\mathrm{Pr} / \mathrm{Ph}$ ratio than the samples taken in $2017(\leq 1)$ (Table 1). Only one of the Comitini MV samples has sufficient amounts of $\mathrm{Pr}$ and $\mathrm{Ph}$ in their saturated fraction to calculate $\mathrm{PPr} / \mathrm{Ph}$ value of 0.67 . The CPI index values are around 1 for the $M$ accalube di A ragona fresh mud breccias, whereas the mud pond samples from this area show higher values about 1.3 to 1.4 in both sampling years. The OEP ratio is ranging from 1.0 to 1.1 in the Maccalube di Aragona MV and does not indicate much difference between the different sample types and years. For the other two M V s, Santa B arbara and Comitini, the CPI is relatively constant around 1.5 to 1.6, with the exception of a high CPI of 2.9 in the altered mud breccia SB 4A (17) taken further away from the main active $M V$ area and from an area covered with vegetation. The OEP ranges from 1.0 to 1.2 in all sample types and years in the Santa B arbara and Comitini M V s.

\subsubsection{Distribution of hopanes}

The composition of hopanes was determined using mass chromatograms of $\mathrm{m} / \mathrm{z}$ 191 (Fig. $2 \mathrm{E}-\mathrm{H}$ ). In the MVs, the most abundant hopane is the $17 \alpha, 21 \beta(\mathrm{H}) \mathrm{C}_{30}$ hopane $\left(\mathrm{C}_{30} \mathrm{H}\right)$ followed by a series of $\mathrm{C}_{31}$ to $\mathrm{C}_{35} 22 \mathrm{~S}$ and $22 \mathrm{R} 17 \alpha, 21 \beta(\mathrm{H})$ - and $17 \beta, 21 \alpha(\mathrm{H})$-homohopanes of decreasing abundance with increasing carbon number. The hopane distribution pattern is strikingly similar between the three different $M V$ sites with minor changes only in the relative abundance of the $22 \mathrm{~S}$ versus $22 \mathrm{R}$ hopanes. For example, in the $\mathrm{M}$ accalube di A ragona $\mathrm{MV}$ and mud pond samples (Fig. 2E and F) only the 22R $17 \beta, 21 \alpha(\mathrm{H})-\mathrm{C}_{31}$ homohopane is detected, while in the other two M V s Santa Barbara and Comitini the both the $22 \mathrm{~S}$ and $22 \mathrm{R} 17 \beta, 21 \alpha(\mathrm{H})-\mathrm{C}_{31}$ hopanes are present. A nother relatively abundant hopane is the $17 \alpha, 21 \beta(\mathrm{H})-29$-norhopane $\left(\mathrm{C}_{29} \mathrm{NH}\right)$, while also the trisnorhopanes Ts $(18 \alpha(\mathrm{H})-22,29,30$-trisnorneohopane $)$ and Tm $(17 \alpha(\mathrm{H})-22,29,30-$ trisnorhopane) were detected of which $\mathrm{Tm}$ is more abundant than Ts in all M V sites. Finally, the Santa Barbara and Comitini MVs feature 17 $\alpha, 18 \alpha(\mathrm{H}) 29,30$ bisnorhopane $(\mathrm{BNH})$, whereas the $\mathrm{M}$ accalube di A ragona $\mathrm{MV}$ samples do not reveal this compound.

To compare the source and thermal maturity of the expelled organic matter from the three $\mathrm{MVs}$, we calculated characteristic biomarker indices of hopanes (Peters et al., 2005) (Table 1). The $\mathrm{C}_{29} \mathrm{NH} / \mathrm{C}_{30} \mathrm{H}$ hopane ratio is an indicator for the source of organic matter (Peters et al., 2005) and shows relatively low values ranging from 0.58 to 0.81 in all three MVs. The $\mathrm{Ts} /(\mathrm{Ts}+\mathrm{Tm})$ index gives insight into the source and thermal maturity of organic 
matter (Seifert and Moldowan, 1978; M cK irdy et al., 1984; M oldowan et al., 1986) and ranges from 0.35 to 0.48 for the M accalube di A ragona M V , around 0.3 for the Santa B arbara M V and approximately 0.4 to 0.5 for the Comitini M V . The $22 \mathrm{~S} /(22 \mathrm{~S}+22 \mathrm{R})$ isomerization ratio of $\mathrm{C}_{31}$ and $\mathrm{C}_{32}$ homohopanes is a proxy for the thermal maturity of organic material (Seifert and Moldowan, 1980; Schoell et al., 1983) and varies from 0.49 to 0.66 for both $C_{31}$ and $C_{32}$ homohopanes in the three M V sites.

\section{EIC m/z 74 (fatty acids)}
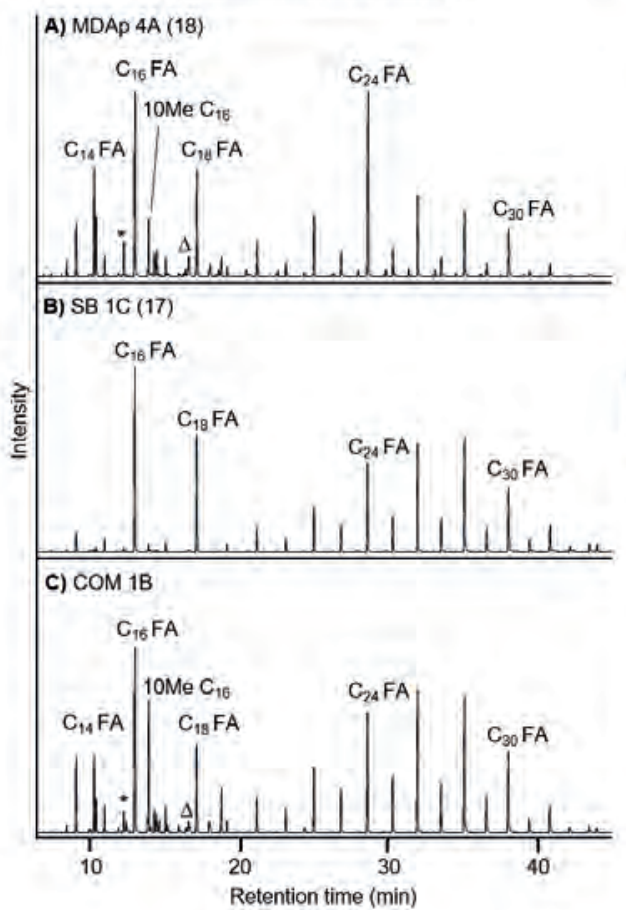

EIC m/z 191 (hopanoic acids)

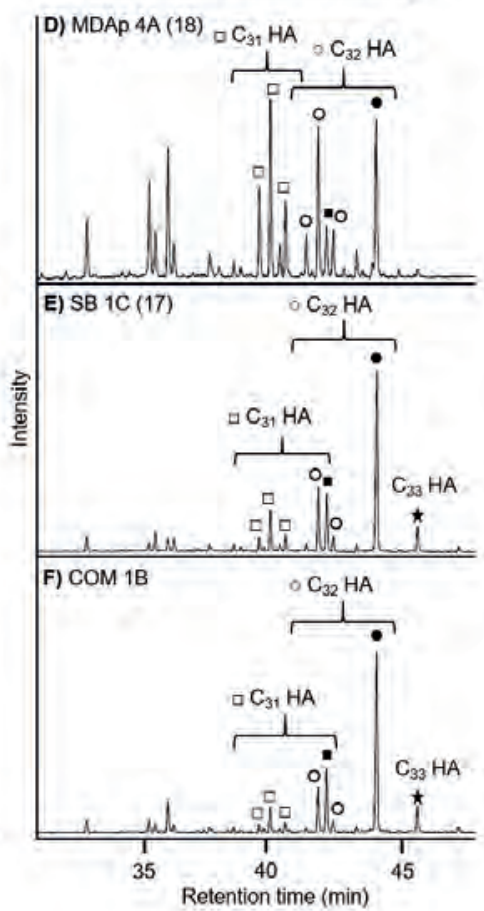

Figure 3.M ass chromatograms of $\mathrm{m} / \mathrm{z} 74$ showing the distribution of fatty acids (A-C) and $\mathrm{m} / \mathrm{z} 191$ hopanoic acids (D- F) of the fatty acid methyl ester fractions of the three $M V$ sites. The left panel displays fatty acids (FAs) e.g. $\mathrm{C}_{16} \mathrm{FA}$ or $\mathrm{C}_{24} \mathrm{FA}$, and some unsaturated counterparts * =unsaturated $\mathrm{C}_{16} \mathrm{FAs}, \Delta=$ unsaturated $\mathrm{C}_{18}$ FAs and $10 \mathrm{M} \mathrm{e}_{16}=10$-methyl hexadecanoic acid. The right panel shows the hopanoic acid ( $\mathrm{HA}$ ) distribution ranging from $\square=\mathrm{C}_{31} 22 \mathrm{~S}$ and $22 \mathrm{R} 17 \alpha, 21 \beta(\mathrm{H}), \mathrm{C}_{31} 22 \mathrm{~S}$ and $22 \mathrm{R} 17 \beta, 21 \alpha(\mathrm{H})$-hopanoic acids, $\mathrm{o}=\mathrm{C}_{32} 22 \mathrm{~S}$ and $22 \mathrm{R} 17 \alpha, 21 \beta(\mathrm{H}), \mathrm{C}_{32} 22 \mathrm{~S}$ and $22 \mathrm{R} 17 \beta, 21 \alpha(\mathrm{H})$-hopanoic acids, $=\mathrm{C}_{31} 22 \mathrm{R} 17 \beta, 21 \beta(\mathrm{H})$-hopanoic acid (homohopanoic acid), $\bullet=\mathrm{C}_{32} 22 \mathrm{R} 17 \beta, 21 \beta(\mathrm{H})$-hopanoic acid (bishomohopanoic acid) and filled star $=\mathrm{C}_{33} 22 \mathrm{R}$ $17 \beta, 21 \beta(\mathrm{H})$-hopanoic acid (trishomohopanoic acid).

\subsection{Distribution and $\delta^{13} \mathrm{C}$ values of fatty and hopanoic acid biomarkers}

In the fatty acid methyl ester fractions, the main lipids identified were fatty (FAs) and hopanoic acids (analyzed as their methyl ester derivatives), whose relative distributions are shown by mass chromatograms of $\mathrm{m} / \mathrm{z} 74$ (typical for FAs; Figs. 
3A-C) and m/z 191 (typical for hopanoic acids; Figs. 3D-F), respectively. The $M$ accalube di A ragona fresh mud breccias from the active $M V$ field hardly contained FAs or hopanoic acids and thus only a representative mass chromatogram of the fatty acid methyl ester fraction of the $M$ accalube mud pond (MDAp; Fig. 3D) is shown.

The Comitini mud breccia and $M$ accalube mud pond sample contain a range of FA s with major relative abundances of saturated $C_{14}, C_{16}$ and $C_{18} F A s$ as well as some of their unsaturated counterparts, whereas in the Santa Barbara mud breccia only the saturated $\mathrm{C}_{16}$ and $\mathrm{C}_{18} \mathrm{FA}$ were detected. The Comitini and $M$ accalube sites also show a major relative abundance of 10-methyl $C_{16} F A$ which is absent at the Santa B arbara M V site. Furthermore, longer chain FAs are also present in the $M V$ sites, the $M$ accalube di $A$ ragona mud pond is dominated by $\mathrm{C}_{24} \mathrm{FA}$ with a decreasing abundance of the longer chain $\mathrm{FAs} \mathrm{C}_{26}, \mathrm{C}_{28}$ and $\mathrm{C}_{30}$ with an even over odd predominance. In contrast, the other two MV sites Santa $B$ arbara and Comitini feature higher abundances of $C_{26}$ and $C_{28} F A s$ with lower relative abundance of $\mathrm{C}_{24}$ and $\mathrm{C}_{30} \mathrm{FA} s$ with an even over odd $\mathrm{FA}$ predominance (Figs. 3A-C).

Table 2 Stable carbon isotope values $\delta^{13} \mathrm{C}$ of present fatty acids (FAs) and hopanoic acids (HAs) in the fatty acid methyl ester fraction extracted from the three M V sites M accalube di A ragona, Santa B arbara and Comitini with standard deviation calculated from triplicate $\delta^{13} \mathrm{C}$ measurements. n. $\mathrm{p} .=$ not present.

\begin{tabular}{|l|c|c|c|c|c|}
\hline $\begin{array}{l}\text { Sample } \\
\text { ID }\end{array}$ & $\mathbf{C}_{14}$ FA & $\mathbf{C}_{16}$ FA & $\begin{array}{c}\text { 10M eC }_{16} \\
\text { FA }\end{array}$ & $\mathbf{C}_{18}$ FA & $\begin{array}{c}\mathbf{1 7 \beta , 2 1 \beta ( H )} \\
\mathbf{C}_{\mathbf{3 2}} \mathbf{H A}\end{array}$ \\
\hline $\begin{array}{l}\text { M DAp } \\
\text { 4A (18) }\end{array}$ & $-5.0 \pm 0.6$ & $-14.5 \pm 0.1$ & $-11.7 \pm 0.1$ & $-19.1 \pm 0.3$ & n.p. \\
\hline $\begin{array}{l}\text { 3M DAp } \\
\text { 1A (17) }\end{array}$ & $-9.2 \pm 1.2$ & $-19.3 \pm 0.3$ & $-21.4 \pm 0.5$ & $-22.9 \pm 0.7$ & n.p. \\
\hline $\begin{array}{l}\text { SB 1A } \\
\text { (17) }\end{array}$ & n.p. & $-29.6 \pm 0.4$ & $-31.1 \pm 0.5$ & $-27.9 \pm 0.8$ & $-29.5 \pm 0.4$ \\
\hline $\begin{array}{l}\text { SB 1C } \\
\text { (17) }\end{array}$ & n.p. & $-27.5 \pm 0.5$ & n.p. & $-28.5 \pm 0.6$ & $-29.3 \pm 0.1$ \\
\hline $\begin{array}{l}\text { C 0M 1B } \\
\text { (18) }\end{array}$ & $-11.5 \pm 0.9$ & $-26.7 \pm 0.2$ & $-21.8 \pm 0.6$ & $-25.1 \pm 0.7$ & $-28.6 \pm 0.3$ \\
\hline
\end{tabular}

The m/z 191 mass chromatograms of the fatty acid methyl ester fractions show a series of hopanoic acids (Fig. 3D-F). The mud breccias of the Santa Barbara and Comitini M V s (Fig. 3E and F) feature a series of low present signals of $22 \mathrm{~S}$ and $22 \mathrm{R} 17 \alpha, 21 \beta(\mathrm{H})$ - and $17 \beta, 21 \alpha(\mathrm{H})$-homohopanoic acids as well as a higher signal of $22 \mathrm{R} 17 \beta, 21 \beta(\mathrm{H})$-homohopanoic acid. Furthermore, 22R $17 \alpha, 21 \beta(\mathrm{H})$ - and $17 \beta, 21 \alpha(\mathrm{H})$-bishomohopanoic acids, a major $22 \mathrm{R} 17 \beta, 21 \beta(\mathrm{H})$ - 
bishomohopanoic acid as well as a low signal of $22 \mathrm{R} 17 \beta, 21 \beta(\mathrm{H})$ trishomohopanoic acid were detected. In contrast, the $\mathrm{M}$ accalube di A ragona mud pond site (Fig. 3D) shows a relatively high abundance of $C_{31}$ and $C_{32} 22 R$ $17 \alpha, 21 \beta(\mathrm{H})$-hopanoic acids in tandem with a high $22 \mathrm{R} 17 \beta, 21 \beta(\mathrm{H})$ bishomohopanoic acid peak with a lower presence for the other stereochemical configurations of the $C_{31}$ and $C_{32}$ hopanoic acids. Overall, the Santa B arbara and Comitini MV s feature the same hopanoic acid distribution with a major $22 \mathrm{R}$ $17 \beta, 21 \beta(\mathrm{H})$-bishomohopanoic acid, whereas the $\mathrm{M}$ accalube mud pond reveals a higher relative abundance of all $22 \mathrm{~S}$ and $22 \mathrm{R}$ configurations and the whole suite of $C_{31}$ and $C_{32}$ hopanoic acid configurations.

The stable carbon isotopic compositions $\left(\delta^{13} \mathrm{C}\right)$ could only be determined for the major $F A s\left(C_{14}, C_{16}, C_{18}\right.$ and 10 -methyl $\left.C_{16} F A\right)$ due to the low abundance of other FAs and the presence of an UCM. Based on the lipid biomarker distribution, we picked representative samples for ${ }^{13} \mathrm{C}$ measurements, which are reported in Table 2. These major FAs show $\delta^{13} \mathrm{C}$ values ranging from -14 to $30 \%$ in all three $\mathrm{MV}$ sites al though the $\mathrm{C}_{14} \mathrm{FA}$ in the $\mathrm{M}$ accal ube di $\mathrm{A}$ ragona mud pond is substantially more enriched $\left(\delta^{13} \mathrm{C}\right.$ value $=-5 \%$ ). U nfortunately, due to the low abundance of most of the hopanoic acids, only stable carbon isotopic

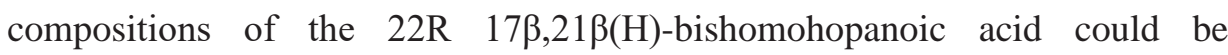
determined, revealing $\delta^{13} \mathrm{C}$ values around -28 to $-30 \%$ in the Santa B arbara and Comitini MV (Table 2).

\subsection{Lipid biomarker signatures of polar biomarkers}

The $\mathrm{GC}$-amenable polar fraction of the three M V sites contained some betahydroxy fatty acids $\left(\mathrm{C}_{16}, \mathrm{C}_{18}, \mathrm{C}_{24}\right.$ and $\left.\mathrm{C}_{26}\right)$ and $\mathrm{C}_{27}-\mathrm{C}_{29}$ sterols (e.g. cholesterol) as well as a large UCM. We were not able to unambiguously detect biomarkers such as hopanols, archaeol and hydroxyarchaeol, possibly because of the large UCM in the polar fraction.

A nalysis of the polar fraction using UHPLC-M S for archaeal derived ether lipids revealed their presence in all three MV sites (Table 3 and Fig. 4). The $M$ accalube di A ragona mud breccia shows high fractional abundances of GDGT-0 ranging from 21.6 to $32.9 \%$ and of GDGT-1 to -4 which varies from $11.4 \%$ (GDGT-4) up to $25.9 \%$ (GDGT-3) in combination with low amounts of crenarchaeol (2.5 to 3\%) and the absence of the crenarchaeol isomer (Table 3). Different GDGT distributions are observed in the Maccalube mud pond with high fractional abundances of GDGT-0 (89\%), low abundances of GDGT-1 to $4(1.9$ to $3 \%)$ as well as very low crenarchaeol $(0.8 \%)$ and the non-detection of the crenarchaeol isomer. Furthermore, we detected high fractional abundances 
of crenarchaeol ranging from 25 to $46 \%$ in the Santa Barbara mud breccias in combination with high GD GT-0 (26 to 39\%) and low crenarchaeol isomer (4 to $5 \%$ ), while the other GD GTs (GDGT-1 to -4) were present in lower abundances $(\leq 14 \%)$. The Comitini mud breccias feature high fractional abundances of GDGT-0 (33 and 37\%) and crenarchaeol (21 and 28\%) with lower abundances of GDGT-1 to -4 (1 to 19\%) and crenarchaeol isomer (ca. 2\%).

Additionally, archaeol was also detected in the three MV sites and the ratio of archaeol/GDGT-0 was calculated ranging from 0.3 to 9.5 in the $M$ accal ube di A ragona mud breccias and mud pond while the Santa B arbara mud breccias had values ranging from 0.5 to 2.4 and the Comitini mud breccias 0.5 and 0.6 (Table 3). The fact that archaeol was detected by UHPLC-M S and not GC-M S might have to do with the higher sensitivity of the UHPLC-M S where selective ion monitoring was used, in contrast to the full scan monitoring of the GC-M S.

The isoprenoidal GDGT based M ethane index (MI index $=($ GDGT-1+ GDGT-2+ GD GT-3) / (GDGT-1+GDGT-2+GDGT-3+Cren+Cren')) has been used to differentiate the GDGT distributions of marine A N M E-archaea involved in A OM from marine Thaumarchaeota (Zhang et al., 2011). In general, high M I values $(\geq 0.5)$ indicate methane or hydrate influenced marine environments, while low values reflect normal marine signals. Here, we applied this index for the three terrestrial MV sites to determine AOM -related GDGT signals. The $M$ accal ube di A ragona site indicates high $M I$ values from 0.90 to 0.96 , while the Santa Barbara M V (0.26 to 0.48) and Comitini MV (0.54 and 0.63) show lower values for the MI (Table 3).

Fig. 4 shows a ternary diagram with the fractional abundances of GD GT0, GDGT -1 to -4 and crenarchaeol among the three Sicilian M V. The M accalube di A ragona mud breccias cluster together at the bottom of the ternary plot and are clearly separated from the other Sicilian M V s due to their minor abundance of crenarchaeol. Interestingly, the Maccalube mud pond samples show differences in the fractional abundance of GDGT-0 which is very high in these two samples with low GDGT-1 to -4 and very low crenarchaeol. The other two $M V$ sites Comitini and Santa B arbara cluster together in the middle of the ternary plot with a high abundance of crenarchaeol, especially in the Santa B arbara M V samples (Fig. 4). Overall, the Santa Barbara MV and Comitini MV differ from the $M$ accalube di A ragona MV by the higher abundances of GDGT-0 and crenarchaeol versus high GDGT-1 to -4 and minor crenarchaeol. 


\begin{tabular}{|c|c|c|c|c|c|c|c|c|c|c|c|c|}
\hline$\frac{\frac{\gamma}{8}}{\underline{\underline{g}}}$ & $\begin{array}{l}\text { hn } \\
0 \\
0\end{array}$ & $\begin{array}{l}\text { นn } \\
\text { م. }\end{array}$ & $\begin{array}{l}8 \\
0 \\
0\end{array}$ & ס̊ & 8 & $\begin{array}{l}\stackrel{\infty}{+} \\
0\end{array}$ & $\begin{array}{c}\stackrel{\sim}{N} \\
0\end{array}$ & $\begin{array}{c}\stackrel{m}{m} \\
0\end{array}$ & $\begin{array}{l}\stackrel{\varphi}{N} \\
0\end{array}$ & $\begin{array}{c}\text { m } \\
\text { o }\end{array}$ & 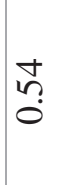 & $\begin{array}{l}\tilde{6} \\
0 \\
0\end{array}$ \\
\hline 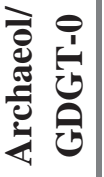 & $\begin{array}{l}\text { กิ } \\
\text { ดे }\end{array}$ & $\begin{array}{l}\text { n̊ } \\
\text { O̊ }\end{array}$ & 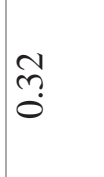 & $\begin{array}{l}\text { ก } \\
\text { r }\end{array}$ & $\stackrel{m}{\stackrel{m}{N}}$ & $\stackrel{\hat{m}}{\mathrm{~N}}$ & f̊ & $\begin{array}{l}\text { tొ } \\
\text { ஸ̂. } \\
0\end{array}$ & $\begin{array}{l}\hat{N} \\
0\end{array}$ & $\underset{r}{8}$ & ర్ & th \\
\hline نَ & ○ & O̊ & ○. & $\stackrel{\circ}{\circ}$ & $\stackrel{\circ}{\circ}$ & กี & $\stackrel{\infty}{m}$ & $\hat{m}$ & $\begin{array}{l}\varphi \\
\dot{+}\end{array}$ & $\stackrel{\circ}{\circ}$ & $\stackrel{\circ}{N}$ & $\stackrel{0}{-1}$ \\
\hline نั & $\stackrel{\circ}{m}$ & $\begin{array}{l}\infty \\
\end{array}$ & $\stackrel{\sim n}{N}$ & $\begin{array}{l}\infty \\
0\end{array}$ & $\begin{array}{l}\infty \\
0\end{array}$ & $\begin{array}{l}\circ \\
\stackrel{\circ}{N}\end{array}$ & $\begin{array}{l}\circ \\
\text { ஸे }\end{array}$ & ஜே & $\begin{array}{l}\text { ด̆ } \\
\text { ทุ }\end{array}$ & $\begin{array}{l}\stackrel{N}{Y} \\
\text { Vे }\end{array}$ & $\begin{array}{l}m \\
\infty \\
N\end{array}$ & $\begin{array}{l}0 \\
\stackrel{\circ}{*}\end{array}$ \\
\hline 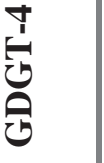 & $\begin{array}{l}m \\
\text { n̊ }\end{array}$ & ন & $\stackrel{\stackrel{n}{N}}{\text { Hิ }}$ & $\stackrel{\circ}{N}$ & $\stackrel{9}{r}$ & $\stackrel{\circ}{m}$ & تr & $\begin{array}{l}\infty \\
\text { N }\end{array}$ & 우 & เก & $\stackrel{+}{r}$ & $\stackrel{N}{N}$ \\
\hline $\begin{array}{l}m \\
1 \\
1 \\
0 \\
0 \\
0\end{array}$ & 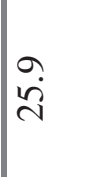 & $\hat{r}$ & $\stackrel{-1}{\ddot{n}}$ & $\stackrel{\Perp n}{N}$ & $\stackrel{\operatorname{n}}{N}$ & $\stackrel{+}{+}$ & $\stackrel{-1}{m}$ & g) & $\begin{array}{l}0 \\
\stackrel{N}{N}\end{array}$ & $\stackrel{\bullet}{N}$ & $\stackrel{\infty}{\wedge}$ & $\begin{array}{l}\varphi \\
\sigma\end{array}$ \\
\hline $\begin{array}{l}\mathbf{N} \\
1 \\
0 \\
0 \\
0 \\
0\end{array}$ & ¿.- & ஸ̃ & $\stackrel{m}{m}$ & $\stackrel{\circ}{\dot{m}}$ & $\stackrel{\infty}{N}$ & $\stackrel{+}{\stackrel{M}{M}}$ & 우 & กุ & $\hat{\infty}$ & $\hat{\sigma}$ & $\begin{array}{l}0 \\
\end{array}$ & $\begin{array}{l}6 \\
\infty \\
-1\end{array}$ \\
\hline كُ & $\underset{\sim}{\stackrel{N}{\sim}}$ & $\begin{array}{l}0 \\
\dot{\varphi}\end{array}$ & 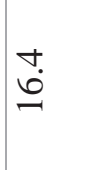 & 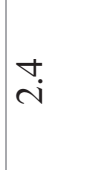 & $\stackrel{N}{N}$ & $\begin{array}{l}\text { m. } \\
\text { ó }\end{array}$ & $\stackrel{\circ}{\wedge}$ & $\stackrel{N}{\sigma}$ & $\begin{array}{l}\infty \\
\bullet \\
0\end{array}$ & $\stackrel{\bullet}{r}$ & $\hat{\sigma}$ & $\begin{array}{l}m \\
\text { o. } \\
r\end{array}$ \\
\hline $\begin{array}{l}0 \\
1 \\
0 \\
0 \\
0 \\
0\end{array}$ & $\begin{array}{l}0 \\
\stackrel{i}{N}\end{array}$ & $\begin{array}{l}\stackrel{g}{\mathrm{~N}} \\
\mathrm{~m}\end{array}$ & $\stackrel{\stackrel{N}{*}}{\stackrel{N}{N}}$ & $\begin{array}{l}\text { Ñ } \\
\infty \\
\infty\end{array}$ & $\begin{array}{l}\text { の } \\
\varnothing \\
\infty\end{array}$ & $\begin{array}{l}\hat{o} \\
\dot{m}\end{array}$ & $\begin{array}{l}r \\
\vec{m}\end{array}$ & $\begin{array}{l}\infty \\
\stackrel{\infty}{N} \\
\stackrel{n}{n}\end{array}$ & ঠे & 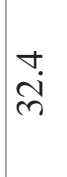 & 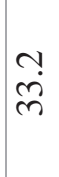 & $\stackrel{\circ}{\stackrel{\text { m}}{ }}$ \\
\hline$\frac{\frac{0}{0}}{\frac{0}{0}}$ & 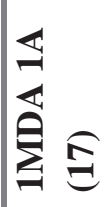 & 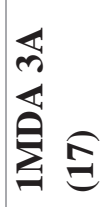 & 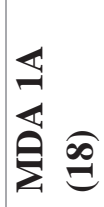 & 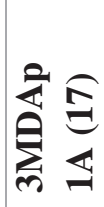 & 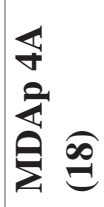 & 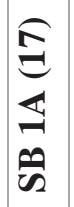 & 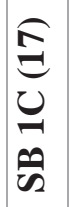 & $\begin{array}{l}\frac{5}{3} \\
S \\
0 \\
0 \\
0\end{array}$ & 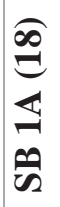 & 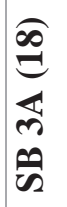 & I & 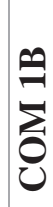 \\
\hline
\end{tabular}




\section{Discussion}

\subsection{Source and thermal maturity of organic matter}

$M$ aterials expelled from M V s are a mixture of mud breccias, waters and gas which may not be all co-genetic in their source strata (Stadnitskaia et al., 2007, 2008; López-Rodríguez et al., 2014). Therefore, lipid biomarker distributions and indices can help to characterize the organic geochemical signatures of potential source strata (Peters et al., 2005). Below, we reconstruct and discuss the potential source and thermal maturity of organic matter in the investigated mud breccias from the three Sicilian M V s.

\subsubsection{Source of organic matter in the expelled mud breccias}

The Maccalube di A ragona MV and mud pond are characterized by a high abundance of short chain n-alkanes $\left(\mathrm{C}_{17}\right.$ to $\left.\mathrm{C}_{21}\right)$ with a slight even over odd predominance and $\mathrm{Pr} / \mathrm{Ph}$ values $<1$ (Table 1 and Fig. 2), suggesting that the source organic matter derives from mature anoxic marine deposited strata connected to carbonates or marls (B ray and Evans, 1961; Didyk et al., 1978; V olkman et al., 1992). This is further supported by the presence of $\mathrm{C}_{29} \mathrm{NH}$ and a major $\mathrm{C}_{30} \mathrm{H}$ together with the extended $\mathrm{C}_{31}-\mathrm{C}_{35}$ homohopane series. These biomarker signatures are usually found in marine strata which were deposited in a shelf environment often forming carbonates, marls or other evaporates (Connan et al., 1986; Seifert and M oldowan, 1978; Peters and M oldowan, 1991). Similar hopane patterns are present in the other two MV s Santa Barbara (SB) and Comitini (COM) implying similar marine deposited source strata for the organic matter in the mud breccias as the $\mathrm{M}$ accalube $\mathrm{MV}$. However, the $\mathrm{C}_{29} \mathrm{~N} \mathrm{H} / \mathrm{C}_{30} \mathrm{H}$ index is $<0.9$ in all three M V sites which slightly disagrees with the origin from marine carbonate deposits as values $>1$ would be expected (Zumberge, 1984; Connan et al., 1986). One reason could be that the organic matter in the mud breccias acts similar to mature petroleum derived compounds from carbonate source rocks which have been found to generate low $\mathrm{C}_{29} \mathrm{NH} / \mathrm{C}_{30} \mathrm{H}$ values like marine evaporitic and carbonate source rocks located in the Brazilian marginal basins ( $M$ ello et al., 1988a, b), marls in the Northern A pennines in Italy (Ten Haven et al., 1985; Sinninghe Damsté et al., 1986) or in carbonate source rocks from the Dead Sea in I srael (Rullkötter et al., 1985). A nother more likely reason is that the organic matter represents a mixture from different geological strata in the MV s subsurface at which the biomarker signal from carbonate reefs gets diluted with hydrocarbons from other strata, e.g. shales producing lower $\mathrm{C}_{29} \mathrm{NH} / \mathrm{C}_{30} \mathrm{H}$ values. This is further supported by the fresh Santa B arbara mud breccias which indicate noticeable differences in their $\mathrm{Pr} / \mathrm{Ph}$ ratio in the two 
different sampling years 2017 and 2018 (Table 1) proposing a change in the predominant source strata of the expelled organic matter and $\mathrm{MV}$ activity over one year time.

Additionally, the Maccalube mud pond site, the Santa Barbara and Comitini M V s feature a relatively high abundance of long chain $n$-alkanes with an odd over even carbon number predominance $\left(C_{25}\right.$ to $\left.C_{29}\right), C P I$ and $O E P$ values generally above 1.3 (Table 1 and Fig. 2). Here, the odd longer chain n-alkanes might derive from input of land-plant material produced from epicuticular waxes in higher plants from the surrounding vegetation or from buried terrestrial strata in the M V subsurface (Eglinton and Hamilton, 1967; Volkman et al., 1992). $M$ oreover, the high abundance of even carbon numbered long-chain fatty acids (Fig. 3) also implies a major input of immature allochthonous terrestrial material (Eglinton and Hamilton, 1967) into these mud breccias, as these compounds would not be expected to be in high abundances in mature petrol eum like organic matter. Only at the M accalube di A ragona M V, we did not detect long-chain even carbon numbered fatty acids, which coincides with a low CPI of long chain n-alkanes (Table 1). Hence, it seems to be most likely that the mud breccias from the $M$ accalube di A ragona $M V$ derive from marine more mature source strata whereas the organic material from the $M$ accalube mud pond originates from a mix of mature marine carbonate strata and more immature terrestrial strata with a high input of plant material. Similar assumptions can be drawn for the Santa Barbara and Comitini mud breccias which possibly derive from a mixture of thermally mature and immature marine (e.g. carbonates or marls) and terrestrial organic matter from different source strata. Indeed, previous studies mainly about marine $\mathrm{MV}$ V also suggested that the lipid biomarkers (e.g. $n$-alkanes and hopanes) in the mud breccias originate from different mature geological sections in the subsurface (Stadnitskaia et al., 2007; L ópez-R odríguez et al., 2014).

\subsubsection{Thermal maturity}

The degree of thermal maturation of organic matter can be determined by a suite of lipid biomarkers. The $22 \mathrm{~S} /(22 \mathrm{~S}+22 \mathrm{R})$ homohopane isomerization index of $\mathrm{C}_{31}$ and $C_{32}$ homohopanes ranges between 0.50 to 0.66 in the three different $M V S$ (Table 1 ) suggesting that at least part of the organic matter in the mud breccias experienced a moderate to high degree of thermal maturation (Seifert and Moldowan, 1980; van Duin et al., 1997; Peters et al., 2005). Besides, the calculated values of the $22 \mathrm{~S} /(22 \mathrm{~S}+22 \mathrm{R})$ homohopane isomerization index are close to the thermodynamic equilibrium values of ca. 0.6 (Seifert and M oldowan, 1980; van Duin et al., 1997), thus indicating that most of the organic matter in 
the $M$ accalube di A ragona mud breccias experienced slightly higher maturations than in the other two M V s due to higher values in this index. A nother hopane maturity indicator is the $\mathrm{Ts} /(\mathrm{Ts} / \mathrm{T} \mathrm{m})$ index which shows low values of about 0.30 to 0.48 in the three $M V$ sites indicating relatively immature source organic matter (Peters et al., 2005). However, certain factors such as lithology are known to affect the rate of isomerization of hopanes. The presence of high amounts of clay in the MVs could also cause clay-catalyzed reactions which produce mature signals by $17 \alpha, 21 \beta(\mathrm{H})$-hopanes or influence Ts and Tm distribution (M cK irdy et al., 1983; Kolaczkowska et al., 1990). A dditionally, the occurrence of both the biological 22R $17 \beta, 21 \beta(\mathrm{H})$ configuration in $C_{31}$ and $C_{32}$ hopanoic acids in tandem with the diagenetically altered $22 \mathrm{R}$ and $22 \mathrm{~S} 17 \alpha, 21 \beta(\mathrm{H})$-hopanoic acids indicate the presence of at least two sources of organic matter with different maturity degrees in the three M V s (van Duin et al., 1997). It seems likely that the organic matter from the $M$ accalube di A ragona $M V$ derives from slightly more mature source strata than the other two MVs since they feature more abundant $22 \mathrm{R}$ and $22 \mathrm{~S} 17 \alpha, 21 \beta(\mathrm{H})$-hopanoic acids as well as slightly higher $22 \mathrm{~S} /(22 \mathrm{~S}+22 \mathrm{R})$ homohopane isomerization values. Overall, the coincidence of $17 \beta, 21 \beta(\mathrm{H})$ and $17 \alpha, 21 \beta(\mathrm{H})$ configurations next to thermally mature $22 \mathrm{~S} /(22 \mathrm{~S}+22 \mathrm{R})$ homohopane values and immature signals of the $\mathrm{Ts} /(\mathrm{Ts} / \mathrm{Tm})$ index clearly suggest the presence of more than one source of organic matter in the mud breccias as observed in other studies about MVs e.g. in the M editerranean or Black Sea (López-Rodríguez et al., 2014; Stadnitskaia et al., $2007,2008)$. The aforementioned $n$-alkanes, pristane and phytane distributions as well as the CPI and OEP indices also confirm this hypothesis, having both immature organic matter and moderately mature or petroleum derived compounds in the investigated mud breccias.

\subsubsection{Potential source strata of mud breccias}

The three M V s are located in the Caltanisetta B asin in Central Sicily in which potential source strata have rarely been investigated yet. Potential source strata for the mud breccia organic matter in the M accalube di A ragona and Comitini M V s might be of M iocene age (Burdigalian and Aquitarian) and related to carbonate reefs or platform carbonates of the Trapanese-Saccense units and/or basinal facies of Triassic age of the Sicani units (Granath and Casero, 2004). The pristane/phytane and the $\mathrm{C}_{29} \mathrm{NH} / \mathrm{C}_{30} \mathrm{H}$ biomarker indices (Table 1) as well as the distribution of $n$-alkanes relate partly the organic matter from the $M$ accalube di A ragona and Comitini M V sites to oils from the Gela 93 well at the Ragusa platform (Pieri and Mattavelli, 1986; Mattavelli and Novelli, 1990) but in 
contrast to these mature oils we could not detect gammacerane in the muds of the M V s. M oreover, the Santa Barbara M V is located more northern and closer to the thrust belt where potential source strata could be related to a Lower J urassic carbonate facies (M attavelli and N ovelli, 1990). In general, the organic matter from the three investigated MV systems seems to be linked to rather unidentified source strata which share some of the characteristics of known geological sections and petroleum characteristics in Sicily.

\subsection{Microbial lipid signatures}

\subsubsection{Aerobic methane oxidation}

The fatty acid composition of the mud breccias revealed abundant $C_{14}, C_{16}$ and $\mathrm{C}_{18} \mathrm{FAs}$ in all three MV sites, which likely derive from microbes involved in the utilization of the released gases or petroleum hydrocarbons. For example, Type I or Type II methanotrophs (Gammaproteobacteria or A lphaproteobacteria) are known to synthesize $C_{14}, C_{16}$ and $C_{18} F A s$ as well as their unsaturated counterparts (Bull et al., 2000; Dedysh et al., 2007; Bodelier et al., 2009). Furthermore, the $\mathrm{C}_{18: 0} \mathrm{FA}$ in tandem with the presence of $\mathrm{C}_{14}$ and $\mathrm{C}_{15} \mathrm{FAs}$ have been identified previously in Verrucomicrobia (Op den Camp et al., 2009) and in terrestrial M V s in Taiwan (Chang et al., 2012; Cheng et al., 2012). However, the $\delta^{13} \mathrm{C}$ values of the major $\mathrm{FAs}\left(\mathrm{C}_{14}, \mathrm{C}_{16}\right.$ and $\mathrm{C}_{18} \mathrm{FAs}$ ) (Table 2 ) rather exclude an origin from aerobic methanotrophic bacteria since one would expect $\delta^{13} \mathrm{C}$ values more depleted than the one of the released methane, which generally ranges from -45 to $-50 \%$ in the three MV sites (Grassa et al., 2004; Heller, 2011).

V arious hopanoic acids were also detected; they can originate from a range of methanotrophic A I pha-and Gammaproteobacteria but are al so known to be synthesized by other bacterial phyla including Planctomycetes or A cidobacteria (Thiel et al., 2003; Sinninghe Damsté et al., 2004, 2017; Birgel and Peckmann, 2008). The mud breccias and mud pool samples from the three $M V$ s contain different stereoisomeric configurations of hopanoic acids the $22 \mathrm{~S}$ and 22R $17 \alpha, 21 \beta(\mathrm{H})$ and $17 \beta, 21 \beta(\mathrm{H})$ suggesting at least two different sources of hopanoic acids since they cannot coexist with each other (Seifert and M oldowan,

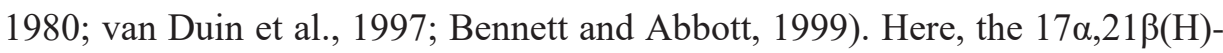
hopanoic acids probably derive from thermally mature source strate in the deeper layers of the M V s and not from recent bacterial biomass as mentioned earlier in section 4.1.2 (van Duin et al., 1997; B ennett and A bbott, 1999; Farrimond et al., 2002). In contrast, $22 \mathrm{R} 17 \beta, 21 \beta(\mathrm{H})$-hopanoic acids could derive from recent bacterial biomass in the upper MV layers or directly in the mud breccias and represent a signal from e.g. aerobic methanotrophic bacteria. A lthough the acid 
group of these hopanoids suggest a certain diagenetic alteration, which could be caused by clay-catalyzed reactions in the mud or through other processes, $22 \mathrm{R}$ $17 \beta, 21 \beta(\mathrm{H})$-hopanoic acids are regularly found in recent sediments and soils where they derive from the early steps of bacteriohopanepolyol diagenesis (Rohmer et al., 1984; B ennett and A bbott, 1999; Crossman et al., 2005; Inglis et al., 2018). Unfortunately, due to minor abundances of the $C_{31}$ and $C_{33} 22 R$ $17 \beta, 21 \beta(\mathrm{H})$-hopanoic acids and the $\mathrm{UCM}$, it was only possible to measure $\delta^{13} \mathrm{C}$ on one hopanoic acid, namely the $17 \beta, 21 \beta(\mathrm{H})$-bishomohopanoic acid. It displays regular $\delta^{13} \mathrm{C}$ values of about -28 to $-30 \%$ in the mud breccias (Table 2 ). These relatively high $\delta^{13} \mathrm{C}$ values compared to the released methane confirm that it is probably not derived from microbes related to AMO and might originate from other bacterial sources such as oil degrading bacteria or SRBS. However, it should be noted that some aerobic methanotrophs, for examples ' $\mathrm{C}$. Methylomirabilis oxyfera' do not use methane as their carbon source as they autotrophically fix carbon dioxide, and thus its biomass and lipids do not feature the characteristic $\delta^{13} \mathrm{C}$ depletion ( $\mathrm{Kool}$ et al., 2012; Rasigraf et al., 2014). Additionally, the hopanoic and fatty acids seem to derive from more than one source of organic matter which could also dilute the typical $\delta^{13} \mathrm{C}$ signatures of aerobic methanotrophs.

\subsubsection{Anaerobic oxidation of methane}

The high abundance of $\mathrm{CH}_{4}$ in tandem with the probably marine derived organic matter in the mud breccias suggest that the Sicilian M V s could al so host sulfate dependent $\mathrm{AOM}$ as found previously in other terrestrial and marine M V s via molecular and lipid biomarker based techniques (e.g. Stadnitskaia et al., 2005; A lain et al., 2006; López-Rodríguez et al., 2014; L ee et al., 2018). The relatively high abundant 10-methyl $\mathrm{C}_{16} \mathrm{FA}$ in the $\mathrm{M}$ accalube di A ragona and Comitini M V s (Fig. $3 \mathrm{~A}$ and $\mathrm{C}$ ) suggests a possible presence of sulfate reducing bacteria (SRB) of the genera Desulfobacter and Desulfobacula (Dowling et al., 1986; Kuever et al., 2001; B ühring et al., 2005) or the intra-aerobic methanotroph "C a. M ethylomirabilis oxyfera" (Kool et al., 2012). In SRBs, 10-methyl $C_{16} F A$ is found to make up approximately 5 to $25 \%$ of the total lipids, while in " $\mathrm{Ca}$. M ethylomirabilis oxyfera" it accounts for 35 to $45 \%$ of total FAs. Since we did not find the typical demethylated hopanoids and 10-methyl $\mathrm{C}_{16: 1 \Delta 7} \mathrm{FA}$ for " $\mathrm{Ca}$. M ethylomirabilis oxyfera" (K ool et al., 2012; Smit et al., 2019), this source can likely be excluded, although their signals might be suppressed by the high presence of petroleum like hydrocarbons and UCM in the mud breccias. This suggests that 10-methyl $C_{16}$ FA could originate from SRBs. However, we did not 
observe the usually depleted $\delta^{13} \mathrm{C}$ isotopic values (Table 2), which hints to a heterotrophic origin of this FA (Elvert et al., 2003; Blumenberg et al., 2004). Furthermore, the $\delta^{13} \mathrm{C}$ signal could be diluted by signals from other bacteria since the 10-methyl $\mathrm{C}_{16} \mathrm{FA}$ is also occasionally found in other bacterial species like A ctinobacteria (Campbell and N aworal, 1969; Park et al., 2008), Geobacter sp. (Lovley et al., 1993) or Planctomycetes (Sinninghe Damsté et al., 2005) but generally in low abundances. Previous studies at the terrestrial Salse di Nirano $\mathrm{MV}$ in Northern Italy found partly ${ }^{13} \mathrm{C}$-depleted non-isoprenoidal dialkyl glycerol diethers (DAGE) and archaeol indicating active AOM (Heller et al., 2012), while A lain et al. (2002) found hydroxyarchaeol, archaeol, some iso and anteiso $\mathrm{C}_{17} \mathrm{FAs}$ plus 10-methyl $\mathrm{C}_{16} \mathrm{FA}$ in $\mathrm{M} \mathrm{V} \mathrm{s}$ in the Carpathian M ountains, Romania, suggestive of AOM . In contrast, only traces of archaeol were detected besides the 10-methyl $C_{16} F A$ in the $\mathrm{GC}$-amenable compounds of the three Sicilian MVs, indicating that SRBs might be more involved in other microbial processes as methanogensis than A OM (Parkes, 1999; Zengler et al., 1999).

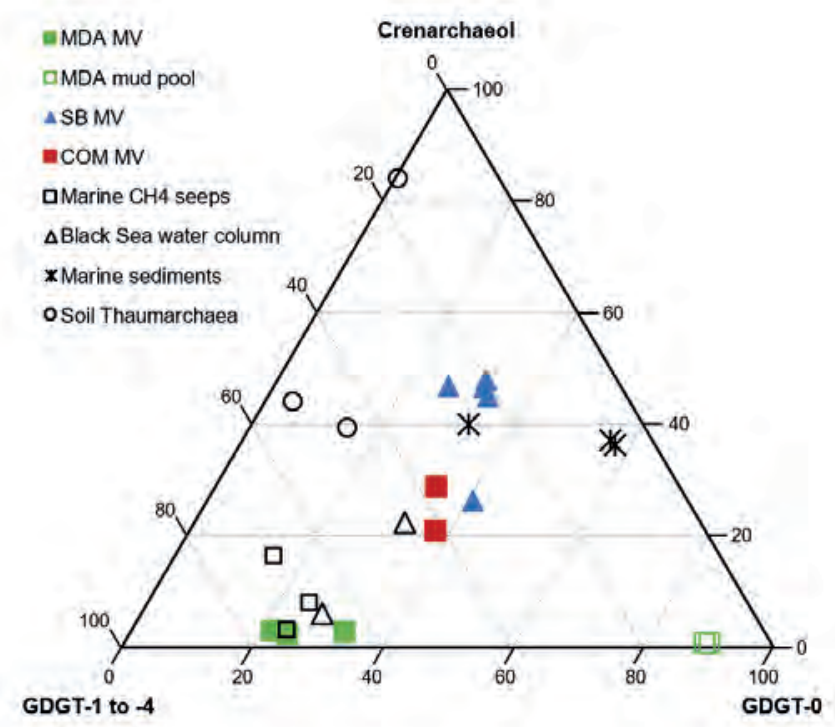

Figure4. Ternary diagram showing the distribution of GDGT-0, crenarchaeol and sum of GDGT-1 to 4 in the three Sicilian MV sites M accalube di A ragona (M DA), Santa B arbara (SB) and Comitini (COM). Black data points indicate literature data from previous studies from marine $\mathrm{CH}_{4}$ seeps, the Black Sea water column, marine sediments and soil Thaumarchaea (Schouten et al., 2000; W akeham et al., 2003; W akeham et al., 2004; Stadnitskaia et al., 2005; Sinninghe Damsté et al., 2012).

Additionally, UHPLC-MS analysis revealed the presence of archaeol and GDGTs-0 to -4 plus crenarchaeol in the three MV sites with differences in their 
distribution depending on the MV location (Table 3 and Fig. 4). A rchaeol is synthesized by most archaeal species including methanotrophic A N M E-archaea or methanogenic Euryarchaea as well as Thaumarchaea (Koga et al., 1993; Hinrichs et al., 1999; Pancost et al., 2001b; Schouten et al., 2013). Therefore, the GDGT distribution can give a more distinctive insight on the archaeal species present in the M V s. High abundances of GDGT-1 to -4 in combination with very low abundances of crenarchaeol in the Maccalube di A ragona mud breccias indicate a presence of ANME-archaea at this site, as they match distributions found in these microbes (Pancost et al., 2001a; Wakeham et al., 2003; Blumenberg et al., 2004). Furthermore, considerably high values in the GDGTbased methane index $\geq 0.9$ (Zhang et al., 2011) and the clustering of the Maccalube MV data in the ternary plot (Fig. 4), with other AOM influenced environments e.g. marine M V s and Black Sea water column strongly suggests the activity of ANME-archaea (Schouten et al., 2000; Wakeham et al., 2003, 2004; Stadnitskaia et al., 2005). It is unclear whether the A N M E-archaea are present at the surface of the M V or are derived from the subsurface. Interestingly, besides high amounts of GDGT-1 and GDGT-2 there are also high amounts of GDGT-3 and GDGT-4 suggesting an origin of thermophilic A N M E-archaea and thus thermophilic A OM processes (Schouten et al., 2003). This would indicate that the AOM signal is either derived from the subsurface or represents a mixed signal of thermophilic and non-thermophilic A OM from different MV depths in the $M$ accalube di A ragona $M V$.

In comparison, the $M$ accalube di A ragona mud pool samples show less abundant GDGT-1 to -4 and a high presence of GDGT-0 with almost absent crenarchaeol suggesting probably less present A N M E-archaea but methanogenic Euryarchaeota since methanogens usually produce high abundances of GDGT-0 and archaeol with less GDGT-1 to -4 (Blumenberg et al., 2004; Schouten et al., 2013). In contrast, the high relative abundances of crenarchaeol in combination with the presence of the crenarchaeol isomer and low GDGT-1 to -4 abundances in the Santa Barbara and Comitini M V s (Table 3 and Fig. 4) imply that these lipids likely originate from marine pelagic Thaumarchaea or from terrestrial Thaumarchaea from buried immature source strata (Sinninghe Damsté et al., 2012; Schouten et al., 2013; Elling et al., 2017). M oreover, the GDGT abundance of these two M V s cluster together with normal marine sediments (Schouten et al., 2000) and are close to soil thaumarchaeal signals (Sinninghe Damsté et al., 2012) in the ternary plot (Fig. 4) which is in accordance with the low values of the cal culated methane index. In general, it seems that the $M$ accal ube di A ragona $M V$ reveals evidence for A N M E-archaea involved in AOM processes due high 
abundances of GD GT-1 to - 4 and high methane index values next to presence of SRB typical 10-methyl $C_{16}$ FA. Interestingly, the Comitini MV indicates a moderate methane index around 0.5, GDGT distributions clustering in the middle of the ternary plot and the presence of 10-methyl $C_{16} F A$ as well as moderate levels of crenarchaeol, suggesting a mix of AOM biomarker signals and immature marine or terrestrial thaumarchaeal biomarkers from the $\mathrm{MV}$ subsurface strata. The Santa B arbara M V only demonstrates signals of marine or terrestrial Thaumarchaea, probably from immature source strata thus suggesting no active $A O M$ at this $M V$. This could potentially be related to the constant fluid seepage and episodic eruptions preventing the settlement of a stable microbial community which is also suggested by variations in the saturated biomarker composition in the two different sampling campaign years 2017 and 2018 in the Santa B arbara mud breccias (Table 1).

\subsection{Comparison between terrestrial and marine MV systems}

Up to now, only a few studies have investigated the composition of lipid biomarkers as well as the microbial community especially in terrestrial MV systems. A ll investigated mud breccias from the three Sicilian M V s seem to be a mixture of immature and mature organic matter originating from at least two different source strata. B esides, we did find evidence for A OM in the M accalube di A ragona M V through characteristic GDGT distributions clustering with data from other $A O M$ rich environments. The Comitini MV might also host AOM but to a lesser extent than the M accalube MV , whereas the Santa B arbara M V did not indicate $\mathrm{A} O \mathrm{M}$ processes. Furthermore, we could not detect unambiguous evidence for microbes involved in AMO processes in all three Sicilian M Vs. Other terrestrial MV s in the Northern A pennines and Romania did show also other archaeal and SRB specific biomarkers e.g. hydroxyarchaeol, DAGE and MAGE suggestive of $A O M$, besides high amounts of petroleum like hydrocarbons (A lain et al., 2006; Heller et al., 2012). However, the $\delta^{13} \mathrm{C}$ enriched values of SRB specific lipids at these sites suggested that mainly heterotrophic $S R B S$ are active in MVS of the Northern A pennines and to a lesser extent involved in AOM. A lthough, genetic studies in the Northern A pennines (Salse di Nirano) M V s did show the presence of aerobic methanotrophic bacteria from the phylum Methylococcales and found ANME-2 archaea (e.g. Methanosarcinales) (Wrede et al., 2012). Terrestrial Taiwanese MVs also indicated the presence of ANME-2 archaea (Methanosarcinales) next to methanogenic Euryarchaeota (M ethanomicrobiales) and various bacterial phyla like Gammaproteobacteria and Firmicutes (Chang et al., 2012; Cheng et al., 
2012). However, it was also found that microbial processes are compartmentalized into discrete stratified niches in the M V s themselves, where methanogenesis is the most abundant metabolism and AOM only occurs in the bubbling fluids. Pore-water profiles in these other terrestrial M V s showed that methane concentrations were inversely correlated with $\mathrm{Fe}^{2+} / \mathrm{Mn}^{2+}$ mineral concentrations, thus suggesting $\mathrm{AOM}$ being coupled to metal reduction instead of sulfate reduction in the Taiwanese M V s (Chang et al., 2012; Cheng et al., 2012). Similar conclusions were also drawn for the Romanian M V s where the microbial community of sulfate dependent A OM was present although less well developed than in marine MV and cold seep systems (A lain et al., 2006). The reason why only the $M$ accalube di A ragona $M V$ indicates clear markers for $\mathrm{AOM}$ and all three MV S lack signals for AMO to other terrestrial MV $\mathrm{S}$ is not completely clear. We speculate that especially the Santa Barbara M V could lack sufficient concentrations of oxidizing agents necessary for AOM like sulfate, nitrate or iron in the mud breccias generated in the deep reservoirs, limiting the presence of microbes involved in A OM. M oreover, A M O is possibly limited to the upper few centimeters of the mud breccias where oxygen is available and therefore might only be present in very stratified niches as suggested for the Taiwanese M V s (Chang et al., 2012; Cheng et al., 2012)

In comparison to terrestrial MVs, marine $M V s$ feature a higher abundance and larger diversity of archaeal and bacterial lipid biomarker signatures with distinct $\delta^{13} \mathrm{C}$ values characteristic for anaerobic and aerobic methane oxidation including biomarkers like hydroxyarchaeol, 2,6,10,15,19pentamethyleicosane (PMI), DAGE, diplopterol or fatty acids (Stadnitskaia et al., 2005; Niemann et al., 2006a, b; Lee et al., 2018). Possibly, communities involved in AM O or A OM in terrestrial M V s have a different lipid composition and occur in much lower abundances then in marine $\mathrm{M} \mathrm{V} \mathrm{s}$. It seems likely that it is connected to environmental factors such as oxygen availability for AM 0 or the more limited abundance of certain oxidizing agents connected to AOM like sulfate, iron and manganese than in marine MV systems. Alternatively, petroleum like hydrocarbons might be more dominant in terrestrial MVs compared to marine M V s serving as a more constant and longer lasting carbon source for the living microbes than the released gases. O ne reason could be that the gases are more rapidly released into the atmosphere at terrestrial $\mathrm{MV} \mathrm{s}$, while the petroleum compounds stay in the muds after deposition. However, our study suggests at least for one investigated MV ( $M$ accalube di A ragona MV) the presence of $A O M$ characteristic lipid biomarkers (10-methyl $C_{16} F A$, high abundance of GDGT-1 to -4 and a high MI of $\geq 0.9$ ), similar to those found in 
marine M Vs. Furthermore, this study is, to best of our knowledge, the first one demonstrating specific GDGT patterns for A NME-archaea in a terrestrial M V system.

Future work should investigate gas and mineral concentrations as well as microbial communities via DNA-based techniques in depth profiles in the Sicilian MVs but also in other terrestrial MVs to gain new insights into the microbial metabolisms in these extraordinary gas rich environments.

\section{Condusion}

The mud breccias of the three investigated terrestrial Sicilian M V s (M accalube di A ragona, Santa Barbara and Comitini) reveal signatures of saturated petroleum like hydrocarbons ( $n$-alkanes, acyclic isoprenoids and hopanes) that dominate over those of lipid biomarkers from living bacteria and archaea. The saturated hydrocarbon distribution as well as source- and maturity-related biomarker indices suggest that the organic matter in the mud breccias derived from a mix of at least two different source strata with different maturity degrees in all three Sicilian MVs. Some source strata seem to be connected to mature anoxic marine deposited marls or carbonates while other strata reflect immature terrestrial plant signals. The $\mathrm{M}$ accalube di Aragona source organic matter probably experienced slightly higher thermal maturities than the other two M V sites as suggested by distinctive $n$-alkanes distributions, a higher $22 \mathrm{~S} /(22 \mathrm{~S}+22 \mathrm{R})$ ratio of $C_{31}$ and $C_{32}$ homohopanes and trends of $22 \mathrm{~S}$ and $22 \mathrm{R} 17 \alpha, 21 \beta(\mathrm{H})$ hopanoic acids compared to the other two M V s. Furthermore, the three M V s contain regular saturated and unsaturated $C_{14}, C_{16}$ and $C_{18} F A s$, a major 10methyl $C_{16} F A$ in the Comitini and $M$ accalube $M V s$ and $C_{31}$ and $C_{32} 22 R$ $17 \beta, 21 \beta(\mathrm{H})$-hopanoic acids. However, none of the fatty and hopanoic acids was substantially depleted in $\delta^{13} \mathrm{C}$ suggesting either no active methane oxidation processes or signals from a mixture of different heterotrophic and autotrophic bacterial producers. In contrast, the isoprenoidal-GDGT distributions with a high $\mathrm{MI} \geq 0.9$ and high abundances of GDGT- 1 to -4 clustering with those from A OM rich environments suggesting $A O M$ at the $M$ accalube di A ragona MV. The Comitini MV and especially the Santa Barbara MV revealed relatively high abundances of crenarchaeol and the presence of the crenarchaeol isomer next to low amounts of GDGT-1 to -4 suggesting a major input of immature marine or terrestrial thaumarchaeal biomass into these $\mathrm{MV}$ s. These results imply the first detection of AOM involved ANME-archaea through characteristic GDGT patterns in terrestrial MVs. Furthermore, our results clearly suggest that terrestrial MV $\mathrm{s}$ differ from marine $\mathrm{MV}$ s which host a higher abundance and 
diversity of isotopically depleted lipid biomarkers linked to aerobic/anaerobic methane oxidation, possibly due to limitations of oxygen and specific oxidizing agents (e.g. sulfate or nitrate) necessary for A M 0 and A OM.

\section{Acknowledgements}

We thank Caitlyn R. Witkowski for helping with sample collection in 2017 as well as Fiona M iddleton for helping with sample collection in 2018 and initial lipid analysis on some MV samples. We also thank Jort Ossebaar and M arcel van der $\mathrm{M}$ eer for assistance in isotope analysis. This study received funding from the N etherlands E arth System Science Center (NESSC) through a grant to J SSD and SS (024.002.001) from the Dutch Ministry for Education, Culture and Science. 
112 | Chapter 4 


\section{Chapter 5}

Analysis of non-derivatized bacteriohopanepolyols using UHPLC-HRMS reveals great structural diversity in environmental lipid assemblages

Ellen C. Hopmans, Nadine T. Smit, Rachel Schwartz-Narbonne, Jaap S. Sinninghe Damsté, Darci Rush

Under review at Organic Geochemistry 
114 | Chapter 5 


\section{Abstract}

Bacteriohopanepolyols (BHPs) are lipids with great chemotaxonomic potential for microbial populations and biogeochemical processes in the environment. The most commonly used methods for BHP analysis are chemical degradation followed by gas chromatography-mass spectrometry (MS) or derivatization followed by high performance liquid chromatography (HPLC)- atmospheric pressure chemical ionization/M S. Here we report on significant advances in the analysis of non-derivatized BHPs using U (Itra)HPLC-electrospray ionizationhigh resolution $\mathrm{MS}^{2}$. Fragmentation mass spectra provided information on the BHP core, functionalized side chain, as well as the conjugated moiety of composite B HPs. W e successfully identified the common bacteriohopanepolyols and their (di)methylated and (di)unsaturated homologues, aminoBHPs, and composite B HPs (e.g., cyclitol ethers and methylcarbamateB HPs) in biomass of several known BHP-producing micro-organisms. To show how the method can be exploited to reveal the diversity of B HPs in the environment, we investigated a soil from an active methane seep, in which we detected ca. 130 individual BHPs, including a complex distribution of adenosylhopanes. We identified the nucleoside base moiety of both adenosyl type-2 and type-3. A denosyl hopane type-3 contains a methylated adenine as its nucleobase, while type- 2 appears to contain a deaminated and methylated adenine, or N 1-methylinosine. In addition, we detected novel adenosyl hopanes. Furthermore, we identified a novel series of composite BHPs comprising of bacteriohopanepolyols conjugated to an ethenolamine moiety. The novel ethenolamineB HPs as well as aminoB HPs were also detected acylated to fatty acids. The analytical approach described allows for simultaneous analysis of the full suite of IPLS, now including BHPS, and represents a further step towards environmental lipidomics.

\section{Keywords}

non-derivatized bacteriohopanepolyols, UHPLC-HRMS, novel composite BHPs, adenosylhopanes

\section{Introduction}

Bacteriohopanepolyols (BHPs) are membrane lipids with great chemotaxonomic potential with regards to microbial populations as well as biogeochemical processes in the environment. BHPs are composed of a pentacyclic triterpenoid ring system with an extended side chain containing 4, 5, or 6 functional groups (Fig. S1) comprised of either all hydroxyl moieties (bacteriohopanetetrol (BHT), 
bacteriohopane pentol (BHpentol), and bacteriohopane hexol (BHhexol); Rohmer et al., 1984; Talbot et al., 2003a; Talbot and Farrimond, 2007) or 3, 4, or 5 hydroxyl moieties and a single terminal amino-group (i.e., aminotriol, tetrol, and -pentol; e.g., N eunlist and Rohmer, 1985; Rohmer, 1993). The basic, unmodified ring system with a linear side chain is usually the dominant B HP in both culture and environmental samples (see also review of BHP sources in (Talbot and Farrimond, 2007; Talbot et al., 2008). BHPs can be further modified by methylation at the C-2 (2M eBHPs; e.g., Talbot et al., 2008 and references therein), C-3 (3MeBHPs; e.g., Cvejic et al., 2000a), both C-2 and C-3 (2,3diM eB HPs; Sinninghe Damsté et al., 2017), C-31 (Simonin et al., 1994), or C-12 (Costantino et al., 2000) carbon positions. BHPs can also include unsaturation in the ring system located at $\Delta^{6}, \Delta^{11}$ or both (see section 3.3.3 and Fig. 3; e.g., Talbot et al., 2007b and references therein). A BHP with an unsaturation in the side chain was identified in a methanotrophic M ethylovulum bacterium (van Winden et al., 2012). A large variety of so-called composite BHPs, where the terminal functional group is bound to complex, often polar moiety, have also been identified (Talbot et al., 2007a and references therein), such as the adenosylhopanes, acylated B HPs, and cyclitol ether B HPs (B HP-CE) (see Results and Discussion and accompanying figures for structures). BHPS with novel side chains are continually being discovered (e.g., Kool et al., 2014; Rush et al., 2016). The diverse nature of B H P lipid structures has led to particular BHPs being used as biomarkers for unique bacterial source organisms (van Winden et al., 2012; Kool et al., 2014; Rush et al., 2014), environmental conditions (Ricci et al., 2014; Welander and Summons, 2012), and organic matter origin (Zhu et al., 2011).

The first reports of BHPs in the natural environments were based on analysis with gas chromatography coupled to mass spectrometry (GC-M S; Rohmer et al., 1980). Traditionally, the GC-M S identification and quantification of BHPs in organic extracts are based on a degradation with periodic acid which converts the intact BHPs into $C_{30}-C_{32}$ primary alcohols, followed by acetylation. A nalyses of these derivatized hopanols provide information about the number of functional groups present in the original intact molecule (Rohmer et al., 1984). The analysis of hopanoids by way of GC-M S has been a big step forward in understanding the distribution of BHPs in modern systems and the geological archive. However, by removing all but one functional group from the side chain using the Rohmer reaction, much of the source-, environment-, or process-specific information is lost. In addition to this being a laborious method, 
it is also completely unable to detect composite BHPs, leading to potential underestimation of B HP abundance and complexity. To fully elucidate the array of BHP structures, alternative methodologies have been developed. In 2013, Sessions et al. published a high temperature (HT)GC-M S method that achieves elution and separation of more complex acetylated intact BHPs on two different GC columns (BHT, BHpentol and aminotriol on DB-5HT; $2 \mathrm{MeBHPs}$ on DB$X L B$ stationary phase). Though HTGC-M S shows promise, the vast majority of work on intact B HPS, however, has been performed using HPLC-M S.

Schulenberg-Schell et al. (1989) developed a reversed phase HPLC method for analysis of BHPs after acetylation. This method was modified by Talbot et al. (2001), where its applicability was demonstrated in a study of the $\mathrm{BHP}$ profiles from a group of methanotrophic bacteria. A dvances followed with the application of atmospheric pressure chemical ionization $(\mathrm{APCl}) / i$ on trap multi-stage MS, which allowed for more precise control of the fragmentation of the precursor ions. Since 2003, most environmental and culture studies of BHPS have used a version of this reversed phase chromatographic method ( e.g., Blumenberg et al., 2007; Saenz et al., 2011; Talbot et al., 2003a, b). The subsequent investigation of a wider range of hopanoid-producing bacterial cultures (Talbot et al., 2003b, c; Talbot et al., 2007a, b; T al bot et al., 2008) led to the improved understanding of the fragmentation pathways in a greater diversity of B HP structures. This allowed for the identification of known BHPs, and related unknown BHPs (e.g., V an W inden et al., 2012, Rush et al., 2016). Recently, several studies were published successfully applying ultra-high pressure liquid chromatography (UHPLC) for improved separation of acetylated BHPs (K usch et al., 2018, H emingway et al., 2018), especially isomers of BHT.

The analysis of derivatized BHPs using HPLC-MS has its own disadvantages. The acetylation efficiencies and response factors of individual BHPs vary, making quantitation difficult. Some BHPs, e.g., B HT-CE, acetylate incompletely resulting in the production of several acetylomers complicating data interpretation. With the introduction of improved UH PLC-M S instruments and advances in the quality and diversity of the stationary phases, it became possible to introduce improved methods for analyzing non-derivatized BHPS. Based on an application note (I saac et al., 2011), non-derivatized B HPs were successfully identified in bacterial isolates and purified culture material using a U H PLC-tandem M S system (M al ott et al. 2014; W u et al, 2015) but these studies did not show the comprehensiveness and sensitivity necessary to cover a wide range of B HPs. M alott et al. (2014) did not report B H Ps known to be synthesized 
by their investigated organism (i.e., BHT and unsaturated BHT-CE in Burkholderia spp. (Cvejic et al., 2000b)) and Wu et al. (2015) reported a reduction in ionization efficiencies of non-acetylated BHPs compared to their acetylated counterparts. Recently, Talbot et al. (2016) reported on the development of an UHPLC method coupled to APCI/triple Quadrupole M S in multi reaction monitoring (MRM) mode for non-derivatized BHPs. However, this work remained limited to a restricted number of al ready identified BHPs.

Here we report on significant advances in the analysis of non-derivatized BHPS using UHPLC coupled to electrospray ionization (ESI)-high resolution dual-stage MS (HRMS ${ }^{2}$ ). Using an approach, which has been successfully applied to the analysis of intact polar lipids (IPLS), we analyzed a number of bacterial species, a.o. Candidatus 'Scalindua profunda', Ca. 'M ethylomirabilis oxyfera', M ethylococcus capsulatus, and M ethylomarinum vadi, as well as a soil from an active terrestrial methane seep. We discuss elution and fragmentation behavior of a wide range of known BHPs, including $\mathrm{N}$-containing BHPS and composite BHPs, and the tentative identification of an extensive set of novel BHPs.

\section{M aterials and M ethods}

\subsection{Sample description}

Komagataeibacter xylinus strain R-2277 (formerly Gluconacetobacter xylinus and Acetobacter aceti ssp. xylinum) was obtained as frozen cells in culture medium from an industrial culture (Hoffmann-La Roche, Basel). This culture has been used in previous B HP studies (Peiseler and Rohmer, 1992; SchwartzN arbonne et al., 2020).

Ca. 'M ethylomirabilis oxyfera'. A n enrichment culture of Ca. 'M. oxyfera' bacteria was obtained from a bioreactor operated under conditions described previously by Ettwig et al. (2009). The bioreactor population consisted of ca. $67 \%$ Ca. 'M . oxyfera', while the remainder was composed of a mix of A NME$2 \mathrm{~d}$ archaea and different minor bacteria phyla (see Smit et al., 2019, for details). This culture has been used in previous B HP studies by K ool et al., (2014).

M ethylococcus capsulatus. M. capsulatus (strain Bath) was obtained from the University of W arick culture collection (as described in Tal bot et al., 2001). M. capsulatus has been studied in previous BHP studies by Neunlist and Rohmer (1985) and Talbot et al. (2001). 
$\mathrm{Ca}$. 'Scalindua profunda'. A n enrichment culture of $\mathrm{Ca}$. 'S. profunda' was grown in a sequencing batch reactor ase described by van de V ossenberg et al. (2008) and consisted of $80-90 \% \mathrm{Ca}$. 'S. profunda'. B HPs have been previously studied in this enrichment culture by Rush et al. (2014) and Schwartz-N arbonne et al. (2020).

Methylomarinum vadi (strain IT-4) was isolated from a microbial mat of a shallow ( 23 $\mathrm{m}$ water depth) marine hydrothermal system in a coral reef off Taketomi Island, O kinawa, Japan (Hirayama et al., 2007; 2013). Cultivation of this strain was performed at J A M STEC, J apan, using M J met mediumat pH 6.6 at $37^{\circ} \mathrm{C}$. This culture has been used in previous B H P studies (R ush et al., 2016).

Censo $0 \mathrm{~m}$ soil. The Fuoco di Censo seep $\left(37^{\circ} 37^{\prime} 30.1^{\prime \prime} \mathrm{N}, 13^{\circ} 23^{\prime} 15.0^{\prime \prime} \mathrm{E}\right)$, in the mountains of Southwestern Sicily, Italy, is a typical example of a natural 'Everlasting Fire' (Etiope et al., 2002; Grassa et al., 2004; Smit et al., 2021). The Censo seep gas consists of mainly thermally generated methane (76-86\%). A soil sample was recovered from a horizon $5-10 \mathrm{~cm}$ below soil surface directly at the main gas seep (Censo $0 \mathrm{~m}$ ). The soils were stored in a clean geochemical sampling bag and kept frozen at $-20^{\circ} \mathrm{C}$ until freeze drying and extraction. Further details can be found in Smit et al. (2021).

\section{Lipid extraction}

Freeze-dried bacterial biomass and the soil from the Censo seep were extracted using a modified Bligh and Dyer method (Bligh and Dyer, 1959; Bale et al., 2013). The samples were ultrasonically extracted (10 $\mathrm{min}$ ) with a solvent mixture containing methanol $(\mathrm{MeOH})$, dichloromethane (DCM) and phosphate buffer $(2: 1: 0.8, v: v: v)$. Solvent was collected after centrifugation and the residues reextracted twice. A biphasic separation was achieved by adding additional DCM and phosphate buffer to the combined extracts in a ratio of $\mathrm{MeOH}, \mathrm{DCM}$ and phosphate buffer (1:1:0.9, v:v: ). A fter the DCM layer was collected, the aqueous layer was washed twice with DCM . Combined DCM layers were dried under a continuous flow of $\mathrm{N}_{2}$. Prior to injection, extracts were redissolved in $\mathrm{M} \mathrm{eOH}: \mathrm{DCM}(9: 1)$ and filtered through a $0.45 \mu \mathrm{m}$ regenerated cellulose syringe filter (4 mm diameter; Grace A Iltech, Deerfield, IL).

\section{UHPLC/HRMS}

The method described here (adapted from Wörmer et al. (2013)) is the final method used. Steps in method development are discussed below in Results and 
Discussion. All analysis were performed using an Agilent 1290 Infinity I UHPLC, equipped with thermostatted autosampler and column oven, coupled to a quadrupole-orbitrap HRM S equipped with an Ion M ax source and heated ESI probe (HESI) (ThermoFisher Scientific, Waltham, MA). Separations were achieved using an Acquity $\mathrm{C}_{18} \mathrm{BEH}$ column $(2.1 \times 150 \mathrm{~mm}, 1.7 \mu \mathrm{m}$ particle; Waters), fitted with a pre-column, and a solvent system consisting of (A) methanol: $\mathrm{H}_{2} \mathrm{O}(85: 15)$ and $(\mathrm{B})$ methanol:isopropanol (1:1), both containing $0.12 \%(\mathrm{v} / \mathrm{v})$ formic acid and $0.04 \%(\mathrm{v} / \mathrm{v})$ aqueous ammonia. Compounds were eluted with $5 \%$ B for $3 \mathrm{~min}$, followed by a linear gradient to $40 \%$ B at $12 \mathrm{~min}$ and then to $100 \% \mathrm{~B}$ at $50 \mathrm{~min}$, with a total run time of $80 \mathrm{~min}$. The flow rate was $0.2 \mathrm{~mL} \mathrm{~min} \mathrm{~m}^{-1}$. Positive ion HESI settings were: capillary temperature, $300{ }^{\circ} \mathrm{C}$; sheath gas $\left(\mathrm{N}_{2}\right)$ pressure, 40 arbitrary units $(\mathrm{AU})$; auxiliary gas $\left(\mathrm{N}_{2}\right)$ pressure, 10 $\mathrm{AU}$; spray voltage, $4.5 \mathrm{kV}$; probe heater temperature, $50{ }^{\circ} \mathrm{C}$; S-lens $70 \mathrm{~V}$. Detection was achieved using positive ion monitoring of $\mathrm{m} / \mathrm{z} 350-2000$ (resolving power $70,000 \mathrm{ppm}$ at $\mathrm{m} / \mathrm{z} 200$ ), followed by data dependent $\mathrm{MS}^{2}$ (isolation window $1 \mathrm{~m} / \mathrm{z}$; resolution $17,500 \mathrm{ppm}$ at $\mathrm{m} / \mathrm{z} 200$ ) of the 10 most abundant ions, and dynamic exclusion ( $6 \mathrm{~s}$ ), with $3 \mathrm{ppm}$ mass tolerance. In addition, an inclusion list of 165 calculated exact masses of B H Ps from literature was used. Optimal fragmentation of BHPs was achieved using a stepped normalized collision energy of 22.5 and 40 . A mass calibration was performed every $48 \mathrm{~h}$ using the Thermo Scientific Pierce LTQ Velos ESI Positive Ion Calibration Solution. All mass chromatograms were produced within 3 ppm mass accuracy, unless otherwise stated.

\section{Results and Discussion}

\subsection{UHPLC method development}

The suitability of $C_{18}$ columns for the retention and separation of several nonderivatized BHPs was previously demonstrated by Talbot et al. (2016). Two types of $C_{18}$ column were tested in that study: an A cquity BEH UHPLC column and an A ce base-deactivated Excel U HPLC column, of which the latter showed the best chromatographic behavior, particularly for $\mathrm{N}$-containing BHPS. Previously, the A cquity BEH $C_{18}$ column was selected by Wörmer et al. (2013) in a new UHPLC-ESI/M S method for the analysis of IPL s. As BHPs, like IPLs, consist of a large apolar moiety and a polar functionalized side chain with or without an additional, often polar, moiety or head group, we set out to test whether the chromatographic system, combined with positive ion ESI, as described by Wörmer et al. (2013) for IPLs, is suitable for the analysis of non- 
derivatized BHPs. For this purpose, we investigated extracts of biomass of various known BHP-producing micro-organism. The exact distribution of the detected B HPs and their fragmentation spectra are discussed in detail in section 3.3. Here we only discuss the general features of the chromatographic method. BHT was easily identified in several extracts based on its exact mass and diagnostic spectra, however aminotriol and -tetrol produced very broad peaks and were thus difficult to detect, similarly as was described by Talbot et al. (2016). The buffering system according to Wörmer et al. (2013) consists of $0.04 \%$ formic acid and $0.1 \% \mathrm{NH}_{3}$, producing a mobile phase with a $\mathrm{pH}$ 6. The $\mathrm{pH}$ is often a driving factor in the chromatographic behavior of $\mathrm{N}$-containing compounds and therefore a more acidic buffering system with $0.12 \%$ formic acid and $0.04 \% \mathrm{NH}_{3}$, which has al so been frequently used in IPL HPL C-M S analysis (cf. Sturt et al., 2004) was tested. This change in the $\mathrm{pH}$ of the mobile phase to 4 resulted in excellent peak shape for the $\mathrm{N}$-containing $\mathrm{BHPs}$ using the Acquity BEH $C_{18}$ column, allowing detection of e.g., aminotriol and -tetrol, as well as adenosylhopane BHPs. Use of the base deactivated A ce Excel $\mathrm{C}_{18}$ column in combination with the mobile phase with $\mathrm{pH} 4$ did not result in improved chromatography and thus, for all experiments described below, a combination of the Acquity $\mathrm{BEH} \mathrm{C}_{18}$ column combined with the $\mathrm{pH} 4$ buffering system was used.

\subsection{S method development}

MS detection of derivatized BHPs, in general, has been done by using positive ion A PCl combined with ion trap M S² (Talbot et al. 2003a,b, 2007a,b). For nonderivatized BHPs, Talbot et al. (2016) employed APCI combined with MRM using a triple quadrupole MS. Here we explored the use of positive ion ESI combined with a quadrupole-Orbitrap MS for untargeted detection and identification of BHPs with data dependent $M S^{2}$ analysis using HRMS, similar to the approach that has successfully been applied to the analysis of IPLs (M oore et al., 2016; Besseling et al., 2018; Bale et al., 2019). For non-targeted IPL analysis we apply a stepped collision energy of 15, 22.5 and 30 to produce informative and diagnostic spectra (e.g., Bale et al., 2018; Sollai et al., 2018). For relatively simple B HPs, such as B HT, BH pentol and $B H$ hexol, these settings resulted in good quality $\mathrm{M} \mathrm{S}^{2}$ spectra, but especially for $\mathrm{N}$-containing B H Ps such as aminotriol and -tetrol it gave insufficient fragmentation to obtain an informative $\mathrm{M} \mathrm{S}^{2}$ spectrum. Tal bot et al. (2016) al so reported the necessity for a higher fragmentation energy for the $\mathrm{N}$-containing BHPS. However, exploring 
this option led to the $\mathrm{MS}^{2}$ spectra of non $\mathrm{N}$-containing BHPs having too much fragmentation, and thus loss of information on the structure of the side chains. $A$ workable compromise was achieved by using a stepped collision energy of 22.5 and 40 , resulting in $\mathrm{M} \mathrm{S}^{2}$ spectra with diagnostic losses for the different possible functional groups in the tail and diagnostic fragmentation for the hopanoid core. All fragmentation spectra discussed below were produced using these settings.

\subsection{Commonly detected BHPs in various microorganisms}

Tal bot et al. (2016) reported M S² spectra under various fragmentation conditions for non-derivatized $\mathrm{BHT}$. However, no spectra were reported for methylated BHTs, unsaturated BHTs or BHpentol and BHhexol. To establish the chromatographic behavior and fragmentation of various BHPS we analyzed biomass of several known BHP producers.

\subsubsection{Bacteriohopanetetrols}

Biomass of $\mathrm{K}$. xylinus, which has been reported to produce multiple (3M e)B HT isomers with up to two unsaturations at $\Delta^{6}$ and/or $\Delta^{11}$ (Peisler and Rohmer,1992, Tal bot et al., 2007b), was analyzed to study the various isomers and homologues of BHT. Schwartz-Narbonne et al. (2020) already showed the separation of different stereoisomers of non-derivatized BHTs (i.e., BHT-34S, BHT-34R and $B H T-x)$ using the method described here. A nalysis of biomass of $K$. xylinus provided further evidence that various stereoisomers of BHT are (partially) separated under the U HPLC conditions in this study (Fig. 1). Table S1 lists all BHPs discussed below and provides details on preferred ionization, in-source fragmentation and diagnostic fragments.

The summed mass chromatogram of the calculated exact masses of the protonated $\left([\mathrm{M}+\mathrm{H}]^{+}\right)$, ammoniated $\left(\left[\mathrm{M}+\mathrm{NH}_{4}\right]^{+}\right)$and sodiated molecules $\left([\mathrm{M}+\mathrm{Na}]^{+}\right)$of $\mathrm{BHT}(\mathrm{m} / \mathrm{z} 547.472, \mathrm{~m} / \mathrm{z} 564.499, \mathrm{~m} / \mathrm{z} 569.454$, respectively) revealed the presence of multiple isomers of $\mathrm{BHT}$ (Fig. 1A). The two peaks at 20.8 and $21.1 \mathrm{~min}$ (peaks $b$ and $c$ ) match the retention time for BHT with the 22R,34S and 22R,34R stereochemistry, respectively, as established by SchwarzNarbonne et al. (2020). The most abundant isomer of BHT (i.e., labeled a), eluting early at $19.3 \mathrm{~min}$, may be B HT-22S,34S, which was reported in relatively high abundance (13\% of all BHTs) in K. xylinus by Peiseler and R ohmer (1992). In addition to these abundant isomers, there are several isomers present at trace levels (not visible at the scale of Fig. 1) eluting after both the early eluting BHT isomer and the BHT-22R,34S/R. 






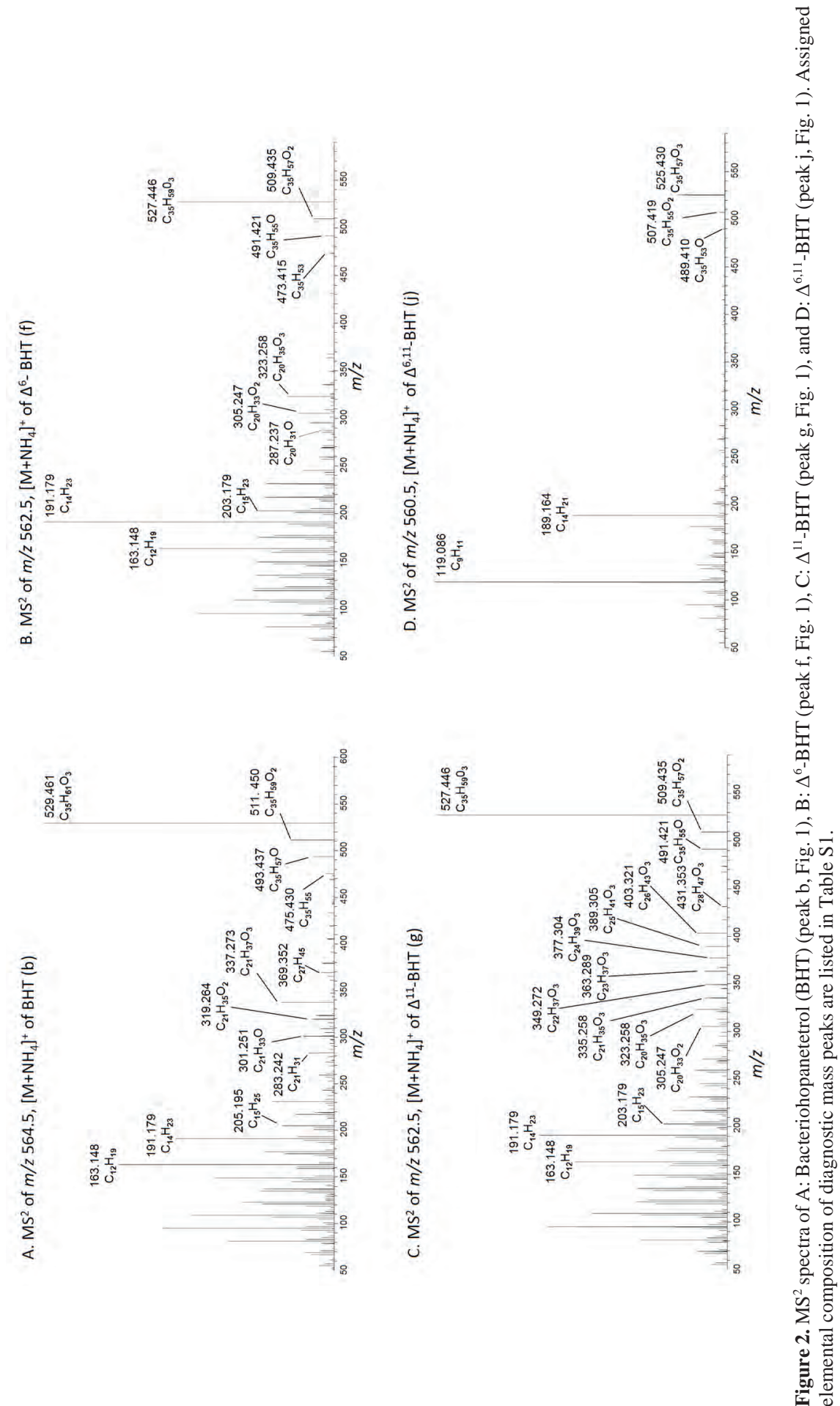
All the BHT isomers described above had similar $\mathrm{MS}^{2}$ spectra, therefore we only discuss the $\mathrm{M} \mathrm{S}^{2}$ spectrum of BHT-22R,34S (peak b, Fig. 2A), obtained from the ammoniated molecule ( $\mathrm{m} / \mathrm{z} 564.5)$. The $\mathrm{M} \mathrm{S}^{2}$ spectrum obtained here is similar to that reported by Talbot et al. (2016) for non-derivatized BHT upon $M^{2}$ fragmentation of $\mathrm{m} / \mathrm{z} 529$ (formed after in source loss of $\mathrm{H}_{2} \mathrm{O}$ from protonated BHT $\left.\left(\left[\mathrm{M}+\mathrm{H}-\mathrm{H}_{2} \mathrm{O}\right]^{+}\right)\right)$. Here, $\mathrm{m} / \mathrm{z} 529.461\left(\mathrm{C}_{35} \mathrm{H}_{61} \mathrm{O}_{3}{ }^{+}, \Delta \mathrm{ppm}-0.65\right)$ is the base peak. Fragment ions at $\mathrm{m} / \mathrm{z} 511.450\left(\mathrm{C}_{35} \mathrm{H}_{59} \mathrm{O}_{2}{ }^{+}, \Delta \mathrm{ppm}-1.56\right), \mathrm{m} / \mathrm{z}$ $493.437\left(\mathrm{C}_{35} \mathrm{H}_{57} \mathrm{O}^{+}, \Delta \mathrm{ppm}-6.73\right)$, and $\mathrm{m} / \mathrm{z} 475.430\left(\mathrm{C}_{35} \mathrm{H}_{55}{ }^{+}, \Delta \mathrm{ppm}-0.80\right)$ represent consecutive losses of hydroxyl moieties as $\mathrm{H}_{2} \mathrm{O}$ (see Table $\mathrm{S} 1$ for assigned elemental composition (AEC) of fragments). In the lower mass range, $\mathrm{m} / \mathrm{z} 163.148\left(\mathrm{C}_{12} \mathrm{H}_{19}{ }^{+}, \Delta \mathrm{ppm}-0.17\right)$ is the dominant fragment, but the universal diagnostic fragment ion for hopanoids (m/z 191.179, $\left.\mathrm{C}_{14} \mathrm{H}_{23}{ }^{+}, \Delta \mathrm{ppm}-0.56\right)$ (Peters and Moldowan, 1993) is clearly present and more dominant than observed in the spectrum of Talbot et al. (2016). U nlike electron ionization (EI) fragmentation, collision-induced dissociation (CID) fragmentation typically does not produce radicals but one protonated fragment and a neutral. Any cleavage results in proton rearrangements and the formation of a double bond equivalent in one of the two fragments (for discussed fragmentation pathways and fragments, see Fig. 3). In case of BHT, the $\mathrm{m} / \mathrm{z} 191$ fragment represents the protonated $A$ and $B$ ring of the hopanoid structure with 2 double bonds (unlike the structure proposed by Talbot et al. (2003b)), generated by the double cleavage at C-9/C-11 and C-8/C-14 following fragmentation pathway $A$. Additional diagnostic fragments are found at $\mathrm{m} / \mathrm{z} 369.352$ (complete hopanoid ring system after loss of side chain; $\mathrm{C}_{27} \mathrm{H}_{45}{ }^{+}, \Delta \mathrm{ppm}-0.21$ ) and at $\mathrm{m} / \mathrm{z} 283.242$ $\left(\mathrm{C}_{21} \mathrm{H}_{31}{ }^{+}, \Delta \mathrm{ppm}-1.58\right), \mathrm{m} / \mathrm{z} 301.251\left(\mathrm{C}_{21} \mathrm{H}_{33} \mathrm{O}^{+}, \Delta \mathrm{ppm}-3.63\right), 319.264$ $\left(\mathrm{C}_{21} \mathrm{H}_{35} \mathrm{O}_{2}{ }^{+}, \Delta\right.$ ppm 3.52), and $337.273\left(\mathrm{C}_{21} \mathrm{H}_{37} \mathrm{O}_{3}+, \Delta\right.$ ppm -1.19). These latter $C_{21}$ fragments are complementary to the fragment at $\mathrm{m} / \mathrm{z} 191$ and represent the $D$ and $\mathrm{E}$ rings and side chain with 0 to 3 alcohol moieties remaining (fragmentation A', Fig. 3). Talbot et al. (2003a,b) observed the equivalent fragments for acetylated BHT.

\subsubsection{M ethylated BHTs}

The distribution of the $3 \mathrm{MeBHTs}$ in $\mathrm{K}$. xylinus in general followed the distribution of the BHTs and they elute roughly $2 \mathrm{~min}$ after their BHTcounterparts but were $c a$. an order of magnitude less abundant. Two isomers of $3 \mathrm{M} \mathrm{eBHT}$ were detected (peaks k and I, Fig. 1D) and based on their relative retention time were identified as 3M eBHT-22R,34S and 3M eB HT-22R,34R, 
respectively. Peiseler and Rohmer (1992) reported only the 3M eBHT-22R,34S in $K$. xylinus, but did observe the $22 R, 34 R$ stereoisomer in the acetic acid bacterium A. pasteurianus. The $M S^{2}$ spectra (Fig. S2A) showed the expected offset of $+14 \mathrm{Da}$ in the fragments containing the $\mathrm{A}$ ring with the methylation ( e.g., m/z $177.164\left(\mathrm{C}_{13} \mathrm{H}_{21}{ }^{+}, \Delta \mathrm{ppm}-0.55\right), \mathrm{m} / \mathrm{z} 205\left(\mathrm{C}_{15} \mathrm{H}_{25}{ }^{+}, \Delta \mathrm{ppm}-0.33\right), \mathrm{m} / \mathrm{z}$ $219\left(\mathrm{C}_{16} \mathrm{H}_{27}{ }^{+}, \Delta \mathrm{ppm}-0.40\right)$ and $\mathrm{m} / \mathrm{z} 383\left(\mathrm{C}_{28} \mathrm{H}_{47}, \Delta \mathrm{ppm} 1.52\right)$, while fragments related to the $D$ and $E$ rings with side chain did not show the offset ( e.g., $\mathrm{m} / \mathrm{z}$ $283.242\left(\mathrm{C}_{21} \mathrm{H}_{31}{ }^{+}, \Delta \mathrm{ppm} 1.21\right), \mathrm{m} / \mathrm{z} 301.253\left(\mathrm{C}_{21} \mathrm{H}_{35} \mathrm{O}_{2}{ }^{+}, \Delta \mathrm{ppm} 1.86\right), \mathrm{m} / \mathrm{z}$ $319.263\left(\mathrm{C}_{21} \mathrm{H}_{35} \mathrm{O}_{2}{ }^{+}, \Delta\right.$ ppm 0.48), $\mathrm{m} / \mathrm{z} 337.274\left(\mathrm{C}_{21} \mathrm{H}_{37} \mathrm{O}_{3}{ }^{+}, \Delta \mathrm{ppm}-0.54\right)$.

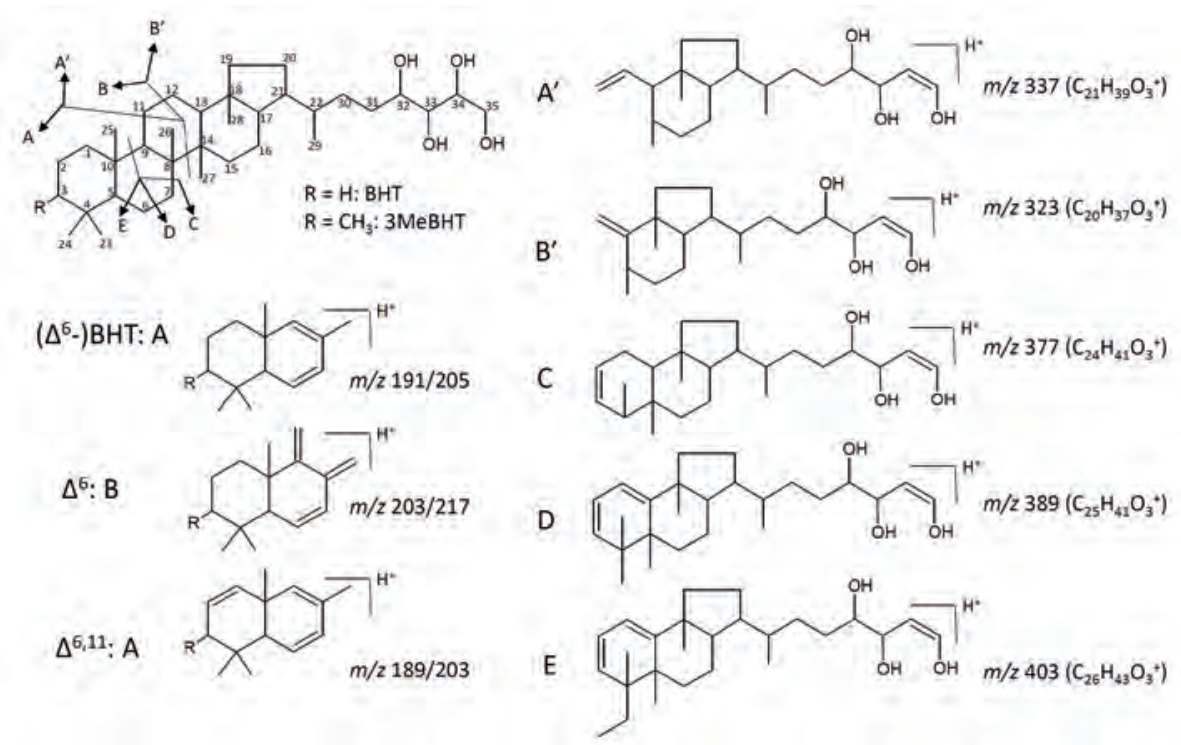

Figure 3. Fragmentation pathways and structures for proposed diagnostic fragments after collision induced fragmentation for $\mathrm{BHT}, \Delta^{6}-\mathrm{BHT}, \Delta^{11}-\mathrm{BHT}, \Delta^{6},{ }^{11}-\mathrm{BHT}$, and their $3 \mathrm{M}$ e-counterparts.

\subsubsection{Unsaturated BHTs}

We al so detected several isomers of unsaturated BHTs in biomass of $K$. xylinus (Fig. 1B). The summed mass chromatogram of the calculated exact masses of the protonated, ammoniated, and sodiated molecules of unsaturated BHT $(\mathrm{m} / \mathrm{z}$ $545.456+562.483+567.438$ ) showed 2 main peaks at 18.5 and 18.7 min (e and f), as well as a minor early eluting isomer at $17.8 \mathrm{~min}$ (d) and a pair of late eluting isomers at 19.5 and $19.6 \mathrm{~min}$ ( $\mathrm{g}$ and $\mathrm{h}$ ). Peiseler and Rohmer (1992) reported two isomers of $\Delta^{6}$-BHT $(22 R, 34 S$ and $22 R, 34 R)$ in relatively high abundance in $K$. xylinus ( 20 and $36 \%$ respectively of total $B H T s$ ). Based on this distribution it is likely that peaks e and f represent $\Delta^{6}-B H T-22 R, 34 S$ and $\Delta^{6}-B H T-22 R, 34 R$, 
respectively. The $M^{2}$ spectra of the ammoniated molecules $(\mathrm{m} / \mathrm{z} 562.5)$ associated with peaks e and f (e.g., Fig. 2B) are almost identical. The H PLC-M S ${ }^{2}$ analysis of acetylated unsaturated BHTs was extensively discussed by Talbot et al. (2007b), but not for non-derivatized BHTs (Talbot et al. 2016). The unsaturation in $\Delta^{6}$ - $\mathrm{BHT}-22 \mathrm{R}, 34 \mathrm{R}$ (peak $\mathrm{f}, \mathrm{Fig} .2 \mathrm{~B}$ ) is clearly observed in several fragments formed after consecutive losses of $\mathrm{H}_{2} \mathrm{O}$ from the side chain, that are offset by $2 \mathrm{Da}$ from the spectrum of $\mathrm{BHT}$, e.g., $\mathrm{m} / 2527.466\left(\mathrm{C}_{35} \mathrm{H}_{59} \mathrm{O}_{3}{ }^{+}, \Delta \mathrm{ppm}\right.$ -0.36), 509. $435\left(\mathrm{C}_{35} \mathrm{H}_{57} \mathrm{O}_{2}{ }^{+}, \Delta \mathrm{ppm}-0.37\right), 491.421\left(\mathrm{C}_{35} \mathrm{H}_{55} \mathrm{O}^{+}, \Delta \mathrm{ppm}-6.76\right)$ and $473.415\left(\mathrm{C}_{35} \mathrm{H}_{53}{ }^{+}, \Delta \mathrm{ppm} 1.88\right)$. Interestingly, and similar as described by Talbot et al. (2007), no such offset is observed in the diagnostic fragment ion at $\mathrm{m} / \mathrm{z}$ $191.179\left(\mathrm{C}_{14} \mathrm{H}_{23}{ }^{+}, \Delta \mathrm{ppm}-0.88\right)$. W hile in case of $\mathrm{BHT}$ the fragment at $\mathrm{m} / \mathrm{z} 191$ is produced by cleavage at $\mathrm{C}-9 / \mathrm{C}-11$ and $\mathrm{C}-8 / \mathrm{C}-14$ and a proton rearrangement resulting in 2 double bonds in the $A$ and $B$ Ring fragment (as discussed above), it appears that the presence of a pre-existing double bond at $\Delta^{6}$ results in an alternative proton rearrangement: only one additional double bond is formed in the $A$ and $B$ ring fragment, thus generating the $\mathrm{m} / \mathrm{z} 191$ also seen in $B H T$, and the other double bond is formed in the neutral loss fragment (fragmentation $A$, Fig. 3). Talbot et al. (2007b) also observed evidence for an alternative fragmentation pathway in acetylated $\Delta^{6}-\mathrm{B} H \mathrm{H}$, with cleavage of the $\mathrm{C}-11 / \mathrm{C}-12$ and $\mathrm{C}-8 / \mathrm{C}-14$ bonds (pathway $\mathrm{B}, \mathrm{Fig} .3$ ). W ith proton rearrangement to form two additional double bonds on the $A$ and $B$ ring fragment this fragmentation would produce the here observed $\mathrm{m} / \mathrm{z} 203.179\left(\mathrm{C}_{15} \mathrm{H}_{23}{ }^{+}, \Delta\right.$ ppm -0.233; Fig. 3). A complementary series of $\mathrm{C}_{20}$ fragments with 1 to 3 hydroxyl moieties are observed at $\mathrm{m} / \mathrm{z} 287.237\left(\mathrm{C}_{20} \mathrm{H}_{31} \mathrm{O}^{+}, \Delta \mathrm{ppm} 0.41\right), 305.247\left(\mathrm{C}_{20} \mathrm{H}_{33} \mathrm{O}_{2}{ }^{+}, \Delta \mathrm{ppm}-\right.$ $0.42)$ and $323.258\left(\mathrm{C}_{20} \mathrm{H}_{35} \mathrm{O}_{3}{ }^{+}, \Delta \mathrm{ppm}-0.44\right)$ and represent the $\mathrm{D}$ and $\mathrm{E}$ rings with the (partially dehydroxylated) side chain. The $\mathrm{MS}^{2}$ spectrum of the early eluting isomer (d) is almost identical to those of peaks e and $\mathrm{f}$. Based on this similarity in spectra and the off-set in retention time between the 22S,34R and 22R,34R isomers observed for $\mathrm{BHT}$, we tentatively identify the early eluting isomer (d) as the $22 \mathrm{~S}, 34 \mathrm{~S}$ isomer of $\Delta^{6}-\mathrm{BHT}$.

The $\mathrm{M} \mathrm{S}^{2}$ spectra of peaks $g$ and $\mathrm{h}$ (Fig. 1B) are largely similar to those of peaks $d-f$, however there are some notable differences in the middle mass range (Fig. $2 \mathrm{C}$ ), which shows a series of $\mathrm{C}_{20}$ to $\mathrm{C}_{28}$ fragments with up to 3 alcohol moieties. It is possible that the presence of a double bond in the $C$ ring leads to a multitude of alternative fragmentation pathways involving the $A$ and $B$ rings. For example, the larger fragments $\left(>C_{24}\right)$ appear to originate from cleavage of the $\mathrm{C}-9 / \mathrm{C}-10$ bond in combination with cleavage at $\mathrm{C}-5 / \mathrm{C}-6, \mathrm{C}-6 / \mathrm{C}-7$, or $\mathrm{C}-7 / \mathrm{C}$ - 
8 (Fig. 3, pathways $C, D, E$ ). We, therefore, tentatively identify peaks $g$ and $h$ as $\Delta^{11}$ - B HT-22R,34S and $\Delta^{11}-B H T-22 R, 34 R$. Peiseler and Rohmer (1992) did not report $\Delta^{11}$-BHT in $K$. xylinus, although two isomers of $\Delta^{11}$-3M eBHT were reported in that culture.

The summed mass chromatogram revealing the distribution of diunsaturated B HTs (Fig. 1C) shows two main peaks at 17.5 and 17.7 min (peaks $i$ and j), most likely the $34 \mathrm{~S}$ and $34 \mathrm{R}$ stereoisomers of $\Delta^{6,11}$-BHT as described by Peiseler and Rohmer (1992). MS $^{2}$ spectra of the ammoniated molecule of diunsaturated BHTs (m/z 560.5, Fig. 2D) reveal double unsaturations in the fragments that result from the loss of hydroxyl moieties from the side chain ( e.g., $\mathrm{m} / \mathrm{z} 525.430\left(\mathrm{C}_{35} \mathrm{H}_{57} \mathrm{O}_{3}{ }^{+}, \Delta \mathrm{ppm} 0.03\right), \mathrm{m} / \mathrm{z} 507.419\left(\mathrm{C}_{35} \mathrm{H}_{55} \mathrm{O}_{2}{ }^{+}, \Delta \mathrm{ppm}-\right.$ $0.98)$, and $\mathrm{m} / \mathrm{z} 489.410\left(\mathrm{C}_{35} \mathrm{H}_{53} \mathrm{O}^{+}, \Delta \mathrm{ppm} \mathrm{1.61)}\right)$. However, the $\mathrm{M} \mathrm{S}^{2}$ is dominated by fragments at $\mathrm{m} / \mathrm{z} 119.086\left(\mathrm{C}_{9} \mathrm{H}_{11}{ }^{+}, \Delta \mathrm{ppm} 0.03\right)$ and $\mathrm{m} / \mathrm{z} 189.164\left(\mathrm{C}_{14} \mathrm{H}_{21}{ }^{+}, \Delta\right.$ ppm -0.36), similar to what was observed by Talbot et al. (2007b) for $M^{2}$ spectra of acetylated di-unsaturated BHT. Rohmer and Ourisson (1986) attributed a fragment at $\mathrm{m} / \mathrm{z} 119$, formed after EI from both $\Delta^{6}$ - and $\Delta^{6,11}$-BHPS, to the B-ring and assigned a trimethylbenzene structure. However, a trimethylbenzene would yield, if protonated, a fragment at $\mathrm{m} / \mathrm{z} 121\left(\mathrm{C}_{9} \mathrm{H}_{13}{ }^{+}\right)$and thus is seems the fragment at $\mathrm{m} / \mathrm{z} 119$ formed upon CID fragmentation, represents a different, and as yet unknown, fragment. The fragment at $\mathrm{m} / \mathrm{z} 189$ likely represents the $A$ and $B$ rings. Although formation of an $A$ and $B$ ring fragment with 3 double bonds does not appear to be favored in case of a $\Delta^{6}$. unsaturation, an additional unsaturation at $\Delta^{11}$ apparently forces this proton rearrangement, thus producing a fragment at $\mathrm{m} / \mathrm{z} 189$ (pathway A, Fig. 3). It is therefore important to recognize that with $\mathrm{CID}, \mathrm{m} / \mathrm{z} 189$ is not diagnostic for a $\Delta^{6}$-unsaturation (as is the case with El fragmentation), but instead indicates a $\Delta^{6,11}$-unsaturation. The fragments in the middle mass range in the $\mathrm{MS}^{2}$ spectrum of the di-unsaturated $\mathrm{BHT}$ are less abundant $(<1 \%)$, with minor fragments representing cleavages at C $9-\mathrm{C} 11$ (pathway A, Fig. 3) and C-11/C-12 (pathway B, Fig. 3) both present.

\subsubsection{U nsaturated methylated BHTs}

The summed mass chromatogram for the unsaturated $3 \mathrm{M} \mathrm{eBHT}$ showed two pairs of peaks at 20.0 and 20.2 min (peaks $\mathrm{m}$ and $\mathrm{n}$ ) and at 21.2 and $21.4 \mathrm{~min}$ (peaks 0 and p) (Fig. 1E). The M S ${ }^{2}$ spectra of peaks $m$ and $n$ (Fig. S2b) showed very similar fragmentation to the $\Delta^{6}$-unsaturated $B H T s$, with the expected +14 $\mathrm{Da}$ offsets in the $A$ and $B$ ring fragments. The fragments in the middle mass 
range were largely absent. The spectra of peaks 0 and $p$ (Fig. S2c) showed the same series of $C_{20}$ to $C_{26}$ fragments as observed for the two unsaturated $B H T$ peaks $(\mathrm{g}$ and $\mathrm{h})$ designated as $\Delta^{11}$. B ased on the relative retention times and similarities of their spectra to the unsaturated BHTs we identify these peaks as (m) $\Delta^{6}-3 \mathrm{M} \mathrm{eBHT}-22 \mathrm{R}, 34 \mathrm{~S}$, (n) $\Delta^{6}-3 \mathrm{M}$ eB HT-22R,34R, (o) $\Delta^{11}-3 \mathrm{M}$ eB HT$22 R, 34 S$, and (p) $\Delta^{11}-3 M$ eBHT-22R,34R. All but $\Delta^{11}-3 M$ eB HT-22R,34R were also reported by Peiseler and Rohmer (1992) in K. xylinus.

We also detected two isomers of di-unsaturated 3M e-B HT at 19.00 and 19.12 min (Fig. 1F, peaks q and r). Peiseler and Rohmer (1992) also detected two isomers of $\Delta^{6,11}-3 \mathrm{M} \mathrm{eBHT}$ in $\mathrm{K}$. xylinus, differing in stereochemistry at the $C-34$. B ased on this and the relative retention times we identify peaks $q$ and $r$ as $\Delta^{6,11}-3 \mathrm{M} \mathrm{eBHT}-22 \mathrm{R}, 34 \mathrm{~S}$ and $\Delta^{6,11}-3 \mathrm{M}$ eBHT-22R,34R, respectively. The observed fragmentation spectrum (Fig. S2d) closely matched those of $\Delta^{6,11}-B H T$. It is noteworthy that the fragment at $\mathrm{m} / \mathrm{z} 203$ (analogous to $\mathrm{m} / \mathrm{z} 189$ in the $\mathrm{M} \mathrm{S}^{2}$ spectrum of $\Delta^{6,11}$-BHT) is diagnostic for a di-unsaturated $M$ eBHT and not for $\Delta^{6}-\mathrm{MeBHT}$ as is the case with El ionization. However, the $\mathrm{m} / \mathrm{z} 203$ fragment alone is not sufficient to identify a $\Delta^{6,11}-\mathrm{M}$ eB HT as a fragment with identical $\mathrm{m} / \mathrm{z}$ is al so present in the fragmentation spectrum of $\Delta^{6}-\mathrm{BHT}$, al though it is generated via a different fragmentation pathway.

\subsubsection{Bacteriohopanepentols and -hexols}

In order to establish elution and fragmentation patterns for bacteriohopanepentol and -hexol (BHpentol and BHhexol, respectively), as well as their $3 \mathrm{Me}$ homologues, we analyzed an extract of Ca. 'M . oxyfera' (K ool et al., 2014). Fig. $4 \mathrm{~A}$ shows summed mass chromatograms revealing the presence of BHT (peak a), BH pentol (peak b) and BHhexol (peak c) and their methylated analogues (peaks $d, e$, and f). The B H Ps el ute in reversed order of number of hydroxylations on the side chain. Whereas ammoniation is the preferred ionization for $\mathrm{BHT}$, the balance shifts towards protonation for BHhexol (Table S1). Fig. 4D shows the $M^{2}$ spectra of the protonated molecule $\left([\mathrm{M}+\mathrm{H}]^{+}\right)$of $B H$ hexol. The observed fragmentation pattern is comparable to the one described above for $\mathrm{BHT}$, with major fragments representing losses of 1 to 5 hydroxyl moieties at $\mathrm{m} / \mathrm{z} 561.451$ $\left(\mathrm{C}_{35} \mathrm{H}_{61} \mathrm{O}_{5}{ }^{+}, \Delta \mathrm{ppm}-0.86\right), 543.441\left(\mathrm{C}_{35} \mathrm{H}_{59} \mathrm{O}_{4}{ }^{+}, \Delta \mathrm{ppm}-0.14\right), 525.431$ $\left(\mathrm{C}_{35} \mathrm{H}_{57} \mathrm{O}_{3}{ }^{+}, \Delta \mathrm{ppm} 1.65\right), 507.421\left(\mathrm{C}_{35} \mathrm{H}_{55} \mathrm{O}_{2}{ }^{+}, \Delta \mathrm{ppm} 0.16\right)$, and 489.406 $\left(\mathrm{C}_{35} \mathrm{H}_{53} \mathrm{O}^{+}, \Delta \mathrm{ppm}-6.65\right)$, respectively. The base peak is the diagnostic ion for BHPs at $\mathrm{m} / \mathrm{z} 191.179\left(\mathrm{C}_{14} \mathrm{H}_{23}{ }^{+}, \Delta \mathrm{ppm}-1.50\right)$. The fragment at $\mathrm{m} / \mathrm{z} 369.353$ $\left(\mathrm{C}_{29} \mathrm{H}_{49}{ }^{+}, \Delta \mathrm{ppm}-2.51\right)$ representing the ring system after loss of the side chain is only present in very low abundance $(<5 \%)$, but instead a fragment at $\mathrm{m} / \mathrm{z}$ 
$397.383\left(\mathrm{C}_{29} \mathrm{H}_{49}{ }^{+}, \Delta \mathrm{ppm} 0.31\right)$ is formed with the cleavage apparently occurring at the $\mathrm{C}-22 / \mathrm{C}-30$ bond. Similar to what was observed for $\mathrm{BHT}$, we observe several fragments at $\mathrm{m} / \mathrm{z} 297.222\left(\mathrm{C}_{21} \mathrm{H}_{29} \mathrm{O}, \Delta \mathrm{ppm} 3.56\right), \mathrm{m} / \mathrm{z} 315.233\left(\mathrm{C}_{21} \mathrm{H}_{31} \mathrm{O}_{2}\right.$, $\Delta$ ppm 2.96), m/z $333.243\left(\mathrm{C}_{21} \mathrm{H}_{33} \mathrm{O}_{3}, \Delta\right.$ ppm 1.59) and $\mathrm{m} / \mathrm{z} 351.253\left(\mathrm{C}_{21} \mathrm{H}_{35} \mathrm{O}_{4}\right.$, $\Delta$ ppm -0.33), which based on their assigned elemental composition, appear to be complimentary to the ion at $\mathrm{m} / \mathrm{z} 191$ ( $A$ and $B$ ring) and represent the remainder of the ring system and the side chain with 0 to 4 hydroxyl moieties.

The $\mathrm{MS}^{2}$ spectrum of the ammoniated molecule for $\mathrm{BH}$ pentol (Fig. 4B) shows the same characteristics as discussed for BHT and BHhexol. $3 \mathrm{M} \mathrm{eBH}$ pentol and $3 \mathrm{M} \mathrm{eBH}$ hexol elute ca. 2 min after and fragment similarly to their non-methylated counterparts, generating a.o. the diagnostic fragment at $\mathrm{m} / \mathrm{z}$ 205 and with all ions containing the A-ring shifted by +14 Da (see Fig. S2 for mass spectra).

\subsubsection{Aminobacteriohopanepolyols}

$M$ ass chromatograms of the protonated molecules of aminotriol, -tetrol, and pentol (Fig. 5A; peaks a, b, $c$, and $d$, respectively), as well as their $3 \mathrm{Me}$ counterparts ( $F$ ig. $5 B$; peaks e, $f$, and $g$, respectively) show their distribution in M. capsulatus, a well-studied producer of these aminoB HPs (e.g., Neunlist and Rohmer, 1985; Talbot et al., 2001). As expected, the aminoBHPs elute in reversed order of the number of functional groups. The $3 \mathrm{M} \mathrm{e-aminoBHPs}$ elute ca. 1 to $2.5 \mathrm{~min}$ after their corresponding non-methylated counterparts (see Table S1 for exact retention times). Fig. 5A shows a partially resolved, late-eluting isomer of aminotetrol (peak c). A lthough Talbot et al. (2001) observed a late eluting isomer to aminotetrol in Methylocystis parvus, it has to the best of our knowledge not been observed in M. capsulatus.

Talbot et al. (2016) discussed the fragmentation characteristics of nonderivatized aminotriol only and, based on those observations, predicted suitable M RM target ions for (3M e)aminotetrol and (3M e)aminopentol. Here we show $M^{2}$ spectra of aminopentol (Fig. 5C) and 3Me-aminopentol (Fig. 5D) (additional spectra for the aminotriols and -tetrols are shown in Fig. S4; the late eluting isomer of aminotetrol shows similar fragmentation as the main isomer). As was observed by Talbot et al. (2003a) for acetylated aminotriol and Talbot et al. (2016) for non-derivatized aminotriol, fragmentation of the amino-B H Ps only occurs with increased collision voltage. Under the conditions used here, i.e., with a stepped collision energy, fragmentation was still limited, but yielded sufficient diagnostic features for positive identification of the full series of aminoB HPs. 

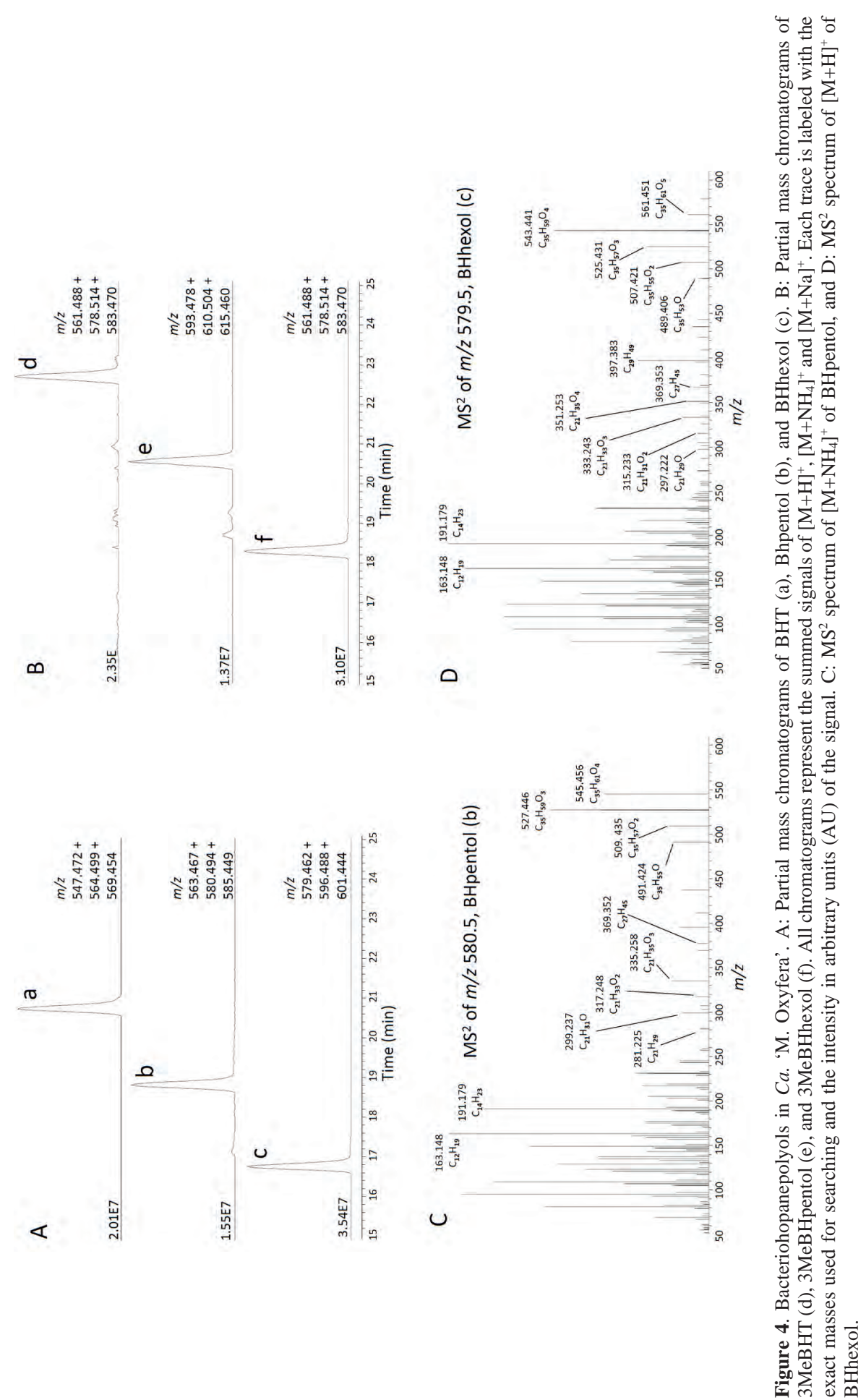


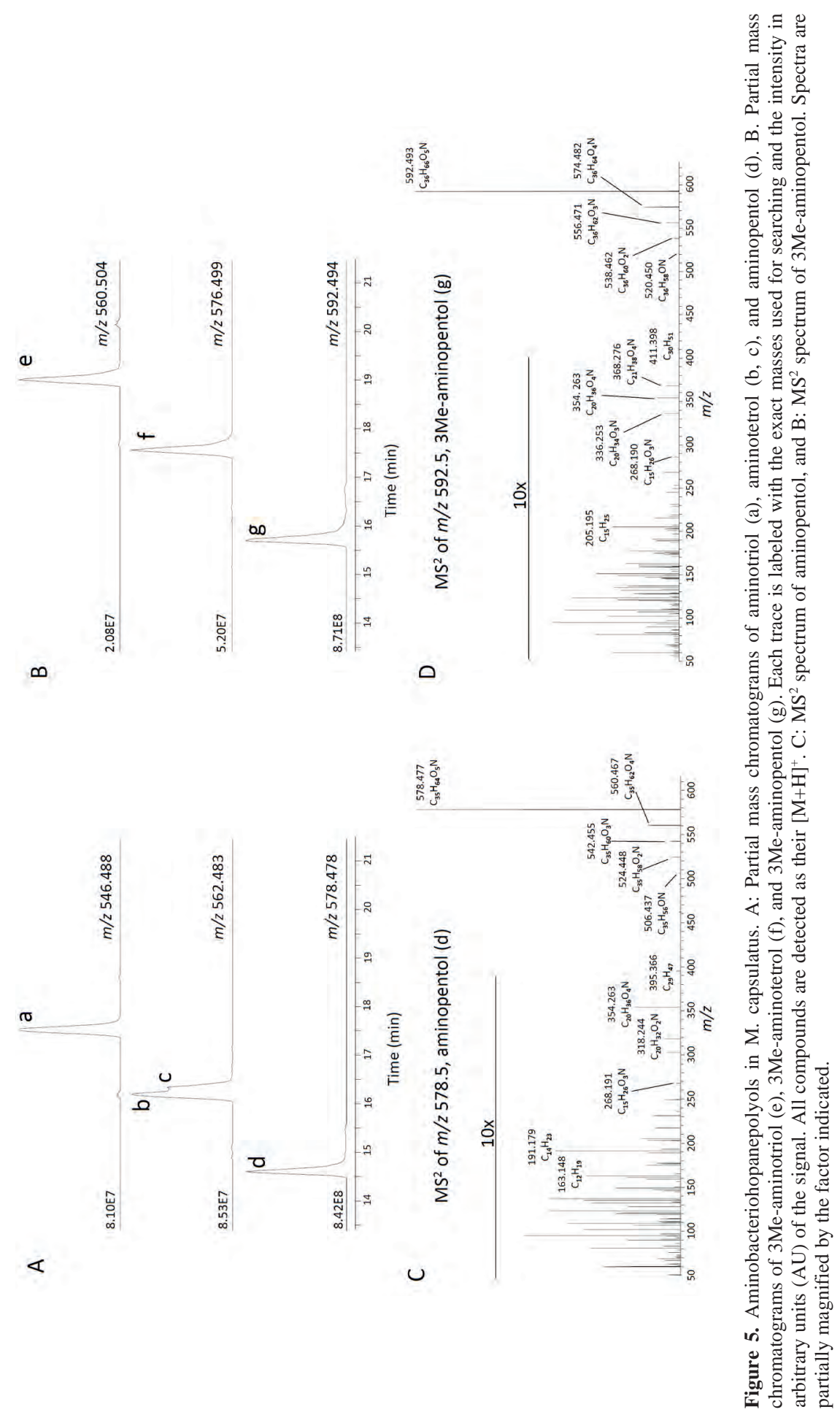


As is the case with the previous discussed BHPs, the alcohol moieties in the side chain are readily lost as $\mathrm{H}_{2} \mathrm{O}$, yielding a series of fragments at $\mathrm{m} / \mathrm{z}$ $506.437\left(\mathrm{C}_{35} \mathrm{H}_{62} \mathrm{O}_{4}{ }^{+}, \Delta \mathrm{ppm} 2.19\right), \mathrm{m} / \mathrm{z} 524.448\left(\mathrm{C}_{35} \mathrm{H}_{58} \mathrm{O}_{2} \mathrm{~N}^{+}, \Delta \mathrm{ppm} 0.48\right), \mathrm{m} / \mathrm{z}$ $542.455\left(\mathrm{C}_{35} \mathrm{H}_{60} \mathrm{O}_{3} \mathrm{~N}^{+}, \Delta \mathrm{ppm}-2.99\right)$, and $\mathrm{m} / \mathrm{z} 560.467\left(\mathrm{C}_{35} \mathrm{H}_{62} \mathrm{O}_{4} \mathrm{~N}^{+}, \Delta \mathrm{ppm} 0.65\right)$ for aminopentol and $\mathrm{m} / \mathrm{z} 520.450\left(\mathrm{C}_{36} \mathrm{H}_{58} \mathrm{ON}^{+}, \Delta \mathrm{ppm}-2.58\right), \mathrm{m} / \mathrm{z} 538.462$ $\left(\mathrm{C}_{36} \mathrm{H}_{60} \mathrm{O}_{2} \mathrm{~N}^{+}, \Delta\right.$ ppm -0.12), m/z $556.471\left(\mathrm{C}_{36} \mathrm{H}_{64} \mathrm{O}_{2} \mathrm{~N}^{+}, \Delta \mathrm{ppm}-1.98\right)$, and $\mathrm{m} / \mathrm{z}$ $574.482\left(\mathrm{C}_{36} \mathrm{H}_{66} \mathrm{O}_{4} \mathrm{~N}^{+}, \Delta \mathrm{ppm}-1.09\right)$ for $3 \mathrm{M}$ e-aminopentol. In the lower mass range the diagnostic fragments at $\mathrm{m} / \mathrm{z} 191.179\left(\mathrm{C}_{14} \mathrm{H}_{23}{ }^{+}, \Delta \mathrm{ppm}-3.75\right)$ for BHPs and $\mathrm{m} / \mathrm{z} 205.195\left(\mathrm{C}_{15} \mathrm{H}_{25}{ }^{+}, \Delta \mathrm{ppm}-1.40\right)$ for M eB HPs are relatively abundant. In addition, there are several $\mathrm{N}$-containing fragments in the mass range between $\mathrm{m} / \mathrm{z} 300$ and 400 (Figs. $5 C$ and D, Table S1) that represent the $D$ and $E$ rings with side chain, equivalent to the fragmentation observed for $\mathrm{BHPs}$ described above.

\subsection{Composite BH Ps}

3.4.1 Cyclitol ether bacteriohopanetetrol

BHT-CE is a commonly detected, so-called composite BHP (Talbot et al., 2007a). Composite B HPs consist of a linear functionalized side chain bound to a more complex, often polar moiety or head group. In case of B HT-CE, the B HT is ether bound to an amino sugar on the $\mathrm{C}-35$ position (Fig. 6B). Here we analyzed cell material of $\mathrm{Ca}$. 'Scalindua profunda', in which BHT-CE was previously detected by Rush et al. (2014), to establish elution and fragmentation of this B HP. Fig. 6 A shows the mass chromatogram for the $[\mathrm{M}+\mathrm{H}]^{+}$of $\mathrm{BHT}-\mathrm{CE}$ ( $\mathrm{m} / \mathrm{z}$ 708.541). Whereas R ush et al. (2014) detected 3 isomers of B HT-CE in Ca. 'S. profunda', eluting closely together, we detected 2 isomers (Fig. 6A, peak a and $b)$. Fig. $6 \mathrm{~B}$ shows the $\mathrm{M} \mathrm{S}^{2}$ spectrum of the most abundant isomer, peak $\mathrm{b}$. Talbot et al. (2016) also discussed the fragmentation of non-derivatized BHT$C E$, which is very similar to the fragmentation pattern observed here. Fragmentation is limited, but several fragments resulting from loss of up to three hydroxyl moieties are observed at $\mathrm{m} / \mathrm{z} 690.529\left(\mathrm{C}_{41} \mathrm{H}_{72} \mathrm{O}_{7} \mathrm{~N}^{+}, \Delta \mathrm{ppm}-1.32\right), \mathrm{m} / \mathrm{z}$ 672. $529\left(\mathrm{C}_{41} \mathrm{H}_{70} \mathrm{O}_{6} \mathrm{~N}^{+}, \Delta \mathrm{ppm}-0.65\right)$ and $\mathrm{m} / \mathrm{z} 654.508\left(\mathrm{C}_{41} \mathrm{H}_{68} \mathrm{O}_{5} \mathrm{~N}^{+}, \Delta \mathrm{ppm}-\right.$ 2.60). In the lower mass range several fragments representing the intact headgroup ( $\left.\mathrm{m} / \mathrm{z} 180.087\left(\mathrm{C}_{6} \mathrm{H}_{14} \mathrm{O}_{5} \mathrm{~N}^{+}, \Delta \mathrm{ppm}-0.72\right)\right)$ and the headgroup after loss of several alcohol moieties (m/z $162.076\left(\mathrm{C}_{6} \mathrm{H}_{12} \mathrm{O}_{4} \mathrm{~N}^{+}, \Delta \mathrm{ppm}-1.45\right), \mathrm{m} / \mathrm{z} 144.066$ $\left(\mathrm{C}_{6} \mathrm{H}_{10} \mathrm{O}_{3} \mathrm{~N}^{+}, \Delta\right.$ ppm -0.62) and $\left.\mathrm{m} / \mathrm{z} 126.065\left(\mathrm{C}_{6} \mathrm{H}_{8} \mathrm{O}_{2} \mathrm{~N}^{+}, \Delta \mathrm{ppm} 0.28\right)\right)$ are observed. Fragments at $\mathrm{m} / \mathrm{z} 222.097\left(\mathrm{C}_{8} \mathrm{H}_{16} \mathrm{O}_{6} \mathrm{~N}^{+}, \Delta \mathrm{ppm}-1.37\right)$ and $\mathrm{m} / \mathrm{z} 204.86$ $\left(\mathrm{C}_{8} \mathrm{H}_{14} \mathrm{O}_{5} \mathrm{~N}^{+}, \Delta \mathrm{ppm}-0.98\right)$ appear to consist of the headgroup with two additional carbons from the side chain after fragmentation at the $\mathrm{C}-33 / \mathrm{C}-34$ bond. 


\subsubsection{M ethylcarbamate-aminoBH Ps}

A more recently described series of composite BHPs are the methylcarbamateaminoBHPs (M C-aminoBHPs; Rush et al., 2016). Fig. 7A shows the series detected in $M$. vadi. The $\mathrm{MS}^{2}$ spectrum of $M C$-aminotriol (Fig. 7B; spectra of $\mathrm{MC}$-aminotetrol and - pentol are shown in Fig. S5) showed the predicted losses of up to 3 hydroxyl moieties as $\mathrm{H}_{2} \mathrm{O}$ generating ions at $\mathrm{m} / \mathrm{z} 586.483\left(\mathrm{C}_{37} \mathrm{H}_{64} \mathrm{O}_{4} \mathrm{~N}^{+}\right.$, $\Delta$ ppm -0.23), $568.474\left(\mathrm{C}_{37} \mathrm{H}_{62} \mathrm{O}_{3} \mathrm{~N}^{+}, \Delta\right.$ ppm 2.38), and $550.461\left(\mathrm{C}_{37} \mathrm{H}_{60} \mathrm{O}_{2} \mathrm{~N}^{+}, \Delta\right.$ ppm -2.99). A loss of $32 \mathrm{Da}\left(\mathrm{CH}_{3} \mathrm{OH}\right.$, representing the methoxy moiety) from the ion at $\mathrm{m} / \mathrm{z} 586$ to produce $\mathrm{m} / \mathrm{z} 554.456\left(\mathrm{C}_{36} \mathrm{H}_{60} \mathrm{O}_{3} \mathrm{~N}^{+}, \Delta \mathrm{ppm}-1.64\right)$ was also observed. Losses of 75 Dalton $\left(\mathrm{C}_{2} \mathrm{H}_{5} \mathrm{O}_{2} \mathrm{~N}\right)$, representing the methylcarbamate moiety, were observed from the mass peaks at $\mathrm{m} / \mathrm{z} 568$ or 550 leading to fragment ions at $\mathrm{m} / \mathrm{z} 493.438\left(\mathrm{C}_{35} \mathrm{H}_{57} \mathrm{O}^{+}, \Delta \mathrm{ppm}-4.81\right)$ and $\mathrm{m} / \mathrm{z} 475.430\left(\mathrm{C}_{35} \mathrm{H}_{55}, \Delta \mathrm{ppm}\right.$ 0.17). These losses were al so observed by $\mathrm{R}$ ush et al. (2016) after fragmentation of acetylated $\mathrm{M} \mathrm{C}$-aminoB HPs. $\mathrm{N}$-containing product ions were observed at $\mathrm{m} / \mathrm{z}$ $76.040\left(\mathrm{C}_{2} \mathrm{H}_{6} \mathrm{O}_{2} \mathrm{~N}^{+}, \Delta\right.$ ppm 9.40), $88.040\left(\mathrm{C}_{3} \mathrm{H}_{6} \mathrm{O}_{2} \mathrm{~N}^{+}, \Delta\right.$ ppm 5.85) and 118.050 $\left(\mathrm{C}_{4} \mathrm{H}_{8} \mathrm{O}_{3} \mathrm{~N}^{+}, \Delta\right.$ ppm 1.61) and likely represent the methylcarbamate moiety after fragmentation between the nitrogen and $\mathrm{C}-35$, at $\mathrm{C}-34 / \mathrm{C}-35$, and at $\mathrm{C}-33 / \mathrm{C}-34$, respectively.

\subsection{B HPs in a soil from a terrestrial methane seep}

To further examine the performance of the UHPLC-HRMS method for environmental samples with more complex matrices than biomass, we analyzed a soil from a terrestrial methane seep in Sicily (Censo $0 \mathrm{~m}$ ). A base peak chromatogram is shown in Fig. S6. We were able to detect several of the above discussed BHPs. All detected BHPs are listed in Table S2 and additional M S $^{2}$ spectra of BHPs that are not further discussed in the text are shown in supplemental figures. Here we will focus on the description of not previously discussed and new composite B HPs.

\subsubsection{AdenosylB HPS}

Adenosylhopanes occur ubiquitously in soils (Cooke et al., 2008a,b). Their occurrence and relative abundance have been used to trace soil organic matter during riverine transport and deposition into the marine environment (Zhu et al., 2011). Three types of adenosylhopanes have been described: type-1, -2 , and -3 (see Fig. 9A for general structure; Talbot et al., 2007a; Rethemeyer et al., 2010) of which only the polar head group of adenosylhopane type-1 has been fully identified (Neunlist and Rohmer, 1985) as adenosine. 

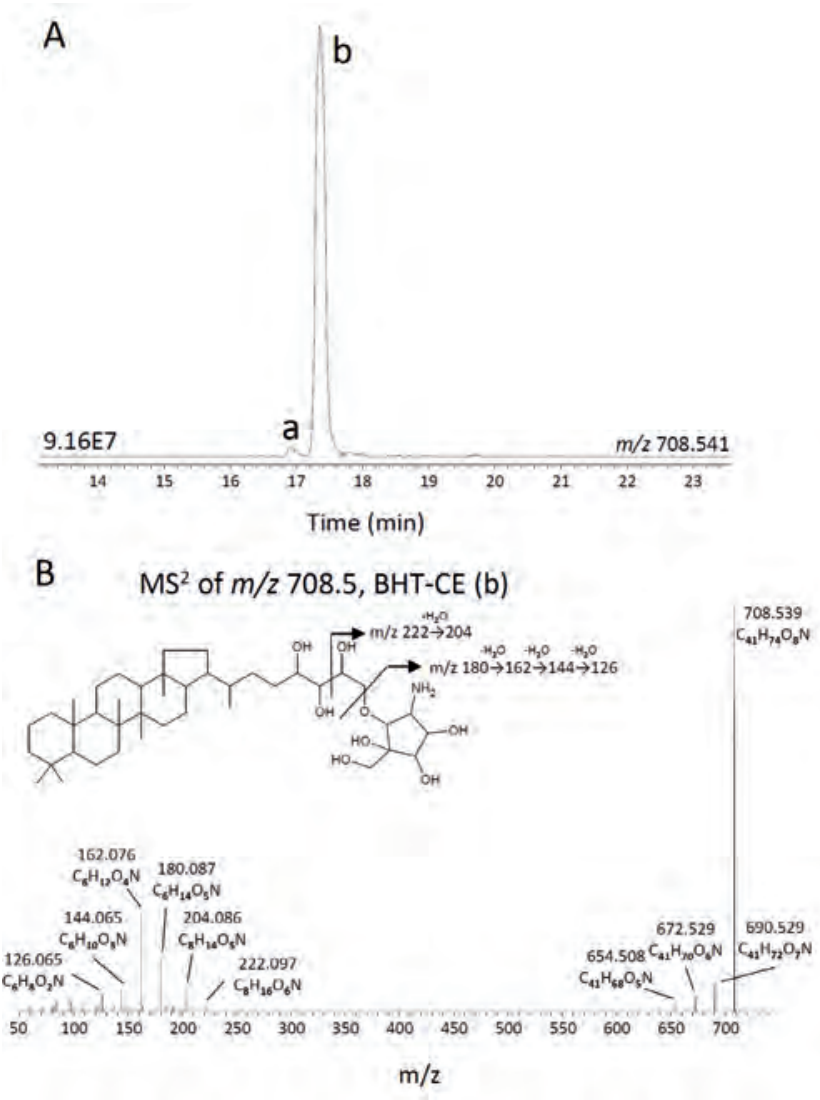

Figure 6. Cyclitol ether BHT (BHT-CE) in Ca. 'Scalindua profunda'. A: Partial mass chromatogram of the $[\mathrm{M}+\mathrm{H}]^{+}$of $\mathrm{BHT}-\mathrm{CE}$. The trace is labeled with the exact mass used for searching and the intensity in arbitrary units (AU) of the signal. $B$ : M S ${ }^{2}$ spectrum of B HT-CE. A Iso shown is the structure of B HT-CE with diagnostic fragmentations indicated.

A denosylhopane type-2 and -3 show similar fragmentation behavior to type-1, but have an unknown, presumably, nucleoside-type polar head group. Upon fragmentation of adenosylhopanes, a diagnostic fragment, representing the nucleoside, is formed with $\mathrm{m} / \mathrm{z} 136$ for type-1 (adenosine), $\mathrm{m} / \mathrm{z} 151$ for type-2, and $\mathrm{m} / \mathrm{z} 150$ for type-3 (Talbot et al., 2016). M ethylated homologues have been observed for each of the three adenosylhopane types (Talbot and Farrimond, 2007; Rethemeyer et al., 2010). A denosylhopane type-1 and its (di)methylated homologues are the only adenosylhopanes with a known elemental composition and, therefore, searchable based on their exact mass. For adenosylhopanes type2 and -3 we initially mined the data using a nominal mass approach. This revealed several peaks, of which we then further investigated both the $M S^{1}$ and corresponding $\mathrm{M} \mathrm{S}^{2}$ spectra and which are discussed below. 
Fig. 8 shows the full distribution of adenosylhopanes with increasing degree of methylation, as detected in the Censo $0 \mathrm{~m}$ soil. The mass chromatogram of the calculated exact mass of the protonated molecule for adenosylhopane type- $1\left(\mathrm{EC}=\mathrm{C}_{40} \mathrm{H}_{64} \mathrm{O}_{3} \mathrm{~N}_{5}{ }^{+} ; \mathrm{m} / \mathrm{z} 662.500\right)$ revealed a single peak (a) at $22.0 \mathrm{~min}$ (Fig. 8A ). The $\mathrm{M} \mathrm{S}^{2}$ spectrum (Fig. 9B) contains a single dominant ion at $\mathrm{m} / \mathrm{z} 136.062$ with an assigned elemental composition of $\mathrm{C}_{5} \mathrm{H}_{6} \mathrm{~N}_{5}{ }^{+}(\Delta \mathrm{ppm}$ $-0.16)$, confirming the identity of the adenosyl head group. The mass chromatogram of $\mathrm{m} / \mathrm{z} 676.516$, i.e., the exact mass of the methylated homologue of adenosylhopane type- 1 , showed a series of 4 peaks (b through e) (Fig. 8B). Peaks $b, c$ and e all produced the same fragment at $\mathrm{m} / \mathrm{z} 136$ as found for adenosylhopane type-1, thus indicating the position of the methylation to be on the B H P core. Peaks b, c, and e are therefore likely M e-adenosylhopane type-1, similar to the cluster of three isomers detected by Talbot et al. (2016) in a sediment of River Tyne. Both acetylated and non-derivatized $2 \mathrm{M} \mathrm{eBHPs}$ elute very closely after their non-methylated counterparts using reversed phase chromatography, while 3M eB HPs elute later (Talbot et al. 2003a,b; 2007a,b; 2016) and as observed here, as discussed above). B ased on the elution order and retention time differences compared to adenosylhopane type-1, we identify peak $\mathrm{b}$ as $2 \mathrm{M}$ e-adenosylhopane type-1, peak e as 3M e-adenosylhopane type-1, and peak $\mathrm{C}$ as an unknown M e-adenosylhopane type-1 isomer. This distribution of M e-adenosylhopane type- 1 isomers mirror the distribution of methylated B HTs detected in this soil (see Table S.2). Peak d (Fig. 8B) showed an M S $^{2}$ spectrum with a single fragment at $\mathrm{m} / \mathrm{z} 150.077$ with an assigned elemental composition of $\mathrm{C}_{6} \mathrm{H}_{8} \mathrm{~N}_{5}$ ( $\Delta$ ppm-0.01; Fig. 9C). A fragment ion at $\mathrm{m} / \mathrm{z} 150$ is diagnostic for adenosylhopane type-3, and in fact Tal bot et al. (2016) used the predicted M RM transition of $\mathrm{m} / \mathrm{z} 676$ to 150 to successfully detect this compound in the River Tyne sediments. W e, therefore, identify peak $d$ as adenosylhopane type-3. B ased on the AEC, we propose that the polar head group of adenosylhopane type-3 contains a methylated adenine (see Fig. 7C for proposed structure; placement of the methylation is arbitrary).

Fig. $8 \mathrm{C}$ shows the mass chromatogram of $\mathrm{m} / \mathrm{z} 690.532$ ( $E C=$ $\mathrm{C}_{42} \mathrm{H}_{68} \mathrm{O}_{3} \mathrm{~N}_{5}{ }^{+}$) and shows one dominant peak at $25.5 \mathrm{~min}(\mathrm{~h})$ and two minor earlier eluting peaks ( $f$ and $g$ ). The $M S^{2}$ spectrum of peak $f(F i g .9 D)$ contains two fragments related to the head group, i.e., the base peak at $\mathrm{m} / \mathrm{z} 150.077$ $\left(\mathrm{C}_{6} \mathrm{H}_{8} \mathrm{~N}_{5}{ }^{+} ; \Delta\right.$ ppm -0.01) and a fragment at $\mathrm{m} / \mathrm{z} 164.093\left(\mathrm{C}_{7} \mathrm{H}_{10} \mathrm{~N}_{5}{ }^{+}, \Delta \mathrm{ppm}-0.07\right)$. This suggests that this peak represents a co-elution of $\mathrm{M}$ e-adenosylhopane type3 and (a minor) adenosylhopane type-3 with a second methylation on the 
adenine. Talbot et al. (2016) used an M R M transition from m/z 690 to 150 and detected a single peak in a sediment from the River Tyne. It is likely that this $\mathrm{BHP}$ is similar to the here observed peak $\mathrm{f}$. The $\mathrm{MS}^{2}$ spectrum of peak $\mathrm{g}$ (Fig. 9E) showed a base peak at $\mathrm{m} / \mathrm{z} 136.061\left(\mathrm{EC}=\mathrm{C}_{5} \mathrm{H}_{6} \mathrm{~N}_{5}{ }^{+}\right)$and a minor fragment at $\mathrm{m} / \mathrm{z} 150.077\left(\mathrm{C}_{6} \mathrm{H}_{8} \mathrm{~N}_{5}{ }^{+}\right)$. We, therefore, propose peak $\mathrm{g}$ to be a co-elution of diM e-adenosyl type- 1 and $M$ e-adenosylhopane type-3. Peak $\mathrm{h}$ again appears to be an adenosylhopane type-3, with an additional methylation on the adenine, based on the product ion at $\mathrm{m} / \mathrm{z} 164.093\left(\mathrm{C}_{7} \mathrm{H}_{10} \mathrm{~N}_{5}{ }^{+} ; \Delta\right.$ ppm $\left.-0.99 ; \mathrm{Fig} .9 \mathrm{~F}\right)$, similar to the minor co-elution in peak $\mathrm{f}$.

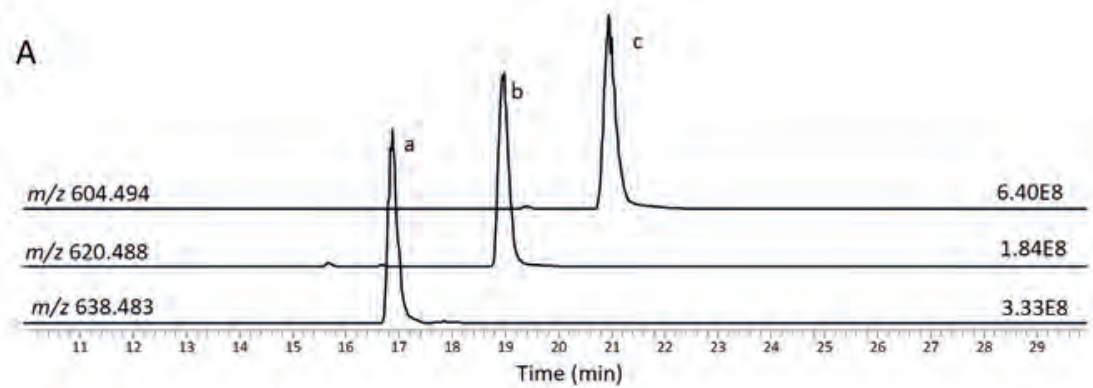

B

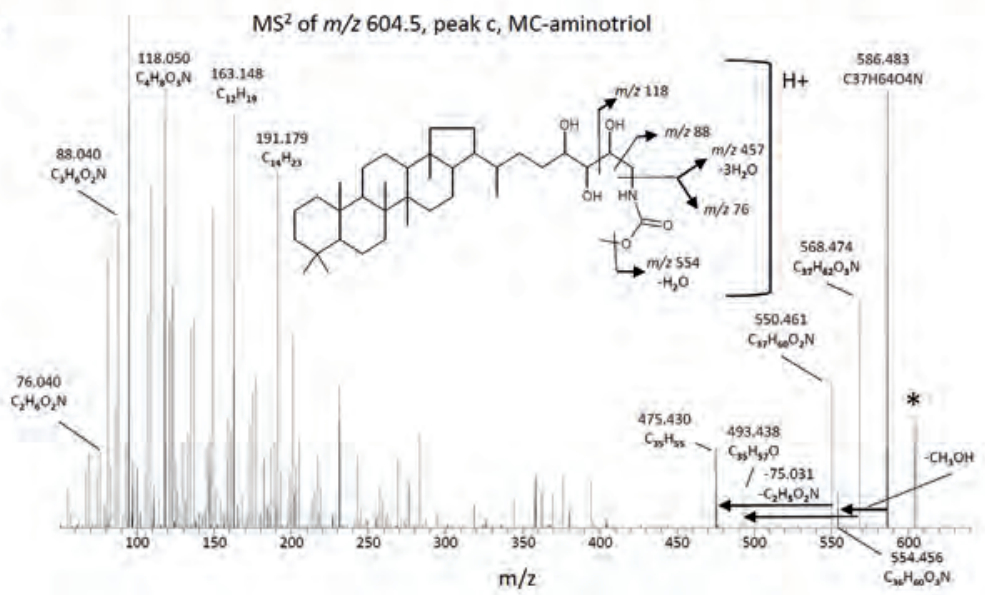

Figure 7. M ethylcarbamate-aminoB H Ps (M C-aminoB H Ps) in M . vadi. A : partial mass chromatograms of the $[\mathrm{M}+\mathrm{H}]^{+}$of $\mathrm{M} \mathrm{C}$-aminopentol (a), -aminotetrol (b) and -aminotriol (c). Each trace is labeled with the exact mass used for searching, and the intensity in arbitrary units (AU) of the signal. B. M S ${ }^{2}$ of $M C$-aminotriol (mass peak labeled with * result from co-trapping of a co-eluting compound and is not related to this B HP). A lso shown is the structure of M C-aminotriol with diagnostic fragmentations indicated.

The mass chromatogram of adenosylhopanes with an $\mathrm{EC}$ of $\mathrm{C}_{43} \mathrm{H}_{70} \mathrm{O}_{3} \mathrm{~N}_{5}{ }^{+}$ ( $\mathrm{m} / \mathrm{z}$ 704.547; Fig. 8D) revealed a series of peaks, i, j and $\mathrm{k}$. The $\mathrm{M} \mathrm{S}^{2}$ spectra of all three peaks (shown for peak $\mathrm{i}$ in Fig. 9G) show a single fragment at $\mathrm{m} / \mathrm{z}$ 164.093, and therefore we tentatively identify these BHPs as methyl- 
adenosylhopanes type-3, with an additional methylation on the adenine head group. Peak $\mathrm{j}$ also shows minor fragments related to fragmentation in the hopanoid ring system, including m/z 191 (Fig. S7A). These BHPs appear to be the core-methylated homologues of peak $h$, and based on the offset in retention times to peak $h$, are tentatively identified as a having a methylation at $\mathrm{C}-2$, methylation at unknown position, and a methylation at $\mathrm{C}-3$; a similar distribution as observed for the M eB HTs and the M e-adenosylhopane type-1 peaks.

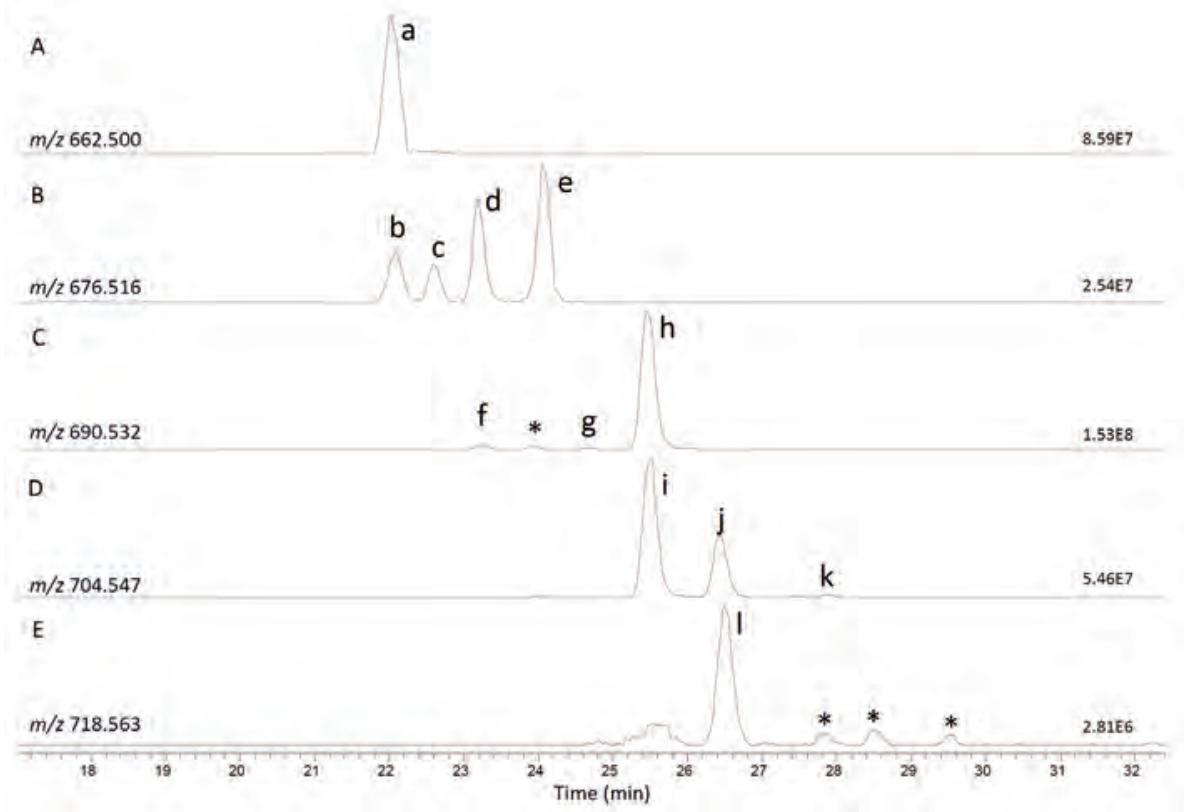

Figure 8. Partial mass chromatograms of adenosylhopanes, with increasing number of methylations, in a soil from a terrestrial methane seep (Censo $0 \mathrm{~m}$ ). Each trace is labeled with the exact mass used for searching, and the intensity in arbitrary units (AU) of the signal. $\mathrm{M} \mathrm{S}^{2}$ spectra are shown in Fig. 9 if discussed in text; additional $M S^{2}$ spectra are shown in Fig. S7 Peaks labeled with '*' are potential isomers but have no M S$^{2}$ spectrum associated.

A search for adenosylhopanes with an $\mathrm{EC}$ of $\mathrm{C}_{44} \mathrm{H}_{72} \mathrm{O}_{3} \mathrm{~N}_{5}{ }^{+}(\mathrm{m} / \mathrm{z} 718.563)$ showed a series of peaks (Fig. 8E) with relative low abundance (two orders of magnitude less than the adenosylhopanes with $\mathrm{m} / \mathrm{z} 690.532$ ). Only peak $\mathrm{m}$ had an associated $M \mathrm{~S}^{2}$ spectrum, which showed one fragment ion related to the head group at $\mathrm{m} / \mathrm{z} 164.093$ and minor fragments related to fragmentation in the ring structure (Fig. 7H). We have tentatively identified this BHP as dimethyladenosylhopane type-3 with an additional methylation on the adenine head group. Evidence for B HPs methylated at C -2 and $\mathrm{C}-3$ was previously seen in $\mathrm{C}$. 
'Koribacter versatilis', isolated from a pasture soil (Sinninghe Damsté et al., 2017). A denosylhopanes with $\mathrm{m} / \mathrm{z} 732.579\left(\mathrm{EC} \mathrm{C}_{45} \mathrm{H}_{74} \mathrm{O}_{3} \mathrm{~N}_{5}{ }^{+}\right)$were not detected.

As the elemental composition of adenosyl type-2 is unknown, we searched the $\mathrm{MS}^{2}$ data for the diagnostic fragment ion with a nominal $\mathrm{m} / \mathrm{z}$ of 151 (Talbot et al., 2016). Several signals were found, mostly associated with amino acid lipids such as ornithines, but one $\mathrm{M} \mathrm{S}^{2}$ spectrum (Fig. 10B) clearly showed an adenosylhopane signature, with a single dominant fragment ion at $\mathrm{m} / \mathrm{z}$ $151.061\left(\mathrm{C}_{6} \mathrm{H}_{7} \mathrm{ON}_{4}^{+}, \Delta \mathrm{ppm}-0.38 \mathrm{ppm}\right)$. Interestingly, this elemental composition matches the EC for N1-methylinosine, which is formed from adenosine via inosine in transfer RNAs, and is found in the RNA of eukaryotes and halo- and thermophilic archaea (Grosjean and Constantinesco, 1996). The $\mathrm{EC}$ of the protonated molecule of adenosylhopane type-2 was determined to be $\mathrm{C}_{41} \mathrm{H}_{65} \mathrm{~N}_{4} \mathrm{O}_{4}{ }^{+}$(m/z 677.500). Fig. $10 \mathrm{~A}$ shows the mass chromatogram of $\mathrm{m} / \mathrm{z}$ 677.500 from Censo $0 \mathrm{~m}$ with the relatively low abundance peak at $24.24 \mathrm{~min}$ from which the $\mathrm{MS}^{2}$ spectrum was derived. A homologue of the tentatively identified N 1-methylinosylhopane, methylated on the BHP core $(\mathrm{m} / \mathrm{z}$ 691.516; $\mathrm{C}_{42} \mathrm{H}_{67} \mathrm{~N}_{4} \mathrm{O}_{4}{ }^{+}$), was detected at 24.30 min (peak b, Figs. 10A and S7B). B ased on the retention time, we tentatively identify this BHP as 2Me-N1methylinosylhopane. As N1-methylinosine is formed from adenosine via an initial hydrolytic deamination to inosine, we also searched for the proposed intermediate between adenosylhopane and N1-methylinosylhopane, i.e., inosylhopane $\left(\mathrm{C}_{40} \mathrm{H}_{63} \mathrm{O}_{4} \mathrm{~N}_{4}{ }^{+} ; \mathrm{m} / \mathrm{z} 663.484\right)$. At 20.63 min a peak was identified with an associated $\mathrm{M} \mathrm{S}^{2}$ spectrum showing the predicted head group fragment at $\mathrm{m} / \mathrm{z} 137.0458\left(\mathrm{C}_{5} \mathrm{H}_{5} \mathrm{ON} \mathrm{N}_{4}{ }^{+}, \Delta\right.$ ppm -0.20; peak C, Fig. 10A ). M inor fragments at $\mathrm{m} / \mathrm{z} 529.461\left(\mathrm{C}_{35} \mathrm{H}_{61} \mathrm{O}_{3}{ }^{+}\right)$and $\mathrm{m} / \mathrm{z} 511.450\left(\mathrm{C}_{35} \mathrm{H}_{59} \mathrm{O}_{2}{ }^{+}\right)$further confirmed the anhydro-BHT core structure (Fig. 10C).

\subsubsection{A novel composite BH P with an N-containing moiety}

During a broad search for known BHPs in the Censo $0 \mathrm{~m}$ soil, two peaks matching the exact mass and EC of protonated MC-aminotriol and -tetrol $(\mathrm{m} / \mathrm{z}$ $604.494, \quad \mathrm{C}_{37} \mathrm{H}_{66} \mathrm{O}_{5} \mathrm{~N}^{+}$and $\mathrm{m} / \mathrm{z} 620.488, \mathrm{C}_{37} \mathrm{H}_{66} \mathrm{O}_{6} \mathrm{~N}^{+}$, respectively) were encountered (Fig. 11A, peaks a and b). However, these peaks elute later than the equivalent BHPs described for $M$. vadi (see above). A lthough the $M S^{2}$ spectra of the peaks detected in the Censo $0 \mathrm{~m}$ soil share many characteristics with those of the $\mathrm{MC}$-aminoB HPs, there are several distinct differences. 


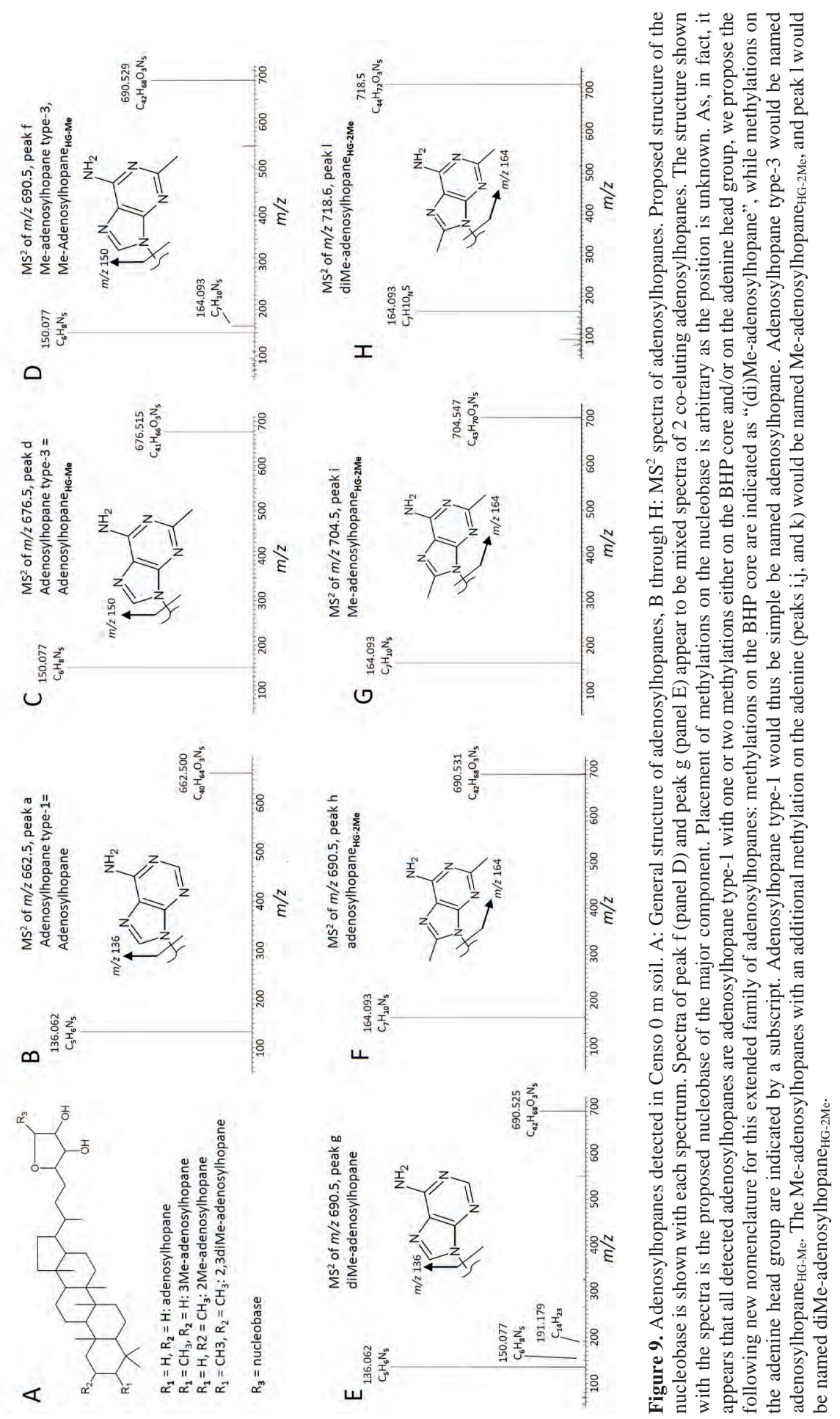



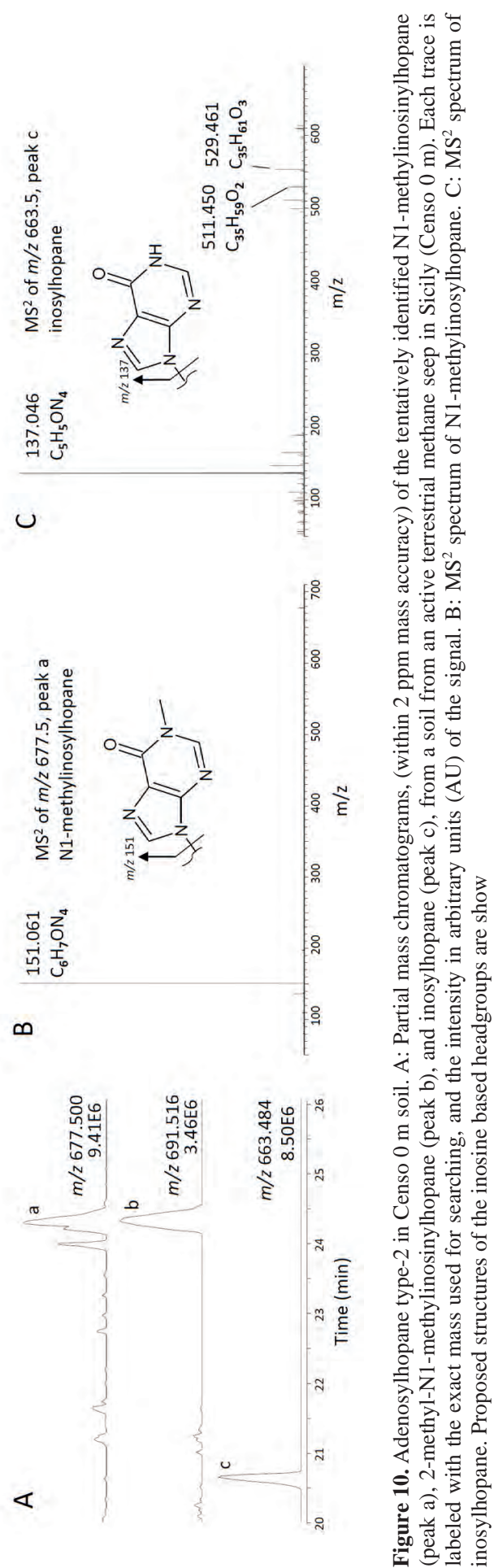
The $\mathrm{MS}^{2}$ spectrum of peak $\mathrm{b}$ (Fig. 11B) is characterized by a series of initial losses of $\mathrm{H}_{2} \mathrm{O}(-18)$ from the protonated molecule producing ions at $\mathrm{m} / \mathrm{z} 586.483$ $\left(\mathrm{C}_{37} \mathrm{H}_{64} \mathrm{O}_{4} \mathrm{~N}^{+}, \Delta \mathrm{ppm}-0.33\right), \mathrm{m} / \mathrm{z} 568.474\left(\mathrm{C}_{37} \mathrm{H}_{62} \mathrm{O}_{3} \mathrm{~N}^{+}, \Delta\right.$ ppm 2.23$), \mathrm{m} / \mathrm{z}$ $550.462\left(\mathrm{C}_{37} \mathrm{H}_{60} \mathrm{O}_{2} \mathrm{~N}^{+}, \Delta\right.$ ppm -0.23), and $\mathrm{m} / \mathrm{z} 532.453\left(\mathrm{C}_{37} \mathrm{H}_{58} \mathrm{ON}^{+}, \Delta\right.$ ppm 2.64). How ever, instead of the characteristic loss of $75 \mathrm{Da}$, representing the loss of the methylcarbamate, losses of $41 \mathrm{Da}\left(\mathrm{C}_{2} \mathrm{H}_{3} \mathrm{~N}\right)$ and $59 \mathrm{Da}\left(\mathrm{C}_{2} \mathrm{H}_{5} \mathrm{ON}\right)$ were observed here, generating fragment ions at $\mathrm{m} / \mathrm{z} 491.424\left(\mathrm{C}_{35} \mathrm{H}_{55} \mathrm{O}^{+}, \Delta \mathrm{ppm}-2.43\right)$ and $\mathrm{m} / \mathrm{z}$ $473.414\left(\mathrm{C}_{35} \mathrm{H}_{55}{ }^{+}, \Delta \mathrm{ppm}-1.41\right)$, respectively. Dominant $\mathrm{N}$-containing product ions are observed at $\mathrm{m} / \mathrm{z} 60.045\left(\mathrm{C}_{2} \mathrm{H}_{6} \mathrm{ON}^{+}, \Delta\right.$ ppm 4.52) and $\mathrm{m} / \mathrm{z} 102.055$ $\left(\mathrm{C}_{4} \mathrm{H}_{8} \mathrm{O}_{2} \mathrm{~N}^{+}, \Delta\right.$ ppm 1.90). The middle $\mathrm{m} / \mathrm{z}$ region shows similar minor fragments, representing the $D$ and $E$ ring and the side chain after loss of the functionalities, as observed for BHpentol. Based on the assigned EC and the fragmentation pattern, we propose this BHP is a composite BHP based on B Hpentol bound to an ethenolamine moiety $\left(\mathrm{C}_{2} \mathrm{H}_{4} \mathrm{~N}\right)$ via an ether bond. To the best of our knowledge this composite BHP has not been observed before.

After having tentatively identified this ethenolamine-BHpentol, we identified the B HT and B H hexol homologues (peak a and c, respectively, in Fig. $11 \mathrm{~A}$ ), based on calculated exact mass and $\mathrm{M} \mathrm{S}^{2}$ fragmentations (Table S3, Figs. $\mathrm{S} 8 \mathrm{~A}$ and $\mathrm{B}$ ). Although methylated ethenolamine-BHPs were not detected in Censo $0 \mathrm{~m}$, a BHP matching the calculated exact mass and EC of methylated ethenolamine-BHT $\left(\mathrm{C}_{38} \mathrm{H}_{68} \mathrm{O}_{4} \mathrm{~N}^{+}\right)$was detected at 21.44 min (for details see Table S3). The fragmentation pattern was almost identical to what was observed for ethenolamine-BHT (Fig. 11B). However, both diagnostic N-containing product ions were offset by $+14 \mathrm{Da}$ resulting in fragments at $\mathrm{m} / \mathrm{z} 74.061$ $\left(\mathrm{C}_{3} \mathrm{H}_{8} \mathrm{ON}{ }^{+}, \Delta \mathrm{ppm} 9.446\right.$ ), and $\mathrm{m} / \mathrm{z} 116.071\left(\mathrm{C}_{5} \mathrm{H}_{10} \mathrm{O}_{2} \mathrm{~N}^{+}, \Delta \mathrm{ppm} 3.575\right)$ (Fig. $\mathrm{S} 8 \mathrm{C})$. No diagnostic losses could be observed in this case. This BHP was, therefore, tentatively identified as a propenolamine-BHT. A butenolamine homologue was not detected.

\subsubsection{Acylated ethenolamines}

Using the exact mass of the most common diagnostic ion for BHPs, i.e., $\mathrm{m} / \mathrm{z}$ $191.179\left(\mathrm{C}_{14} \mathrm{H}_{23}{ }^{+}\right)$, the $\mathrm{MS}^{2}$ data was investigated for other potential unknown BHPs. This revealed the presence of a series of late eluting (35-40 min) compounds with $\mathrm{m} / \mathrm{z}$ values $>800$ (Fig. S9). One of the most abundant of these unknowns was a compound with $\mathrm{m} / \mathrm{z} 840.743$ and an assigned $\mathrm{EC}$ of $\mathrm{C}_{54} \mathrm{H}_{98} \mathrm{O}_{5} \mathrm{~N}$ ${ }^{+}(\Delta \mathrm{ppm}-1.54)$. A mass chromatogram for this EC showed a cluster of peaks consisting of at least 8 isomers (peaks a to h, Fig. 12A) with near identical M S ${ }^{2}$ spectra. 

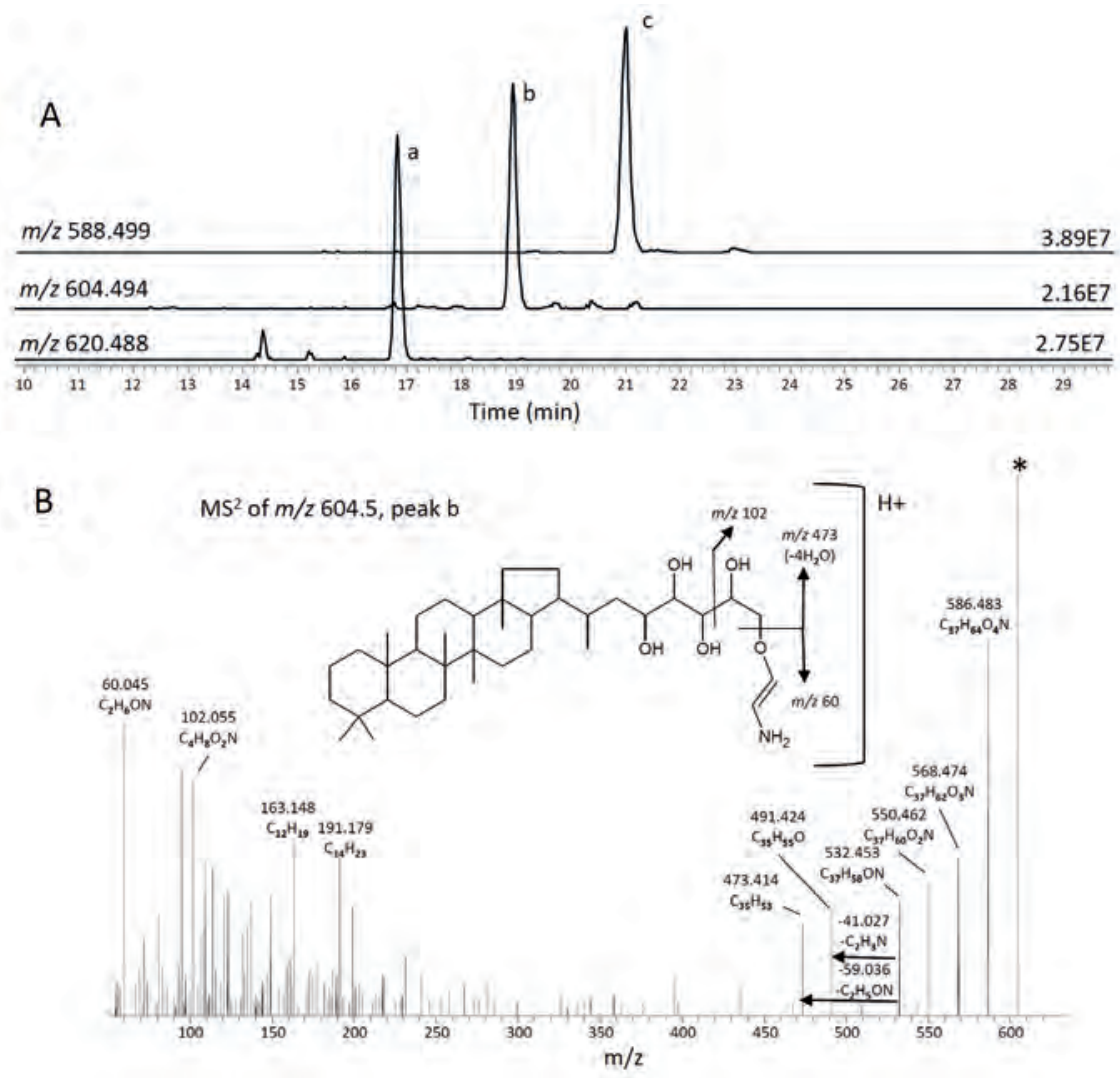

Figure 11 N ovel $\mathrm{N}$-containing composite B H Ps in Censo $0 \mathrm{~m}$ soil. A. Partial mass chromatograms of a series of novel composite B HPs $(a, b, c)$. Each trace is labeled with the exact mass used for searching, and the intensity in arbitrary units (AU) of the signal. B. M S ${ }^{2}$ spectrum associated with peak $b$. (mass peak labeled with * results from co-isolation of a co-eluting compound and is not related to this BHP). Also shown is the proposed structure of ethenolamine- $\mathrm{BH}$ pentol with diagnostic fragmentations indicated.

Fig. 12B shows the $\mathrm{MS}^{2}$ spectrum of the most abundant peak e. Two losses of $\mathrm{H}_{2} \mathrm{O}$ are observed from the parent ion resulting in fragment ions at $\mathrm{m} / \mathrm{z} 822.733$ $\left(\mathrm{C}_{54} \mathrm{H}_{96} \mathrm{O}_{4} \mathrm{~N}^{+}, \Delta\right.$ ppm -0.26$)$ and $\mathrm{m} / 2804.720\left(\mathrm{C}_{54} \mathrm{H}_{94} \mathrm{O}_{3} \mathrm{~N}^{+}, \Delta\right.$ ppm -0.46$)$. In the middle region of the mass spectrum a cluster of fragment ions are observed, which are formed after an initial loss of $252.246\left(\mathrm{C}_{17} \mathrm{H}_{32} \mathrm{O}, \Delta \mathrm{ppm} 0.81\right)$ from the parent ion and further losses of $-18 \mathrm{Da}\left(\mathrm{H}_{2} \mathrm{O}\right)$ and, interestingly, $-41 \mathrm{Da}\left(\mathrm{C}_{2} \mathrm{H}_{3} \mathrm{~N}\right)$ and $-59 \mathrm{Da}\left(\mathrm{C}_{2} \mathrm{H}_{5} \mathrm{ON}\right)$, similar to the fragmentation pattern observed for the earlier described ethenolamine BHPs. Indeed, the diagnostic product ions of this novel class of BHPs at $\mathrm{m} / \mathrm{z} 60$ and 102 were also present. Based on the resemblance of the $\mathrm{M} \mathrm{S}^{2}$ spectrum to that of ethenolamine-BHT and the loss of a $\mathrm{C}_{17} \mathrm{H}_{32} \mathrm{O}$ moiety, we tentatively identified this compound as a $\mathrm{C}_{17: 0-} \mathrm{N}$-acylethenolamine-B HT (Fig. 12B). The fatty acid moiety can, based on the data here, only be identified to the level of carbon number and double bond equivalent. 
Several causes are possible for the multitude of isomers. The head group can be bound to the polyol tail of the B HP at a different positions (C-32, C-33, C-34, or $\mathrm{C}-35)$, and/or by isomery within the BHT core structure, or by structural differences (linear vs. branched) in the fatty acid tail.
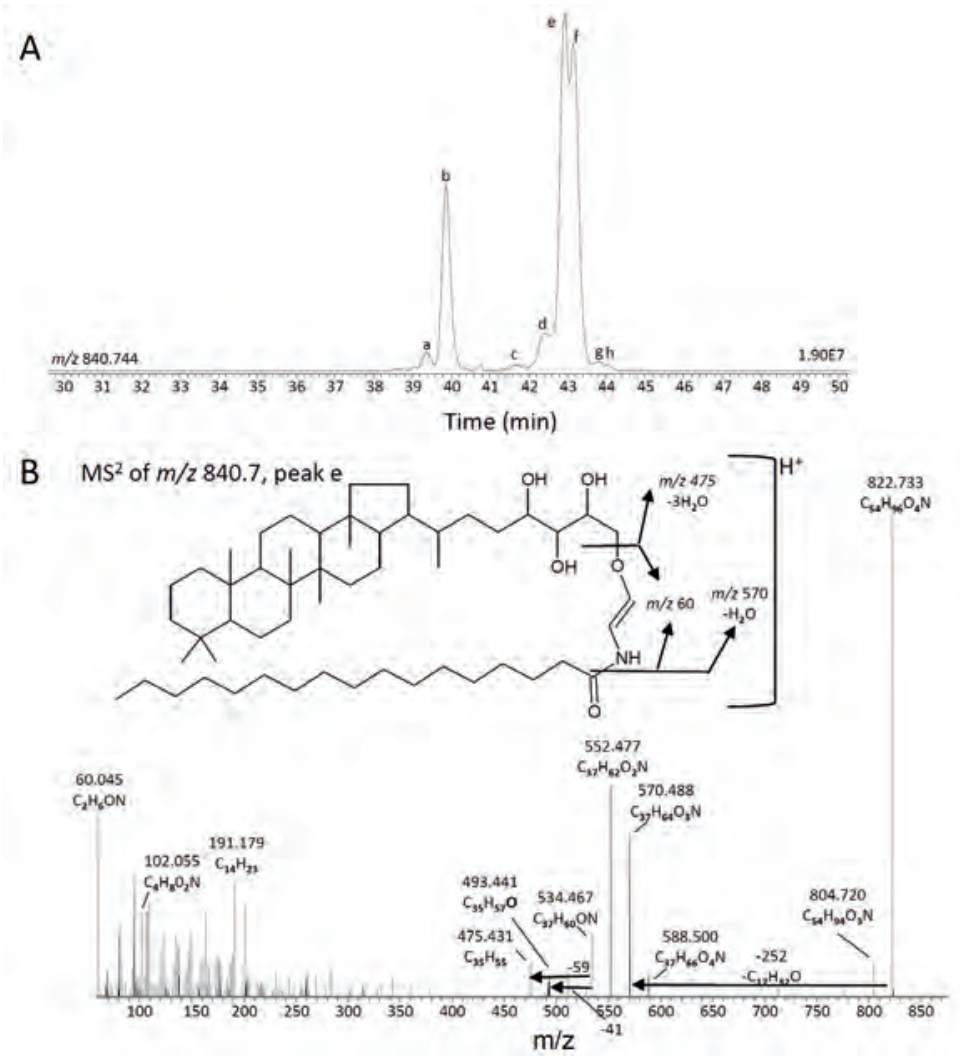

Figure 12 A n example of an $\mathrm{N}$-acyl-ethenolamine-BHT in Censo $0 \mathrm{~m}$, a soil from a terrestrial methane seep in Sicily. A. Partial mass chromatogram of $\mathrm{C}_{17: 0-\mathrm{N}} \mathrm{N}$-acyl-ethenolamine-B $\mathrm{HT}$. The trace is labeled with the exact mass used for searching, and the intensity in arbitrary units (A U) of the signal. B. M S ${ }^{2}$ spectrum of peak e from panel $A$ with the proposed structure for $\mathrm{C}_{17: 0^{-}} \mathrm{N}$-acyl-ethenolamine-BHT with diagnostic fragmentations indicated. Position of the conjugation is arbitrary as the exact position is unknown. The fatty acid moiety is shown with a linear carbon chain, as the exact structure cannot be determined here.

In addition to the $\mathrm{C}_{17: 0} \mathrm{~N}$-acyl-ethenolamine-B $\mathrm{HT}$ s we detected complex distributions of $C_{15: 0}$ to $C_{18: 0^{-}} \mathrm{N}$-acyl-ethenolamine-BHTs (Fig. S9). $C_{14: 0^{-}}$and $\mathrm{C}_{19: 0} \mathrm{~N}$-acyl-ethenolamine-B HTs appeared only present at trace levels and could not be confirmed by obtaining $M \mathrm{~S}^{2}$ spectra. A full listing by retention time, for those isomers confirmed by $\mathrm{MS}^{2}$, is given in Table S2. Ethenolamine-BHTs bound to $C_{15: 0}$ and $C_{17: 0}$ fatty acids were most abundant in the Censo $0 \mathrm{~m}$ soil, but the $\mathrm{C}_{\text {16:0 }}$ bound ethenolamine BHTs showed the most complex distribution with 12 isomers confirmed by $\mathrm{M} \mathrm{S}^{2}$ spectra. A search for unsaturated homologues 
resulted in the detection of ethanolamine-BHTs bound to $C_{17: 1}$ and $C_{18: 1}$ fatty acids (Table S2, Fig. S10), which were only present at trace levels. A cylated ethenolamine-B HTs comprising an unsaturated hopanoid core were not detected. Acylated ethenolamine-BHPs based one BHpentol and BHhexol were also detected (Table S2, Fig. S10) and comprised $C_{15: 0}$ to $C_{18: 0}$, and $C_{17: 1}$ and $C_{18: 1} \mathrm{~N}$ bound acyl moieties, i.e., comparable with the distribution of the ethenolamineBHTs. Interestingly, many more isomers were identified for ethenolamineBHhexol than for ethenolamine-BHpentol, while BHhexol itself was not detected.

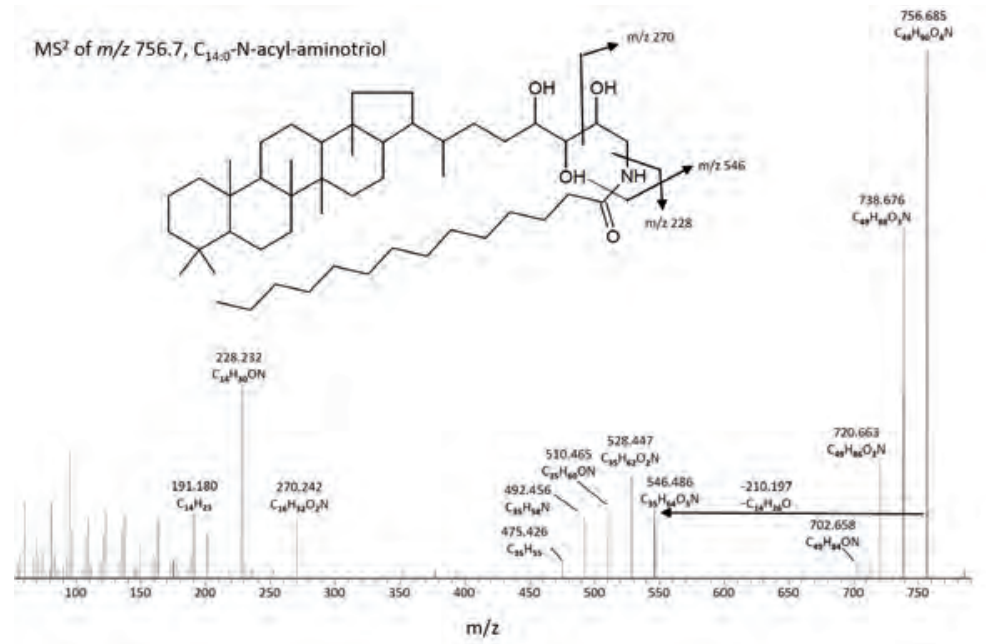

Figure 13. $\mathrm{MS}^{2}$ spectrum of $\mathrm{C}_{14: 0} \mathrm{-N}$-acyl-aminotriol from Censo $0 \mathrm{~m}$, a soil from a terrestrial methane seep in Sicily. Proposed structure and diagnostic fragmentations are shown. The fatty acid moiety is shown with a linear carbon chain, as the exact structure cannot be determined here. Further details can be found in table $\mathbf{S 2}$.

\subsubsection{Acylated aminotriols}

A further search for acylated B H Ps revealed a series of $\mathrm{N}$-acyl-aminotriols in the Censo $0 \mathrm{~m}$ soil (Fig. S11). HPLC-MS detection of derivatized $\mathrm{N}$-acylaminotriols was previously reported by Tal bot et al. (2007a) in N. europaea and

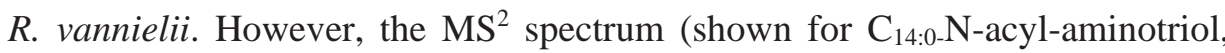
Fig. 13) of the non-derivatized molecule proves to be much more diagnostic than that produced from the derivatized molecule. Here, three losses of $\mathrm{H}_{2} \mathrm{O}$ are observed from the parent ion resulting in fragment ions at $\mathrm{m} / \mathrm{z} 738.676$ $\left(\mathrm{C}_{49} \mathrm{H}_{86} \mathrm{O}_{2} \mathrm{~N}^{+}, \Delta\right.$ ppm 0.04), m/z $720.663\left(\mathrm{C}_{49} \mathrm{H}_{86} \mathrm{O}_{2} \mathrm{~N}^{+}, \Delta \mathrm{ppm}-3.078\right)$ and $\mathrm{m} / \mathrm{z}$ $702.658\left(\mathrm{C}_{49} \mathrm{H}_{84} \mathrm{ON}^{+}, \Delta \mathrm{ppm}-3.17\right)$. L oss of $210.199 \mathrm{Da}\left(\mathrm{C}_{14} \mathrm{H}_{26} \mathrm{O}, \Delta \mathrm{ppm} 4.07\right)$ leads to a product ion at $\mathrm{m} / 2546.486\left(\mathrm{C}_{35} \mathrm{H}_{64} \mathrm{O}_{3} \mathrm{~N}^{+}, \Delta\right.$ ppm 4.07), matching the $[\mathrm{M}+\mathrm{H}]^{+}$of aminotriol. Further fragmentation indeed matches the fragmentation for amino BHPs as described earlier, although fragment ions in the lower mass 
region appear more abundant here. The acyl moiety is easily defined by a prominent fragment ion at $\mathrm{m} / \mathrm{z} 228.232\left(\mathrm{C}_{14} \mathrm{H}_{30} \mathrm{ON}{ }^{+}, \Delta \mathrm{ppm}-4.12\right)$. A $n$ additional $\mathrm{N}$-containing fragment ion is observed at $\mathrm{m} / \mathrm{z} 270.243\left(\mathrm{C}_{16} \mathrm{H}_{32} \mathrm{O}_{2} \mathrm{~N}^{+}, \Delta \mathrm{ppm}\right.$ 3.01) and is likely formed after cleavage of the $\mathrm{C}-33 / \mathrm{C}-34$ bond.

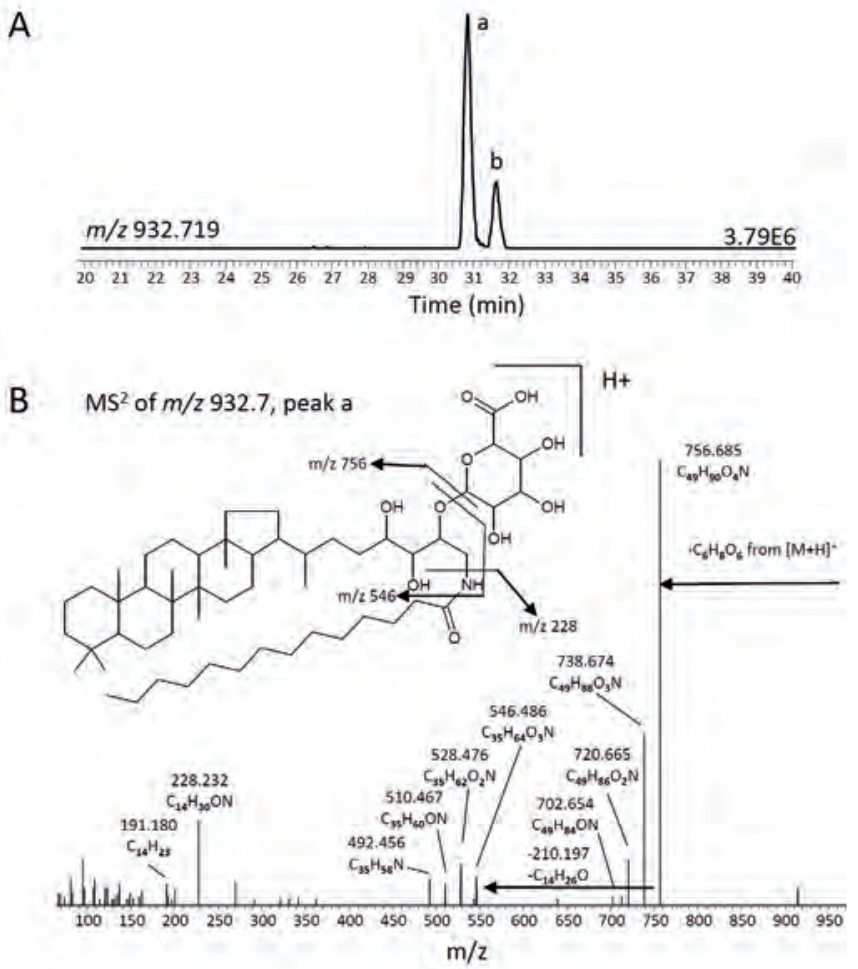

Figure 14. Novel multi-substituted aminotriol in Censo $0 \mathrm{~m}$, a soil from a terrestrial methane seep in Sicily. A: Partial mass chromatogram of $\mathrm{C}_{14: 0} \mathrm{~N}$-acyl-aminotriol with additional glucuronic acid substitution. Trace is labeled with the exact mass used for searching, and the intensity in arbitrary units (AU) of the signal. B. M S spectrum associated with peak a with proposed structure of $\mathrm{C}_{14: 0-\mathrm{N}}$-acyl-glucuronyl-aminotriol with diagnostic fragmentations indicated. Position of the glucuronyl moiety is arbitrary. The fatty acid moiety is shown with a linear carbon chain, as the exact structure cannot be determined here.

Whereas Talbot et al. (2007a) reported aminotriol acylated to $C_{16: 0}$ and $C_{16: 1}$ FAs in N. europaea and to $C_{18: 0}, C_{18: 1}$, and $C_{19: 0}$ in $R$. vannieli, we detect aminotriols acylated to much shorter chain fatty acids ranging from $C_{8: 0}$ to $C_{18: 0}$ $\mathrm{FA}$, with the $\mathrm{C}_{11: 0} \mathrm{~N}$-acyl-aminotriol being the most abundant homologue (peak d, Fig. S11). In addition, aminotriols acylated to $C_{11: 1,} C_{12: 1,} C_{14: 1}$ and $C_{16: 1}$ fatty acids were detected (Table S2). $\mathrm{N}$-acyl-aminotetrols were not detected, and only trace levels of a $\mathrm{C}_{16: 0} \mathrm{-} \mathrm{N}$-acyl-aminopentol were detected in the Censo $0 \mathrm{~m}$ soil (Fig. S12). A complicating factor in identifying the full spectrum of acyl-B HPS is the fact that there is a considerable overlap in elemental composition between the acyl-ethenolamine-BHPs with the N-acyl-aminoB HPs. For illustration, the 
$[\mathrm{M}+\mathrm{H}]^{+}$of an aminotetrol bound to $\mathrm{C}_{17: 1} \mathrm{FA}$ has an elemental composition of $\mathrm{C}_{52} \mathrm{H}_{94} \mathrm{O}_{5} \mathrm{~N}^{+}$, which is identical to that of an ethenolamineB HT bound to a $\mathrm{C}_{15: 0}$ FA. It is, therefore, important to evaluate the fragmentation of each detected compound.

\subsubsection{Multi-conjugated composite aminotriols}

While charting the full inventory of $\mathrm{N}$-acyl-aminotriols, we also encountered several compounds that were clearly related to the $\mathrm{N}$-acyl-aminotriols as evident from their $\mathrm{MS}^{2}$ spectra ( e.g., Fig. 14B). The most abundant of these was a compound revealed in a mass chromatogram of $\mathrm{m} / \mathrm{z} 932.719$ (Fig. 14A, peak a) and an assigned $\mathrm{EC}$ of the protonated molecule $\mathrm{C}_{55} \mathrm{H}_{98} \mathrm{O}_{10} \mathrm{~N}^{+}(\Delta \mathrm{ppm}-1.07)$. A n initial loss of $176\left(\mathrm{C}_{6} \mathrm{H}_{8} \mathrm{O}_{6}\right)$ yields a base peak at $\mathrm{m} / \mathrm{z} 756.685$ with an assigned EC matching that of $\mathrm{C}_{14: 0} \mathrm{~N}$-acyl-aminotriol $\left(\mathrm{C}_{49} \mathrm{H}_{90} \mathrm{O}_{4} \mathrm{~N}^{+}, \Delta \mathrm{ppm}-1.42\right)$. The initial loss of $176 \mathrm{Da}$ matches the predicted loss and EC for a glucuronic acid moiety. Further fragmentation was identical to that observed for $\mathrm{C}_{14: 0-\mathrm{N}} \mathrm{N}$-acylaminotriol, revealing the aminotriol core at $\mathrm{m} / \mathrm{z} 546$ and the $\mathrm{C}_{14: 0}$ fatty acid moiety at $\mathrm{m} / \mathrm{z} 228$. The $M \mathrm{~S}^{2}$ spectrum of peak $\mathrm{b}$ is identical to that of peak $\mathrm{a}$, and peak $b$ thus probably reflects an isomer. Although glucuronic acid is not a very common head group in intact polar lipids, it has been observed in bacteria and fungi (e.g., Burugupalli et al., 2020; Fontaine et al., 2009; W ang et al., 2020). We therefore tentatively identify these compounds as $\mathrm{C}_{14}: 0-\mathrm{N}$-acylglucuronosyl-aminotriols (Fig. 14B). In addition to the $\mathrm{C}_{14: 0-\mathrm{N}-\text {-acyl- }}$ glucuronosyl-aminotriol, a $\mathrm{C}_{\text {15:0- }} \mathrm{N}$-acyl-glucuronyl-aminotriol was also detected (Table S2). To the best of our knowledge this is the first report of BHPs with conjugations on more than one position on the B HP core.

\section{Condusions}

W e have shown the applicability of U HPL C-ESI/HR M S ${ }^{2}$ for the analysis of nonderivatized BHPs in both microbial cultures as well as environmental samples. The chromatographic system used here allows separation of a broad range of $\mathrm{BHPs}$, ranging from the relatively simple B H Ps to nitrogen-containing B H Ps and complex composite BHPs. Furthermore, isomers are readily separated. Identification is achieved based on diagnostic spectra, that contain information on the core B HP core structure, the functionalized tail, as well as bound moieties. For the first time we established the el emental composition of the nucleobase of adenosylhopanes type-2 and type-3, showing that in fact, all adenosylhopanes identified so far are modifications of adenosyl either by one or two methylations on the adenine head group (type-3) or by deamination followed by methylation 
(type-2). Furthermore, we have demonstrated the usefulness of HRMS in the identification of novel composite B HPs. We have tentatively identified several new composite BHPs in a soil (e.g., the ( $\mathrm{N}$-acyl-)ethenolamine-BHPs), showing a previously unobserved diversity and complexity in existing BHP structures. The analytical approach described here allows for simultaneous analysis of the full suite of IPLs, now including BHPs, and represents a further step towards environmental lipidomics. With this method a more complete view of the full assembly of BHPs will be possible. Connecting specific intact BHPs to specific sources and/or geochemical cycles will further aid in the interpretation of their diagenetic products, the geohopanoids, in the geological record. Future work will aim to establish a quantitative protocol for this method using isolated BHPS as well as synthetic internal standards.

\section{Acknowledgements}

This work was funded by Netherlands Earth System Science Center (NESSC) through a Gravitation grant to JSSD (grant no. 024.002.001) from the Dutch Ministry for Education, Culture and Science, NWO middelgroot grant no. 834.13.004 to ECH, and a Natural Environment Research Council (NERC; United Kingdom) grant to DR (project ANAMMARKS (NE/N011112/1)). Cultures were kindly provided by H. Hirayama (J A M STEC), G.H.L. Nuijten, 0. Rasigraf, and M .S.M . J etten (R adboud U niversity), M . Rohmer and P. Schaeffer (Strasbourg U niversity). W e thank F. Grassa (INGV) for assistance to NS during field work.

\section{Supplementary material (available upon request)}

Table S1. B HPs detected in biomass. Diagnostic fragments are only shown for the main isomer.

Table S2. B H Ps detected in Censo $0 \mathrm{~m}$, a soil from a terrestrial methane seep in Sicily. 




\begin{tabular}{|c|c|c|c|c|c|c|c|c|}
\hline BHP & $\mathbf{R}_{1}$ & $\mathrm{R}_{2}$ & $\mathbf{R}_{3}$ & $\mathrm{R}_{4}$ & $\mathbf{R}_{5}$ & $\mathbf{R}_{6}$ & $\mathbf{R}_{7}$ & $\mathbf{R}_{8}$ \\
\hline BHT & $\mathrm{H}$ & H & H & $\mathrm{H}$ & $\mathrm{OH}$ & $\mathrm{OH}$ & $\mathrm{OH}$ & $\mathrm{OH}$ \\
\hline 2MeBHT & $\mathrm{CH}_{3}$ & H & H & $\mathrm{H}$ & $\mathrm{OH}$ & $\mathrm{OH}$ & $\mathrm{OH}$ & $\mathrm{OH}$ \\
\hline 3МеBHT & $\mathrm{H}$ & $\mathrm{CH}_{3}$ & H & $\mathrm{H}$ & $\mathrm{OH}$ & $\mathrm{OH}$ & $\mathrm{OH}$ & $\mathrm{OH}$ \\
\hline 2,3-diMe- & $\mathrm{CH}_{3}$ & $\mathrm{CH}_{3}$ & H & $\mathrm{H}$ & $\mathrm{OH}$ & $\mathrm{OH}$ & $\mathrm{OH}$ & $\mathrm{OH}$ \\
\hline BHpentol & $\mathrm{H}$ & H & H & $\mathrm{OH}$ & $\mathrm{OH}$ & $\mathrm{OH}$ & $\mathrm{OH}$ & $\mathrm{OH}$ \\
\hline $2 \mathrm{Me}-$ & $\mathrm{CH}_{3}$ & H & H & $\mathrm{OH}$ & $\mathrm{OH}$ & $\mathrm{OH}$ & $\mathrm{OH}$ & $\mathrm{OH}$ \\
\hline 3Me- & $\mathrm{H}$ & $\mathrm{CH}_{3}$ & H & $\mathrm{OH}$ & $\mathrm{OH}$ & $\mathrm{OH}$ & $\mathrm{OH}$ & $\mathrm{OH}$ \\
\hline 2,3-diMe- & $\mathrm{CH}_{3}$ & $\mathrm{CH}_{3}$ & H & $\mathrm{OH}$ & $\mathrm{OH}$ & $\mathrm{OH}$ & $\mathrm{OH}$ & $\mathrm{OH}$ \\
\hline BHhexol & $\mathrm{H}$ & H & $\mathrm{OH}$ & $\mathrm{OH}$ & $\mathrm{OH}$ & $\mathrm{OH}$ & $\mathrm{OH}$ & $\mathrm{OH}$ \\
\hline $2 \mathrm{Me}-$ & $\mathrm{CH}_{3}$ & $\mathrm{H}$ & $\mathrm{OH}$ & $\mathrm{OH}$ & $\mathrm{OH}$ & $\mathrm{OH}$ & $\mathrm{OH}$ & $\mathrm{OH}$ \\
\hline $3 \mathrm{Me}-$ & $\mathrm{H}$ & $\mathrm{CH}_{3}$ & $\mathrm{OH}$ & $\mathrm{OH}$ & $\mathrm{OH}$ & $\mathrm{OH}$ & $\mathrm{OH}$ & $\mathrm{OH}$ \\
\hline 2,3-diMe- & $\mathrm{CH}_{3}$ & $\mathrm{CH}_{3}$ & $\mathrm{OH}$ & $\mathrm{OH}$ & $\mathrm{OH}$ & $\mathrm{OH}$ & $\mathrm{OH}$ & $\mathrm{OH}$ \\
\hline aminotriol & $\mathrm{H}$ & $\mathrm{H}$ & H & $\mathrm{H}$ & $\mathrm{OH}$ & $\mathrm{OH}$ & $\mathrm{OH}$ & $\mathrm{NH}_{\mathrm{S}}$ \\
\hline $2 \mathrm{Me}-$ & $\mathrm{CH}_{3}$ & H & H & $\mathrm{H}$ & $\mathrm{OH}$ & $\mathrm{OH}$ & $\mathrm{OH}$ & $\mathrm{NH}_{\mathrm{S}}$ \\
\hline $3 \mathrm{Me}-$ & $\mathrm{H}$ & $\mathrm{CH}_{3}$ & $\mathrm{H}$ & $\mathrm{H}$ & $\mathrm{OH}$ & $\mathrm{OH}$ & $\mathrm{OH}$ & $\mathrm{NH}$ \\
\hline 2,3-diMe- & $\mathrm{CH}_{3}$ & $\mathrm{CH}_{3}$ & H & $\mathrm{H}$ & $\mathrm{OH}$ & $\mathrm{OH}$ & $\mathrm{OH}$ & $\mathrm{NH}_{\mathrm{S}}$ \\
\hline aminotetrol & $\mathrm{H}$ & $\mathrm{H}$ & H & $\mathrm{OH}$ & $\mathrm{OH}$ & $\mathrm{OH}$ & $\mathrm{OH}$ & $\mathrm{NH}_{2}$ \\
\hline $2 \mathrm{Me}-$ & $\mathrm{CH}_{3}$ & H & H & $\mathrm{OH}$ & $\mathrm{OH}$ & $\mathrm{OH}$ & $\mathrm{OH}$ & $\mathrm{NH}_{2}$ \\
\hline 3Me- & $\mathrm{H}$ & $\mathrm{CH}_{3}$ & H & $\mathrm{OH}$ & $\mathrm{OH}$ & $\mathrm{OH}$ & $\mathrm{OH}$ & $\mathrm{NH}_{3}$ \\
\hline 2,3-diMe- & $\mathrm{CH}_{3}$ & $\mathrm{CH}_{3}$ & H & $\mathrm{OH}$ & $\mathrm{OH}$ & $\mathrm{OH}$ & $\mathrm{OH}$ & $\mathrm{NH}_{3}$ \\
\hline aminopentol & $\mathrm{H}$ & H & $\mathrm{OH}$ & $\mathrm{OH}$ & $\mathrm{OH}$ & $\mathrm{OH}$ & $\mathrm{OH}$ & $\mathrm{NH}_{3}$ \\
\hline $2 \mathrm{Me}-$ & $\mathrm{CH}_{3}$ & H & $\mathrm{OH}$ & $\mathrm{OH}$ & $\mathrm{OH}$ & $\mathrm{OH}$ & $\mathrm{OH}$ & $\mathrm{NH}_{2}$ \\
\hline 3Me- & $\mathrm{H}$ & $\mathrm{CH}_{3}$ & $\mathrm{OH}$ & $\mathrm{OH}$ & $\mathrm{OH}$ & $\mathrm{OH}$ & $\mathrm{OH}$ & $\mathrm{NH}_{2}$ \\
\hline 2,3-diMe- & $\mathrm{CH}_{3}$ & $\mathrm{CH}_{3}$ & $\mathrm{OH}$ & $\mathrm{OH}$ & $\mathrm{OH}$ & $\mathrm{OH}$ & $\mathrm{OH}$ & $\mathrm{NH}$ \\
\hline
\end{tabular}

FigureS1 Core structure of B H Ps discussed in text. Complex structures are shown in figures where applicable. 


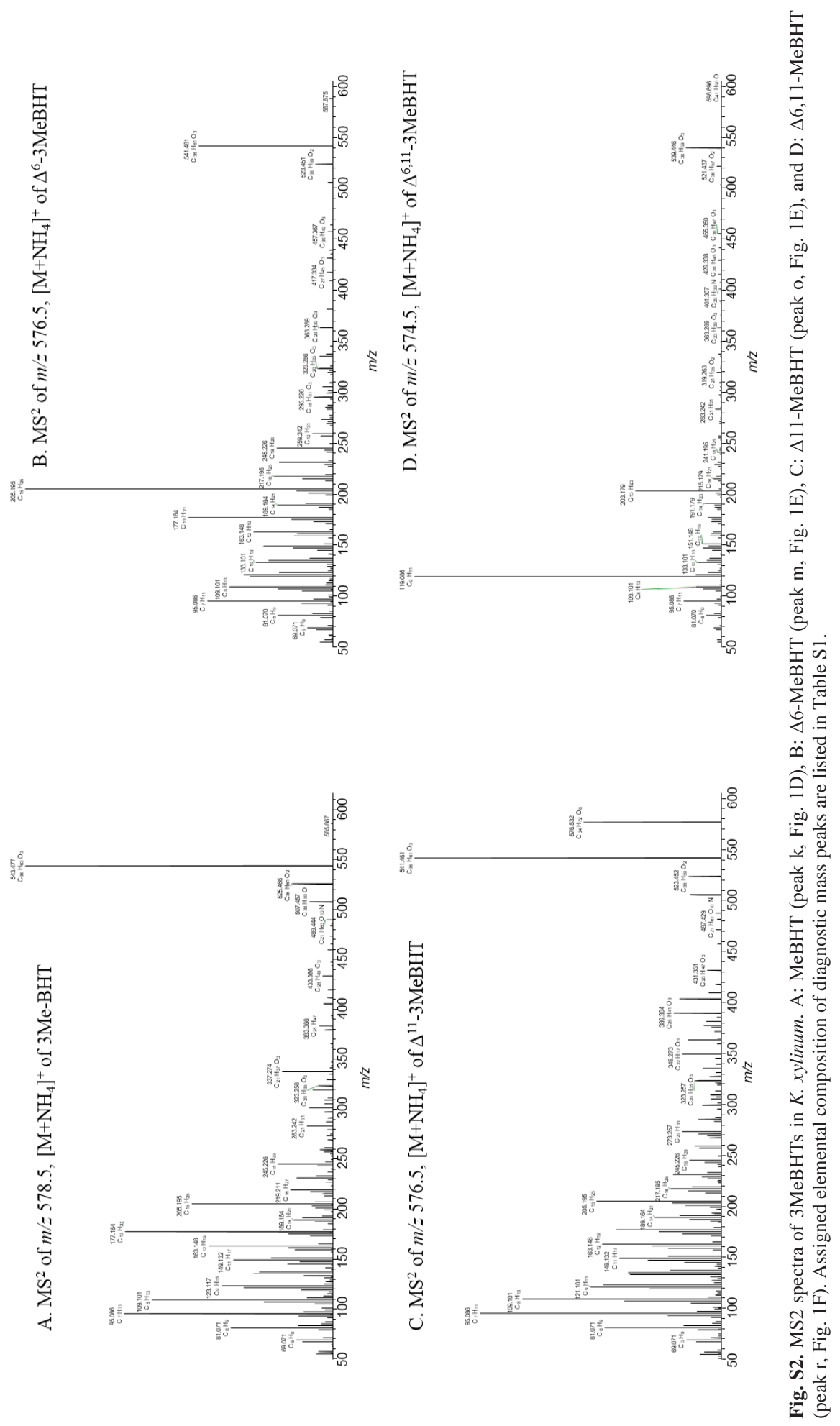




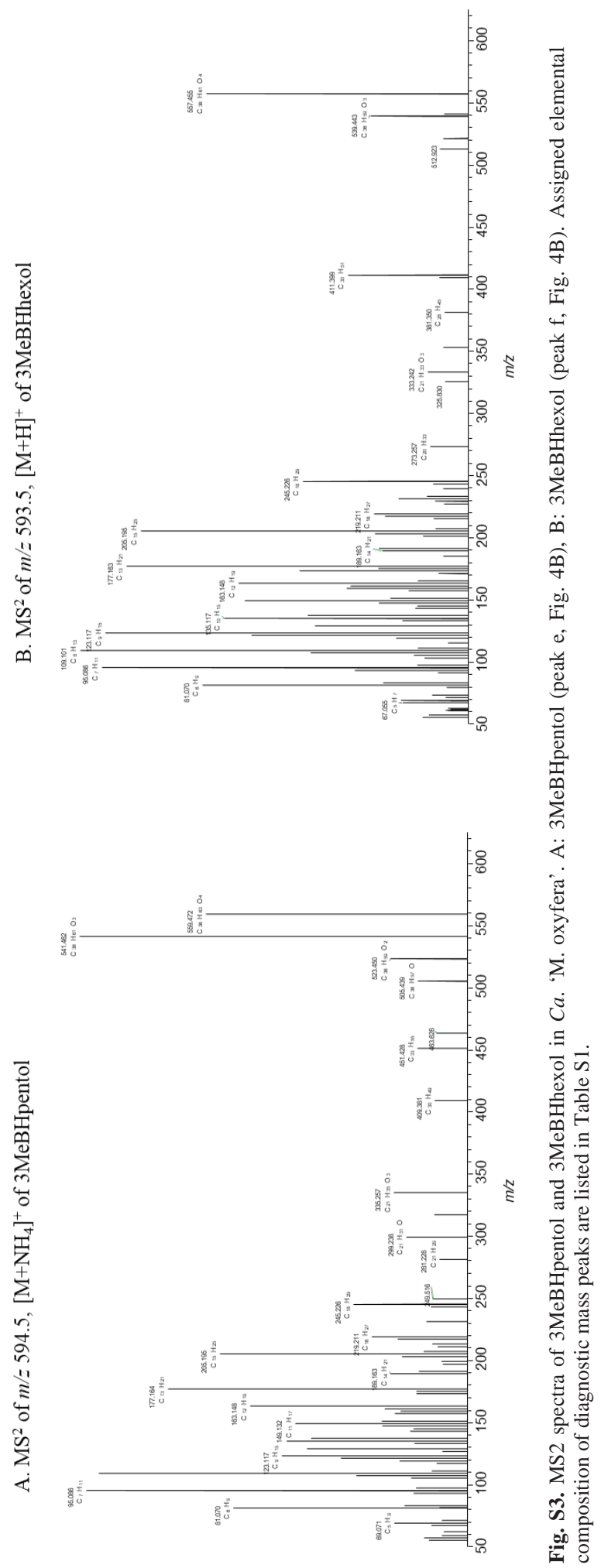



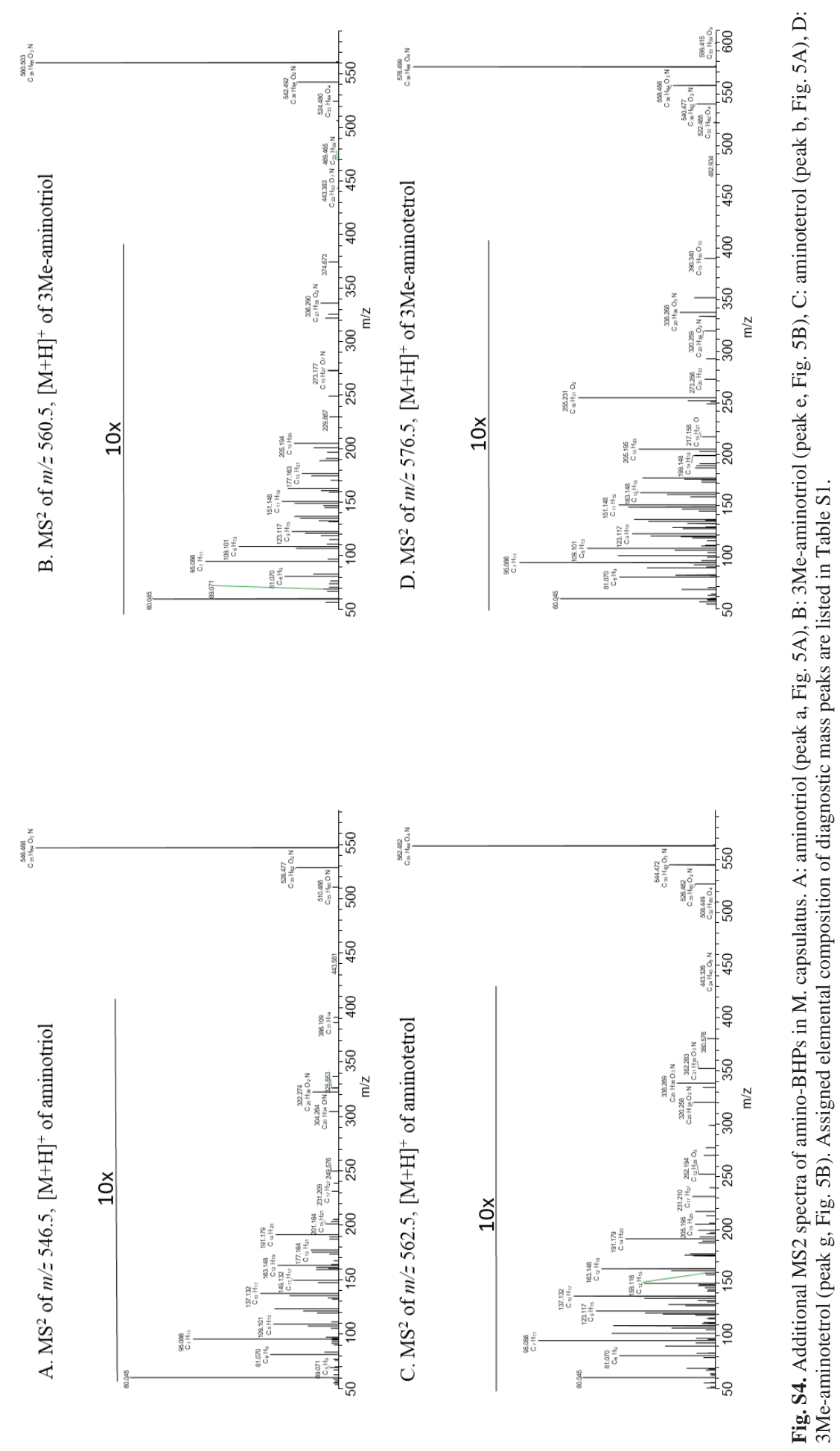


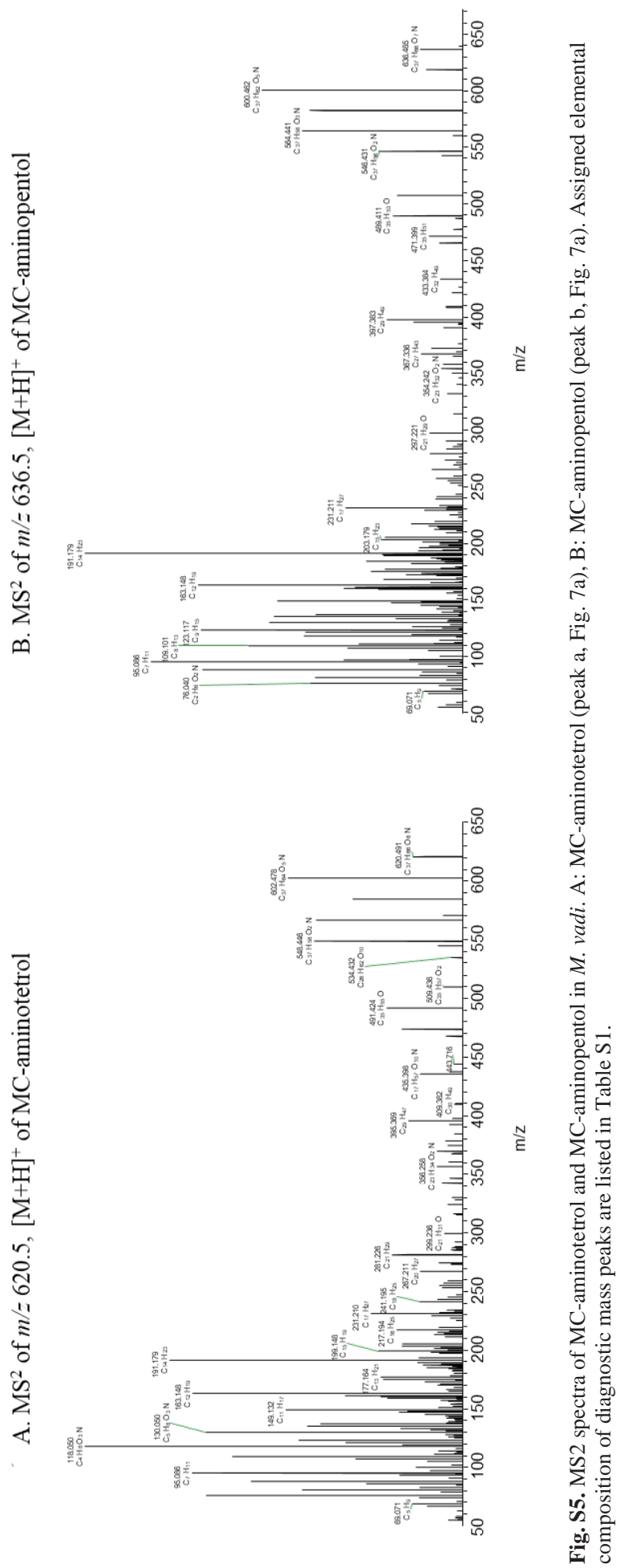


154 | Chapter 5

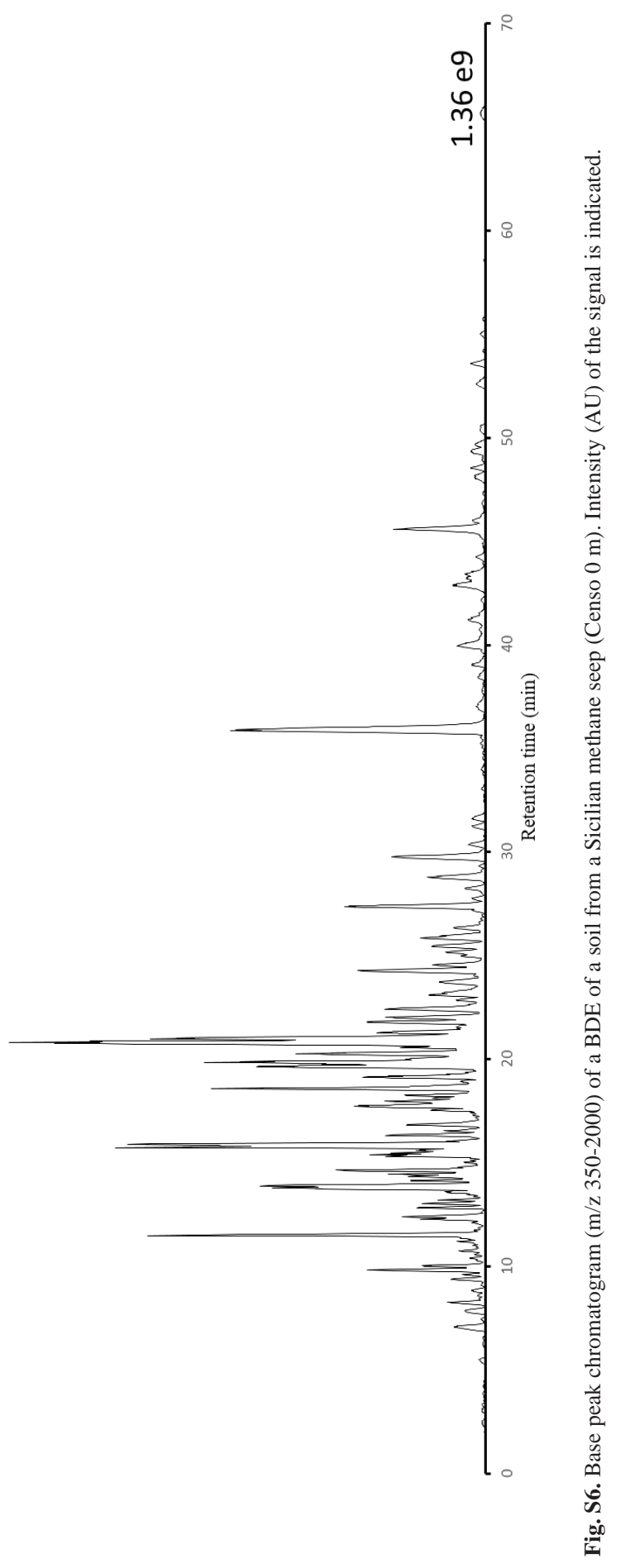




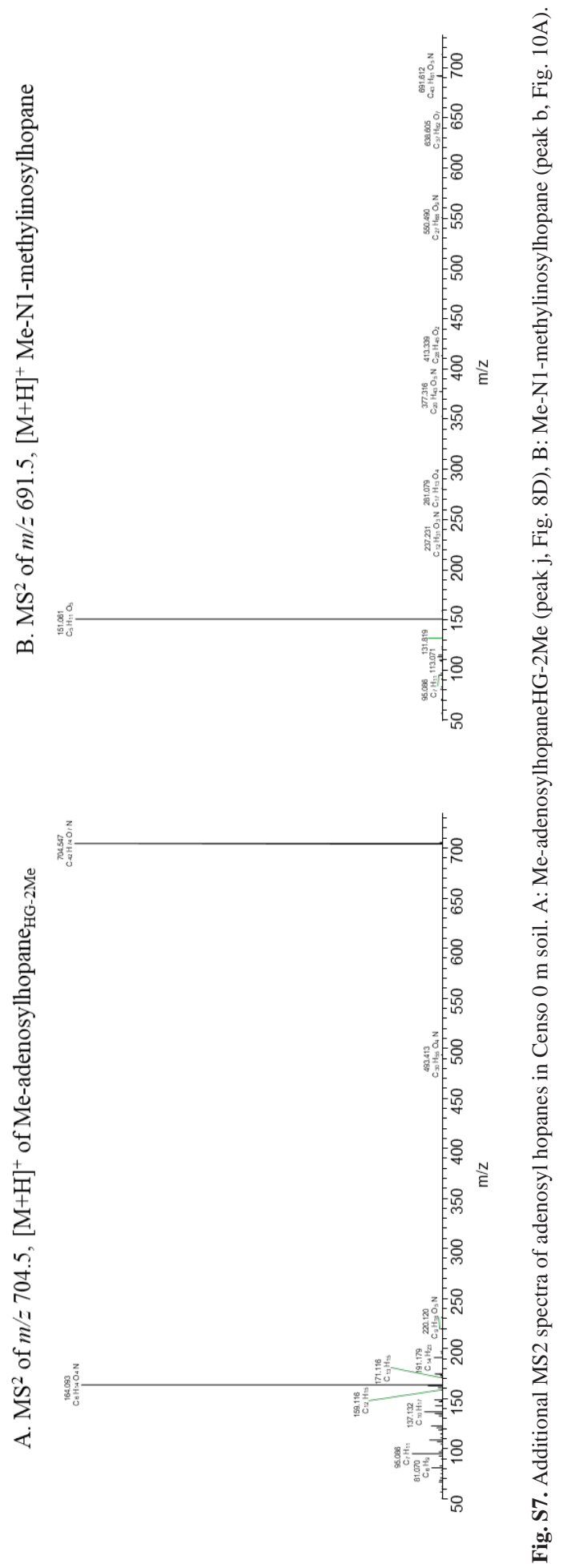



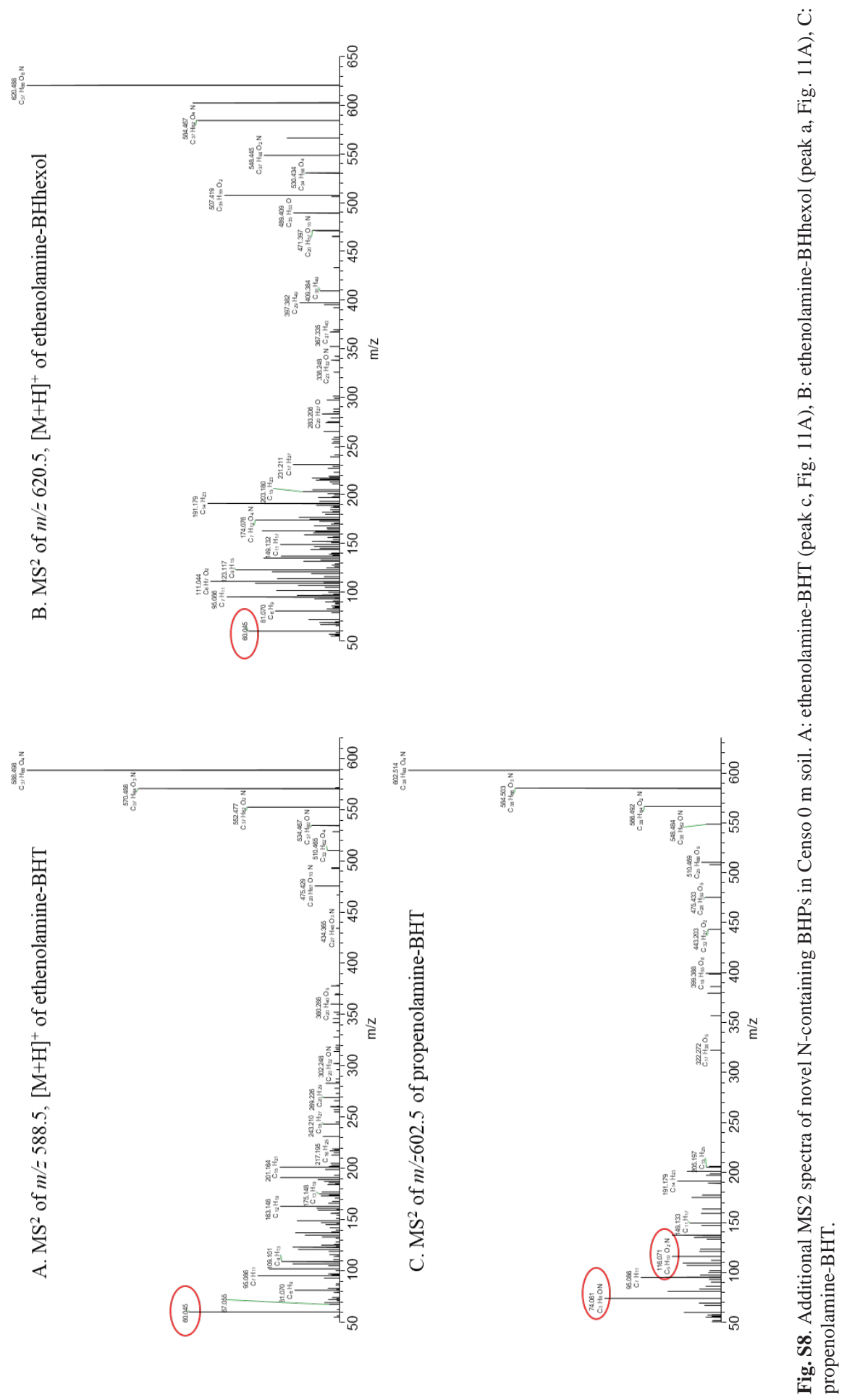


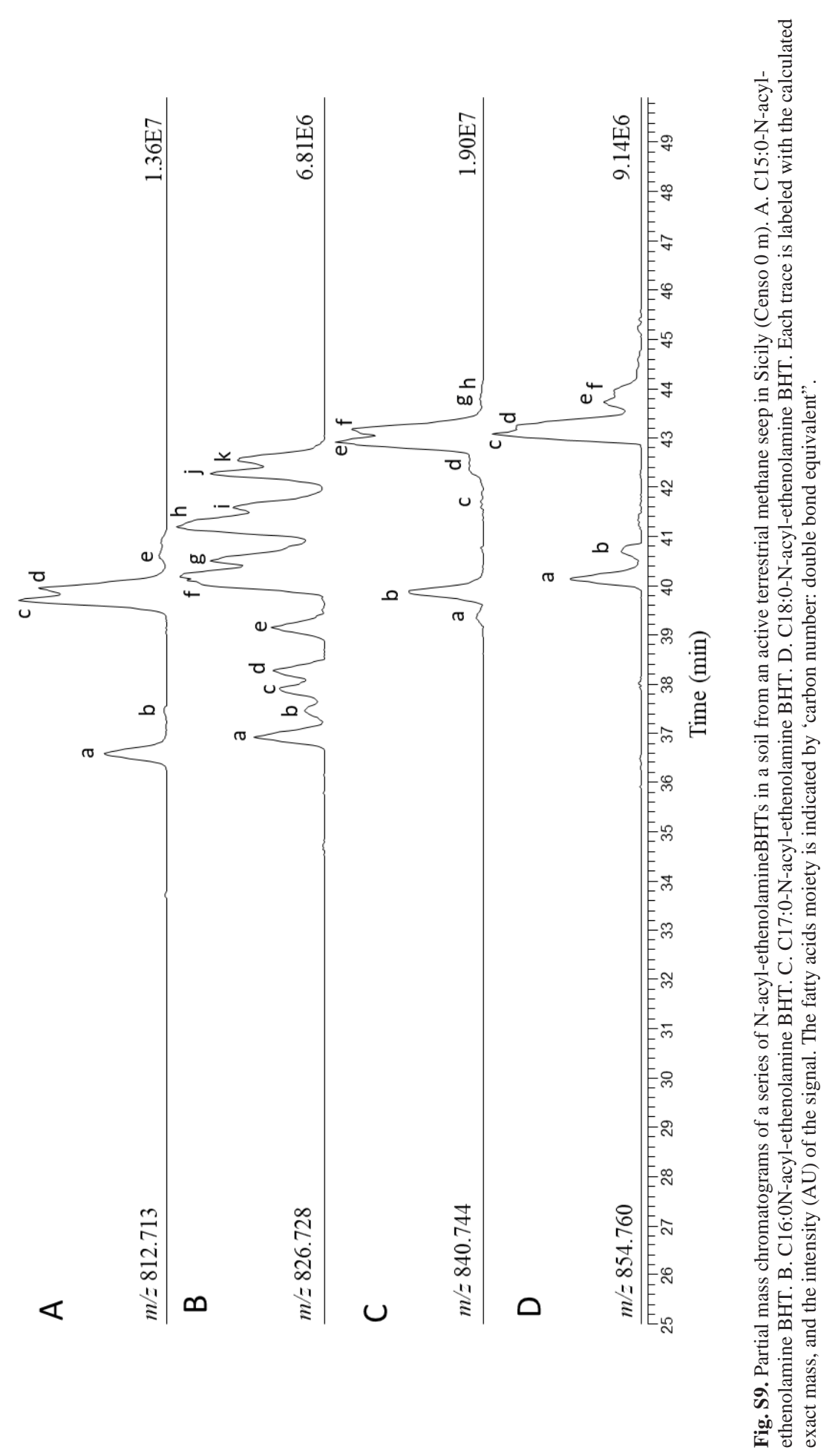



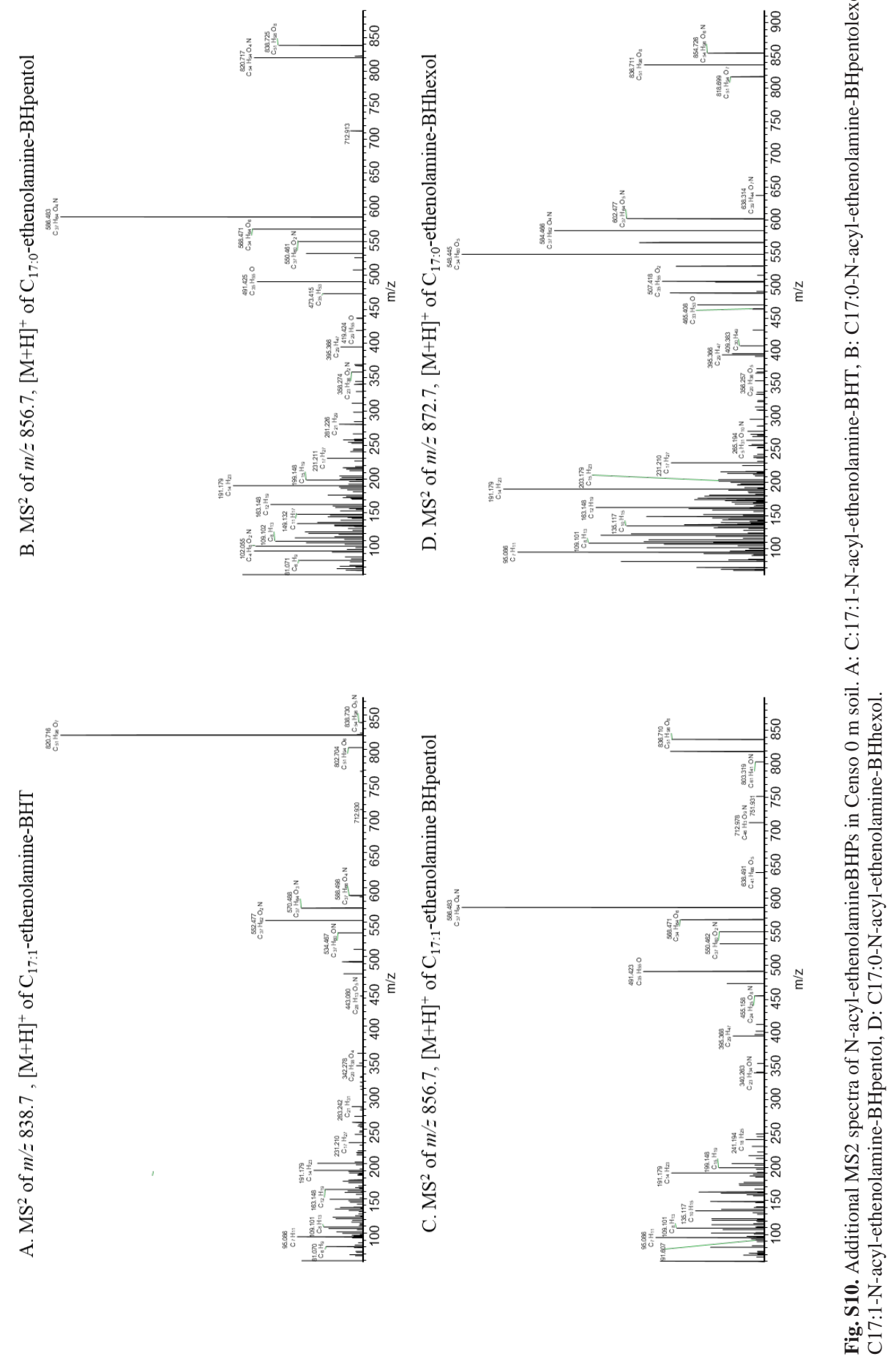


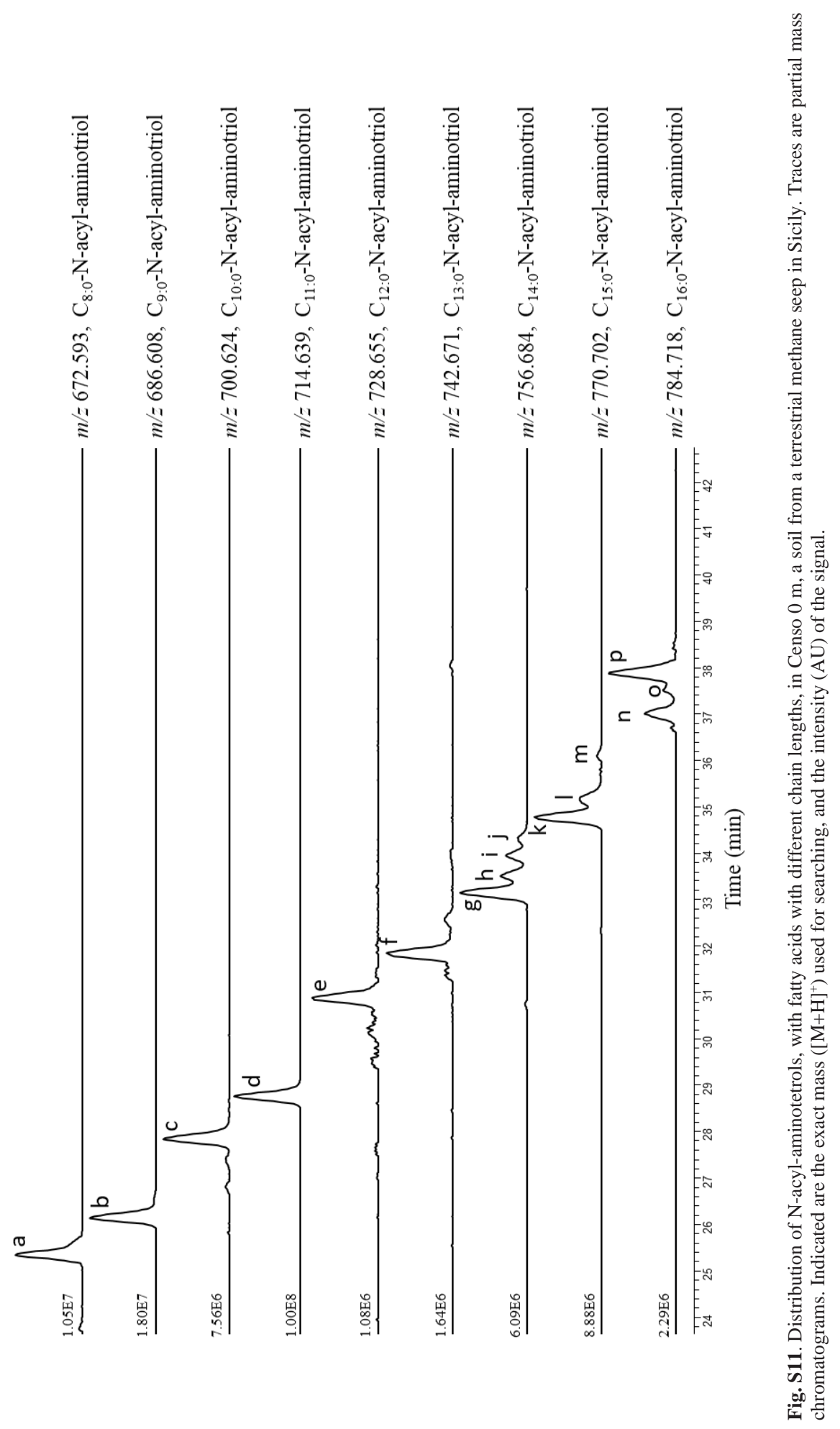




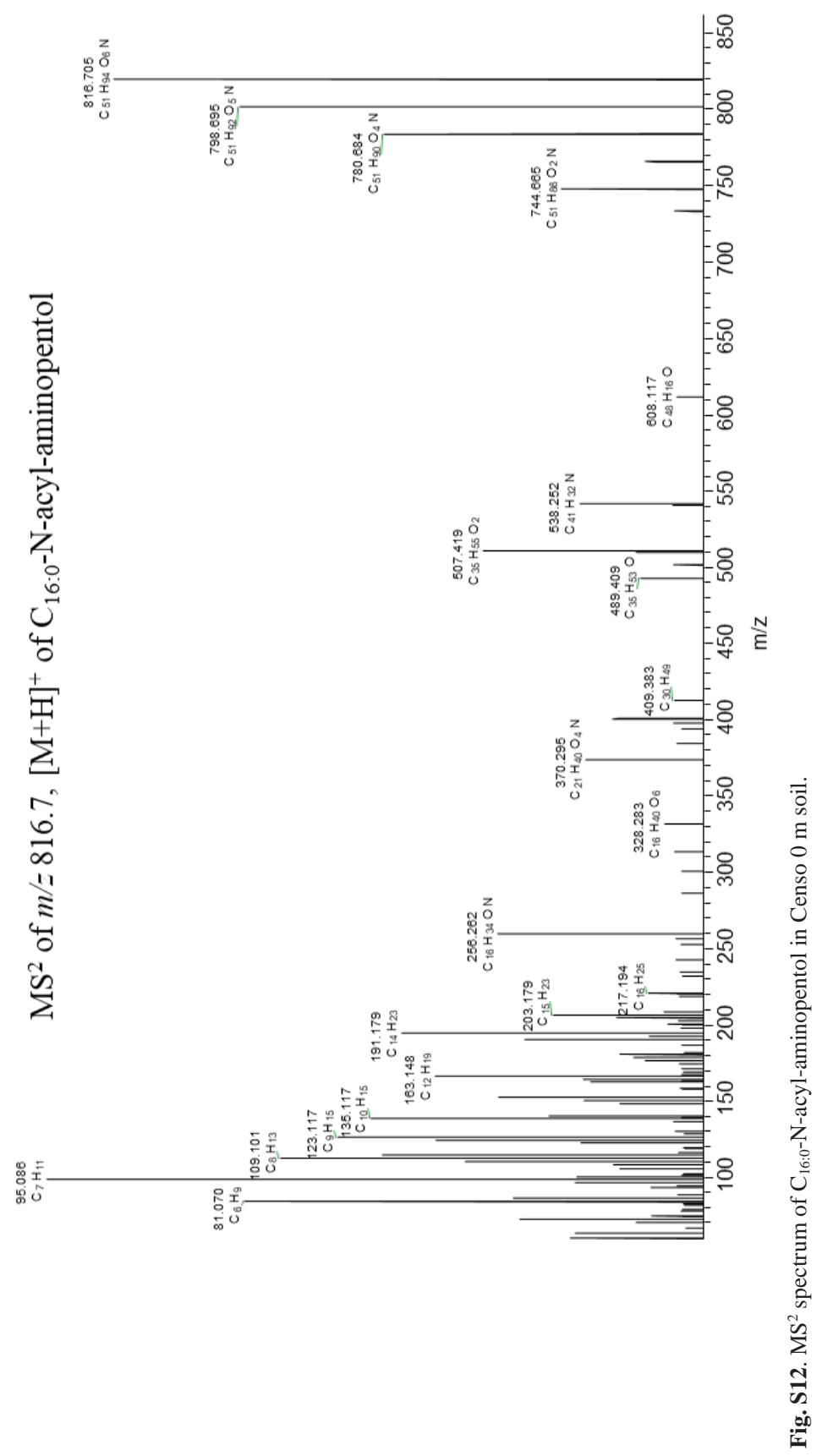




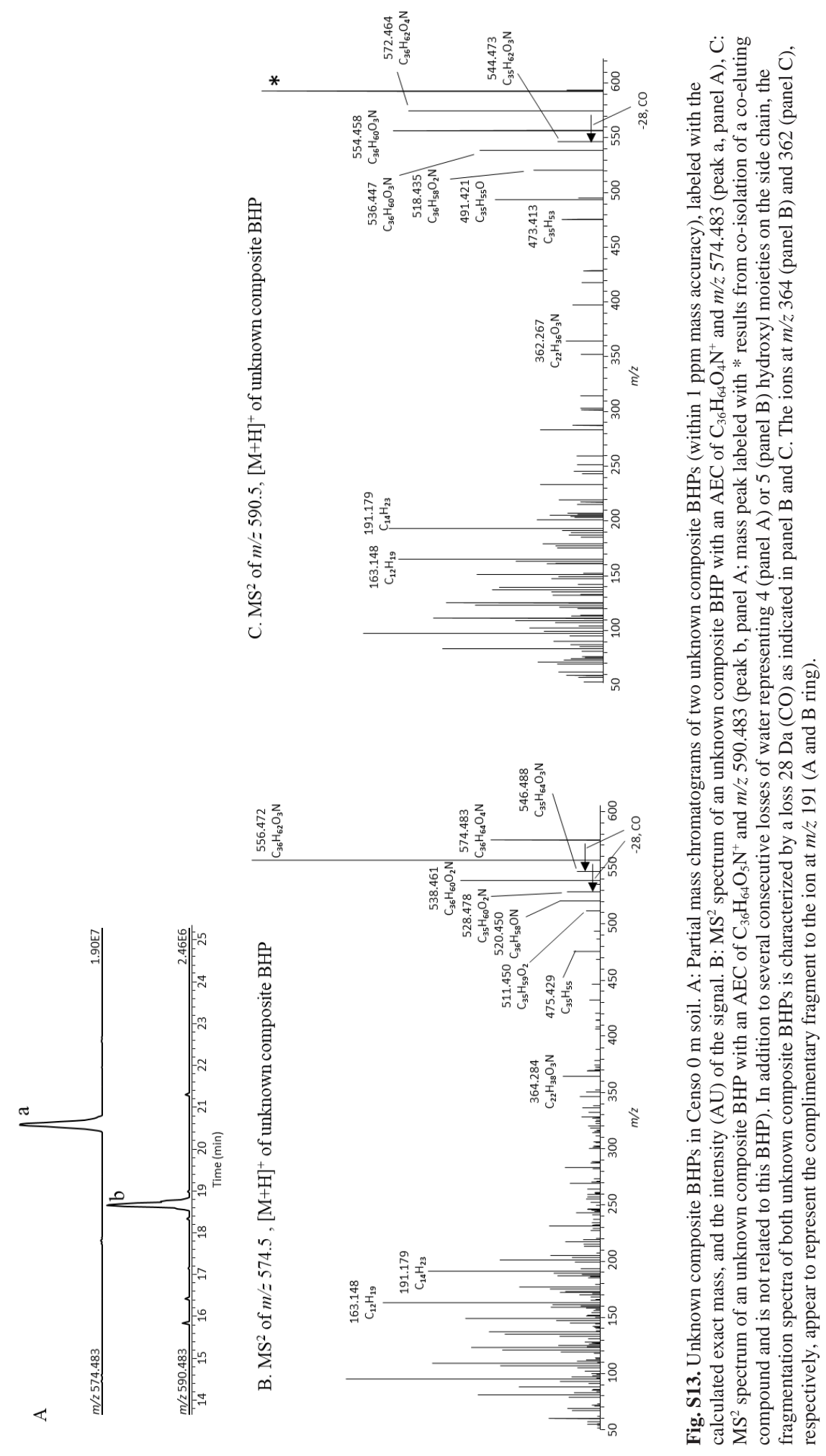


162 | Chapter 5 


\section{Chapter 6}

The abundance of nitrogen-containing bacteriohopanepolyols reflect aerobic methane oxidation at two terrestrial hydrocarbon seeps in Sicily

Nadine T. Smit, Ellen C. Hopmans, Laura Villanueva, Dina Boukhchtaber Castillo, Fausto Grassa, Carmen Hogendoorn, Huub J. M. Op den Camp, Jaap S. Sinninghe Damsté, Stefan Schouten, Darci Rush

In preparation for Geochimica et Cosmochimica Acta 


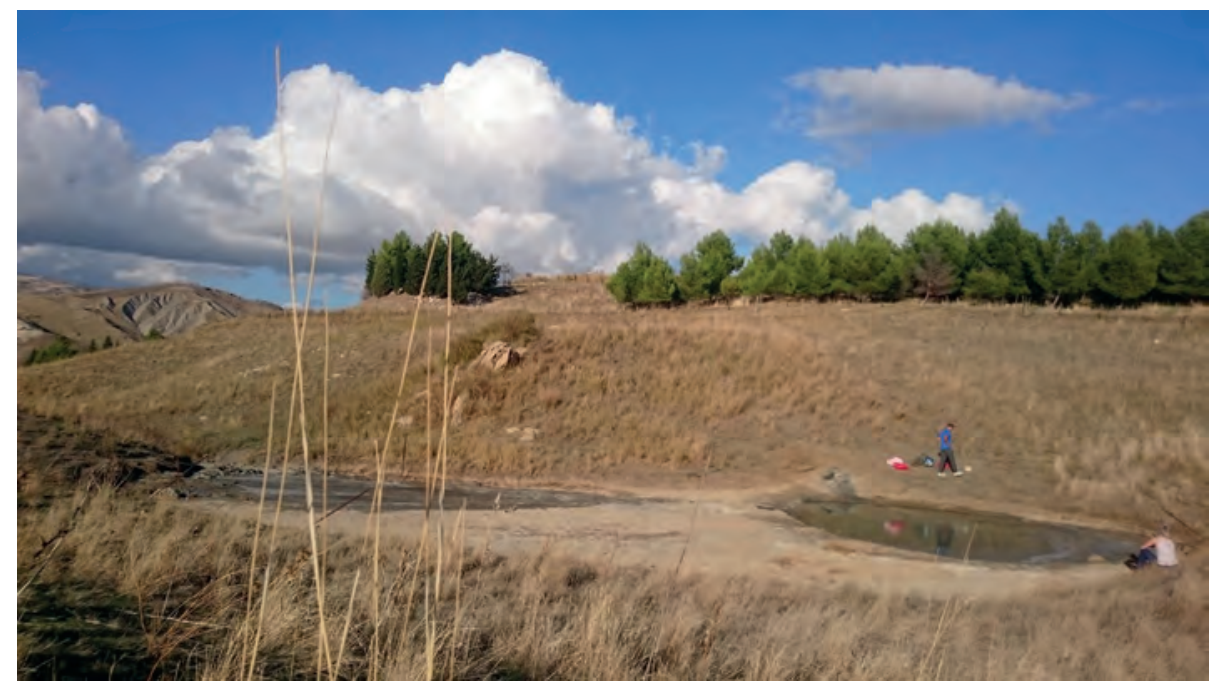

Bissana seep near Cattolica Eraclea in Sicily, Italy

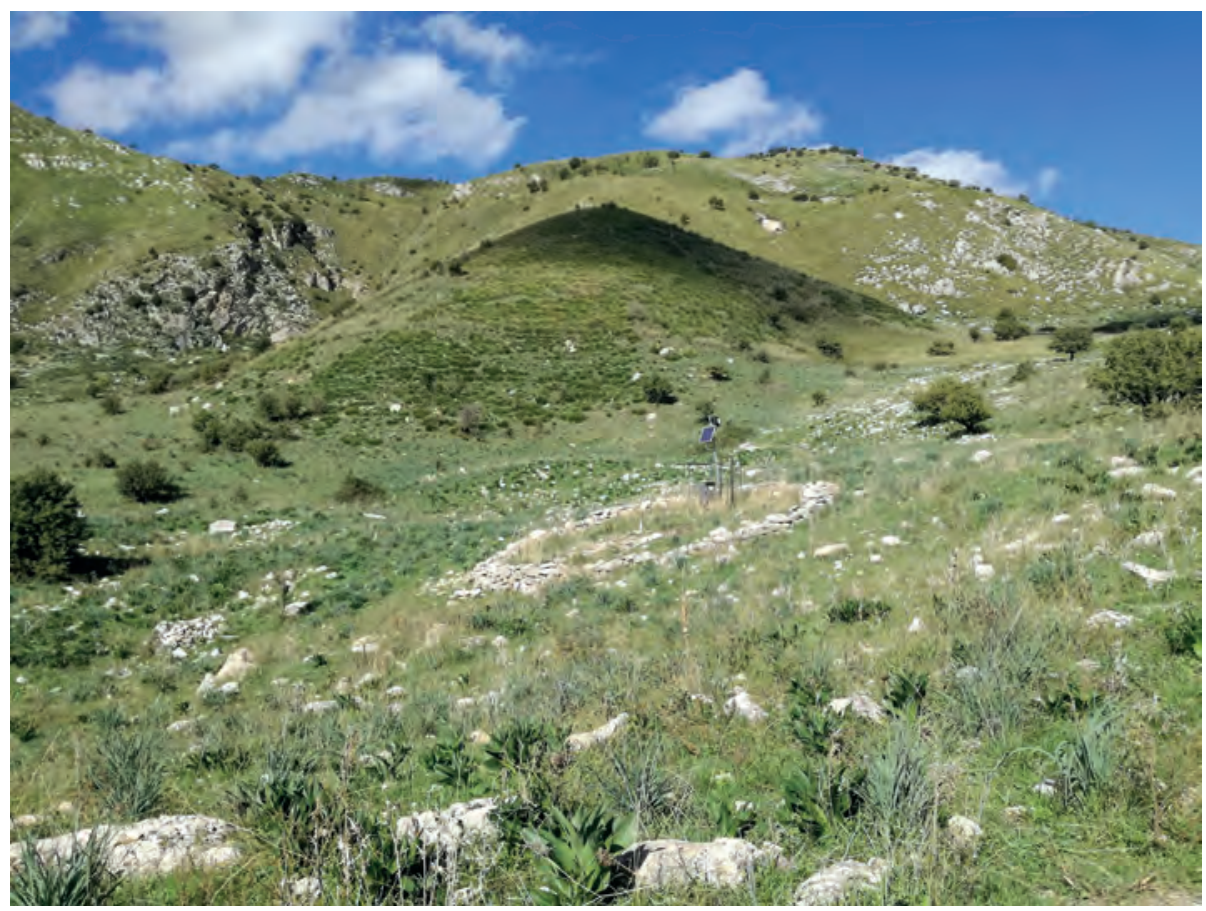

Fuoco di Censo everlasting fire in Sicily, Italy 


\section{Abstract}

Bacterial lipid biomarkers such as bacteriohopanepolyol (BHP) derivatives that contain a nitrogen atom, e.g. in a terminal amine group (aminoBHPs), can be used to trace methanotrophic bacterial communities, and thus aerobic oxidation of methane, in modern and ancient environments. However, the distributions of $\mathrm{N}$-containing B HPs as potential indicators for aerobic oxidation of methane have not yet been fully explored. Here, we investigate the distribution of $\mathrm{N}$-containing BHPs for two terrestrial methane seep transects (C enso seep and B issana seep) in Sicily, Italy. The Censo and Bissana seeps show high relative abundances of three aminoB HPs (aminotriol, aminotetrol and aminopentol) as well as recently identified ethenolamineB HPs (ethenolamine-BHT, -pentol and -hexol) and Nacyl-aminotriols at, and close to, the active seep sites. Principal component analysis (PCA) demonstrate that the aminoB H Ps cluster together with the novel ethenolamineB H Ps and $\mathrm{N}$-acyl-aminotriols thus suggesting an origin likely from aerobic methanotrophs. 16S rRNA gene sequencing showed that Type I methanotrophs comprise up to $8 \%$ of the bacterial community at the Censo seep while they comprised only up to $0.2 \%$ at the Bissana seeps. Possibly, some groups within the Gammaproteobacteria, which comprised a major part of the bacterial 16S rRNA gene reads at the Bissana seeps, were also a source of aminoB HPs and their 3-methylated homologues. The Censo seep contained high relative abundances of a novel late eluting aminotriol, which was also identified in a verrucomicrobial strain, Methylacidimicrobium cyclopophantes 3B, suggesting it as a potential biomarker for these methanotrophic Verrucomicrobia. Both seep sites show increasing relative abundances of soilmarker BHPs (i.e. adenosylhopane and N 1-methylinosylhopane) with increasing distance from the seeps and an opposite trend in the abundance of the $\mathrm{N}$ containing BHPs. A $n$ index for aerobic oxidation of methane based on selected BHPs was developed which showed high values close to the seeps $(\geq 0.4)$ and drop to $<0.2$ at distances $>3 \mathrm{~m}$ from the active seeps. Further development and application of this novel A minoB HP-index may offer a new biomarker tool to reconstruct present and past aerobic oxidation of methane in terrestrial environments.

\section{Introduction}

The greenhouse gas methane $\left(\mathrm{CH}_{4}\right)$ plays an important role in the Earth's carbon cycle (Reeburgh, 1996, 2007; Myhre et al., 2014; Dean et al., 2018). Atmospheric methane concentrations have substantially increased since preindustrial times, but terrestrial methane sources, sinks and chemical reaction 
pathways remain poorly constrained (Reeburgh, 1996; Myhre et al., 2014; Schwietzke et al., 2016). V arious natural sources are known to emit methane into the atmosphere, e.g. biogenic methane is emitted from wetlands, thawing permafrost soils, and marine sediments, while thermogenic methane is emitted from marine and terrestrial hydrocarbon seeps (Reeburgh, 1996; Etiope et al., 2009; O'Connor et al., 2010; Dean et al., 2018).

In many terrestrial and marine environments, biogenic and thermogenic methane is subject to microbial oxidation processes, which convert methane to $\mathrm{CO}_{2}$ thus reducing methane emission to the atmosphere and affecting biogeochemical carbon cycling (Hanson and Hanson, 1996). The anaerobic oxidation of methane (A OM) is conducted by anaerobic methanotrophic archaea (A N M Es) found in marine (Hinrichs et al., 1999; B oetius et al., 2000; Pancost et al., 2000a) and freshwater environments (Takeuchi et al., 2011; Haroon et al., 2013). A erobic oxidation of methane plays a key role in removing methane not only in marine environments (e.g. oxic water columns) but also in the terrestrial realm (e.g. soils or peatlands) (B ull et al., 2000; B odelier et al., 2009; B owman, 2011). The main aerobic methane-oxidizing bacteria ( $M O B s$ ) are from three different phylogenetic groups, i.e. Gammaproteobacteria (Type I methanotrophs), Alphaproteobacteria (Type II methanotrophs) and the (thermo)acidophilic Verrucomicrobia (Hanson and Hanson, 1996; Pol et al., 2007; Op den Camp et al., 2009; Schmitz et al., 2021).

In addition to DNA-based techniques, lipid biomarkers offer a tool to investigate bacterial communities involved in methane oxidation in the environment. Lipids are more stable over long timescales than DNA, which favours their use to reconstruct past biogeochemical cycles, including the methane cycle (H ofreiter et al., 2001; B rocks and Pearson, 2005; B oere et al., 2011). Besides fatty acids and hopanoids (Bull et al., 2000; Crossman et al., 2005; D edysh et al., 2007; B odelier et al., 2009), bacteriohopanepolyols and their derivatives (here abbreviated as B HPs) have been used to trace M OB s and thus the aerobic oxidation of methane (van W inden et al., 2012; Tal bot et al., 2014; Wagner et al., 2014). BHPs are a diverse group of compounds with a large structural diversity especially in the length, position and complexity of the functional groups located on the side chain (e.g. Neunlist et al., 1985; T albot and Farrimond, 2007; Tal bot et al., 2007a, b; Cooke et al., 2008a; Hopmans et al., 2021).

Previous studies suggested that methylation at the $\mathrm{C}-3$ position in hopanoids, BHPs and especially aminoBHPs (structures ac; see Fig. 1) is specific to M OBs (Summons et al., 1994; Farrimond et al., 2004). However, 
W elander and Summons (2012) identified the hpnR gene responsible for the methylation at C-3 in hopanoids and revealed it is distributed amongst various bacterial taxa other than methanotrophs. M oreover, the 3-methylation was only found in a limited number of Type I methanotrophic bacteria (W elander and Summons, 2012). In general, 3-methyl hopanoids and BHPs can be used as biomarkers for aerobic oxidation of methane when accompanied by depleted ${ }^{13} \mathrm{C}$ isotopic signatures mainly in marine environments (Collister et al., 1992; Summons et al., 1994; Jahnke et al., 1999). However, recent investigations demonstrated that not all MOB-derived lipids have substantially depleted ${ }^{13} \mathrm{C}$ values, especially when derived from Type II methanotrophs and N C10 bacteria in terrestrial environments such as modern peat bogs, past lignite deposits or wetlands (Pancost et al., 2000b; van Winden et al., 2010; Ettwig et al., 2010; Rasigraf et al., 2014; Inglis et al., 2018).

A erobic methanotrophs in culture produce a range of distinct $\mathrm{N}$ containing BHPS, such as those with an amine group at position C-35 and 3, 4 or 5 hydroxy groups on the side chain of the hopanoid skel eton (structures a c, Fig. 1) (Cvejic et al., 2000; van W inden et al., 2012; Talbot et al., 2014; R ush et al., 2016). The 35-aminobacteriohopane-30,31,32,33,34-pentol ('aminopentol'; structure c) is produced almost solely by Type I methanotrophs (Neunlist and Rohmer, 1985; Cvejic et al., 2000). Furthermore, aminopentol and its unsaturated homologues were detected in different environments like soils, peats, geothermal sinters, the water column, or marine and lake sediments (Gibson et al., 2008; Sáenz et al., 2011; van W inden et al., 2012; Tal bot et al., 2014; Rush et al., 2016; Kusch et al., 2019). Previous studies have used aminopentol as biomarker to trace aerobic oxidation of methane in the marine realm (Talbot and Farrimond, 2007; Sáenz et al., 2011; Talbot et al., 2014). However, a more recent study (Rush et al., 2016) showed that aminopentol might be a more reliable marker for MOBs in methane-influenced terrestrial environments than marine environments as aminopentol was only found to be present in one marine Type I methanotroph species and in low abundance in sediments and authigenic carbonates from marine methane-rich environments.

Finally, two additional amino-BHPs are synthesized by Type I and Type Il methanotrophs as well as by methanotrophic Verrucomicrobia: 35aminobacteriohopane-31,32,33,34-tetrol ('aminotetrol'; b) and 35aminobacteriohopane-32,33,34-triol ('aminotriol'; a) (Tal bot et al., 2001, 2014; Tal bot and Farrimond, 2007; van W inden et al., 2012). However, aminotetrol is also biosynthesized in low relative abundances by some sulfate-reducing bacteria of the Genus Desulfovibrio (Neunlist et al., 1985; Blumenberg et al., 2006; 
Talbot and Farrimond, 2007), while aminotriol is produced by a wide variety of non-methanotrophic bacteria like sulfate-reducing bacteria or cyanobacteria (Talbot et al., 2008; Blumenberg et al., 2012). Therefore, these BHPs, and especially aminotriol, appear less suitable for tracing MOBs and aerobic oxidation of methane.

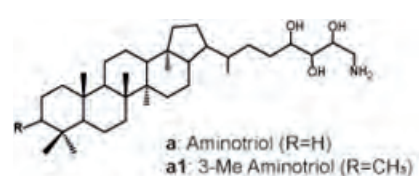

a1 : $3-\mathrm{Me}$ Aminotriol $(\mathrm{R}=\mathrm{CH}$ s)

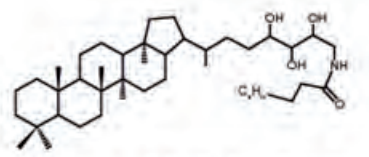

d. $\mathrm{N}$-acyl-Aminotriol $+\mathrm{C}_{n} \mathrm{H}_{\mathrm{n}}$

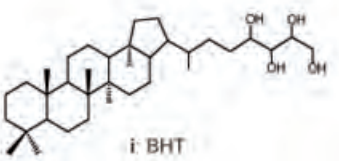

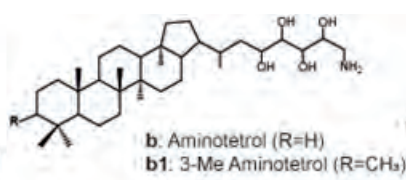

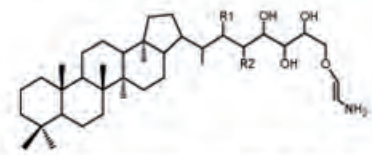

e. Ethenolarnine-BHT $\mathrm{R} 1=\mathrm{H} ; \mathrm{R} 2=\mathrm{H}$ f Ethenolamine-BHpentol $\mathrm{R} 1=\mathrm{H}: \mathrm{R} 2=\mathrm{OH}$ g. Ethenolamine-BHhexol: $\mathrm{R} 1=\mathrm{OH}: \mathrm{R} 2=\mathrm{OH}$

h. $\mathrm{N}$-acyl-Ethenolamine- $\mathrm{BHT}+\mathrm{C}_{n} \mathrm{H}_{\mathrm{n}}$

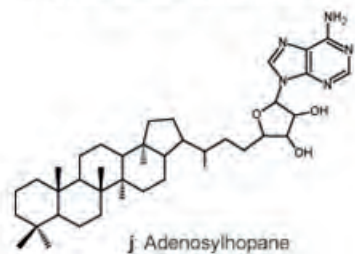



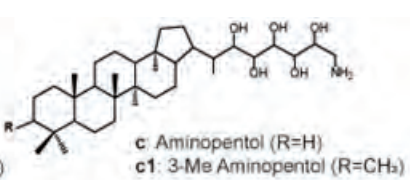

c1: 3 -Me Aminopental $\left(\mathrm{R}=\mathrm{CH}_{3}\right)$

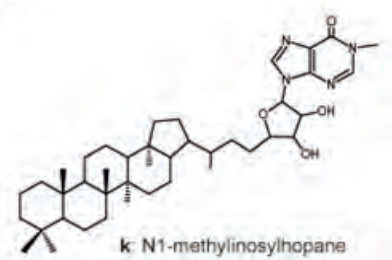

Figure1 Chemical structures of the most relevant bacteriohopanepolyol derivatives in the Bissana and Censo seep soils (for indicative mass spectra see Hopmans et al., 2021).

Despite soils being one of the biggest microbial sinks for atmospheric methane (Fierer et al., 2012; Dean et al., 2018), only few studies in terrestrial environments have used BHPs to trace the presence of MOBs. To date, only peatlands geothermal sinters and lake sediments were investigated for MOB specific B HPs (Coolen et al., 2008; Gibson et al., 2008; van W inden et al., 2012; Tal bot et al., 2016) which showed the presence of all three aminoB H Ps and some of their 3-methylated homologues. In these environments, aminopentol and its 3-methyl homologue were suggested to derive from Type I methanotrophs, while aminotetrol originates from Type I and Type II methanotrophs and its 3-methyl homologue from Type I methanotrophs. A minotriol and its 3-methyl counterpart are known to derive from Type II methanotrophs but also from other more ubiquitous bacterial species such as A cidobacteria (Gibson et al., 2008; van Winden et al., 2012; T albot et al., 2016; Sinninghe Damsté et al., 2017).

In this study, we used an ultra-high pressure liquid chromatography-high resolution mass spectrometry (UHPLC-HRM S) method (Hopmans et al., 2021) to analyse the diversity of $\mathrm{B} \mathrm{HPs}$ al ong transects of two continuous terrestrial $\mathrm{CH}_{4}$ 
seeps, Bissana and Fuoco di Censo (everlasting fire) in Sicily, Italy (Etiope et al., 2002; Smit et al., 2021a). Previous studies on a few soils from the Censo seep showed the presence of methanotrophic bacteria and ${ }^{13} \mathrm{C}$ depleted fatty acids (Smit et al., 2021a) as well a large diversity in B HPs (Hopmans et al., 2021), making them excellent candidates to investigate the presence of BHPs selective for aerobic oxidation of methane. The changes in distribution of BHPs were evaluated in tandem with those in the prokaryotic community as determined by $16 \mathrm{~S}$ rRN A gene amplicon sequencing. O ur results led to the establishment of an index that can potentially be used to trace back aerobic oxidation of methane in modern and past terrestrial environments.

\section{M aterial and methods}

\subsection{Study sites}

The B issana seep $\left(37^{\circ} 29^{\prime} 00.4^{\prime \prime} \mathrm{N}, 13^{\circ} 23^{\prime} 17.5^{\prime \prime} \mathrm{E}\right)$ near Cattolica Eraclea and the Fuoco di Censo seep $\left(37^{\circ} 37^{\prime} 30.1^{\prime \prime} \mathrm{N}, 13^{\circ} 23^{\prime} 15.0^{\prime \prime} \mathrm{E}\right)$, in the following referred to as B issana seep and Censo seep, respectively, are both located in the mountains of Southwestern Sicily, Italy (Etiope et al., 2002, 2007; G rassa et al., 2004). The investigated area is part of the Alpine orogenic belt in the M editerranean and located along the boundary of the A frican and European plates (B asilone, 2012). The Bissana and Censo seeps are located in the Bivona and Cattolica Eraclea areas, which are characterized by a complex geological setting including formations with sandy clays, marls or carbonates from the Tortonian-M essinian often covered by thrusting limestones or other Pliocene/Pleistocene deposits (Trincianti et al., 2015).

The Bissana seep is characterized by a wide pool (about $10 \mathrm{~m}$ in diameter) in which gases, mud and salty waters gurgle with varying intensities from different smaller gas and mud seeps (Piepoli, 1931; Etiope et al., 2002). The pool contains dry and wet areas with active seeps at its edges. The gas composition at the Bissana seep mainly contains methane (96.2\%) with minor proportions of other gases like $\mathrm{N}_{2}, \mathrm{CO}_{2}, \mathrm{He}$ or $\mathrm{H}_{2}$ (Etiope et al., 2002). Soil degassing occurs with an average methane flux of $1 \times 10^{5} \mathrm{mg} \mathrm{m}^{-2} \mathrm{~d}^{-1}$ and a total methane emission of 2.7 tons $\mathrm{yr}^{-1}$ (Etiope et al ., 2002). The released methane has a $\delta^{13} \mathrm{C}$ value of $-47 \%$ and $\mathrm{C} 1 /(\mathrm{C} 2+\mathrm{C} 3)$ gas ratios greater than ca.130 (G rassa et al, unpublished results).

The Censo seep is a typical example of a natural 'everlasting fire' at which the released gas consists mainly of methane (76-86\%) and $\mathrm{N}_{2}$ (10-17\%) as well as some other minor gases like $\mathrm{CO}_{2}, \mathrm{O}_{2}$, ethane, propane, $\mathrm{He}$ and $\mathrm{H}_{2}$ (Etiope et al., 2002; Grassa et al., 2004). A diffuse soil degassing was present 
within an area of $80 \mathrm{~m}^{2}$ with an average methane flux of $7 \times 10^{6} \mathrm{mg} \mathrm{m}^{-2} \mathrm{~d}^{-1}$ and a total methane emission of 6.2 tons $\mathrm{yr}^{-1}$ (Etiope et al., 2002, 2007). The methane is suggested to be generated by the thermal alteration of organic matter from overmature marine source rocks (kerogen type II) and is characterized by a $\delta^{13} \mathrm{C}$ value of $-35 \%$ and $C 1 /(C 2+C 3)$ ratios greater than 100 (G rassa et al., 2004).

\subsection{Samples}

Soil and mud samples of the B issana seep and Censo seep (Smit et al., 2021a) were taken during a field campaign in 0 ctober 2017. The samples were obtained in triplicate within $0.5 \mathrm{~m}^{2}$ from a horizon 5 to $10 \mathrm{~cm}$ below the soil surface and at different distances from the active seeps (T able 1). A t the Censo seep, the area with the major gas flux is determined as the main seep site (Censo $0 \mathrm{~m}$ ), whereas at the B issana seep three active seep sites (B is seep 1, 2 and 3) were discovered, which all actively bubbled a mixture of gas and liquid mud (Table 1). The in-situ temperature of the soil and mud from both seep sites at the time of collection were ranging between 18-20 $\stackrel{\circ}{ }$. The soil and mud from both seep sites were directly transferred into a clean geochemical sampling bag and stored frozen at $-20 \stackrel{\circ}{C}$ until freeze drying and extraction.

A mesophilic acidophilic verrucomicrobial strain (M ethylacidimicrobium cyclopophantes $3 \mathrm{~B}$ ) was isolated from a volcanic soil taken from the Solfatara crater, which is at the centre of the Campi Flegrei caldera, near $\mathrm{N}$ aples (Italy) (van Teeseling et al., 2014). The strain was grown under optimal conditions as described by van Teeseling et al. (2014) at $44{ }^{\circ} \mathrm{C}$ and a pH of 2.5.

\subsection{L ipid extraction}

Freeze-dried B issana (ca. 5-6 g) and Censo (ca. $12 \mathrm{~g}$ ) seep soil and mud as well as freeze-dried bacterial biomass of $M$. cyclopophantes $3 B$ were extracted with a modified Bligh and Dyer extraction (Bale et al., 2013). The samples were ultrasonically extracted for $10 \mathrm{~min}$ with a solvent mixture containing methanol $(\mathrm{M} \mathrm{eOH})$, dichloromethane (DCM) and phosphate buffer (2: 1: 0.8, v: v: v). A fter centrifugation, the solvent was collected, combined and the residues re-extracted twice. A biphasic separation was achieved by adding additional DCM and phosphate buffer to a ratio of $\mathrm{M} \mathrm{eOH}, \mathrm{DCM}$ and phosphate buffer (1: 1: 0.9, v: v: v). The aqueous layer was washed two more times with DCM and the combined organic layers dried over a $\mathrm{Na}_{2} \mathrm{SO}_{4}$ column followed by drying under $\mathrm{N}_{2}$. A liquots of the Bligh and Dyer extracts (BDEs) were obtained and $0.4 \mu \mathrm{g} / \mathrm{ml}$ (Censo) or $0.04 \mu \mathrm{g} / \mathrm{ml}$ (Bissana) DGTS-D 9 (1,2-dipalmitoyl-sn-glycero-3-0-4'$[\mathrm{N}, \mathrm{N}, \mathrm{N}$-trimethyl(D 9)]-homoserine, A vanti Polar Lipids (Alabaster, AL)) was 
added as internal standard before they were filtered through a $0.45 \mu \mathrm{m}$ regenerated cellulose filter with $4 \mathrm{~mm}$ diameter and evaporated until dryness. Finally, the filtered BDEs were dissolved in $\mathrm{MeOH}: \mathrm{DCM}(9: 1)$ and analysed using U HPLC-HRMS.

\section{UHPLC-HRMS of BHPs}

Intact B HP analysis on the extracts of the soil samples and the M. cyclopophantes 3B biomass was performed by UHPLC-HRMS according to Hopmans et al. (2021) using an A gilent 1290 Infinity I UHPLC, equipped with thermostatted autosampler and column oven, coupled to a quadrupole-orbitrap HRMS equipped with an Ion $M$ ax source (Thermo F isher Scientific, W altham, M A) with heated electrospray ionization (HESI) probe. A $\mathrm{C}_{18} \mathrm{BEH}$ column $(2.1 \times 150 \mathrm{~mm}$, $1.7 \mu \mathrm{m}$ particle; Waters) fitted with a pre-column, and a solvent system consisting of eluent $\mathrm{A}$ methanol: $\mathrm{H}_{2} \mathrm{O}(85: 15)$ and eluent $\mathrm{B}$ methanol:isopropanol (1:1) both containing $0.12 \%(\mathrm{v} / \mathrm{v})$ formic acid and $0.04 \%(\mathrm{v} / \mathrm{v})$ aqueous ammonia were used for separation. Compounds were eluted with $5 \% \mathrm{~B}$ for $3 \mathrm{~min}$, followed by a linear gradient to $60 \% \mathrm{~B}$ at $12 \mathrm{~min}$ and then to $100 \% \mathrm{~B}$ at $50 \mathrm{~min}$, with a total run time of $80 \mathrm{~min}$. The flow rate was constant at $0.2 \mathrm{~mL} \mathrm{~min}{ }^{-1}$. Positive ion HESI settings were: capillary temperature, $300^{\circ} \mathrm{C}$; sheath gas (N2) pressure, 40 arbitrary units (A U); auxiliary gas (N2) pressure, $10 \mathrm{AU}$; spray voltage, 4.5 $\mathrm{kV}$; probe heater temperature, $50^{\circ} \mathrm{C}$; S-lens $70 \mathrm{~V}$. D etection was achieved using positive ion monitoring of $\mathrm{m} / \mathrm{z} 350-2000$ (resolving power 70,000 ppm at $\mathrm{m} / \mathrm{z}$ 200), followed by data dependent $M S^{2}$ (isolation window $1 \mathrm{~m} / z$; resolving power $17,500 \mathrm{ppm}$ at $\mathrm{m} / \mathrm{z} 200$ ) using a top 10 approach, dynamic exclusion (6s) and an inclusion list of calculated exact masses of ca. $165 \mathrm{BHPs}$ (from literature), with 3 ppm mass tolerance. Optimal fragmentation of all B HPs was achieved using a stepped normalized collision energy of 22.5 and 40. A mass calibration was performed every $48 \mathrm{~h}$ using the Thermo Scientific Pierce LTQ Velos ESI Positive Ion Calibration Solution.

BHPs were identified based on the exact mass of the protonated or ammoniated molecular ion (see Tables S1 and S2), relative retention time and $M^{2}$ fragmentation spectra conform Hopmans et al. (2021). Individual BHPS were (semi-)quantified based peak integrations of selected mass chromatogram of the most abundant molecular ion (see abundance in Tables S1 and S2 for the exact mass of ions used in integration) using a 3 ppm mass accuracy window. The peak area of the DGTS-d9 internal standard was used to control for MS variability and ion suppression. 
Table 1. Sampling sites and description of the soil and mud samples from the two terrestrial gas seeps Bissana and Censo in Sicily, Italy.

\begin{tabular}{|c|c|c|c|}
\hline Site & $\begin{array}{l}\text { Distance } \\
\text { from seep } \\
\text { (m) }\end{array}$ & Sample ID & Sample description \\
\hline \multicolumn{4}{|c|}{ Bissana } \\
\hline & At seep 1 & B is seep 1 & $\begin{array}{l}\text { Mud soil mix; directly from seep } \\
1 \text { with active gas and mud } \\
\text { bubbling }\end{array}$ \\
\hline & 1.0 & Bis1 +1 m & Dry soil with little vegetation; \\
\hline & 3.0 & Bis1 +3 m & Dry soil with vegetation \\
\hline & 8.0 & Bis1 +8 m & Dry soil with vegetation \\
\hline & 14.0 & Bisl +14 m & $\begin{array}{l}\text { Dry soil with vegetation (control } \\
\text { site seep 1) }\end{array}$ \\
\hline & N ear seep 2 & $\begin{array}{l}\text { B is near } \\
\text { seep } 2\end{array}$ & $\begin{array}{l}\text { M ud from dried mud pool; next } \\
\text { to bubbling mud and gas pool } \\
\text { (seep 2) }\end{array}$ \\
\hline & A t seep 3 & B is seep 3 & $\begin{array}{l}\text { M ud from bubbling gas and mud } \\
\text { seep } 3\end{array}$ \\
\hline & 3.0 & Bis3 $+3 \mathrm{~m}$ & Dry soil with vegetation \\
\hline \multicolumn{4}{|c|}{$\begin{array}{l}\text { Fuoco di } \\
\text { Censo }\end{array}$} \\
\hline & At seep & Censo $0 \mathrm{~m}$ & $\begin{array}{l}\text { Dry soil; directly from main gas } \\
\text { seep }\end{array}$ \\
\hline & 2 & Censo $+2 \mathrm{~m}$ & $\begin{array}{l}\text { Dry soil with vegetation; uphill } \\
\text { from main seep site }\end{array}$ \\
\hline & 1.5 & $\begin{array}{l}\text { Censo }+1.5 \\
\mathrm{~m}\end{array}$ & $\begin{array}{l}\text { Dry soil with little vegetation; } \\
\text { uphill from main seep site }\end{array}$ \\
\hline & 0.8 & $\begin{array}{l}\text { Censo }-0.8 \\
\mathrm{~m}\end{array}$ & $\begin{array}{l}\text { Dry soil; downhill from main } \\
\text { seep site }\end{array}$ \\
\hline & 1.2 & $\begin{array}{l}\text { Censo }-1.2 \\
\mathrm{~m}\end{array}$ & $\begin{array}{l}\text { Dry soil; downhill from main } \\
\text { seep site }\end{array}$ \\
\hline & 1.8 & $\begin{array}{l}\text { Censo }-1.8 \\
\mathrm{~m}\end{array}$ & $\begin{array}{l}\text { Dry soil; downhill from main } \\
\text { seep site }\end{array}$ \\
\hline & 2.2 & $\begin{array}{l}\text { Censo }-2.2 \\
\mathrm{~m}\end{array}$ & $\begin{array}{l}\text { Dry soil; downhill from main } \\
\text { seep site }\end{array}$ \\
\hline & 13.2 & $\begin{array}{l}\text { Censo }-13.2 \\
\mathrm{~m}\end{array}$ & $\begin{array}{l}\text { Dry soil with vegetation; } \\
\text { downhill } 13.2 \mathrm{~m} \text { from main seep } \\
\text { site (control site) }\end{array}$ \\
\hline
\end{tabular}

As no authentic standards were available for the BHPs, abundances are reported based on peak areas of the BHP (i.e. in arbitrary units $(A U) / g$ soil). The 
abundances of specific BHPs were calculated relative to total integrated BHPS and BHPs in the triplicate samples for each distance were averaged assuming identical M S response factors and reported as percentages. B H Ps included in the B HP inventory are listed in Table S1 for Censo seep soils, Table S2 for Bissana seep soils and Table S3 for biomass of M. cyclopophantes 3B .

Principal Component A nalysis (PCA) was performed on the combined data set of the $B$ issana and Censo seep soil samples where only B HPs were used which occurred at both seeps, fourteen in total. PCA was performed using Sigmaplot 14.0.

\subsection{DNA extraction and 16S rR NA gene amplification}

DNA was extracted from the Censo and Bissana soils and muds with the PowerM ax soil DNA isolation kit (Qiagen) and DNA extracts were stored at -80 ${ }^{\circ} \mathrm{C}$ until further analysis. The general $16 \mathrm{~S}$ rRNA archaeal and bacterial primer pair 515F and 806R B targeting the $V 4$ region was used for the $16 \mathrm{~S}$ rRNA gene amplicon sequencing (Caporaso et al., 2012; B esseling et al., 2018). Polymerase chain reaction (PCR) products were gel purified using the QIAquick GelPurification kit (Qiagen), pooled and diluted. Sequencing was performed using an Illumina M iSeq sequencing platform at the Utrecht Sequencing Facility (Utrecht, the Netherlands). The 16S rRNA gene amplicon sequences were analysed by an in-house pipeline (A bdala Asbun et al., 2020) that includes quality assessment by FastQ C (A ndrews, 2010), assembly of the paired end reads with Pear (Zhang et al., 2013), and assignment of taxonomy (including picking representative set of sequences with 'longest' method) with blast by using the Silva 132 release as a reference database (https://www.arb-silva.de/). The relative abundances of bacterial phyla and methanotrophic bacterial species are reported as a percentage of total bacterial 16S rRNA gene reads and average for the triplicate samples of each distance (Table S4).

\section{Results}

The C enso seep contains one active seep site, at which dry gas is emitted through the soils, although soil degassing was present within an area of $80 \mathrm{~m}^{2}$ around the site and thus likely affecting soils within a few meters of the seep site. Soil samples (in triplicate) were investigated uphill and downhill from the seep site with increasing distance from the main seep (Table 1). In contrast to the Censo seep area, at the Bissana seep three separate seep sites were discovered that show ed active mud and gas bubbling around and in a mud pond. For seep 1, mud and soils were sampled with increasing distance from the active seep (Table 1). 
For seep 3, the seep itself and a soil from $3 \mathrm{~m}$ away were sampled. For seep 2 only a soil from close to the seep was obtained.

\subsection{B H P composition}

The BH P composition of the samples taken at the two Sicilian gas seep sites was analysed using U HPLC-HRM S and relative abundances, normalized on the sum of all quantified BHPs, were calculated based on the integrated peak areas of mass chromatograms of either the protonated or ammoniated molecular ion (Tables S1 and S2). Soils are known to be heterogenous and therefore the B HP distributions of the triplicate samples, taken within $0.5 \mathrm{~m}^{2}$, were averaged.

\subsubsection{Censo seep.}

The Censo seep soils contain a diversity of $\mathrm{N}$-containing B HPs, whose structural identification was described in detail by Hopmans et al. (2021) for a Censo soil sampled directly at the seep (Censo $0 \mathrm{~m}$ ). Here we describe the B H Ps relevant to $\mathrm{MOBs}$ and the most commonly occurring BHPs (Table S1). Directly at the seep (Censo $0 \mathrm{~m}$ ), there are high relative abundances of the aminoB HPs aminotriol $(13.4 \%)$, a late-eluting aminotriol isomer (5.7\%), aminotetrol (1.1\%) and aminopentol (6.9\%) (Fig. 2a). High relative abundances of aminotriol and its isomer are found in all soils but are particularly high close to the seep in $-0.8 \mathrm{~m}$ and $-1.2 \mathrm{~m}$, together comprising over $50 \%$ of total BHPs. A minotetrol is only present in high relative abundance directly at the seep and occurs in minor abundances at $-0.8 \mathrm{~m}$ distance from the seep, while aminopentol is detected in all soils, including the soil at $-13.2 \mathrm{~m}$ from the seep, although with the highest relative abundances at and close to the main seep. With respect to 3-methylated aminoBHPs, only minor amounts of the 3-methyl aminotriol were detected in soils of the $C$ enso transect.

We also detected the novel composite $\mathrm{N}$-containing BHPs, ethenolamine-BHT, ethenolamine-BH pentol and ethenolamine- $\mathrm{BH}$ hexol (structures e-g; Fig. 1), which were recently identified in a Censo seep soil (Hopmans et al., 2021). In general, almost all soils contain the three ethenolamineB HPs of which especially high abundances occur between 0 and $2.2 \mathrm{~m}$ distance from the seep with exception of the soil at $-0.8 \mathrm{~m}$ distance, while the remaining three soils more remote from the seep had low $(<5 \%)$ relative abundances (Fig. 2b). Ethenolamine-B HT shows the highest relative abundance ranging from 1.2 to $11 \%$, followed by ethenolamine- $\mathrm{BH}$ pentol with 0.2 to $13 \%$ and ethenolamine-BH hexol with 0.5 to $2.5 \%$ of total B HPS. 


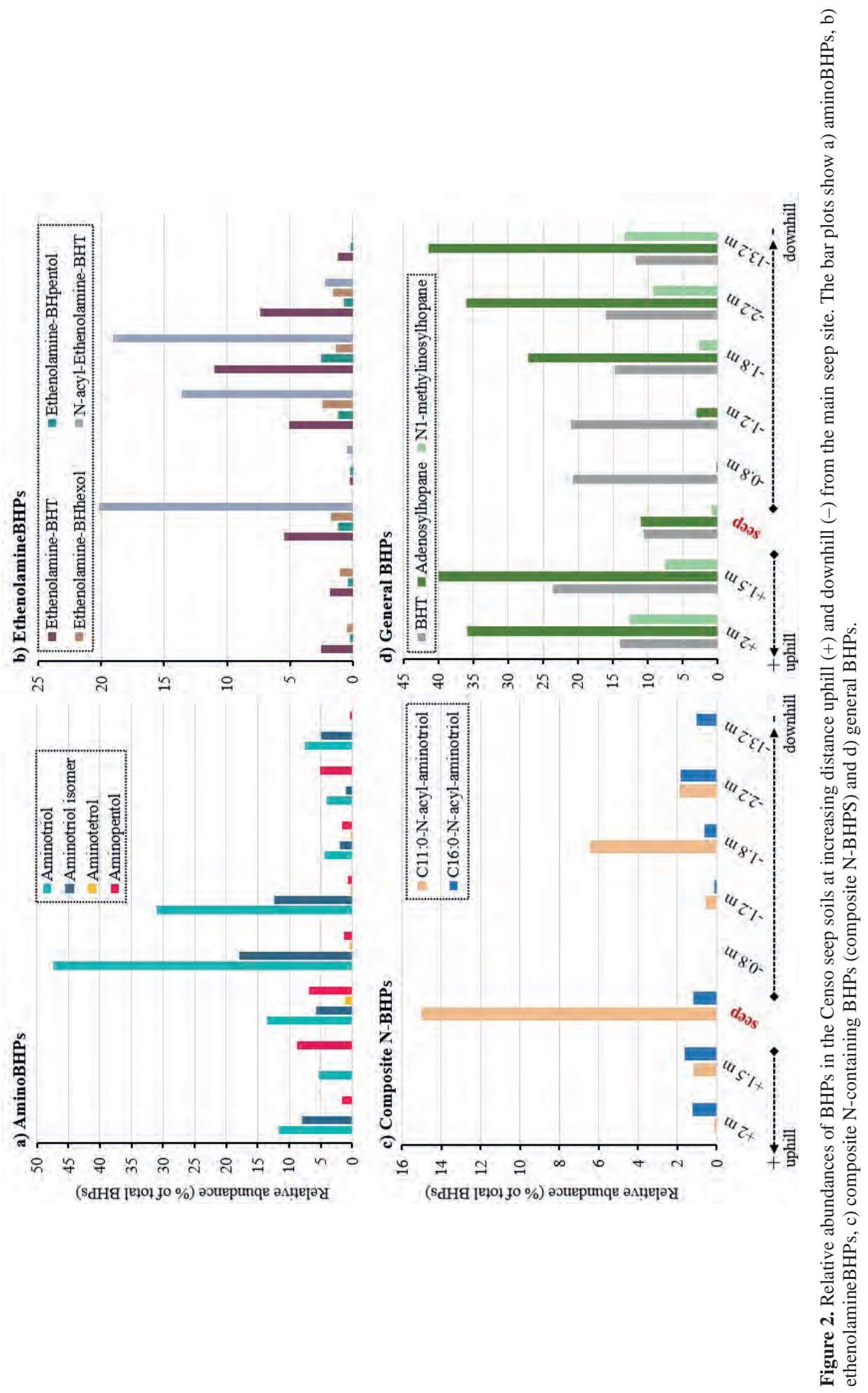


A dditionally, directly at the seep (Censo $0 \mathrm{~m}$ ), a high relative abundance (20\%) of $\mathrm{N}$-acyl-ethenolamine-B HT bound to fatty acids $\mathrm{C}_{15: 0}$ to $\mathrm{C}_{18: 0}$ (structure $\mathbf{h}$ ) were observed, which remained high at $-1.2 \mathrm{~m} \mathrm{(14 \% )}$ and $-1.8 \mathrm{~m}(19 \%)$ distance from the main seep and then decreased with further distance (Fig. 2b). Furthermore, $\mathrm{N}$-acyl-aminotriols (structure $\mathbf{d}$ ) were found to be abundant at the Censo seep of which the most abundant one, the $\mathrm{C}_{11: 0} \mathrm{~N}-\mathrm{N}$-acyl-aminotriol, shows high abundances at the seep (15\%) and at $-1.8 \mathrm{~m}(6.4 \%)$ distance but decreases in relative abundance further aw ay from the seep (at $+1.5 m,-1.8 m$ and $-2 m, 0.1$ to $1.9 \%$ ) (Fig. 2C). In contrast, the less abundant $\mathrm{C}_{16: 0}-\mathrm{N}$-acyl-aminotriol showed no particular trend over the seep transect.

The relative abundance of $\mathrm{BHT}$ (structure i) ranges from 11 to $24 \%$ in the seep transect but shows not trend with increasing distance from the seep (Fig. $2 d)$. Furthermore, directly at the seep, and at $-0.8 \mathrm{~m}$ and $-1.2 \mathrm{~m}$ distance from the seep, low relative abundances of adenosylhopane (structure $\mathbf{j}$; previously adenosylhopane type 1) and N1-methylinosylhopane (structure $\mathbf{k}$; previously named adenosylhopane type 2; see Hopmans et al., 2021 for structural description) are observed (from 0.2 to $10.9 \%$ ), whereas the soils at increased distance from the seep contain high relative abundances, with adenosylhopane and N 1-methylinosylhopane making up more than $50 \%$ of total B HPs (Fig. 2d).

\subsubsection{Bissana seeps.}

A nalysis of the BHP inventory showed that directly at Bissana seep 1 (Bis seep $1)$, there are high relative abundances of aminotriol (26\% of total BHPs), aminotetrol (6.8\%) and aminopentol (15\%) (Fig. 3a; Table S2). A similar distribution is also observed near seep 2 ( $B$ is near seep 2 ) and at seep 3 ( $B$ is seep 3 ), where high relative abundances of total B H Ps of aminotriol (15.3 and 19.9\%), aminotetrol (2.4 and 1.9\%) and aminopentol (2.9 and 2.9\%) are detected, but with slightly lower relative abundances than at seep 1 . At seep 1 , the relative abundances of these B HPs decrease with increasing distance from the seep (Fig. 3a). This is al so observed at seep 3 , where aminoB HPs decrease at $3 \mathrm{~m}$ from seep 3 (Bis3 $+3 \mathrm{~m}$ ) to only $0.1 \%$ (aminopentol), $0.9 \%$ (aminotetrol) and $3.2 \%$ (aminotriol) of total BHPs. Furthermore, 3-methyl homologues of the three aminoB HPs occur relatively abundant only directly at or near the three seeps and disappear with increasing distance from the seeps (Fig. 3b). 3-M ethyl aminotriol is the most abundant methylated $\mathrm{BHP}$ with relative abundances ranging from 1.7 to $5.2 \%$, while 3 -methyl aminotetrol shows values of 0.1 to $1.6 \%$ and 3-methyl aminopentol 0.4 to $1.4 \%$. 

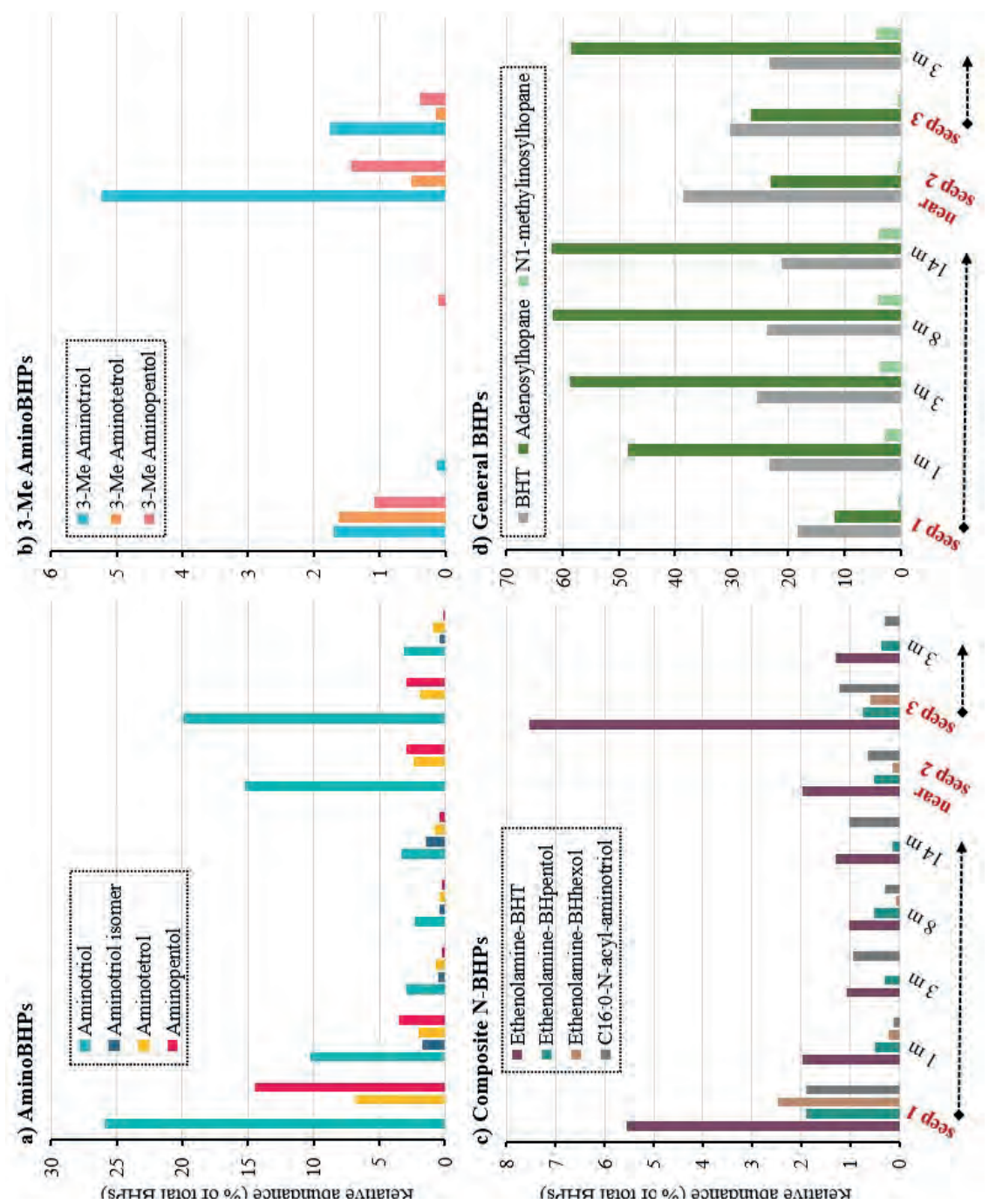
In the seeps and some soils close to the seeps (i.e. Bis1 $+1 \mathrm{~m}$ ), there are high relative abundances of the three novel ethenolamineBHPs (Fig. 3c). Ethenolamine-BHT shows the highest relative abundance ranging from 2 to $7.5 \%$, followed by ethenolamine- $\mathrm{BH}$ pentol with 0.5 to $1.9 \%$ and ethenolamineBHhexol with 0.1 to $2.5 \%$ of total BHPs. Additionally, another previously identified $\mathrm{N}$-containing $\mathrm{BHP}$, namely $\mathrm{C}_{16: 0} \mathrm{-N}$-acyl-aminotriol (Talbot et al., 2007a), was identified at the Bissana seeps in relative abundances up to $1.9 \%$ but this B HP was also detected in some soils away from the three seeps (Fig. 3C).

At the soil transect, the relative abundance of BHT varies from 18 to $39 \%$ but does not follow a particular trend with respect to distance from the seep (Fig. 3d). The general B HPs adenosylhopane and N 1-methylinosylhopane were detected in all Bissana soils and show a clear increase in their relative abundances with increasing distance from the seeps (Figs. 3d). At Bissana seep 1 , adenosylhopane shows a relative abundance of $12 \%$, which increases with increasing distance from seep 1 until it reaches its maximum at $14 \mathrm{~m}$ distance from B issana seep 1 (62\%). N ear B issana seep 2 and at seep 3 there is a relatively lower abundance of adenosylhopane (23-27\%) and increases with $3 \mathrm{~m}$ distance to seep 3 to $59 \%$. A similar trend is found for N 1-methylinosylhopane, albeit with lower relative abundances compared to adenosylhopane (0.6-4.5\%; Fig. 3d).

3.1.3 Principal component analysis (PCA) of the BHP distributions.

To investigate the variance in the BHP distributions in the seep transects, PCA analysis was performed on the fractional abundances of the fourteen B H Ps which are found at both sites (Fig. 4). For this analysis, we used the B HP distributions of the triplicate samples as separate input. Three principal components (PCs) account for $26.3 \%$ (PC 1), $19.9 \%$ (PC 2) and $18.6 \%$ (PC 3) of the total variance in the dataset. A II N-containing B HPs (aminoB HPs, ethenolamineB HPs and $\mathrm{N}$ acyl-aminotriol) score positively on PC1, whereas adenosylhopane, N1methylinosylhopane and 2-M e B HT have a negative loading on PC 1 (Fig. 4a). $\mathrm{BHT}$ and 3-Me BHT show a high loading at PC 2, while aminotriol and the aminotriol isomer show a negative loading on PC 2.

The sample loading plot (Fig. 4b) shows that the triplicates samples from within $0.5 \mathrm{~m}^{2}$ score sometimes quite differently, indicating the heterogeneity of the BHP distributions within short distances. The seeps score more positive on $P C 1$, while the soils more remote from the seeps tend to have more negative scores on PC1. The Bissana seep soils score generally higher on PC 2 than the Censo seep soils. 

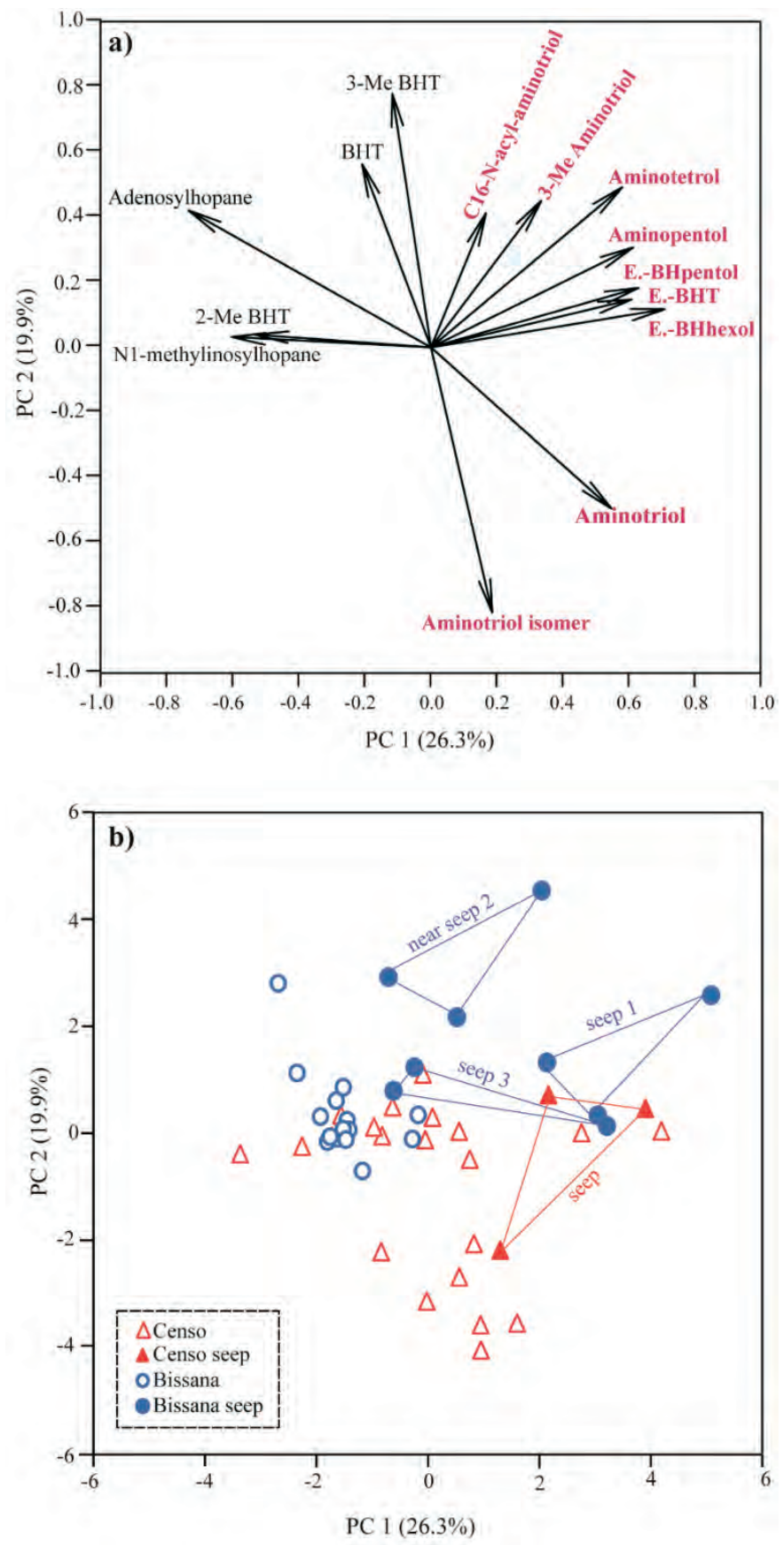

Figure 4. Principal component analysis (PCA) of the fractional abundances of different B HPs and triplicate samples in the Censo seep and B issana seeps soils $(n=48)$. The first principal component (PC) explains $26.3 \%$ and the second $19.9 \%$ of the variance. Panel a) shows PC 1 versus PC 2 of the 14 different B H Ps abundant at both seep sites. Panel b) shows the sample loading plot with the triplicate samples (taken within $0.5 \mathrm{~m}^{2}$ ) at both seeps. 


\subsection{Bacterial diversity}

$16 S$ rR N A gene amplicon sequencing performed on the DN A extracted from the two Sicilian gas seep sample sets was used to investigate the bacterial diversity in the seep transects. On average 87,200 reads per sample w ere obtained of which on average $94 \%$ were attributed to bacteria. The archaeal $16 \mathrm{~S}$ rRNA gene reads were not considered here as A rchaea are not sources of $\mathrm{BHPs}$. The remaining bacterial $16 \mathrm{~S}$ rRNA sequences were assigned into operational taxonomic units (OTUs) and further phylogenetically classified. The number of bacterial reads of the different bacterial phyla were then normalized as a percentage to total number of bacterial 16S rR NA gene reads (Table S4). Finally, the bacterial 16S rRNA gene distributions of the triplicate samples, taken within $0.5 \mathrm{~m}^{2}$, were averaged.

\subsubsection{Censo seep.}

A variety of diverse bacterial phyla was detected in the Censo seep soils with high relative abundances of A ctinobacteria at (14\%) and close to ( $99 \%$ ) the seep site (Fig. 5a). At and close to the Censo seep, representatives of the phylum Actinobacteria are mainly novel ethane-oxidizing Mycobacteria (Smit et al., $2021 a, b)$. High relative abundances of Gammaproteobacteria ranging from 9 to $29 \%$ are found at and close to the Censo seep site and are lower at the $-13.2 \mathrm{~m}$ control site (5\%). Furthermore, the high relative abundances of Patescibacteria (4\%) and Cyanobacteria (4\%) at the seep is notew orthy; they are not detected in most other samples. In the $-1.8 \mathrm{~m}$ soil, the high relative abundance of Chloroflexi (49\%) stands out since they are much less predominant in the other soils. The high relative abundances of Verrucomicrobia (38 \%) in the soil at $1.2 \mathrm{~m}$ distance from the seep is also remarkable. At the seep site and also close to the seep $(-1.2 \mathrm{~m}$ and $-1.8 \mathrm{~m})$, there are low relative abundances $(<3 \%)$ of A cidobacteria, but their relative abundance increases with increasing distance uphill and downhill from the seep ( $\geq 5 \%$ ). Additionally, other bacterial phyla such as D el taproteobacteria, A I phaproteobacteria and Planctomycetes were also present in the soils but did not show any particular trend over the seep transect.

High percentages of bacterial reads of known MOBs, i.e. Type I and Type II methanotrophs and V errucomicrobia, are found at the Censo seep site (Fig. 5b). An exceptionally high relative abundance of about $38 \%$ of reads related to the verrucomicrobial methanotroph family Methylacidiphilaceae is reveal ed at $-1.2 \mathrm{~m}$ distance from the Censo seep, while its relative abundance is only minor in the seep soils $(\leq 0.2 \%)$. Furthermore, $16 \mathrm{~S}$ rRNA gene reads attributed to the Type I methanotroph families Methylomonaceae and 
M ethylococcaceae, ranging from 0.5 to $6 \%$, were present at the seep as well as in the soils at $+1.5 m,-1.2 m,-1.8 m$ and $-2.2 m$ distance from the seep site. M inor relative abundances of $16 \mathrm{~S}$ rRNA gene reads assigned to the Type II methanotrophs $(\leq 0.4 \%)$, from the genera Methylovirgula, M ethylosinus and $M$ ethylobacterium, were detected at and around the Censo seep site but remained undetected at $13.2 \mathrm{~m}$ distance.

\subsubsection{Bissana seeps.}

The $16 \mathrm{~S}$ rRNA gene amplicon sequencing showed high relative abundances of Gammaproteobacteria directly at seep 1, seep 3 and near seep 2 ranging from 49 to $56 \%$, while their relative abundances decreased with increasing distance to the seeps to $<6 \%$ of total bacterial reads (Fig. 6a). An opposite distribution is shown by the $16 \mathrm{~S}$ rRNA gene reads of A ctinobacteria and A cidobacteria, which show low relative abundances at and near the three seeps $(\leq 2 \%)$ and increase to up to $43 \%$ (A ctinobacteria) and $12 \%$ (A cidobacteria) with increasing distance from the seep sites. Other relatively abundant bacterial phyla $(\geq 5 \%)$ are Bacteriodetes, Chloroflexi, Gemmatimonadetes, Planctomycetes and A Iphaproteobacteria in the Bissana seep soils of which only the Bacteriodetes showed some higher relative abundances at and close to seep 1 and seep 3.

With respect to bacterial OTUs falling in groups of known MOBs, the Bissana seep soils showed the presence, albeit in very low relative abundance (< $0.5 \%$ ), of some common Type I (Gammaproteobacteria) and Type II methanotrophs (A Iphaproteobacteria) (Fig. 6b). At seep 1 and seep 3 slightly increased levels of Methylohalobiaceae are present $(0.11$ and $0.05 \%$, respectively). A $1 \mathrm{~m}$ distance from seep 1, there is slightly elevated abundance of representatives from the families Methylomonaceae $(0.1 \%)$ and Methylococcaceae $(0.1 \%)$ accompanied with low abundances of $M$ ethylohalobiaceae and M ethylobacteriaceae. Some low read percentages of Methylococcaceae and Methylobacteriaceae are also visible until $14 \mathrm{~m}$ ( $\leq$ $0.05 \%$ ) distance to seep 1 .

\section{Discussion}

In this study we examined both the relative abundances of diverse B HPs as well as the relative abundances of bacterial reads at the two Sicilian gas seeps. A quantitative comparison of these two data sets is hampered by the fact that both datasets represent relative abundances, rather than absolute amounts, and suffer from different biases such as e.g. different ionization efficiencies for BHPs and a varying $16 \mathrm{~S}$ rR NA gene copy number in bacteria. Furthermore, it is well known 
that a considerable part of the bacteria species do not have the capability to synthesise B HPs (Rohmer et al., 1984; K annenberg and Poralla, 1999; Pearson and R usch, 2009; Rezanka et al., 2010; Sinninghe Damsté et al., 2017). This also applies to uncultivated bacteria which BHP composition has not been characterised at all. These considerations should be kept in mind when inferring sources of BHPs using 16S rRNA gene data and making quantitative comparisons.

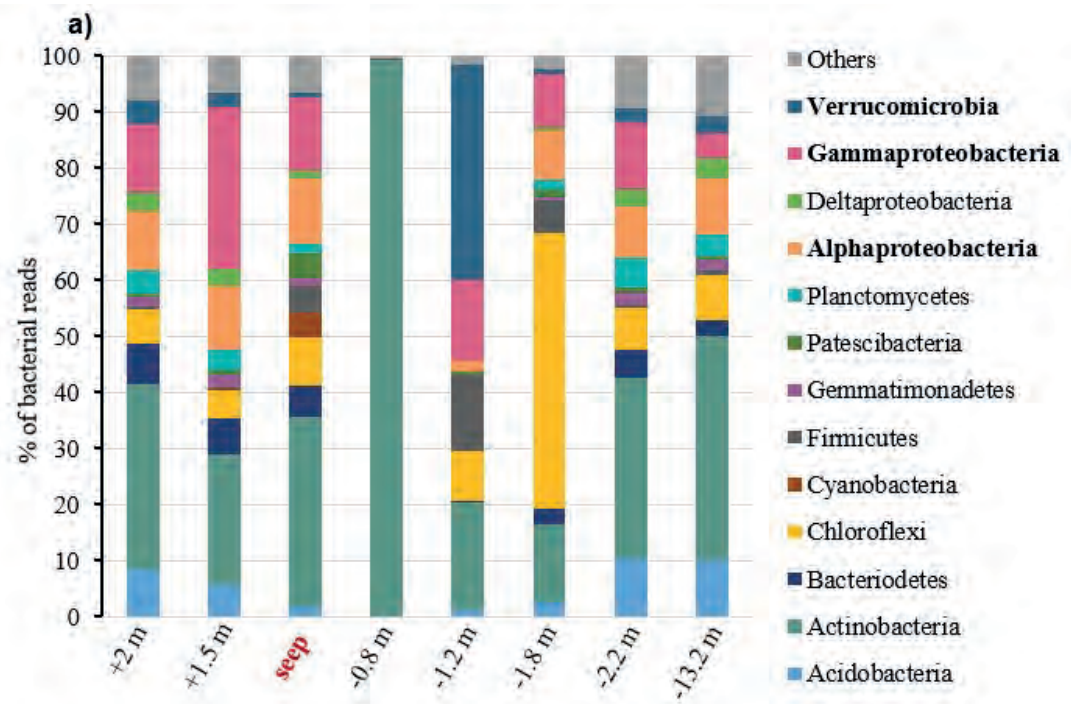

b)



Figure 5. Relative abundance (as percentage of total bacterial reads) of the a) main bacterial phyla and $b$ ) known aerobic methanotrophic bacteria (in percentage of assigned bacterial reads) based on 16S rR NA gene amplicon sequencing in the Censo seep soils uphill $(+)$ and downhill $(-)$ from the main seep site.

\subsection{A minoB H Ps as biomarkers for aerobic methanotrophic bacteria}

The Censo and Bissana seeps show both high relative abundances of typical aminoB HPs, namely aminopentol, aminotetrol, and the less specific aminotriol 
(Figs. 2 and 3), which are thought to be characteristic for $\mathrm{M} \mathrm{OBS}$ and thus aerobic oxidation of methane (e.g. Neunlist and Rohmer, 1985; Cvejic et al., 2000; Talbot et al., 2001; van Winden et al., 2012). Indeed, PCA analysis show that seep samples are generally characterized by elevated abundances of these aminoB HPs (Fig. 4a) compared to more general BHPs like BHT. These high abundances of aminoB HPs at $\mathrm{CH}_{4}$-rich sites agree with previous studies which show ed al so high abundances of these B HPs where aerobic oxidation of methane was likely prevalent in peatlands, estuaries, lakes, or the water column (Coolen et al., 2008; Zhu et al., 2010; Berndmeyer et al., 2013; van W inden et al., 2012; Tal bot et al., 2014, 2016). I sotopic analysis of degradation products of B HPs in these environments have shown they are relatively depleted in ${ }^{13} \mathrm{C}$ confirming their origin from M OBs (e.g. Jahnke et al., 1999; Coolen et al., 2008; Talbot et al., 2014). Furthermore, 16S rRNA gene analysis in lake sediments from the Antarctic Ace Lake further supported an origin of the three ${ }^{13} \mathrm{C}$ depleted aminoB HPs from Type I M OBs (Coolen et al., 2008).

At the Censo seep, aminotetrol is only present at the seep site while aminopentol is abundant at the seep and also around the seep sites (Fig. 2a). These results suggest that $\mathrm{CH}_{4}$ flux might stimulate the $\mathrm{MOB}$ community not only at the seep but al so in the soils further away from the Censo seep since only Type I methanotrophs are known to synthesize aminopentol (Neunlist and Rohmer, 1985; Cvejic et al., 2000; Talbot et al., 2001; van W inden et al., 2012). Indeed, a previous study found diffuse soil degassing being abundant within an area of $80 \mathrm{~m}^{2}$ at the Censo seep site (Etiope et al., 2002). Furthermore, the presence of aminopentol at and around the Censo seep site agrees with the presence of $16 \mathrm{~S}$ rRNA gene reads related to Type I methanotrophs from the $M$ ethylomonaceae and $M$ ethylococcaceae families in most Censo soils. A t much longer distance (13.2 m away), 16S rR NA gene reads of these methanotrophs are present in low relative abundance, consistent with the low abundances of aminopentol compared to other BHPs (Fig. 2a and 5b). At the Bissana seep, aminopentol and aminotetrol are al so abundant directly at the three seep sites and at $1 \mathrm{~m}$ from seep 1, while they are almost absent further away from the seeps (Fig. 3a). This also coincides with the presence of Type I M OB 16S rR NA gene sequences at these sites. Surprisingly, however, the relative abundances of reads of Type I M OBs at Bissana are much lower compared to Censo $(\sim 0.2 \%$ versus $\sim 8 \%)$, suggesting that known M OBs do not comprise a large part of the bacterial community (Fig. 6b). This contrasting result suggests that possibly a large part of the aminoBHPs at the Bissana seeps are not derived from methanotrophic bacteria and may be sourced by other bacterial groups. Interestingly, high 
abundances of Gammaproteobacteria are observed directly at the three seeps, i.e. they are making up over $50 \%$ of the bacterial reads (Fig. 6a), and Proteobacteria are known to be a significant source of BHPs in the environment (Pearson and Rusch, 2009; K harbush et al., 2013). Thus, besides the known Type I M OBs, other groups within the Gammaproteobacteria might al so be a source of the high amounts of aminopentol, and al so other aminoBHPs, at the B issana seeps.

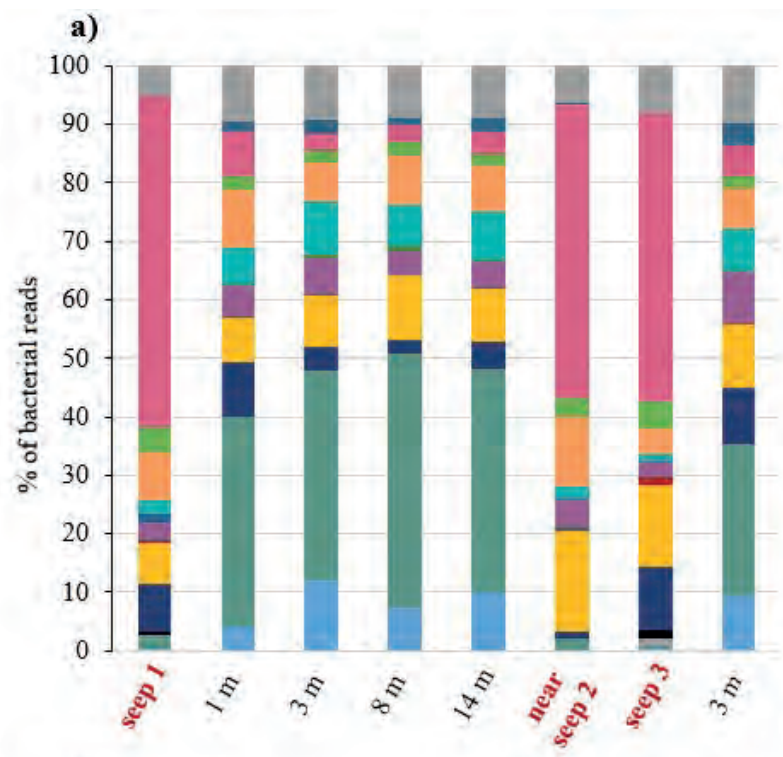

- Others

- Verrucomicrobia

- Gammaproteobacteria

Deltaproteobacteria

Alphaproteobacteria

- Planctomycetes

- Patescibacteria

- Nitrospiraea

- Gemmatimonadetes

- Firmicutes

- Cyanobacteria

- Cloacimonetes

Chloroflexi

- Bacteriodetes

- Atribacteria

Aegiribacteria

- Actinobactería

- Acidobacteria

b)

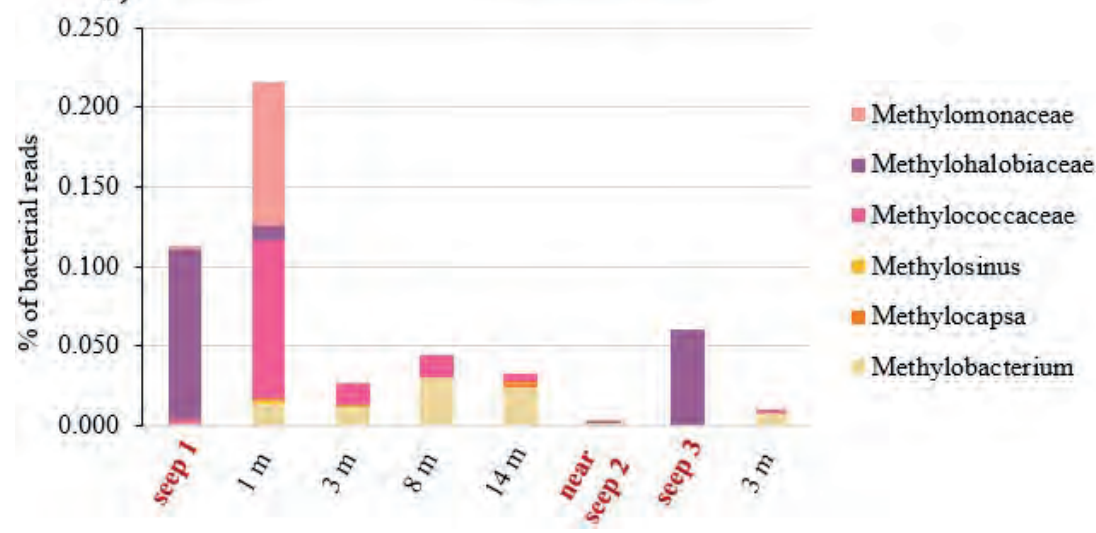

Figure 6. Relative abundance (as percentage of total bacterial reads) of the a) main bacterial phyla and b) known aerobic methanotrophic bacteria (in percentage of assigned bacterial reads) based on 16S rR NA gene amplicon sequencing in the different Bissana seeps soils at increasing distance from seep 1 and seep 3 as well as near seep 2.

A minotetrol seems to behave similar to the aminopentol at both seep sites. However, at Censo it is only abundant directly at the seep (Figs. 2, 3, 5 and 
6). A minotetrol can also be synthesized by Type II M OBs (Talbot et al., 2001; van W inden et al., 2012) and sequences of Type II M OB s were detected though they make a small portion $(<0.3 \%)$ of the bacterial reads (Figs. $5 \mathrm{~b}$ and $6 \mathrm{~b}$ ). The high abundance of the less specific aminotriol at both seeps and its decrease with increasing distance from the seeps suggest that this BHP might derive from M OBs. However, PCA analysis shows that it plots somewhat differently from aminotetrol and aminopentol (Fig. 4a). A minotriol is known to be produced by some Type I and Type II methanotrophs but it is also synthesized by various other bacterial species (N eunlist et al., 1985; N eunlist and R ohmer, 1985; Tal bot and Farrimond, 2007), potentially explaining its somewhat different behavior compared to aminotetrol and aminopentol. Nevertheless, aminotriol still seems largely derived from MOBs at both seeps as it plots opposite to more general BHPs like BHT (Fig. 4a).

Finally, 3-methyl aminoB HPs are solely abundant at the three Bissana seeps (Fig. 3b) and, except for 3-methyl aminotriol, not detected or in low abundance at the Censo seep site. The presence of 3-methyl aminopentol is noteworthy as it has only been observed rarely in the environment, i.e. in a lake sediment (Talbot and Farrimond, 2007) and a geothermal silica sinter (Gibson et al., 2008), where aerobic oxidation of methane was also shown to occur. Similar to their non-methylated homologue, the 3-methyl aminopentol likely originates from Type I methanotrophs (N eunlist and Rohmer, 1985; Cvejic et al., 2000). It should be noted that the hpnR gene responsible for the 3-methylation was only found in a limited number of Type I methanotrophs but also in other bacteria such as Actinobacteria, Nitrospirae, and Acidobacteria (Welander and Summons, 2012). However, the presence of 3-methyl aminoB H Ps predominantly at the $B$ issana seeps and the low relative abundances of the other bacterial groups known to carry the hpnR gene suggest that these compounds likely derive from M OB s or other bacterial involved in gas oxidation at the seep. Interestingly, the 3-methyl aminotriol clusters with aminotetrol and aminopentol, in contrast to its non-methylated homologue aminotriol (Fig. 4a), suggesting it has a more predominant origin from M OB s compared to the latter.

\subsection{Exploring aminotriol isomer as new marker for Verrucomicrobia}

Several Censo soils contain high relative abundances of aminotriol together with a new late-eluting aminotriol isomer, representing $40-60 \%$ of total BH Ps in two Censo seep soils close to the seep (Fig. 2a). Interestingly, they plot differently in the PCA analysis from the other amino BHPs, suggesting potentially different bacterial sources. In an earlier study, van W inden et al. (2012) reported that the 
verrucomicrobial methanotrophic species Methylacidiphilum fumariolicum strain SolV contained high abundances of aminotriol, and close examination of their LC-MS data reveals what appears to be a double peak for aminotriol, possibly suggesting an incomplete separation of aminotriol isomers. To further explore this, the B HP inventory of the verrucomicrobial methanotrophic species M. cyclopophantes 3B (van Teeseling et al., 2014) was analyzed, which shows high abundances of two aminotriol isomers, namely aminotriol $(61 \%)$ and a lateeluting aminotriol isomer (34\%), together making up about $95 \%$ of all BHPs in the culture (Fig. $7 \mathrm{a}$ and Table S3). Comparisons show that the two aminotriol isomers elute at the same retention time as those in the Censo seep and show similar proportions (Fig. 7b). This suggests a different origin of aminotriol, and especially aminotriol isomer, compared to the other aminoB HPs, and seems to be connected to the presence of methanotrophic $V$ errucomicrobia. This is further supported by the high relative abundances of V errucomicrobia phyla in the $16 \mathrm{~S}$ rRNA gene sequences in $-1.2 \mathrm{~m}$ which are affiliated to $\mathrm{Ca}$. 'M ethylacidiphilum' (Fig. 5). These Ca. 'M ethylacidiphilum' verrucomicrobia are the closest related methanotrophic bacterial genus (Fig. S1) and show about 63\% sequence similarity with the investigated M. cyclopophantes 3B culture (van Teeseling et al., 2014; Schmitz et al., 2021). Overall, this suggests that high amounts of aminotriol accompanied by a later eluting aminotriol isomer might represent a new BHP-biomarker to detect verrucomicrobial methanotrophs in the environment.

\subsection{Novel composite N-containing BHPs: potential biomarker to detect MOBs}

Novel composite $\mathrm{N}$-containing B HPs, which are connected to an ethenolamine functional group probably at position C-35 in the B HP side chain (Hopmans et al., 2021), were identified at both seep sites. At the Bissana seeps, all three ethenolamineBHPs (ethenolamine-BHT, ethenolamine-BHpentol and ethenolamine-BHhexol) reveal high relative abundances at the seeps and decrease with increasing distance from the seeps (Fig. 3c), whereas at the Censo seep the ethenolamineB HPs demonstrate high relative abundances at the seep and downhill from the seep (Fig. 2b). The distributions of the ethenolamineB HPs indicate a similar trend as the aminoB HPs (Figs. $2 c$ versus $2 a$, $3 a$ versus $3 b$ ), suggesting that they might derive from Type I MOBs and other MOBs that are present at both seep sites. M oreover, PCA revealed that the ethenolamineB HPS cluster closely with aminotetrol and aminopentol (Fig. 4a), further supporting that their source organism(s) are probably involved in the oxidation of methane 
or from bacteria which occupy a similar environmental niche. Thus, they may represent new BHP based biomarkers for aerobic oxidation of methane. However, no source organism(s) are known yet as they have not been reported in any culture study to the best of our knowledge. For this, further research on pure M OB cultures is needed and our results suggest that probably Type I M OB s or groups of Gammaproteobacteria detected at B issana might be good potential candidates to screen for the presence of ethenolamineB HPs.

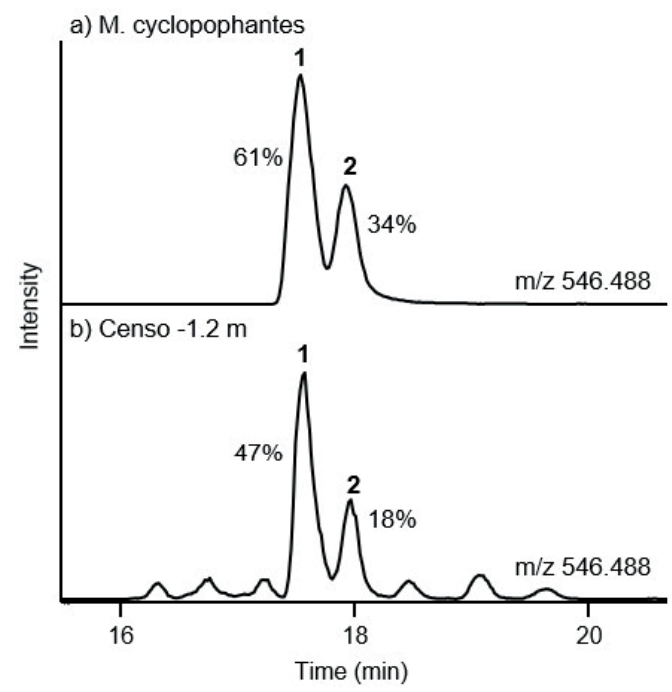

Figure7. Partial mass chromatograms of aminotriol (1) and aminotriol isomer (2) and their relative abundances (in \%) in a) M. cyclopophantes 3B (verrucomicrobial methanotroph) and b) Censo $-1.2 \mathrm{~m}$. The traces are labeled with the exact mass of $\mathrm{m} / \mathrm{z} 546.488[\mathrm{M}+\mathrm{H}]^{+}$for aminotriol used for searching.

A dditionally, two composite aminoB HPs were found to be present in the Censo soils: $\mathrm{C}_{16: 0}-\mathrm{N}$-acyl-aminotriol and $\mathrm{C}_{11: 0}-\mathrm{N}$-acyl-aminotriol, of which only $\mathrm{C}_{16: 0} \mathrm{~N}$-acyl-aminotriol could be identified also in the B issana seep soils. A t both sites, the $C_{16: 0}-\mathrm{N}$-acyl-aminotriol show high relative abundance at the seeps but also further away from the seeps (Figs. $2 \mathrm{C}$ and $3 \mathrm{C}$ ). In the PCA, $\mathrm{C}_{16: 0}-\mathrm{N}$-acylaminotriol clusters between 3-M e aminotriol and BHT and 3-M e B HT (Fig. 4a) suggesting a mixed origin. This is also supported by the finding of $\mathrm{C}_{16: 0}$ and $\mathrm{C}_{16: 1^{-}}$ $\mathrm{N}$-acyl-aminotriol in Nitrosomonas europaea, an ammonia-oxidizing bacterium (Talbot et al., 2007a). The $\mathrm{C}_{11: 0^{-}} \mathrm{N}$-acyl-aminotriol reveals high relative abundance directly at the Censo seep and at $-1.8 \mathrm{~m}$ (Fig. 2c) which is in accordance with higher relative abundance of Type I MOB M ethylococcaceae species in these soils (Fig. 5b). A lthough, $\mathrm{N}$-acyl-aminoB HPs were previously found in N. europaea and R. vannieli (Talbot et al., 2007a), no N-acyl- 
aminoBHPs with such short fatty acid chains were previously reported. This suggests a potential production of this $\mathrm{C}_{11: 0-} \mathrm{N}$-acyl-aminotriol by Type I M OB species. Since no source organism(s) of either $\mathrm{N}$-acyl-aminotriols are known, further research is needed using Type I methanotroph cultures.

\subsection{General and soil specific BHPs at both Sicilian gas seeps}

The distribution of more ubiquitous B HPs (i.e. BHT) and the general soil-marker B H Ps adenosylhopane and N1-methylinosylhopane (previously adenosylhopane type 1 and 2) was investigated at the two gas seeps (Figs. $2 d, 3 d$ and Tables S1, S2). In the Censo and Bissana seep soils, BHT show little variation in relative abundance over the seep transects and did not reveal a particular trend in respect to increasing distance from the seeps. BHT is one of the most ubiquitous B HPS found in terrestrial and marine environments and is synthesized by a wide variety of bacterial species (e.g. Cooke et al., 2008a; Tal bot and Farrimond, 2007; K usch et al., 2019). Therefore, B HT probably derives from numerous bacterial species present in both seep sites (Figs. 5 and 6) such as those from the phyla A ctinobacteria, A cidobacteria, Planctomycetes or various Proteobacteria (e.g. Neunlist et al., 1985; Zundel and Rohmer, 1985; Sinninghe Damsté et al., 2004, 2017; B lumenberg et al., 2006). This interpretation is supported by the separate clustering of BHT from $\mathrm{N}$-containing BHPs and soil-specific BHPs like adenosylhopane in the PCA plot (Fig. 4). In the Censo soils, B HT could also be produced by the highly abundant novel soil mycobacteria as some exploratory searches for the squalene-hopane-cyclase (shc) in closely related mycobacterial species ( $M$. simiae complex) showed the potential to synthesize biohopanoids (Smit et al., 2021a).

Adenosylhopanes are precursors to all side-chain extended BHPS (Bradley et al., 2010), however, they have been reported to be abundant mainly in terrestrial environments and have thus been used as proxies for terrestrial input into marine systems (C ooke et al., 2008a, b; Zhu et al., 2011; K usch et al., 2019). A denosylhopane and N 1-methylinosylhopane follow the opposite trend in their relative abundances with distance from the seeps compared to the $\mathrm{N}$-containing BHPs, which is also demonstrated by the opposite behaviour of these two soil BHPs compared to the N-containing BHPs in the PCA plot (Figs. 2, 3 and 4). Likely, typical soil bacteria such as A cidobacteria and A ctinobacteria present in the soils (Figs. 5 and 6) produce adenosylhopane and N1-methylinosylhopane (A lloisio et al., 2005; Sinninghe Damsté et al., 2017). Thus, M OB s and potential undescribed novel MOBs likely produce $\mathrm{N}$-containing BHPs directly at and close to the seeps, whereas other general soil bacteria producing adenosylhopane 
and N1-methylinosylhopane might dominate the BHP producing community further away from the seeps.

\subsection{An index of $\mathrm{N}$-containing BHPs to trace aerobic methane oxidation in the environment}

The PCA analysis of BHP inventories over both seep transects show M OBspecific aminoB H Ps (aminotriol, aminotetrol and aminopentol) plotting opposite of adenosylhopane and N1-methylinosylhopane derived from general soil bacteria. These results enable us to produce an index to trace the presence of $\mathrm{MOBs}$, and thus aerobic oxidation of methane, in terrestrial environments. For this, we suggest the three aminoBHPs and their 3-methylated homologues as $\mathrm{BHP}$-markers for aerobic oxidation of methane as they have well constrained M OB sources in contrast to the novel BHPs like the ethenolamineB HPs and $\mathrm{N}$ acyl-aminotriols. In contrast, the soil-marker BHPs, adenosylhopane and N 1methylinosylhopane are fully unrelated to aerobic oxidation of methane and can be used as indicators for the general abundance of soil bacteria. This leads to the following definition of the so-called A minoB HP-index:

\section{AminoB HP-index =}

$(a+a 1+b+b 1+c+c 1) /((j+k)+(a+a 1+b+b 1+c+c 1))$

with letters referring to the BHPs shown in Figure 1. This index theoretically ranges from 0 to 1 , with 1 meaning BHPs only comprising methanotrophic biomarkers, and thus intense aerobic oxidation of methane, while 0 indicates the absence of the specific methanotrophic biomarkers. A pplying this A minoB HPindex to the Sicilian seeps sites reveals values ranging from 0.44 to 0.84 at and very close to the Censo and Bissana seeps (Fig. 8 and Table S5). B etween $1 \mathrm{~m}$ to $2 \mathrm{~m}$ distance from the seeps, most data points cluster around 0.2 with a few much higher indicating still a high input of $M O B$ derived BHPS, in agreement with the high relative abundance of reads from MOB at the Censo site. Even further away, values are well below 0.2 suggests that there is no significant input of BHPs from methanotrophs. Therefore, we suggest 0.2 as a threshold, above which indicates the presence of $\mathrm{MOBS}$, and thus aerobic oxidation of methane. It should be noted that aminotriol, included in this index, can also be produced by bacteria other than methanotrophs (e.g. Neunlist et al., 1985; Talbot and Farrimond, 2007; B lumenberg et al., 2012) although here they are likely partially sourced by methanotrophic Verrucomicrobia (see above). Nevertheless, it is 
suggested to apply the index with caution when no 3-methylated homologue and no aminoB H Ps other than aminotriols are abundant in the soils. In our study, the consistent decrease of the A minoBHP-index values with increasing distance from the main seep sites clearly demonstrates the potential to apply the index to modern and past environments where aerobic oxidation of methane is thought to be present. Indeed, some BHPs (BHT) have been dated back to 50.4-49.7 M a ago in samples from marine Palaeogene cores from Tanzania (van D ongen et al., 2006) and back to 125 ka in M editerranean sapropels (Rush et al., 2019). Other studies showed that the aminoBHPs and especially aminopentol reflected periods of aerobic oxidation of methane in marine sediment records (1.2 $\mathrm{M}$ a) (Talbot et al., 2014) and peat deposits which dated back until the PETM (56 M a) implying a high preservation of aminoB HPs (van Winden et al., 2012; Tal bot et al., 2016). Future work should investigate the long-term preservation potential of aminoBH Ps and soil-specific BHPs as well as the impact of diagenesis on this index before it can be applied confidently to paleorecords.

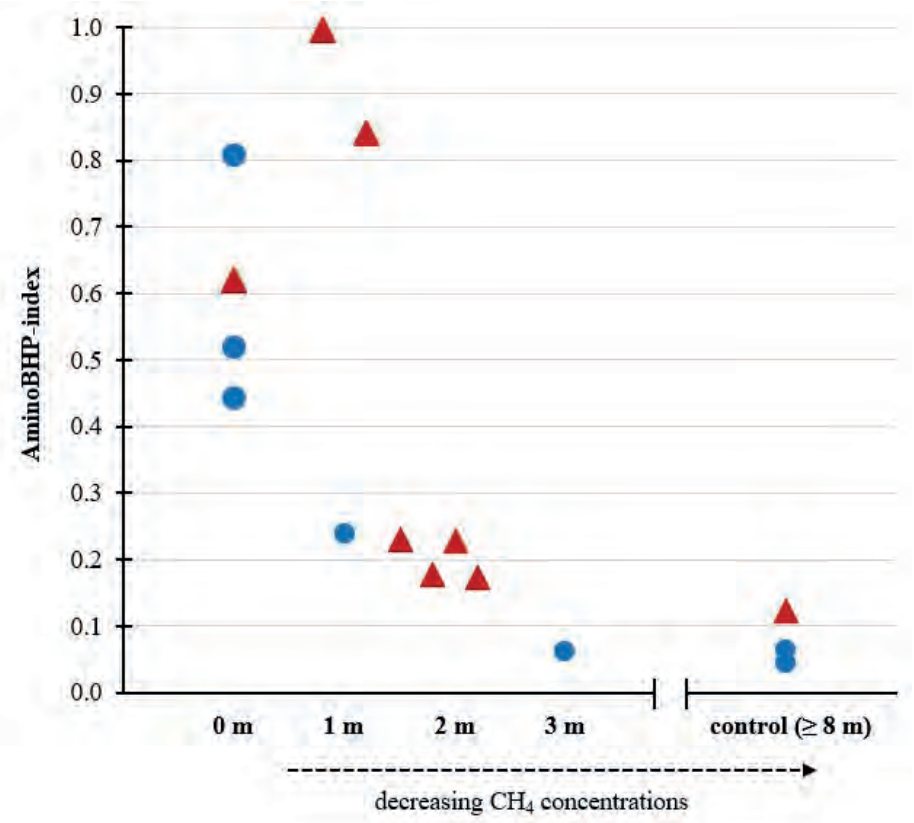

Figure 8. A minoB HP-index of soils from the Bissana and Censo seeps at increasing distance to the active seeps. The standard deviation for the A minoB H P-index from three triplicate samples ranges from 0.01 to 0.3 . K ey: B issana seep = blue filled circles; Censo seep = red filled triangles.

\section{Condusions}

The soils from the Censo and Bissana seeps show high relative abundances of aminoBHPs (aminotriol, aminotetrol and aminopentol) and novel 
ethenolamineBHPs (ethenolamine-BHT, -pentol and -hexol) that generally decrease with increasing distance from the seeps. The B issana seep contained 3methylated aminoBHPs at and near the seeps while the Censo seep did not contain high abundances of 3-methylated B HPs but did show high abundances of novel $\mathrm{C}_{11: 0} \mathrm{~N}-\mathrm{N}$-acyl-aminotriol around the main seep. $16 \mathrm{~S}$ rR NA gene analysis and clustering in PCA suggest that aminopentol and aminotetrol as well as the novel ethenolamineB HPs derive from Type I methanotrophs and possibly other methanotrophic bacteria. The Censo seep contains high abundances of aminotriol and a novel late eluting aminotriol isomer, based on its presence in the novel isolated verrucomicrobial strain $M$. cyclopophantes $3 B$ and the abundance of specific 16S rRNA gene sequences in the Censo soils, which are attributed to the verrucomicrobia 'Candidatus Methylacidiphilum'. The presence of aminotriol together with the late-eluting aminotriol isomer could be a new indicator for verrucomicrobial methanotrophs in the environment. The opposite behaviour of MOB-specific aminoBHPs compared to typical soilmarker BHPs (i.e. adenosylhopane) in PCA and the trends in their relative abundances, clearly suggest changes in the B HP-producing bacterial community away from the seeps related to the availability of methane. A new A minoB HPindex was developed based on aminoBHPs and their 3-metlylated homologues (as indicators for M OBs) and adenosylhopane and N 1-methylinosylhopane (as indicators of typical soil bacteria). The application of this A minoB HP-index shows high values $(\geq 0.4)$ close to the Bissana and Censo seeps and decreases with increasing distance from the seeps until it falls below 0.2 at more than $8 \mathrm{~m}$ distance from the seeps. The novel A minoB HP-index may offer a new biomarker tool to trace aerobic oxidation of methane in present and past terrestrial environments.

\section{A uthor contributions}

NTS, DR and SS planned the research. NTS and FG collected the samples. $\mathrm{HJMOC}$ and $\mathrm{CH}$ cultivated the verrucomicrobial Methylacidimicrobium cyclopophantes $3 \mathrm{~B}$ and provided biomass. NTS performed lipid extraction and BHP data analysis, while DBC performed $16 S$ rRNA analysis and LV analysed $16 S$ rRNA gene sequencing data. NTS, ECH, DR, SS, J SSD and LV interpreted the data. NTS wrote the paper with help of DR, SS and JSSD. All authors approved the final text.

\section{Competing inter ests}

The authors declare that they have no conflict of interest. 


\section{Acknowledgements}

We thank Denise van der Slikke-D orhout, M onique Verweij, M ichel K oenen, Sanne $V$ reugdenhil and $M$ aartje B rouwer for technical assistance. We also thank Caitlyn R. W itkowski for help with sample collection. NTS, SS and J SSD were supported by the Netherlands Earth System Science Centre (NESSC) through grant no. 024.002.001. LV, DR and JSSD were supported by the Soehngen Institute for Anaerobic Microbiology (SIAM) through Gravitation grant 024.002.002 from the Dutch Ministry for Education, Culture and Science. $\mathrm{CH}$ and $\mathrm{HJM} \mathrm{OC}$ were supported by the European Research Council (ERC A dvanced Grant project VOLCANO 669371). ECH received funding from the NWO middel groot grant no. 834.13.004.

\section{Supplemental M aterial (available upon request)}

Table S1. Relative and total abundances of integrated BHPs with standard deviations of averaged triplicate samples for the Censo seep.

Table S2. Relative and total abundances of integrated BHPs with standard deviations of averaged triplicate samples for the Bissana seeps.

Table S3. Relative abundances of integrated BHPs for the verrucomicrobial methanotroph M. cyclopophantes 3B.

Table S4. Relative abundances of main bacterial phyla and known M OB species reported as a percentage of total bacterial 16S rRNA gene reads. Triplicate samples of each distance were averaged, and standard deviations noted.

Table S5. A minoB HP-index values for the Censo and Bissana seeps. 

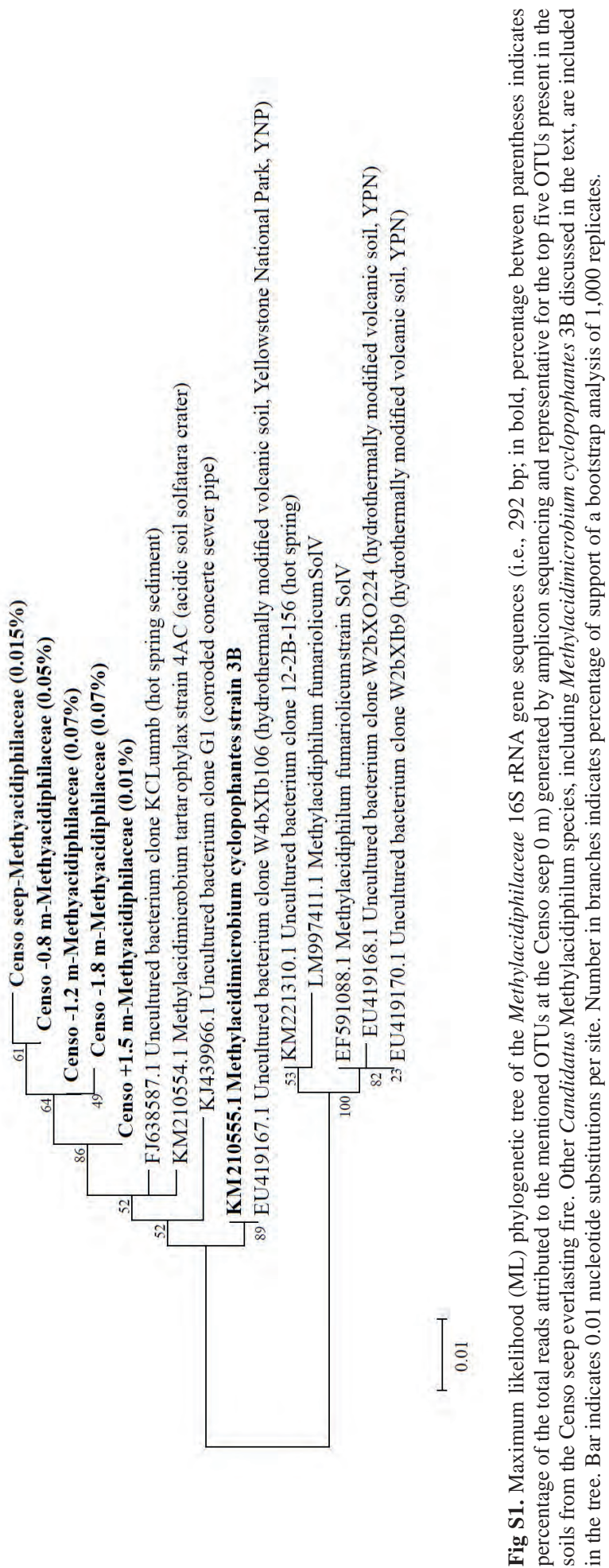
194 | Chapter 6 


\section{Chapter 7}

Novel hydrocarbon-utilizing soil mycobacteria synthesize unique mycocerosic acids at a Sicilian everlasting fire

Nadine T. Smit, Laura Villanueva, Darci Rush, Fausto Grassa, Caitlyn R.

Witkowski, Mira Holzheimer, Adriaan J. Minnaard, Jaap S. Sinninghe

Damsté, Stefan Schouten

Published in Biogeosciences 

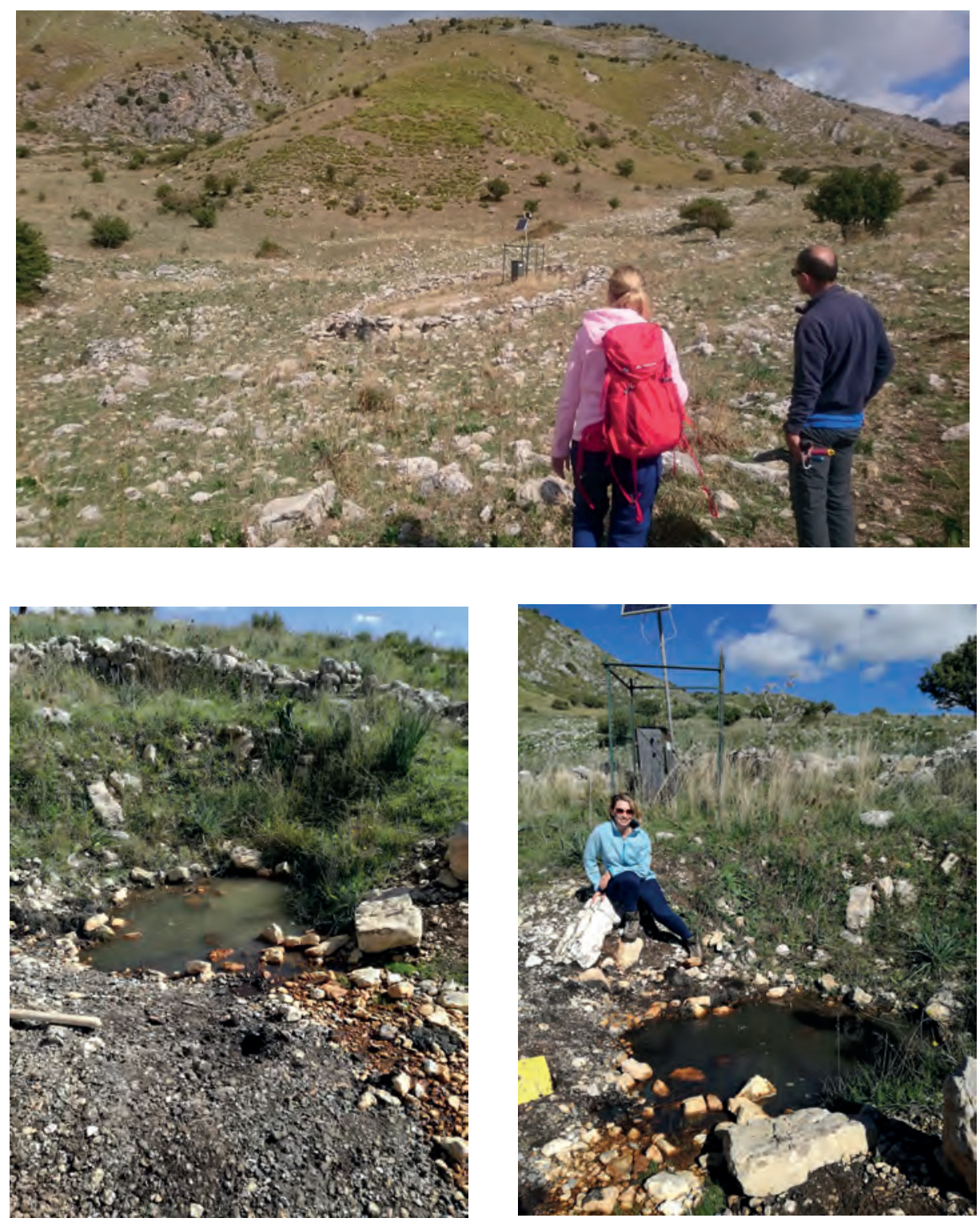

Fuoco di Censo everlasting fire in Sicily, Italy 


\section{Abstract}

Soil bacteria rank among the most diverse groups of organisms on Earth and actively impact global processes of carbon cycling, especially in the emission of greenhouse gases like methane, $\mathrm{CO}_{2}$ and higher gaseous hydrocarbons. An abundant group of soil bacteria are the mycobacteria, which colonize various terrestrial, marine and anthropogenic environments due to their impermeable cell envelope that contains remarkable lipids. These bacteria have been found to be highly abundant at petroleum and gas seep areas, where they might utilize the released hydrocarbons. However, the function and the lipid biomarker inventory of these soil mycobacteria are poorly studied. Here, soils from the Fuoco di Censo seep, an everlasting fire (gas seep) in Sicily, Italy, were investigated for the presence of mycobacteria via 16S rRNA gene sequencing and fatty acid profiling. The soils contained high relative abundances (up to $34 \%$ of reads assigned) of mycobacteria, phylogenetically close to the M ycobacterium simiae complex and more distant to the well-studied M. tuberculosis and hydrocarbonutilizing $M$. paraffinicum. The soils showed decreasing abundances of mycocerosic acids (M As), fatty acids unique for mycobacteria, with increasing distance from the seep. The major M As at this seep were tentatively identified as 2,4,6,8-tetramethyl tetracosanoic acid and 2,4,6,8,10-pentamethyl hexacosanoic acid. Unusual MAs with mid-chain methyl branches at positions C-12 and C-16 (i.e. 2,12-dimethyl eicosanoic acid and 2,4,6,8,16-pentamethyl tetracosanoic acid) were also present. The molecular structures of the Fuoco di Censo MAs are different from those of the well-studied mycobacteria like $M$. tuberculosis or $M$. bovis and have relatively $\delta^{13} \mathrm{C}$-depleted values (-38 to $-48 \%$ ), suggesting a direct or indirect utilization of the released seep gases like methane or ethane. The structurally unique MAs in combination with their depleted $\delta^{13} \mathrm{C}$ values identified at the Fuoco di Censo seep offer a new tool to study the role of soil mycobacteria as hydrocarbon gas consumers in the carbon cycle.

\section{Introduction}

Soils harbor the largest diversity of microorganisms on our planet and have a large influence on the Earth's ecosystem as they actively impact nutrient and carbon cycling, plant production and the emissions of greenhouse gases (Tiedje et al., 1999; B ardgett and van der Putten, 2014; D elgado-B aquerizo et al., 2018). Soil bacteria rank among the most diverse and abundant groups of organisms on Earth. However, numerous studies suggest that most of their function and diversity in our ecosystems is still undescribed (T iedje et al., 1999; B ardgett and van der Putten, 2014). The assessment of soil bacterial diversity has mainly 
relied on 165 ribosomal RNA ( $r R N A$ ) gene sequencing and has indicated that the most abundant bacterial phylotypes in global soils include Alphaproteobacteria, Gammaproteobacteria, Betaproteobacteria, A ctinobacteria, A cidobacteria and Planctomycetes (Fierer et al., 2012; DelgadoBaquerizo et al., 2018). Besides the use of DNA-based techniques, lipid biomarkers offer an additional tool to investigate soil bacterial communities, such as branched glycerol dialky glycerol tetraether (brGDGTs) believed to derive from soil acidobacteria (Weijers et al., 2009; Peterse et al., 2010; Sinninghe Damsté et al., 2018) or lipids derived from methanotrophic bacteria like certain fatty acids (Bull et al., 2000; Bodelier et al., 2009), specific bacteriohopanepolyols (van Winden et al., 2012; Talbot et al., 2016) or ${ }^{13} \mathrm{C}$ depleted hopanoids (Inglis et al., 2019; van W inden et al., 2020).

Mycobacteria of the genus Mycobacterium belonging to the phylum Actinobacteria form an abundant microbial group in global soils (Falkinham, 2015; Walsh et al., 2019). Some members of the genus M ycobacterium are obligate pathogens (e.g. Mycobacterium tuberculosis and Mycobacterium leprae) and are the cause of more than 1.5 million annual human deaths worldwide through the diseases tuberculosis and leprosy (World Health Organization, 2019). Thus, they have consequently been more frequently studied than opportunistic pathogenic and non-pathogenic environmental mycobacteria. Interestingly, early studies from the 1950s reported high abundances of nonpathogenic hydrocarbon-consuming mycobacteria (M . paraffinicum) in areas of oil and gas production, gas seeps, and in common garden soils (Davis et al., 1956; Dworkin and Foster, 1958; Davis et al., 1959). Cultivation and genomic studies show that mycobacteria can oxidize a range of greenhouse gases (ethane, propane, alkenes, carbon monoxide or hydrogen) and can degrade toxic polycyclic aromatic hydrocarbons (M iller et al., 2007; Hennessee et al., 2009; Coleman et al., 2012; M artin et al., 2014). M ycobacteria are able to colonize a wide variety of habitats from soils to aquatic and human-engineered environments (Brennan and Nikaido, 1995; Falkinham, 2009). Their impermeable cell envelope may play an important role in their ecological dominance. It consists of a peptidoglycan polymer that is surrounded by a thick hydrophobic lipid-rich outer membrane. This impermeability favors the formation of biofilms, thus enabling mycobacteria to be often the first colonizers at environmental interfaces like air-water or surface-water (Brennan and Nikaido, 1995). Additionally, the impermeable cell membrane allows a resistance to acidic conditions, anoxic survival and the possibility to metabolize recal citrant carbon compounds. M ycobacteria feature an unusual lipid inventory 
such as extremely long fatty acids with chains up to 90 carbon atoms long and with numerous methyl groups, hydroxylations and/or methoxylations produced by two fatty acid biosynthesis systems, i.e. FAS type I (eukaryotic type) and FAS type II (prokaryotic type) (Minnikin et al., 1985; Minnikin et al., 1993a; D onoghue et al., 2017; Daffé et al., 2019). Furthermore, mycobacteria are known to synthesize characteristic fatty acids like tuberculostearic acid (10-M e $\mathrm{C}_{18: 0}$ ) and the multi methyl-branched mycocerosic acids (M As) that can contain 3 to 5 methyl branches at regularly spaced intervals such as at positions C - 2, C - 4, C - 6 and C-8 (M innikin et al., 1985; M innikin et al., 1993a; M innikin et al., 2002; Redman et al., 2009). MAs are synthesized by the mycocerosic acid synthase (encoded by the mas gene) through the FAS type pathway I using a methyl mal onyl COA instead of a malonyl COA generating the unique methyl branching pattern of M A s (B rennan, 2003; Gago et al., 2011). These unusual fatty acids are bound to complex glycolipids like phthiocerol dimycocerosates (PDIM s), diacyl trehalose (DATs) or phenolic glycolipids (M innikin et al., 2002; Jackson et al., 2007). However, in contrast to the pathogenic and opportunistic pathogenic mycobacteria, the lipid biomarker inventory of non-pathogenic mycobacteria in soils and other environments remains poorly described.

In this study, we investigated soils near a continuous gas seep named "F uoco di Censo" ("Everlasting Fire") in Sicily, Italy to explore the presence of nonpathogenic, potentially hydrocarbon-utilizing, mycobacterial species using $16 \mathrm{~S}$ rRNA gene amplicon sequencing and fatty acid profiling. It resulted in the identification of potential biomarkers for the presence of mycobacteria in terrestrial environments and hydrocarbon seeps. Furthermore, their stable carbon isotopic composition provided hints for their role in the carbon cycle in this gas seepage environment.

\section{Material and Methook}

\section{Study area}

The Fuoco di Censo seep $\left(37^{\circ} 37^{\prime} 30.1^{\prime \prime} \mathrm{N}, 13^{\circ} 23^{\prime} 15.0^{\prime \prime} \mathrm{E}\right)$, in the following referred to as the Censo seep, is located at $800 \mathrm{~m}$ above sea level in the mountains of Southwestern Sicily, Italy (Etiope et al., 2002; Grassa et al., 2004). The area is part of the Alpine orogenic belt in the M editerranean and located along the boundary of the A frican and European plates (Basilone, 2012). The Censo seep belongs to the Bivona area, which is characterized by a complex geological setting. The seep is located in an area with sandy clays, marls and evaporites from the Tortonian-M essinian that are covered by a thrusting limestone of Carnian-Rhetian age (Trincianti et al., 2015). The Censo seep is a typical 
example of a natural 'E verlasting Fire', which is characterized by the absence of water and the temporal production of flames, which can be several meters high, by a continuous gas flux (Etiope et al., 2002). The Censo seep gas consists mainly of $\mathrm{CH}_{4}(76-86 \%)$ and $\mathrm{N}_{2}(10-17 \%)$ as well as some other minor gases like $\mathrm{CO}_{2}, \mathrm{O}_{2}$, ethane, propane, $\mathrm{He}$ and $\mathrm{H}_{2}$ (Etiope et al., 2002; Grassa et al., 2004). A diffuse soil degassing is detectable within an area of $80 \mathrm{~m}^{2}$ with an average $\mathrm{CH}_{4}$ flux of $7 * 10^{6} \mathrm{mg} \mathrm{m}^{-2} \mathrm{~d}^{-1}$ and a total $\mathrm{CH}_{4}$ emission of $6.2 * 10^{3} \mathrm{~kg} \mathrm{yr}^{-1}$ (Etiope et al., 2002; Etiope et al., 2007). The $\mathrm{CH}_{4}$ is suggested to be generated by the thermal alteration of organic matter and is characterized by a stable carbon isotopic composition of $\delta^{13} \mathrm{C}=-35 \%$ and $\delta^{2} \mathrm{H}=-146 \%$ (Grassa et al., 2004). This thermogenic $\mathrm{CH}_{4}$ possibly derives from mature marine source rocks (kerogen type II) with a thermal maturity beyond the oil window, resulting in a dry gas with $C_{1} /\left(C_{2}+C_{3}\right)$ ratios greater than 100 (G rassa et al., 2004).

\subsection{Sample collection}

Soil samples of the Censo seep were recovered during a field campaign in October 2017. The soil was collected from a horizon 5 to $10 \mathrm{~cm}$ below the surface and at three distances from the seep, i.e. $0 \mathrm{~m}$ (seep site), $1.8 \mathrm{~m}$, and a control at $13.2 \mathrm{~m}$ distance from the main vent. The in-situ temperature of the soils at the time of collection was ca. $18 \stackrel{\circ}{\circ}$. The soils were directly transferred into a clean geochemical sampling bag and stored frozen at $-20 \stackrel{\circ}{\circ}$ until freeze drying and extraction.

\subsection{Extraction and saponification}

Freeze-dried Censo soils were extracted with a modified Bligh and Dyer extraction for various compound classes (Schouten et al., 2008; Bale et al., 2013). Soil samples (ca. $12 \mathrm{~g}$ ) were ultrasonically extracted (10 min) with a solvent mixture containing methanol $(\mathrm{MeOH})$, dichloromethane (DCM) and phosphate buffer (2: 1: 0.8, v: v: v). After centrifugation, the solvent was collected, combined and the residues re-extracted twice. A biphasic separation was achieved by adding additional DCM and phosphate buffer to a ratio of $\mathrm{M} \mathrm{eOH}, \mathrm{DCM}$ and phosphate buffer (1: 1: 0.9, v: v: v). The aqueous layer was washed two more times with DCM and the combined organic layers dried over a $\mathrm{Na}_{2} \mathrm{SO}_{4}$ column followed by drying under $\mathrm{N}_{2}$.

Saponification (base hydrolysis) was conducted on aliquots (1-7 mg) of the Bligh Dyer extracts (BDEs) to release fatty acids from structurally complex intact polar lipids by the addition of $2 \mathrm{ml} 1 \mathrm{~N} \mathrm{KOH}$ in $\mathrm{MeOH}$ solution and refluxing for $1 \mathrm{~h}$ at $130^{\circ} \mathrm{C}$. A fter cooling, the $\mathrm{pH}$ was adjusted to 5 by using a $2 \mathrm{~N} \mathrm{HCL}$ in $\mathrm{M} \mathrm{eOH}$ 
solution, separated with $2 \mathrm{ml}$ bidistilled water and $2 \mathrm{ml} \mathrm{DCM}$, and the organic bottom layer was collected. The aqueous layer was washed two more times with DCM and the combined organic layers dried over a $\mathrm{Na}_{2} \mathrm{SO}_{4}$ column followed by drying under $\mathrm{N}_{2}$.

\section{Derivatization of fatty adids}

2.4.1 Preparation of fatty acid methyl esters using $B F_{3}$

A liquots of the saponified Censo seep BDEs and aliquots of a mycocerosic acid standard (2,4,6-trimethyl-tetracosanoic acid; $\mathrm{C}_{27} \mathrm{MA}$ standard) synthesized by hydrogenation with palladium and charcoal from mycolipenic acid (Holzheimer et al., 2020), were esterified with $0.5 \mathrm{ml}$ of a boron trifluoride-methanol solution (BF $\mathrm{BF}_{3}$ solution) for $10 \mathrm{~min}$ at $60{ }^{\circ} \mathrm{C}$. A fter cooling, $0.5 \mathrm{ml}$ bidistilled water and $0.5 \mathrm{ml} \mathrm{DCM}$ were added and shaken, and the DCM bottom layer pipetted off. The water layer was extracted twice with DCM and the combined DCM layers were dried over an $\mathrm{MgSO}_{4}$ column. The soil extracts were eluted over a small silica gel column with ethyl acetate as an eluent to remove polar compounds. Extracts were subsequently separated using a small column packed with activated al uminum oxide into two fractions. The first fraction (fatty acid methyl ester fraction) was eluted with 4 column volumes of DCM followed by a second fraction (polar fraction) eluted with 3 column volumes of DCM/M eOH (1:1). The fatty acid methyl ester fractions were dried under a continuous flow of $\mathrm{N}_{2}$ and analyzed using gas chromatography-mass spectrometry (GC-M S) and GCisotope ratio mass spectrometry (IRMS).

2.4.2 Preparation of fatty acid "picolinyl esters" derivatives using 3pyridylcarbinol

Aliquots of saponified Censo seep BDEs, as well as aliquots of the $C_{27} \mathrm{MA}$ standard, were derivatized into picolinyl esters. This technique enhances the abundance of diagnostic fragment ions in the mass spectrum, such as those of methyl branching points in fatty acids, enabling an improved structural identification (Christie, 1998; Harvey, 1998). Different 'picolinyl' derivatization protocols were tested on the $\mathrm{C}_{27} \mathrm{MA}$ standard and the highest yields were achieved by the procedure in Harvey, 1998. In this procedure, $0.5 \mathrm{ml}$ of thionyl chloride was added using a $1 \mathrm{ml}$ disposable syringe to $1 \mathrm{mg}$ aliquot of the dried saponified Censo seep BDEs in a pressure vial and left for ca. 2 min at room temperature. The vials were then dried by a continuous flow of $\mathrm{N}_{2} .0 .5 \mathrm{ml}$ of a $1 \%$ 3-pyridylcarbinol in acetonitrile solution was added in the reaction vials and left at room temperature for $2 \mathrm{~min}$. The volumes of reagents in this protocol were 
reduced $(0.1 \mathrm{ml})$ for $0.1 \mathrm{mg}$ of the M A standard. The 'picolinyl' esters were transferred with acetonitrile to $2 \mathrm{ml}$ analysis vials and the concentration was adjusted to $1 \mathrm{mg} / \mathrm{ml}$ with acetonitrile. The 'picolinyl' esters were analyzed using GC-M S with acetonitrile as injection solvent.

2.4.3 Preparation of fatty acid methyl sulfide esters using dimethyl disulfide (DMDS)

To determine the position of the double bonds in unsaturated fatty acids, dimethyl disulfide (DMDS) derivatization was used (Francis, 1981; Nichols et al., 1986). For this, $100 \mu \mathrm{l}$ of hexane, $100 \mu \mathrm{l}$ of DMDS solution (Merck $\geq 99 \%$ ) and $20 \mu \mathrm{l}$ of $\mathrm{I}_{2} /$ ether were added to the dry aliquot and heated overnight at $40 \stackrel{\circ}{\circ}$. The mixture was left to room temperature and $400 \mu \mathrm{l}$ of hexane and $200 \mu \mathrm{l}$ of a $5 \%$ aqueous solution of $\mathrm{N}_{2} \mathrm{~S}_{2} \mathrm{O}_{3}$ (for iodine deactivation) were added and mixed. The upper hexane layer was removed, and the aqueous layer washed twice with hexane. The three hexane layers were combined and dried over a $\mathrm{Na}_{2} \mathrm{SO}_{4}$ column before GC-M S analysis with hexane as injection solvent.

\subsection{Instrumental analysis}

2.5.1 Gas chromatography-mass spectrometry (GC -M S)

GC-MS was performed using an A gilent Technologies GC-MS Triple Quad $7000 \mathrm{C}$ in full scan mode. A CP-Sil5 CB column $(25 \mathrm{~m} \times 0.32 \mathrm{~mm}$ with a film of $0.12 \mu \mathrm{m}$, Agilent Technologies) was used for the chromatography with $\mathrm{He}$ as carrier gas (constant flow $2 \mathrm{ml} \mathrm{min}{ }^{-1}$ ). The samples $(1 \mu \mathrm{l})$ were injected on column at $70^{\circ} \mathrm{C}$, the temperature was increased at $20^{\circ} \mathrm{C} \mathrm{min}-1$ to $130{ }^{\circ} \mathrm{C}$, raised further by $4{ }^{\circ} \mathrm{C} \min ^{-1}$ to $320{ }^{\circ} \mathrm{C}$, at which it was held for $20 \mathrm{~min}$. The mass spectrometer was operated over a mass range of $\mathrm{m} / \mathrm{z} 50$ to 850 , the gain was set on 3 , with a scan time of $700 \mathrm{~ms}$.

\subsubsection{Gas chromatography-isotope ratio mass spectrometry (GC-IRM S)}

GC-IRMS was carried out with a Thermo Scientific Trace 1310 with a GCI solink II, a ConFlo IV and a Delta A dvantage IRM S. The gas chromatography was performed on a CP-Sil5 CB column ( $25 \mathrm{~m} \times 0.32 \mathrm{~mm}$ with a film thickness of $0.12 \mu \mathrm{m}$, Agilent) with $\mathrm{He}$ as carrier gas (constant flow $2 \mathrm{ml} \mathrm{min}{ }^{-1}$ ). The $B F_{3}$ methylated samples (dissolved in ethyl acetate) were on-column injected at 70 $\stackrel{\circ}{ } \mathrm{C}$ and subsequently, the oven was programmed to $130{ }^{\circ} \mathrm{C}$ at $20 \stackrel{\circ}{\circ} \mathrm{min}^{-1}$, and then at $4{ }^{\circ} \mathrm{C} \mathrm{min}^{-1}$ to $320{ }^{\circ} \mathrm{C}$, which was held for $10 \mathrm{~min}$. Stable carbon isotope ratios are reported in del ta-notation against $V$ ienna Pee Dee B elemnite (VPDB) 
${ }^{13} \mathrm{C}$ standard. V alues were determined by two analysis and results averaged to a mean value.

\subsection{DNA extraction, 16S rR NA gene amplification, analysis and phylogeny}

DNA was extracted from sediments using the PowerM ax soil DNA isolation kit (Qiagen). DNA extracts were stored at $-80{ }^{\circ} \mathrm{C}$ until further analysis. The $16 \mathrm{~S}$ rRNA gene amplicon sequencing and analysis was performed with the general $16 \mathrm{~S}$ rR NA archaeal and bacterial primer pair $515 \mathrm{~F}$ and $806 \mathrm{RB}$ targeting the $\mathrm{V} 4$ region (Caporaso et al., 2012; B esseling et al., 2018). Polymerase chain reaction (PCR) products were gel purified using the QIAquick Gel-Purification kit (Qiagen), pooled and diluted. Sequencing was performed at the Utrecht Sequencing Facility (Utrecht, the Netherlands) using an Illumina MiSeq sequencing platform. The $16 \mathrm{~S}$ rR NA gene amplicon sequences were analyzed by an in-house pipeline (Abdala Asbun et al., 2020) that includes quality assessment by FastQ $C$ (A ndrews, 2010), assembly of the paired-end reads with Pear (Zhang et al., 2013), and assignment of taxonomy (including picking representative set of sequences with 'longest' method) with blast by using the A R B Silva 128 database (https://www.arb-silva.de/, last access: 5 A ugust 2018, release 128). Representative operational taxonomic unit (OTU) sequences (assigned with OTU picking method based on $97 \%$ nucleotide similarity with U clust) (Edgar, 2010), attributed to the family M ycobacteriaceae were aligned by using Muscle (Edgar, 2004) implemented in MEGA6, and then used to construct a phylogeny together with $16 \mathrm{~S}$ rR N A gene sequences of characterized $M$ ycobacterium species and closely related uncultured M ycobacteriaceae 16S rRNA gene sequences. The phylogenetic tree was inferred using the M aximum Likelihood method based on the General Time Reversible model ( $\mathrm{Nei}$ and Kumar, 2000). The analysis involved 32 nucleotide sequences with 294 base pairs positions in the final dataset. Evolutionary analyses were conducted in MEGA 6 (Tamura et al., 2013).

\section{R esults and discussion}

\subsection{M icrobial diversity in the C enso seep soils}

Soils were sampled at the Censo seep and with increasing distance from the seep (Table 1). To investigate the microbial diversity, 16S rR NA gene libraries were generated from extracted DNA using $16 \mathrm{~S}$ rR N A gene amplicon sequencing. This analysis showed a high relative abundance of $16 \mathrm{~S}$ rRNA gene reads attributed to $M$ ycobacteriaceae ranging from 0.7 to $34.1 \%$ of assigned bacterial plus archaeal reads in the soils with relative abundances increasing with decreasing distance 
to the seep (Table 1). Sequences assigned to known methanotrophs are Gammaproteobacteria (M ethylococcales), Alphaproteobacteria (M ethylocystaceae and Methylobacteriaceae) and Verrucomicrobia ('Candidatus Methylacidiphilum') but only accounted for 0.2 to $5.1 \%$ of the total number of reads assigned (Table 1). Phylogenetic analysis indicated that there are two sequences representative for operational taxonomic units (OTUs) attributed to mycobacteria (i.e. sequences Censo seep 1 and Censo seep 2) present in the soils (Fig. 1). B oth OTU s are phylogenetically most closely related to sequences of the M ycobacterium simiae complex (Tortoli, 2014) (Fig. 2; >98 $\%$ identical considering the 294 bp sequence fragment analyzed), which include M. simiae, M. europaeum, M. kubicae and M. heidelbergense (Hamieh et al., 2018). Previously described cultivated mycobacteria of the $M$. simiae complex are slow-growing mycobacterium species isolated from environmental niches but also associated to infections in humans as opportunistic pathogens (LévyFrébault et al., 1987; Heap, 1989; B ouam et al., 2018). The Censo seep sequences are more distantly related ( $94-95 \%$ identical) to frequently studied pathogenic mycobacteria (such as $M$. tuberculosis and $M$. leprae) and other environmental mycobacteria like hydrocarbon-utilizers (e.g. M. paraffinicum and M. vanbaalenii) (Fig. 1). To the best of our knowledge the hydrocarbon-utilizing bacteria have not been isolated from humans or animals (e.g. M. vanbaalenii) and are mostly able to degrade aromatic hydrocarbons (K weon et al., 2015). 0 ur data reveal abundances of up to $34 \%$ of uncultured mycobacteria (Censo $0 \mathrm{~m}$ ) in the soils around the Censo seep. This is in line with previous reports of the occurrence of mycobacteria near petroleum seeps and gas fields (Davis et al., 1956; Davis et al., 1959).

\subsection{F atty acid composition of $\mathrm{C}$ enso seep soils}

A nalysis of the fatty acid fractions of the Censo seep soils reveal a distinct pattern that changes with increasing distance from the main seep (Fig. 2). Common fatty acids such as $C_{16: 0,}, C_{16: 1 \omega 6,}, C_{16: 1 \omega 7}, C_{18}, C_{18: 1 \omega 9}$ and $C_{18: 1 \omega 7}$ as well as the longer chain $C_{22}$ and $C_{24}$ fatty acids occur in all three soils. $C_{16}$ and $C_{18}$ fatty acids are abundant lipids in soils and are synthesized by diverse bacteria and fungi, whereas the longer chain $\left(\mathrm{C}_{22}-\mathrm{C}_{24}\right)$ fatty acids originate commonly from higher

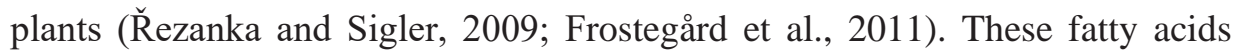
could also derive from mycobacteria which can produce fatty acids ( $C_{14}$ to $C_{26}$ ) with high amounts of $\mathrm{C}_{16}$ and $\mathrm{C}_{18}$ fatty acids and their unsaturated homologues (Chou et al., 1996; Torkko et al., 2003). 
Table 1 Distribution of the main microbial groups (in percentage of assigned reads) based on 16S rRNA gene amplicon sequencing at three distances from the main gas seep in the Censo soils. The bold typeface annotates the relative abundances of mycobacteria in the Censo soils.

\begin{tabular}{|c|c|c|c|}
\hline & $\mathbf{0 m}$ & $1.8 \mathrm{~m}$ & $13.2 \mathrm{~m}$ \\
\hline A rchaea; Euryarchaeota & 53.5 & 0.0 & 0.0 \\
\hline A rchaea; Thaumarchaeota & 0.0 & 0.0 & 2.5 \\
\hline B acteria; A cidobacteria & 0.2 & 3.0 & 10.5 \\
\hline B acteria; A ctinobacteria & 36.8 & 23.6 & 46.0 \\
\hline A cidimicrobiales, other & 0.0 & 0.3 & 2.3 \\
\hline $\begin{array}{l}\text { Corynebacteriales, M ycobacteriaceae, } \\
\text { M ycobacterium }\end{array}$ & 34.1 & 8.5 & 0.7 \\
\hline $\begin{array}{l}\text { Frankiales, G eodermatophilaceae, } \\
\text { G eodermatophilus }\end{array}$ & 0.0 & 5.1 & 0.1 \\
\hline $\begin{array}{l}\text { M icrococcales, M icrobacteriaceae, } \\
\text { Humibacter }\end{array}$ & 0.1 & 3.0 & 0.0 \\
\hline $\begin{array}{l}\text { M icromonosporales, M icromonosporaceae, } \\
\text { M icromonospora }\end{array}$ & 1.0 & 0.0 & 0.1 \\
\hline $\begin{array}{l}\text { Pseudonocardiales, Pseudonocardiaceae, } \\
\text { Pseudonocardia }\end{array}$ & 0.0 & 0.0 & 1.6 \\
\hline $\begin{array}{l}\text { Rubrobacterales, Rubrobacteriaceae, } \\
\text { Rubrobacter }\end{array}$ & 0.0 & 0.0 & 6.2 \\
\hline Gaiellales, Gaiellaceae, Gaiella & 0.0 & 0.0 & 5.1 \\
\hline $\begin{array}{l}\text { Solirubrobacterales, 288-2, uncultured } \\
\text { bacterium }\end{array}$ & 0.0 & 0.0 & 2.2 \\
\hline $\begin{array}{l}\text { Solirubrobacterales, Elev-16S-1332, } \\
\text { uncultured bacterium }\end{array}$ & 0.0 & 0.6 & 4.3 \\
\hline $\begin{array}{l}\text { Solirubrobacterales, Solirubrobacteraceae, } \\
\text { Solirubrobacter }\end{array}$ & 0.0 & 0.0 & 1.8 \\
\hline others & 1.6 & 6.0 & 21.5 \\
\hline B acteria; A rmatimonadetes & 0.0 & 0.0 & 0.2 \\
\hline B acteria; B acteroidetes & 0.3 & 1.2 & 2.1 \\
\hline B acteria; Chloroflexi & 0.2 & 30.5 & 10.5 \\
\hline $\begin{array}{l}\text { A naerolineales, A naerolineae, } \\
\text { A naerolineales }\end{array}$ & 0.0 & 7.9 & 0.2 \\
\hline K tedonobacteria & 0.1 & 17.8 & 0.1 \\
\hline B acteria; Firmicutes & 5.2 & 15.7 & 0.6 \\
\hline B acteria; Gemmatimonadetes & 0.0 & 0.0 & 3.1 \\
\hline
\end{tabular}




\begin{tabular}{|l|c|c|c|} 
B acteria; L atescibacteria & 0.0 & 0.0 & 0.2 \\
\hline B acteria; Nitrospirae & 0.0 & 0.0 & 0.2 \\
\hline B acteria; Planctomycetes & 0.2 & 1.5 & 3.7 \\
\hline B acteria; Proteobacteria & 2.9 & 21.1 & 17.2 \\
\hline $\begin{array}{l}\text { A Iphaproteobacteria, R hizobiales, } \\
\text { M ethylobacteriaceae }\end{array}$ & 0.0 & 0.3 & 0.8 \\
\hline $\begin{array}{l}\text { A lphaproteobacteria, R hizobiales, } \\
\text { M ethylocystaceae }\end{array}$ & 0.0 & 4.2 & 0.0 \\
\hline Gammaproteobacteria, M ethylococcales & 0.2 & 5.1 & 0.2 \\
\hline B acteria; Saccharibacteria & 0.1 & 2.1 & 0.2 \\
\hline B acteria; Tectomicrobia & 0.0 & 0.0 & 0.7 \\
\hline B acteria; Verrucomicrobia & 0.3 & 0.3 & 1.7 \\
\hline $\begin{array}{l}\text { V errucomicrobia Incertae Sedis, } \\
\text { Candidatus M ethylacidiphilum }\end{array}$ & 0.2 & 0.0 & 0.0 \\
\hline Number of reads assigned & $\mathbf{1 4 0 , 2 0 6}$ & $\mathbf{6 3 , 9 1 6}$ & $\mathbf{2 5 9 , 7 1 4}$ \\
\hline
\end{tabular}

B esides mycobacteria which are abundant in the soils close to the main seepage (Table 1 ), the $C_{16}$ fatty acids may also originate from Type I methanotrophs (Gammaproteobacteria), whereas $C_{18}$ fatty acids could derive from type II methanotrophs (A I phaproteobacteria), present in these Censo seep soils (Fig. 2 and Table 1) (Bull et al., 2000; Bowman et al., 1993; Bodelier et al., 2009). However, the relative abundances of $16 \mathrm{~S}$ rR NA gene reads of this Type I and II methanotrophs are only minor in the Censo soils (Table 1 ).

The Censo seep soils also feature $C_{31}-C_{33} 17 \beta, 21 \beta(\mathrm{H})$-homohopanoic acids, the most abundant of which is the $C_{32} 17 \beta, 21 \beta(H)$-hopanoic acid (bishomohopanoic acid) (Fig. 2). Hopanoic acids are common components in terrestrial environments (Ourisson et al., 1979; Rohmer et al., 1984; Ries-K autt and A Ibrecht, 1989; Crossman et al., 2005; Inglis et al., 2018) and can be derived from a range of bacteria, including Alpha-and Gammaproteobacteria, Planctomycetes and A cidobacteria (Thiel et al., 2003; Sinninghe Damsté et al., 2004; Birgel and Peckmann, 2008; Sinninghe Damsté et al., 2017). Explorative searches of genomic databases for the biosynthetic gene encoding squalenehopane-cyclase (shc) in mycobacteria from the M. simiae complex revealed a potential for biohopanoid production. In contrast, the more distantly related pathogenic mycobacteria, e.g. M . tuberculosis, are known to synthesize steroids instead of hopanoids (Lamb et al., 1998; Podust et al., 2001). Therefore, 


\section{mycobacteria from the M. simiae complex may be an additional source for hopanoic acids in the Censo seep soils.}

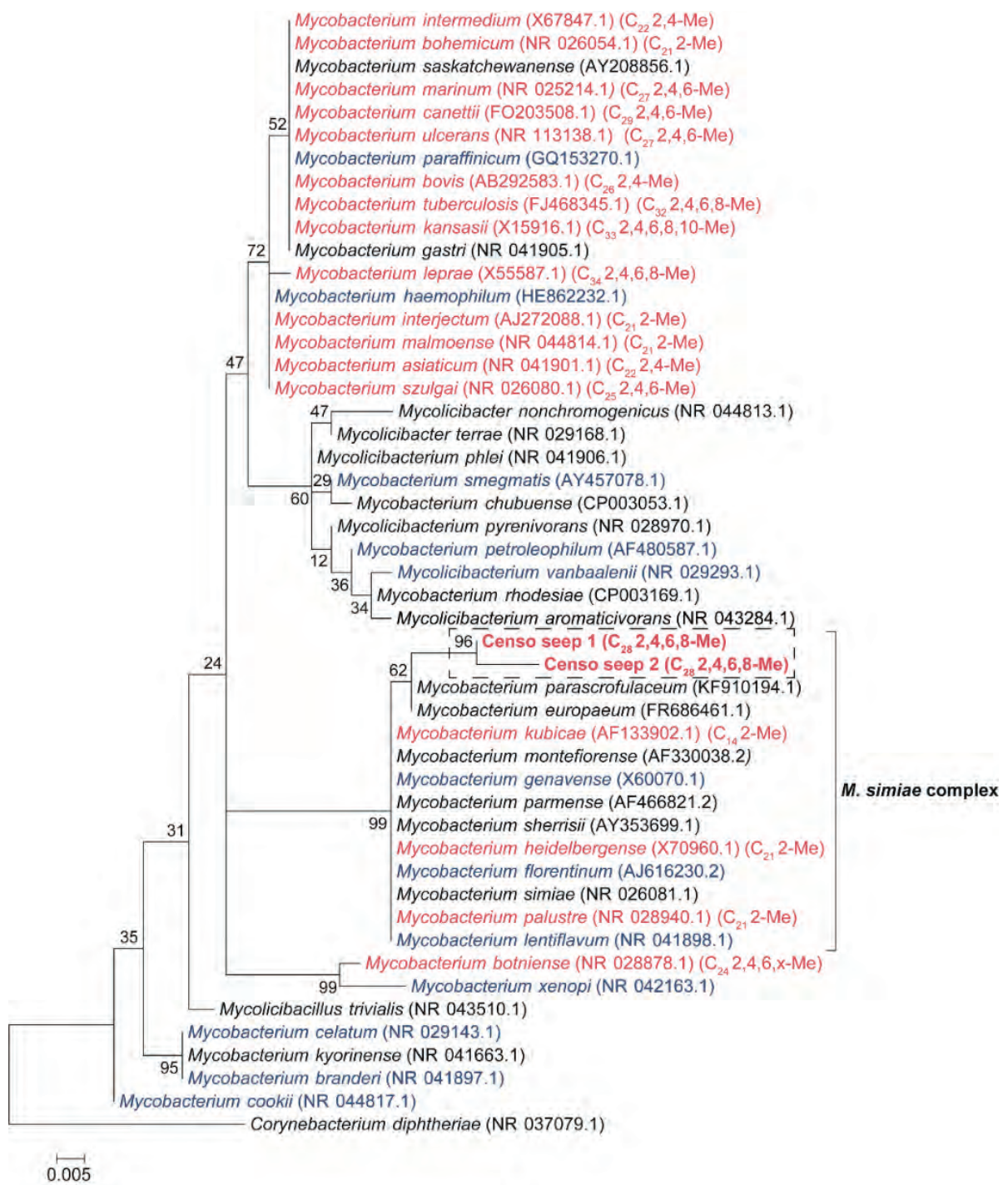

Figure $1 \mathrm{M}$ aximum likelihood (ML) phylogenetic tree of the Mycobacterial $16 \mathrm{~S}$ rRNA gene fragments (i.e. $294 \mathrm{bp}$; in bold) generated by amplicon sequencing and representative for the two OTU s present in the soils from the Censo seep "everlasting fire". The 16S rRNA gene sequence of Corynebacterium diphtheriae was used as an outgroup and other M ycobacterial $16 \mathrm{~S}$ rR NA gene sequence are plotted for reference. The M L tree is based on the General Time Reversible model with gamma distribution plus invariable sites. M ycobacterial species biosynthesizing MAs are indicated in red font, species not containing MAs are shown in blue and species for which M A s have not been analyzed are shown in black. The mycobacterial species producing M As (in red) are labelled with their dominant $\mathrm{MA}$ in brackets (total carbon number, $\mathrm{M} e=$ methyl, $\mathrm{x}=$ unidentified position of methyl group). 
Interestingly, at the seep $(0 \mathrm{~m})$ the FA pattern is dominated by unusual FAs ranging from $C_{19}$ to $C_{31}$, which are absent further away from the main seepage (Fig. 2). The mass spectra of the three most abundant representatives of these fatty acids are shown in Figure 3. Mass spectra of the methyl ester derivatives of these fatty acids show major fragment ions of $\mathrm{m} / \mathrm{z} 88$ and 101. These fragments result from " $\mathrm{M} \mathrm{CL}$ afferty" rearrangements associated with the presence of the carboxylic acid methyl ester group (L ough, 1975; R an-Ressler et al., 2012). The presence of the even-numbered $\mathrm{m} / \mathrm{z} 88$ fragment ion, rather than the typical fragment ion at $\mathrm{m} / \mathrm{z} 74$ in the mass spectra of methyl esters of $n-F A s$, strongly suggests a methyl group at position C-2 (Fig. 3). One FA shows also high fragment ions at $\mathrm{m} / \mathrm{z} 213$ and $\mathrm{m} / \mathrm{z} 241$ (Fig. 3A). This difference of $28 \mathrm{Da}$ hints at a second methyl group at position C-12 (Fig. 3A). Two of these fatty acids show a fragment ion at $\mathrm{m} / \mathrm{z} 129$ (Figs. $3 \mathrm{C}$ and $\mathrm{E}$ ), suggesting the presence of an additional methyl at position C-4 of the fatty acids. The apparent methyl branches in these fatty acids are in agreement with the relatively early retention times of these FAs compared to the regular straight-chain counterparts (Fig. 2). Other fragment ions, including those potentially revealing the positions of additional methyl groups, were only present in low abundance, complicating further structural identification. Nevertheless, the presence of methyl branches at $\mathrm{C}-2$ and $\mathrm{C}-4$ in a number of these fatty acids does suggest that they may be related to mycobacteria-derived MAs, which share the same structural characteristics (A lugupalli et al., 1998; Nicoara et al., 2013). Indeed, the mass spectrum of the methyl ester of a synthetic $C_{27}$ MA standard (2,4,6-trimethyltetracosanoic acid) (Holzheimer et al., 2020) shows identical mass spectral features (i.e. m/z 88 and 129; Fig. 4A ). However, full structural interpretation of the mass spectrum of this authentic standard is also complicated by the low abundances of diagnostic fragment ions indicative for the position of the methyl branches in the alkyl chain.

To enhance the diagnostic fragmentation patterns of these potential MAs, the fatty acids were also transformed into a "picolinyl ester" (Harvey, 1998). The potential of this technique is revealed by the mass spectrum of the synthetic MA standard (2,4,6-trimethyl-tetracosanoic acid) "picolinyl ester" derivative (Fig. 4B), which shows fragment ions revealing all positions of methylation of the fatty acid $n$-alkyl chain. The high intensity of the fragment ion of $\mathrm{m} / \mathrm{z} 165$ indicates the presence of a methyl group at position C-2, while the presence of the fragment ions at $\mathrm{m} / \mathrm{z} 178$ and 206 combined with the absence of an $\mathrm{m} / \mathrm{z} 192$ fragment ion indicates the presence of a methyl group at C-4. Similarly, the presence of the third methyl group at position C -6 is revealed by 
the fragment ions at $\mathrm{m} / \mathrm{z} 220$ and 248 and the low abundance of the fragment ion at $\mathrm{m} / \mathrm{z} 234$. Thus, the "picolinyl derivatization" technique substantially increases the confidence in the structural identification of multi-methyl-branched fatty acids using mass spectrometry. Therefore, this "picolinyl ester" derivatization technique was also applied to determine the methylation pattern of the potentially novel MAs in the Censo seep soils (Fig. 3).

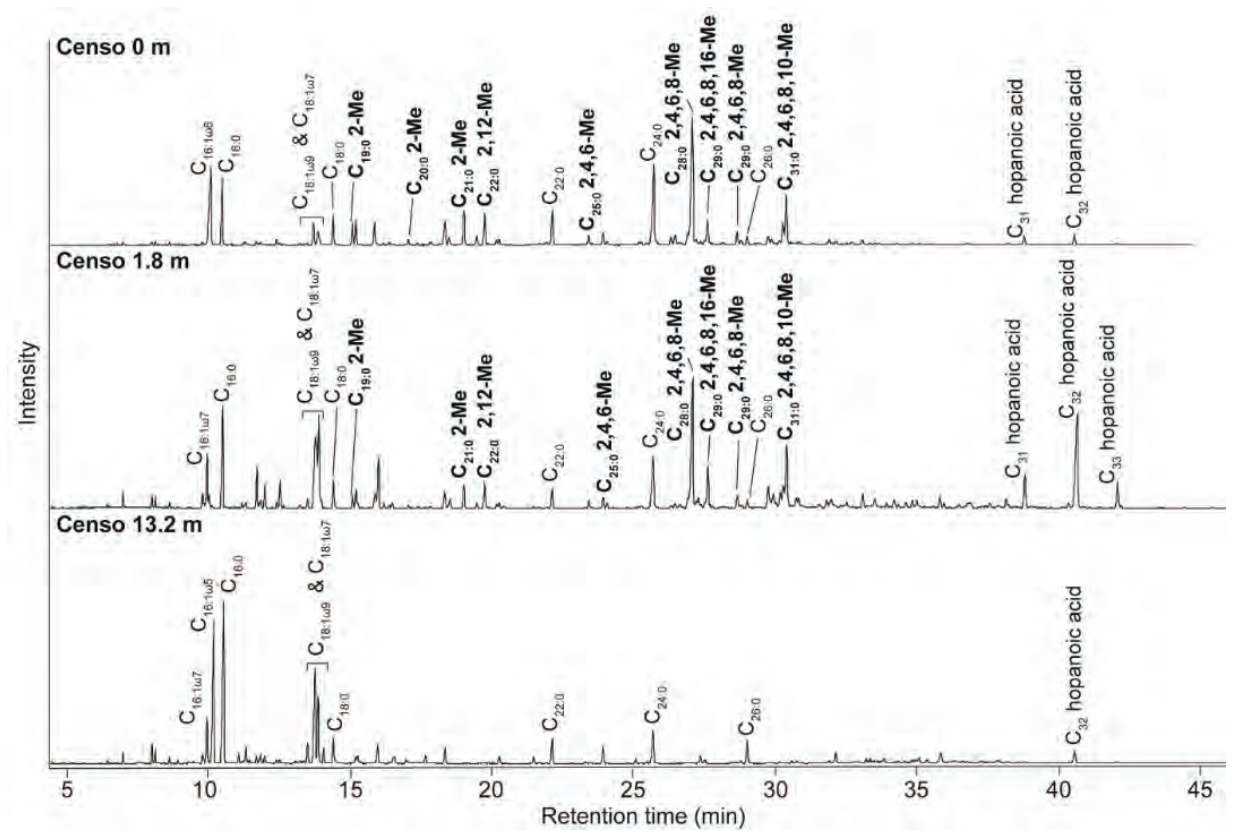

Figure2 Total ion chromatograms of the saponified and derivatized $\left(\mathrm{BF}_{3}\right)$ fatty acid fractions from the $C$ enso seep soils in increasing distance from the main seepage showing the distributions of FAs, hopanoic acids, and MAs. The black bold annotations show the tentatively identified M As and the carbon position of their methyl groups (Me).

To illustrate this approach, we discuss the identification of the three major M As. When analyzed as "picolinyl ester derivatives" (Fig. 3B, D and F), these MAs respectively showed molecular ions $\left(\mathrm{M}^{+}\right)$431, 515, and 557, indicating $C_{22}, C_{28}$, and $C_{31} M A s$, respectively. The mass spectrum of the "picolinyl ester derivative" $C_{28}$ MA (Fig. 3D), the most abundant MA in the Censo seep soils, confirms the methylation at C-2 with the fragment ion of $\mathrm{m} / \mathrm{z}$ 165. Furthermore, this spectrum also shows abundant fragment ions at $\mathrm{m} / \mathrm{z} 178$, $206,220,248,262$ and 290 . Combined with the absence of the fragment ions at $\mathrm{m} / \mathrm{z} 192,234$ and 276, this strongly suggests the presence of three additional methyl groups at position C -4, C -6 and C -8 . 
A)
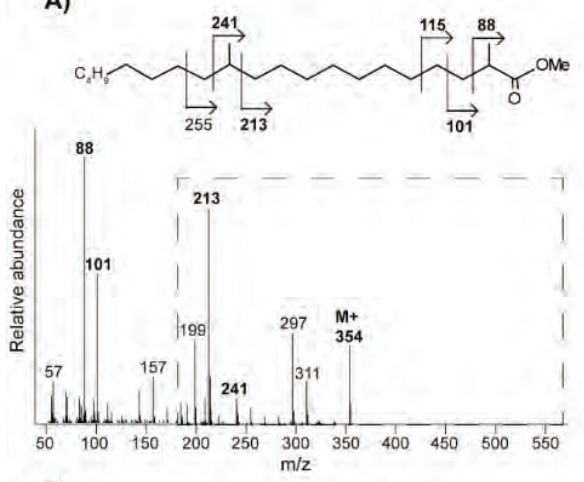

C)
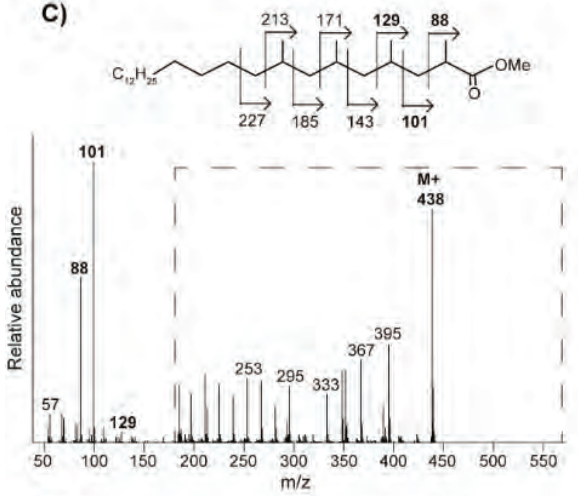

E)
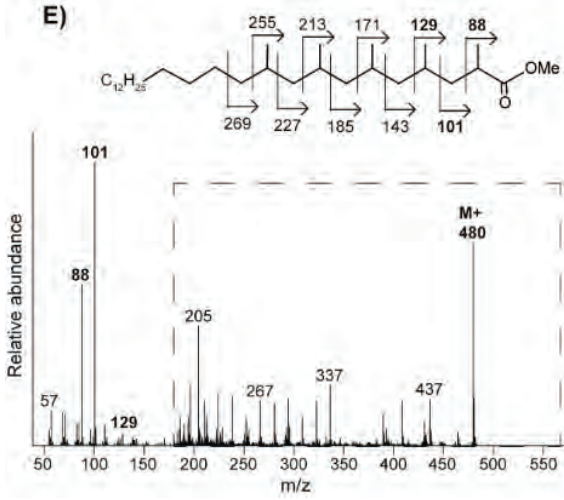

B)
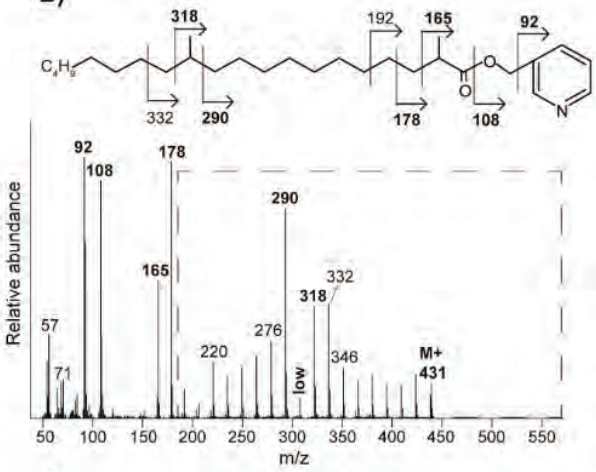

D)
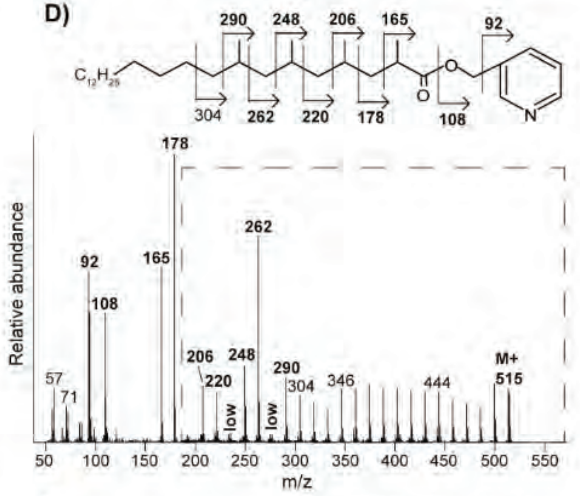

F)
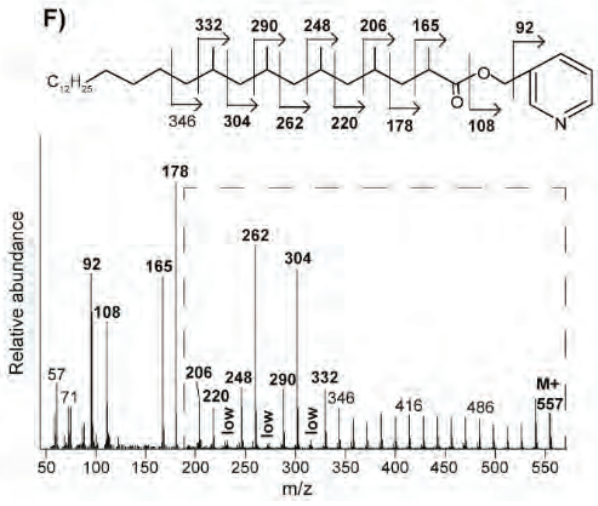

Figure $3 \mathrm{M}$ ass spectra of the methyl ester (left panels) and 'picolinyl' -ester (right panels) derivatized M A s of the Censo $0 \mathrm{~m}$ soil sample, with proposed molecular structures and fragmentation patterns. 2,12-Dimethyleicosanoic acid ( $C_{22}$ 2,12-M e M A) (A and B), 2,4,6,8-tetramethyl-tetracosanoic acid ( $C_{28}$ 2,4,6,8-M e M A) (C and $D)$, and 2,4,6,8,10-pentamethyl-hexacosanoic acid ( $C_{31} 2,4,6,8,10-M$ e M A) (E and F). The dashed boxes show a 10 times exaggerated view into the indicated area of the mass spectrum.

The mass spectrum of the $\mathrm{C}_{22}$ "picolinyl ester derivative" (Fig. 3B) also confirms the methyl branch at position C-2 through the mass ion $\mathrm{m} / \mathrm{z} 165$. Elevated fragment ions at $\mathrm{m} / \mathrm{z} 290$ and 318 in combination with the low intensity of the fragment ion at $\mathrm{m} / \mathrm{z} 304$ suggests a methyl group at position $\mathrm{C}-12$. Further 
mass spectral interpretations can be made for the $C_{31} M A$, with mass spectrum similar to that of the $\mathrm{C}_{28} \mathrm{MA}$ but including an additional methyl group at position $\mathrm{C}-10$, as indicated by the presence of fragment ions at $\mathrm{m} / \mathrm{z} 304$ and 332 and the absence of a fragment ion at $\mathrm{m} / \mathrm{z} 318$ (Fig. 3F). Thus, we tentatively identified these MAs as 2,12-dimethyl-eicosanoic acid ( $C_{22}$ 2,12-dimethyl $M A$ ), 2,4,6,8tetramethyl-tetracosanoic acid ( $C_{28}$ 2,4,6,8-tetramethyl $\left.M A\right)$ and 2,4,6,8,10pentamethyl-hexacosanoic acid ( $C_{31} 2,4,6,8,10$-pentamethyl $\left.M A\right)$, respectively (Figs. 2, 3 and Table 2). Other abundant M As tentatively identified include 2methyl-octadecanoic acid ( $\mathrm{C}_{19}$ 2-methyl $\mathrm{M} A$ ), 2-methyl-nonadecanoic acid $\left(\mathrm{C}_{20}\right.$ 2-methyl MA), 2-methyl-eicosanoic $\left(C_{21}\right.$ 2-methyl $\left.M A\right)$, 2,4,6-trimethyldocosanoic acid ( $C_{25}$ 2,4,6-trimethyl $M A$ ), 2,4,6,8-tetramethyl-pentacosanoic acid ( $C_{29}$ 2,4,6,8-tetramethyl) and 2,4,6,8,16-pentamethyl-tetracosanoic acid ( $C_{29}$ 2,4,6,8,16-pentamethyl M A) M As (Fig. 2 and Table 2).

A)
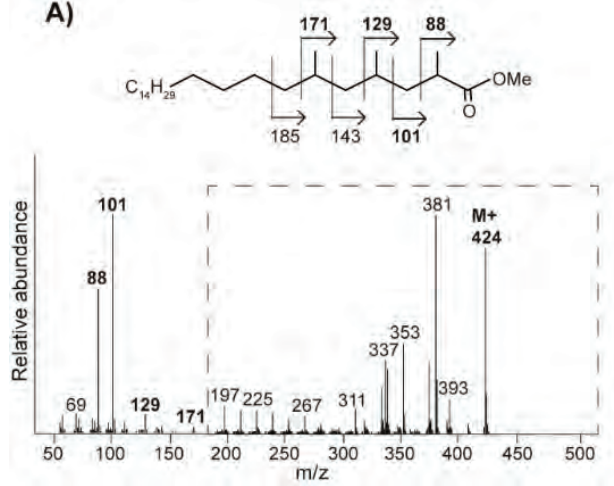

B)
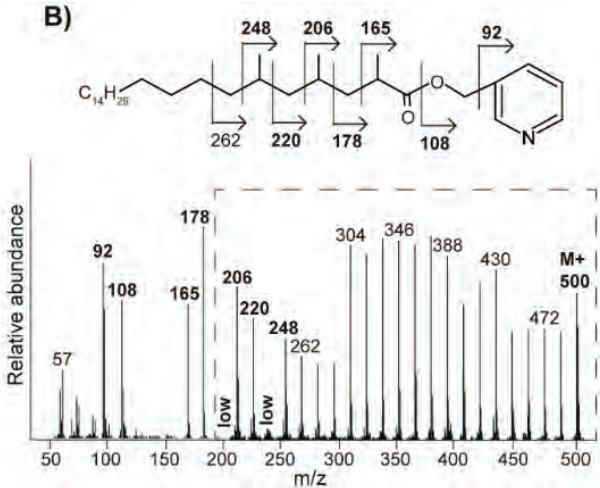

Figure 4. $M$ ass spectra with fragmentation and annotated molecular structures of the $A$ ) methyl ester and $B$ ) 'picolinyl' ester synthetic 2,4,6-trimethyl-tetracosanoic acid ( $\mathrm{C}_{27}$ 2,4,6-M e M A standard). The dashed boxes show a 10 times exaggerated view into the indicated area of the mass spectrum.

A t the seep $(0 \mathrm{~m})$, the M A s have a high relative abundance, representing ca. $44 \%$ of the total FAs. Their abundance decreases to ca. $20 \%$ in the soil at 1.8 $\mathrm{m}$ from the seep, whereas M A s were not detected in the soil at $13.2 \mathrm{~m}$ distance from the seep (Fig. 2). These lipids show a similar distribution trend as the $16 \mathrm{~S}$ rRNA gene sequencing results, which show high relative abundances of sequences from mycobacteria at the seep (ca. $34.1 \%$ at $0 \mathrm{~m}$ ), decrease to $8.5 \%$ at $1.8 \mathrm{~m}$, and are $<1 \%$ at $13.2 \mathrm{~m}$ (Table 1). Therefore, both the specific structure and the $16 \mathrm{~S}$ rRNA gene data strongly suggest that the unusual FAs are derived from mycobacteria. 


\subsection{M ycocerosic acids as biomarkers for mycobacteria in the environment}

$M$ ycocerosic acids are thought to be only synthesized by mycobacteria and have been mainly studied as biomarkers for diseases from pathogenic (e.g. M. tuberculosis or M. leprae) or opportunistic pathogenic (e.g. the M. simiae complex) mycobacteria in the last decades (e.g. M innikin et al., 1993a; M innikin et al., 1993b; Torkko et al., 2003). These studies revealed a high structural variability of MAs with distribution patterns characteristic for different mycobacterial species. For example, the frequently studied $M$. tuberculosis shows a major $C_{32}$ 2,4,6,8-tetramethyl $M A$ and $M$. leprae a $C_{34}$ 2,4,6,8tetramethyl M A (M innikin et al., 1993a; M innikin et al., 1993b), whereas other mycobacteria feature shorter chain major $M A s$ like $C_{21}$ 2-methyl $M A$ in $M$. palustre and $C_{22}$ 2,4-dimethyl M A in M . intermedium (Chou et al., 1996; Torkko et al., 2002) (Fig. 1 and Table 2).

The Censo seep soils reveal a high number of tentatively identified M A S which have not been reported previously (Fig. 1 and Table 2), e.g. those biosynthesized by pathogenic mycobacteria like M. tuberculosis and M. leprae and by mycobacteria belonging to the more closely related $M$. simiae complex like M. heidel bergense (M innikin et al., 1993a; M innikin et al., 1993b; Torkko et al., 2003). The M A distribution of the Censo seep soils is characterized by a dominant $C_{28}$ 2,4,6,8-tetramethyl $M A$, while the $M A$ distribution of $M$. heidelbergense or $M$. palustre from the $M$. simiae complex is dominated by the $C_{21}$ 2-methyl MA. Other more distantly related environmental opportunistic pathogens besides those of the $M$. simiae complex, like $M$. marinum or $M$. intermedium, produce a dominant 2,4,6- $C_{27}$ trimethyl or $C_{22}$ 2,4-dimethyl M A. As mentioned earlier, pathogenic mycobacteria like $M$. tuberculosis feature a major $C_{32} 2,4,6,8$-tetramethyl $M A$ as well as $M$. leprae produces a dominant $C_{34}$ 2,4,6,8-tetramethyl M A, clearly different from the major M A in the Censo soils (Fig. 1 and Table 2). Possibly, these unusual MAs could help to differentiate environmental Censo mycobacteria from opportunistic pathogenic and pathogenic mycobacteria in various modern and past environments.

Interestingly, the Censo mycobacteria show relatively high abundances of pentamethylated MAs ( $C_{29}$ 2,4,6,8,16-pentamethyl $M A$ and $C_{31} 2,4,6,8,10$ pentamethyl MA) compared to other studied mycobacteria. $M$. kansasii has a dominant pentamethyl MA ( $C_{33}$ 2,4,6,8,10-pentamethyl MA; Table 2), which was also been reported in $M$. tuberculosis and $M$. leprae albeit in very low abundances, while $M$. botniense features a partially identified pentamethylated $C_{27}(2,4,6, x, x)$ M A (M innikin et al., 1985; Daffé and L aneelle, 1988; Torkko et al., 2003). Shorter chain MAs are also abundant in the Censo soils, some of 
which have been identified in other mycobacterial species (Fig. 1 and Table 2): $C_{20}$ 2-methyl MA (M. palustre), $C_{21}$ 2-methyl MA (e.g. M. palustre, $M$. heidelbergense or $M$. interjectum) and $C_{25}$ 2,4,6-trimethyl $M A$ ( $M$. bohemicum, M. szulgai and M . intermedium) (Torkko et al., 2001; Torkko et al., 2002; Torkko et al., 2003). The presence of $C_{20} 2$-methyl and $C_{21}$ 2-methyl M As in both Censo mycobacteria and mycobacteria from the closely related $M$. simiae complex indicate that these M A s might be a common feature in the M. simiae complex. However, these MAs have been also found in more distantly related mycobacterial species like $M$. interjectum and $M$. malmoense, while common pathogenic mycobacteria like $M$. tuberculosis or $M$. bovis do not produce these shorter chain M As. These pathogenic mycobacteria contain a $\mathrm{C}_{27}$ 2,4,6-methyl M A ( $M$. tuberculosis) and a $C_{26}$ 2,4-methyl (M . bovis) as the shortest chain M As (M innikin et al., 1993a; R edman et al., 2009) which are not present in the Censo soils. Some more distantly related mycobacteria can even contain much shorter chain fatty acids like $C_{11}$ 2-methyl $M A$ ( $M$. interjectum or $M$. intermedium), $C_{15}$ 2-methyl MA (e.g. M. kansaii or M . intermedium) or $C_{16}$ 2,4-dimethyl MA (M. marinum) (Torkko et al., 2003), but these are not found in the Censo MA inventory.

Table 2 Chemical variability and occurrence of MAs in the Censo seep soils and in the most relevant mycobacterial species. The underlined names of the mycobacterial species indicate the major $\mathrm{MA}$ configuration in the mycobacterial species. The $x$ in the position of methylations in the $n$-alkyl chain features an unidentified position of the methyl group. M A s indicated in bold typeface are M A s identified in the Censo seep soils.

\begin{tabular}{|c|c|c|}
\hline \multicolumn{2}{|c|}{ Chemical structure of M As } & \multirow[t]{2}{*}{ Occurrence } \\
\hline $\begin{array}{l}\text { Length of } \mathbf{n} \\
\text { alkyl chain }\end{array}$ & $\begin{array}{l}\text { Position of } \\
\text { methyl group(s) }\end{array}$ & \\
\hline $\mathrm{C}_{16}$ & 2,4 & M. marinum ${ }^{a}$ \\
\hline $\mathrm{C}_{18}$ & 2 & Censo \\
\hline $\mathrm{C}_{19}$ & 2 & Censo, M. palustre ${ }^{b}$ \\
\hline $\mathrm{C}_{20}$ & 2 & $\begin{array}{l}\text { Censo, } M \text {. bohemicum, } M \text {. } \\
\text { heidel bergense, } \frac{M \text {. malmoense, }}{M \text {. }} \text {. } \\
\text { interjectum, } M \text {. palustre }^{a, b, c, d, e}\end{array}$ \\
\hline $\mathrm{C}_{20}$ & 2,4 & $\begin{array}{l}\text { M. asiaticum, } M \text {. szulgai, }, \underline{M} \text {. } \\
\text { intermedium, } \\
\text { malmoense }{ }^{a, b, d, e}\end{array}$ \\
\hline $\mathrm{C}_{20}$ & 2,9 & M. palustre ${ }^{b}$ \\
\hline $\mathrm{C}_{20}$ & 2,12 & Censo \\
\hline $\mathrm{C}_{20}$ & $2,4,6, x$ & M. botniense $^{d}$ \\
\hline
\end{tabular}




\begin{tabular}{|l|l|l|}
\hline $\mathbf{C}_{\mathbf{2 2}}$ & $\mathbf{2 , 4 , 6}$ & $\begin{array}{l}\text { Censo, M. bohemicum, M. szulgai, M. } \\
\text { intermedium }\end{array}$ \\
\hline$C_{22}$ a,b,d
\end{tabular}

The most unique feature that distinguishes the MAs of the Censo mycobacteria from cultivated mycobacterial species is the occurrence of methyl groups in the middle of the fatty acid chain at positions C-12 and C-16 in $\mathrm{C}_{22}$ 2,12-dimethyl and $C_{29} 2,4,6,8,16$-pentamethyl M As, respectively. To the best of our knowledge, this mid-chain methyl branching has only been reported once before, in the mycobacterial species $M$. palustre, also from the M. simiae complex (Torkko et al., 2002), which is closely related to the species living in the Censo soil. However, the methyl branching in $\mathrm{M}$. palustre is at position C-9 ( $C_{22}$ 2,9-dimethyl M A) (Torkko et al., 2002).

The fatty acid profile of the Censo soils shows longer chain M As (e.g. $C_{28}$ 2,4,6,8-tetramethyl and $C_{31}$ 2,4,6,8,10-pentamethyl $\left.M A s\right)$ which are even more abundant than $\mathrm{C}_{24}$ and $\mathrm{C}_{26}$ long-chain $\mathrm{n}$-alkyl fatty acids. This feature has not been previously reported in mycobacteria including mycobacteria from the closely-related $M$. simiae complex like $M$. heidelbergense and $M$. palustre, 
which synthesize much higher amounts of regular fatty acids over M A s (Torkko et al., 2002; Torkko et al., 2003). Some mycobacterial species from the M . simiae complex (i.e. M . lentiflavum, M . florentinum and M . genavense) and other more distantly related mycobacteria (e.g. M . paraffinicum and M . smegmatis) (Torkko et al., 2002; Torkko et al., 2003; Fernandes and K olattukudy, 1997; Chou et al., 1998) do not even contain M As.

In conclusion, the MA patterns in the Censo soil mycobacteria are clearly different from those of previously cultivated mycobacterial species. This could be caused by environmental conditions near the Censo seep, which may have induced adaptions and regulation processes within the biosynthesis systems of MAs in the Censo mycobacteria or may just be a chemotaxonomic feature. Further studies of other soils that contain mycobacteria should reveal how unique the M A s detected in the Censo soils are.

\subsection{R ole of the mycobacteria at the Censo seep}

The high relative abundances of mycobacteria and MAs based on both the relative 165 rRNA gene abundance and FA composition in the soil close to the main Censo seep (Table 1 and Fig. 2), combined with the decrease of these abundances in soils further away from the seep, hint to the potential involvement of mycobacteria in gas oxidation processes at the gas seep system. To further investigate this, the $\delta^{13} \mathrm{C}$ values of the MAs, as well as regular fatty acids and hopanoic acids, were analyzed in the Censo seep soils (Fig. 5) and compared with that of the thermogenic derived methane $(-30$ to $-35 \%$ ) and ethane $(-25 \%)$ at the Censo seep, as previously reported by Grassa et al. (2004).

At the seep site, regular and unsaturated $C_{16}, C_{18}, C_{22}$ and $C_{24}$ fatty acids showed no significant depletion in their carbon isotopic composition $\left(\delta^{13} \mathrm{C}=-25\right.$ to $-30 \%$ ), while at $1.8 \mathrm{~m}$ distance these FAs feature a bit more depleted $\delta^{13} \mathrm{C}$ values ranging from -33 to $-37 \%$ (Fig. 5). A s mentioned before, the $C_{16}$ and $C_{18}$ FAs could originate from Type I and Type II methanotrophs (e.g. Bowman, 2006; D edysh et al., 2007; B odelier et al., 2009) although larger depletion of ca. 10 to $20 \%$ relative to the methane source is generally expected for fatty acids of aerobic methanotrophs (Jahnke et al., 1999; Blumenberg et al., 2007; Berndmeyer et al., 2013). Thus, a mixed bacterial community of heterotrophic and methanotrophic bacteria (e.g. Inglis et al., 2019) or other soil microbes using soil organic matter as a carbon source are likely to contribute to the pool of these fatty acids at Censo $0 \mathrm{~m}$ and $1.8 \mathrm{~m}$. This agrees with the typical bulk $\delta^{13} \mathrm{C}$ values of -25 to $-30 \%$ in temperate soils (Balesdent et al., 1987; Huang et al., 1996) 
and the presence of saturated and unsaturated $\mathrm{C}_{16}$ and $\mathrm{C}_{18}$ fatty acids even further away from the seep, at $13.2 \mathrm{~m}$ (Fig. 2).

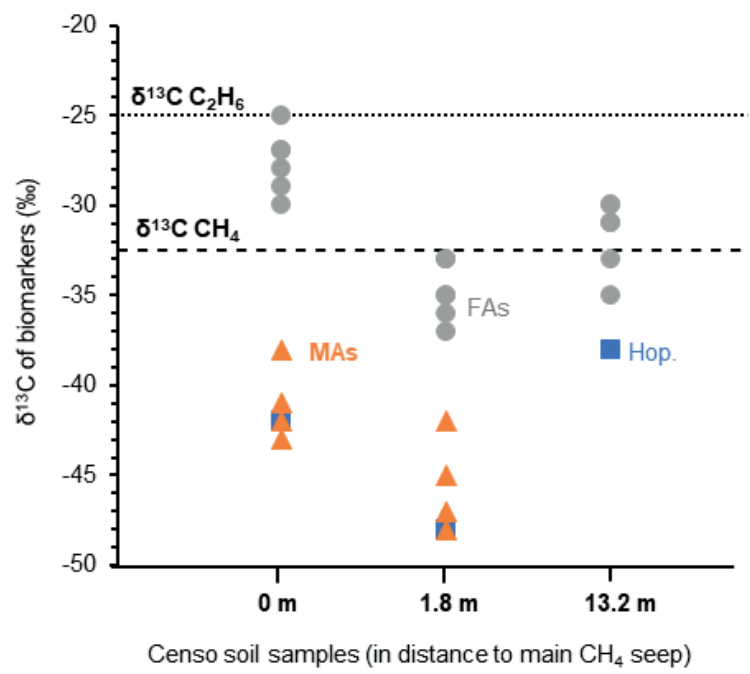

Figure5. The stable carbon isotopic composition $\left(\delta^{13} \mathrm{C}\right)$ of biomarkers in the Censo soils at increasing distance from the main gas seepage. Biomarkers shown are fatty acids ( $F A s=$ grey circle), mycocerosic acids (MAs = orange triangle), and the $\mathrm{C}_{32}$ hopanoic acid ( $\mathrm{Hop} .=$ blue square). Data points represent the mean average of two analysis. The $\delta^{13} \mathrm{C}$ values of the released methane $\left(\mathrm{CH}_{4} \sim-32.5 \%\right)$ and ethane $\left(\mathrm{C}_{2} \mathrm{H}_{6}=-25 \%\right)$ are indicated by dashed lines in the plot.

The $\mathrm{C}_{32} 17 \beta, 21 \beta(\mathrm{H})$-hopanoic acid shows more depleted $\delta^{13} \mathrm{C}$ values ranging from -42 to $-48 \%$, at Censo $0 \mathrm{~m}$ and $1.8 \mathrm{~m}$, respectively (Fig. 5), suggesting an origin from bacteria involved in the cycling of a ${ }^{13} \mathrm{C}$ depleted carbon source like methane at this gas seep. The $\mathrm{C}_{32}$ hopanoic acid is a diagenetic product of bacteriohopanepolyols (Rohmer et al., 1984; R ies-K autt and A Ibrecht, 1989; Farrimond et al., 2002), which could be produced by some of the aerobic methanotrophs (e.g. Methylocystaceae or Methylococcales) (Zundel and Rohmer, 1985; van W inden et al., 2012) identified in the Censo seep soils (T able 1). However, as discussed above, the mycobacteria in the soil, which are closely related to the $M$. simiae complex (Fig. 1), might also be able to synthesize hopanoids and therefore could be contributing to the hopanoid pool.

Depleted $\delta^{13} \mathrm{C}$ values are observed in the MAs (-38 to $-48 \%$ ) close to the Censo seep at $0 \mathrm{~m}$ and $1.8 \mathrm{~m}$ (Fig. 5), indicating that these are likely synthesized by organisms that use a ${ }^{13} \mathrm{C}$-depleted carbon source rather than soil organic matter. The Censo seep releases high amounts of methane $(76-86 \%$ of total released gas) and minor amounts of higher gaseous hydrocarbons (ethane, propane etc.) as well as $\mathrm{CO}_{2}$ and $\mathrm{N}_{2}$ (Etiope et al., 2002; Grassa et al., 2004). 
Thus, it would appear that the Censo mycobacteria are using ${ }^{13} \mathrm{C}$-depleted methane as their carbon source as it is the major released gas at the Censo seep. This is in agreement with the decreasing relative abundance of mycobacteria and M As away from the main seepage according to the decrease in the released gas. Furthermore, the $\delta^{13} \mathrm{C}$ values of the MAs are more negative than the $\delta^{13} \mathrm{C}$ value of the released methane, as expected for methanotrophs, and dissimilar to bulk soil organic matter and the simple FAs likely derived from heterotrophic bacteria.

However, these results are not completely in agreement with previous incubation and genetic studies, which showed that mycobacteria are not able to utilize methane but rather use other gaseous hydrocarbons like ethane and propane as well as alkenes, methanol, and carbon monoxide as their carbon source (Park et al., 2003; Coleman et al., 2011; Coleman et al., 2012; M artin et al., 2014). Studies from the 1950s reported high abundances of mycobacteria in soils from areas of oil and gas production and in areas of petroliferous gas seeps, hinting to their potential involvement in gas oxidation processes (Davis et al., 1956; Davis et al., 1959). Cultivation experiments of those soils confirmed that mycobacteria did not utilize methane but higher gaseous hydrocarbons (ethane and propane) (Davis et al., 1956; Dworkin and Foster, 1958). These results suggest that the mycobacteria in the Censo soils are perhaps not using methane, but possibly other gaseous hydrocarbons in the seep, like ethane or propane. However, it should be noted that two previous studies have described mycobacterial species M ycobacterium flavum var. methanicum, M ycobacterium methanicum n. sp. and M ycobacterium ID-Y that were able to oxidize methane (Nechaeva, 1954; Reed and Dugan, 1987). Alternatively, mycobacteria at the Censo seep could act as indirect methane utilizers by using secondary products of methane oxidation performed by other methanotrophs, like methanol. Indeed, some studies have shown that cultured pathogenic mycobacteria were able to utilize methanol (Reed and Dugan, 1987; Park et al., 2003; Park et al., 2010). However, this is difficult to reconcile with their very high abundances (up to 34.1 $\%$ ) compared to the low abundance of typical methanotrophs like M ethylococcales or M ethylocystaceae (up to $5.1 \%$ ) near the seep (Table 1).

Overall, based on the clear abundance of mycobacterial 16S rRNA sequences in the Censo seep soils, the novel ${ }^{13} \mathrm{C}$ depleted M A s identified here may be useful biomarkers for the presence of hydrocarbon-oxidizing mycobacteria in soils. These unique MAs in combination with ${ }^{13} \mathrm{C}$ depletion could be used to trace mycobacteria in present and past environments, specifically those influenced by hydrocarbon seepage. Longer chain fatty acids 
and branched fatty acids like MAs have been shown to be more resistant than other biomolecules (e.g. short-chain fatty acids) to diagenetic changes in diverse studies of fossil forests, sediment cores from the Gulf of California, and petroleum systems (Staccioli et al., 2002; W enger et al., 2002; Camacho-Ibar et al., 2003). Under the right conditions, fatty acids may be preserved as bound compounds in ancient sediments through the M iocene (A hmed et al., 2001). Indeed, studies have indicated the presence of M A s of M t tuberculosis on ancient bones from a 17,000 year old bison and from a ca. 200 year old human skeleton (Redman et al., 2009; Lee et al., 2012), suggesting a high preservation potential of these lipids.

Nevertheless, future research should investigate the presence and stable carbon isotope composition of MAs in other modern terrestrial and marine hydrocarbon seeps as well as in past environments where gas seepage might have played an important role. A dditionally, further detailed incubation studies and genomic analysis of the $C$ enso mycobacteria and mycobacteria at other terrestrial gas seeps are required to elucidate the exact role of the mycobacteria in gas oxidation processes at the Censo seep and in other gas rich environments.

\section{Condusion}

Soils from the Fuoco di Censo Everlasting Fire show high relative abundances (up to $34 \%$ ) of uncultivated mycobacterial 16S rRNA gene sequences. These Censo mycobacteria are phylogenetically distant from the typical pathogenic mycobacteria Mycobacterium tuberculosis or M. leprae, and more closely related to the $M$. simiae complex like $M$. heidel bergense and $M$. palustre. A the main seep, Censo soils feature a unique $M A$ pattern especially in the longer chain M As. The most abundant M A s were tentatively identified as 2,4,6,8-tetramethyltetracosanoic acid ( $\mathrm{C}_{28}$ 2,4,6,8-tetramethyl $\mathrm{MA}$ ) and 2,4,6,8,10-pentamethylhexacosanoic acid $\left(C_{31}\right.$ 2,4,6,8,10-pentamethyl MA). The Censo soils also contained M As with novel mid-chain methyl branching at positions $C-12$ and $C$ 16 ( $C_{22}$ 2,12-dimethyl and $C_{29}$ 2,4,6,8,16-pentamethyl M A s). The M A pattern in the $C$ enso seep soils is clearly different from those reported for the well-studied mycobacteria like $M$. tuberculosis or $M$. leprae and from the closely related $M$. simiae complex. Only $\mathrm{C}_{20}$ 2-methyl, $\mathrm{C}_{21}$ 2-methyl and $\mathrm{C}_{25}$ 2,4,6-trimethyl M A S have been found previously in other mycobacteria from the $M$. simiae complex (e.g. M. heidelbergense) and three more distantly related mycobacteria (e.g. M. interjectum). These MAs have relatively low $\delta^{13} \mathrm{C}$ values, suggesting that Censo mycobacteria use a carbon source depleted in ${ }^{13} \mathrm{C}$, such as methane, higher gaseous hydrocarbons or secondary products of gas oxidation processes, like 
methanol. The novel identified MAs in the Censo samples offer a new tool, besides DNA-based techniques, to investigate soils from present and past terrestrial environments for the presence of mycobacteria potentially involved in the cycling of gases.

\section{C ode availability}

The 16S rRNA amplicon reads (raw data) have been deposited in the NCBI Sequence Read A rchive (SRA) under B ioProject number PRJ NA 701386.

\section{Data availability}

Data will be made available on request to the corresponding author.

\section{A uthor contribution}

NTS, DR and SS planned research. NTS, FG and CRW collected samples. MH and $A$ J M provided the synthetic $C_{27}$ mycocerosic acid standard. NTS performed lipid analysis. LV analyzed $16 S$ rRNA gene sequencing data. NTS, SS and LV interpreted the data. NTS wrote the paper with input from all authors.

\section{Competing inter ests}

The authors declare that they have no conflict of interest.

\section{Acknowledgements}

We thank Marianne Baas, Monique Verweij, Jort Ossebaar, Ronald van Bommel, Sanne V reugdenhil and $M$ aartje B rouwer for technical assistance and $M$ arcel van der Meer for discussion about isotopic values of the fatty acids. Sebastian Naeher, Rienk Smittenberg and Gordon Inglis are thanked for their useful comments which improved the manuscript.

\section{Financial support}

Stefan Schouten, Laura Villanueva and Jaap S. Sinninghe Damsté have been supported by the Netherlands Earth System Science Center (NESSC) and the Soehngen Institute for A naerobic Microbiology (SIAM) through Gravitation grants (grant nos. 024.002 .001 and 024.002.002) from the Dutch M inistry for Education, Culture and Science.

\section{R eview statement}

This paper was edited by Sebastian Naeher and reviewed by Rienk Smittenberg and Gordon Inglis. 
220 | Chapter 7 


\section{Chapter 8}

The role of soil mycobacteria in the uptake of methane and ethane at a Sicilian everlasting fire

Nadine T. Smit, Darci Rush, Marcel T. J. van der Meer, Fausto Grassa, Jaap S. Sinninghe Damsté, Stefan Schouten

In preparation for Biogeosciences 


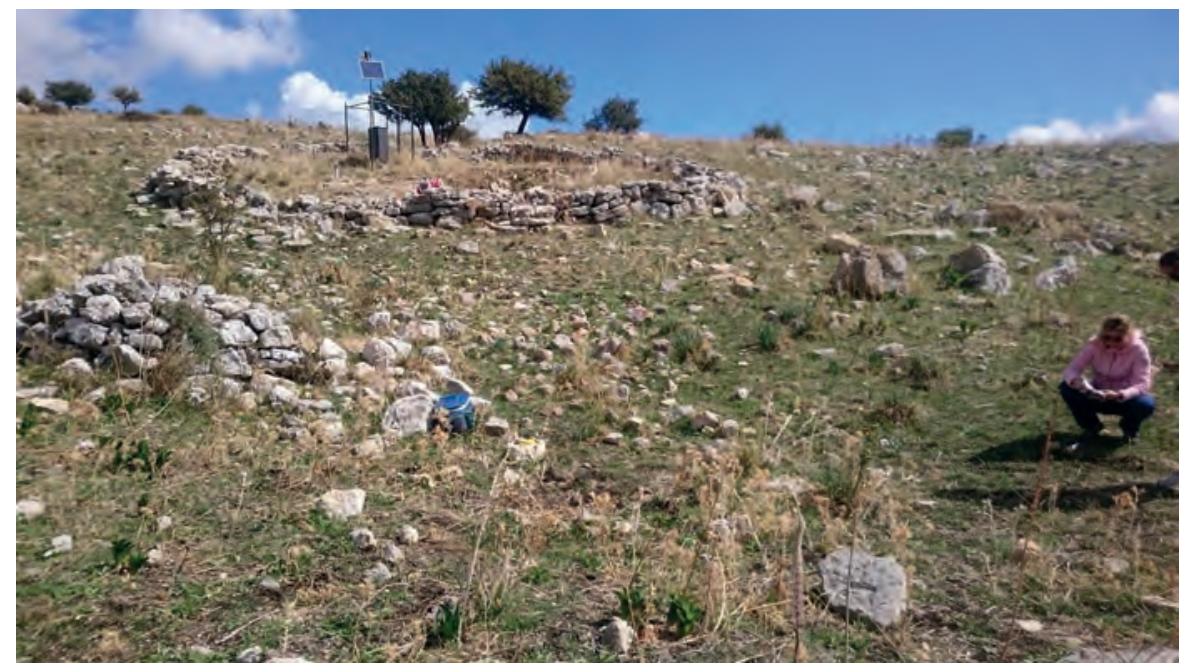

Fuoco di Censo everlasting fire in Sicily, Italy

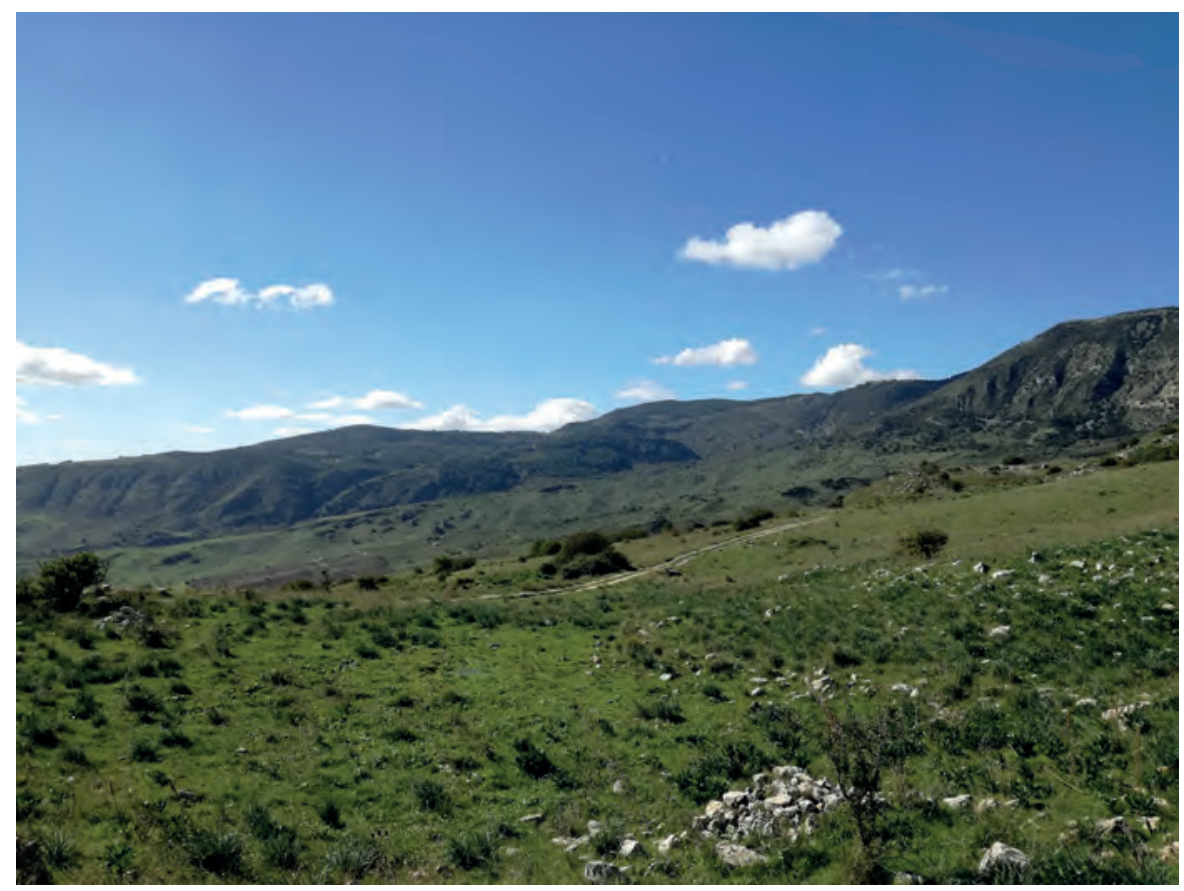

View from Fuoco di Censo downhill over the valleys of central Sicily, Italy 


\section{Abstract}

Studies from the 1950s have shown that mycobacteria are ubiquitous near terrestrial gas seeps but their role in the cycling of the emitted gasses is still unclear. Recently, we found that novel mycobacterial species, closely phylogenetically related to the Mycobacterium simiae complex, as well as common aerobic methanotrophic bacteria were present in soils from a terrestrial Sicilian everlasting fire named Fuoco di Censo. The mycobacteria produced novel mycocerosic acids that were depleted in ${ }^{13} \mathrm{C}$, suggesting a direct or indirect utilization of the gases like methane and ethane released at the Fuoco di Censo seep. Here, this hypothesis is tested by using polar lipid derived fatty acidsstable isotope probing (SIP) with ${ }^{13} \mathrm{C}$-labeled methane or ethane on Fuoco di Censo seep soils, which showed rapid consumption of both gases. SIP incubations with ${ }^{13} \mathrm{C}$-labeled methane for 5 days revealed incorporation of the ${ }^{13} \mathrm{C}$ label in regular and unsaturated $\mathrm{C}_{16}$ and $\mathrm{C}_{18}$ fatty acids, indicative of Type I and Type II methanotrophic activity, but mycocerosic acids did not incorporate ${ }^{13} \mathrm{C}$. In contrast, the incubations with ${ }^{13} \mathrm{C}$-labeled ethane for 9 days showed ${ }^{13} \mathrm{C}$ incorporation in $\mathrm{C}_{16}$ and $\mathrm{C}_{18}$ fatty acids as well as in mycocerosic acids, suggesting active ethane utilization by methanotrophs as well as mycobacteria. The ${ }^{13} \mathrm{C}$ incorporation of ${ }^{13} \mathrm{C}$-labelled ethane but not methane in the structurally distinct mycocerosic acids at the Fuoco di Censo seep shows that soil mycobacteria might be an important group of microbes oxidizing gaseous higher hydrocarbons in global terrestrial gas seeps and soils. Therefore, the presence of unique mycocerosic acids, in combination with a ${ }^{13} \mathrm{C}$-depleted signature, offers a new biomarker tool to detect hydrocarbon gas-consuming mycobacteria in present and past environments.

\section{Introduction}

M ethane and higher gaseous hydrocarbons (ethane, propane and butane) are important greenhouse gases that directly affect global carbon cycles (Reeburgh, 1996; Etiope and Ciccioli, 2009). The reconstruction and understanding of the sources, sinks and chemical reaction pathways in greenhouse gas cycling is important to constrain the impact of methane and higher gaseous hydrocarbons on climate change. Worldwide, the aerobic oxidation of methane and of higher gaseous hydrocarbons (e.g., ethane, propane) in soils is one of their largest sinks (Solomon et al., 2007; Etiope and Ciccioli, 2009; Etiope et al., 2009; D ean et al., 2018). However, which microbes oxidize gaseous hydrocarbon in these terrestrial systems are not well constrained. 
Soils harbour the most diverse and abundant groups of microbes on Earth, including aerobic methanotrophic bacteria and gaseous higher hydrocarbon-utilizing bacterial species (Fierer et al., 2012; Delgado-B aquerizo et al., 2018). A erobic methanotrophic bacteria include three different phylogenetic groups: Type I methanotrophs (Gammaproteobacteria), Type II methanotrophs (Alphaproteobacteria) and Verrucomicrobia (e.g. Hanson and Hanson, 1996; Pol et al., 2007; O p den Camp et al., 2009; B odelier et al., 2009). Some Type I methanotrophs are known to be able to utilize higher gaseous hydrocarbons, e.g. ethane (K innaman et al., 2007; Redmond et al., 2010). Other studies have shown that a group of gram-positive organisms in the Corynebacterium-N ocardia-M ycobacterium-R hodococcus group (Dworkin and Foster, 1958; A shraf et al., 1994) and some gram-negative Pseudomonas species are able to oxidize ethane (Takahashi, 1980; Hamamura et al., 1997). Genomic and cultivation studies revealed that mycobacteria can oxidize a range of greenhouse gases (ethane, propane, alkenes, carbon monoxide or hydrogen) and can degrade toxic polycyclic aromatic hydrocarbons (Hennessee et al., 2009; Coleman et al., 2012; M artin et al., 2014).

In the environment, bacteria involved in aerobic oxidation of methane can be traced via characteristic lipid biomarkers such as ${ }^{13} \mathrm{C}$-depleted unsaturated, regular $\mathrm{C}_{16}$ and $\mathrm{C}_{18}$ fatty acids (FAs), hopanoids as well as bacteriohopanepolyols (e.g. Dedysh et al., 2007; Bodelier et al., 2009; van W inden et al., 2012; Talbot et al., 2014). In contrast, lipid biomarkers to detect microbes potentially involved in higher gaseous hydrocarbon oxidation are limited to ${ }^{13} \mathrm{C}$-depleted $\mathrm{C}_{16}$ FAs derived from Type I methanotrophs like Methylococcaceae (K innaman et al., 2007; Redmond et al., 2010).

Several studies have shown that mycobacteria may be involved in gaseous hydrocarbon oxidation (Coleman et al., 2012; M artin et al., 2014). Indeed, studies from the 1950s found high abundances of non-pathogenic mycobacteria (M . paraffinicum) in areas of oil and gas production, gas seeps and common garden soils where mycobacteria have been show $n$ to utilize ethane and propane (Davis et al., 1956, 1959; Dworkin and Foster, 1958). A recent study investigating soils from a terrestrial Sicilian everlasting fire named Fuoco di Censo found high relative abundances of 165 rRNA gene sequences attributed to novel environmental mycobacteria related to the $M$. simiae complex at and close to the gas seepage (Smit et al., 2021). Interestingly, unique environmental mycobacterial lipids namely multi-methyl-branched mycocerosic acids (MAs) with three to five methyl branches at regularly spaced intervals such as at positions C-2, C-4, C- 6 and C-8 were detected as well as methyl branches at 
positions C-12 and C-16 (Smit et al., 2021). The M A s identified at this seep were different from the known MAs in pathogenic and opportunistic pathogenic mycobacteria and showed relatively depleted $\delta^{13} \mathrm{C}$ values, suggesting a potential involvement of their producers in the oxidation of the gases at the seep. How ever, the exact role and function of the mycobacteria and other methanotrophs in the cycling of methane and other gaseous hydrocarbons remained unclear.

Stable isotope probing (SIP)-incubations with ${ }^{13} \mathrm{CH}_{4}$ have been frequently used to study the activity and diversity of methane-oxidizing bacteria in terrestrial and marine environments (B ull et al., 2000; Crossman et al., 2005; Evershed et al., 2006; M axfield et al., 2006; Redmond et al., 2010). The SIP technique allows the identification of organisms actively consuming ${ }^{13} \mathrm{C}$-labelled substrates, based on the incorporation of ${ }^{13} \mathrm{C}$ into biomass, DNA, or lipid biomarkers. Therefore, we incubated soils directly taken from a terrestrial gas seep site in Sicily (Italy) with ${ }^{13} \mathrm{C}$-labelled methane $\left({ }^{13} \mathrm{CH}_{4}\right)$ and ethane $\left({ }^{13} \mathrm{C}_{2} \mathrm{H}_{6}\right)$ and analysed label uptake in fatty acid and mycocerosic acid biomarker inventories. These results shed new light on the role of mycobacteria in the cycling of methane and ethane at terrestrial gas seeps.

\section{M aterial and methods}

\subsection{Sampling site and sample collection}

The Fuoco di Censo seep $\left(37^{\circ} 37^{\prime} 30.1^{\prime \prime} \mathrm{N}, 13^{\circ} 23^{\prime} 15.0^{\prime \prime} \mathrm{E}\right)$, in the following referred to as the Censo seep, is located in the mountains of Southwestern Sicily, I taly (Etiope et al., 2002, 2007; Grassa et al., 2004; Smit et al., 2021). The Censo seep is a typical example of a natural 'everlasting fire' at which the released thermogenic gas consists mainly of $\mathrm{CH}_{4}(76-86 \%)$ and $\mathrm{N}_{2}(10-17 \%)$ as well as some other minor gases like $\mathrm{CO}_{2}, \mathrm{O}_{2}$, ethane, propane, $\mathrm{He}$ and $\mathrm{H}_{2}$ (Etiope et al., 2002; G rassa et al., 2004). The released $\mathrm{CH}_{4}$ is characterized by a stable carbon isotopic composition of $\delta^{13} \mathrm{C}=-35 \%$, while the released ethane has a $\delta^{13} \mathrm{C}$ values of $-25 \%$ (G rassa et al., 2004).

Soil samples of the Censo seep were taken during a field campaign in October 2018 for incubation experiments. The soil was collected from a horizon $5-10 \mathrm{~cm}$ bel ow surface directly at the main seep site with in-situ temperatures of ca. $18-20^{\circ} \mathrm{C}$. The soils were directly transferred into a clean geochemical sampling bag and stored open to oxygen at $4{ }^{\circ} \mathrm{C}$ for 7 days (soil for ${ }^{13} \mathrm{CH}_{4}$ incubations) and 14 days (soil for ${ }^{13} \mathrm{C}_{2} \mathrm{H}_{6}$ incubations) until the start of the incubation experiments in the laboratory.

\subsection{Incubation experiments}


Two sets of incubation experiments with stable isotope probing (SIP), the first with $99 \%{ }^{13} \mathrm{C}$-labeled $\mathrm{CH}_{4}$ (Sigma-Aldrich), and the second using fully ${ }^{13} \mathrm{C}$ labeled $99 \% \mathrm{C}_{2} \mathrm{H}_{6}$ (Sigma-Aldrich), were performed using the Censo soil samples. All soil slurries were prepared in clean autoclaved $160 \mathrm{ml}$ glass bottles that were closed with butyl rubber stoppers and sealed with aluminium crimps. The bottles were inoculated with ca. $5 \mathrm{~g}$ aliquots of homogenized Censo soil and moistened with $0.5 \mathrm{ml} \mathrm{Milli-Q}$ water. The first incubation set comprised of three bottles amended with $5 \%{ }^{13} \mathrm{CH}_{4}$ in the ca. $150 \mathrm{ml}$ headspace and one heat-killed control bottle amended with $5 \%{ }^{13} \mathrm{CH}_{4}$. The second incubation set comprised of three bottles amended with $5 \%$ of ${ }^{13} \mathrm{C}_{2} \mathrm{H}_{6}$ in the ca. $150 \mathrm{ml}$ headspace and one heat-killed control bottle amended with $5 \%{ }^{13} \mathrm{C}_{2} \mathrm{H}_{6}$. An unamended bottle (i.e. incubation control) was used to measure baseline levels of gases in the soil. The heat-killed control bottles from both set ups were autoclaved at $121{ }^{\circ} \mathrm{C}$ for 20 min and allowed to cool to ambient room temperature before ${ }^{13} \mathrm{CH}_{4}$ or ${ }^{13} \mathrm{C}_{2} \mathrm{H}_{6}$ was added. Both incubation sets were incubated at $25^{\circ} \mathrm{C}$ in the dark and constantly shaken by a lab shaker. The oxygen levels in the gas phase of the incubation bottles were regularly measured by using a $\mathrm{PICO}-\mathrm{O}_{2}$ optical oxygen meter (Pyroscience) on oxygen sensor spots (OX SP5, Pyroscience), which were glued into the glass bottles before incubations started. During the incubations, oxygen concentration never fell below a threshold of $6.5 \%$. The headspace methane and ethane concentrations were sampled at regular intervals with a gastight syringe (50 $\mu \mathrm{l}$ gas) and measured via gas chromatography with flame ionization detection (GC-FID; Thermo Scientific Focus). M ethane and ethane concentrations were determined with reference to standard gas calibrations. ${ }^{13} \mathrm{CH}_{4}$ and ${ }^{13} \mathrm{C}_{2} \mathrm{H}_{6}$ incubations continued until all ${ }^{13} \mathrm{CH}_{4}$ (5 days) and until about $95 \%$ of ${ }^{13} \mathrm{C}_{2} \mathrm{H}_{6}$ (9 days) in the amended sets had been consumed (Fig. 1). M ethane consumption rates were calculated based on a $150 \mathrm{ml}$ headspace with $5 \mathrm{~g}$ soil (dry weight). A fter termination of both SIP incubation experiments, half of the incubated soils were freeze-dried and analysed for lipids.

\section{Extraction, saponification, and derivatization}

Freeze-dried Censo soils (ca. $0.5 \mathrm{~g}$ ) from both SIP incubation set-ups were extracted with a modified Bligh and Dyer extraction for various compound classes (Schouten et al., 2008; Bale et al., 2013). Samples were ultrasonically extracted $(10 \mathrm{~min})$ with a solvent mixture containing methanol $(\mathrm{MeOH})$, dichloromethane (DCM) and phosphate buffer (2: $1: 0.8 ; \mathrm{v}: \mathrm{v}: \mathrm{v})$. After centrifugation, the solvent was collected and combined, and the residues reextracted twice. A biphasic separation was achieved by adding additional DCM 
and phosphate buffer to a ratio of $\mathrm{M} \mathrm{eOH}, \mathrm{DCM}$ and phosphate buffer $(1: 1: 0.9$; $v: v: v)$. The aqueous layer was washed two more times with DCM and the combined organic layers were eluted over a $\mathrm{Na}_{2} \mathrm{SO}_{4}$ column followed by drying under $\mathrm{N}_{2}$.

Aliquots of the Bligh and Dyer extract (BDE) were saponified using 2 $\mathrm{ml}$ of a $1 \mathrm{~N} \mathrm{KOH} \mathrm{MeOH}$ solution and refluxed for $1 \mathrm{~h}$ at $130^{\circ} \mathrm{C}$. A fter cooling the $\mathrm{pH}$ was adjusted to 5 with a $2 \mathrm{~N} \mathrm{HCl} \mathrm{MeOH}$ solution. The layers were separated by $2 \mathrm{ml}$ bidistilled water and $2 \mathrm{ml} \mathrm{DCM}$, and the organic bottom layer was collected. The aqueous layer was washed two more times with DCM and the combined organic layers were dried first over a $\mathrm{Na}_{2} \mathrm{SO}_{4}$ column and then by $\mathrm{N}_{2}$.

A liquots of the saponified BDEs were esterified with $0.5 \mathrm{~mL}$ of a boron trifluoride-methanol solution ( $\mathrm{BF}_{3}$ solution) for $10 \mathrm{~min}$. A fter cooling, $0.5 \mathrm{~mL}$ bidistilled water and $0.5 \mathrm{~mL} D C M$ were added and shaken, and the DCM bottom layer was pipetted off. The water layer was extracted twice with DCM, and the combined DCM layers were eluted over an $\mathrm{MgSO}_{4}$ column. The derivatized extracts were eluted over a small silica gel column with ethyl acetate to remove polar compounds.

Subsequently, the derivatized extracts were separated using a small column packed with activated aluminium oxide into two fractions. The first fraction (fatty acid methyl ester fraction) was eluted with 4 column volumes of DCM and the second fraction (polar fraction) eluted with 3 column volumes of $\mathrm{DCM} / \mathrm{M} \mathrm{eOH}(1: 1, \mathrm{v} / \mathrm{v})$. The fatty acid methyl ester fractions were dried under a continuous flow of $\mathrm{N}_{2}$ and afterwards analysed using gas chromatography-mass spectrometry (GC-MS) for compound identification and gas chromatographyisotope ratio mass spectrometry (GC-irMS) for compound specific isotope analysis with ethyl acetate as injection solvent.

\subsection{Gas chromatography-mass spectrometry (GC-MS) and gas chromatography-isotope ratio mass spectrometry (G C-irM S)}

GC-MS was carried out using an Agilent Technologies GC-MS Triple Quad $7000 \mathrm{C}$ in full scan mode with a scan time of $700 \mathrm{~ms}$ and a mass range of $\mathrm{m} / \mathrm{z} 50$ to 850. GC-irM S was performed with a 265 Thermo Scientific Trace 1310 with a GC-Isolink II, a ConFlo IV and a Delta A dvantage irM S. GC for both GC-M S and GC-irM S was performed on a CP-Sil 5 column $(25 \mathrm{~m} \times 0.32 \mathrm{~mm}$ with a film thickness of $0.12 \mu \mathrm{m}$ ) with He as carrier gas (constant flow $2 \mathrm{ml}$ min-1). The methylated samples (dissolved in ethyl acetate) were on-column injected at 70 ${ }^{\circ} \mathrm{C}$ and subsequently, the oven was programmed to $130{ }^{\circ} \mathrm{C}$ at $20{ }^{\circ} \mathrm{C} \mathrm{min}^{-1}$, and 
then at $4 \stackrel{\circ}{\circ} \mathrm{C} \min ^{-1}$ to $320{ }^{\circ} \mathrm{C}$, which was held for $10 \mathrm{~min}$. Stable carbon isotope ratios are reported in atom $\%(\mathrm{AT} \%)^{13} \mathrm{C}$. V alues for fatty acids were corrected for the methyl groups introduced by the methylation and the results are reported as the average of the triplicate soil incubation bottles with standard deviation, the latter representing both analytical and experimental error.

\section{R esults}

\subsection{M ethane and ethane consumption}

M easurements of the ${ }^{13} \mathrm{CH}_{4}$ concentrations via GC-FID in the ${ }^{13} \mathrm{CH}_{4}$ incubation set up showed that ca. $40 \%$ of the amended ${ }^{13} \mathrm{CH}_{4}$ was consumed within $24 \mathrm{~h}$ (Fig. 1a). This corresponds to a consumption rate of $25 \mu \mathrm{mol} \mathrm{CH}_{4} \mathrm{~d}^{-1} \mathrm{~g} \mathrm{soil}^{-1}$. The methane concentration decreased further in the following days until most of the ${ }^{13} \mathrm{CH}_{4}$ was oxidized after 5 days, with an average rate of ${ }^{13} \mathrm{CH}_{4}$ consumption of ca. $15 \mu \mathrm{mol} \mathrm{CH} \mathrm{C} \mathrm{d}^{-1} \mathrm{~g} \mathrm{soil}^{-1}$. The heat-killed control only showed slight changes in the $\mathrm{CH}_{4}$ concentrations during the 5 days of the experiment.

In the first $24 \mathrm{~h}$ of the ${ }^{13} \mathrm{C}_{2} \mathrm{H}_{6}$ incubations, ca. $9 \%$ of the amended ${ }^{13} \mathrm{C}_{2} \mathrm{H}_{6}$ was utilized (Fig. 1 b), corresponding to an ethane consumption rate of $8 \mu \mathrm{mol}$ $\mathrm{C}_{2} \mathrm{H}_{6} \mathrm{~d}^{-1} \mathrm{~g} \mathrm{soil}^{-1}$. The ethane consumption increased after 1 day of incubation to ca. $20 \mu \mathrm{mol} \mathrm{C}_{2} \mathrm{H}_{6} \mathrm{~d}^{-1} \mathrm{~g}$ soil ${ }^{-1}$. The average rate of ${ }^{13} \mathrm{C}_{2} \mathrm{H}_{6}$ consumption was about $15 \mu \mathrm{mol} \mathrm{C}_{2} \mathrm{H}_{6} \mathrm{~d}^{-1} \mathrm{~g}$ soil ${ }^{-1}$ during the whole 9 days of incubation, after which most of the ethane had been consumed. The ethane concentration of the heat-killed control of the ${ }^{13} \mathrm{C}_{2} \mathrm{H}_{6}$ incubation remained relatively stable (Fig. 1b). The control incubation experiment where the Censo soil was not amended with either ${ }^{13} \mathrm{CH}_{4}$ or ${ }^{13} \mathrm{C}_{2} \mathrm{H}_{6}$ did not reveal substantial production nor consumption of methane (Fig. 1a) or ethane.

\subsection{F atty acid composition}

At the end of the incubations, the fatty acid (FA) fractions of the soils from both the ${ }^{13} \mathrm{CH}_{4}$ (5 days) and ${ }^{13} \mathrm{C}_{2} \mathrm{H}_{6}$ Censo (9 days) incubations contained common FA s such as shorter chain FAs, including unsaturated and saturated $\mathrm{C}_{14}, \mathrm{C}_{16}$ and $\mathrm{C}_{18} \mathrm{FAs}$, as well as longer chain FAs namely $\mathrm{C}_{22}, \mathrm{C}_{24}$ and $\mathrm{C}_{26} \mathrm{FAs}$ (Fig. $2 \mathrm{a}, \mathrm{b}$ ). The ${ }^{13} \mathrm{CH}_{4}$ incubations showed slightly higher relative abundance of $\mathrm{C}_{24}$ and $\mathrm{C}_{26}$ FAs than the ${ }^{13} \mathrm{C}_{2} \mathrm{H}_{6}$ incubated Censo soils (Fig. 2a). Furthermore, the $\mathrm{C}_{31}, \mathrm{C}_{32}$ and $\mathrm{C}_{33} 22 \mathrm{R} 17 \beta, 21 \beta(\mathrm{H})$-homohopanoic acids were al so abundant in both $\mathrm{C}$ enso soil incubations with slightly higher relative abundance of the $\mathrm{C}_{32}$ hopanoic acid in the ${ }^{13} \mathrm{CH}_{4}$ Censo incubations. A dditionally, both soil incubations showed high relative abundances of different $M A s$ ranging from $C_{21}$ to $C_{31}$. These $M A$ had 2 to 5 methyl groups in the carbon chain mostly located close to the acid group in 
a distribution, comparable to what was previously reported in these soils (Smit et al., 2021). In the ${ }^{13} \mathrm{C}_{2} \mathrm{H}_{6}$ Censo incubations, the major $\mathrm{C}_{28}$ M A was relatively more abundant compared to common $\mathrm{FA} \mathrm{s}_{\text {like }} \mathrm{C}_{22}$ and $\mathrm{C}_{24}$ (Fig. 2b).
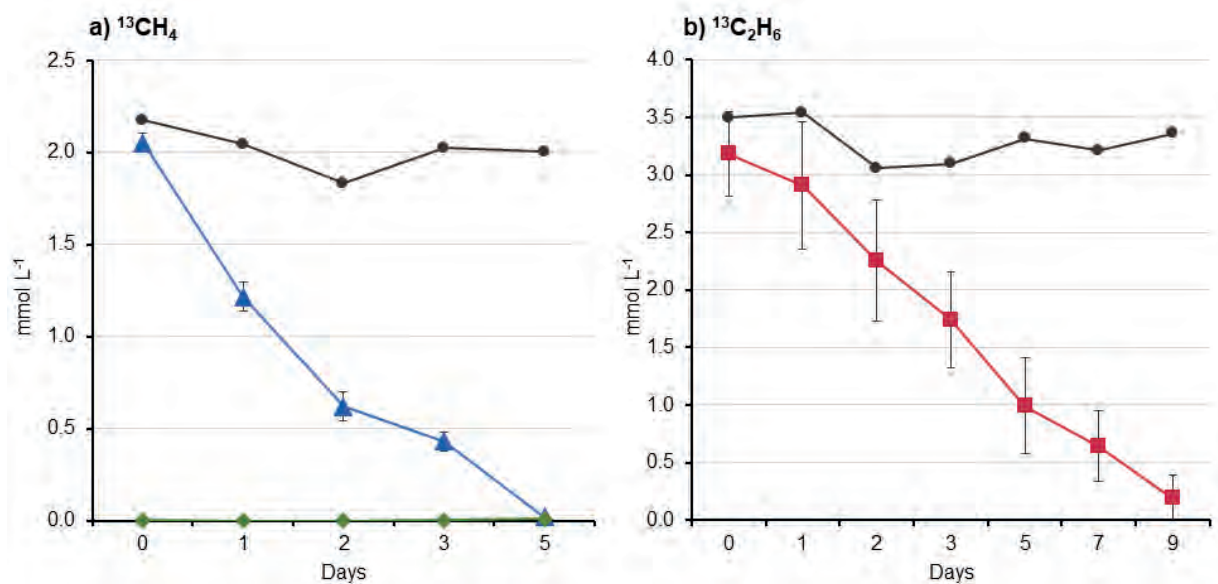

Figure 1. Concentration of methane and ethane $\left(\mathrm{mmol} \mathrm{L}^{-1}\right)$ in the Censo soil incubations. a): data points show the ${ }^{13} \mathrm{CH}_{4}$ consumption (blue triangles) with standard deviation of three incubated soil samples, the heat killed control sample (HK; grey circles) and unamended soil sample (UA; green diamond) over 5 days. In b): data points show the ${ }^{13} \mathrm{C}_{2} \mathrm{H}_{6}$ consumption (red squares) with standard deviation of three incubated soil samples and the heat killed control sample (HK ; grey circles) over 9 days.

\subsection{Labelling of FAs, MAs and hopanoic adids after incubation with ${ }^{13} \mathrm{CH}_{4}$ and ${ }^{13} \mathrm{C}_{2} \mathrm{H}_{6}$}

The ${ }^{13} \mathrm{C}$ labelling (expressed in $\mathrm{AT} \%{ }^{13} \mathrm{C}$ ) of the main regular $\mathrm{FAs}$, the hopanoic acids and several MAs was determined for the Censo soil ${ }^{13} \mathrm{CH}_{4}$ and ${ }^{13} \mathrm{C}_{2} \mathrm{H}_{6}$ incubations (Fig. 3). The Censo soils incubated with ${ }^{13} \mathrm{CH}_{4}$ showed high levels of ${ }^{13} \mathrm{C}$ incorporation into regular and unsaturated $\mathrm{C}_{16}$ and $\mathrm{C}_{18} \mathrm{FAs}$ (2 to $11 \mathrm{AT} \%$ ${ }^{13} \mathrm{C}$ ) (Fig. 3a). Especially the unsaturated $\mathrm{C}_{16}$ and $\mathrm{C}_{18} \mathrm{FA} s$ were heavily enriched with ${ }^{13} \mathrm{C}$ ranging from 8 to $11 \mathrm{AT} \%{ }^{13} \mathrm{C}$. In contrast, the $\mathrm{C}_{32} 22 \mathrm{R} 17 \beta, 21 \beta(\mathrm{H})$ hopanoic acid and all MAs $\left(\mathrm{C}_{21}\right.$ to $\left.\mathrm{C}_{31} \mathrm{MA}\right)$ did not show a significant ${ }^{13} \mathrm{C}$ enrichment in the Censo soil ${ }^{13} \mathrm{CH}_{4}$ incubations. The heat-killed control showed no significant ${ }^{13} \mathrm{C}$ incorporation in any of the investigated $\mathrm{FAs}, \mathrm{C}_{32}$ hopanoic acid or MAs, i.e. they had similar values as previously reported for the Censo soil (Smit et al., 2021).

The Censo soil incubations with ${ }^{13} \mathrm{C}_{2} \mathrm{H}_{6}$ also revealed heavily ${ }^{13} \mathrm{C}$ enriched regular and unsaturated $\mathrm{C}_{16}$ and $\mathrm{C}_{18} \mathrm{FAs}$ with $\mathrm{AT} \%{ }^{13} \mathrm{C}$ values ranging from 6 to $13 \%$ (Fig. 3b). The $\mathrm{C}_{32} 22 \mathrm{R} 17 \beta, 21 \beta(\mathrm{H})$-hopanoic acid showed no substantial incorporation of ${ }^{13} \mathrm{C}$. In contrast to the methane incubation, all M As had high $\mathrm{AT} \%{ }^{13} \mathrm{C}$ values, ranging from 1.4 to $2.0 \mathrm{AT} \%$ with the highest ${ }^{13} \mathrm{C}$ enrichment seen in the $\mathrm{C}_{21} \mathrm{MA}$. The heat killed control of the ${ }^{13} \mathrm{C}_{2} \mathrm{H}_{6}$ Censo 
incubations did not reveal any significant incorporation of ${ }^{13} \mathrm{C}$ label into the FAs, the $\mathrm{C}_{32}$ hopanoic acid or M As.

\section{Discussion}

\subsection{Methane and ethane consumption in the Censo seep soil incubation experiments}

The consumption of ${ }^{13} \mathrm{CH}_{4}$ and ${ }^{13} \mathrm{C}_{2} \mathrm{H}_{6}$ in the incubation bottles (Fig. 1) indicates that an active hydrocarbon gas-utilizing bacterial community is present in the Censo soil, i.e. hydrocarbon gas-utilizing bacteria which oxidized high amounts of $\mathrm{CH}_{4}$ and $\mathrm{C}_{2} \mathrm{H}_{6}$ and incorporated the carbon derived from the gases into their biomass, including their lipids. The stable ${ }^{13} \mathrm{CH}_{4}$ and ${ }^{13} \mathrm{C}_{2} \mathrm{H}_{6}$ concentrations, and thus lack of gas consumption, in the heat killed controls robustly indicate that the uptake of methane and ethane was mediated by microbes.

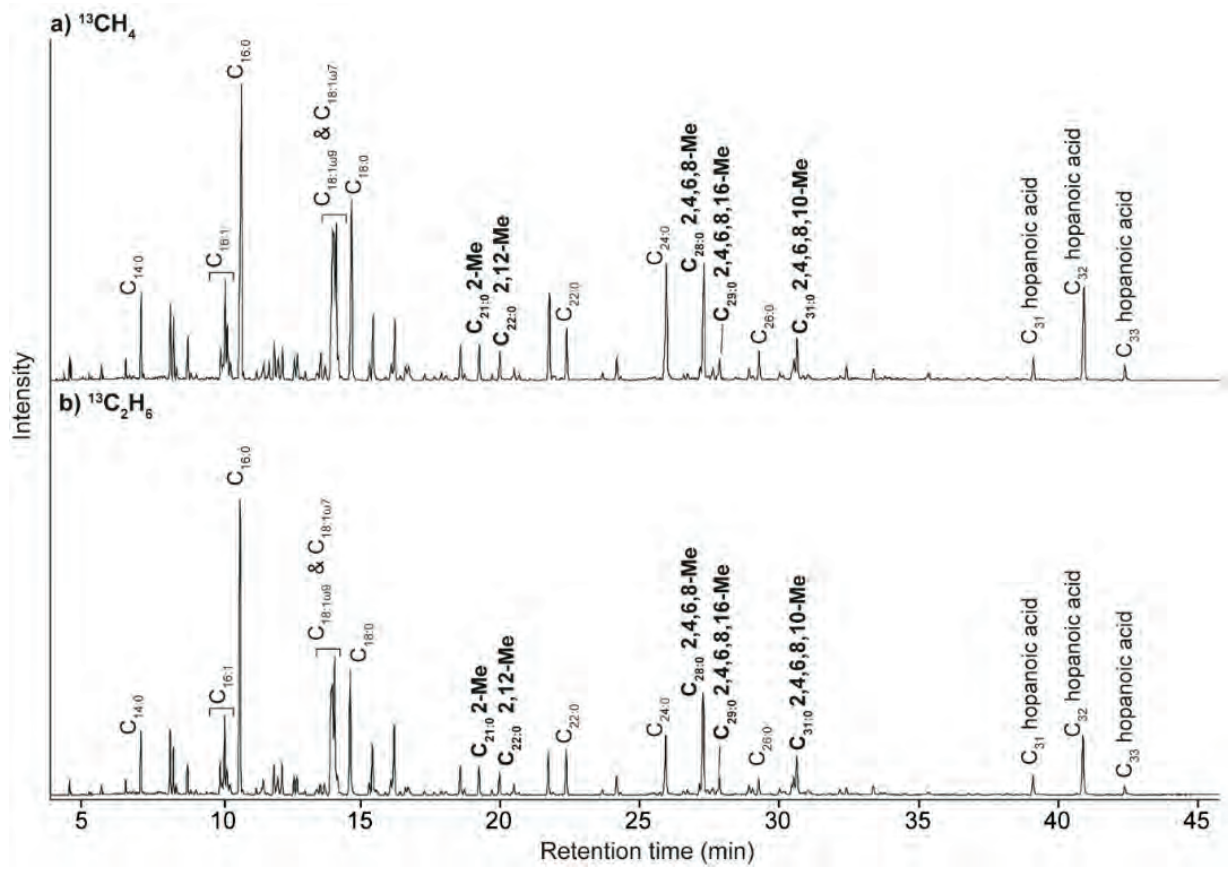

Figure 2. T otal ion chromatograms of the fatty acid methyl ester fractions from the Censo seep soil incubations with a) ${ }^{13} \mathrm{CH}_{4}$ after 5 days and b) ${ }^{13} \mathrm{C}_{2} \mathrm{H}_{6}$ after 9 days showing the distribution of $\mathrm{FAs}$, hopanoic acids and mycocerosic acids (MAs). The black bold annotations show the previously identified MAs and the carbon position of their methyl groups (M e) (Smit et al., 2021).

The hydrocarbon gas consumption was fastest in the first $24 \mathrm{~h}$ in the ${ }^{13} \mathrm{CH}_{4}$ incubations (5 days) while consumption of ${ }^{13} \mathrm{C}_{2} \mathrm{H}_{6}$ was about 3 times slower, although the overall average gas consumption rates were the same in both incubations set ups (Fig. 1). The differences in the early phase of the two 
incubations might be related to the speed of adaptation and the initial microbial composition of the methane and ethane oxidizing community as well as to their ability to utilize high gas concentrations. A difference in initial gas consumption rates has also been observed in SIP incubations of sediments from marine hydrocarbon seeps at Coal Oil Point, California where the faster consumption of ${ }^{13} \mathrm{CH}_{4}$ than ${ }^{13} \mathrm{C}_{2} \mathrm{H}_{6}$ was related to faster changes in the microbial communities, as revealed by DNA -based analyses (K innaman et al., 2007; R edmond et al., 2010).

\subsection{A erobic methane-oxidizing bacteria at the $C$ enso seep}

The regular and unsaturated $\mathrm{C}_{16}$ and $\mathrm{C}_{18} \mathrm{FAs}$ produced during the ${ }^{13} \mathrm{CH}_{4}$ Censo soil incubations are most likely derived from Type I and Type II methanotrophs (e.g. Methylococcales or Methylocystaceae), which were identified previously in the Censo seep soil by $16 \mathrm{~S}$ rRNA gene sequencing (Smit et al., 2021). The observation that methane oxidation in the Censo soil might be performed by these Type I and Type II methanotrophs confirms previous observations in fatty acid inventories of cultured methanotrophic bacteria (Dedysh et al., 2007; Bodelier et al., 2009) as well as ${ }^{13} \mathrm{CH}_{4}$ SIP studies of soils (Bull et al., 2000; Evershed et al., 2006). ${ }^{13} \mathrm{CH}_{4}$ SIP studies in temperate forest soils (Bull et al., 2000; C rossman et al., 2005; Evershed et al., 2006), peats (Chen et al., 2008) and marine gas seep sediments (Kinnaman et al., 2007; Redmond et al., 2010) also show ed a high degree of ${ }^{13} \mathrm{C}$ incorporation in regular and unsaturated $\mathrm{C}_{16}$ and $\mathrm{C}_{18}$ FAs with moderate to high $\mathrm{CH}_{4}$ concentrations. Furthermore, the lower ${ }^{13} \mathrm{C}$ incorporation in the saturated $\mathrm{C}_{16}$ and $\mathrm{C}_{18} \mathrm{FAs}$ compared to their unsaturated homologues could be related to a mixed bacterial community of heterotrophic and methanotrophic bacteria being the source of the saturated compounds (Boschker et al., 1998), thereby diluting the ${ }^{13} \mathrm{C}$ signals of the latter bacteria. Interestingly, the natural ${ }^{13} \mathrm{C}$ abundance of these fatty acids was not depleted or only by $5-10 \%$ compared to the released $\mathrm{CH}_{4}$ at the Censo seep (Smit et al., 2021).

No incorporation of ${ }^{13} \mathrm{C}$ was observed in the $22 \mathrm{R} 17 \beta, 21 \beta(\mathrm{H})$ bishomohopanoic acid in the ${ }^{13} \mathrm{CH}_{4}$ SIP incubations. Hopanoic acids are a diagenetic product of bacteriohopanepolyols, which can be produced by some methanotrophs but also from a variety of other bacterial species (Rohmer et al., 1984; Zundel and Rohmer, 1985; Talbot et al., 2001; Talbot and Farrimond, 2007). The lack of ${ }^{13} \mathrm{C}$ incorporation in the ${ }^{13} \mathrm{CH}_{4}$ SIP incubation suggests that the pool of $\mathrm{C}_{32}$ hopanoic acid was not produced by active methanotrophic bacteria during the short incubation time and may predominantly reflect fossil diagenetic compounds. 




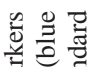

ह 당

응

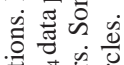

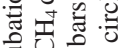

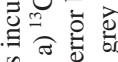

त्र

बें के

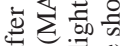

to

ป v

7 ज

월

๙0 80

ते हो त्र

ำ 은

过 은

T.

क है है

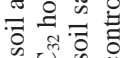

ด $8 \frac{8}{8}$

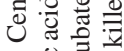

\& $\frac{\cup}{0}$.

ᄃ $\frac{2}{8} \frac{1}{4}$

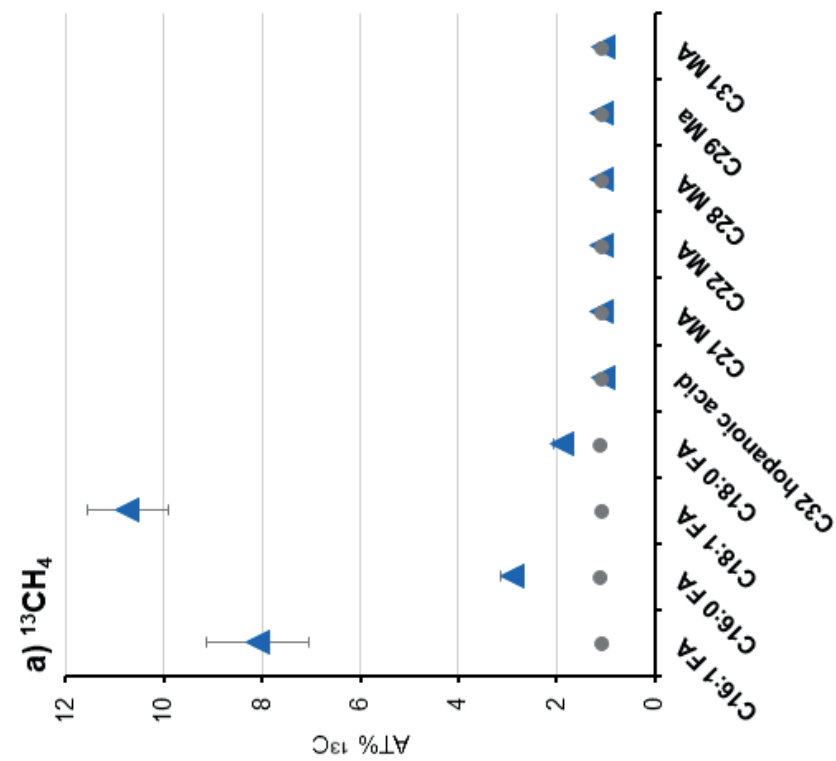

है क

ह 워

을 잉

to 至宛

บ

ऽ ํำ

다응

$\varangle \stackrel{्}{N}$

है Nै पे ठั

क्ष के

$\therefore$ पूरते

ธ。 近通

证 흥

है $\frac{\pi}{8}$

응

응 $\frac{4}{8} \cdot \frac{8}{8}$

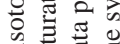

至要

농

(1) है

응 응

क ए

\&

$\dot{x} \circlearrowright$

भु ฮิ

논 
A nother possibility could be that the $\mathrm{C}_{32}$ hopanoic acid is synthesized by bacteria that do no utilise $\mathrm{CH}_{4}$ as carbon source, such as heterotrophs or aerobic methanotrophs that do not directly incorporate $\mathrm{CH}_{4}$. For example, Type II methanotrophs and methanotrophic Verrucomicrobia can assimilate both $\mathrm{CH}_{4}$ and $\mathrm{CO}_{2}$ as their carbon source thus only a portion of the fixed carbon may originate from depleted $\mathrm{CH}_{4}$ or ${ }^{13} \mathrm{CH}_{4}$ in SIP incubations (H anson and $\mathrm{H}$ anson, 1996; $M$ axfield et al., 2006; $K$ hadem et al., 2011).

The observation that M As were relatively depleted in ${ }^{13} \mathrm{C}$ in natural soils at and close to the Censo seep, suggested a potential involvement of mycobacteria in $\mathrm{CH}_{4}$ oxidation in the Censo soils (Smit et al., 2021). However, the lack of incorporation of ${ }^{13} \mathrm{C}$ in $\mathrm{MAs}$ in the ${ }^{13} \mathrm{CH}_{4}$ incubation experiments indicates that the Censo mycobacteria might not be able to utilize $\mathrm{CH}_{4}$. This is supported by previous genome-based studies, which suggests that mycobacteria show the potential to oxidize higher gaseous hydrocarbons e.g. ethane and alkenes, methanol, and carbon monoxide but not methane (Park et al., 2003; Coleman et al., 2011, 2012; M artin et al., 2014). A lthough two studies have suggested that certain mycobacterial species are able to utilize methane directly (Nechaeva, 1949; Reed and Dugan, 1987), it is not clear if these mycobacteria use the $\mathrm{CH}_{4}$ as their energy or carbon source and thus their biomass could remain unlabelled, like 'Ca. Methylomirabilis oxyfera' which fixes carbon autotrophically (Kool et al., 2012; Rasigraf et al., 2014). Other possibilities include the incubation time being too short for the mycobacteria to grow or produce sufficient MAs, or that they were outcompeted by the other methanotrophs. Therefore, we cannot completely exclude that the Censo mycobacteria could oxidize $\mathrm{CH}_{4}$, and this should be tested by future incubations experiments and metagenome analysis.

\subsection{Ethane-utilizing bacteria in the Censo soils}

The fatty acid fraction of the ${ }^{13} \mathrm{C}_{2} \mathrm{H}_{6}$ SIP Censo incubations shows a similar distribution and inventory of FAs, hopanoic acids and MAs as the ${ }^{13} \mathrm{CH}_{4} \mathrm{SIP}$ incubations (Fig. 2b). The oxidation of solely $\mathrm{C}_{2} \mathrm{H}_{6}$ has been rarely investigated in the past and the few studies done show that a group of gram-positive organisms in the Corynebacterium-Nocardia-M ycobacterium Rhodococcus group (D workin and Foster, 1958; A shraf et al., 1994), along with some gramnegative Pseudomonas species are able to oxidize ethane (Takahashi, 1980; Hamamura et al., 1997). ${ }^{13} \mathrm{C}_{2} \mathrm{H}_{6}$ SIP experiments of sediments from marine hydrocarbon seeps at Coal Oil Point offshore California showed that M ethylococcaceae species can oxidize ethane in addition to methane and they 
produce high abundances of unsaturated and saturated $\mathrm{C}_{16} \mathrm{FAs}$ (K innaman et al., 2007; R edmond et al., 2010). In the Censo soils, Methylococcaceaespecies were identified previously (Smit et al., 2021) and might synthesize the ${ }^{13} \mathrm{C}$-labelled saturated and unsaturated $\mathrm{C}_{16}$ FAs in the ${ }^{13} \mathrm{CH}_{4}$ as well as in the ${ }^{13} \mathrm{C}_{2} \mathrm{H}_{6}$ incubations. Therefore, the ${ }^{13} \mathrm{C}$ label in $\mathrm{C}_{16}$ and $\mathrm{C}_{18} \mathrm{FAs}$ in the ${ }^{13} \mathrm{C}_{2} \mathrm{H}_{6}$ incubation experiments probably indicate that hydrocarbon gas-oxidizing bacteria are able to not only utilize $\mathrm{CH}_{4}$ but also $\mathrm{C}_{2} \mathrm{H}_{6}$, in agreement with previous observations for some methanotrophic bacterial species (Hazeu and de B ruyn, 1980).

Intriguingly, the MAs in the ${ }^{13} \mathrm{C}_{2} \mathrm{H}_{6}$ incubated Censo soil do show significant ${ }^{13} \mathrm{C}$ incorporation after nine days of incubation time, in contrast to the methane incubations ( $\mathrm{Fig} .3 \mathrm{~b}$ ). The ${ }^{13} \mathrm{C}$-labelling of the MAs is in accordance with previous studies that showed mycobacteria are one of the rare groups of microbes that can utilize ethane (Park et al., 2003; Coleman et al., 2011, 2012). Furthermore, studies from the 1950s showed high abundances of mycobacteria in soils from areas of oil and gas production and in areas of petroliferous gas seeps, suggesting a potential involvement of mycobacteria in hydrocarbon gas oxidation processes (Davis et al., 1956, 1959). Subsequent cultivation experiments of those soils confirmed that mycobacteria did not utilize methane but higher gaseous hydrocarbons like ethane (D avis et al., 1956; D workin and Foster, 1958), which is in accordance with our Censo soil SIP incubation results. However, a slower rate of MA synthesis pathways, growth or abundance of mycobacteria could also influence the appearance of ${ }^{13} \mathrm{C}$ label in the ethane incubation experiments compared to the methane incubation experiments.

Our results of the ${ }^{13} \mathrm{C}_{2} \mathrm{H}_{6}$ SIP incubations in tandem with the ${ }^{13} \mathrm{CH}_{4}$ incubations suggest that mycobacteria are involved in the oxidation of ethane rather than methane at the Censo seep. If confirmed in other settings, then M A s may be used as biomarkers for ethane oxidation by mycobacteria in recent and past environments. However, further research in the lipid inventory and genes responsible for hydrocarbon gas oxidation in environmental mycobacteria should be done in other terrestrial gas seeps and soils.

\section{Condusion}

SIP incubations using ${ }^{13} \mathrm{CH}_{4}$ and ${ }^{13} \mathrm{C}_{2} \mathrm{H}_{6}$ with soils from the terrestrial Censo gas seep showed a substantial ${ }^{13} \mathrm{C}$ label incorporation into regular and unsaturated $\mathrm{C}_{16}$ and $\mathrm{C}_{18}$ FAs characteristic for common Type I and II methanotrophs. These common methanotrophs seem to be able to not only utilize $\mathrm{CH}_{4}$ but also $\mathrm{C}_{2} \mathrm{H}_{6}$. Furthermore, the ${ }^{13} \mathrm{C}$ incorporation in $\mathrm{MAs}$ was observed in the ${ }^{13} \mathrm{C}_{2} \mathrm{H}_{6}$ incubations but not in ${ }^{13} \mathrm{CH}_{4}$ incubations, which indicates that Censo seep 
mycobacteria oxidize $\mathrm{C}_{2} \mathrm{H}_{6}$ at the $\mathrm{Censo}$ seep and not $\mathrm{CH}_{4}$. This is in accordance with previous genetic and cultivation studies of gas-utilization of mycobacteria. However, it should be noted that the experimental conditions, the time period of incubation or other factors could also influence the rate of synthesis of M A s by the Censo mycobacteria in the SIP incubations and thus the degree of the ${ }^{13} \mathrm{C}$ label incorporation. O ur results do suggest, however, that ${ }^{13} \mathrm{C}$ depleted M A s in soils and terrestrial hydrocarbon seeps may offer new biomarkers to trace ethane oxidation in terrestrial gas seeps and soils.

\section{Author contributions}

NTS, DR and SS designed the study. NTS and FG collected the samples. NTS performed incubation experiments and lipid analysis. NTS, DR, M vdM , SS and J SSD interpreted the data. NTS wrote the manuscript with input from all authors.

\section{Competing interests}

The authors declare that they have no conflict of interest.

\section{Acknowledgements}

We thank M arianne Baas, Monique Verweij, J ort Ossebaar and Ronald van Bommel for technical assistance. We also thank Helge Niemann and M aaike Goudriaan for providing the oxygen meter unit and assistance in SIP incubation set up. This study received funding from the Netherlands E arth System Science Centre (NESSC) through grant (024.002.001) to JSSD and SS from the Dutch $M$ inistry for Education, Culture and Science. 
236 | Chapter 8 


\section{Chapter 9}

Synthesis and Outlook 


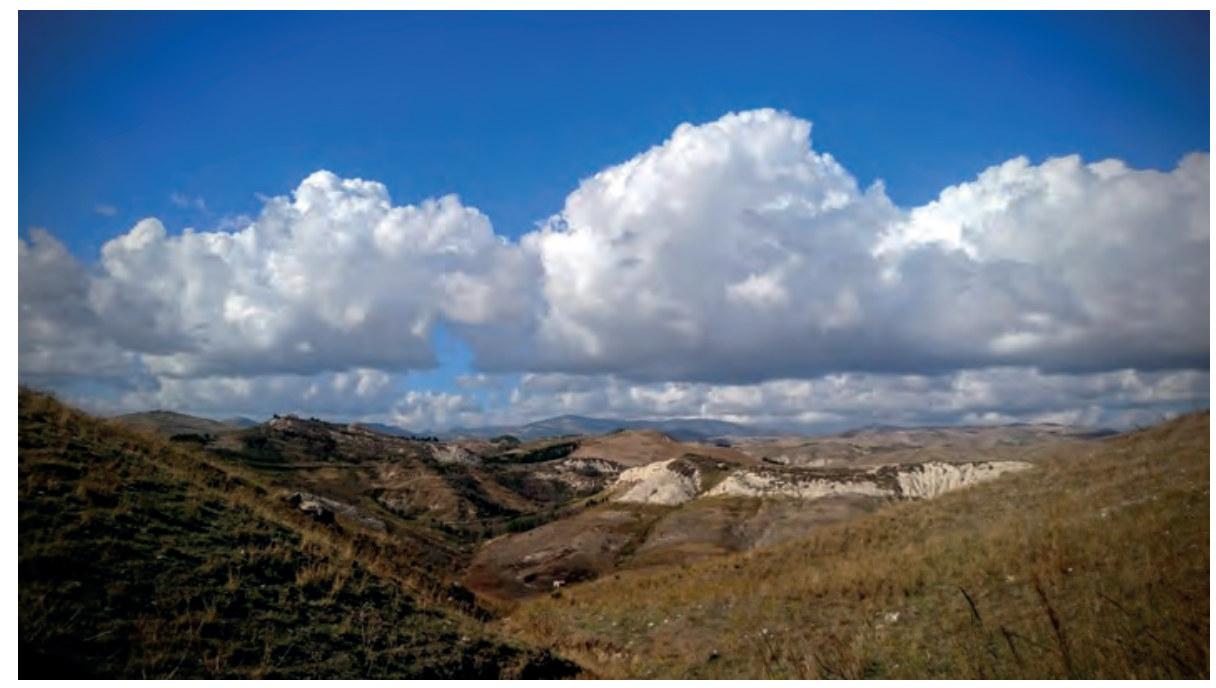

View from the Bissana seep near Cattolica Eraclea in Sicily, Italy

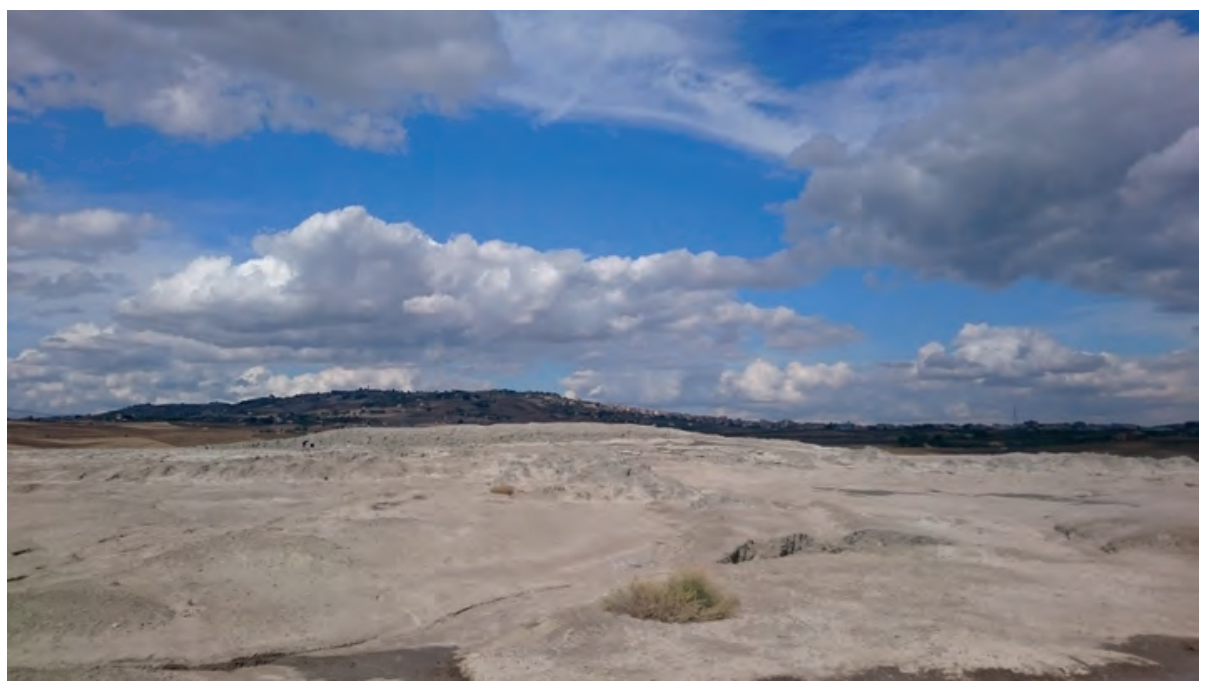

M accalube di A ragona mud volcano field (mud breccias from old eruptions) in Sicily, Italy 


\section{Synthesis and Outlook}

In this thesis, novel characteristic lipid biomarkers are developed to detect microbes involved in the aerobic oxidation of methane but also of other gaseous hydrocarbons especially in terrestrial environments. The recognition of such lipid biomarkers is essential to unravel the cycling of methane and higher gaseous hydrocarbons, essential processes in global climate change in the present-day and past Earth system. Finding reliable lipid biomarkers to trace microbial methane oxidation has proven difficult in the past, highlighting the need for the research presented in this thesis.

\section{Lipid biomarkers for nitrite/nitrate-dependent methane oxidation}

Over the last decade the process of nitrite/nitrate-dependent methane oxidation was discovered and investigated (Raghoebarsing et al., 2006; Ettwig et al., 2010; Haroon et al., 2013) but distinct lipid biomarkers to detect this process have only rarely been investigated until now (K ool et al., 2012, 2014). Therefore, lipid biomarker inventories specific for bacteria and archaea performing nitrite/nitrate-dependent methane oxidation were investigated in Chapters 2 and 3 using enrichment cultures of the intra-aerobic methanotroph ' $C$ andidatus Methylomirabilis oxyfera' ('Ca. M. oxyfera') and the ANME-2d archaeon 'Candidatus Methanoperedens'. 'Ca. M. oxyfera' synthesizes four unique demethylated hopanoids (22,29,30-trisnorhopan-21-ol, 3-methyl-22,29,30trisnor hopan-21-one and 3-methyl-22,29,30-trisnorhopan-21-ol), of which only 22,29,30-trisnorhopan-21-one had been identified previously. A new multiple reaction monitoring (MRM) method was developed and used to successfully detect these trisnorhopanoids in a peatland. 'C $\mathrm{C}$. M ethanoperedens' produced archaeol and hydroxyarchaeol as well as isoprenoidal GDGTs and unusually high amounts of hydroxy-GDGTs. The novel demethylated hopanoids and high abundances of hydroxy-GDGTs may thus be used in future studies to trace nitrite/nitrate-dependent methane oxidation in various present and past environments. It is particularly promising to employ these new biomarkers for nitrite/nitrate-dependent methane oxidation in marine environments, e.g. oxygen minimum zones, since this process has only been investigated in freshwater environments and peatlands until now (K ool et al., 2012; V aksmaa et al., 2017).

However, 'C $\mathrm{C}$. M . oxyfera' was discovered in the offshore environment in northern Mexico and Costa Rica using molecular ecological techniques (Padilla et al., 2016) and these environments would form a promising testing ground for the new biomarkers. Furthermore, the preservation potential of especially the demethylated hopanoids should be determined so that it is clear 
how far back in time nitrite-dependent methane oxidation in pal eo-environments can be investigated.

Preliminary aerobic biodegradation experiments using ' $\mathrm{C}$. . M . oxyfera' biomass for 90 days showed good preservation of the four demethylated hopanoids when typical fatty acids were already degraded (Smit et al., unpublished results). Interestingly, 'Ca. M. oxyfera' (and Planctomycetes; Sinninghe Damsté et al., 2004) directly synthesize demethylated hopanoids, contrasting previous ideas that demethylated hopanoids represent diagenetic alteration products in the environment (M oldowan et al., 1984; Noble et al., 1985; Peters et al., 2005). This observation may impact the interpretation of the presence of demethylated hopanes in present and past environments significantly.

M ethane oxidation in terrestrial mud volcanoes

M ud volcanoes ( $M V s$ ) are a major source of methane, however, mainly marine $M V$ s have been studied for aerobic and anaerobic oxidation of methane and their characteristic lipid biomarkers (Stadnitskaia et al., 2007; Elvert and Niemann, 2008; Lee et al., 2018). In Chapter 4, investigations of prominent terrestrial Sicilian M V s showed that freshly emitted mud breccias have high abundances of petroleum-derived hydrocarbons but low amounts of microbial lipid biomarkers such as fatty acids and hopanoic acids. These fatty and hopanoic acids were not depleted in ${ }^{13} \mathrm{C}$, likely indicating an origin from bacteria other than methane-oxidizing bacteria (M OBs). In contrast, the isoprenoidal GDGTs present in one $M V$ possess a distribution indicative for anaerobic oxidation of methane by A N M E archaea, in contrast to studies in other terrestrial M V s which showed only presence of partly ${ }^{13} \mathrm{C}$-depleted archaeol and dialkyl glycerol diethers (DA GE) specific for sulfate-dependent anaerobic oxidation of methane (A lain et al., 2006; Heller et al., 2012). The absence of strong indications for methane oxidation processes is surprising, in particular compared to marine mud volcanos (Stadnitskaia et al., 2005, 2008; Elvert and Niemann, 2008; L ee et al., 2018) and warrants further investigations. Future research should investigate the intact polar lipid inventory of these terrestrial M V s to more specifically examine living source organisms that actively synthesize GDGTs and fatty acids (Schubotz et al., 2009; Rossel et al., 2011) or study the distributions of BHPS, indicative for aerobic oxidation of methane (Chapters 5 and 6).

Further confirmation of the importance of methane oxidation processes can come from molecular ecological techniques such as the sequencing of $16 \mathrm{~S}$ rRNA or pmoA/mcrA genes (Hanson and Hanson, 1996; Hallam et al., 2003; 
K nief, 2015), which may identify aerobic or anaerobic methanotrophs present in the mud breccias. The activity of these processes, as well as better constraints of fatty acid sources can come from SIP (stable isotope probing) or RIP (radioisotope probing), using ${ }^{13} \mathrm{C}$ or ${ }^{14} \mathrm{C}$ labeled methane and/or DIC or $\mathrm{D}_{2} \mathrm{O}$, respectively (e.g. Bull et al., 2000; K ellermann et al., 2012; Evans et al., 2019).

U sing bacteriohopanepolyol derivatives to detect aerobic oxidation of methane Bacteriohopanepolyols and their derivatives are known to be indicative for distinct bacterial species involved in methane oxidation (N eunlist and Rohmer, 1985; Zundel and Rohmer, 1985; Cvejic et al., 2000; Talbot et al., 2014; van Winden et al., 2012) and this was applied in Chapters 5 and 6 By analyzing underivatized bacteriohopanepolyol (BHP) derivatives using UHPLC-HRM S numerous common and novel composite BHPs (e.g. ethenolamineBHPs or aminoB HPs acylated to fatty acid chains) were detected in bacterial cultures as well as in natural environments. Application of this methodology in two terrestrial methane seeps transects (Censo and Bissana seep) showed high relative abundance of aminoB HPs and the novel ethenolamineB HPs at and close to the seeps, which are likely synthesized by Type I MOBs (e.g. $M$ ethylococcaceae) and potentially other Proteobacteria species.

The detection of a new late eluting aminotriol isomer, which was also identified in a verrucomicrobial strain, Methylacidimicrobium cyclopophantes $3 B$, indicates for the first time that it may be used as a new biomarker for methanotrophic Verrucomicrobia. Verrucomicrobia have only been shown to produce common fatty acids (Op den Camp et al., 2009) and less distinct B HPS such as aminotriol (van Winden et al., 2012), both of which are also produced by other M OBs and bacterial species and are thus not useful for the identification of Verrucomicrobia in complex environmental samples. Therefore, the identification of the aminotriol isomer offers a new way to scan for Verrucomicrobia in modern and past environments besides DNA-based tools.

Soil-marker BHPS (adenosylhopane and N1-methylinosylhopane) showed contrasting behavior to $\mathrm{N}$-containing BHPs (aminoBHPs and ethenolamineBHPs), implying general bacterial producer(s) such as A cidobacteria or A ctinobacteria. F urther analysis on the hopanoid synthesis (e.g. shc gene) potential (Pearson and Rusch, 2009; Sinninghe Damsté et al., 2017) in the detected bacterial reads is required to shed light on the potential of certain bacteria to synthesize bacteriohopanepolyols.

Based on the above work, the A minoBHP-index was developed as an index to trace aerobic oxidation of methane, showing high values close to the 
seeps $(\geq 0.4)$ and dropping to $<0.2$ at distances $>3 \mathrm{~m}$ from the active seeps. Future work should investigate the potential to apply this new A minoB HP-index to other terrestrial methane-rich environments such as other seeps, peatlands or stratified lakes where aerobic methane oxidation is thought to be present (e.g. Coolen et al., 2008; Talbot et al., 2016; Inglis et al., 2019). Furthermore, the long-term preservation potential of aminoBHPs and the soil-specific BHPs (adenosylhopane and N1-methylinosylhopane) should be investigated by diagenetic alteration experiments using for example hydrous pyrolysis. Once further established, this A minoB HP-index could help to reconstruct past aerobic oxidation of methane and thus past methane concentrations over longer timescales than the currently existing ice-core records, which only date back 800,000 years (L oulergue et al., 2008).

Unique mycocerosic acids trace novel hydrocarbon gas-oxidizing soil mycobacteria

Soils from a natural everlasting fire named Fuoco di Censo in Sicily, Italy showed high abundances of novel mycobacteria via 16S rR NA gene sequencing and mycocerosic acids (M As), multi-methyl branched fatty acids, at and close to the seep (Chapters7 and 8). These novel soil mycobacteria are phylogenetically closely related to the M ycobacterium simiae complex but more remotely to wellstudied pathogenic mycobacteria such as M. tuberculosis. A range of new M As were identified and even very unusual ones with mid-chain methyl branches at positions C-12 and C-16 were present at and close to the seep. These M A s were naturally depleted in ${ }^{13} \mathrm{C}$, suggesting a direct or indirect utilization of the released gases (methane and/or ethane). Confirmation of the use of these hydrocarbon gasses as a carbon source came from SIP incubations using ${ }^{13} \mathrm{C}$ label ed methane and ethane, which showed ${ }^{13} \mathrm{C}$ label incorporation of ethane, but not of methane, into the MAs. These results imply that mycobacteria at the Censo seep oxidize ethane but not methane, in agreement with studies from the 1950s in areas of petroleum production and gas seeps (Davis et al., 1956, 1959; Dworkin and Foster, 1958) as well as genomic studies (Coleman et al., 2012; M artin et al., 2014). Thus, soil mycobacteria might represent a major group of microbes involved in the cycling of ethane and maybe also higher gaseous hydrocarbons in terrestrial environments and possibly in marine environments, as they are present in a wide range of environmental niches (Brennan, 2003; Falkinham, 2015).

The novel structurally specific M A s in tandem with ${ }^{13} \mathrm{C}$ depleted isotopic signatures offer unique biomarkers to trace higher gaseous hydrocarbon 
oxidation and gas-consuming soil mycobacteria in modern and past environments. Other terrestrial and marine gas seeps should be investigated for the presence of these new biomarkers to confirm their presence in other settings where also sequences of mycobacteria have been detected. Interestingly, mycobacteria are able to synthesize a number of other highly specific lipids due to the fact that they possess a double lipid membrane and two fatty acid biosynthesis systems (B rennan, 2003; Gago et al., 2011; D onoghue et al., 2017; Daffé et al., 2019). These lipids include extremely long fatty acids with chains up to $\mathrm{C}_{90}$ and with numerous methyl groups, hydroxylations and/or methoxylations bound to complex glycolipids, all known from pathogenic mycobacteria (M innikin et al., 1993a, b; Donoghue et al., 2017). Potentially these lipids classes can be picked up by using UHPLC-HRM S ${ }^{2}$ techniques. Finally, whole genome analysis of the mycobacteria in the Censo soils could reveal the pathways for M A synthesis (B rennan, 2003; Gago et al., 2011), and their relation with those of pathogenic mycobacteria, as well as shed more light on their carbon and energy assimilation pathways.

Overall the work presented in this thesis has substantially expanded our lipid biomarker tool set to detect past methane and ethane oxidation by the development of proxies such as mycocerosic acids and the A minoB HP-index. Together with more established biomarker proxies, these can potentially be used to study methane and higher gaseous hydrocarbon oxidation in present and past environments and thereby lead to more insight into past cycling of greenhouse gases. 
244 | Chapter 9 


\section{References}




\section{References}

A bdala A sbun, A., B esseling, M .A ., B alzano, S., van B leijswijk, J.D.L., Witte, H.J., Villanueva, L. and Engelmann, J.C. (2020) Cascabel: A Scalable and V ersatile A mplicon Sequence Data A nalysis Pipeline Delivering Reproducible and Documented Results. Frontiers in Genetics 11.

A hmed, M., Schouten, S., Baas, M. and De Leeuw, J. (2001) Bound lipids in kerogens from the Monterey Formation, Naples Beach, California. The M onterey Formation: From R ock to M olecules. Columbia U niversity Press, $\mathrm{New}$ Y ork, 189-205.

A lain, K., Holler, T., M usat, F., Elvert, M., Treude, T. and K rüger, M . (2006) Microbiological investigation of methane-and hydrocarbon-discharging mud volcanoes in the Carpathian M ountains, Romania. Environmental M icrobiology $8,574-590$.

Albaiges, J. and Albrecht, P. (1979) Fingerprinting marine pollutant hydrocarbons by computerized gas chromatography-mass spectrometry. International J ournal of Environmental A nalytical Chemistry 6, 171-190.

Alloisio, N., M arechal, J., Vanden Heuvel, B., Normand, P. and Berry, A.M. (2005) Characterization of a gene locus containing squalene-hopene cyclase (she) in Frankia alni ACN 14a, and an she homolog in Aeidothermus eellulolytieus. Symbiosis 39, 83-90.

Alugupalli, S., Sikka, M. K., Larsson, L., and White, D. C. (1998) Gas chromatography-mass spectrometry methods for the analysis of mycocerosic acids present in Mycobacterium tuberculosis, Journal of Microbiological M ethods, 31, 143-150.

A mann, R.I., Binder, B.J., Olson, R.J ., Chisholm, S.W ., Devereux, R. and Stahl, D.A. (1990) Combination of 16S rRNA-targeted oligonucleotide probes with flow cytometry for analyzing mixed microbial populations. Applied Environmental M icrobiology 56, 1919-1925.

A ndrews, S. (2010) FastQ C: a quality control tool for high throughput sequence data. available at: http://www.bioinformatics.babraham.ac.uk/projects/fastqc

A rshad, A ., Speth, D.R., de Graaf, R.M ., Op den Camp, H.J.M ., J etten, M .S.M . and W elte, C.U. (2015) A M etagenomics-B ased M etabolic M odel of NitrateDependent Anaerobic Oxidation of $M$ ethane by Methanoperedens-Like A rchaea. Frontiers in M icrobiology 6.

A shraf, W ., M ihdhir, A . and M urrell, J . C. (1994) B acterial oxidation of propane. FEM S M icrobiology Letters 122, 1-6. 
A tlas, R. and Bartha, R. (1973) Inhibition by fatty acids of the biodegradation of petroleum. A ntonie van L eeuw enhoek 39, 257-271.

Bale, N., V illanueva, L., Hopmans, E., Schouten, S. and Sinninghe Damsté, J. (2013) Different seasonality of pelagic and benthic Thaumarchaeota in the N orth Sea. Biogeosciences 10, 7195-7206.

Bale, N.J., Sorokin, D.Y., Hopmans, E.C., Koenen, M., Rijpstra, W.I.C., Villanueva, L., W ienk, H. and Sinninghe Damsté, J.S. (2019) N ew insights into the polar lipid composition of extremely halo(alkali)philic euryarchaea from hypersaline lakes. Frontiers in M icrobiology 10, 377.

Balesdent, J., M ariotti, A ., and Guillet, B. (1987) Natural ${ }^{13} \mathrm{C}$ abundance as a tracer for studies of soil organic matter dynamics, Soil Biology and Biochemistry, 19, 25-30.

Bard, M ., Bruner, D., Pierson, C., Lees, N ., Biermann, B ., Frye, L., K oegel, C. and Barbuch, R. (1996) Cloning and characterization of ERG25, the Saccharomyces cerevisiae gene encoding C-4 sterol methyl oxidase. Proceedings of the National A cademy of Sciences 93, 186-190.

Bardgett, R. D., and van der Putten, W. H. (2014) Below ground biodiversity and ecosystem functioning, Nature 515, 505, 2014.

Basilone, L. (2012) Litostratigrafia della Sicilia, Dipartimento di scienze della terra e del mare, Università degli studi, A rti G rafiche Palermitane s.r.I, Palermo, Italy, ISB N : 978-88-97559-09-2.

Beal, E.J., House, C.H., and Orphan, V.J. (2009) Manganese- and irondependent marine methane oxidation. Science 325, 184-187.

Bennett, B . and A bbott, G.D. (1999) A natural pyrolysis experiment-hopanes from hopanoic acids? Organic Geochemistry 30, 1509-1516.

Berg, I.A., Kockelkorn, D., V era, W.H.R., Say, R.F., Zarzycki, J. and Hügler, M . (2010) A utotrophic carbon fixation in archaea. Nature Reviews M icrobiology $8,447-460$.

Berger, S., Frank, J ., D al cin M artins, P., J etten, M .S.M ., and W elte, C.U . (2017) High-quality draft genome sequence of "Candidatus M ethanoperedens sp." Strain BLZ2, a nitrate-reducing anaerobic methane-oxidizing archaeon enriched in an anoxic bioreactor. genome A nnouncements 5: e01159-17.

Bernard, B.B., Brooks, J.M . and Sackett, W .M . (1978) Light hydrocarbons in recent Texas continental shelf and slope sediments. Journal of Geophysical Research: Oceans 83, 4053-4061. 
B erndmeyer, C., Thiel, V., Schmale, O. and Blumenberg, M . (2013) B iomarkers for aerobic methanotrophy in the water column of the stratified Gotland Deep (Baltic Sea). Organic Geochemistry 55, 103-111.

Besseling, M .A., Hopmans, E. C., Boschman, C.R., Sinninghe Damsté, J.S. and Villanueva, L. (2018) Benthic archaea as potential sources of tetraether membrane lipids in sediments across an oxygen minimum zone. Biogeosciences 15, 4047-4064.

Birgel, D. and Peckmann, J. (2008) A erobic methanotrophy at ancient marine methane seeps: a synthesis. Organic Geochemistry 39, 1659-1667.

Bligh, E.G. and Dyer, W.J . (1959) A rapid method of total lipid extraction and purification. Canadian J ournal B iochemistry Physiology 37, 911-917.

Blumenberg, M., Seifert, R., Reitner, J., Pape, T. and M ichaelis, W. (2004) Membrane lipid patterns typify distinct anaerobic methanotrophic consortia. Proceedings of the National A cademy of Sciences 101, 11111-11116.

Blumenberg, M., Seifert, R., Nauhaus, K ., and Pape, T. (2005) In vitro study of lipid biosynthesis in an anaerobically methane-oxidizing microbial mat. A pplied Environmental M icrobiology 71, 4345-4351.

Blumenberg, M., K rüger, M., Nauhaus, K., Talbot, H.M., Oppermann, B.I., Seifert, R., Pape, T. and M ichaelis, W . (2006) Biosynthesis of hopanoids by sulfate-reducing bacteria (genus Desulfovibrio). Environmental M icrobiology 8 , 1220-1227.

Blumenberg, M ., Seifert, R . and M ichaelis, W . (2007) A erobic methanothrophy in the oxic-anoxic transition zone of the Black Sea water column. Organic Geochemistry 38, 84-91.

B lumenberg, M ., H oppert, M ., K rüger, M ., D reier, A . and Thiel, V . (2012) N ovel findings on hopanoid occurrences among sulfate reducing bacteria: Is there a direct link to nitrogen fixation? Organic geochemistry 49, 1-5.

Bodelier, P.L., Gillisen, M.-J .B., Hordijk, K., Sinninghe Damsté, J.S., Rijpstra, W .I.C., Geenevasen, J.A . and Dunfield, P.F. (2009) A reanalysis of phospholipid fatty acids as ecological biomarkers for methanotrophic bacteria. The ISME J ournal 3, 606.

Boere, A.C., Rijpstra, W.I.C., De Lange, G.J., Sinninghe Damsté, J.S. and Coolen, M.J.L. (2011) Preservation potential of ancient plankton DNA in Pleistocene marine sediments. Geobiology 9, 377-393.

B oetius, A ., Ravenschlag, K., Schubert, C.J ., Rickert, D., W iddel, F., Gieseke, A ., A mann, R ., Jørgensen, B .B ., W itte, U. and Pfannkuche, O. (2000) A marine 
microbial consortium apparently mediating anaerobic oxidation of methane. Nature 407, 623.

Bonini, M. (2009) Mud volcano eruptions and earthquakes in the Northern A pennines and Sicily, Italy. Tectonophysics 474, 723-735.

Boschker, H., Nold, S., Wellsbury, P., B os, D., De Graaf, W., Pel, R., Parkes, R.J. and Cappenberg, T. (1998) Direct linking of microbial populations to specific biogeochemical processes by 13 C-labelling of biomarkers. N ature 392, 801-805.

Botz, R., Schmidt, M., Wehner, H., Hufnagel, H. and Stoffers, P. (2007) Organic-rich sediments in brine-filled Shaban-and K ebrit deeps, northern Red Sea. Chemical Geology 244, 520-553.

Bouam, A., A rmstrong, N., Levasseur, A., and Drancourt, M. (2018) Mycobacterium terramassiliense, Mycobacterium rhizamassiliense and M ycobacterium numidiamassiliense sp. nov., three new M ycobacterium simiae complex species cultured from plant roots. Scientific Reports, 8, 1-13.

Bowman, J.P. (2011) A pproaches for the characterization and description of novel methanotrophic bacteria. M ethods in Enzymology 459, 45-62.

Bowman, J.P. (2006) The methanotrophs - the families M ethylococcaceae and M ethylocystaceae, The Prokaryotes, 5, 266-289.

Bowman, J.P., Sly, L.I., Nichols, P.D. and Hayward, A. (1993) Revised taxonomy of the methanotrophs: description of Methylobacter gen. nov., emendation of Methylococcus, validation of Methylosinus and Methylocystis species, and a proposal that the family Methylococcaceae includes only the group I methanotrophs. International Journal of Systematic and Evolutionary Microbiology 43, 735-753.

Bradley, A.S., Pearson, A ., Sáenz, J.P. and M arx, C.J . (2010) A denosylhopane: The first intermediate in hopanoid side chain biosynthesis. Organic Geochemistry 41, 1075-1081.

Brassell, S.C., Eglinton, G., M arlowe, I.T., Pflaumann, U. and Sarnthein, M. (1986) M olecular stratigraphy: a new tool for climatic assessment. Nature 320, 129-133.

B ray, E. and Evans, E. (1961) Distribution of n-paraffins as a clue to recognition of source beds. Geochimica et Cosmochimica A cta 22, 2-15.

B rennan, P.J., and Nikaido, H. (1995) The envelope of mycobacteria, A nnual Review of Biochemistry 64, 29-63. 
B rennan, P.J . (2003) Structure, function, and biogenesis of the cell wall of M ycobacterium tuberculosis. Tuberculosis 83, 91-97.

B rocks, I.J ., L ove, G.D., Summons, R.E., K noll, A .H., L ogan, G .A . and B owden, S.A. (2005) Biomarker evidence for green and purple sulphur bacteria in a stratified Palaeoproterozoic sea. N ature 437, 866.

B rocks, J.J. and Pearson, A . (2005) B uilding the biomarker tree of life. Reviews in M ineralogy and Geochemistry 59, 233-258.

Bühring, S., Elvert, M . and W itte, U. (2005) The microbial community structure of different permeable sandy sediments characterized by the investigation of bacterial fatty acids and fluorescence in situ hybridization. Environmental M icrobiology 7, 281-293.

Bull, I.D., Parekh, N.R., Hall, G.H., Ineson, P. and Evershed, R.P. (2000) Detection and classification of atmospheric methane oxidizing bacteria in soil. Nature 405, 175.

Burugupalli, S., A Imeida, C.F., Smith, D.G.M , Shah, S., Patel, O., Rossjohn, J ., Uldrich, A.P., Godfrey, D.I. and S. J. Williams (2020) $\alpha$-Glucuronosyl and $\alpha$ glucosyl diacylglycerides, natural killer T cell-activating lipids from bacteria and fungi. Chemical Science 11, 2161-2168.

Cadillo-Quiroz, H., Yashiro, E., Y avitt, J.B., and Zinder, S.H. (2008) Characterization of the archaeal community in a minerotrophic fen and terminal restriction fragment length polymorphism-directed isolation of a novel hydrogenotrophic methanogen. A pplied Environmental M icrobiology 74, 20592068.

Cai, C., Leu, A.O., Xie, G.-J., Guo, J., Feng, Y. and Zhao, J.-X. (2018) A methanotrophic archaeon couples anaerobic oxidation of methane to $\mathrm{Fe}$ (III) reduction. The ISM E J ournal 12, 1929-1939.

Camacho-Ibar, V. C. F., A veytua-A Icázar, L., and Carriquiry, J. D. (2003) Fatty acid reactivities in sediment cores from the northern Gulf of California, Organic Geochemistry 34, 425-439.

Campbell, I.M. and Naworal, J. (1969) Composition of the saturated and monounsaturated fatty acids of $\mathrm{M}$ ycobacterium phlei. J ournal of lipid research 10, 593-598.

Cangemi, M . and M adonia, P. (2014) M ud volcanoes in onshore Sicily: a short overview. Spongy, slimy, cosy \& more, 123.

Caporaso, J.G ., L auber, C.L., W alters, W .A ., B erg-L yons, D ., H untley, J ., Fierer, N., Owens, S.M., Betley, J., Fraser, L. and Bauer, M. (2012) Ultra-high- 
throughput microbial community analysis on the Illumina HiSeq and MiSeq platforms. The ISM E J ournal 6, 1621.

Catalano, S., De Guidi, G., Romagnoli, G., Torrisi, S., Tortorici, G. and Tortorici, L. (2008) The migration of plate boundaries in SE Sicily: Influence on the large-scale kinematic model of the A frican promontory in southern Italy. Tectonophysics 449, 41-62.

Chang, Y.H., Cheng, T.W., Lai, W.J., Tsai, W.Y., Sun, C.H., Lin, L.H. and Wang, P.L. (2012) Microbial methane cycling in a terrestrial mud volcano in eastern Taiwan. Environmental M icrobiology 14, 895-908.

Chen, Y., Dumont, M.G., M cNamara, N.P., Chamberlain, P.M ., B odrossy, L., Stralis-Pavese, N. and Murrell, J.C. (2008) Diversity of the active methanotrophic community in acidic peatlands as assessed by mRNA and SIPPLFA analyses. Environmental Microbiology 10, 446-459.

Cheng, T.-W ., Chang, Y .-H., Tang, S.-L., Tseng, C.-H., Chiang, P.-W., Chang, K .-T., Sun, C.-H., Chen, Y .-G., Kuo, H.-C. and Wang, C.-H. (2012) M etabolic stratification driven by surface and subsurface interactions in a terrestrial mud volcano. The ISM E Journal 6, 2280-2290.

Chou, S., Chedore, P., Haddad, A., Paul, N. and Kasatiya, S. (1996) Direct identification of $\mathrm{M}$ ycobacterium species in $\mathrm{B}$ actec $7 \mathrm{H} 12 \mathrm{~B}$ medium by gas-liquid chromatography. Journal of Clinical M icrobiology 34, 1317-1320.

Chou, S., Chedore, P., and K asatiya, S. (1998) U se of gas chromatographic fatty acid and mycolic acid cleavage product determination to differentiate among $M$ ycobacterium genavense, M ycobacterium fortuitum, M ycobacterium simiae, and $M$ ycobacterium tuberculosis. J ournal of Clinical M icrobiology 36, 577-579.

Christie, W.W. (1998) Gas chromatography-mass spectrometry methods for structural analysis of fatty acids. Lipids 33, 343-353.

Coleman, N.V., Y au, S., W ilson, N.L., N olan, L.M., M igocki, M .D., Ly, M .a., Crossett, B . and Holmes, A .J . (2011) Untangling the multiple monooxygenases of $M$ ycobacterium chubuense strain NBB 4, a versatile hydrocarbon degrader. Environmental M icrobiology Reports 3, 297-307.

Coleman, N.V., Le, N.B., Ly, M.A., Ogawa, H.E., M cCarl, V., W ilson, N.L. and Holmes, A.J. (2012) Hydrocarbon monooxygenase in Mycobacterium: recombinant expression of a member of the ammonia monooxygenase superfamily. The ISM E J ournal 6, 171. 
Collister, J.W., Summons, R.E., Lichtfouse, E. and Hayes, J.M. (1992) An isotopic biogeochemical study of the Green River oil shale. Organic Geochemistry 19, 265-276.

Connan, J., Bouroullec, J., Dessort, D. and A lbrecht, P. (1986) The microbial input in carbonate-anhydrite facies of a sabkha palaeoenvironment from Guatemala: a molecular approach. Organic Geochemistry 10, 29-50.

Conrad, R. (2009) The global methane cycle: Recent advances in understanding the microbial processes involved. Environmental M icrobiology Reports 1, 285292.

Conte, M., Dickey, T., W eber, J., J ohnson, R. and K nap, A . (2003) Transient physical forcing of pulsed export of bioreactive material to the deep Sargasso Sea. D eep Sea Research Part I: O ceanographic R esearch Papers 50, 1157-1187.

Conte, M.H., W eber, J. and Ralph, N. (1998) E pisodic particle flux in the deep Sargasso Sea: an organic geochemical assessment. Deep Sea Research Part I: Oceanographic Research Papers 45, 1819-1841.

Cooke, M .P., Tal bot, H.M . and W agner, T. (2008a) Tracking soil organic carbon transport to continental margin sediments using soil-specific hopanoid biomarkers: A case study from the Congo fan (ODP site 1075). Organic Geochemistry 39, 965-971.

Cooke, M.P, Talbot, H.M. and Farrimond, P. (2008b) Bacterial populations recorded in bacteriohopanepolyol distributions in soils from Northern England. Organic G eochemistry 39, 1347-1358.

Cooke, M .P., van Dongen, B.E., Talbot, H .M ., Semiletov, I., Shakhova, N ., Guo, L. and Gustafsson, O. (2009) Bacteriohopanepolyol biomarker composition of organic matter exported to the A rctic 0 cean by seven of the major A rctic rivers. Organic G eochemistry 40, 1151-1159.

Coolen, M .J .L., Tal bot, H.M ., A bbas, B.A., W ard, C., Schouten, S., V olkman, J.K. and Sinninghe Damsté, J.S. (2008) Sources for sedimentary bacteriohopanepolyols as revealed by $16 \mathrm{~S}$ rDNA stratigraphy. Environmental M icrobiology 10, 1783-1803.

Costantino, V ., Fattorusso, E., Imperatore, C. and M angoni, A . (2000) The first 12-methylhopanetetrol from the marine sponge Plaktoris simplex. Tetrahedron 56, 3781-3784.

Crossman, Z., Ineson, P. and Evershed, R. (2005) The use of $13 \mathrm{C}$ labelling of bacterial lipids in the characterisation of ambient methane-oxidising bacteria in soils. Organic Geochemistry 36, 769-778. 
Cvejic, J.H., Bodrossy, L., Kovács, K.L. and Rohmer, M. (2000a) Bacterial triterpenoids of the hopane series from the methanotrophic bacteria Methylocaldum spp.: phylogenetic implications and first evidence for an unsaturated aminobacteriohopanepolyol. FEM S M icrobiology Letters 182, 361365.

Cvejic, J.H., Putra, S.R., El-Beltagy, A., Hattori, R., Hattori, T. and Rohmer, M. (2000b) Bacterial triterpenoids of the hopane series as biomarkers for the chemotaxonomy of Burkholderia, Pseudomonas and Ralstonia spp.. FEMS M icrobiology Letters 183, 295-299.

Daffé, M ., and L aneelle, M . (1988) Distribution of phthiocerol diester, phenolic mycosides and related compounds in mycobacteria. M icrobiology 134, 20492055.

Daffé, M., Quémard, A. and Marrakchi, H. (2019) Mycolic Acids: From Chemistry to Biology. Biogenesis of Fatty A cids, Lipids and M embranes, 181216.

Daims, H., B rühl, A ., A mann, R ., Schleifer, K.-H . and Wagner, M . (1999) The Domain-specific Probe EUB 338 is Insufficient for the Detection of all Bacteria: Development and Evaluation of a more Comprehensive Probe Set. Systematic and A pplied M icrobiology 22, 434-444.

Dalton, H . (1980) Oxidation of hydrocarbons by methane monooxygenases from a variety of microbes. In, Advances in Applied M icrobiology. Elsevier, pp. 7187.

D'A ndréa, S., Canonge, M., B eopoulos, A ., Jolivet, P., Hartmann, M ., M iquel, M ., Lepiniec, L. and Chardot, T. (2007) A t5g50600 encodes a member of the short-chain dehydrogenase reductase superfamily with $11 \beta$-and $17 \beta$ hydroxysteroid dehydrogenase activities associated with A rabidopsis thaliana seed oil bodies. Biochimie 89, 222-229.

Davis, J., Chase, H. and Raymond, R. (1956) Mycobacterium paraffinicum n. sp., a bacterium isolated from soil. A pplied M icrobiology 4, 310-315.

Davis, J., Raymond, R. and Stanley, J. (1959) A real contrasts in the abundance of hydrocarbon oxidizing microbes in soils. A pplied M icrobiology 7, 156-165.

Dean, J.F., M iddelburg, J.J ., Röckmann, T., A erts, R., Blauw, L.G., Egger, M ., J etten, M.S.M ., de Jong, A.E.E., M eisel, O.H., Rasigraf, O., Slomp, C.P., in't Zandt, M.H. and D olman, A .J. (2018) M ethane Feedbacks to the G lobal Climate System in a W armer W orld. R eviews of Geophysics 56, 207-250.

Dedysh, S.N., B elova, S.E., B odelier, P.L., Smirnova, K .V ., K hmelenina, V .N., Chidthaisong, A., Trotsenko, Y.A., Liesack, W. and Dunfield, P.F. (2007) 
Methylocystis heyeri sp. nov., a novel type II methanotrophic bacterium possessing 'signature' fatty acids of type I methanotrophs. International J ournal of Systematic and Evolutionary M icrobiology 57, 472-479.

Delgado-Baquerizo, M ., Oliverio, A .M ., B rewer, T.E., B enavent-González, A ., Eldridge, D.J ., Bardgett, R.D., M aestre, F.T., Singh, B.K. and Fierer, N. (2018) A global atlas of the dominant bacteria found in soil. Science 359, 320-325.

Delmotte, M., Chappellaz, J., Brook, E., Y iou, P., Barnola, J.M., Goujon, C., Raynaud, D. and Lipenkov, V.I. (2004) A tmospheric methane during the last four glacial-interglacial cycles: Rapid changes and their link with Antarctic temperature. J ournal of Geophysical R esearch: A tmospheres 109.

Deppenmeier, U., M üller, V. and Gottschalk, G. (1996) Pathways of energy conservation in methanogenic archaea. A rchives of M icrobiology 165, 149-163.

De Rosa, M . and Gambacorta, A . (1988) The lipids of archaebacteria. Progress in Lipid Research 27, 153-175.

De Rosa, M ., Gambacorta, A ., and Nicolaus, B. (1980) Regularity of isoprenoid biosynthesis in the ether lipids of archaebacteria. Phytochemistry 19, 791-793.

Didyk, B., Simoneit, B., Brassell, S.T. and Eglinton, G. (1978) Organic geochemical indicators of palaeoenvironmental conditions of sedimentation. Nature 272, 216-222.

Dimitrov, L.I. (2002) Mud volcanoes- the most important pathway for degassing deeply buried sediments. Earth-Science Reviews 59, 49-76.

Dimitrov, L.I. (2003) Mud volcanoes-a significant source of atmospheric methane. Geo-M arine L etters 23, 155-161.

Dlugokencky, E.J., Bruhwiler, L., W hite, J.W .C., Emmons, L.K., N ovelli, P.C., M ontzka, S.A., M asarie, K.A., L ang, P.M., Crotwell, A.M., Miller, J.B. and Gatti, L.V. (2009) Observational constraints on recent increases in the atmospheric $\mathrm{CH}_{4}$ burden. Geophysical Research L etters 36 .

Donoghue, H., Taylor, G., Stewart, G., L ee, O., W u, H., Besra, G and M innikin, D. (2017) Positive diagnosis of ancient leprosy and tuberculosis using ancient DNA and lipid biomarkers. Diversity 9, 46.

Dowling, N.J., Widdel, F. and White, D.C. (1986) Phospholipid ester-linked fatty acid biomarkers of acetate-oxidizing sulphate-reducers and other sul phideforming bacteria. M icrobiology 132, 1815-1825.

Dworkin, M. and Foster, J. (1958) Experiments with some microorganisms which utilize ethane and hydrogen. J ournal of B acteriology 75, 592. 
Edgar, R.C. (2004) M USCLE: multiple sequence alignment with high accuracy and high throughput. Nucleic A cids Research, 32, 1792-1797.

Edgar, R.C. (2010) Search and clustering orders of magnitude faster than BLAST. Bioinformatics, 26, 2460-2461.

Eglinton, G. and Hamilton, R.J . (1967) Leaf epicuticular waxes. Science 156, 1322-1335.

Eickhoff, M., Birgel, D., Talbot, H.M., Peckmann, J. and Kappler, A . (2013) Bacteriohopanoid inventory of Geobacter sulfurreducens and Geobacter metallireducens. Organic G eochemistry 58, 107-114.

Ekiel, I. and Sprott, G.D. (1992) Identification of degradation artifacts formed upon treatment of hydroxydiether lipids from methanogens with methanolic $\mathrm{HCl}$. Canadian J ournal of M icrobiology 38, 764-768.

Elling, F.J ., K önneke, M., Nicol, G.W., Stieglmeier, M., Bayer, B., Spieck, E., de la Torre, J.R., B ecker, K.W., Thomm, M ., Prosser, J .I ., H erndl, G .J ., Schleper, C. and Hinrichs, K.-U. (2017) Chemotaxonomic characterisation of the thaumarchaeal lipidome. Environmental M icrobiology 19, 2681-2700.

Elvert, M., Suess, E., and W hiticar, M.J . (1999) A naerobic methane oxidation associated with marine gas hydrates: superlight $\mathrm{C}$-isotopes from saturated and unsaturated $C_{20}$ and $C_{25}$ irregular isoprenoids. $N$ aturwissenschaften $86,295-300$.

Elvert, M., B oetius, A ., K nittel, K . and Jørgensen, B.B. (2003) Characterization of specific membrane fatty acids as chemotaxonomic markers for sulfatereducing bacteria involved in anaerobic oxidation of methane. Geomicrobiology Journal 20, 403-419.

Elvert, M., Hopmans, E., Treude, T., B oetius, A., and Suess, E. (2005) Spatial variations of methanotrophic consortia at cold methane seeps: implications from a high-resolution molecular and. Geobiology 3, 195-209.

Elvert, M. and Niemann, H. (2008) Occurrence of unusual steroids and hopanoids derived from aerobic methanotrophs at an active marine mud volcano. Organic G eochemistry 39, 167-177.

Etheridge, D.M., Steele, L.P., Francey, R.J. and Langenfelds, R.L. (1998) A tmospheric methane between 1000 A.D. and present: Evidence of anthropogenic emissions and climatic variability. Journal of Geophysical Research: A tmospheres 103, 15979-15993.

Etiope, G., Caracausi, A ., Favara, R., Italiano, F. and B aciu, C. (2002) M ethane emission from the mud volcanoes of Sicily (I taly). Geophysical Research L etters 29, 56-51-56-54. 
Etiope, G., M artinelli, G., Caracausi, A . and Italiano, F. (2007) M ethane seeps and mud volcanoes in Italy: gas origin, fractionation and emission to the atmosphere. G eophysical Research Letters 34.

Etiope, G., Feyzullayev, A. and Baciu, C.L. (2009) Terrestrial methane seeps and mud volcanoes: a global perspective of gas origin. M arine and Petroleum Geology 26, 333-344.

Etiope, G. and Ciccioli, P. (2009) Earth's Degassing: A M issing Ethane and Propane Source. Science 323, 478-478.

Ettwig, K.F., Zhu, B., Speth, D., Keltjens, J.T., J etten, M.S.M ., and K artal, B. (2016) A rchaea catalyze iron-dependent anaerobic oxidation of methane. Proceedings of the National A cademy of Sciences 113, 127922-12796.

Ettwig, K.F., Butler, M .K ., Le Paslier, D., Pelletier, E., M angenot, S., K uypers, M .M., Schreiber, F., Dutilh, B.E., Zedelius, J. and De Beer, D. (2010) Nitritedriven anaerobic methane oxidation by oxygenic bacteria. Nature 464, 543-548.

Ettwig, K.F., V an A len, T., van de Pas-Schoonen, K.T., J etten, M .S. and Strous, M. (2009) Enrichment and molecular detection of denitrifying methanotrophic bacteria of the NC10 phylum. A pplied and Environmental Microbiology 75, 3656-3662.

Ettwig, K.F., Shima, S., Van De Pas-Schoonen, K.T., Kahnt, J., Medema, M.H., Op Den Camp, H.J., Jetten, M.S. and Strous, M. (2008) Denitrifying bacteria anaerobically oxidize methane in the absence of A rchaea. Environmental M icrobiology 10, 3164-3173.

Evans, T.W., Coffinet, S., Könneke, M., Lipp, J.S., Becker, K.W., Elvert, M., Heuer, V. and Hinrichs, K.-U. (2019) A ssessing the carbon assimilation and production of benthic archaeal lipid biomarkers using lipid-RIP. Geochimica et Cosmochimica A cta 265, 431-442.

Evershed, R.P., Crossman, Z.M., Bull, I.D., Mottram, H., Dungait, J.A.J., M axfield, P.J . and B rennand, E.L. (2006) 13C-L abelling of lipids to investigate microbial communities in the environment. Current Opinion in Biotechnology $17,72-82$.

Falkinham, J.0. (2009) The biology of environmental mycobacteria. Environmental M icrobiology Reports 1, 477-487.

Falkinham, J.0. (2015) Environmental sources of nontuberculous mycobacteria. Clinics in Chest M edicine 36, 35-41. 
Farrimond, P., Griffiths, T. and Evdokiadis, E. (2002) Hopanoic acids in $M$ esozoic sedimentary rocks: their origin and relationship with hopanes. Organic Geochemistry 33, 965-977.

Farrimond, P., Talbot, H., Watson, D., Schulz, L. and Wilhelms, A. (2004) Methylhopanoids: molecular indicators of ancient bacteria and a petroleum correlation tool. Geochimica et Cosmochimica A cta 68, 3873-3882.

Farwell, C., Reddy, C.M., Peacock, E., Nelson, R.K., Washburn, L. and Valentine, D.L. (2009) Weathering and the fallout plume of heavy oil from strong petroleum seeps near Coal Oil Point, CA. Environmental Science \& Technology 43, 3542-3548.

Fernandes, N.D., and Kolattukudy, P.E. (1997) M ethylmalonyl coenzyme A selectivity of cloned and expressed acyltransferase and beta-ketoacyl synthase domains of mycocerosic acid synthase from M ycobacterium bovis B CG. J ournal of Bacteriology 179, 7538-7543.

Ferretti, D.F., M iller, J.B ., W hite, J.W.C., Etheridge, D.M ., Lassey, K .R ., L owe, D.C., M eure, C.M.M., Dreier, M.F., Trudinger, C.M., van Ommen, T.D. and Langenfelds, R.L. (2005) U nexpected Changes to the Global M ethane Budget over the Past 2000 Y ears. Science 309, 1714-1717.

Ferry, J.G. (1999) Enzymology of one-carbon metabolism in methanogenic pathways. FEM S M icrobiology Reviews 23, 13-38.

Fierer, N., L eff, J.W., A dams, B.J., Nielsen, U.N., Bates, S.T., L auber, C.L., Owens, S., Gilbert, J.A., Wall, D.H. and Caporaso, J.G. (2012) Cross-biome metagenomic analyses of soil microbial communities and their functional attributes. Proceedings of the N ational A cademy of Sciences 109, 21390-21395.

Fontaine, T., Lamarre, C., Simenel, C., Lambou, K ., Coddeville, B ., D elepierre, $M$. and Latgé, J-P (2009) Characterization of glucuronic acid containing glycolipid in Aspergillus fumigatus mycelium. Carbohydrate research 344, 19601967.

Francis, G. W. (1981) Alkylthiolation for the determination of double-bond position in unsaturated fatty acid esters. Chemistry and Physics of Lipids 29, 369-374.

Franzmann, P.D., Stackebrandt, E., Sanderson, K., V olkman, J.K., Cameron, D.E. and Stevenson, P.L. (1988) Halobacterium lacusprofundi sp. nov., a halophilic bacterium isolated from Deep Lake, Antarctica. Systematic and A pplied M icrobiology 11, 20-27. 
Freeman, K .H., Hayes, J., Trendel, J .-M . and A lbrecht, P. (1990) Evidence from carbon isotope measurements for diverse origins of sedimentary hydrocarbons. Nature 343, 254-256.

Frieling, J., Svensen, H.H., Planke, S., Cramwinckel, M .J ., Selnes, H. and Sluijs, A . (2016) Thermogenic methane release as a cause for the long duration of the PETM . Proceedings of the National A cademy of Sciences 113, 12059-12064.

Frostegård, A., Tunlid, A., and B ååth, E. (2011) Use and misuse of PLFA measurements in soils. Soil B iology and Biochemistry, 43, 1621-1625.

Gachotte, D., Barbuch, R., Gaylor, J., Nickel, E. and Bard, M. (1998) Characterization of the Saccharomyces cerevisiae ER 26 gene encoding the C3 sterol dehydrogenase (C-4 decarboxylase) involved in sterol biosynthesis. Proceedings of the National A cademy of Sciences 95, 13794-13799.

Gachotte, D., Sen, S., Eckstein, J., B arbuch, R., K rieger, M ., Ray, B . and B ard, M. (1999) Characterization of the Saccharomyces cerevisiae ERG27 gene encoding the 3-keto reductase involved in C-4 sterol demethylation. Proceedings of the National A cademy of Sciences 96, 12655-12660.

Gago, G., Diacovich, L., A rabolaza, A ., Tsai, S.-C. and Gramajo, H. (2011) Fatty acid biosynthesis in actinomycetes. FEM S M icrobiology Reviews 35, 475-497.

Gibson, R.A ., Talbot, H.M., K aur, G., Pancost, R.D. and M ountain, B . (2008) Bacteriohopanepolyol signatures of cyanobacterial and methanotrophic bacterial populations recorded in a geothermal vent sinter. Organic Geochemistry 39, 1020-1023.

Gibson, J.A.E., Miller, M.R., Davies, N.W., N eill, G.P., Nichols, D.S., and V olkman, J.K. (2005) U nsaturated diether lipids in the psychrotrophic archaeon Halorubrum lacusprofundi. Systematic and A pplied M icrobiology 28, 19-26.

Granath, J. W ., and P. Casero (2004) Tectonic setting of the petroleum systems of Sicily. In: R. Swennen, F. Roure, and J. W. Granath, eds., D eformation, fluid flow, and reservoir appraisal in foreland fold and thrust belts: AAPG Hedberg Series 1, 391-411.

Grassa, F., Capasso, G., Favara, R., Inguaggiato, S., Faber, E. and V alenza, M. (2004) Molecular and isotopic composition of free hydrocarbon gases from Sicily, Italy. G eophysical Research L etters 31, 6.

Grosjean, H. and Constantinesco, F. (1996) Enzymatic conversion of adenosine to inosine and to N 1-methylinosine in transfer RNAs: A review. Biochimie 78, 488-501. 
Guerrero-Cruz, S., Cremers, G., van A len, T.A., Op den Camp, H.J.M ., Jetten, M.S.M., Rasigraf, O., and Vaksmaa, A. (2018) Response of the anaerobic methanotroph "Candidatus $M$ ethanoperedens nitroreducens" to oxygen stress. A pplied Environmental M icrobiology 84, 1-17.

Hafenbradl, D., Keller, M., Thiericke, R., and Stetter, K.0. (1993) A novel unsaturated archaeal ether core lipid from the hyperthermophile M ethanopyrus kandleri. Systematic and A pplied M icrobiology 16, 165-169.

Hallam, S.J ., Putnam, N ., Preston, C.M ., D etter, J.C., Rokhsar, D., Richardson, P.M . and D eL ong, E.F. (2004) Reverse M ethanogenesis: Testing the Hypothesis with Environmental Genomics. Science 305, 1457-1462.

Hallam, S.J., Girguis, P.R., Preston, C.M ., Richardson, P.M . and DeL ong, E.F. (2003) Identification of methyl coenzyme $M$ reductase $A$ (mcrA) genes associated with methane-oxidizing archaea. Applied and Environmental M icrobiology 69, 5483-5491.

Hamamura, N., Page, C., Long, T., Semprini, L. and Arp, D.J. (1997) Chloroform cometabolism by butane-grown CF 8, Pseudomonas butanovora, and Mycobacterium vaccae JOB5 and methane-grown Methylosinus trichosporium OB 3b. A pplied and Environmental M icrobiology 63, 3607-3613.

Hamieh, A., Tayyar, R., Tabaja, H., EL Zein, S., Bou Khalil, P., Kara, N., Kanafani, Z. A., Kanj, N., B ou A kl, I., and Araj, G. (2018) Emergence of Mycobacterium simiae: A retrospective study from a tertiary care center in Lebanon. PloS O ne 13, e0195390.

Hanson, R.S. and Hanson, T.E. (1996) M ethanotrophic bacteria. M icrobiological Reviews 60, 439-471.

Haroon, M .F., Hu, S., Shi, Y ., I melfort, M ., K eller, J ., Hugenholtz, P., Y uan, Z. and Tyson, G.W. (2013) A naerobic oxidation of methane coupled to nitrate reduction in a novel archaeal lineage. Nature 500, 567-570.

Harvey, D. J. (1998) Picolinyl esters for the structural determination of fatty acids by GC/M S, M olecular B iotechnology 10, 251-260.

Hayes, J.M. (1993) Factors controlling $13 C$ contents of sedimentary organic compounds: principles and evidence. M arine Geology 113, 111-125.

Hayes, J.M. (2001) Fractionation of carbon and hydrogen isotopes in biosynthetic processes. Reviews in M ineralogy and Geochemistry 43, 225-277.

Hazeu, W. and de Bruyn, J.C. (1980) Ethane oxidation by methane-oxidizing bacteria. A ntonie $V$ an L eeuwenhoek 46, 443-455. 
Heap, B . (1989) M ycobacterium simiae as a cause of intra-abdominal disease: a case report. Tubercle 70, 217-221.

Heller, C. (2011) Fluid venting structures of terrestrial mud volcanoes (Italy) and marine cold seeps (Black Sea) - Organo-geochemical and biological approaches. PhD-thesis, Georg-A ugust-U niversität Göttingen, Germany.

Heller, C., Blumenberg, M., Hoppert, M., Taviani, M. and Reitner, J. (2012) Terrestrial mud volcanoes of the Salse di Nirano (Italy) as a window into deeply buried organic-rich shales of Plio-Pleistocene age. Sedimentary Geology 263, 202-209.

Hemingway, J. D., K usch, S., Walter, S. R. S., Polik, C. A., Elling, F. J. and Pearson, A. (2018) A novel method to measure the $C-13$ composition of intact bacteriohopanepolyols. Organic G eochemistry 123, 144-147.

Hennessee, C.T., Seo, J.-S., Alvarez, A.M. and Li, Q.X. (2009) Polycyclic aromatic hydrocarbon-degrading species isolated from Hawaiian soils: Mycobacterium crocinum sp. nov., Mycobacterium pallens sp. nov., Mycobacterium rutilum sp. nov., Mycobacterium rufum sp. nov. and Mycobacterium aromaticivorans sp. nov. International Journal of Systematic and Evolutionary M icrobiology 59, 378-387.

Hinrichs, K .-U., Hayes, J.M ., Sylva, S.P., B rewer, P.G . and D eL ong, E.F. (1999) $M$ ethane-consuming archaebacteria in marine sediments. N ature 398, 802-805.

Hinrichs, K.-U., Pancost, R.D., Summons, R.E., Sprott, G.D., Sylva, S.P., Sinninghe Damsté, J.S., and Hayes, J.M. (2000) Mass spectra of sn-2hydroxyarchaeol, a polar lipid biomarker for anaerobic methanotrophy. Geochemistry Geophysics Geosystems 1: 2000G C000042.

Hinrichs, K .-U and B oetius, A . (2002) The anaerobic oxidation of methane: new insights in microbial ecology and biogeochemistry. In, W efer, G., Billett, D., Hebbeln, D., J ørgensen, B., Schlüter, M., and van Weering, T. (eds), O cean margin systems. Springer-V erlag, Berlin, pp. 457-477.

Hirayama, H., Sunamura, M., Takai, K., N unoura. T., Noguchi, T., Oida, H., Furushima, Y., Y amamoto, H., O omori, T. and Horikoshi, K. (2007) Culturedependent and -independent characterization of microbial communities associated with a shallow submarine hydrothermal system occurring within a coral reef off Taketomi Island, Japan. A pplied and Environmental M icrobiology 73, 7642-7656.

Hirayama, H., Fuse, H., A be, M., M iyazaki, M., Nakamura, T., Nunoura, T., Furushima, Y., Y amamoto, H. and Takai, K. (2013) M ethylomarinum vadi gen. 
nov., sp nov., a methanotroph isolated from two distinct marine environments. International J ournal of Systematic and E volutionary M icrobioly 63, 1073-1082.

Hirayama, H., A be, M., M iyazaki, M ., N unoura, T ., Furushima, Y ., Y amamoto, H. and Takai, K. (2014) M ethylomarinovum caldicuralii gen. nov., sp. nov., a moderately thermophilic methanotroph isolated from a shallow submarine hydrothermal system, and proposal of the family M ethylothermaceae fam. nov. International J ournal of Systematic and E volutionary M icrobiology 64, 989-999.

Hoehler, T.M ., A Iperin, M .J., A lbert, D.B ., and M artens, C.S. (1994) Field and laboratory studies of methane oxidation in an anoxic marine sediment: Evidence for a methanogen-sulfate reducer consortium. Global Biogeochemical Cycles 8, 451-463.

Hoffmann, C., M ackenzie, A ., L ewis, C., M axwell, J., Oudin, J., D urand, B . and $V$ andenbroucke, M . (1984) A biological marker study of coals, shales and oils from the M ahakam D elta, Kalimantan, Indonesia. Chemical Geology 42, 1-23.

Hofreiter, M ., Serre, D., Poinar, H.N ., K uch, M . and Pääbo, S. (2001) A ncient DN A. Nature R eviews Genetics 2, 353-359.

Holmes, A.J., Roslev, P., McDonald, I.R., Iversen, N., Henriksen, K. and M urrell, J.C. (1999) Characterization of methanotrophic bacterial populations in soils showing atmospheric methane uptake. Applied and Environmental Microbiology 65, 3312-3318.

Holzheimer, M., Reijneveld, J. F., Ramnarine, A. K., M isiakos, G., Y oung, D. C., Ishikawa, E., Cheng, T.-Y ., Y amasaki, S., M oody, D. B., V an R hijn, I. and M innaard A. J. (2020) A symmetric Total Synthesis of Mycobacterial Diacyl Trehaloses Demonstrates a Role for Lipid Structure in Immunogenicity. ACS Chemical Biology 7, 1835-1841.

Hopmans, E.C., Schouten, S., Sinninghe Damsté, J.S., 2016. The effect of improved chromatography on GDGT-based palaeoproxies. Organic Geochemistry 93, 1-6.

Hopmans E.C., Smit N.T., Schwartz-N arbonne R., Sinninghe Damsté J.S. and Rush D. (2021) A nalysis of non-derivatized bacteriohopanepolyols using UHPLC-HRMS reveals great structural diversity in environmental lipid assemblages. Under review at Organic Geochemistry.

Hu, S., Zeng, R.J., Burow, L.C., Lant, P., Keller, J., and Y uan, Z. (2009) Enrichment of denitrifying anaerobic methane oxidizing microorganisms. Environmental M icrobiology Reports 1, 377-384.

Huang, Y., B ol, R., Harkness, D. D., Ineson, P., and Eglinton, G. (1996) Postglacial variations in distributions, ${ }^{13} \mathrm{C}$ and ${ }^{14} \mathrm{C}$ contents of aliphatic hydrocarbons 
and bulk organic matter in three types of British acid upland soils. Organic Geochemistry 24, 273-287.

Inglis, G.N., N aafs, B.D.A., Zheng, Y., M cClymont, E.L., Evershed, R.P. and Pancost, R.D., (2018) Distributions of geohopanoids in peat: I mplications for the use of hopanoid-based proxies in natural archives. Geochimica et Cosmochimica A cta 224, 249-261.

Inglis, G.N ., Naafs, B.D.A ., Zheng, Y ., Schellekens, J . and Pancost, R.D. (2019) $\delta 13 \mathrm{C}$ values of bacterial hopanoids and leaf waxes as tracers for methanotrophy in peatlands. Geochimica et Cosmochimica A cta 260, 244-256.

Innes, H.E., Bishop, A .N ., Head, I.M . and Farrimond, P. (1997) Preservation and diagenesis of hopanoids in recent lacustrine sediments of Priest Pot, England. Organic G eochemistry 26, 565-576.

Isaac, G., M cD onald, S. and A starita, G. (2011) Lipid separation using UPLC with charged surface hybrid technology. Waters Corporation, Milford, MA, USA, internal report.

Ivanov, M., Limonov, A. and Van Weering, T.C. (1996) Comparative characteristics of the Black Sea and Mediterranean Ridge mud volcanoes. M arine Geology 132, 253-271.

Jackson, M., Stadthagen, G., and Gicquel, B. (2007) Long-chain multiple methyl-branched fatty acid-containing lipids of Mycobacterium tuberculosis: biosynthesis, transport, regulation and biological activities, Tuberculosis 87, 7886.

Jahnke, L.L., Summons, R.E., Hope, J.M . and Des M arais, D.J. (1999) Carbon isotopic fractionation in lipids from methanotrophic bacteria II: The effects of physiology and environmental parameters on the biosynthesis and isotopic signatures of biomarkers. Geochimica et Cosmochimica A cta 63, 79-93.

J udd, A.G. (2004) Natural seabed gas seeps as sources of atmospheric methane. Environmental G eology 46, 988-996.

K annenberg, E.L . and Poralla, K . (1999) Hopanoid biosynthesis and function in bacteria. Naturwissenschaften 86, 168-176.

Kellermann, M.Y., W egener, G., Elvert, M., Y oshinaga, M.Y., Lin, Y.-S., Holler, T., M ollar, X .P., K nittel, K . and Hinrichs, K.-U . (2012) A utotrophy as a predominant mode of carbon fixation in anaerobic methane-oxidizing microbial communities. Proceedings of the National Academy of Sciences 109, 1932119326.

Kellermann, M.Y., Y oshinaga, M.Y., W egener, G., K rukenberg, V., and Hinrichs, K.-U. (2016) Tracing the production and fate of individual archaeal 
intact polar lipids using stable isotope probing. Organic Geochemistry 95, 1320.

K hadem, A.F., Pol, A., Wieczorek, A., M ohammadi, S.S., Francoijs, K.-J., Stunnenberg, H.G., Jetten, M.S.M. and Op den Camp, H.J.M. (2011) Autotrophic Methanotrophy in Verrucomicrobia: Methylacidiphilum fumariolicumSolV U ses the Calvin-B enson-Bassham Cycle for Carbon Dioxide Fixation. J ournal of Bacteriology 193, 4438-4446.

K harbush, J.J ., U galde, J.A ., H ogle, S.L., A llen, E.E. and A luwihare, L.I. (2013) Composite bacterial hopanoids and their microbial producers across oxygen gradients in the water column of the California Current. Applied and Environmental M icrobiology 79, 7491-7501.

Killops, S.D. and Killops, V.J. (2013) Introduction to organic geochemistry. John Wiley \& Sons.

Kinnaman, F.S., V alentine, D.L. and Tyler, S.C. (2007) Carbon and hydrogen isotope fractionation associated with the aerobic microbial oxidation of methane, ethane, propane and butane. Geochimica et Cosmochimica A cta 71, 271-283.

Kip, N., van Winden, J.F., Pan, Y., B odrossy, L., Reichart, G.-J., Smolders, A.J.P., J etten, M .S.M ., Sinninghe Damsté, J.S. and Op den Camp, H.J .M . (2010) Global prevalence of methane oxidation by symbiotic bacteria in peat-moss ecosystems. N ature G eoscience 3, 617-621.

Kirschke, S., B ousquet, P., Ciais, P., Saunois, M., Canadell, J.G., Dlugokencky, E.J., B ergamaschi, P., B ergmann, D., Blake, D.R. and B ruhwiler, L. (2013) Three decades of global methane sources and sinks. N ature Geoscience 6, 813823.

Kits, K.D., K lotz, M.G. and Stein, L.Y . (2015) M ethane oxidation coupled to nitrate reduction under hypoxia by the Gammaproteobacterium M ethylomonas denitrificans, sp. nov. type strain FJ G1. Environmental M icrobiology 17, 32193232.

Knief, C. (2015) Diversity and Habitat Preferences of Cultivated and Uncultivated A erobic M ethanotrophic Bacteria Evaluated Based on pmoA as M olecular M arker. Frontiers in M icrobiology 6.

K nittel, K. and B oetius, A . (2009) A naerobic Oxidation of M ethane: Progress with an Unknown Process. A nnual Review of M icrobiology 63, 311-334.

Koga, Y . and M orii, H. (2007) B iosynthesis of ether-type polar lipids in A rchaea and evolutionary considerations. M icrobiology and M olecular Biology Reviews 71, 97-120. 
Koga, Y ., M orii, H., A kagawa-M atsushita, M ., and Ohga, M . (1998) Correlation of polar lipid composition with 16S rRNA phylogeny in methanogens. Further analysis of lipid component parts. B iosciences Biotechnology Biochemistry 62, 230-236.

Koga, Y ., Nishihara, M ., M orii, H., and A kagawa-M atsushita, M . (1993) Ether polar lipids of methanogenic bacteria: structures, comparative aspects, and biosyntheses. M icrobiology Reviews 57, 164-182.

Kolaczkowska, E., Slougui, N.-E., Watt, D.S., M aruca, R.E. and M oldowan, J.M. (1990) Thermodynamic stability of various alkylated, dealkylated and rearranged 17 $\alpha$-and 17 $\beta$-hopane isomers using molecular mechanics calculations. Organic Geochemistry 16, 1033-1038.

Kool, D.M., Talbot, H.M., Rush, D., Ettwig, K. and Sinninghe Damsté, J.S. (2014) Rare bacteriohopanepolyols as markers for an autotrophic, intra-aerobic methanotroph. Geochimica et Cosmochimica A cta 136, 114-125.

Kool, D.M., Zhu, B ., Rijpstra, W.I.C., J etten, M .S., Ettwig, K.F. and Sinninghe Damsté, J.S. (2012) Rare branched fatty acids characterize the lipid composition of the intra-aerobic methane oxidizer "Candidatus M ethylomirabilis oxyfera". A pplied and Environmental M icrobiology 78, 8650-8656.

Kopf, A., Klaeschen, D. and M ascle, J. (2001) Extreme efficiency of mud volcanism in dewatering accretionary prisms. Earth and Planetary Science Letters 189, 295-313.

Kopf, A . (2003) Global methane emission through mud volcanoes and its past and present impact on the E arth's climate. International J ournal of E arth Sciences 92, 806-816.

K rüger, M ., M eyerdierks, A ., Glöckner, F.O., A mann, R., W iddel, F., K ube, M ., Reinhardt, R., Kahnt, J., Böcher, R., Thauer, R.K. and Shima, S. (2003) A conspicuous nickel protein in microbial mats that oxidize methane anaerobically. Nature 426, 878-881.

Kuever, J ., Könneke, M ., Galushko, A . and D rzyzga, 0. (2001) Reclassification of Desulfobacterium phenolicum as Desulfobacula phenolica comb. nov. and description of strain SaxT as Desulfotignum balticum gen. nov., sp. nov. International J ournal of Systematic and E volutionary M icrobiology 51, 171-177.

Kusch, S., W alter, S., Hemingway, S.R. and Pearson, J.D.A . (2018) Improved chromatography reveals multiple new bacteriohopanepolyol isomers in marine sediments. Organic G eochemistry 124, 12-21.

Kusch, S., Sepúlveda, J. and Wakeham, S.G. (2019) Origin of Sedimentary B H Ps A long a M ississippi River-Gulf of M exico Export T ransect: Insights From Spatial and Density Distributions. Frontiers in M arine Science 6. 
Kweon, O., Kim, S.--., Blom, J., Kim, S.-K., K im, B.-S., Baek, D.-H., Park, S. I., Sutherland, J. B., and Cerniglia, C. E. (2015) Comparative functional pangenome analyses to build connections between genomic dynamics and phenotypic evolution in polycyclic aromatic hydrocarbon metabolism in the genus M ycobacterium. B M C Evolutionary Biology 15, 21.

Lamb, D. C., K elly, D. E., M anning, N. J., and Kelly, S. L. (1998) A sterol biosynthetic pathway in M ycobacterium. FEBS L etters 437, 142-144.

Lee, D.H., K im, J.H., L ee, Y .M ., Stadnitskaia, A ., J in, Y .K ., Niemann, H., K im, Y.G. and Shin, K.H. (2018) Biogeochemical evidence of anaerobic methane oxidation on active submarine mud volcanoes on the continental slope of the Canadian B eaufort Sea. Biogeosciences 15, 7419-7433.

Lee, A.K., Banta, A.B., W ei, J.H., Kiemle, D.J., Feng, J., Giner, J.-L. and W elander, P.V . (2018) C-4 sterol demethylation enzymes distinguish bacterial and eukaryotic sterol synthesis. Proceedings of the National Academy of Sciences 115, 5884-5889.

Lee, O.Y., W u, H.H., Donoghue, H.D., Spigelman, M., Greenblatt, C.L., Bull, I.D., Rothschild, B.M., M artin, L.D., M innikin, D.E., and Besra, G.S. (2012) $M$ ycobacterium tuberculosis complex lipid virulence factors preserved in the 17,000-year-old skeleton of an extinct bison, Bison antiquus. PloS One 7, e41923.

Lee, S. and Poulter, C.D. (2008) Cloning, solubilization, and characterization of squalene synthase from Thermosynechococcus elongatus BP-1. Journal of bacteriology 190, 3808-3816.

Lévy-Frébault, V ., Pangon, B ., B uré, A ., K atlama, C., M arche, C., and David, $H$. (1987) M ycobacterium simiae and M ycobacterium avium- $M$. intracellulare mixed infection in acquired immune deficiency syndrome. Journal of Clinical M icrobiology 25, 154-157.

Lickorish, W.H., Grasso, M., Butler, R.W., A rgnani, A. and M aniscalco, R. (1999) Structural styles and regional tectonic setting of the "Gela Nappe" and frontal part of the Maghrebian thrust belt in Sicily. Tectonics 18, 655-668.

Lipp, J.S., M orono, Y., Inagaki, F., and Hinrichs, K.-U. (2008) Significant contribution of A rchaea to extant biomass in marine subsurface sediments. National A cademy Science L etters 454, 991-994.

Liu, X.-L., Lipp, J.S., Simpson, J.H., Lin, Y .-S., Summons, R.E., and Hinrichs, K.-U. (2012) M ono- and dihydroxyl glycerol dibiphytanyl glycerol tetraethers in marine sediments: Identification of both core and intact polar lipid forms. Geochimica et Cosmochimica A cta 89, 102-115. 
Liu, X., Leider, A., Gillespie, A., Gröger, J., V ersteegh, G.J.M., and Hinrichs, K.-U. (2010) Organic Geochemistry Identification of polar lipid precursors of the ubiqui tous branched GDG T orphan lipids in a peat bog in N orthern G ermany. Organic G eochemistry 41, 653-660.

Liu, Y. and Whitman, W.B. (2008) Metabolic, phylogenetic, and ecological diversity of the methanogenic archaea. A nnals of the N ew Y ork A cademy of Sciences 1125, 171-189.

Llopiz, P., N eunlist, S. and Rohmer, M . (1992) Prokaryotic triterpenoids: 0- $\alpha$ D-glucuronopyranosyl bacteriohopanetetrol, a novel hopanoid from the bacterium R hodospirillum rubrum. Biochemical Journal 287, 159-161.

López-Rodríguez, C., Stadnitskaia, A., De Lange, G.J., M artínez-Ruíz, F., Comas, M., Sinninghe Damsté, J.S. (2014) Origin of lipid biomarkers in mud volcanoes from the Alboran Sea, western Mediterranean. Biogeosciences 11, 3187-3204.

Lough, A . (1975) The chemistry and biochemistry of phytanic, pristanic and related acids. Progress in the Chemistry of Fats and other Lipids 14, 1-48.

Loulergue, L., Schilt, A., Spahni, R., M asson-Delmotte, V., Blunier, T., Lemieux, B., B arnola, J.-M., Raynaud, D., Stocker, T.F. and Chappellaz, J. (2008) O rbital and millennial-scale features of atmospheric $\mathrm{CH}_{4}$ over the past 800,000 years. Nature 453, 383-386.

Lovley, D.R., Giovannoni, S.J ., W hite, D.C., Champine, J .E., Phillips, E., Gorby, Y.A., Goodwin, S. (1993) Geobacter metallireducens gen. nov. sp. nov., a microorganism capable of coupling the complete oxidation of organic compounds to the reduction of iron and other metals. A rchives of M icrobiology 159, 336-344.

M acF arling M eure, C., Etheridge, D., Trudinger, C., Steele, P., L angenfelds, R., van $\mathrm{Ommen}, \mathrm{T}$., Smith, A and Elkins, J. (2006) Law Dome $\mathrm{CO}_{2}, \mathrm{CH}_{4}$ and $\mathrm{N}_{2} \mathrm{O}$ ice core records extended to 2000 years BP. Geophysical R esearch L etters 33.

Madigan, M.T., Martinko, J.M. and Parker, J. (1997) Brock biology of microorganisms. $8^{\text {th }}$ Edition, Prentice Hall International, Inc., New Y ork.

Madonia, P., Grassa, F., Cangemi, M. and Musumeci, C. (2011) Geomorphological and geochemical characterization of the 11 A ugust 2008 mud volcano eruption at S. B arbara village (Sicily, I taly) and its possible relationship with seismic activity. N atural H azards Earth System Sciences 11, 1545-1557.

M alott, R.J., Wu, C.-H., Lee, T.D., Hird, T.J., Dalleska, N.F., Zlosnik, J.E.A., Newman, D.K. and Speert, D.P. (2014) Fosmidomycin decreases membrane 
hopanoids and potentiates the effects of colistin on Burkholderia multivorans clinical isolates. A ntimicrobial A gents and Chemotherapy 58, 5211-5219.

Martin, K.E., Ozsvar, J. and Coleman, N.V. (2014) SmoXYB1C1Z of M ycobacterium sp. strain NBB 4: a soluble methane monooxygenase (sM M O)like enzyme, active on $\mathrm{C} 2$ to $\mathrm{C} 4$ alkanes and alkenes. A pplied and E nvironmental Microbiology 80, 5801-5806.

M atsumi, R., A tomi, H., D riessen, A .J .M ., and van der Oost, J . (2011) I soprenoid biosynthesis in archaea - biochemical and evolutionary implications. Research in M icrobiology 162, 39-52.

Mattavelli, L. and Novelli, L. (1990) Geochemistry and habitat of the oils in Italy. A APG Bulletin 74, 1623-1639.

M axfield, P.J., Hornibrook, E.R.C. and Evershed, R.P. (2006) Estimating HighAffinity Methanotrophic Bacterial Biomass, Growth, and Turnover in Soil by Phospholipid Fatty Acid ${ }^{13} \mathrm{C}$ Labeling. Applied and Environmental Microbiology 72, 3901-3907.

M cA nulty, M .J., Poosarla, V .G., K im, K .-Y ., J asso-Chávez, R ., L ogan, B .E., and Wood, T.K. (2017) Electricity from methane by reversing methanogenesis. Nature Communications 8, 15419.

M cDonald, I.R., Bodrossy, L., Chen, Y. and Murrell, J.C. (2008) M olecular Ecology Techniques for the Study of A erobic Methanotrophs. A pplied and Environmental M icrobiology 74, 1305-1315.

M cK irdy, D., A ldridge, A . and Y pma, P. (1983) A geochemical comparison of some crude oils from pre-Ordovician carbonate rocks. Advances in Organic Geochemistry 1981. W iley Chichester, 99-107.

McKirdy, D.M., Kantsler, A.J., Emmett, J.K. and A ldridge, A.K. (1984) Hydrocarbon genesis and organic facies in Cambrian carbonates of the Eastern Officer Basin, South A ustralia. AA PG Special V olumes 30, 13.

M ello, M.R., Gaglianone, P.C., Brassell, S.C. and Maxwell, J.R. (1988a) Geochemical and biological marker assessment of depositional environments using B razilian offshore oils. M arine and Petroleum G eology 5, 205-223.

M ello, M.R., Telnaes, N., Gaglianone, P.C., Chicarelli, M .I., Brassell, S.C. and Maxwell, J.R. (1988b) Organic geochemical characterisation of depositional palaeoenvironments of source rocks and oils in Brazilian marginal basins, in: Mattavelli, L., Novelli, L. (Eds.), Organic Geochemistry in Petroleum Exploration. Pergamon, A msterdam, pp. 31-45.

Menzel, P., Ng, K.L., and Krogh, A. (2016) Fast and sensitive taxonomic classification for metagenomics with $\mathrm{K}$ aiju. Nature Communications 7, 1-9. 
Milkov A.V. (2005) Global Distribution of Mud Volcanoes and Their Significance in Petroleum Exploration as a Source of $M$ ethane in the $A$ tmosphere and Hydrosphere and as a Geohazard. In: M artinelli G., Panahi B. (eds) M ud Volcanoes, Geodynamics and Seismicity. NATO Science Series (Series IV: Earth and Environmental Series), vol 51. Springer, Dordrecht.

M iller, C., Child, R., Hughes, J., Benscai, M ., Der, J., Sims, R ., and A nderson, A. (2007) Diversity of soil mycobacterium isolates from three sites that degrade polycyclic aromatic hydrocarbons. Journal of A pplied M icrobiology 102, 16121624.

M innikin, D., Dobson, G., Goodfellow, M., Magnusson, M., and Ridell, M. (1985) Distribution of some mycobacterial waxes based on the phthiocerol family. M icrobiology 131, 1375-1381.

M innikin, D., Besra, G., B olton, R., Datta, A., M allet, A ., Sharif, A ., Stanford, J., Ridell, M . and M agnusson, M. (1993a) Identification of the leprosy bacillus and related mycobacteria by analysis of mycocerosate profiles, A nnales-Societe B elge De M edecine Tropicale. Institute of Tropical M edicine, pp. 25-25.

M innikin, D., Bolton, R., Hartmann, S., Besra, G., J enkins, P., M allet, A., Wilkins, E., Lawson, A . and Ridell, M . (1993b) A $n$ integrated procedure for the direct detection of characteristic lipids in tuberculous patients, A nnales-Societe B elge De M edecine Tropicale. Institute of Tropical M edicine, pp. 13-13.

M innikin, D. E., Kremer, L., Dover, L. G., and B esra, G. S. (2002) The methylbranched fortifications of M ycobacterium tuberculosis. Chemistry \& Biology 9 , 545-553.

Moldowan, J.M. and M CCaffrey, M.A . (1995) A novel microbial hydrocarbon degradation pathway reveal ed by hopane demethylation in a petrol eum reservoir. Geochimica et Cosmochimica A cta 59, 1891-1894.

Moldowan, J.M., Sundararaman, P. and Schoell, M. (1986) Sensitivity of biomarker properties to depositional environment and/or source input in the Lower Toarcian of SW -Germany. Organic G eochemistry 10, 915-926.

M oldowan, J.M ., Seifert, W .K ., A rnold, E. and Clardy, J . (1984) Structure proof and significance of stereoisomeric 28, 30-bisnorhopanes in petroleum and petroleum source rocks. G eochimica et Cosmochimica A cta 48, 1651-1661.

Monaco, C. and Tortorici, L. (1996) Clay diapirs in Neogene-Quaternary sediments of central Sicily: evidence for accretionary processes. Journal of Structural Geology 18, 1265-1269.

M oore, E.K., Hopmans, E.C., Rijpstra, W.I.C., Villanueva, L. and Sinninghe Damsté, J.S. (2016) Elucidation and identification of amino acid containing 
membrane lipids using liquid chromatography/high-resolution mass spectrometry. Rapid Communications in M ass Spectrometry 30, 739-750.

M urrell, J.C. and Dalton, H. (1983) Purification and properties of glutamine synthetase from Methylococcus capsulatus (Bath). M icrobiology 129, 11871196.

M yhre, G ., Shindell, D., B réon, F.-M ., Collins, W ., Fuglestvedt, J., Huang, J ., et al. (2014) A nthropogenic and $N$ atural Radiative Forcing, in: Intergovernmental Panel on Climate, C. (E d.), Climate Change 2013 - The Physical Science Basis: Working Group I Contribution to the Fifth Assessment Report of the Intergovernmental Panel on Climate Change. Cambridge University Press, Cambridge, pp. 659-740.

Nauhaus, K., A lbrecht, M., Elvert, M., B oetius, A., and Widdel, F. (2007) In vitro cell growth of marine archaeal-bacterial consortia during anaerobic oxidation of methane with sulfate. Environmental M icrobiology 9, 187-196.

NCBI Resource Coordinators (2016) Database resources of the National Center for Biotechnology Information. N ucleic A cids Research 44, 7-19.

Nechaeva, N. (1949) Two species of methane oxidizing mycobacteria. Mikrobiologiya 18, 310-317 (English Translation: Associated Technical Service, E ast Orange, $\mathrm{N}$ J).

Nei, M ., and K umar, S. (2000) M olecular evolution and phylogenetics, Oxford University Press, ISB N : 0-19-513584-9.

Neunlist, S., Holst, O. and Rohmer, M. (1985) Prokaryotic triterpenoids: The hopanoids of the purple non-sulphur bacterium Rhodomicrobium vannielii: an aminotriol and its aminoacyl derivatives, N-tryptophanyl and N-ornithinyl aminotriol. European J ournal of B iochemistry 147, 561-568.

Neunlist, S. and Rohmer, M . (1985) Novel hopanoids from the methylotrophic bacteria Methylococcus capsulatus and Methylomonas methanica. (22S)-35aminobacteriohopane-30,31,32,33,34-pentol and (22S)-35-amino-3 $\beta$ methylbacteriohopane-30,31,32,33,34-pentol. Biochemical J ournal 231, 635639.

Nichols, P.D. and F ranzmann, P.D. (1992) U nsaturated diether phospholipids in the Antarctic methanogen Methanococcoides burtonii. FEMS Microbiology Letters 98, 205-208.

Nichols, P.D., Shaw, P.M., Mancuso, C.A., and Franzmann, P.D. (1993) A nalysis of archaeal phospholipid-derived di- and tetraether lipids by high temperature capillary gas chromatography. J ournal of M icrobiological M ethods 18, 1-9. 
Nichols, P.D., Guckert, J.B., and White, D.C. (1986) Determination of monosaturated fatty acid double-bond position and geometry for microbial monocultures and complex consortia by capillary GC-MS of their dimethyl disulphide adducts. Journal of M icrobiological M ethods 5, 49-55.

Nicoara, S.C., M innikin, D.E., Lee, O.C., O'Sullivan, D.M., M cNerney, R., Pillinger, C.T., Wright, I.P., and Morgan, G.H. (2013) Development and optimization of a gas chromatography/mass spectrometry method for the analysis of thermochemolytic degradation products of phthiocerol dimycocerosate waxes found in Mycobacterium tuberculosis. Rapid Communications in M ass Spectrometry, 27, 2374-2382.

Niemann, H. and Elvert, M . (2008) Diagnostic lipid biomarker and stable carbon isotope signatures of microbial communities mediating the anaerobic oxidation of methane with sulphate. Organic Geochemistry 39, 1668-1677.

Niemann, H., Duarte, J., Hensen, C., Omoregie, E., M agal haes, V., Elvert, M., Pinheiro, L., Kopf, A. and B oetius, A . (2006a) M icrobial methane turnover at mud volcanoes of the Gulf of Cadiz. Geochimica et Cosmochimica Acta 70, 5336- 5355.

Niemann, H., Lösekann, T., De B eer, D., Elvert, M., Nadalig, T., K nittel, K., A mann, R., Sauter, E.J., Schlüter, M . and K lages, M. (2006b) Novel microbial communities of the $\mathrm{H}$ aakon M osby mud volcano and their role as a methane sink. Nature 443, 854-858.

Nisbet, E.G., Dlugokencky, E.J . and B ousquet, P. (2014) M ethane on the RiseA gain. Science 343, 493-495.

Nishihara, M., M orii, H., and Koga, Y . (1989) Heptads of polar ether lipids of an archaebacterium, Methanobacterium thermoautotrophicum: structure and biosynthetic relationship. Biochemistry 28, 95-102.

Nishihara, M., M orii, H., M atsuno, K., Ohga, M., Stetter, O., and Koga, $Y$. (2002) Structural analysis by reductive cleavage with $\mathrm{LiAlH} 4$ of an allyl ether choline-phospholipid, archaetidylcholine, from the hyperthermophilic methanoarchaeon M ethanopyrus kandleri. A rchaea 1, 123-131.

Noble, R., A lexander, R. and K agi, R.I. (1985) The occurrence of bisnorhopane, trisnorhopane and 25-norhopanes as free hydrocarbons in some Australian shales. Organic Geochemistry 8, 171-176.

O chs, D., Tappe, C.H., G aertner, P., K ellner, R. and Poralla, K . (1990) Properties of purified squalene-hopene cyclase from Bacillus acidocaldarius. European journal of biochemistry 194, 75-80. 
O'C onnor, F.M ., B oucher, O., Gedney, N., J ones, C.D., Folberth, G.A ., Coppell, R., Friedlingstein, P., Collins, W .J ., Chappellaz, J., Ridley, J. and J ohnson, C.E. (2010) Possible role of wetlands, permafrost, and methane hydrates in the methane cycle under future climate change: $A$ review. Reviews of Geophysics $48,4$.

Ogniben, L. (1954) Le A rgille B recciate" Siciliane: con i rilievi di dettaglio di Grottacalda (Valguarnera, Enna), Passarello (Licata, Agrigento), Zubbi (S. Cataldo, Caltanissetta). Società Cooperativa Tipografica.

Ohtake, K., Saito, N., Shibuya, S., K obayashi, W ., A mano, R., Hirai, T., Sasaki, S., Nakano, C. and Hoshino, T. (2014) Biochemical characterization of the water-soluble squalene synthase from Methylococcus capsulatus and the functional analyses of its two DXXD (E) D motifs and the highly conserved aromatic amino acid residues. The FEBS journal 281, 5479-5497.

Op den Camp, H.J ., Islam, T., Stott, M .B., Harhangi, H.R., Hynes, A ., Schouten, S., J etten, M.S., Birkeland, N.K., Pol, A. and Dunfield, P.F. (2009) Environmental, genomic and taxonomic perspectives on methanotrophic Verrucomicrobia. Environmental M icrobiology Reports 1, 293-306.

Orphan, V., Hinrichs, K.-U., Ussler, W., Paull, C.K., Taylor, L., Sylva, S.P., Hayes, J.M. and DeLong, E.F. (2001) Comparative analysis of methaneoxidizing archaea and sulfate-reducing bacteria in anoxic marine sediments. A pplied and Environmental M icrobiology 67, 1922-1934.

Orphan, V.J., House, C.H., Hinrichs, K.-U., M cK eegan, K.D., and D eL ong, E.F. (2002) M ultiple archaeal groups mediate methane oxidation in anoxic cold seep sediments. Proceedings of the National A cademy of Sciences USA 99, 76637668.

Ourisson, G. and Albrecht, P. (1992) Hopanoids. 1. Geohopanoids: the most abundant natural products on Earth? Accounts of Chemical Research 25, 398402.

Ourisson, G., Albrecht, P. and Rohmer, M. (1979) The hopanoids: palaeochemistry and biochemistry of a group of natural products. Pure and A pplied Chemistry 51, 709-729.

Padilla, C.C., Bristow, L.A., Sarode, N., Garcia-Robledo, E., Ramírez, E.G., Benson, C.R ., B ourbonnais, A ., A ltabet, M .A., Girguis, P.R. and Thamdrup, B. (2016) N C10 bacteria in marine oxygen minimum zones. The ISM E J ournal 10, 2067.

Pagani, M ., Caldeira, K ., A rcher, D. and Zachos, J.C. (2006) An ancient carbon mystery. Science 314, 1556. 
Pan, J.-J ., Solbiati, J .O ., Ramamoorthy, G., Hillerich, B.S., Seidel, R.D., Cronan, J.E., A Imo, S.C. and Poulter, C.D. (2015) B iosynthesis of squalene from farnesyl diphosphate in bacteria: three steps catalyzed by three enzymes. ACS central science 1, 77-82.

Pancost, R.D., Sinninghe Damsté, J.S., de Lint, S., van der M aarel, M.J. and Gottschal, J.C. (2000) Biomarker evidence for widespread anaerobic methane oxidation in M editerranean sediments by a consortium of methanogenic archaea and bacteria. A pplied and Environmental M icrobiology 66, 1126-1132.

Pancost, R.D., van Geel, B ., B aas, M . and Sinninghe Damsté, J.S. (2000b) $\delta 13 C$ values and radiocarbon dates of microbial biomarkers as tracers for carbon recycling in peat deposits. Geology 28, 663-666.

Pancost, R.D., B ouloubassi, I., A loisi, G. and Sinninghe Damsté, J.S. (2001a) Three series of non-isoprenoidal dialkyl glycerol diethers in cold-seep carbonate crusts. Organic Geochemistry 32, 695-707.

Pancost, R.D., Hopmans, E.C. and Sinninghe Damsté, J.S. (2001b) A rchaeal lipids in Mediterranean cold seeps: molecular proxies for anaerobic methane oxidation. Geochimica et Cosmochimica A cta 65, 1611-1627.

Pancost, R.D., Sinninghe Damsté, J.S. (2003) Carbon isotopic compositions of prokaryotic lipids as tracers of carbon cycling in diverse settings. Chemical Geology 195, 29-58.

Park, S.W., Park, S.T., Lee, J.E. and Kim, Y.M. (2008) Pseudonocardia carboxydivorans sp. nov., a carbon monoxide-oxidizing actinomycete, and an emended description of the genus Pseudonocardia. International Journal of Systematic and Evolutionary M icrobiology 58, 2475-2478.

Park, H., Lee, H., Ro, Y . T., and Kim, Y. M . (2010) Identification and functional characterization of a gene for the methanol: $\mathrm{N}$, N'-dimethyl-4-nitrosoaniline oxidoreductase from M ycobacterium sp. strain JC1 (DSM 3803). M icrobiology 156, 463-471.

Park, S.W., Hwang, E.H., Park, H., K im, J.A ., Heo, J., Lee, K.H., Song, T., Kim, E., R o, Y .T and K im, S.W . (2003) Growth of mycobacteria on carbon monoxide and methanol. Journal of B acteriology 185, 142-147.

Parkes, J. (1999) Cracking anaerobic bacteria. Nature 401, 217-218.

Pearson, A. and Rusch, D.B. (2009) Distribution of microbial terpenoid lipid cyclases in the global ocean metagenome. The ISM E J ournal 3, 352-363. 
Peisler, B . and R ohmer, M . (1992) Prokaryotic triterpenoids of the hopane series. bacteriohopanetetrols of new side-chain configuration from Acetobacter species. J ournal of Chemical Research - Part S 9, 289-299.

Peters, K .E. and M oldowan, J.M . (1991) Effects of source, thermal maturity, and biodegradation on the distribution and isomerization of homohopanes in petroleum. Organic Geochemistry 17, 47-61.

Peters, K.E. and M oldowan, J.M . (1993) The B iomarker Guide, Prentice Hall, Englewood Cliffs, NJ, USA.

Peters, K.E., Peters, K.E., Walters, C.C. and Moldowan, J. (2005) The Biomarker Guide. Cambridge University Press.

Peterse, F., Hopmans, E.C., Schouten, S., M ets, A., Rijpstra, W.I.C., and Sinninghe Damsté, J.S. (2011) Identification and distribution of intact polar branched tetraether lipids in peat and soil. Organic Geochemistry 42, 1007-1015.

Peterse, F., Nicol, G. W., Schouten, S., and Sinninghe Damsté, J. S. (2010) Influence of soil pH on the abundance and distribution of core and intact polar lipid-derived branched GDGTs in soil. Organic Geochemistry 41, 1171-1175.

Piepoli, P. (1931) Studio geologico della zona Bivona-Cattolica Eraclea (A grigento) con riferimento alle manifestazioni di idrocarburi, Riv. It. del Petrolio, n.7.

Pieri, M. and Mattavelli, L. (1986) Geologic framework of Italian petroleum resources. A APG Bulletin 70, 103-130.

Podust, L. M., Poulos, T. L., and Waterman, M. R. (2001) Crystal structure of cytochrome P450 14a-sterol demethylase (CYP51) from Mycobacterium tuberculosis in complex with azole inhibitors. Proceedings of the $\mathrm{National}$ A cademy of Sciences 98, 3068-3073.

Pol, A., Heijmans, K., Harhangi, H.R., Tedesco, D., Jetten, M.S.M . and Op den Camp, H.J.M. (2007) Methanotrophy below pH 1 by a new Verrucomicrobia species. N ature $450,874-878$.

Raghoebarsing, A.A., Pol, A., V an de Pas-Schoonen, K.T., Smolders, A.J., Ettwig, K.F., Rijpstra, W.I.C., Schouten, S., Sinninghe Damsté, J.S., Op den Camp, H.J. and Jetten, M.S. (2006) A microbial consortium couples anaerobic methane oxidation to denitrification. N ature 440, 918.

Ran-Ressler, R. R., Lawrence, P., and Brenna, J. T. (2012) Structural characterization of saturated branched chain fatty acid methyl esters by collisional dissociation of molecular ions generated by electron ionization. J ournal of Lipid Research 53, 195-203. 
Rasigraf, O., K ool, D.M ., J etten, M .S., Sinninghe D amsté, J.S. and Ettwig, K .F. (2014) Autotrophic carbon dioxide fixation via the Calvin-Benson-Bassham cycle by the denitrifying methanotroph M ethylomirabilis oxyfera. A pplied and Environmental M icrobiology, AEM . 04199-04113.

Redman, J. E., Shaw, M . J ., M allet, A . I., Santos, A . L ., R oberts, C. A ., Gernaey, A. M., and Minnikin, D. E. (2009) Mycocerosic acid biomarkers for the diagnosis of tuberculosis in the Coimbra Skeletal Collection. Tuberculosis 89, 267-277.

Redmond, M.C., V alentine, D.L. and Sessions, A.L. (2010) Identification of novel methane-, ethane-, and propane-oxidizing bacteria at marine hydrocarbon seeps by stable isotope probing. A pplied and Environmental M icrobiology 76, 6412-6422.

Reeburgh, W.S. (1996) "Soft spots" in the global methane budget, M icrobial growth on $\mathrm{C} 1$ compounds. Springer, pp. 334-342.

Reeburgh, W.S. (2007) Oceanic methane biogeochemistry. Chemical Reviews 107, 486-513.

Reed, W.M. and Dugan, P.R. (1987) Isolation and characterization of the facultative methylotroph M ycobacterium ID-Y . M icrobiology 133, 1389-1395.

Rethemeyer, J., Schubotz, F., Talbot, H.M., Cooke, M.P., Hinrichs, K.-U., M ollenhauer, G., 2010. Distribution of polar membrane lipids in permafrost soils and sediments of a small high A rctic catchment. Organic Geochemistry 41, 1130- 1145.

Rezanka, T., Siristova, L., M elzoch, K. and Sigler, K. (2010) Hopanoids in bacteria and cyanobacteria-their role in cellular biochemistry and physiology, analysis and occurrence. M ini-Reviews in Organic Chemistry 7, 300-313.

Řezanka, T., and Sigler, K. (2009) Odd-numbered very-long-chain fatty acids from the microbial, animal and plant kingdoms. Progress in Lipid Research 48, 206-238.

Ricci, J.N., Coleman, M.L., Welander, P.V ., Sessions, A.L., Summons, R.E., Spear, J.R. and Newman, D.K. (2014) Diverse capacity for 2-methylhopanoid production correlates with a specific ecological niche. The ISM E J ournal 8, 675684.

Ries-K autt, M ., and Albrecht, P. (1989) Hopane-derived triterpenoids in soils. Chemical Geology 76, 143-151.

Rohmer, M. and Ourisson, G. (1976) Structure des bactériohopanetétrols d'A cetobacter xylinum. Tetrahedron L etters 17, 3633-3636. 
Rohmer, M., Dastillung, M. and Ourisson, G. (1980) Hopanoids from C30 to C35 in Recent muds - chemical markers for bacterial activity. Naturwissenschaften 67, 456-458.

Rohmer, M ., B ouvier-Nave, P. and Ourisson, G . (1984) Distribution of hopanoid triterpenes in prokaryotes. M icrobiology 130, 1137-1150.

Rohmer, M and Ourisson, G. (1986) Unsaturated bacteriohopanepolyols from Acetobacter aceti ssp. Xylinum. J ournal of Chemical Research. Synopses 10, 356 $-357$.

Rohmer, M . (1993) The biosynthesis of triterpenoids of the hopane series in the Eubacteria: A mine of new enzyme reactions. Pure and Applied Chemistry 65, 1293-1298.

Rossel, P.E., Lipp, J.S., Fredricks, H.F., A rnds, J., Boetius, A ., Elvert, M ., and Hinrichs, K.U. (2008) Intact polar lipids of anaerobic methanotrophic archaea and associated bacteria. Organic Geochemistry 39, 992-999.

Rossel, P.E., Elvert, M., Ramette, A., B oetius, A . and Hinrichs, K.-U. (2011) Factors controlling the distribution of anaerobic methanotrophic communities in marine environments: evidence from intact polar membrane lipids. Geochimica et Cosmochimica A cta 75, 164-184.

Ruddiman, W.F. (2003) The A nthropogenic Greenhouse Era Began Thousands of $Y$ ears A go. Climatic Change 61, 261-293.

Ruetters, H., Sass, H., Cypionka, H., and Rullkoetter, J. (2002) Phospholipid analysis as a tool to study complex microbial communities in marine sediments. J ournal of M icrobiological M ethods 48, 149-160.

Rullkötter, J., V onderdick, H. and Welte, D. (1982) Organic petrography and extractable hydrocarbons of sediment from the Gulf of California, Deep-Sea Drilling Project L eg-64. Initial reports of the deep sea drilling project 64 , 837853.

Rullkötter, J., Spiro, B. and Nissenbaum, A. (1985) Biological marker characteristics of oils and asphalts from carbonate source rocks in a rapidly subsiding graben, Dead Sea, Israel. Geochimica et Cosmochimica Acta 49, 1357-1370.

Rush, S., Sinninghe Damsté, J.S., Poulton, S.W., Thamdrup, B., Garside, A .L., González, J.A ., Schouten, S., J etten, M .S.M . and Tal bot, H.M . (2014) A naerobic ammonium-oxidising bacteria: A biological source of the bacteriohopanetetrol stereoisomer in marine sediments. G eochimica et Cosmochimica A cta 140, 5064. 
Rush, D., Osborne, K .A ., B irgel, D., K appler, A ., Hirayama, H., Peckmann, J., Poulton, S.W., Nickel, J.C., M angelsdorf, K., Kalyuzhnaya, M. Sidgwick, F.R. and Talbot, H.M. (2016) The bacteriohopanepolyol inventory of novel aerobic methane oxidizing bacteria reveals new biomarker signatures of aerobic methanothropy in marine systems. PL OS ONE 11, e0165635.

Rush, D., Talbot, H.M., van der M eer, M.T.J ., Hopmans, E.C., Douglas, B. and Sinninghe Damsté, J.S. (2019) Biomarker evidence for the occurrence of anaerobic ammonium oxidation in the eastern Mediterranean Sea during Quaternary and Pliocene sapropel formation. Biogeosciences 16, 2467-2479.

Sáenz, J.P., Wakeham, S.G., Eglinton, T.I. and Summons, R.E. (2011) N ew constraints on the provenance of hopanoids in the marine geologic record: Bacteriohopanepolyols in marine suboxic and anoxic environments. Organic Geochemistry 42, 1351-1362.

Santos, V., Billett, D.S., Rice, A.L. and Wolff, G.A. (1994) Organic matter in deep-sea sediments from the Porcupine A byssal Plain in the north-east $A$ tlantic Ocean. I-Lipids. Deep Sea Research Part I: O ceanographic Research Papers $41,787-819$.

Sapart, C.J ., M artinerie, P., Witrant, E., Chappellaz, J., van de Wal, R.S.W., Sperlich, P., van der Veen, C., Bernard, S., Sturges, W.T., Blunier, T., Schwander, J., Etheridge, D. and Röckmann, T. (2013) Can the carbon isotopic composition of methane be reconstructed from multi-site firn air measurements? A tmospheric Chemistry and Physics 13, 6993-7005.

Sassen, R., R oberts, H.H., Carney, R., M ilkov, A.V ., Def reitas, D .A ., L anoil, B. and Zhang, C. (2004) Free hydrocarbon gas, gas hydrate, and authigenic minerals in chemosynthetic communities of the northern Gulf of Mexico continental slope: relation to microbial processes. Chemical G eology 205, 195-217.

Saunois, M ., B ousquet, P., Poulter, B ., Peregon, A ., Ciais, P., Canadell, J. G ., et al. (2016) The global methane budget 2000-2012. Earth System Science Data, $8(2), 697-751$.

Scalan, E. and Smith, J. (1970) An improved measure of the odd-even predominance in the normal alkanes of sediment extracts and petroleum. G eochimica et Cosmochimica A cta 34, 611-620.

Schäffer, A .A ., A ravind, L ., M adden, T.L., Shavirin, S., Spouge, J.L., W olf, Y .I., K oonin, E.V . and Altschul, S.F. (2001) Improving the accuracy of PSI-BLAST protein database searches with composition-based statistics and other refinements. Nucleic acids research 29, 2994-3005.

Schmitz, R.A., Peeters, S.H., V ersantvoort, W., Picone, N., Pol, A., J etten, M.S.M. and Op den Camp, H.J.M. (2021) Verrucomicrobial methanotrophs: 
ecophysiology of metabolically versatile acidophiles. FEMS Microbiology Reviews.

Schoell, M., Teschner, M., Wehner, H., Durand, B. and Oudin, J. (1983) $M$ aturity related biomarker and stable isotope variations and their application to oil/source rock correlation in the Mahakam Delta, Kalimantan, Advances in Organic Geochemistry 1981. Wiley Chichester, pp. 156-163.

Schoell, M ., M cC affrey, M ., Fago, F. and M oldowan, J. (1992) Carbon isotopic compositions of 28,30-bisnorhopanes and other biological markers in a M onterey crude oil. G eochimica et Cosmochimica A cta 56, 1391-1399.

Schouten, S., B ow man, J.P., Rijpstra, W .I.C. and Sinninghe Damsté, J.S. (2000) Sterols in a psychrophilic methanotroph, Methylosphaera hansonii. FEMS M icrobiology Letters 186, 193-195.

Schouten, S., Hopmans, E.C., Pancost, R.D. and Sinninghe Damsté, J.S. (2000) Widespread occurrence of structurally diverse tetraether membrane lipids: Evidence for the ubiquitous presence of low-temperature relatives of hyperthermophiles. Proceedings of the National Academy of Sciences 97, 14421-14426.

Schouten, S., De Loureiro, M.R., Sinninghe Damsté, J.S. and de Leeuw, J.W. (2001a) Molecular biogeochemistry of Monterey sediments, Naples Beach, California: I. Distributions of hydrocarbons and organic sulfur compounds. The Monterey Formation: from Rocks to Molecules (eds. CM Isaacs and J. Rullkötter). Columbia U niversity Press, N ew Y ork, 150-174.

Schouten, S., Schoell, M., Sinninghe Damsté, J.S., Summons, R.E. and De Leeuw, J.W. (2001b) Molecular biogeochemistry of Monterey sediments, Naples Beach, California: II. Stable carbon isotopic compositions of free and sulphurbound carbon skeletons. The Monterey Formation: From Rocks to M olecules (eds. CM Isaacs and J. Rullkötter). Columbia University Press, N ew Y ork, 175-188.

Schouten, S., Wakeham, S.G., Hopmans, E.C. and Sinninghe Damsté, J.S. (2003) Biogeochemical Evidence that Thermophilic Archaea Mediate the A naerobic Oxidation of $\mathrm{M}$ ethane. A pplied and Environmental M icrobiology 69, 1680-1686.

Schouten, S., Hopmans, E.C., Baas, M., B oumann, H., Standfest, S., Könneke, M., Stahl, D.A. and Sinninghe Damsté, J.S. (2008) Intact membrane lipids of "Candidatus Nitrosopumilus maritimus," a cultivated representative of the cosmopolitan mesophilic group I crenarchaeota. Applied and Environmental M icrobiology 74, 2433-2440. 
Schouten, S., Hopmans, E.C. and Sinninghe Damsté, J.S. (2013) The organic geochemistry of glycerol dialkyl glycerol tetraether lipids: a review. Organic Geochemistry 54, 19-61.

Schubotz, F., Lipp, J.S., Elvert, M., Kasten, S., Mollar, X.P., Zabel, M., Bohrmann, G. and Hinrichs, K.-U. (2011) Petroleum degradation and associated microbial signatures at the Chapopote asphalt volcano, Southern Gulf of M exico. Geochimica et Cosmochimica A cta 75, 4377-4398.

Schubotz, F., Wakeham, S.G., Lipp, J.S., Fredricks, H.F. and Hinrichs, K.-U. (2009) Detection of microbial biomass by intact polar membrane lipid analysis in the water column and surface sediments of the Black Sea. Environmental M icrobiology 11, 2720-2734.

Schulenberg-Schell, H., Neuss, B. and Sahm, H. (1989) Quantitative determination of various hopanoids in microorganisms. A nalytical Biochemistry 181, 120-124.

Schwartz-Narbonne, R., Schaeffer, P., Hopmans, E.C., Schenesse, M ., Charlton, E. A., J ones, D. M., Sinninghe Damsté, J.S., UI Haque, M.F., Jetten, M .S.M., Lengger, S.K., M urrell, J.C., N ormand, P., N uijten, G.H.L., Tal bot, H.M. and Rush, D. 2020. A unique bacteriohopanetetrol stereoisomer of marine anammox. Organic G eochemistry 143, 103994.

Schwietzke, S., Sherwood, O.A., B ruhwiler, L.M .P., Miller, J.B., Etiope, G., Dlugokencky, E.J., M ichel, S.E., A rling, V .A., V aughn, B.H., W hite, J.W.C. and Tans, P.P. (2016) U pward revision of global fossil fuel methane emissions based on isotope database. N ature $538,88-91$.

Seifert, W .K . and M oldowan, J.M . (1978) A pplications of steranes, terpanes and monoaromatics to the maturation, migration and source of crude oils. Geochimica et Cosmochimica A cta 42, 77-95.

Seifert, W .K . and M oldowan, J.M . (1980) The effect of thermal stress on sourcerock quality as measured by hopane stereochemistry. Physics and Chemistry of the Earth 12, 229-237.

Sessions, A.L., Zhang, L., Welander, P.V., Doughty, D, Summons, R.E. and Newman, D.K. (2013) Identification and quantification of polyfunctionalized hopanoids by high temperature gas chromatography-mass spectrometry. Organic G eochemistry 56, 120-130.

Simoneit, B.R. (1977) The Black Sea, a sink for terrigenous lipids. Deep Sea Research 24, 813-830.

Simonin, P., Tindall, B. and Rohmer, M. (1994) Structure elucidation and biosynthesis of 31-methylhopanoids from Acetobacter europaeus. European J ournal of B iochemistry 225, 765-771. 
Sinninghe Damsté, J., Ten Haven, H., De Leeuw, J. and Schenck, P. (1986) Organic geochemical studies of a Messinian evaporitic basin, Northern A pennines (Italy) II. Isoprenoid and $\mathrm{n}$-alkyl thiophenes and thiolanes. Organic Geochemistry 10, 791-805.

Sinninghe Damsté, J.S., Rijpstra, W .I.C., Schouten, S., Fuerst, J .A ., J etten, M .S. and Strous, M. (2004) The occurrence of hopanoids in planctomycetes: implications for the sedimentary biomarker record. Organic Geochemistry 35, 561-566.

Sinninghe Damsté, J.S., Rijpstra, W.I.C., Geenevasen, J.A., Strous, M. and J etten, M .S.M . (2005) Structural identification of Iadderane and other membrane lipids of planctomycetes capable of anaerobic ammonium oxidation (anammox). The FEBS Journal 272, 4270-4283.

Sinninghe Damsté, J.S., Rijpstra, W .I.C., Hopmans, E.C., J ung, M .-Y ., K im, J .G., R hee, S.-K ., et al. (2012) Intact polar and core glycerol dibiphytanyl glycerol tetraether lipids of group I.1a and I.1b Thaumarchaeota in soil. A pplied and Environmental M icrobiology 78, 6866-6874.

Sinninghe Damsté, J.S., Rijpstra, W.I.C., Dedysh, S.N., Foesel, B.U. and Villanueva, L. (2017) Pheno-and genotyping of hopanoid production in A cidobacteria. Frontiers in M icrobiology 8, 968.

Sinninghe Damsté, J. S., Rijpstra, W. I. C., Foesel, B. U., Huber, K. J., Overmann, J., Nakagawa, S., Kim, J. J., Dunfield, P. F., Dedysh, S. N., and Villanueva, L. (2018) An overview of the occurrence of ether-and ester-linked iso-diabolic acid membrane lipids in microbial cultures of the Acidobacteria: Implications for brGDGT paleoproxies for temperature and $\mathrm{pH}$. Organic Geochemistry 124, 63-76, 2018.

Smit, N.T., Rush, D., Sahonero-Canavesi, D.X., Verweij, M ., Rasigraf, O., Cruz, S.G., Jetten, M.S., Sinninghe Damsté, J.S. and Schouten, S. (2019) Demethylated hopanoids in 'Ca. M ethylomirabilis oxyfera' as biomarkers for environmental nitrite-dependent methane oxidation. Organic Geochemistry 137, 103899.

Smit, N.T., V illanueva, L., R ush, D., Grassa, F., W itkowski, C.R ., H olzheimer, M., M innaard, A.J., Sinninghe Damsté, J.S. and Schouten, S. (2021a) Novel hydrocarbon-utilizing soil mycobacteria synthesize unique mycocerosic acids at a Sicilian everlasting fire. Biogeosciences 18, 1463-1479.

Smit, N. T., Rush, D., van der M eer, M. T. J ., Grassa, F., Sinninghe Damsté, J. S. and Schouten, S. (2021b) The role of soil mycobacteria in the uptake of methane and ethane at a Sicilian everlasting fire. In preparation for Biogeosciences. 
Smith, K .A ., D obbie, K.E., B all, B.C., B akken, L.R., Sitaula, B.K ., Hansen, S., B rumme, R., B orken, W., Christensen, S., Priemé, A ., Fowler, D., M acdonald, J.A ., Skiba, U., K lemedtsson, L., K asimir-K lemedtsson, A., Degórska, A . and Orlanski, P. (2000) Oxidation of atmospheric methane in Northern European soils, comparison with other ecosystems, and uncertainties in the global terrestrial sink. Global Change Biology 6, 791-803.

Sollai, M, Villanueava, L., Hopmans, E.C., Reichart, G.-J. and Sinninghe Damsté, J.S. (2019) A combined lipidomic and 16S rRNA gene amplicon sequencing approach reveals archaeal sources of intact polar lipids in the stratified B lack Sea water column. Geobiology 17, 91-109.

Solomon, S., Qin, D., M anning, M ., A veryt, K . and M arquis, M . (2007) Climate change 2007-the physical science basis: Working group I contribution to the fourth assessment report of the IPCC. Cambridge U niversity Press.

Staccioli, G., McMillan, N., M eli, A., and Bartolini, G. (2002) Chemical characterisation of a 45-million-year bark from Geodetic Hills fossil forest, A xel Heiberg Island, Canada. W ood Science and Technology, 36, 419-427.

Stadnitskaia, A ., Blinova, V ., I vanov, M ., Baas, M ., H opmans, E., V an W eering, T. and Sinninghe Damsté, J.S. (2007) Lipid biomarkers in sediments of mud volcanoes from the Sorokin Trough, NE B lack Sea: Probable source strata for the erupted material. Organic G eochemistry 38, 67-83.

Stadnitskaia, A., M uyzer, G., A bbas, B., Coolen, M., Hopmans, E., B aas, M., V an W eering, T., Ivanov, M ., Poludetkina, E. and Sinninghe Damsté, J.S. (2005) Biomarker and 16S rDNA evidence for anaerobic oxidation of methane and related carbonate precipitation in deep-sea mud volcanoes of the Sorokin Trough, Black Sea. M arine G eology 217, 67-96.

Stadnitskaia, A., Nadezhkin, D., A bbas, B., Blinova, V., Ivanov, M.K. and Sinninghe Damsté, J.S. (2008) Carbonate formation by anaerobic oxidation of methane: Evidence from lipid biomarker and fossil $16 \mathrm{~S}$ rDNA. Geochimica et Cosmochimica A cta 72, 1824-1836.

Sturt, H.F., Summons, R.E., Smith, K ., Elvert, M ., and Hinrichs, K . (2004) Intact polar membrane lipids in prokaryotes and sediments deciphered by highperformance liquid chromatography / electrospray ionization multistage mass spectrometry - new biomarkers for biogeochemistry and microbial ecology. Rapid communications in mass spectrometry 18(6), 617-628.

Summons, R.E., Jahnke, L.L. and Roksandic, Z. (1994) Carbon isotopic fractionation in lipids from methanotrophic bacteria: relevance for interpretation of the geochemical record of biomarkers. Geochimica et Cosmochimica A cta 58, 2853-2863. 
Summons, R.E. and Jahnke, L.L. (1992) Hopenes and hopanes methylated in ring-A : correlation of the hopanoids of extant methylotrophic bacteria with their fossil analogues. Biomarkers in sediments and petroleum. Prentice Hall, Englewood Cliffs, 182-200.

Summons, R.E. and Powell, T.G. (1986) Chlorobiaceae in Palaeozoic seas revealed by biological markers, isotopes and geology. N ature 319, 763-765.

Takahashi, J. (1980) Production of Intracellular and Extracellular Protein from n-Butane by Pseudomonas butanovora sp. nov. Advances in Applied Microbiology. Elsevier, pp. 117-127.

Takeuchi, M., Y oshioka, H., Seo, Y., Tanabe, S., Tamaki, H., Kamagata, Y., Takahashi, H.A., Igari, S., Mayumi, D. and Sakata, S. (2011) A distinct freshwater-adapted subgroup of ANME-1 dominates active archaeal communities in terrestrial subsurfaces in J apan. Environmental M icrobiology 13, 3206-3218.

Talbot, H.M ., W atson, D.F., M urrell, J.C., Carter, J.F. and Farrimond, P. (2001) Analysis of intact bacteriohopanepolyols from methanotrophic bacteria by reversed-phase high-performance liquid chromatography-atmospheric pressure chemical ionisation mass spectrometry. J ournal of Chromatography A 921, 175185.

Talbot, H.M ., Squier, A .H., K eely, B.J . and Farrimond, P. (2003a) A tmospheric pressure chemical ionisation reversed-phase liquid chromatography/ion trap mass spectrometry of intact bacteriohopanepolyols. Rapid Communications in M ass Spectrometry 17, 728-737.

Talbot, H.M., Summons, R., Jahnke, L., Farrimond, P. (2003b) Characteristic fragmentation of bacteriohopanepolyols during atmospheric pressure chemical ionization liquid chromatography/ion trap mass spectrometry. Rapid Communications in M ass Spectrometry 17, 2788-2796.

Talbot, H.M., W atson, D.F., Pearson, E.J . and Farrimond, P. (2003c). Diverse biohopanoid compositions of non-marine sediments, Organic Geochemistry 34, 1353-1371.

Talbot, H.M . and Farrimond, P. (2007) B acterial populations recorded in diverse sedimentary biohopanoid distributions. Organic Geochemistry 38, 1212-1225.

Talbot, H.M., Rohmer, M. and Farrimond, P. (2007a) Rapid structural elucidation of composite bacterial hopanoids by atmospheric pressure chemical ionization liquid chromatography/ion trap mass spectrometry. Rapid Communications in M ass Spectrometry 21, 880-892.

Tal bot, H.M ., Rohmer, M . and Farrimond, P. (2007b). Structural characterisation of unsaturated bacterial hopanoids by atmospheric pressure chemical ionisation 
liquid chromatography/ion trap mass spectrometry. Rapid Communications in M ass Spectrometry 21, 1613-1622.

Talbot, H.M, Summons, R.E., Jahnke, L.L., Cockell, C.S., Rohmer, R. and Farrimond, P. (2008) Cyanobacterial bacteriohopanepolyol signatures from cultures and natural environmental settings. Organic Geochemistry 39, 232-263.

Tal bot, H.M ., H andley, L., Spencer-J ones, C.L., Dinga, B.J ., Schefuß, E., M ann, P.J., Poulsen, J.R., Spencer, R.G.M., Wabakanghanzi, J.N. and Wagner, T. (2014) V ariability in aerobic methane oxidation over the past 1.2 M yrs recorded in microbial biomarker signatures from Congo fan sediments. Geochimica et Cosmochimica A cta 133, 387-401.

Talbot, H.M ., M cClymont, E.L., Inglis, G.N., Evershed, R.P. and Pancost, R.D. (2016) Origin and preservation of bacteriohopanepolyol signatures in Sphagnum peat from Bissendorfer M oor (Germany). Organic G eochemistry 97, 95-110.

Talbot, H.M ., Sidgwick, F.R., Bischoff, J., Osborn, K.A., Rush, D., Sherry, A and Spencer-Jones, C.L. (2016) A nalysis of non-derivatized bacteriohopanepolyols by ultrahigh-performance liquid chromatography/tandem mass spectrometry. Rapid Communications in Mass Spectrometry 30, 20872098.

Tamura, K., Stecher, G., Peterson, D., Filipski, A., and Kumar, S. (2013) MEGA6: molecular evolutionary genetics analysis version 6.0, Molecular Biology and Evolution, 30, 2725-2729.

Ten Haven, H., De Leeuw, J. and Schenck, P. (1985) Organic geochemical studies of a Messinian evaporitic basin, northern Apennines (Italy) I: Hydrocarbon biological markers for a hypersaline environment. Geochimica et Cosmochimica A cta 49, 2181-2191.

Ten H aven, H., B aas, M ., De L eeuw, J., M aassen, J ., Schenck, P. (1987) Organic geochemical characteristics of sediments from the anoxic brine-filled Tyro basin (eastern M editerranean). Organic geochemistry 11, 605-611.

Thauer, R.K., Kaster, A .-K ., Seedorf, H., Buckel, W . and Hedderich, R. (2008) $M$ ethanogenic archaea: ecologically relevant differences in energy conservation. Nature R eviews M icrobiology 6, 579-591.

Thiel, V., Blumenberg, M., Pape, T., Seifert, R. and Michaelis, W. (2003) Unexpected occurrence of hopanoids at gas seeps in the Black Sea. Organic Geochemistry 34, 81-87.

Tiedje, J. M ., A suming-B rempong, S., N üsslein, K ., M arsh, T. L., and Flynn, S. J. (1999) Opening the black box of soil microbial diversity. A pplied Soil Ecology 13, 109-122. 
Timmers, P.H .A ., W elte, C.U., K oehorst, J.J ., Plugge, C.M ., J etten, M .S.M ., and Stams, A.J.M. (2017) Reverse methanogenesis and respiration in methanotrophic archaea. A rchaea 2017: 1654237.

Torkko, P., Suomalainen, S., livanainen, E., Suutari, M ., Paulin, L., Rudbäck, E., Tortoli, E., Vincent, V., Mattila, R., and Katila, M.-L. (2001) Characterization of Mycobacterium bohemicum isolated from human, veterinary, and environmental sources. Journal of Clinical Microbiology 39, 207-211.

Torkko, P., Suomalainen, S., livanainen, E., Tortoli, E., Suutari, M ., Seppänen, J., Paulin, L., and Katila, M.-L. (2002) Mycobacterium palustre sp. nov., a potentially pathogenic, slowly growing mycobacterium isolated from clinical and veterinary specimens and from Finnish stream waters, International J ournal of Systematic and Evolutionary M icrobiology, 52, 1519-1525.

Torkko, P., Katila, M.-L., and K ontro, M. (2003) Gas-chromatographic lipid profiles in identification of currently known slowly growing environmental mycobacteria, Journal of M edical M icrobiology, 52, 315-323.

Tornabene, T.G. and Langworthy, T.A. (1979) Diphytanyl and dibiphytanyl glycerol ether lipids of methanogenic archaebacteria. Science 203, 51-53.

Tortoli, E. (2014) M icrobiological features and clinical relevance of new species of the genus M ycobacterium. Clinical M icrobiology Reviews 27, 727-752.

Trincianti, E., Frixa, A. and Sartorio, D. (2015) Palynology and stratigraphic characterization of subsurface sedimentary successions in the Sicanian and Imerese Domains-Central Western Sicily. Review of Palaeobotany and Palynology 218, 48-66.

Trudinger, C.M ., Etheridge, D.M ., R ayner, P.J ., Enting, I.G., Sturrock, G .A . and Langenfelds, R.L. (2002) Reconstructing atmospheric histories from measurements of air composition in firn. J ournal of Geophysical Research 107 (D24), 4780.

Tsutsumi, Y., Iijima, A., Y oshida, K., Shoji, H. and Lee, J.T. (2009) HCCI combustion characteristics during operation on DME and methane fuels. International J ournal of A utomotive Technology 10, 645.

UniProt Consortium, 2018. UniProt: a worldwide hub of protein knowledge. Nucleic acids research 47, D506-D515.

Vaksmaa, A., Guerrero-Cruz, S., van A len, T.A., Cremers, G., Ettwig, K.F., Lüke, C. and Jetten, M.S. (2017) Enrichment of anaerobic nitrate-dependent methanotrophic 'Candidatus M ethanoperedens nitroreducens' archaea from an 
Italian paddy field soil. A pplied Microbiology and Biotechnology 101, 70757084.

Vaksmaa, A., Jetten, M .S.M., Ettwig, K.F., and Lüke, C. (2017) M crA primers for the detection and quantification of the anaerobic archaeal methanotroph "Candidatus Methanoperedens nitroreducens." Applied Microbiology and Biotechnology 101, 1631-1641.

Valentine, D.L. and Reeburgh, W.S. (2000) New perspectives on anaerobic methane oxidation: minireview. Environmental M icrobiology 2, 477-484.

Valero-Guillén, P., M artín-L uengo, F., Larsson, L., J imenez, J., J uhlin, I., and Portaels, F. (1988) Fatty and mycolic acids of Mycobacterium malmoense. J ournal of Clinical M icrobiology 26, 153-154.

V an de V ossenberg, J., Rattray, J.E., G eerts, W ., K artal, B., van Niftrik, L., van Donselaar, E. G., Sinninghe Damsté, J.S., Strous, M . and J etten, M .S.M . (2008) Enrichment and characterization of marine anammox bacteria associated with global nitrogen gas production. Environmental M icrobiology 10, 3120-3129.

V an Dongen, B.E., Talbot, H.M ., Schouten, S., Pearson, P.N . and Pancost, R.D. (2006) W ell preserved Palaeogene and Cretaceous biomarkers from the K ilwa area, Tanzania. Organic G eochemistry 37, 539-557.

V an Duin, A .C.T., Sinninghe Damsté, J.S., K odpmans, M .P., van de Graaf, B ., de Leeuw, J.W., 1997. A kinetic calculation method of homohopanoid maturation: A pplications in the reconstruction of burial histories of sedimentary basins. Geochimica et Cosmochimica A cta 61, 2409-2429.

Van Teeseling, M.C.F., Pol, A., Harhangi, H.R., van der Zwart, S., Jetten, M.S.M., Op den Camp, H.J.M. and van Niftrik, L. (2014) Expanding the Verrucomicrobial M ethanotrophic W orld: Description of Three N ovel Species of M ethylacidimicrobium gen. nov.. A pplied and Environmental M icrobiology 80,6782 .

V an W inden, J.F., K ip, N., Reichart, G.-J ., J etten, M .S., Op den Camp, H.J . and Sinninghe Damsté, J.S. (2010). Lipids of symbiotic methane-oxidizing bacteria in peat moss studied using stable carbon isotopic labelling. Organic Geochemistry 41, 1040-1044.

Van Winden, J.F., Talbot, H.M., Kip, N., Reichart, G.-J., Pol, A., M cNamara, N.P., Jetten, M.S., Op den Camp, H.J. and Sinninghe Damste, J.S. (2012) $B$ acteriohopanepolyol signatures as markers for methanotrophic bacteria in peat moss. Geochimica et Cosmochimica A cta 77, 52-61.

V an W inden, J.F., Talbot, H.M ., R eichart, G.-J ., M cN amara, N .P., B enthien, A., and Sinninghe Damsté, J.S. (2020) Influence of temperature on the $\delta 13 \mathrm{C}$ values 
and distribution of methanotroph-related hopanoids in Sphagnum-dominated peat bogs. Geobiology, 18, 497-507.

Volkman, J.K., Alexander, R., K agi, R.I. and Rullkötter, J. (1983) GC-M S characterisation of C27 and C28 triterpanes in sediments and petroleum. Geochimica et Cosmochimica A cta 47, 1033-1040.

Volkman, J.K., Holdsworth, D.G., Neill, G.P. and Bavor Jr, H. (1992) Identification of natural, anthropogenic and petroleum hydrocarbons in aquatic sediments. Science of the Total Environment 112, 203-219.

Volkman, J.K. (2003) Sterols in microorganisms. A pplied Microbiology and Biotechnology 60, 495-506.

Wagner, T., K allweit, W., Talbot, H.M ., M ollenhauer, G., Boom, A . and Zabel, M . (2014) M icrobial biomarkers support organic carbon transport from methanerich A mazon wetlands to the shelf and deep sea fan during recent and glacial climate conditions. Organic Geochemistry 67, 85-98.

Wakeham, S.G., Lewis, C.M., Hopmans, E.C., Schouten, S. and Sinninghe Damsté, J.S. (2003) A rchaea mediate anaerobic oxidation of methane in deep euxinic waters of the Black Sea. Geochimica et Cosmochimica A cta 67, 13591374.

Wakeham, S.G., Hopmans, E.C., Schouten, S. and Sinninghe Damsté, J.S. (2004) A rchaeal lipids and anaerobic oxidation of methane in euxinic water columns: a comparative study of the Black Sea and Cariaco Basin. Chemical Geology 205, 427-442.

W akeham, S.G., A mann, R., Freeman, K.H., Hopmans, E.C., Jørgensen, B .B., Putnam, I.F., Schouten, S., Sinninghe Damsté, J.S., Talbot, H.M . and W oebken, D. (2007) Microbial ecology of the stratified water column of the Black Sea as revealed by a comprehensive biomarker study. Organic G eochemistry 38, 20702097.

Walsh, C. M ., Gebert, M . J., Delgado-Baquerizo, M ., M aestre, F., and Fierer, N . (2019) A global survey of mycobacterial diversity in soil. Applied Environmental M icrobiology, 85, e01180-19.

W ang, H-Y, Tatituri, R.V.V., Goldner, N.K ., Dantas, G. and Hsu, F-F. (2020) Unveiling the biodiversity of lipid species in Corynebacteria - characterization of the uncommon lipid families in C. glutamicum and pathogen $\mathrm{C}$. striatum by mass spectrometry. Biochimie 178, 158-169.

W ang, M., Tian, J., Bu, Z., L amit, L.J., Chen, H., Zhu, Q., and Peng, C. (2019) Structural and functional differentiation of the microbial community in the 
surface and subsurface peat of two minerotrophic fens in China. Plant and Soil 437, 1, 21-40.

Weber, H.S., Habicht, K.S., and Thamdrup, B. (2017) A naerobic methanotrophic archaea of the A N M E-2d cluster are active in a low-sulfate, ironrich freshwater sediment. Frontiers in M icrobiology 8, 1-13.

W egener, G., N iemann, H., Elvert, M ., Hinrichs, K.-U ., and B oetius, A . (2008) Assimilation of methane and inorganic carbon by microbial communities mediating the anaerobic oxidation of methane. Environmental M icrobiology 10, 2287-2298.

Wegener, G., K rukenberg, V., Ruff, S.E., and Kellermann, M.Y. (2016) Metabolic capabilities of microorganisms involved in and associated with the anaerobic oxidation of methane. Frontiers in M icrobiology 7, 1-16.

W eijers, J.W ., Panoto, E., van B leijswijk, J ., Schouten, S., Rijpstra, W .I.C., Balk, M ., Stams, A .J ., and Sinninghe Damsté, J.S. (2009) Constraints on the biological source (s) of the orphan branched tetraether membrane lipids. Geomicrobiology Journal 26, 402-414.

W elander, P.V . and Summons, R.E. (2012) Discovery, taxonomic distribution, and phenotypic characterization of a gene required for 3-methylhopanoid production. Proceedings of the National Academy of Sciences 109, 1290512910.

Wenger, L.M., Davis, C.L. and Isaksen, G.H. (2002) Multiple controls on petroleum biodegradation and impact on oil quality. SPE Reservoir Evaluation \& Engineering 5, 375-383.

W elte, C. and Deppenmeier, U. (2014) B ioenergetics and anaerobic respiratory chains of aceticlastic methanogens. Biochimica et Biophysica Acta (BBA) Bioenergetics 1837, 1130-1147.

Whiticar, M.J . (1999) Carbon and hydrogen isotope systematics of bacterial formation and oxidation of methane. Chemical Geology 161, 291-314.

Whitman, W.B. (1994) Autotrophic acetyl coenzyme A biosynthesis in methanogens. In, D rake,H.L. (ed), Acetogenesis. Chapman \& Hall., N ew Y ork, pp. 521-538.

W olff, E. and Spahni, R. (2007) M ethane and nitrous oxide in the ice core record. Philosophical Transactions of the Royal Society A: M athematical, Physical and Engineering Sciences 365, 1775-1792.

World Health Organization (2019) World health statistics 2019: monitoring health for the SDGs, sustainable development goals, W orld Heal th O rganization, 120 pp., ISBN: 9241565705. 
Wörmer, L., Lipp, J.S., Schröder, J.M . and Hinrichs, K.-U . (2013) A pplication of two new LC-ESI-MS methods for improved detection of intact polar lipids (IPLs) in environmental samples. Organic G eochemistry 59, 10-21.

W rede, C., Brady, S., Rockstroh, S., D reier, A ., K okoschka, S., Heinzelmann, S., Heller, C., Reitner, J., Taviani, M. and Daniel, R. (2012) Aerobic and anaerobic methane oxidation in terrestrial mud volcanoes in the Northern A pennines. Sedimentary Geology 263, 210-219.

Wu, C.-H., Kong, L., Bialecka-Fornal, M., Park, S., Thompson, A.L., Kulkarni, G., Conway, S.J. and Newman, D.K. (2015) Quantitative hopanoid analysis enables robust pattern detection and comparison between laboratories. Geobiology 13, 391-407.

Zengler, K., Richnow, H.H., Rosselló-M ora, R., M ichaelis, W. and W iddel, F. (1999) Methane formation from long-chain alkanes by anaerobic microorganisms. Nature 401, 266-269.

Zhang, G., Tian, J., Jiang, N., Guo, X., Wang, Y., and Dong, X. (2008) $M$ ethanogen community in Zoige wetland of Tibetan plateau and phenotypic characterization of a dominant uncultured methanogen cluster ZC-I. Environmental M icrobiology 10, 1850-1860.

Zhang, J., K obert, K., Flouri, T. and Stamatakis, A . (2013) PEA R: a fast and accurate Illumina Paired-End reA d mergeR. B ioinformatics 30, 614-620.

Zhang, Y.G., Zhang, C.L., Liu, X.-L., Li, L., Hinrichs, K.-U. and Noakes, J.E. (2011) Methane Index: A tetraether archaeal lipid biomarker indicator for detecting the instability of marine gas hydrates. Earth and Planetary Science Letters 307, 525-534.

Zhu, B ., van Dijk, G., Fritz, C., Smolders, A .J ., Pol, A ., J etten, M .S. and Ettwig, K.F. (2012) A naerobic oxidization of methane in a minerotrophic peatland: enrichment of nitrite-dependent methane-oxidizing bacteria. Applied and Environmental M icrobiology 78, 8657-8665.

Zhu, C., T albot, H.M., Wagner, T., Pan, J .M . and Pancost, R .D . (2010) Intense aerobic methane oxidation in the $Y$ angtze Estuary: A record from 35aminobacteriohopanepolyols in surface sediments. Organic Geochemistry 41 , 1056-1059.

Zhu, C. Talbot, H.M., Wagner,T., Pan, J.-M. and Pancost, R.D. (2011) Distribution of hopanoids along a land to sea transect: I mplications for microbial ecology and the use of hopanoids in environmental studies. Limnology and Oceanography 56, 1850-1865. 
Zumberge, J.E. (1984) Source rocks of the La Luna Formation (Upper Cretaceous) in the Middle Magdalena Valley, Colombia. AAPG Special Volumes 30, 127.

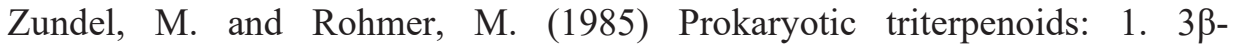
Methylhopanoids from A cetobacter species and Methylococcus capsulatus. European J ournal of B iochemistry 150, 23-27. 
Acknowledgements/ Danksagung 


\section{Acknowledgements / Danksagung}

When I started my PhD about 4 years ago who would have thought that a global pandemic would get in the way of all our plans. Despite these difficult times shortly before and during Corona I, or better we, still managed to finish this thesis. There are many great people who I'm thankful to for their support and help.

First of all I would like to thank my three supervisors Stefan, Darci and Jaap for their hel $p$ and support during my PhD. From the start on you believed in me, my decisions and my knowledge in Organic Geochemistry even if I doubted myself or was going through some difficult times. I'm very grateful that you taught me how to become an independent, critical thinking and confident scientist in the crazy world of academia.

Stefan: It is really hard to find the right words to say how thankful I am for all your support, knowledge and wisdom during the last 4 years. Y our door was always open when I had questions or was puzzling with my data. Y our undestroyable calmness helped me through a lot of difficult moments and taught me to stay calm before making a possibly stupid decision. One of my best memories are the endless afternoon meetings which we had together to puzzle all these weird new biomarkers (e.g. trisnorhopanoids or mycocerosic acids) together while drinking hot chocolate (Stefan) and coffee (I). Even when I wanted to go to Sicily to sample methane seeps, you supported my crazy ideas and who would have thought that an everlasting fire would give us so many exciting new data - Probably you are still trying to make sense out of these weird big glycolipids there... Thanks for being such an amazing and inspiring supervisor to me!

Darci: A s you tend to say I was your test student since I was the first PhD student you supervised and it is time to let you know that your experiment worked out very well (at least I think so...). Thanks for all your help and support over the last years which have been al ways accompanied with lots of laughs and humor! Y ou were always there for questions or just having a chat about some data, literature or experiments I wasn't certain of. Y our positive vibes and your humor were al ways there to cheer me up even when data didn't turn out as we expected them to. Thanks for fascinating me about BHPs, helping me with presentations or setting up experiments. I will miss working with you and look forward to a lot of fun conferences together in the future where we can rock the dancefloor =). 
J aap: I'm so thankful for all your help and mentorship while interpreting data, writing manuscripts and getting this thesis finished. Unfortunately, we did not work together as much as we probably planned or thought in the beginning, however, I'm very grateful for all your input and help especially during the last year of my PhD. Y ou taught me how to critically think about my data and write a perfect manuscript and I need to admit that you often drove me nuts with it. In the end, it turned out as a perfect manuscript which didn't need many revisions. It was a pleasure working together with you and get inspired by your knowledge and never ending curiosity to understand our science even better than we al ready do.

I would like to thank the reading committee members and the sitting committee members for their assessments of my thesis and the public defense.

B efore starting this PhD, my interest in the field of Organic Geochemistry was fueled by many other great people. I would like to thank the Organic Geochemistry group at the MARUM in Bremen to awaken my interest in biomarkers and isotopes and teaching me a lot of my first lab skills. Furthermore, there are three people who I would like to especially thank for their inspiration to become a scientist. First of all, Florence you are an amazing and inspiring female scientist whose knowledge I will al ways appreciate. Y ou were not only a fantastic mentor during my times as a master student, moreover, you (and your family) became very good friend to me who I can al ways ask for honest feedback and advice. I'm really looking forward to working together with you again at MARUM and having more nice dinners together. A very big thanks goes also to Christian and $\mathbf{J}$ ohan who were great advisors and mentors during my time as a master student.

What would have been my thesis without all the great scientists, collaborators, technicians, friends and family at NIOZ and back home.

Ellen: Thank you so much for teaching me about crazy BH Ps and so much more. I always enjoyed our meetings together with your humor and your endless knowledge about all kinds of intact lipids. I'm still amazed about many many new B HPs you identified in the cultures and the Censo soil (130 different B HPs). It was a pleasure working with you. I will miss our gezellig meetings and shitchats. 
Laura: I'm thankful to you for all your help and input with the microbiological side of my data sets. Thanks for explaining a geochemist what 16S rR NA gene sequencing can do and what not. The whole mycobacteria story would only have been half as great as it became with your help and the DNA -data.

Marce: Thanks a lot for having your door always open when I had some questions about my data or was just looking for some good advice. It was great to chat and discuss things with you and I always went back to my office with a more positive feeling.

Fausto: M y Italian collaborator and friend. Grazie for your help with the two sampling trips in Sicily. It was great to see these fascinating places like the mud volcanoes, mud ponds and of course Fuoco di Censo. Thanks for your numerous explanations about these unique places and for your hospitality and the amazing food as well as the tasty fresh olive oil. I'm so happy that I did not only get a lot of nice research results but also found a very great person!

I would like to say a big thank you to all our amazing technicians at NIOZ, who do a great job in running the labs and instruments. Without all of you my research would have not been possible. Thanks to M onique (for all your support and help with the triplequad), Anchelique (extracting and analyzing a lot of my mud volcano samples), Denise (keeping the Orbitrap running), Jort and Ronald (running and maintaining all the IRM S), M arianne (doing a great job as labhead), J essica, Irene, M ichel, Caglar, Carsten, Alle, M aartje and Sanne.

Thanks to all the other PhDs and Postdocs for nice lunches, coffee breaks and drinks who accompanied me on my way at NIOZ and at M MB. Thank you, Diana, for all the nice exchanges over microbiology and geochemistry at the office next door and at coffee breaks together. A lso thanks for the nice dinners together with you and Ale I would al so like to thank J essica and Philipfor nice evenings together with self-brewed beers and all the chats. Thank you, Nicole for your humor, advice and chats when I sometimes popped into your office or at lunch. Thanks to Alena for the nice cooking events and long Texel walks together. A Iso I would like to thank Marijkeand Laura for a great time at EGU, Milou, Fonsand Sigrid for being al ways great people to chat to over a coffee.

My paranymphs Dina and Maaike (aka the M M B wannabe fit girls): I'm so grateful that I met you two during my time at NIOZ. We al ways had each other's backs and I feel we have been on a long rollercoaster ride regarding our PhD 
projects. We went together through quite some good but also bad times and I think without your friendship I would have been definitely sometimes lost on Texel. I'm very happy that we became friends and I'm looking forward to many more exciting times in the future.

Cait: Thank you for being such a great friend to me over the last years. We always had a good time at conferences together, on Sicily or just at our numerous dinners and coffee breaks. I'm very happy that we still talk so often even if it is only via videochat and share our research experiences but also private matters with each other. Y ou are always a critical and honest friend whose opinion I value very much.

Uli: Danke, dass du meine deutsche Freundin auf der niederländischen Insel warst. U nsere unzähligen Gespräche über das L eben und unsere PhDs auf Texel haben mir vieles versüßt. Danke für die vielen $B$ arbecues und Partys zusammen. Ich bin so froh, dass du nun wieder so nah bei mir wohnst und wir beide als Postdocs am AWI und MARUM arbeiten werden. Hoffentlich ziehen du und deine Familie ganz bald nach Bremen. Ich freue mich auf gemeinsame Zeit zusammen hier als Dr. Uli und Dr. Nadine.

E mily: Thank you so much for our vacations and conferences together as well as for a bed to stayover in Utrecht. Y ou are an amazing friend to me and we always have so much fun together. Can't wait for the exciting times together which lie ahead of us.

I would also like to thank all my NESSC colleagues and conference buddies for great times at several events and conferences together. Especially I would like to thank the conference crew for lots of fun times at IMOG and GRC: Tommy, Hendrik, J erome, Allix, C ait and E mily and many more.

Danke an alle unsere/meine B remen Freunde, welche immer ein offenes $0 \mathrm{hr}$ haben und mit denen ich viele schöne Tage und A bende erlebt habe. Speziell danken möchte ich Rebecca, Merle \& Bene, Corinna \& Lars, Daniel V. \& J ulia, M aja \& J onas und A nna \& Till für ihre U nterstützung während meines PhDs.

J enny: Was wäre diese Danksagung, ohne dir zu danken für deine jahrelange großartige F reundschaft. A uch wenn du meine Forschung nicht immer verstehst, bin ich dir dankbar für deine Unterstützung und deinen Rat. Egal was wieder K omisches passiert, wir verstehen uns immer und haben zusammen viele schöne, aber auch nicht so positive Zeiten geteilt. 
A Is nächstes möchte ich meinem Partner und besten Freund Stefan von Herzen danken. Danke, dass du immer an mich glaubst auch wenn ich es manchmal selbst nicht tue. Danke für deine U nterstützung in den ganzen J ahren zusammen und besonders durch die letzten vier J ahre die uns vieles abverlangt haben. $\mathrm{Nach}$ PhD Stress plus Fernbeziehung B remen-Texel kam auf uns Corona und vieles mehr zu trotz allem haben wir es geschafft zusammenzuziehen und vor allem immer zusammen zu bleiben. Ich kann mir keinen besseren $M$ enschen vorstellen, mit dem ich zusammen sein möchte und der mich bedingungslos unterstützt und liebt. Danke für alles, auch wenn mir dafür die richtigen W orte fehlen. Ich liebe dich.

Danken möchte ich auch Familie Wenau, die mich herzlich in ihre Familie aufgenommen haben und die uns immer unterstützt. Danke für das großartige Flessenow, wo ich so manche Teile meiner Doktorarbeit geschrieben habe.

Zum Schluss möchte ich meiner Familie danken. Das größte Dankeschön geht an meine $\mathbf{E}$ Itern, die mich immer in meinen eigenen Entscheidungen unterstützt haben und den Grundstein für mein Wissen und meine Fähigkeiten mit ihrem Engagement während meiner Schulzeit gesetzt haben. M ama, danke für alles was du für mich und uns geleistet hast die ganzen Jahre. Du bist viel zu gut für diese Welt. Papa, danke für dein ganzes Wissen was du mir in den Naturwissenschaften vermittelt hast, wenn auch du nicht viel mit Chemie (meiner L eidenschaft) am Hut hast. Danke für deinen Rat und unsere unzählig lange Diskussion über die W elt. C hantal, danke fürs kleine Schwestersein und alles was damit zu tun hat ;). O nkel Arno, dankeschön für deine Unterstützung und $M$ otivation auf allen meinen Lebenswegen. $\mathbf{O}$ ma L enchen, danke für alles, deine Fürsorge als wir Kinder waren und dein Glaube an mich. Jetzt ist deine Enkeltochter sogar noch Dr. Nadine geworden! Schade, dass Opa viel zu früh gegangen ist, um dies mitzubekommen. Zuletzt auch ein großes Dankeschön an O ma E dith (auch wenn du ein paar M onate zu früh gegangen bist, um meine Promotion noch erleben zu können). Danke fürs Reden und manchmal einfach nur Zuhören. Viele Dank euch allen, ohne euch wäre ich nicht der M ensch der ich heute bin. 


\section{About theauthor}

Nadine Talea Smit was born on the $7^{\text {th }}$ of J une 1990 in M eerbusch, Germany. From 2010 to 2013, she completed her bachelor's degree in Geoscience at the University of B remen. During this time she worked as a student assistant in the Organic G eochemistry group of Kai-U we Hinrichs at M ARUM, B remen where she gained experience in laboratory skills and started to get fascinated by lipid biomarkers and isotopes. Her Bachelor thesis dealt with the calibration of the paleotemperature proxy $\mathrm{TEX}_{86}$ using pure archaeal cultures under different growth temperatures. Afterwards, Nadine attended the international MSc

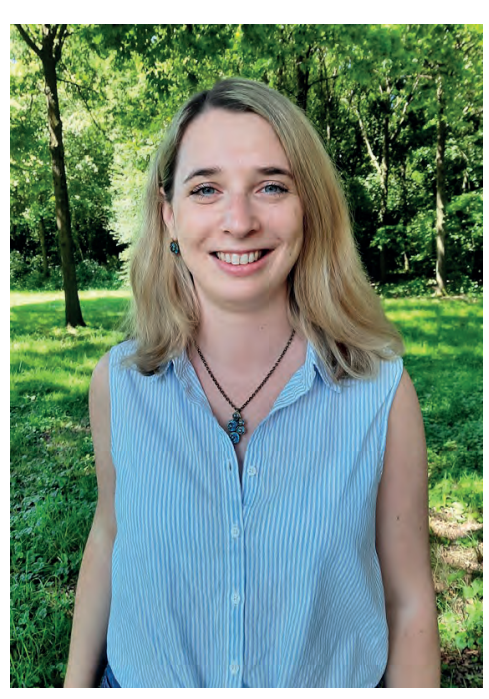
program of Marine Geoscience at the University of Bremen and at M A RU M . During this time she worked together with Florence Schubotz and Christian Hallmann on several projects, gaining more insight into petroleum lipid biomarkers. Her thesis entitled "Geochemical characterization of asphalt deposits in the Campeche B ay (southern Gulf of Mexico) - Insights in the persistence of heavy oil in the marine environment" in cooperation with Shell Global Solutions in the Netherlands under the supervision of Florence Schubotz, Christian Hallmann and Johan Weijers was completed in 2016. Her keen interest in Organic G eochemistry led her to apply for a PhD position at the Royal Netherlands Institute for Sea Research (NIOZ) on Texel, the Netherlands. Nadine started her PhD studying novel lipid biomarkers for microbial methane oxidation in the environment within the NESSC program (Netherlands Earth System Science Center) in February 2017 under the supervision of Stefan Schouten, Darci Rush and Jaap Sinninghe Damsté. She will continue her scientific career as a postdoctoral researcher in a cluster project together with Victoria Orphan and Kai-Uwe Hinrichs at MARUM, University of Bremen, Germany and partly at California Institute of Technology, USA. In this project she will use diverse isotope tracing techniques to study e.g. methane oxidation and methanogenesis in aerobic and anaerobic marine sedimentary microbes. 



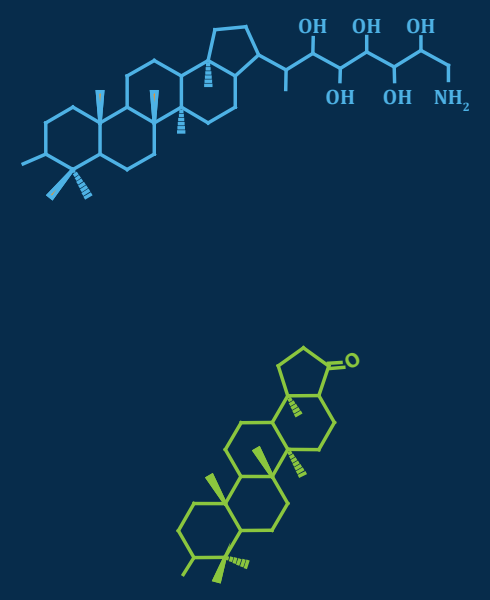

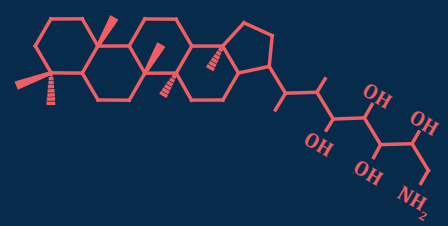
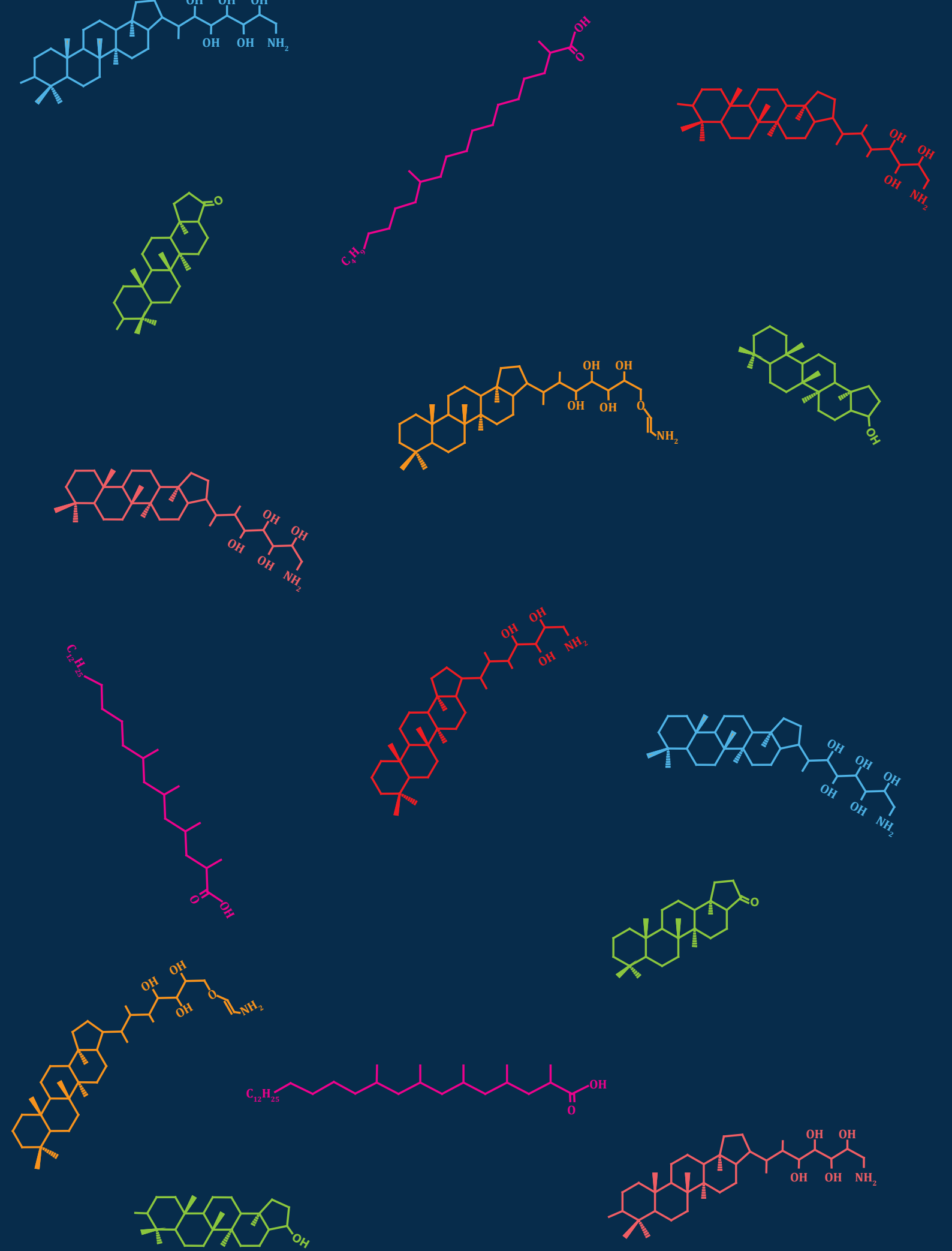

Royal Netherlands Institute for Sea Research \& Utrecht University 